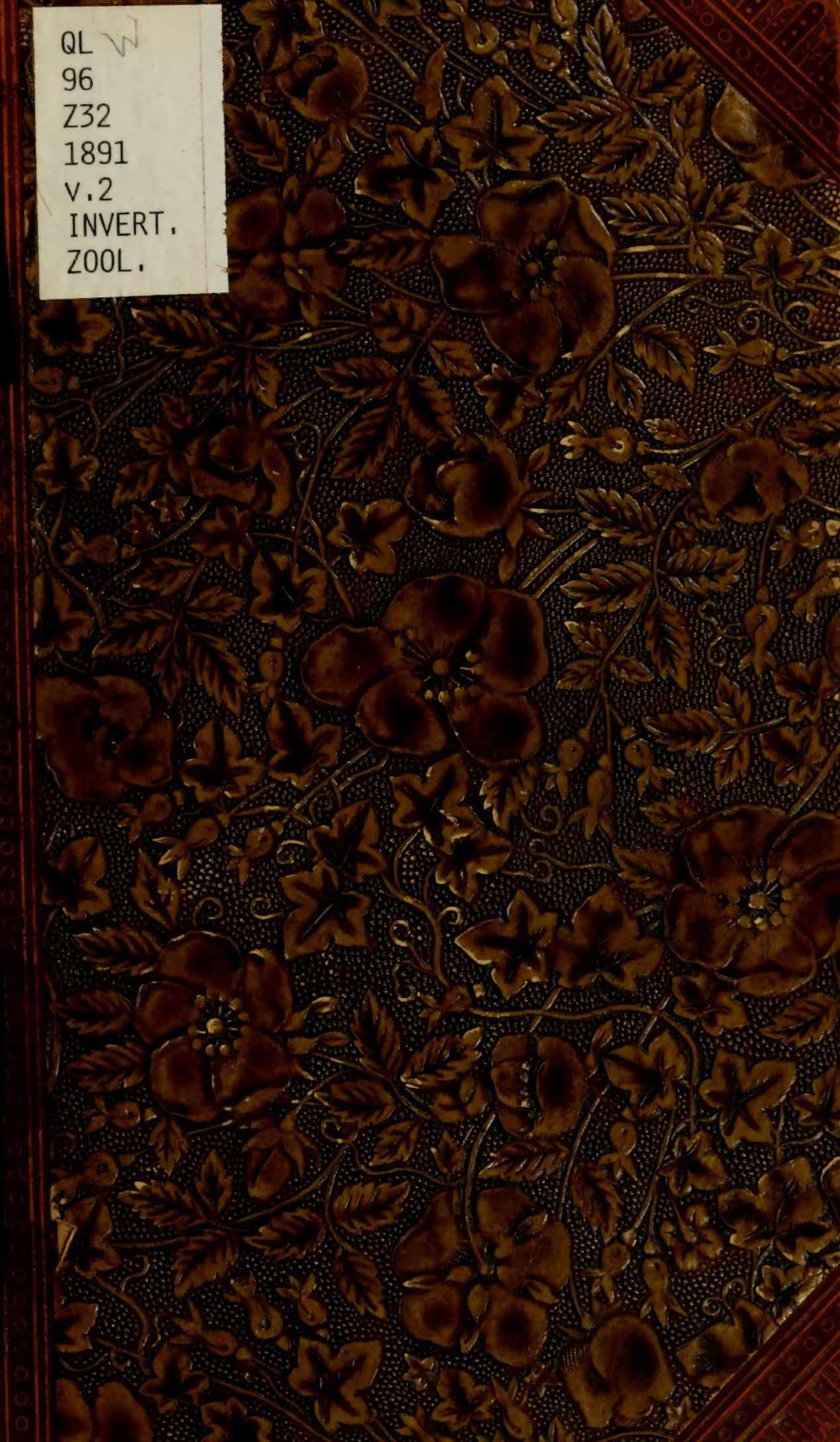




K. F. Koehler's Antiquarium LEIPZIG

Universitlitsstrasse 26 .

Specialgeschäft fuir Philologie und Naturwissenschaften. 
Die

\section{Tier- und Pflanzenwelt des}

Süsswassers. 



\section{Die}

\section{Tier- und Pflanzenwelt des}

\section{Süsswassers.}

Einführung in das Studium derselben.

\section{Unter Mitwirkung von}

Dr. C. Apstein (Kiel), Fr. Borcherding (Vegesack), S. Clessin (Ochsenfurt), Prof. Dr. F. A. Forel (Morges, Schweiz), Prof. Dr. A. Gruber (Freiburg i. Br.), Prof. Dr. P. Kramer (Halle a. d. S.), Prof. Dr. F. Ludwig (Greiz), Dr. W. Migula (Karlsruhe), Dr. L. Plate (Marburg), Dr. E. SchmidtSchwedt (Berlin), Dr. A. Seligo (Danzig), Dr. J. Vosseler (Tübingen), Dr. W. Weltner (Berlin) und Prof. Dr. F. Zschokke (Basel)

herausgegeben

von

\section{Dr. Otto Zacharias,}

Direktor der Biologischen Station am Grossen Plöner See in Holstein.

\section{Zweiter Band.}

Mit 51 in den Text gedruckten Abbildungen.

\section{Leipzig}

Verlagsbuchhandlung von J. J. Weber

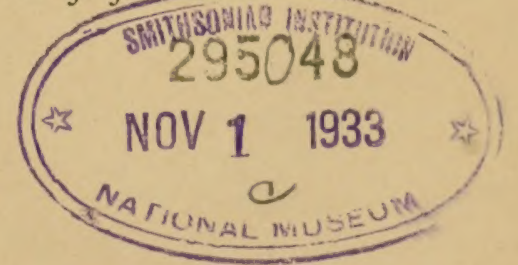


Alle Rechte vorbehalten. 


\section{Vorwort.}

Nach der Aufnahme zu urteilen, welche der erste Teil des vorliegenden Werkes in den nächst interessierten Kreisen sowohl als auch in der Tagespresse gefunden hat, ist mit unserer „Einführung in das Studium der Tier- und Pflanzenwelt des Süsswassers" eine in der biologischen Litteratur wirklich vorhandene Lücke ausgefüllt worden.

Die Absicht des Herausgebers ist demnach vollständig erreicht; aber mit der Befriedigung, die er hierüber empfindet, wird sogleich auch der Wunsch rege, sämtlichen Herren, welche der Aufforderung zur Mitarbeiterschaft an diesem Buche in so freundlicher Weise entsprochen haben, beim Erscheinen des Schlussbandes den verbindlichsten Dank für ihre wertvollen Beiträge abzustatten. Der Unterzeichnete nimmt an, 
dass er damit nicht nur seinen eigenen Empfindungen Ausdruck giebt, sondern zugleich auch im Namen aller Derjenigen spricht, welche eine umfassende, gemeinverständliche und sichere Unterweisung in betreff der einheimischen Wasserwelt bisher vermisst haben.

Biologische Station am Grossen Plöner See.

Ende September 189 I.

Dr. Otto Zacharias. 


\section{Inhaltsverzeichnis.}

I. Die Hydrachniden (Wassermilben). Von T'rof. Dr. 1'. Kramer in Halle.

Geschichtliches. - Stellung der Süsswassermilben zu den übrigen Milben. - Beschreibung der äussern Gestalt von Piona flavescens. Die hauptsächlichsten inneren Organe der Hydrachnidae. - Die typischen Gruppen der WVassermilben, durch Beispiele erlïutert. - Geographische Verbreitung und Lebensweise. - Entwickelung, erläutert an Nesnea fuscata, Diplodontus filipes und Hydrachna globosa. - Anhang: Tabelle zux Bestimmung der bis jetzt unterschiedenen Gattungen . . . . I-50

II. Kerfe und Kerflarven des süssen Wassers, besonders der stehenden Gewässer. Von Dr. E. Schmidt-Schwedt in Berlin.

Einleitende Bemerkungen. - Vergleich mit den Wassersïugetieren. Besondere Wichtigkeit von Atmung und Bewegung. - r. Kïfer: a) Taumelkïfer. - b) Schwimmkäfer. - c) Kolbenwasserkäfer. d) P’arnus, Cyphon, Donacia. — 2. Ziweiflïgler: Larven und I'uppen. Kennzeichnung derselben : a) Mücken : Culex, Anopheles, Dixa, Corethra, Mochlonyx, Chironomus, Tanypus, Simulia. - b) Phalacrocera. c) Stratiomyden. - d) Eristalis. - 3. Schmetterlingslarven: Parapony.x; Iydrocampa, Cataclysta. - 4. Netzflüglcrlarven: a) Irühlingslliegen: Limnoplizilus, Polycentropus, Iyydropsyche. - b) Sialis, Sisyra. - 
5. Geradflïglerlarven: a) Libellen: Agrion-, Libellala-, Acschna-Gruppe, Calopteryx, Gomphus. - b) Eintagsfliegen: Chloëon, Caenis. c) Afterfrühlingsfliegen: Nemura. - Gegensatz der Netzflügler und Geradfügler hinsichtlich des Wasserlebens zu den übrigen Ordnungen. 6. Schnabelkerfe: a) Hydrometriden. - b) Notonecta, Plea. c) Corisa. - d) Nepa, Ranatra, Naucoris. - Schlussbemerkungen: Hinweis auf die Kerfe des Meeres. - Anhang: Tabelle zu annähernder Bestimmung der Kerflarven des Süsswassers . . . . . 51-122

III. Die Mollusken des Siisswassers. Von S. Clessin in Ochsenfurt.

Einteilung der Mollusken. - Wolnorte und Gewohnheiten. - Entwickelung und Alter der Mollusken. - Anpassungsfahighkeit der Mollusken. - Die Mollusken der Tiefenfauma. - Höhlen-Mollusken. Die Perlenmuschel . . . . . . . . . . 123-150

\section{Die deutschen Süsswasserfische und ihre Lebensverhält-} nisse. Von Dr. A. Seligo in Heiligenbrunn bei Danzig.

Das Wasser als Lebenselement der Fische. - Das Süsswasser. Ausbreitung der Süsswasserfische. - Umgrenzung des zu besprechenden Gewïssergebietes. - Der Ursprung der Cypriniden und Salmoniden. Aufzählung der im Gebiete vorkommenden Arten der Knochenfische, Ganoidfische und Neunaugen und die Verbreitung derselben. - Die Organe der Fische und ihre Ferrichtungen: Haut, Schuppen, Glanz, Firbe. - Virbelsäıle. - Kürperform. - Ortsbewegung, Flossen, Muskeln. - Lcibeshöhle, Zwerchfell, Brusthöhle, Herz, Leber, Nieren, Milz. - Mundhöhle und Bezahnung. - Kiemen. - Atmung und Sauerstoff bedürfnis, Fischregionen der Gewïisser. - Darm und Magen. Verdauung. - Körpertemperatur, Einflüsse der Temperatur des Nediums. - Nahrung, Fütterung, Wachstum. - Schwimmblase. Die Fortpllanzungsorgane und das Laichen. - Samenfiden und Eier. fortpflanzung des Aals, des Lachses und der Forellen. - Kü̈nstliche Fischzucht. - Teichwirtschaft. - Einführung auslïndischer und Ausbreitung einheimischer Fischarten auf künstlichem Wege. - Brutpllege. - Gehirn und Sinnesorgane: Auge, Hörorgan, Seitenorgan, Geschmack und Geruch, Tastorgane. - Fischfang . . . 151-208 
V. Die Parasiten unserer Süsswasserfische. Ton Prof. Dr. Fr. Zschokke in Basel.

Algemeines über den Parasitismus. - Verbreitung der parasitischen Würmer der Wanderfische. - Zahl der Arten in den verschiedenen Organen des Fischkörpers. - Aufzählung von 29 Fischarten und ihrer Parasiten. - Nematoden (Fadenwïrmer): Cucullanus elegans, Ascaris acus, Agamonema capsularia. - Echinorhynchen (Kratzer): Echin. proteus, Echin. angustatus, Ecluin. clavacceps. - Trematoden (Saugwïrmer): Distoma laureatum, Dist. globiporum, Dist. nodulosum. Diplozoon paradoxum, Gyrodactylus elegans. - Cestoden (Bandwï̈mer): Caryophyllaeus mutabilis, Cyathocephalus truncatus, Triaenophorus nodulosus, Ligula simplicissima, Schistocephalus dimorphus, Bothriocephalus latus $209-254$

\section{Die quantitative Bestimmung des Plankton im Süss-} wasser. Von Dr. C. Apstein in Kiel.

Einleitung. - Vertikalnetz. - Filtrator. - Konservierung. - Anwendung der Apparate. - Volumenbestimmung. - Vorbereitung zur Zählung. — Stempelpipetten. — Das Hensensche Zählmikrosliop. Zählung und Protokoll derselben. - Ein Beispiel zur Methodik 255-294

\section{Die Fauna des Süsswassers in ihren Beziehungen zu} der des Meeres. Von Dr. Otto Zacharias in Plön (Holstein).

Das Vorkommen von marinen Gattungen im Süsswasser. - Reliktenseen. - Eine Meduse als Bewohnerin von Strandseen auf Trinidad. Die Einwanderung von Meerestieren in den Ortoire-Fluss. - Freischwimmende MIuschellarven (Dreyssena polymorpha) im Süsswasser. Die Verbreitung der kleinen Wasserfauna durch ,passive WVanderung" Der Süsswasser-Monotıs. - Die ,Fauna relegata" des Professors Pavesi. - Der Transport kleiner Wasserorganismen durch Schwimmvögel, WVasserkïfer und strömende Luft. - Hakenborsten und Klebzellen der Würmer als Anheftungswerkzeuge. - Das Wandern der Wasserschnecken und Muscheln. - Spezialisierte Haftorgane bei Protozoen (Diffugia) . . . . . . . . . . 295-3í2 
VIII. Über die wissenschaftlichen Aufgaben biologischer Siisswasser-Stationen. Von Dr. Otto Zacharias in Plön (Holstein).

Die Begründung der "Biologischen Station" zu Plön. - Vorteile eines solchen Forschungsinstituts, - Die pelagischen Organismen des Grossen Plöner Sees. - Die besonderen Aufgaben von Süsswasserstationen. Die Winterfauna unserer Binnenseen. - Beobachtung der Wasserinsekten und der im Wasser lebenden Larven von Landkerbtieren. Erforschung der eigentümlichen Fortpflanzungsverhuiltnisse mancher Turbellarien und Oligochäten. - Faunistische Exkursionen und vergleichende Untersuchungen. - Praktische Gesichtspunkte. - Beschreibung der Plöner Station. - Die Erforschung der bühmischen Gewiisser durch Prof. Anton Fritsch . . . . . . 313-33I

\section{Das Tierleben auf Flussinseln und am Ufer der Flïsse} und Seen. Von Fr. Botrcherding in Vegesack:

Einleitende Bemerkungen. - Die Säugeticre an und in dem Süsswasser. - Die Brutvögel. - Die Gäste auf dem Frühjahrs- ¡und Herbstzuge. - Die Sumpfschildkröte, Emys europaca Gray. - Die Anuren und Urodelen des süssen WVassers. - Die Fischfauna eines Flusses, eines Geest- und eines Moorsees. - Dic Mollusken an und in den Gewïssern. - Die niedere Tierwelt. . . . . 333-369 


\section{Die Hydrachniden (Wassermilben).}

Von Prof. Dr. P. Kramer in Halle a. d. S. 

Die Hydrachniden oder Süsswassermilben gehören mit ihren auf dem Lande lebenden Verwandten jenem unermesslichen Heere spinnenartiger Tiere an, welche im Systeme der Zoologen den Namen Acarida tragen, und deren Formenreichtum bei einem gewissen gemeinsamen Grundzug der Gestalt ein ausserordentlich grosser ist.

Noch bis gegen Ende des vorigen Jahrhunderts waren es im ganzen nur wenige Milben, auf welche sich die Aufmerksamkeit der Beobachter gelenkt hatte. Sie gehörten zumeist den auf dem Menschen und den Haustieren lebenden Schmarotzern an und wurden um der Krankheiten willen, die sie hervorrufen, beachtet und beschrieben. Die erste grössere Arbeit über andere Acarida lieferte erst der sorgfilitig beobachtende und scharftlickende dïnische Naturforscher O. Fr. MIüller, indem er im Jahre I $78 \mathrm{r}$ eine grosse Zahl der in Dänemark einheimischen Süsswassermilben abbildete und die vortrefflichen Abbildungen durch kurze Erklïrungen erläuterte. So war es also gerade die uns beschäftigende Milbengruppe, welche zuerst mit einer für lange Zeit unerreichten Vollständigkeit behandelt worden ist.

Manches Jahrzehnt hindurch geschah darnach für die nähere Kenntnis der Acariden wenig Entscheidendes. Erst die Arbeiten Dugès' 1834 und des Forstrats C. L. Koch 1837-I 850 bezeichnen einen neuen wesentlichen Fortschritt. So brachte namentlich des ersteren eingehende Darstellung die Kenntnis der Entwickelung von Hydrachna globosa, während letzterer durch die 
grosse Zahl der von ihm beobachteten Milben, unter denen sich auch sehr zahlreiche Süsswissermillben befanden, zuerst überhaupt eine Vorstellung von dem Reichtum der Milbenklasse gab, wenn auch freilich die nicht hinreichende Genauigkeit seiner Abbildungen und Beschreibungen dem Systematiker noch heute viel Mühe bereitet.

In der neuesten Zeit ist den Acariden ein immer grösseres Interesse entgegengebracht worden, wenn auch lange noch nicht in dem Maste, als es die in mehr als einer Hinsicht merkwürdige Lebens- und Entwickelungsgeschichte derselben verclient. Allerdings sind die Beobachtungsobjekte meist sehr klein und schwierig zu behandeln und daraus mag sich der im ganzen langsame Fortschritt unserer Kenntnis über diese Tiergruppe erklären. Die Süsswassermilben bilden aber noch die am wenigsten Schwierigkeiten bietende Gruppe und laden durch ihre zierliche Gestalt und MIunterkeit des Wesens, auch durch verhältnismässige Grüsse zur Beobachtung ein. Auch sind sie fast überall reichlich $\mathrm{zu}$ finden, wo nur irgend fliessendes oder stehendes Wasser Jahr für Jahr vorhanden ist.

Die meisten anderen Milben bleiben unserem Auge in der Regel verborgen, obwohl es kaum einen Ort geben dürfte, wo einem genaueren Beobachter nicht irgend eir charakteristischer Vertreter dieser Tiergruppe begegnete. Zumeist möchte wohl eine feuchte Umgebung dem Leben dieser der Mehrzahl nach zarten Geschöpfe günstig sein, aber doch wird man auch an den kahlen, in trockenster Luft des Sommers am Wege liegenden sieinen nicht umsonst nach einer mit zierlichem Stechapparat versehenen blauroten Acaride (Bryobia speciosa) suchen, der sich noch manche Vertreter unserer zierlichen Panzermilben (Oribatidac) anschliessen. Milben finden sich unter Laub und Steinen, im Moose und auf den Blättern der Bäume, auf und unter ihrer Rinde und im anbrüchigen Holze, auf und unter der Haut zahlreicher kalt- und warmblütiger Tiere, auf den Federn der Vögel, ja sogar in denselben: wo sich nur überhaupt irgendwelche Nahrung darbieten mag, sei sie natürlichen oder künstlichen Ursprungs, überall begegnen wir Milben, ihre Leibesgestalt oft in wunderbarer Weise 
dem Aufenthaltsort anpassend und ihre Lebensgewohnheiten einrichtend nach den Bedingungen, die derselbe bietet.

Bei der immer noch vorhandenen sehr unvollständigen Kenntnis auch unserer heimatlichen Nilben ist es noch nicht möglich gewesen; eine sogenannte natürliche Anordnung dieser Tiere vorzunehmen, d. h. eine solche, bei welcher die Abstammung, die gegenseitige V'erwandtschaft ausscillaggebend ist, doch heben sich schon einige grüssere Verwandtschaftskreise aus dem Schwann der ïberhaupt hierhergehürigen Tiere ab. So bilden die soeben schon erwähnten Panzermilben, denen jeder Sammler am häufigsten im Moose begegnet, einen in sich vüllig abgeschlossenen Stamm. Sie sind reine Landbewohner, und wenn man auch in jüngster Zeit im Meere einige Vertreter gefunden haben will, so ist das doch mit Torsicht aufzunehmen. Ebensu stellen die Gamasidac, diejenigen Milben, zu welchen die auf den Dungküifern so häufig scharenweise anzutreffenden braunen Acariden gehüren, eine wohl abgeschlossene Gruppe dar. So vielgestaltig aber auch die Wohnstïtten derselben sind, in das Wasser ist doch keins davon hinabgestiegen. Zwar hat man einen ihrer Vertreter in den wohl gewiss mit Wasser stets und reichlich bespülten Nasengüngen einer Seehundsart aufgefunden, auch haben eifrige Naturforscher unter den durch die Flutwelle regelmässig überspülten Steinen des Seestrandes einige Gamasiden entdeckt, aber wirkliche Wassertiere haben wir damit doch nicht vor uns. Nicht besser steht es mit den zahllosen Geschlechtern der die Haut und die Federn der Vögel oder die Haare der kleinen Süugetiere bevülliernden Milben (Sarcoptidai) oder denjenigen, welche dem grossen Stamm der durch die Mehlmilbe gekennzeichneten Acariden (Tyroglyplidac) angehüren. Wenn sie auch meist der Feuchtigkeit als einer notwendigen Voraussetzung ihres Lebens bedürfen, so sind sie doch niemals Bewohner unserer Teiche und Flüsse geworden. Einzig und allein diejenige Gruppe unter den Milben, denen ich die allgemeine Bezeichnung Vurderatmer gegreben habe, weil sie ihre beiclen kleinen I_uftlïcher ganz vorn an dem kegelfürmig hervorspringenden Mundilwschnitt führen, bietet uns Beispiele von auch dem Leben in Wasser angepassten 
Milben dar. Diese Vorderatmer werden am besten durch die so häufig in unseren Gärten am Fusse der Obstbäume anzutreffende Samtmilbe (Trombidium fuliginosum) veranshaulicht. Trombidiunartige Milben also sind es, welche in grosser Zahl die süssen Gewässer, nur mit wenigen Arten die See bewohnen.

Eine Naturgeschichte dieser Iydrachniden muss vor allen Dingen ein Bild der ausserlich wahrnehmbaren Gestalt entwerfen und so mag sich denn zunächst darauf die Aufmerksamkeit richten.

Ein Zug mit dem Fangnetz durch das klare Wasser eines Teiches fördert in der Regel ausser zahlreichen kleinen Krustern auch manche undurchichtige und durchsichtige Hydrachnide zutage. Wir entnehmen eine Milbe der letzteren Sorte, es ist eine

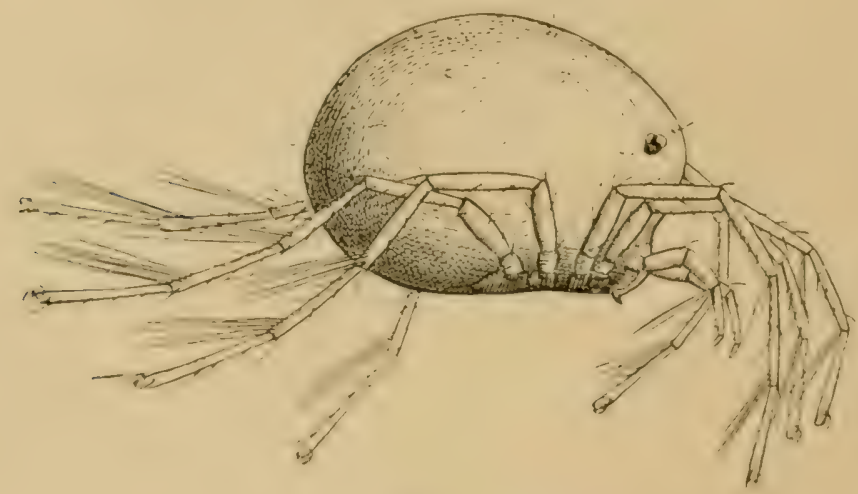

Fig. I:

Piona flavescens, von der Seite gesehen.

Piona flavescens, und betrachten sie, nachdem sie in ein Uhrgläschen übergeführt ist, zunächst mit der Lupe.

Der rundliche Rumpf ist, wie wir bald bemerken, ungeteilt, oben hochgewölbt, unten abgeflacht, so wie Fig. I es zeigt. Bei den meisten Hydrachniden hat er diese Gestalt, nur ausnahmsweise treffen wir einen flachen Rumpf, einen stark in die Länge gezogenen, oder einen durch besondere Anhïnge am hinteren Rande ausgezeichneten. Der vorderen Hälfte der Unterfläche entspringen die acht Füsse. 
Wie schlank und zierlich sind diese hellen völlig durchsichtigeii Füsschen, die das Tier oft in ganzer Länge von sich streckt und so eine Zeitlang still und unbeweglich liegen bleibt, um mit einem plötzlichen Ruck eine Strecke fortzueilen. Wieder liegt es still da und fingt nach einer kurzen Ruhe an langsam auf dem Grunde fortzukriechen. Jetzt eilt es wieder, sich wie im Wirbel überschlagend, in hastiger Bewegung eine Strecke fort, um bald $\mathrm{zu}$ ruhen, bald langsam im Wasser $\mathrm{zu}$ wandeln.

Betrachten wir die einzelnen Füsse noch genauer, so fallen besonders an den hinteren Paaren lange, seidenglänzende Haarborsten auf, welche gedrängt stehen und leicht beweglich sind. Die zahlreichsten bemerken wir am vorletzten und drittletzten Gliede der beiden hinteren Fusspaare. Es sind dies die für unsere Süsswassermilben ganz besonders charakteristischen Schwimmborsteri, und von ihrer Anzahl, ihrer Breite und Stellung hảngt zum grossen Teil die Gewandtheit und Schnelligkeit ab, mit der sich die Tierchen im Wasser bewegen. Als Regel können wir annehmen, dass bei den erwachsenen Milben die vorderen Füsse nur wenige, die hinteren dagegen zahlreiche Schwimmborsten führen, und dass wiederum an jedem Fusse, der überhaupt welche besitzt, das vorletzte Glied die meisten, die dem Körper näheren Glieder immer weniger solche Borsten tragen. Ausnahmen von dieser Regel sind allerdings beobachtet. So bemerkt man, dass bei einer der grössten einheimischen Arten, einer der schnellsten und gewandtesten Schwimmerinnen, Eylaïs extendens, welche als tiefrote Jägerin die Wasser durcheilt, das vierte Fusspaar gar keine Schwimmborsten besitzt. Das Tier hat sich daher gewöhnt, den letzten Fuss jeder Körperseite beim Schwimmen ruhig nach hinten gestreckt zu tragen. Diese Haltung giebt ein untrügliches. Erkennungsmittel für die soeben namhaft gemachte, in unseren stillstehenden Gewiissem häufigere MIilbe ab. Einigen Wassermilben fehlen die Schwimmborsten sumar gänzlich. Sie sind dadurch gezwungen, eine durchaus kriechende Lebensweise zu führen, und leben meist im Schlamme verborgen.

Wie wenig übrigens der Besitz oder Mangel von Schwimmbarsten eine Verwandtschaft zwischen manchen in diesem einen 
Punkte übercinstimmenden MIiben mit sich bringt, beweisen zwei Gattungen, deren Vertretern die Schwimmborsten fehlen, nämlich Bradybates und Limnochares (die Tiefschreiter und Schlammfreuncle). Diese Milben sind in ihrer ganzen Erscheinung ausserordentlich verschieden von einander. Erștere müchte wohl als das Urbild einer, der Lebensweise im Wasser angepassten Samtmilbe angesehen werden künnen, so vollständig wiederholt sie Zug um Zug die Gestalt dieser Landmilbe. Ganz anders bietet sich Limnochares dem Beobachter dar. Ein unfürmlicher linsengrosser roter Klumpen, welcher mühsam von den auffallend kurzen dünnen Füssen fortgeschleppt wird und das langgezogene schnabelfürmige MIundstück beim Zurückziehen ganz in sich aufzunchmen vermagr, ist sie ganz darauf angewiesen, dass die Tragkraft des Wassers ihre Muskeln bei der Fortbewegung ihres Leibes unterstützt.

Hervorgehoben mag noch werden, dass das Schwimmborstensrstem am ausgebildetsten bei den Hartmilben des süssen Wassers, den Hartschwimmern, deren hervorstechendste Gattung A Iremurus (Hartschwanz) ist, gefunden wird. Hier zeigt jeder der beiden Hinterfüsse eine doppelte Reihe solcher Borsten.

Steht es nun auch gewiss fest, dass die Schwimmfertigkeit durch die Schwimmborsten wesentlich bedingt ist, so beweist doch die Beobachtung derjenigen Milben, welche die tiefen Regionen des Genfersees bewohnen, dass damit die Frage nach den Gründen des Schwimmens noch nicht ganz erledigt ist. Dort im Genfersee, und vermutlich auch in anderen sehr tiefen Seen der Schweiz, hat Prof. Furel in den tiefsten Schichten eine Hyclrachnide gefunden, welche sich trotz aller vorhandenen Schwimmborsten nicht imstande zeigt, den Buden zu verlassen und schwimmend die Oberllïche zu erreichen. Wird eine solche Milbe in ein noch so flaches Gefiss gethan, so vermag sie nur auf dem Boden zu kriechen. Wird ihr, wenn man sie an die Oberfliche gezogen hat, der Unterstïtzungsfunkt genommen, so sinkt sie trotz allen Fusslewegungen, die sie alusführt, doch auf den Boden zurück. Offenbar hat sie sich unter dem Einfluss des bereits erheblichen Wasserdrucks auf dem Boden des Genfersees entwöhnt, von ihren schwimmborsten einen richtigen 
Gebrauch zu machen, sie hat ihre Füsse niemals im Schwimmen geübt und hat so, trotz den vorhandenen Schwimmborsten, die zum Schwimmen notwendigen liriftigen Bewegungen diuternd verlemt. Es scheint also auch ein richtiger Gebrauch der sonst zum Schwimmen hinreichend ausgerüsteten Füsse vorausgesetzt werden zu müssen, damit die Schwimmborsten eine dem Wasser hinreichenden Widerstand entgegensetzende Fläche bilden und so die Fortbewegung bewirken können.

Wir wenden uns nun wieder der Gestalt unserer Piona zu. Während die gewölbte Oberseite derselben dem beobachtenden Blick ausser den deutlich wahrnehmbaren dunklen Augenpunkten wenig bietet, wird er, nachdem man die Milbe auf den Rücken. gelegt hat, bei Betrachtung der Unterseite von einigen besonderen Organen gefesselt.

Auf der Bauchflḯche bemerkt man nämlich vier von einander getrennt stehende härtere Hautplatten, und an jeder sind zwei Füsse eingelenkt*). Bei näherer Betrachtung ergiebt es sich, dass jede der Platten aus zwei mit einander verschmolzenen Plättchen zusammengesetzt ist und dass jedes der acht Plïttchen die Gelenkhöhle für das Hüftglied je eines der acht Füsse trägt. Wir nennen die Plättchen die Hüftplatten der Füsse oder die Epimeren. Unsere Piona flavesccns lüsst erkennen, dass die Hüftplatten für die beiden vierten Füsse, rechts und links, die umfangreichsten sind. Das ist nicht immer der Fall. Überhaupt finden wir in der Ausbildung und gegenseitigen Gruppierung dieser Epimeren eine so ausserordentliche Mannigfaltigkeit, dass nicht mit Unrecht die hieraus sich ergebenden Unterschiede zur schürferen Trennung der Gattungen verwendet worden sind.

Zwischen den Epimeren der beiden vorderen Füsse befindet sich der Mundapparat, in der Regel gestützt durch eine vermutlich als Unterlippe zu deutende, erhärtete Platte. Diese Platte trägt zunächst die meist fünfgliedrigen Taster.

*) Vergleiche auch Fig. 3 e S. 39 . 
Dieselben dienen wohl hauptsïchlich dem Gefühlssinn, werden aber auch zum Festhalten der Beute benutzt. Die Mundöffnung selbst wird in der Regel in der Tiefe eines oben offenen, eine kurze IFalbrïhre darstellenden kopfithnlichen Anhangs gefunden, in welchem sich als wesentlichstes Mundwerkzeug die Kaukiefer eingelassen finden. Diese Kiefer bilden einen wichtigen Anhalt zur Untersheidung griosserer Abteilungen unter den Süsswassermilhen. indem sie bei einigen Gattungen eingliedrig sind und die Gestalt eines kriftigen nach vorn gerichteten Stachels haben, bei anderen dagegen aus zwei Gliedern bestehen, von denen das zweite einer mit der Spitze nach oben gewendeten Kilaue oder Kralle gleicht. Ganz derselben Verschiedenheit begegnet man auch bei derjenigen Gruppe der Landmilben, welche ich bereits oben als die den Süsswassermilben am nächsten stehende bezeichnet habe, bei den Trombididen.

Was für Gliedmassen oder Teile ausserdem noch zu dem Mundapparat gehoren, ist noch durch weitere Beobachtungen genauer zu erforschen. Es giebt nach Ansicht einiger Beobachter noch ein zweites Kieferpaar, welches dieselben in gewissen verhärteten Stäbchen entdeckt zu haben glauben, während andere diese Deutung jener Stäbchen leugnen. Es ist daher auch die verwandtschaftliche Stellung der Milben durchaus noch nicht allgemein festgestellt. Die einen, z. B. G. Haller, wollen sie zu den krebsartigen Tieren ziehen, indem das Vorhandensein einer grössern Anzahl von Kiefern dafür geltend gemacht wird. Die anderen sind der Meinung, dass die Milhen den spinnenartigen Tieren zuzuzihblen sind. Sicherlich kamn hierüber lediglich aus anatomischen Gründen ein sicheres Urteil nicht gezogen werden, vielmehr muss die Entwickelungsgeschichte ein entscheidencles Wort mitsprechen. Viellevicht gedinet es zuniichst aus den an Gamasiden nuch anzustellenden liculbathtungen, hierüber mehr Licht zu verbreiten.

Auf der Unterseite unserer Milben begegnen wir nun noch

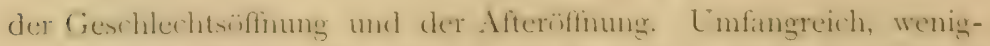
stens heim weiblichen (iesthlechte, ist die crstere, meist punktfimmig klein die zweite, jedoch fehlt letztere nirgends, wie irrtümlich 
behauptet worden. Die Geschlechtsöffnung ist bei den allermeisten Gattungen von eigentümlichen, entweder napfartigen oder porenartigen Gebilden begleitet, welche meist neben ihr zu Gruppen rereinigt auf besonderen verhärteten Plittchen aufgestellt oder in die weiche Haut eingebettet sind, in einzelnen Fällen aber auch auf der innern Fläche der die Öffnung schliessenden Klappen ihren Platz gefunden haben. Die Abbildung dieser Gebilde, wie sie sich beim Münnchen und Weibchen von Nesaea fuscata finden, in Fig. $3 i$ und $k$, giebt wohl eine hinreichend deutliche Vorstellung davon. Stehen diese sogenannten Haftnäpfe neben der Geschlechtsöffnung, so dürften sie kaum noch ihrem Zweck als Haft- oder Tastorgan genügen, finden sie sich dagegen auf der innern Deckklappenfläche, so ist ihre" Funktion noch unbeeinträchtigt.

Die einzelnen Gattungen der Wassermilben zeigen in der Zahl, Anordnung und Grösse dieser Näpfe eine so ausserordentliche Verschiedenheit, dass sie hierdurch häufig mit grosser Leichtigkeit von einander unterschieden werden können. Es gehören diese Haftnüpfe zu einer ganz besonders charakteristischen Eigentümlichleit gerade unserer Süsswassermilben, so dass es gerechtfertigt erscheint, noch einen Augenblick bei ihnen zu verweilen. Es sind offenbar umgebildete Oberhautporen. Betrachtet man nämlich die Oberflïche einer Süsswassermilbe genauer, so findet man dieselbe mit einer Anzahl regelmässig verteilter grösserer Porenöffnungen versehen, welche meistens zu kleinen, häufig aber auch sehr umfangreichen Hautdrüsen führen. Bei sehr vielen Milben ist die nächste Umgebung einer solchen Pore verhärtet, so dass dort eine kleine Platte in die Haut eingelassen scheint, auch wird die Öffnung regelmiissig von einer Haarborste begleitet. Diese Hautdrüsen mögen wohl rine Flüssigkeit absondern, welche anderen Wassertieren Ekel erregt. so dass sie die Wassermilben nicht verspeisen mögen. Hat man doch beobachtet, dass unsere Milben von den Fischen verschmäht werden. Welchen Vorrat an solcher Flüssigkeit diese Hautdrüsen, wenn sie enorm entwickelt sind, enthalten, lïsst sich bei den Hartmilben (Arrentrus) erkennen. Wird eine solche in Spiritus gelegt, so fährt nach kurzer Zeit der Drüseninhalt wie ein langer sich 
kräuselnder Faden aus der Pore hervor, so dass die ganze Milbe völlig eingewickelt wird. Nun ist es wohl nicht falsch geurteilt, wie bereits oben angedeutet wurde, wenn wir annehmen, dass die Haftnäpfe auf der Lnterseite des Hinterleibes ursprünglich solche Hautdrüsenüfnungen gewesen sind. Die ursprünglichen Drüsengebilde sind aber in Haftorgane umgewandelt und dementsprechend hat sich die Öffnung samt der Platte, in welcher sie steht, umgestaltet. Meistens bemerkt man noch deutlich innerhalb des Cmrisses eines sulchen Napfes die Porenöffnung. In anderen Fällen ist sie aber auch schon geschwunden, was darauf hindeutet, dass das Organ seine Funktion wieder eingebüsst hat.

Wenn ich soeben bemerkte, dass diese Haftnäpfe eines der wesentlicheren Merkmale unserér Süsswassermilben darstellen, so ist damit dennoch nicht gesagt, dass es unter ihnen nicht auch solche grabe, die überhaupt dieser Organe entbehrten. Dic Mannigfaltigkeit der Formen, die wir allerwärts im Tierreiche finden und die dem urdnenden Zoologen oft so viele Schwierigkeiten entgegenstellt, findet sich auch bei den winzigen, das süsse Wasser belebenden Acariden. Die Kråfte der Natur lassen sich in kein Schema und System zwingen, sondern gestalten die Formen nach den vorhandenen Lebensbedingungen aus. So mag es denn wohl sein, dass die Masse der das süsse Wasser bevölkernden Milben aus mehreren verschiedenen Hauptstitmmen erwuchs, deren Ursprung wir nicht mehr deutlich unterscheiden können. Der eine Stamm, der namentlich alle schwimmenden Süsswassermilben umfasst, hat Haftnäpfe auf der Bauchfläche erzeugt, der andere, zu denen einige kriechende Gattungen zu rechnen wären, hat solche Näpfe nicht hervorgel racht. Es ist auch bemerkenswert, dass die ersten Larvenstadien, also die eben dem Ei entschlüpften Jungen, keine Haftnäpfe besitzen.

Im Vorhergehenden sind die wesentlichsten Organe und die hauptsichlichsten Erscheinungen der äussern Gestalt kurz berührt. Es wird später sich noch Gelegenheit bieten, manches, was jetzt übergangen werden musste, so z. B. die besonderen Kennzeichen und Abzeirhen der Männchen im Gegensatz zu den Weibchen, zur 
Sprache zu bringen und so das Bild der äussern Gestalt zu vervollständigen. Auch die Beschaffenheit der ïussem Körperhaut, (t) sie hart oder weich ist, ob glatt oder mit Fortsätzen versehen, hat wohl für die Beurteilung der äussern Gestalt im weitern Sinne Bedeutung, kann jeduch in einer nur kurz schildernden Darstellung bloss andeutungsweise berührt werden. Ebenso ist es mit dem Grössenverhältnis der Glieder zum Rumpfe, indem nur erwähnt werden kann, dass der Rumpf wie bei Atax gegen die ungemein grossen Füsse fast verschwindet, während bei anderen Gattungen, wie beispielsweise Axona, die Füsschen kaum über den Rand des Rumpfes hervorragen. Dies Alles und manches Andere würde einer Spezialgeschichte der Hydrachniden Stoff zu ausführlichen Betrachtungen geben. Wir aber verlassen die äussere Gestalt und wenden uns einer weitern wichtigen Angelegenheit zu, der Darstellung der inneren Organe.

Die inneren Organe sind in neuester Zeit mehrfach eingehend beobachtet und beschrieben worden. Wir finden in der Regel eine sehr feine, nach hinten sich erweiternde Speiseröhre, deren vorderer Abschnitt zu einem Saugapparat umgewandelt ist, indem Muskelstränge sich an der obern und untern Röhrenfläche ansetzen, welche diesen Teil des Organs abwechselnd erweitern und verengern künnen. Der MIagen ist sehr umfangreich und besitzt bis fünf blindsackartige Ausstülpungen, deren Oberfläche mit einer Schicht von Leberzellen ausgerüstet ist. Der Enddarm ist in der Regel wiederum ein Kanal von ziemlicher Enge. Die Speiseröhre steht in ihrem vordersten Abschnitt in Zusammenhang mit den nicht unerheblichen Speicheldrüsen. Diese sind in der Regel in mehrfacher Anzahl vorhanden, führen jedoch immer nur jederseits zu einer einzigen Ausflussüffnung. Der Enddarm seinerseits nimmt in seinem letzten Abschnitt den Ausführungsgang der charalteristischen Exkretionsdrüse auf, welche bei allen Milben zu einer so ausserordentlichen Entwickelung gelangt ist. Diese Drüse liegt oberhalb des Magrens und besitzt einen längeren Hauptstamm, welcher sich etwa in der Mitte des Rückens in zwei Äste gabelt. Da der Inhalt dieser Exkretionsdrüse merklich durch die Haut der Mehrzahl der IỊdrachniden 
hindurchschimmert, so hat sie von jeher die Aufmerksamkeit der Beobachter erregt, aber auch solche, die auf die Färbung der Milben ein allzugrosses Gewicht legten, oft irregeführt, da je nach der Füllung der Farbeneindruck ein sehr verschiedener sein kann.

Das Atmungssystem wird bei den Hydrachniden durch zwei in ausserordentlich zahlreiche Tracheenficlen auscinanderfahrencle Tracheenstimme dargestellt, welche in einem Paar von Luftlüchern antiminden. Diese letzteren liegen zwischen den Einlenkungsstellen der Kiefer in einer kleinen Platte. Der Hąuptstamm jeder Trachee ist mit einem Spiralfaden versehen, während die zarten Tracheenfäden selbst keine solchen besitzen.

Das Tracheensystem tritt auch bei den Hydrachniden gerade so wie bei allen anderen Niilben, wo es überhaupt zur Ausbildung getangt, erst nach der crsten Häutung auf, die sechsfüssigen Larven hesitzen noch keine Andeutung davon. Die Luftatmung der Wassermilben giebt uns hier nun Veranlassung, einen kurzen Blick auf andere luftatmende Wassertiere zu werfen.

Tergleicht man das Betragen der hierher gehürigen verschiedenen, dem nieden Tierreich angehürenden Eewohner des süssen Wassers, so bemerkt man bald einen sehr in die Augen fallenden Unterschied. Die Wasserkäfer z. B. und die Mehrzahl der Wassenvanzen vermögen nur kurze Zeit zu tauchen. Immer wieder müssen sie die zum Atmen nötige Luft unmittelbar aus der über dem Wasser

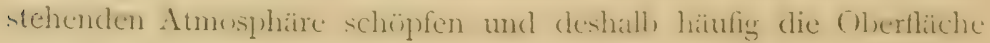
aufsuchen. Auch vielen Mückenlarven geht es nicht besser, sie fahren unruhig bald in die Höhe, bald in die Tiefe. Dagegen sind die in dias Wasser cingewanderten Milhen vällig und ausschliesolich Wassertiere geworden. Sie bleiben stets unter der Obierflache, trotzdem dass sie ein ausgebildetes Luftatmungssystem besitzen. Sie hüllen sich auch nicht etwa, wie zahlreiche Uferkäfer und die merkwürdige grosse Wasserspinne (Argyroncta aquatica), in einen dichten Mantel von Luft, den sic unausgesetzt mit sich führen und immer wieder erneuern, sondern leben gerade wie die Larven von zahlreichen Libellen, Frühlingsfliegen und Mücken nur und allein im Wasser. Ihr Luftröhrensystem ist trotzdem, dass sie niemals 
die Oberfläche aufsuchen, mit Luft durchaus angefüllt. Es weist uns diese Beobachtung auf einen wohl noch nicht ganz aufgekliärten Naturvorgang. Die Frage, auf welche Weise die Luft in die Atmungskanïle der Süsswasscrmilben gelangt und wie sie sich, nachdem sie etwa durch Atmen verbraucht worden ist, wieder erneuert, ist es, welche dabei noch der Lösung harrt. Unter ganz ähnlichen Verhältnissen atmen die durchsichtigen Larven der bei uns häufigen Büschelmücke (Corethra plumicornis). Bei dieser hat der bekannte Zoologe A. Weissmann zuerst beobachtet, dass in den beiden grossen Paaren von Luftsäcken, welche dem Tier zur Aufrechterhaltung des Gleichgewichts beim Schwimmen zu dienen scheinen, die Luft während eines bestimmten Zeitpunktes der Entwickelung ganz von selbst auftritt, ohne dass in der Wandung jener Blasen auch nur die geringste Öfnung vorhanden wäre oder irgend eine Verbindung derselben mit der Oberhaut des Tieres bestünde. Die Luftfüllung tritt plötzlich auf und verbleibt dann in den Blasen. Bei den Wassermilben, welche nach der ersten Häutung zahlreiche Tracheen besitzen, könnte es vielleicht ebenso sein, indem die Luft sich ganz von selbst innerhalb der vorher mit Flüssigkeit angefüllten Luftkanäle bildet. Denn es ist in der That schwer denkbar, dass die im Wasser verteilte Luft sich in die feine Ausmündungsstelle der Luftkanăle eindrängen könne, um von da aus in die zuletzt überaus feinen Fäden zu gelangen. Ein Saugapparat ist bisher an den Atmungsröhrchen noch nicht beobachtet und allein ein solcher künnte die Luft dazu vermügren, die Flüssigkeit aus den Luftrühren zu verdrängen. Genug, wir erwarten von der Zukunft hier, wie noch für so manche Vorkommnisse, eine befriedigende Erklïrung der Thatsachen.

Die Hydrachniden sind getrennten Geschlechtes. Die samenerzeugenden Órgane des Männchens sind wohl in der Regel paarig und haben einen gemeinsamen Ausführungsgang, welcher mit einem besondern Begattungsorgan versehen ist. Die Eierstöcke der Weibchen sind zwar auch paarig, jedoch sind sie mit ihren Enden derart verschmolzen, dass sie ein einziges ringartiges Organ darstellen; die beiden Eileiter sind jedoch zunächst getrennt und bilden erst kurz vor der Geschlechtsöffnung einen kugeligen Uterus. 
Das Nervensystem besteht in einem zentralen sogenannten Schlundganglion und den von diesem ausgehenden Nervensträngen. Das Schlundganglion wird der Länge nach von der Speiseröhre durchsetzt, wodurch es in ein oberes und ein unteres geteilt wird, die indes so nahe an einander gerückt sind, dass sie eine gemeinsame IIasse bilden, an welcher keine Schlundkummissur auffindbar ist*).

Vom obern Schlundganglion gehen die Nerven zu den Augen und den Mundteilen, von dem untern dagegen zu den Füssen und den Geschlechtsorganen. Die Nervenfüden spalten sich übrigens häufig und lösen sich mit Ausnahme der Augennerven in eine Fülle von überallhin sich verbreitenden Nervenfasern auf.

Das Nervensystem möge uns noch einen Augenblick länger fesseln. So klein und zum Teil winzig unsere Süsswassermilben auch sind, so entbehren sie doch der die Aussenwelt auffassenden Sinne nicht. Gesichts- und Gefühlssinn haben sogar eine hohe Entwickelungsstufe erreicht. In der Regel finden wir bei den Hydrachniden zwei Paare von Augen. Dieșe stehen entweder weit von einander getrennt, wie bei jener oben genauer bespruchenen Piona, uder sie sind auf der Mitte des Vorderrückens dicht an einander gestellt, so dass sie an die Augen der Weberknechte (Phalangidae) erinnern. Mag nun die Anordnung die eine odet die andere sein, jedesmal findet sich in einem Milbenauge eine Linse, welche dis Licht nach einem hinter ihr gelegenen Punlite bricht, und eine becherfömirgestaltete Netzhaut mit dunklem l'igment, welche dic Lichteindrücke zur Emplindung bringt. Der Sehnerv leitet dieselten daun dem when erwähnten Gehirn zu. Ob nun die Milbe wohl einen Gesamteindruck von ihrer Umgelung durch ihre Augen gewinnt? Jedenfalls kummt bei Beantwortung dieser Frage der allgemeine Stand des Seelenlebens in betracht und nicht bloss die physikalische Vullitummenheit des Sehapparats. I)iss sie aluer scharfe und dentliche lindrücke durch ihren Gesichtssinn erhalten, scheint mir aus der grossen Raschheit hervorzugehen, mit welcher die Mehrzahl der Süsswassermilben,

*) Dr. v. Schaub, „Anatomic von Hydrodroma“", p. 29. 
welche des Schwimmens kundig sind, entgegenstehenden IHindernissen ausweichen. Allerdings wird hier, wie auch sonst wohl vielfach im Tierreiche, der Gesichtssinn offenbar durch den sehr entwickelten Tastsinn unterstützt. Bei unseren Milben sind Tastorgane in ganz ähnlicher Weise, wie bei den übrigen Gliedertieren, über den ganzen Körper verbreitet und ragen als Haartaster über die Oberfläche des Leibes hervor. NIan wird wohl nicht irregehen, wenn man die in grosser Regelmässigkeit, wenn auch meist in ziemlich spärlicher Anzahl auf der Haut der Tierchen allenthalben zerstreuten, meist kurzen Haarborsten als ebenso viele Tastorgane ansieht. Ebenso ist ein grosser Teil der auf den Beinen und namentlich den Tastern befindlichen Haarborsten zu den Fühlhaaren zu rechnen. An zahlreichen grossen Borsten, welche die ersten Füsse schmücken, hat man die Einrichtung sılcher Fühlhaare genauer untersucht. Die Haarborste steht in einer kleinen Pore der Oberhaut; sie ist selbst zumteil hohl und mit lebendiger Substanz ausgefüllt, welche durch die Pore hindurch mit dem Innern des Milbenkörpers in Zusammenhang steht. Unmittelbar unter das in der Porenöffnung stehende Ende der Borste hat sich ein Nervenfaden hinbegeben und dort ein kleines Knötchen gebildet, welches, sobald durch irgend eine iussere Veranlassung clie Borste gedrückt oder gezerrt wird, durch das untere Borstenende gestreift und in Mitleidenschaft gezogen werden muss. Hierdurch liommt die Tastempfindung und zugleich auch jedenfalls eine Ortsbestimmung zu stande. Die Oberhaut des Tierchens ist, da sie aus einer festen widerstandsfähigen Masse gebildet ist, an sich einer Empfindung nicht fähig. Dieser Mangel wird durch jene Tastborsten fast völlig ausgeglichen. Man hat übrigens auch in dem der Haut von innen anliegenden Zellengewebe zahlreiche Nervenelemente entdeckt und so ist es auch möglich, dass ein an irgend einer Stelle auf die weiche und nachgiebige Hautfläche bei den weichhäutigen $\mathrm{Hy}$ drachniden ausgeübter Druck auch ohne besondere Tasthatare eine Gefühlsempfindung auslöst.

In ganz besonderer Weise sind, wie sich wohl vermuten lïsst, die Taster mit Gefühlshaaren ausgerüstet. Es ist dies um so 
notwendiger, als die meist weit vom MIunde und auf der Stirnwölbung aufgestellten Augen die Limgebung des IIundes nicht zu übersehen vermögen. Von den Mlundteilen kann also nur nach hestimmten Gefühlscindrücken gehandelt werclen. Diese werden durch dicht aufgestellte Tasthaare vermittelt.

Ähnlich ist auch die Unterseite der Füsse und zwar namentlich ihrer Endglieder mit zahlreichen kurzen Haaren versehen, welche beim Schreiten und wohl auch beim Schwimmen, wie ferner beim Ergreifen der Beute die Tastempfindungen veranlassen.

So haben die unscheinbaren und auf den ersten Blick willkürlich über den Körper verstreuten Haarborsten einen wichtigen Beruf.

$\mathrm{Ob}$ die Wassermilben Gehörs- und Geruchsempfindungen besitzen, ist nicht beobachtet. Geschmacksempfindungen werden sie ganz gewiss haben, da es höchst wahrscheinlich ist, dass sie ihre Beute auch durch den Geschmack unterscheiden.

$\mathrm{Ob}$ man nun auch von einem seelischen Leben unserer Geschöpfe sprechen clarf? Einen bestimmten Charaliter hat jedenfalls jede Wassermilbe im Vergleich mit anderen. Darunter kann ich hier freilich nur die Art und Weise ihres Betragens verstehen. Die Schnelligkeit, mit welcher die Bewegungen ausgeführt werden; die Feindschaft oder Freundschaft, um diese Worte hier zu gebrauchen, welche den übrigen Nitgliedern einer und derselben Art entgegengebracht werden; die Gewandtheit, mit welcher eine solche Milbe einer drohenden Gefahr zu entrinnen sucht, alles dieses, namentlich das Zuletzterwähnte, lassen den Schluss gerechtfertigt erscheinen, dass wir bei diesen kleinen Geschöpfen ein verhältnismaissig hoch entwickeltes Seelenleben voraussetzen dürfen. Wenn sich nun auch diese seelischen Regungen wohl zumeist auf den Erwerb der Nahrung, auf Sicherstellung des cinzelnen Ticres und auf Erhaltung der Art richten, so ist doch das Vorhandensein derselben von ausserordentlichem Interesse und fordert zu immer neuen Beobachtungen auf, damit auch für diese niedrigen Geschöpfe die Tiefe und Ausdehnung des ihnen verliehenen seclischen Lebens immer mehr bekannt werde. 
Wir wenden uns nun einer kurzen Besprechung der hauptsächlichsten Gattungen zu.

An der Hand der oben gegebenen Beschreibung von Piona fla'escens und unter Benutzung der beigefügten Abbildung in Fig. I ist jeder leicht imstancle sich eine hinreichend genaue Vorstellung von der Gestalt einer Hydrachnide überhaupt zu machen. Jedoch wird der Naturfreund, der es unternimmt, die häufigeren Mitglieder unserer Tierfamilie in den stehenden und fliessenden Gewässern seiner Heimat genauer zu betrachten, bald bemerken, dass er in der That recht verschiedenartige Geschüpfe in sein Aquarium bringt. Wir wollen $\mathrm{ihm}$ in dem Nachfolgenden einige Winke für das Unterscheiden der gesammelten Tierchen geben, verweisen aber zu einer eingehenderen Betrachtung auf unsern Anhang. Vieles lässt sich schon mittels einer schärferen Lupe deutlich genug erkennen, ganz wird es indessen nicht ohne die Zuhilfenahme eines Miliroskops abgehen. Und gerade die mikroskopische Betrachtung der hier uns beschäftigenden, zumteil recht kleinen Geschöpfe entfaltet eine solche Fülle zierlicher Formen vor unseren Augen, dass wir unwillkürlich von der Begierde ergriffen werden, immer neue Gestalten einer solchen zu unterwerfen.

Die im Anhang gegebene Tabelle nimmt ihre Merkmale nicht mit Rücksicht auf die gegenseitige Verwandtschaft der Hrdrachniden, sondern mit Rücksicht auf Deutlichkeit und leichtes Auffassen. Hier dagegen möchte ich versuchen, die hauptsächlichsten Gruppen herauszuheben.

Betrachtet man die klaren Wasser eines Grabens oder kleinen Teiches aufmerksam, so geschieht es wohl, dass man ein linsengrusses, blutrotes, kugelfurmig aufgeschwollenes Geschiipf in liriftigem Zuge durch die stille Flut eilen sieht, lebhafte Wendungen bald hierin bald dorthin ausführend. Ein schneller Griff mit dem Fangnetz und die Schwimmerin ist in Gefangenschaft geraten. Wir entlassen sie in eine bereitgehaltene flache Schale und können sie nun mit blossem Auge deutlich erkennen und prüfen. Entweder streckt sie den vierten Fuss jederseits beim Schwimmen unbeweglith nach hinten, oder sie macht auch mit ihm, also mit. ssimtlichen 
acht Fü̈sen lehhafte Schwimmbewegungen. Im erstern Falle haben wir eine unserer ansehnlichsten und häufigsten Süsswassermilben vor uns, einen Repräsentanten der oben schon erwähnten (Gattung Evlais \%). Die Milbe ist eine arge Räuberin und überfallt mit ihren kräftigen Füssen und den zwar ausserordentlich kleinen, aber überaus kräftigen Kiefern, was ihr in den Weg kommt. Sie bildet eine ganz besondere Abteilung der Hydrachniden für sich, da bei ihr die MIundöffnung und die damit zusammenhängende Auslildung der Kiefer eine ganz eigentümliche geworden ist. Wie eine sorgfiltige Betrachtung des MIundes mit dem Mikroskop lehrt, hat die ganze Gestalt und Anordnung desselben eine überraschende Ahnlichkeit mit ciner Saugscheibe. Man bemerkt eine kreisrunde Platte, eingerahmt durch einen Kranz zicrlicher Haarborsten, in der Nitte die winzige Mundïffnung tragend, aus welcher die schwirrzlichen Spitzen der Kieferendglieder in Gestalt zweier scharfer Zühnchen etwas hervorgeschoben werden künnen. Gegen diese Zühnchen drücken die kräftigen Taster und Füsse ihre Beute, welche alsbald die tödliche Wunde empfängt. Betrachten wir das in ausgewachsenem Zustande bis $4 m m$ lange Tier von oben her, so wird man auf dem Vorderrücken, und zwar ziemlich nahe der Mittellinie vier schwarze, dicht bei einander stehende Augenpunlite gewahr werden. Lösen wir mit einem scharfen Mlesser die dieselben tragende Hautstelle ab und richten nun das Mikroskop auf sie, so erblicken wir die zu den einzelnen Augen gehörigen Linsen, jede in eine besondere dickwandige Hautkajsel eingeschlosien. Its gielit nur wenige Hydrachniden, bei denen die Augen in der angegelenen Art und Weise angeordnet und geschützt sind. Auffallend ist es und mag hier gleich erwähnt werden, dass die eben dem Ei entschlüpften jungen Eyldïs weit von einander getrennt aufgestellte Aurenpunkte führen, dass alsio die snelen erwahnte eigentümliche und von der Regel abweichende Augenstellung erst in spaiteren Stadien ilures Ledens und zwar nach der craten Ifäutung beobathtet wird. Es ist dies eine Thatsache, welche bei Beurteilung der

*) Siche Anbang. 
Verwandtschaft unserer Gattung auch mit Landmilben nicht ohne Bedeutung ist.

Hatte die gefangene und in die Glasschale entlassene Milbe, wie eine kurze Betrachtung bald ergeben wird, auch am vierten Fusse jeder Seite dichte Büschel von Schwimmborsten, so werden wir eine Vertreterin einer zweiten wichtigen Gruppe von Süsswassermilben vor uns haben, und zwar der Gruppe, nach welcher die ganze Familie ihren Namen bekommen zu haben scheint. Sie ist dann ein Mitglied der Gattung Hydrachna*), welche in mehreren sehr stattlichen Arten unsere Gewässer bevölkert.

Die Gattung Hydrachna ist ausgezeichnet durch ihre sehr eigenartige Nundbildung. Keine andere Süsswassermilbe hat einen ähnlich gebauten, zu einem Stechorgan umgestalteten Schnabel, welcher sanft gekrümmt in ansehnlicher Länge zwischen den kurzen Tastern hervorragt. Dieser Schnabel wird durch die Unterlippe grebildet und stellt eine oben offene Halbröhre dar, ist selbst scharf zugespitzt, dennoch aber nicht als eine gefahrdrohende Waffe anzusehen, so wenig wie die beiden haarscharfen messerartigen eingliedrigen Kiefer, welche in jener Rinne auf- und abgeschoben werden können. Die Milbe scheint nicht von tierischer Nahrung zu leben, sondern benutzt ihr umfangreiches Stechorgan dazu, um Pflanzenstiele anzubohren. Ihre Eier wenigstens legt sie in Hühlungen, welche sie mittels ihres Schnabels in Blattstiele von Wasserpflanzen eingebohrt hat. Der kugelförmig aufgetriebene Körper wird von den weit nach vorn gerückten Füssen nicht besonders schnell durch das Wasser getragen, er scheint sogar häufig durch sein Gewicht cinen hemmenden Einfluss auszuüben, wenigstens wird oftmals die Unterseite des Tieres beim Schwimmen von oben her sichtbar. Auch Hydrachna besitzt, geradé wie Eyläis, Augen, welche paarweise in eine mit wulstigen Rändern versehene, harte Kapsel eingeschlossen sind, jedoch stehen die beiden Augenpaare weit von einander entfernt. Die Bauchfläche trägt jeclerseits von der (jeschlechtsiffnung eine Platte mit zahlreichen Haftniilfen, jecloch sind letztere klein und unansehnlich.

*) Siehe Anbang. 
Im Gegensatze zu den beiden soeben erwathnten Gattungen, denen in gewissem Sinne noch zwei andere beigesellt werden können, nämlich Hydrodroma und Limnochares*), weil sie sechsfüssige Larven von ausgespruchenem Trombidium-Charakter besitzen, bilden die dann noch übrigen etwa 24 Hydrachniden-Gattungen eine grössere Abteilung für sich, da sie viel Verwandtschaftliches zeigen und daher zunächst auch noch zusammengefasst werden kïmnen.

Das Hauptmerkmal dieser Gruppe dürfte wohl darin bestehen, dass die sechsfüssige Larve einen eignen Typus hat, den ich den Nesaea-Typus nenne, und welcher durch die Abbildung in Fig. $3 a$ S. 39 dargestellt ist. Da jedoch diese Larven nicht immer leicht $z u$ beschaffen sind, so müssen wir wohl damit zufrieden sein, die Nilben nach der Form der Kiefer näher zu bezeichnen. Als Beispiel für die gatnze eben in Rede stehende Süsswassermilt)enabteilung gilt die oben näher beschriebene und abgebildete Piona flavescens. Dieselbe besitzt Kiefer, wie sie in Fig. 36 zur Anschaume gebracht sind. Dieselben sind zweigliedrig und das letzte Glied besitzt die Gestalt einer Klaue, wonach die ganze Kieferart den Namen klauenfümiger Kiefer exhalten hat. Dieselben werden von der Nilbe so getragen, dass die Klauen mit ihrer Spitze nach blen schlaren. Die ganze Menge der hierhergehörigen Milben zerfällt in zwei grössere Heerlager, welche wir am einfachsten nach ihrer ätscm Körperhülle in sugenamnte Hartschwimmer und Weichschwimmer zu trennen haben. Hartschwimmer sind solche Süsswassermilben, deren Kürper durch eine feste, allseitig geschlossene wahre Panzerhaut geschützt ist, während die Weichschwimmer eine solche Verhartung der Haut nicht aufzuweisen haben. Bemerkenswert ist es allerdings, dass auch die jüngsten, dem Ei entschlüpften Larven der Weichschwimmer, soweit sie zur Beobachtung gekommen sind, eine wenigstens auf dem Rücken ziemlich weitgehende Hautverhärtung aufzuweisen haben, welche sich aber in späteren Stadien wieder verliert. Diese Beobachtung wird zur Beurteilung der wahren verwandtschaftichen Verhältnisse künftighin wohl nicht ganz ausser Acht gelassen werden können.

") Sielie Anhang. 
$\mathrm{Zu}$ den Hartschwimmern gehört namentlich die ausserordentlich artenreiche Gattung Arrenurus*). Es scheint keinen Teich oder See zu geben, für welchen sich nicht eine eigentümliche Art dieser merkwürdigen Gattung aufweisen liesse. Sie ist ganz besonders der Aufmerksamkeit wert, weil es nach den bisherigen Beobachtungen den Anschein hat, als wäre sie besonders der Veränderlichkeit unterworfen, Grünrote, braune, ja ganz bunte Arten derselben wimmeln häufig durch einander und bereiten, wenn man nur Weibchen vor sich hat, dem Untersucher fast unüberwindliche Schwierigkeiten. Diese verschwinden aber sogleich, sobald die Männchen mit ihren so ganz eigentümlich gebauten Hinterleibsanhängen zu Gebote stehen.

Es bietet sich hier eine passende Gelegenheit, den geschlechtlichen Unterschieden in der äussern Gestalt, welche bei Arronurus in ausserordentlich hohem Masse zu Tage treten, etwas Aufmerksamkeit zu widmen. Es erscheint wunderbar, dass innerhalb einer und derselben Tiergruppe diese Unterschiede in so ungleichem Masse ausgebildet sind, denn während sie bei der eben erwähnten Gattung in einem höchst bedeutenden Grade vorhanden sind, treten sie bei vielen anderen, die mit ihr unter nahezu gleichen Bedingungen leben, eigentlich röllig zurück. Eine Erklïrung dieser Thatsachen ist bis jetzt nicht gut zu erwarten gewesen. Vielleicht lüftet eine fortgesetzte Beobachtung den über dieser ganzen Frage der geschlechtlichen Formverschiedenheiten noch ruhenden Schleier. Jedenfalls ist bei Arrenurus diese Verschiedenheit der Geschlechter am weitesten fortgeschritten und hat ausser den Füssen, wo sie auch bei anderen Gattungen beobachtet wird, noch den Rumpf ergriffen, indem ausser ansehnlichen kegelförmigen Fortsützen auf dem Rücken namentlich der Hinterrand des Leibes in mannigfacher Weise umgestaltet ist. In den Abbildungen Fig. 2 S. 24 haben wir einige Formen solcher Schwanzanhänge zur Anschaumug gelbritcht. Es lassen sich dabei offenbar ganz bestimmte typische Gestalten, die alsdann in freier Weise variieren, unterscheiden. 
So unterscheiden wir eine langgestreckte Schwanzform, wie sie unter $2 b$ von Arremums caudatus abgebildet ist, von einer fischschwanzahnlichen, bei welcher die hinteren Seitenecken in zwei
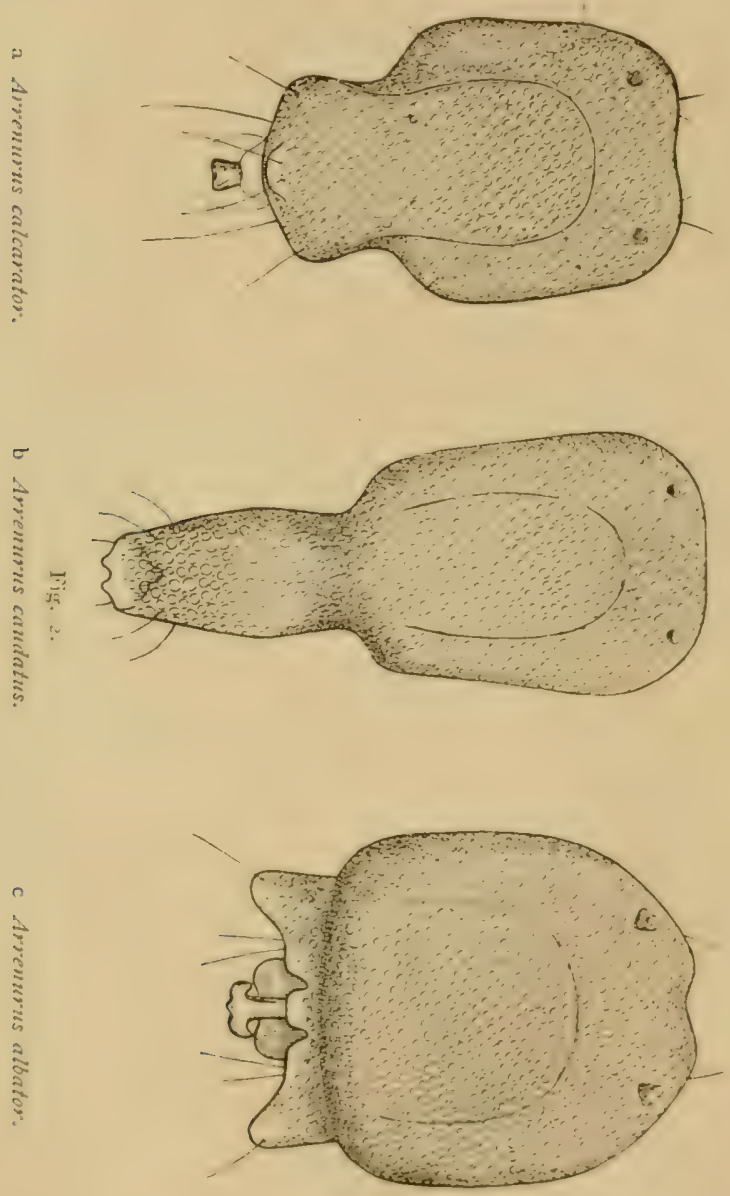

ansehnliche Zipfel ausgezogen sind, zwischen denen in einer mittleren Abteilung oft sonderbar gestaltete Fortsátze und Blattchen auffallen. Ein Beispiel hierfür ist Fig. $2 c$, Arrcmurus albator. 
Eine dritte Form bietet im ganzen an sich unbedeutendere Anhïnge, welche keine leicht bestimmbare Gestalt besitzen und daher der Beschreibung Schwierigkeiten entgegenstellen. Einen solchen Anhang zeigt Fig. $2 a$ von Arrenurus calcarator.

Diese Anhänge wie überhaupt die besonderen geschlechtlichen Eigentümlichkeiten der Gestalt treten erst nach der letzten Häutung des Tieres hervor und sind auch dann nicht gleich voll entwickelt, sondern scheinen erst nach und nach ihre endgültige Form anzunehmen. Ausser durch ihren Schwanzanhang' sind die Männchen von Arrenurus noch durch eine den Weibchen abgehende Bewaffnung des vierten Fusses jeder Seite ausgezeichnet. Beiden Geschlechtern gemeinsam ist jedoch die bereits oben berührte starke Ausstattung der hinteren Füsse mit Schwimmborsten, welche es ihnen ermöglicht, mit ausserordentlich kräftigen Bewegungen das Wasser zu durcheilen. Ihre Nahrung besteht vornehmlich aus den kleinsten Bewohnern des süssen Wassers, den Rüdertierchen, Daphniden etc., sie sind leicht in Gefangenschaft zu halten, selbst in sehr kleinen Aquarien. Drollig nehmen sich beim Schwimmen die Arten mit einem langen Schwanzanhang aus, indem die verhältnismässig schwachen Füsse es nicht verhindern können, dass der langgestreckte Hinterleib gleich einem Pendel fortwährend hin und her schwankt, was dem Schwimmen einen ungeschickten Anschein verleiht.

Die Grösse der bei uns vorkommenden Arrenurus-Arten ist ausserordentlich verschieden und schwankt zwischen 2 und $1 / 2 \mathrm{~mm}$.

Neben dieser sehr artenreichen Gattung Arrenurus sind noch einige weniger in die Augen fallende harthäutige Hydrachniden erwähnenswert, so die kleinen bunten Vertreter der Gattung Axona*). Sie sind zwar mit unbewaffnetem Auge kaum wahrzunehmen, zeichnen sich aber einesteils durch ihre lebhafte Fürbung, anderseits aber auch durch die ganz besonders merkwürdige Gestalt, welche dem vierten Fusse des Männchens eigentümlich ist, aus. Offenbar ist dieses anhangsreiche Glied dem Männchen gegeben,

*) Siehe Anhang. 
um das Weibchen festhalten zu können, doch mag es auch ein blosser Schmuck sein, der die Weibchen fesselt und anzieht, wenn man auch zweifelhaft sein könnte, ob diese winzigen Tiere ein so hohes geistiges Leben entfalten, dass man von Freude am Schmuck bei ihnen reden kann. Dass jedoch die Milben an und für sich auch tieferen Gefühlsbewegungen nicht unzuginglich sind, tritt sehr deutlich bei einer kileinen Landmilbe (Cheyletus) hervor, welche ihre in Häufchen zusammengelegten Eier nicht nur bis zum Ausschlüpfen der Jungen nicht veriässt, sondern dieselben auch gegen Angriffe tapfer verteidigt. Wenn dies auch das einzige mir bis jetzt bekinnte Beispiel eines höheren geistigen Lebens bei unserer Tierfamilie ist, so ist es gerade hinreichend, um überhaupt ein solches bei derselben zu beweisen.

Es bleibt nun noch als letzte Gruppe diejenige zu erwähnen übrig, welche ich im Gegensatze zu den soeben erwähnten Hartschwimmern als die Weichschwimmer bezeichnet hatte.

Gemeinsames Kennzeichen ist bei den erwachsenen Tieren dieser Gruppe eine weiche Körperhaut. Die zahlreichen Gattungen dersell,en bieten sunst allerelings sehr mannigfaltige Terschiedenheiten, dwh dürfte es sellst dem geülteren Devbachter ziemliche sihwerigkeiten bereiten, diese Unterschiede zu bemerken.

Als Repräsentant dieser Gruppe muss wiederum jene oben ausführlicher erwähnte und auch abgebildete Piona dienen, und es mag genügen, hier auf sie zu verweisen. Nur einen Punkt möchte ich auch bei dieser Gruppe besonders hervorheben, nämlich noch cinnal dic Gestaltwerschiedenheiten, welche man zwishen Mimm hen und Weibchen derselben Art beobachtet. Hier sind es besonders und vor allem die Füsse, welche bei beiden Geschlechtern in auffallender Weise verschieden gestaltet sind, indem die Miunnchen mancherlei besondere Anhünge und Umformungen einzelner Fussglieder aufzuweisen haben.

Wie bei zahlulreichen MIännchen von Insekten sind nämlich die Füsse hier in Fangorgane umgestaltet, um die flüchtigen Weibchen festzuhalten. Allerdings findet dies auch nicht bei allen hierhergehürigen Gattungen statt, auch ist 'für zahlreiche Arten überhaupt 
das Männchen noch nicht beobachtet, wo es aber bekannt geworden ist, da dient zugleich auch die besondere Gestalt der Füsse zu einer verhältnismässig leichten Unterscheidung der oft zahlreichen Arten. So muss es als feststehend gelten, dass die in unseren Gewässern neben-der Gattung Arrenumus am häufigsten vorkommende Gattung Nesaea bei allen ihren zahlreichen Arten im münnlichen Geschlecht ein umgeformtes drittes und viertes Fusspaar besitzt. Jeder Fuss des dritten Paares hat ein keulenförmig gestaltetes Endglied, an welchem auch die Kralle eine von der gewöhnlichen abweichende Gestalt besitzt, wie sie Fig. $3 g$ von Nesaea fuscata zeigt. Weiter ist, was auch schon bei geringer Vergrösserung bemerkt werden kann, das drittletzte Glied an den Füssen des vierten Fusspaares hufeisenförmig eingebogen und trägt an den Rändern der Einbuchtung einen Kranz starrer und auffallender Haarborsten (Fig, $3 \mathrm{~h}$ ).

Einer andersgearteten Umgestaltung des vierten Fusses begegnet man bei den Piona-Männchen. Es würde jedoch zu weit fülhren, wenn hier noch mehr in Einzelheiten eingegangen würde.

Jedoch noch einer besonderen Erscheinung, welche bei Männchen und Weibchen einer kleinen Gruppe von Gattungen beobachtet wird, kann ich nicht unterlassen Erwähnung zu thun, weil sie zeigt, wie sonderbar oft die Richtung zu sein scheint, in welcher die Umformung der Gestalt fortschreitet. Hier handelt es sich auch um eine Eigentümlichleit der Füsse. Es ist Regel, dass die Hydrachniden an sämtlichen acht Füssen deutliche und wohl ausgebildete Krallen tragen. Die Abbildung Fig. $3 d$ zeigt eine solche von Nesaea fuscata. Jene kleine Gruppe von Milben, zu denen unter anderen die in unseren Gewässern häufig gefundene Gattung Limmesia*) gehört, hat nun diese Krallen an den beiden vierten Füssen durchaus eingebüsst. Hier endigt das letzte Fussglied mit einer stumpfen kegelförmigen Spitze. Allerdings beobachtet man leicht, dass bei zahlreichen Wassermilben die Krallen an den vierten Füssen ungleich kleiner sind als namentlich am zweiten und clritten 
Fusspaar aber sie sind stets gut ausgebildet und zeigen auch die für die Gattung charakteristische Form. Wie lässt es sich hier nun erklären, dass sie bei Limnesia völlig fehlen. Nur als Vermutung könnte angeführt werden, dass Limnesia das vierte Fusspaar niemals zum Festklammern des Körpers benutzt, sondern stets in schwingende Bewegung setzt, sobald sie vom Schwimmen ausruht, vielleicht um das Wasser um den Leib in Zirkulation zu bringen.

Im Anschluss an die soeben, wenn auch nur in flüchtigen Umrissen gegebene Übersicht der Hauptformen unserer Süsswassermilben möge ein kurzes Wort über ihren Aufenthalt, ihre Verbreitung und allgemeine Lebensweise folgen. Zwar sind auch über diesen Punkt die Beobachtungen nur wenig umfassend, aber so weit sie ein Urteil zulassen, darf man wohl sagen, dass die Hydrachniden stehende klare Gewässer den fliessenden vorzuziehen scheinen. Auch trifft man in grüsseren Wasserbecken, deren Ufer durch die offenbar von Wind und Wellenschlag herrührenden zerstörenden Einflüsse des Wassers mit absterbenden Pflanzenresten bedeckt, atuch haitufig mit modenulem Schlamm überzogen sind, viel seltener Nilben an, als in den kleinen mit dichtem Wasserpflanzengebüsch durchsetzten Weihern und Teichen. Hier, wo die kleinen Kruster, wie Daphniden und Cyclopiden, ihr Wesen treiben, wo die Mücken und zarten Netzflügler ihre Eier massenhaft ablegen, wo zahllose Infusorien an den Wasserpflanzen auf- und niederfahren, da finden unsere zumeist vom Raube lebenden Hydrachniden ein geeignetes Jagelectriet, welches sie in allen Stadien ihrer Entwickelung in meist rastloser Eile durchlaufen, den Beobachter in Erstaumen setzend über die Ausdauer und Kraft ihrer Muskeln, welche, am Tage und oft auch des Nachts angestrengt, dennoch nicht ermüden und in gleichmässiger Schnelligkeit den Körper von Ort zu Ort führen. Doch ist es nicht nur die Reichhaltigkeit der Nahrung, es ist auch die bald hüher steigende Temperatur solcher stehenden Gewasser, welche offenbar unseren Milben sehr angenehm ist. Beobachtet man doch, dass, wenn im Hochsommer die kleinen Wasserbecken bis auf zwanzig und mehr Grad erwirmt werden, die Scharen, namentlich der Arrenurus-Arten, ganz ausserordentlich 
anwachsen. Wie die Ameisen im Sonnenbrand nur um so rastloser ihren Zwecken und Ptlichten nachgehen und für den Beschatur ein Schwindel erregendes Gewimmel hervorbringen, so jagen sich die roten, grünen und bunten Hartschwimmerarten durch die untergetauchten Wasserpflanzen und fallen massenhaft dem Sammler ins Netz. Übereinstimmend hiermit ist die von einem Beobachter gemachte Bemerkung, dass die hiher im Gebirge gelegenen Teiche gewöhnlich arm an Wassermilben sind, weil die Temperatur derselben selbst im Sommer eine verhältnismässig niedrige ist. Dass die Milben allerdings auch in kaltem Wasser gut zu leben vermögen, beweist der Umstand, dass man schon sehr früh im Jahre, wenn das Eis noch auf dem Wasser steht, reichliche Beute findet und zwar nicht bloss erwachsene Tiere, sondern solche auf allen Entwickelungsstadien. Daher ist es wohl möglich, dass die niedrigere Temperatur der Gebirgsteiche die den meisten Milben zur Nahrung dienenden Kruster, sowie andere zartere Geschöpfe, die von ihnen verfolgt werden, nicht recht zur Entwickelung kommen lässt, so dass das Fehlen zahlreicher Milben erst hieraus zu erklären wäre. Diese letztere Ansicht wird vielleicht durch eine Beobachtung unterstützt, welche aus südlicheren Gegenden stammt, wo überhaupt wohl auch in kühlerem Wasser reicheres Leben zu finden ist, so dass auch Milben darin nicht zu darben brauchen. So hat der französische Naturforscher Th. Barrois während einer der Erforschung der Azoren gewidmeten Reise eine Hydrachnide beobachtet, über deren Lebensgewohnheiten er sich folgendermassen auslässt: „Ich fand diese Art stets in rasch fliessendem, wenig tiefem Wasser der Quell- und Sturzbëche, welche von den Bergen herabkommen, um entweder in einen See, was indessen nicht oft vorkommt, oder sogleich ins Meer sich zu ergiessen, und deren Bett zahlreiche Kieselsteine enthält. Obgleich die Tiere sehr gute Schwimmer sind, so habe ich sie niemals mit dem Netz gefangen; sie leben vielmehr auf der Unterseite der Steine, wo sie in Gruppen von fünf, sechs, zehn und noch mehr zusammen sich in die Löcher der basaltigen Laven festsetzen, um nicht von dem Strome mit fortgerissen zu werden. Die Temperatur dieser Büche und Flüsschen 
ist sehr niedrig und steigt auch im August und September höchstens auf $15^{1 / 2^{\circ}}$. Die Verbreitung dieser Art in vertikaler Richtung bictet grosic Lnterschiede. Ich habe sie fast unmittelbar am Meer gesammelt und auch in einer Höhe von 800 Metern". Hierbei wird noch eines besonders merkwürdigen Umstandes wie frigt gedacht: ", )wohl die beubachtete Mille in grosscr Menge in gewissen Giessbächen lebt, welche sich in Seen ergiessen, so findet sie sich in diesen Seen selbst niemals. Zur Erklärung dieses gewiss auffallenden Vorliommnisses lässt sich Folgendes etwa anführen: Enere Hydrachnicle liebt sehr flache, sprudelnde, reine Gewässer. Man trifft sie niemals in Lachen. Nun sind die Seen ruhig und führen, weniger klares und reines Wasser als die Bäche, denn die darin befindlichen Steine sind meist mit einer mehr oder weniger dicken Schicht von Schlamm bedeckt, welchen man sehr selten an den von den Milben besetzten Lavaschlacken der Bäche findet. Vor allem muss man aber in dem Temperaturunterschied der Seen und Bäche den Grund für die Abwesenheit der Milben in den ersteren suchen. Denn in dem See steigt die Wassertemperatur wohl um $9^{\circ}$ höher als in dem Zufluss. Der schroffe Wechsel der Temperatur wird denjenigen Milben, welche von dem Bache mit in den See hinabgerissen werden, verderblich, denn sie sind überhaupt sehr empfindlicher Natur. Es ist mir mehrere Male bei meinen Ausflügen vorgekommen, dass ich versucht habe, sie lebend leimzubringen, aber fast regelmëssieg fanci ich sie trotz aller Vursicht tot vor". So empfindlich wie die soeben angeführte Bewohnerin der Azoren sind nun freilich die meisten unserer Hydrachniden nicht. Zumal gegen erwärmtes Wasser zeigen, wie schon erwähnt, die meisten der unsere Kleingewässer, namentlich die Teiche und Weiher, bewohnenden Milben eine starke Widerstandsfthigkeit.

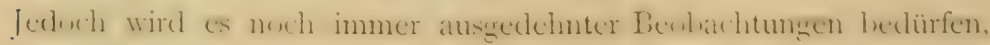
um die Einflüsse der Temperatur auf das Leben unserer Wassertiere genauer liennen zu lernen.

Mit den Azoren ist wohl die von Europa fernste Station, auf welcher Süsswassermilben beobachtet worden sind, genannt irorden. Steht es überhaupt mit der Kenntnis der Acariden in den ausser- 
europäischen Ländern ziemlich schlecht, so sind die Gebiete, in denen man sich nach den im süssen Wasser lebenden Milben umgesehen hat, im wesentlichen in Europa zu suchen und auch da sind noch die meisten Strecken unerforscht. Es folgt fast naturgemäss aus diesem Umstande, dass das Wissen über diese Tiergruppe ein in jeder Beziehung durchaus lückenhaftes sein muss. Allerdings scheinen ja, und das gilt auch von sehr zahlreichen Landmilben, die einzelnen Gattungen und Arten sehr grosse Verbreitungsgebiete zu besitzen, aber dennoch ist noch überall das Fehlen gewisser an anderen Orten vorkommender Formen ausser Zweifel, und es trifft auch hier die Wahrnehmung zu, dass der Süden an Formen reicher ist, als der Norden.

Halten wir eine Überschau ab über die Gegenden, welche überhaupt nach Süsswassermilben durchsucht sind, so sind zu nennen zahlreiche schwedische Gewässer (durchforscht von C. J. Neuman), ein Teil der norditalienischen (d. v. J. Canestrini und A. Berlese), die Schweizer Seen (d. v. G. Forel und G. v. Haller), die nordöstlichen Gebiete Frankreichs (d. v. J. Barrois) und manche Gebiete Deutschlands (d. v. C. L. Koch, Koenike, Kramer).

Wie es aber bei einer erst beginnenden Erforschung einer Tierklasse fast natürlich ist, haben sich die meisten Beobachtungen zunächst auf die äussere Erscheinung der Hydrachniden gerichtet, die Lebensbeziehungen dagegen sind zum grösseren Teil noch übersehen worden. Dennoch lässt sich Einiges auch bereits jetzt hierüber sagen.

Zunächst hat sich wohl als unzweifelhaft ergeben, wie auch schon weiter oben betont worden ist, dass die Hydrachniden auf Grund ihrer Entwickelungsgeschichte in zwei Gruppen gesondert werden können, welche sich durch die Lebenswieise ihrer sechsfüssigen ersten Larven ergeben. Die eine Gruppe besitzt Larven, welche Gestalt und Lebensweise der Trombidiumlarve zeigen, die anderen nicht. Man kann es nämlich wohl als Regel aufstellen, vorbehaltlich freilich einer erst in Zukunft zu gewinnenden ganz allfremeinen Festiitigung, dass die trombielimartigen Millsen wihrend ihrer ersten Jugend vom Blute anderer Tiere, namentlich der 
Insekten, leben und sich daher an solche ansaugen. Erst nachdem sie die erste Hæutung überstanden haben, führen sie nicht mehr ein parasitisches, sondern ein freies Leben. Solche Lebensweise führen nun die Jungen ron Hydrachna, Eylaïs und Limnochar's und, soweit ich sehe, auch von Hydrodroma, einer schön scharlachroten, ziemlich ansehnlichen Wassermilte. Die Beobachtungen sind bei den soeben namhaft gemachten Acariden noch keineswegs in gleichem.Masse willstündig, ganz abgeschlossen dürften sie vielmehr nur bei der Gattung Hydrachna sein, jedoch unterliegt es keinem Zweifel mehr, dass bei allen die Übereinstimmung in der Hauptsache der Entwickelung, der parasitischen Lebensweise, eine sehr weitgehende ist.

Die Jungen von Hydrachna bleiben von dem Augenblick des Ausschlüpfens atıs dem Ei im Wasser, dagegen steigen die der drei anderen Gattungen möglichst bald an die Oberflïche und machen ausgiebigen Gebrauch von ihren Rennbeinen, indem sie mit einer fast staunenswerten Geschwindigkeit auf dem Wasser und den Pflanzen des Ufers auf und ab eilen, um Insekten zu suchen, welche sie besteigen können. Die Larven von Limnochares nehmen z. B. die ebenfalls auf der Wasseroberfläche lebenden Schreitwanzen zu erwünschten Nährtieren und bohren sich in die weichen Chitinskelettpartien ein. Bei den Larven von Hy'drodroma bot sich noch cin anderes Schauspicl, als ich Gelegenheit hatte, einen auskriechenden Schwarm von jungen Tieren zu verfolgen. Nachdem sie an die Oberfläche des Wassers emporgekommen waren und ich die Tierchen sammeln wollte, um sie an Blattlïusen sich festsaugen zu lassen, musste ich zu meinem Erstaunen bemerken, dass sie die Fähigkeit besassen in mächtigen Sprüngen fortzuhüpfen. In kur\%er Zeit war daher der ganze Schwarm zerstreut und den Blicken völlig entschwunden.

Die sechsfüssigen Larven der übrigen Hydrachniden leben, im Gegensatze zu den eben namhaft gemachten, frei schwimmend im Wasser und nahren sich rom Raube. Sie besitzen daher eine dieser Lebensweise angepasste Gestalt, welche zwar ebenfalls von der künftigen des erwachsenen Tieres abweicht, aber namentlich in 
der Bildung der Füsse ganz verschieden ist von den Larven obiger Arten. Eine bemerkenswerte Ausnahme von dieser Lebensweise beobachten wir nur bei einigen Arten der Gattnng Atax*). Von den bisher bekannten sieben oider acht Arten dieser Gattung führe.n etwa drei oder vier ein vollständig freies Leben, während die anderen Arten sich einer ausschliesslich parasitischen Lebensweise ergeben haben. Diese Arten hausen von Generation zu Generation zwischen den Weichteilen der Teich- und der Malermuschel und verlassen ihr Wohntier wahrscheinlich nur während ihrer Larvenzeit, um ein neues aufzusuchen. Dabei sei gleich erwähnt, dass durch das parasitische Leben sich eine bestimmte Veränderung ihres Organismus eingestellt hat, wenigstens möchte ich dieselbe damit in ursächlichen Zusammenhang bringen. Während nämlich die frei lebenden Hydrachniden sümtlich, soweit die Beobachtungen reichen, ein wohl ausgebildetes Atmungssystem haben, fehlt den parasitischen Atax-Arten jede Spur von Tracheen und der mit den Luftlöchern in Verbindung stehende Hauptstamm ist auf ein ausserordentlich geringfügiges Stückchen zurückgebildet, so dass man fast von einem vollständigen Fehlen desselben reden kann. Ob es nun der Aufenthalt in einer so schleimigen und luftarmen Flüssigkeit, wie sie die Muscheln erfüllt, mit sich gebracht hat, dass das Atmungsorgan ausser Thätigkeit gesetzt wurde und daher verkümmerte, darüber eine bestimmte Ansicht auszusprechen scheint noch nicht der rechte Zeitpunkt gekommen zu sein.

Wenn uns die parasitischen Atax-Arten schon darauf führten, von der Auswanderung von einem Wohntier auf ein anderes zu reden, so dürfte es an der Zeit sein, überhaupt die Verbreitung der Süsswassermilben aus ihren doch meist eng begrenzten heimatlichen Wasserbecken in andere etwas nüher zu betrachten. Ich komme dabei auf die Beobachtungen des Dr. Th. Barrois, die er auf den Azoren gemacht hat, noch einmal zurück. Er traf dort zwei Gattungen an und unter diesen eine, welche ja allerdings allgemein verbreitet ist, deren Arten aber nicht gerade zu den

*) Siche Anhang.

Tier- und Pflanzenwelt des Süsswassers. II. 
allergewöhnlichsten gechören. Er fand stets sedir zahlreiche Excmplare der diesen beiden Gattungen angehërigen Milben in den dertigen Bächen an. Dies hatte wohl seinen Grund darin, dass die Gewässer der vulkanischen Azoren in der ersten Periode des Bestehens dieser aus dem Ozean aufgetauchten Inseln wohl noch völlig unbevölkert gewesen sind. Erst nach und nach werden dorthin verschlagene Süsswasserbewohner von dem neuen Gebiet Besitz genommen und frei von aller Konkurrenz sich rasch vermehrt haben. Wie lïsst es sich wohl erklären, dass sich auch die immerhin zarten Wassermilben dabei beteiligten? Unter allen Umständen wird die Verbreitung derselben dorthin auf mechanische Lrsachen zurückzuführen sein. Durch irgend einen Besucher oder Bewohner eines schon ron ihmen besetzten Süsswasserbeckens muss ihre L̈berführung in ein von ihnen noch nicht bewohntes vermittelt worden sein, sobald der natürliche Lauf der Gewätsser auch bei Überschwemmungen die neue Heimat mit der alten nicht in Verbindung zu setzen vermochte. Als Dr. Barrois, um über die Verpflanzung seiner Siperchon-Arten nach den Azuren ins Kiare zu kommen, die dortigen Gewässer aufmerlsam durchforschte, fand er ausser den Milben vor allen Dingen zahlreiche Wasserwanzen von der Gattung Corixa vor. Die Wasserwanzen können, wie sämtliche entwickelte Wasserinsektc11, lange Stunden ausserhalb des Wassers leben, denn sie sincl ja eigentlich Lufttiere und gehen nur um ihrer Nahrung willen ins Wasser. Sie machen auch grosse Flüge, namentlich bei Nacht, um aus einem Becken in ein anderes zu gelangen, wobei sie wahrscheinlich einem scharfen und sicheren Geruch folgen. Solche fliegende. IVasserinseliten werden unter Linständen ganz cibense, wic Schmetterlinge und Heuschrecken, vom Winde erfasst und aufs Meer hinausgetrieben, wobei sie wohl meist zu Grunde gehen, grelegentlich aber auch einsam daliegende Inseln erreichen, deren Gewässer sie dann, wenn es gerade mit befruchteten Eiern beladene Weibchen waren, nun mit ihrer Nachkommenschaft bevölkern können, vorausgesetzt, dass clie Lebensbedingungen sonst ihrem Körper entsprechen. Auf diese Art und Weise werden die Wasserwanzen wahrscheinlich nach den Azoren gekommen sein. 
Nun haben schon häufig Beobachter bemerkt, dass die zur Larvenruhe gelangten noch unentwickelten Milben sich an solche Wassenwanzen, wie eben beschrieben, anheften, um daselbst ihre Verwandlung unter dem Schutze der alten Larvenhaut durchzumachen. So kann es leicht gekommen sein, dass eine Wasserwanze, welche solche Larven von Wassermilben an sich trug, vom Winde nach den Azoren verschiagen wurde. Wenn dann die angeheftete Wassemilbenlare wihrend der gewiss längeren Reise nicht ganz austrocknete, so wird sie, nachdem ihr Träger eine neue Heimat in irgend einem Gewässer der Azoren gefunden hatte, dort nach einiger Zeit ausschlüpfen und, wenn Männchen und Weibchen gleichzeitig hinübergetragen worden sind, ihre Art in den Flüsschen der Azoren weiter fortpflanzen müssen. Nun hat Dr. Barrois bemerkt, dass die in Larvenruhe verfallenen Larven des ersten Stadiums gegen Austrocknung mehr Widerstand entgegensetzen, als es der sonst sehr zarte Körper der Hydrachniden vermag, und dass daher obige Art und Weise die wahrscheinlichste sei, wenn man sich die Verbreitung der Süsswassermilben über das Meer hinüber erklären will. Gewiss ist dies wohl eine MIöglichkeit, aber doch keineswegs eine so einzig gültige, dass man annehmen müsste, die ersten Larven der Wassermilben hätten überhaupt die Gewolmheit angenommen, sich namentlich an Süsswasserinsekten festzusetzen, um dort ihre Larvenruhe abzumachen, und diese Gewohnheit bringe es nun mit sich, dass die während der Larvenruhe gegen das Austrocknen besser gewappneten Tiere von den ausfliegenden Wasserinsekten auch dorthin transportiert würden, wohin sie auf gewühnlichem und ihrer Organisation entsprechendem Wege nicht gelangen könnten. Es sind die Möglichkeiten, eine weit entfernte Station zu erreichen, so mannigfaltige, dass es unserem Ermessen nach noch nicht thunlich ist, zu betonen, dass es die auf den Azoren gefundene Corixa ist, welche zu der Zeit, wo sie selbst durch Zufall die Azoren erreichte, auch die Sperchon-Art mit nach dem neuen Aufenthaltsorte hinüberbrachte. Es ist ja gewiss, dass im Verlauf der Jahrtausende, welche seit dem Auftauchen der Azoren aus dem Neere verstrichen sind, oftmals eine Corixa 
atomaria von Portugal hinübergeführt sein kann und dass immer cinmal wieder ein Sperchong glandulosus an in angeheftet gewesen sei. Wenn man diesen Umstand aber immer wieder durchdenkt, so wird man immermehr zu der Überzeugung sich hinneigen, dass diese MIöglichkeit ja allerdings wohl vorliegt, dass aber ebensosehr auch Wasservögel, welche, wie Barrois in einer Anmerkung selbst hervorhebt, an ihren Füssen und Schnäbeln so häufig Reste von Pflanzen aus süssem Wasser mit sich führen, die Vermittler sein können, ja, dass es nicht bloss Larven zu sein brauchen, welche in die neue Heimat hinübergeführt worden sind, Larven, die der Gefahr der Unfruchtbarkeit ausgesetzt sind, sondern in den feucht bleibenden regetabilischen Resten im Schnabel und an den Zehen künnen die erwachsenen Tiere ebensogut der neuen Heimat zugeführt werden. Zudem sind auch nicht alle Beobachter darin übereinstimmend, dass die Wassermilben, wenn sie ihrem feuchten Elemente entnommen sind, dem Eintrocknen so leicht erliegen. Claparède, der bedeutende Genfer Naturforscher, hat vielmehr an der die Teichmuschel parasitisch bewohnenden Atax-Art gefunden, dass sowohl Muttertiere als Eier sehr lebenskrüftig sind. In den Muscheln, die wochenlang ausserhalb des Wassers in der Dürre gelegen und halb ausgetricknet dem Terde entgegengehen, fand er die Milben zwar durch Verdunstung erstarrt, jedoch beim ersten Wasserzusatz sehr schnell wieder lebendig und die Eier entwickelungsfähig werden.

Es ist also nicht ausgeschlossen, dass die Besiedelung der mitten im Neere gelegenen Inseln mit Süsswassermilben unmittelbar durch Überführung fortptlanzunzsfithiger Individuen geschehen sei und noch geschieht. Es wird sogar die Verbreitung der das süsse Wasser bewohnenden Milben im allgemeinen überhaupt so gedacht werden müssen, dass erwachsene Weibchen, nicht unbefruchtete und unfruchtbare Larven, auf mechanischem Wege von Wasserbecken zu Wasserbecken getragen werden und so ihre Art in Gebieten, wo dieselbe noch nicht vertreten war, heimisch machen. 
Es bleibt uns nun endlich noch ein wichtiger Gegenstand zur Besprechung übrig, nümlich die Entwickelung des Einzelticres vim Ei bis zum erwachsenen Zustand.

Für jedes Lebewesen ist es eine der wichtigsten Aufgaben, seine Art durch Nachkommen zu erhalten. Daher ist für den aufmerksamen Naturfreund die Fortpflanzung und Entwickelung des Einzeltieres ein Gegenstand des grössten Interesses.

Bei den Milben ist nun gerade die Entwickelungsgeschichte noch sehr des weiteren Studiums benötigt, jedoch ist namentlich für die Hydrachniden das Beobachtungsmaterial nicht ganz unerheblich, so dass es gelingen wird, ein Bild des Entwickelungsganges einer Wassermilbe in grossen Zügen zu entwerfen.

Ich wähle zwei Beispiele, nämlich die Entwickelung der in unseren heimischen Gewässern häufigsten kleinen rotbraunen Wassermilbe, Nesaca fuscata Koch, welche für die Nehrzahl aller anderen als Muster dienen kann; daran mag sich die schon seit langer Zeit bekannte Entwickelung der lugeligen Wassermilbe, Hydrachua globosa Dugès, anschliessen.

Die Eierchen der rotbraunen Wassermilbe werden in Häufchen bis zu dreissig und mehr an Wasserpflanzen oder an Steinen des Wassergrundes gelegt. Es trifft sich wohl, dass man ein Weibchen bei seinem Geschäft der Eiablage genauer beobachten kann. Es legt die Eier in lockeren Haufen, dabei meist rückwärts schreitend und sie in schneller Folge aus dem Körper hervorstossend. Die roten Eierchen sind dabei von einer sehr dünnen weisslichen Schicht umgeben. Dieses ist die klebrige Kittsubstanz, welche jedem Ei mitgegeben wird. Schnell quillt dieselbe im Wasser auf, und während die letzten Eier gelegt werden, hat sich bei den ersten bereits ein breiter weisser Hof um dieselben gebildet. Nach Verlauf einiger Stunden sind die Zwischenräume zwischen den Eiern völlig von der Kittsubstanz ausgefüllt, die Eierchen ruhen jetzt, zu einem einzigen Håufchen verschmolzen, unter einer im Wasser vollends erhärtenden Hüllschicht.

Nach gemessener Zeit hat sich aus dem ursprünglichen Eiinhalt der sogenannte Embryo gebildet, zu gleicher Zeit ist aber 
auch noch eine zweite, innere Eihaut entstanden, welche sich nach und nach bedeutend ausdehnt und sich, weil sie innerhalb der harten äusseren Eischale keinen genügenden Raum findet, bald in viele Falten legt. Jetzt platzt die harte aussere Eihaut, die zweite dehnt sich durch Aufsaugen von Wasser sehr rasch aus und glättet sich vollkommen. So geschieht es, dass der Beobachter ein neues, sehr viel grösseres $\mathrm{Ei}$ aus dem ursprünglich gelegten hervorgehen sieht. Die Gestalt desselben ist in Fig $3 f$ dargestellt. Ein solcher Vorgang, dass aus einem Ei nicht ein entwickeltes Tier mit freibeweglichen Gliedmassen hervortritt, sondern ein zweites Ei, ist bisher bei den Milben nicht selten beobachtet worden, jedoch scheint er nur bei den Acariden verbreitet zu sein und zwar bei den trombidiumartigen Milben ganz besonders. So habe ich ihn bei den oben bereits einmal erwähnten Cheyletus vorgefunden. Hier entwickelt das Ei eine innere Eihaut, welche an einer bestimmten Stelle einen scharfen Stechapparat besitzt, der zur bestimmten Zeit die alte Eihaut durchsticht, um dem sogenannten zweiten Ei den. Austritt zu gestatten. Bei Nesaea fallen die alten Eischalen einfach ab, indem sie durch die aufschwellende noch in der zweiten Haut befindliche junge Milbe gesprengt werden.

Ist nun die Larve innerhalb dieser zweiten Eihaut entsprechend entwickelt, so sprengt sie dieselbe, was etwa nach vierzehn Tagen geschieht. Für die ausgeschlüpften Larven ist es aber keine leichte Arbeit, ganz frei zu werden, denn noch trennt die erhairtete OberAächenschicht der Kittsubstanz die Tierchen von ihrem Element. Durch die unruhige Bewegung zahlreicher Füsse wird die innere Nasse der Hüllsubstanz bald zerbröckelt, so dass die immer zahlreicher ansschlüpfenden Laren durch cinander liriechen und drängen: aber noch ist ein Ausweg nicht gefunden.

Endlich hat eine auch glücklich die iussere Hüllschicht an einer lesonelers nathgieligen Stelle durehbrehen und enteilt in die freie Flut. Dies glückt zuletzt allen, aber es geht manche Stunde darüber hin, bis die letzte Milbe dem Gefaingnis entromnen ist. Und vielleicht würde es noch länger dauern, ja mancher gar nicht gelingen, wenn nicht die. Taster unserer jungen Milben auf dieser 


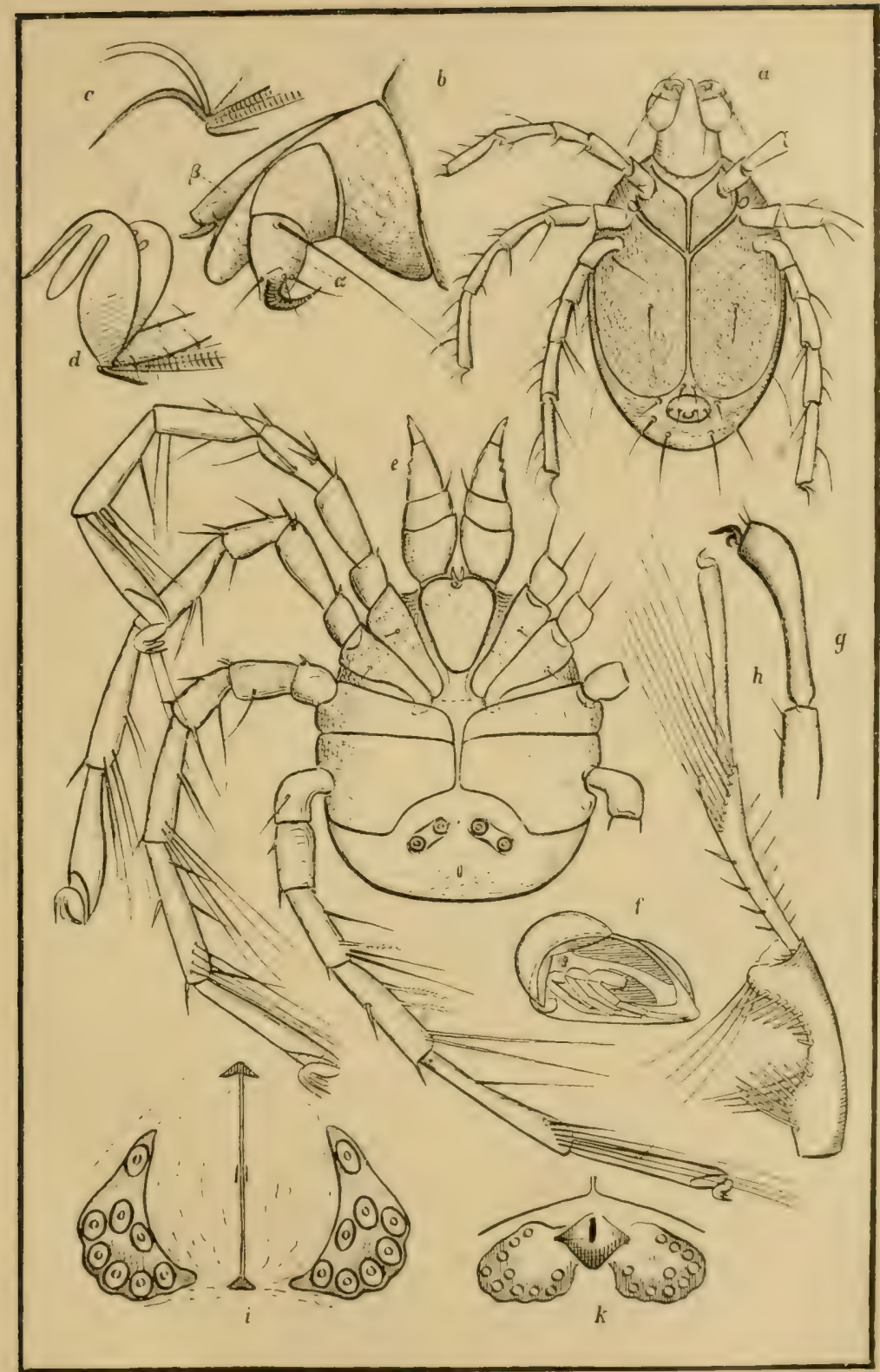

Fig. 3.

a Erste Larve von Nesaea fuscata, ron der Bauchfläche aus betrachtet $-b$ MIundschnabe] derselben, von der Seite, mit Taster $(\boldsymbol{\alpha})$ und Kiefer $(\boldsymbol{\beta})-c$ Fusskralle derselben Larve $d$ Fusskralle der erwachsenen Nesaea - e Zweite Larve von Nesaea fuscata $-f \Lambda$ us der gesprengten ersten Eischale tritt das zweite eiformige Stadium hervor. Der Embryo mit deutlichem Rücken. und Bauchschild ist von dem Apoderma umhüllt - $g$ Endglied des dritten Fusses vom erwachsenen Mlïnnchen der Nesaea fuscata - it Vierter Fuss desselben Mlännchens - $i$ Weibliche Geschlechtsöffnung von Nesnea fuscata mit den Haftnäpfen - k MIinnliche Geschlechtsüffnung von Nesaea fuscata mit den Haftnïpien. 
ersten Entwickelungsstufe eine von der späteren Gestalt sehr abweichende mal hir die spremgung vines entgegenstehenden Hindernisses sehr geeignete Form und Bewaffnung hätten (Fig. $3 b$ ). Sie sind sehr dick und nehmen eine starke Muskulatur auf, so dass sie sehr liraftige Dewegungen zulassen. Am vorkeren Ende des letzten der sehr gedrungenen Glieder bemerkt man eine grosse, stark getrümnnte Hakenkralle, die wie cinc Hippe in die Hüllmasse der Eier einsetzen und dieselbe aufreissen kann. Auf späteren Entwickelungstufen werden die Taster schlank und jene Krallen sind ganz verschwunden. Das Tierchen bedarf ihrer später nicht mehr. Nicht unerwähnt darf ich hier allerdings lassen, dass es auch Nesaca-Arten gricbt, bei denen dic sech-füssigen Larven die Freilneit nicht mehr gewinnen, sondern noch unter der Kitthülle ihre nächste Häutung durchmachen.

Wie es bei den Milben als Regel anzusehen ist - Ausnahmen sind ungemein selten -, hat unsere junge Larve (Fig. 3 a) nur sechs Füsse, jederseits drei, mit denen sie das Wasser lebhaft tritt, um schnell vorwärts zu eilen. Die grossen, als schwarze Pünktchen hervortretenden Augen bestimmen Richtung und Ziel der kräftigen Schwimmbewegung.

Wendet man eine hinreichende Vergrösserung an, so bemerkt man bald, dass cliese erste, jüngste Larve auch noch in anderer Hinsicht, nicht nur mit Rücksicht auf die Taster, gregen die spriteren

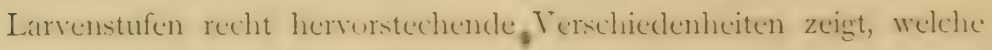
schon nach der nächsten Häutung v'erschwinden. So ist der ganze Rücken durch eine vorn breitere, hinten etwas zugespitzte härtere Deckplatte geschützt (Fig. $3 f$ ). Eine solche findet sich bei den enwachsenen Tieren zahlreicher Wassermilbenarten auch nicht mehr andeutungsweise; bei anderen ist ein geringfügiger Rest übrig geblieben (Hydrodroma) und bei einer nur geringen Anzahl Arten ist die Verhärtung der Rückenhaut eine für alle Lebensstufen dauernde.

Die Unterseite unserer jungen Larven (Fig. $3 a$ ) ist von der der spateren Larvenstufen und der erwachsenen Tiere zwar auch verschieden, doch finclen sich die auch später beobachteten 
Verhältnisse im allgemeinen hier wieder vor. Auffallend ist dagegen, dass die den Wassermilben so eigentümlichen sogenannten Haftnäpfe hier noch völlig fehlen. So stellt die erste jüngste Larvenform eine sehr eigenartige Entwickelungsphase dar und es kommt in der That bei dem Übergang zur zweiten Larvenform zu einer in jeder Beziehung sehr durchgreifenden Gestaltveränderung.

Etwa fünf oder sechs Tage, nachdem das Tierchen sich aus der Eihülle befreit hat, stellen sich die Vorboten clieser Verwandllung ein. Die Milbe fühlt wohl selbst, dass mit ihr etwas Bedeutsames vorgehen sull und hïngt sich, um die inneren Entwickelungsrorgänge ungestört ablaufen zu lassen, mit ihren Tastern an irgend einem geschützten Orte fest an. Die Glieder werden bewegungslos und die innere Körpersubstanz zieht sich aus ihnen zurück, eine rundliche von der alten Haut umschlossene eiartige Masse bildend. Ähnliches wiederholt sich später ebenso bei der zweiten noch eintretenden Häutung und wird auch bei der grossen Mehrzahl der Land und Wasser bewohnenden Milben beobachtet, wenn es auch nicht durchaus bei sämtlichen zu einer völligen Zurückziehung des Körperinhalts aus den Gliedern kommt.

Es gestaltet sich während der jetzt eben in Rede stehenden Larvenruhe unter der alten Haut eine neue Milbe aus. Man beobachtet deutlich die neuen Glieder durch die durchsichtige, num bloss noch einen Schutz für das zarte neue Geschöpf abgebende bisherige Haut hindurch. Nach wenigen Tagen ist es soweit, dass das eingeschlossene Tier die Hülle sprengen kann. Statt einer sechsfüssigen Acaride tritt eine achtfüssige aus der Larvenhaut hervor (Fig. 3c). Und während vorher die sechs Füsse ausserordentlich dünn und verhältnismässig kurz waren, fällt jetzt die Länge der acht neuen Füsse auf. Dieselbe übersteigt um ein Bedeutendes die Gesamtlänge des Rumpfes und giebt dem ganzen Tier etwas Schlankes und Zierliches. Das Rückenschild ist bis auf die letzte Spur verschwunden und auf der Unterseite sieht man ausser den völlig anders greformten grossen Hüftplatten noch jeclerseits von der kaum angredeuteten Geschlechtsüffnung cin schrägrg gestelltes Plättchen, welches zwci deutlich ausgebildete kreisrunde Haftniipfer trigt. Noth 
ein Blick auf die Füsse belehrt uns, daśs nicht nur reichliche Schwimmborsten die mittleren Glieder derselben schmücken, zwar noch nicht so zahlreiche wie beim erwachsenen Tier, aber doch schon genau ebenda aufgestellt wie bei diesem, sondern dass auch die Krallen eine ganz veründerte Form bekommen haben. Fig. $3 c$ zeigt die Kralle der ersten Larve, während Fig. $3 d$ dieienige aller späteren Lebensstufen darstellt, besser als eine $\mathrm{Be}$ schreibung es zu geben vermag. Die grösste Veränderung hat aber der Mundabschnitt erfahren. Der lange Schnabel ist verschwunden und die Taster sind langgestreckt und schlank, auch fehlt ihnen die scharfe Kralle, welche den ersten Larven so eigentümlich ist. Einem genaueren Beobachter entgeht auch nicht, dass die grosse Pore, welche bei letzterer zwischen den Hüftplatten des ersten und zweiten Fusses stand, jetzt ganz verschwunden ist. Dies hängt wohl mit der auffallendsten der inneren Veränderungen zusammen. Jetzt hat nämlich die junge Milbe zahlreiche Luftröhren bekommen, welche alle von zwei am Grunde der Kiefer ausmündenden Hauptstämmen ausgehen. Mit dieser Larvenform, welche in Fig. $3 c$ abgebildet ist, ist für die Hydrachniden die letzte Stufe vor der ganz ausgebildeten Form erreicht. Es ist dies keineswegs Gesetz in dem ganzen Reiche der Acariden, dass zwischen Ei und erwachsenem Tier nur zwei Larvenstadien eingeschaltet sind. Vielmehr zeigen zahlireiche (jattungen, namentlich atus den Familien der Hartmilben und Tyroglyphus-artigen. Milben drei und mehr Larvenstadien zwischen Ei und erwachsenem Tier, so dass es ein interessantes Gebiet der Forschung ist, entweder die Gründe einer (s) cingreifenden Verschiedenheit der Entwickehngegeschichte innerhalb der Familie der Acariden darzulegen oder durch richtigere Auffasung der bestehenden Verhailtnisse eine Ühereinstimmung der scheinbar verschiedenen Entwickelungsformen zu crkennen. Bemerkenswert ist es jedenfalls, dass die Trombidium-Arten eine mit den Iy drathichen im wesentlichen äbereinstimmende Entwirkelungsweise zeigen, so dass auch hierdurch deren nahe Verwandtschaft bestaitigt wird. Doch kehren wir noch einmal zu unserer Larve zurïck. Diese war zunächst dadurch ausgezeichnet, dass die Füsse 
im Vergleich zum Rumpf ausserordentlich lang, wenn auch zierlich sind. Dieses Verhältnis ändert sich jedoch bald, indem die Larve durch sehr reichliche Nahrungsaufnahme schnell und erheblich wächst, so dass der Rumpf mächtig anschwillt, während die Gliedmassen unverändert dieselbe Grösse beibehalten und so allmählich immer mehr gegen den Rumpf zurücktreten.

Bald tritt nun eine neue Pause in der Entwickelung ein. Die Milbe sucht ein Versteck und versinkt in einen neuen Zustand völliger Regungslosigkeit, wiihnend welcher sich innerhalb der Larvenhaut die vollständig ausgebildete Milbe entwickelt. Entschlüpft dann der Larvenhaut das endgültig fertiggestellte Tier, so fällt auch wieder vor allem der Unterschied in der Längenentwickelung der Füsse auf. Aber auch in vielen anderen Punkten ist an dem neuen Geschöpfe eine wesentlich andere Form und Bildung zu bemerken. So sind die Weibchen nunmehr von den Männchen deutlich $\mathrm{zu}$ unterscheiden, während bis zur letzten Larve ein äusserlicher Unterschied der männlichen und weiblichen Larven nicht festgestellt werden konnte. Es sind aber auch abgesehen von diesem Unterschiede in beiden Geschlechtern die Schwimmborsten an den Gliedern namentlich der hinteren beiden Fusspaare ausserordentlich viel zahlreicher geworden. Endlich findet man statt der wenigen Haftnäpfe auf der Unterseite des Hinterleibes nunmehr deren zahlreiche jederseits in einem Häufchen vereinigt (Fig. $3 i$ u. k).

Ist die erwachsene Milbe nach der letzten Häutung noch verhrältnismässig klein, so bewirkt eine reichliche Nahrungszufuhr balel ein ansehnliches Wachstum, so dass es namentlich Weibchen bis zu I $1 / 2 \mathrm{~mm}$ Länge giebt, während die Männchen meist erheblich lileiner bleiben. Überhaupt ist bei den Milben das Männchen meistens ziemlich viel kleiner als das Weibchen, selbst dann, wenn letzteres nicht durch die zahlreichen allmïhlich heranwachsenden Eier aufifuillt.

Wie lange eine erwachsene Milibe zu leben vermag, ist nur selten Gegenstand des Experiments gewesen. Ich selbst habe Larven von Nesaca fuscata einen ganzen Winter hindurch gehalten, ohne dass sie sich verwandelt hätten. Andere Beobachter haben sihnliche 
Resultate bemerkt. Es ist wohl möglich, dass eine Milbe der erwahnten Art mehrere Jahre hindurch ihr Leben erhalten kann.

Den Beschluss dieser Darstellungen aus der Entwickelungsgeschichte der Süsswassermilben mag die Lebensgeschichte der Hydracha grobosa machen. Dieselue ist schom von Dugès in den dreisiger Jahren unseres Jahrhunderts entedect und seitdem oftmals bestatigt worden. Diese Wassermilbe ist, wie bereits oben gesagt, insufern bemerkenswert, als aus ihren Eiem junge Larven schlüpfen, welche von den entsprechenden der Hart- und Weichschwimmer, also auch denen von Nesaea und Atax völlig verschieden sind, dagegen mit den Larven der auf dem Lande lebenden Trombidien grosse Ahnlichlicit besitzen. Eine derartige Larve, welche aber nicht zu Hidrachna, sondern zu einer Gattung gehört, welche den Namen Hydrodroma erhalten hat, ist in Fig. 4 abgebildet. Sie zeichnet sich durch eine mächtige Entwickelung der Kiefer aus und führt Taster, welche unmittelbar an die Taster aller trombidiumartigen Landmill,en crinnern, dadurch, dass das letzte Tasterglied an clem untern Encle des vorletzten Gliedes seitlich und nicht am obern Ende eingelenkt ist. Die Füsse sind mit Krallen bewehrt, welche sich in dieser Form ebenfalls bei zahlreichen Landmilben, selbst bei l'anzermilben (Oribatiden) wiederfinden. Diese kileinen scharlachroten Larven scheinen unter allen Umständen ein parasitisches Leben führen zu müssen. So heften sich die Hydrachna-Larven an Insekten, welche im Wasser leben, fest. Sehr bevorzugt wird die graue Wasserwanze, an welcher man im Frühjahr häufig die schon über stecknadelkopfgrossen Parasiten mit ihrem Kopfe in die weicheren Hautpartien an den Gelenken eingebohrt findet. Da die völlig ausgewachsene Wassermilbe schon in Juni beobachtet wird, so wird bereits Anfang Juli das Ausschlüpfen aus den Eiern stattfinden. Die jungen Milben machen ihre erste Larvenzeit teils freilebend, so lange nänlich, bis sie ein geeignetes Nährtier gefunden haben, teils als Parasiten angeheftet an letzterem durch. Diese letztere Periode erstreckt sich durch den Herbst bis zum Frühjahr. Wtihrend dieser Zeit nimmt die Grösse des Tieres durch unausgesetzte Nahrungszufuhr dauernd $\mathrm{zu}$, so dass Larven bis zu $2 \mathrm{~mm}$ 
Länge an den Nährinsekten angetroffen werden. Der Hinterleib dehnt sich dabei allein aus, während die Gliedmassen keine Grïssenzunahme erfahren. Gewissermassen gestaltet sich das Tier zu einer Vorratskammer von Nährstoffen um, welche nun im Frühjahr zur Neubildung der zweiten Larve verwendet werden. In dem auf-

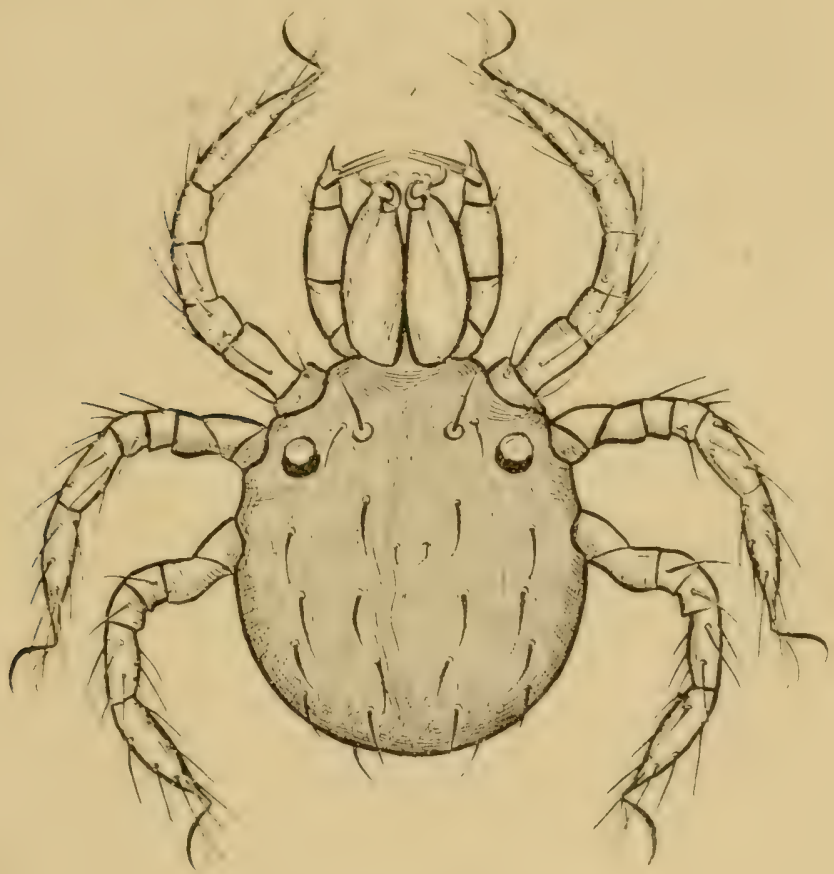

Fig. 4 .

Erste Larve von Hydrodroma rubra.

getriebenen Hinterleibe bemerkt man, wie in einem zugeschnürten Beutel ruhend, nunmehr die völlig anders gestaltete neue Milbe. Dieselbe hat acht Füsse statt der früheren sechs und zeigt ein veründertes Kopfsegment, ist überhaupt in keiner Weise vergleichbar der ersten Larve.

Diese zweite Larve hat bereits im wesentlichen die Gestalt des erwachsenen Tieres, zunächst aber noch nicht dessen Grösse. Durch 
schnelles Wachstum erreicht sie dieselbe aber bald und begiebt sich an einen Ort, wo sie die zweite Larvenruhe durchmachen kann. Zu diesem Zweck entleert sie einen Tropfen ihres Speichelvorrats und heftet dadurch ihren langen Schnabcl an die Lnterlage fest an. Die Glieder verlieren ihre Beweglichkeit und der Leibesinhalt gestaltet sich noch einmal zu einem neuen Tiere um. Nach etwa zehn Tagen durchbricht letzteres die schützende Haut der ruhenden Larve. Nunmehr ist das Tier ausgebildet und erfährt nur noch ein Grössenwachstum.

\section{An ha ng.}

\section{Tabelle zur bestimmunng der bis jetzt bekannt gewordenen Gattungen der IJjdrachiden.}

r. Die Augen nahe bei einander, der Mittellinie des Körpers sehr genühert.

Die Augen in zwei weit von einander getrennte Gruppen gesondert, dem Seitenrande des Körpers genähert . . 3 .

2. Sämtliche Füsse ohne Schwimmborsten . Limnochares, Latr. Nur das vierte Fusspaar ohne Schwimmborsten Eylaïs, Latr.

3. Die Mandibeln eingliedrig, stechborstenartig, in einem schnabelartigen Mundrohr laufend . Hydrachna, Müller Mandibeln zweigliedrig. . . . . . . . . . . . 4 .

4. An den Füssen keine Schwimmborsten . . . . . 5 .

An den Füssen Schwimmborsten . . . . . . . . 6.

5. Auf dem Rücken zahlreiche poly'gonale, einander sehr genäherte erhärtete Felder . . . . Thyas, C. L. Koch. Eine einzige Panzerplatte bedeckt den Rücken Aturus, Kramer. Der Rücken durchaus weichhiutig . . Bradybates, Neuman. 
ט. Die Körperhaut in beiden Geschlechtern überall erhärtet 7 . Auf dem Rücken des Münnchens eine denselben fast vollständig bedeckencle poröse Platte, welche dem Weibchen fehlt . . . . . . . Forelia, Haller. Aufdem Vorderrücken bei beiden Geschlechtern einenur wenig umfangreiche vierzipfelige Stimplatte Hydrodroma, C. L. Koch. Der Rücken bei beiden Geschlechtern durchaus weichhäutig 9 .

7. Am vierten Fusse jeder Seite keine Krallen Marica, C. L. Koch. Am vierten Fusse jeder Seite Krallen . . . . . . . 8.

४. Jederseits nur drei Haftnäpfe . . . . Axona, Kramer. Jederseits sehr zahlreiche kleine, porenartige Haftnäpfe

Arrenurus, Dugès.

4. Die Taster endigen scherenförmig . . Diplodontus, Dugès.

Die Taster endigen nicht scherenförmig ... . . . . IO.

Io. Die Epimeren sämtlicher Füsse jeder Seite bilden ein zusammenhängendes Feld . . . . . . . . II.

Die Epimeren der Füsse jeder Seite sind in zwei von einander getrennte Gruppen gesondert . . . . . . I4.

I I. Der Körper bedeutend mehr lang als breit, oval abgerundet

Psendonnarica, Neuman.

Der Körper kreisrund . . . . . . . . . . . I2.

Der Kürper hinten fast gradlinig abgestutzt Accrcus, C. L. Kooch.

12. Die Haftnäpfe fehlen ganz . . . Pontarachna, Philippi. Jederseits drei Haftnäpfe . . . . . . . . . I3. Jederseits zahlreiche Haftnäpfe . . . . Midca, Bruzelius.

I3. Die Haftnäpfe auf der Innenfläche der Geschlechtsdeckllappe . . . . . . . . Lebertia, Neuman.

Die Haftnäpfe auf der äussem Oberfäiche der Geschlechtsdeckklappe .

Midcopsis, Neuman.

I + . Am vierten Fusse ohne Krallen

I 5 .

Am vierten Fusse Trallen

I1).

1,5. Jederseits drei Haftnäpfe auf der Innenfläche der Geschlechtsklappe . . . . . . . . Teutonia, Koenike.

Jederseits drei Haftnäpfe auf der Aussenfläche der Geschlechtsklappe . . . . . . Limmesia, C.L. Koch. 
r6. Jederseits drei Haftnäpfe auf der Innenfläche der Geschlechtsklappe . . . . . . . Sperchon, Kramer.

Die vorhandenen Haftnäpfe neben dem Geschlechtshof in die Haut eingelassen, oder auf Platten angebracht 17 .

17. Jederseits drei Haftnäpfe . . . . . . . . . . 18.

Jederseits sechs oder viele Haftnäpfe . . . . . . . 2 I.

I 8. Am Vorderrande des vorletzten Tastergliedes ein stumpfer zapfenartiger Fortsatz neben dem fünften Gliede

Piona, C. L. Koch.

Am Vorderrande des vorletzten Tastergliedes kein zapfenartiger Furtsatz . . . . . . . . . . . . I 1 .

19. Die Epimere des vierten Fusses jeder Seite am hintern Rande in der Mitte in eine längere Spitze nach hinten ausgezogen . . . . . . . Hydrochoreutes, C. L. Koch.

Die Epimeren des vierten Fusses jederseits hinten geradlinig abgeschnitten . . . . . . . . . 20.

20. Die Haftniipfe klein, den Geschlechtshof völlig einrahmend

Megapus, Neuman.

Die Haftnäpfe verhältnismässig gross, auf besonderen, neben dem Geschlechtshof stehenden Plïttchen eingelassen . . . . . . . Hygrobates, C. L. Koch.

2 I. Dic Krailen mit blattartig erweiterter Pasis: Männ hen mit besonders umgestaltetem dritten und rierten Fuss

Nesaca, C. L. Koch.

Die Krallen nicht mit blattartig erweiterter Basis, Männchen mit nicht besonders umgestalteten Füssen

Atax, Bruzelius. 


\section{Litteratur.}

1) Otto Friedrich Müller, Hydrachnae, quas in aquis Daniae palustribus detexit, descripsit, pingi et tabulis aeneis XI incidi cur. Lipsiae I78I.

2) Pierre André Latreille, Précis des caractères génériques des Insectes. Paris I 796.

3) Antoine Dugès, Recherches sur l'ordre des Acariens en général et la famille des Trombidiés en particulier. Premier mémoire. Annales des Scienc. nat. Paris 1834 .

4) Carl Ludwig Koch, Deutschlands Crustaceen, IIrriapoda und Arachniden, Heft I-40. Regensburg I835-4I. Desselben Verfassers Uebersicht des Arachnidensystems. Nürnberg I 842.

5) Ragnar Magnus Bruzelius, Beskrifning öfver Hydrachnider, som förekomma inom Skåne. Akad. Abhandl. Lund I 854.

D) Edouard Claparède, Studien an Acariclen. Zeitschrift für wissensch. Zoologie von Siebold und Kölliker, XVIII. Bd. Leipzig 1868.

7) A. Croneberg, Ueber den Bau der Hydrachniden. Zool. Anzeiger von V. Carus. Leipzig I878, Jahrg. I, Nr. I4.

8) C. J. Neuman, Om Sveriges Hydrachnider, med I4 Taflor. Kongl. Svenska Vetenskaps-Akad. Handlingar, Bd. I7, I879.

9) G. Haller, Die Hydrachniden der Schweiz, mit + Tafeln. Bern I 882 .

Io) F. Koenike, Ueber das Hydrachniden-Genus Atax. Bremen - I 88I. 
II) F. Koonike, Revision von A. Leberts Hydrachniden des Genfersees. Zeitschr. f. wiss. Zool. Bd. XXXV, I88I.

I2) F. Koөnike, Zwei neue Hydrachniden vom Isergebirge. Zeitschr. f. wiss. Zool. Bd. XLIII.

I3) F. Koenike, Eine neue Hydrachnide aus dem Karraschsce bei Deutsch-Evlau. Schriften der naturforschenden Gescllschaft zu Danzig. N. F. VII. Bd.

I4) F. Koenike, Ein neues Hydrachniden-Genus (Teutonia). Archiv f. Naturgesch. I890, Bd. I.

I5) F. Koenike, Einige neubenannte Hydrachniden. Abh. des naturw. Vereins in Bremen, Bd. IX.

I6) Robert Schaub, Über die Anatomie von Hydrodroma. Ein Beitrag zur Kenntnis der Hydrachniden (mit 6 Tafeln). Sitzungsberichte der kaiserl. Akad. der Wissenschaften in Wien. Math.-naturw. Klasse, Bd. XCVII, I 888.

I7) Robert Schaub, Über marine Iydrachniden nebst cinigen Bemerkungen über Midea (mit 2 Tafeln). Sitzungsberichte der kaiserl. Akad. der Wissenschaften in Wien. Math.-naturw. Klasse. Bd. XCVIII, I889.

I8) Th. Barrois, Matériaux pour servir à l'étude de la faune des eaux douces des Azores. I. Hydrachnides. Lille 1887.

I (1) Th. Barrois et R. Moniez, Catalogue des Ilydrachnides etc. Lille 1887 .

20) Th. Barrois, Note sur la dispersion des Hydrachnides. Revue biolog. du Nord de la France, T. I. I 888-I889. 
Kerfe und Kerflarven des süssen Wassers, besonders der stehenden Gewässer.

\author{
Von Dr. E. Schmidt-Schwedt in Berlin.
}



Vorbemerkung. Der folgende Aufsatz will nur Skizzen aus der Kerfivelt des süssen Wassers geben; dass dabei ganz wesentlich die Kerfe und Kerflarven der stehenden Gewässer berücksichtigt worden sind, ist schon in der Überschrift angedeutet worden. Ich habe diese Beschränkung geübt, um mich in den Schilderungen fast ganz auf eigene Anschauung, auf eigene Beobachtungen stiitzen zu können. Auch der Kundige, so hoffe ich, wird darin, besonders in biologischer Hinsicht, manches Neue finden; in jedem einzelnen Falle es als solches kenntlich $\mathrm{zu}$ machen oder $\mathrm{zu}$ abweichenden Angaben in der Litteratur besonders Stellung zu nehmen, schien mir in einem Aufsatze wie dem vorliegenden überflüssig.

\section{Einleitung.}

Wenn von dem zahllosen Heer der Kerfe die Rede ist, denkt wohl fast Jeder zunächst nur an die augenfälligen Vertreter derselben, welche dem Luftmeer angehören und auf Blatt und Blüte. wie auf und in der Erde ihr Wesen treiben: dass auch dem Wasser Vertreter dieses "luftigen" Vollies in reichlicher Menge anguhüren. der Gedanke liegt wohl Vielen fern. Wer dann unter kundiger Leitung besonders ein pflanzenreiches stehendes Gewässer etwa im Mai mit dem Netz*) untersuchen will, der dürfte wohl staunen

*) Ich benutze dazu mit Vorliebe wenig tiefe Netze aus weissen Rosshaaren. Dieselben bieten besonders den Vorteil, dass der Stoff im Wasser nicht quillt, also die Lücken gleich weit bleiben und dass ferner Algenscbleim u. dergl, nicht daran baften bleibt. 
über das reiche Insekten - und vornehmlich Insektenlarvenleben derselben und wenn er einiges mit nach Hause nimmt zu genauerer Untersuchung und Beobachtung der Lebenserscheinungen, könnte sich leicht ein dauerndes Interesse für diese Tierwelt daraus entwickeln. Derjenige nun, welcher seine Aufmerksamkeit den Wasserinselten zuwenden will, kamn zeitig in Frühjahr mit seiner Thätigkeit beginnen. Wenn kaum einige Zeit das Eis unserer Gräben und Teiche den wieder kräftiger werdenden Sonnenstrahlen gewichen ist, beginnt schon ein grosser Teil der im Wasser lebenden Insekten und Insektenlarven ihr gewohntes Treiben. Geraume Zeit also, bevor der erste Schmetterling, die erste Grabbiene (Andrena), die erste Pollenia (Fliegenart) erscheint, bietet cin Ausflug nach Teichen und Gräben auf Wasserinsekten reichliche Ausbeute. Ja, manche Vertreter unserer biologischen Gruppe scheinen eine Winterruhe kaum zu halten; wenigstens habe ich, mehrfach selbst im Januar Larven der Käferfliegen unter dem Eise ihrer Lebensaufgabe, dem Frassgeschäf, obliegen und Schwimmkiafer wic Wasserwanzen sich ebendort tummeln sehen. Es ist eben das Wasser, die Urheimat alles Lebendigen, für alle Lebewesen, die in seinen Schoss sich begeben haben, in vieler Hinsicht ein ungleich freundlicheres Element als das Luftmeer. Die besonders im Frühjahr sprungartigen Veränderungen in der Wärme der Luft, die allen Tieren, welche zu früh ihre Winterplïtze verlassen haben, leicht verderblich werden, gleicht das Wasser mässigend aus und die trüben Regenund Schneeschauer des Frühjahrs hält es seinen Inwohnern sicher vom Leibe. Bei den nicht zu hohen Wärmegraden bietet sogar das Wasser im Frühjahr denen unter seinen Bewohnern, welche zur Atmung nicht die atmosphärische Luft, sondern die im Wasser gebundene lenutzen, besonders ginstige T)aseinsbedingungen, dit der Luftgehalt des Wrassers diunn wegen der geringen Wïrme grësisee ist als im Sommer*). Das reichste Insektenleben zeigen die Gewässer wohl im Mai; die Zahl der Larven, welche den grösseren

*) Auch bei den Ausflügen, die dem Fange unserer Tiere gelten, macht sich geringe Wairme als gïnstiger Umstand benerkbar; ungleich leichter als an warmen Sommertagen bringt man die Tiere ohne Abgang an Toten an kühlen Frühlingstagen heim. 
Bestandteil der Insektenwelt des Wassers ausmachen, ist dann auf ihrem Höhepunkt. Zum Hochsommer nimmt deren Zahl wieder ab. Nicht wenige der dem Wasser angehörigen Insektenlarven üherwintern freilich selbst in diesem Zustand, z. B. einzelne Schwimmkïferlarven, zahlreiche Mücken-, Köcherfliegen- und Eintagsfliegenlarven.

Ist nun auch die Zahl der Insekten und besonders der Insektenlarven, welche im Wasser leben, eine recht erkleckliche, so ist doch anderseits zu betonen, dass die eigentliche Stärke dieser Grossmacht des Tierreichs auf der Erde, in der Luft liegt und - was für unsere Betrachtungen wichtiger ist - dass das Verhältnis der Insekten zum Wasserleben im wesentlichen ein gleiches ist wie das der Säugetiere zu demselben. Ich will damit sagen, dass hier wie dort der Grundtypus der Klasse in seiner ganzen Gestaltung auf das Landleben hinweist (wie etwa umgekehrt der der Fische und Krebse auf das Wasserleben) und dass die im Wasser lebenden Vertreter, bei den Säugetieren z. B. Seeotter, Seehund, Walfisch, zwar mehr oder minder weit gehende Abänderungen von jenem Grundtypus zeigen, die eben im Zusammenhange mit ihrem besonderen Aufenthaltsorte stehen, aber doch immer noch deutlich genug erkennen lassen, dass solche Eigentümlichkeiten erst etwas nachträglich Hinzugekommenes sind, oder vom Standpunkte der Abstammungslehre aus: Die Vorfahren dieser im Wasser lebenden Tiere waren Landtiere; erst nachtrïglich haben sich die Anpassungen, welche in Beziehung zum Wasserleben stehen, herausgebildet. Zwei Gebiete der Lebensthätigkeit num werden bei der Gegenülerstellung von Land- und Wasserleben besonders berührt und also auch die denselben dienenden Organe: Atmung und Bewegung*). Diesen beiden Funktionen und ihren Organen werden wir also im Fulgenden in erster Linie unsere Aufmerksamkeit zuzuwenden haben.

Bei den Säugetieren ist die Zahl der Ordnungen, aus denen Vertreter dem Wasser angehören, nicht eben gross, wenige Raubtiere, Nagetiere und die beiden Ordnungen der Robben und Wale;

*) An dritter Stelle wëren die Sinnesorgane in Betracht zu ziehen, doch muss ich dieselben, da dies ein völlig unbebautes Gebiet ist, im Folgenden ausser Betracht lassen. 
ein gleiches trifft für die Insekten zu, wenn man die entwickelten Tiere im Auge hat - es sind dann nur Käfer und Schnabelkerfe (Wanzen) zu nennen. Anders gestaltet sich aber das Bild, wenn man, wie billig, auch die Larven berücksichtigt. Dann ist nur eine Ordnung in Wasser nicht vertreten, nümlich die der Hymenopteren, d. h. der Verwandten von Biene, Wespe und Blattwespe. Um nun die stattliche Reihe aller dieser Vertreter in eine übersichtliche Anordnung zu bringen, dürfte es sich empfehlen, die natürlichen Gruppen des Insektenvolkes, die Ordnungen, zu Grunde zu legen.

\section{Käfer.}

\section{Taumelkäfer (Gyriniden).}

$\mathrm{Zu}$ den wenigen Vertretern der Wasserinsekten, welche sich auch dem flüchtigen Auge des Spaziergängers aufdrïngen, gehë̈ren die mässig grossen (bis $7 \mathrm{~mm}$ ), nicht eben zahlreichen Arten der Taumel- oder Drehkäfer (Gyriniden). In vielfach durch einander greschlungenen Linien schwimmen sie blitzschnell bei schönem Wetter gesellig auf der Oberfläche stehender wie fliessender Gewässer dahin. Diesen Tummelplatz, die Oberfläche des Wassers, teilt mit ihnen unter den Wasserinsekten in gleich ausgesprochener Weise nur noch eine Familie der Schnabellierfe, die Wasserliufer (Hydrodromici), die auf langen Beinen zur Übernaschung des Zuschaucrs auf dem Wasser dahinlaufen*).

Unterscheiden sich die Taumelläfer von den Wasserliufern schon dadurch, dass sie an der Oberfläche dahinschwimmen, nicht auf ihr laufen, so kommt dazu noch weiter, dass sie auch, was jene nie thun, leicht in das Wasser hinabtauchen, sei es nun, um sich der Ungunst des Wetters oder drohender Gefahr zu entzichen oder um Beute zu erhaschen. Wahrend der Kaffer auf der

*) Auf der Oberfläche des Wassers trifft man nicht selteh auch verschiedene Fliegenarten, besonders solche aus der Familie der Dolichopiden und Musciden (Ëphydrinen). Ebenso leicht, wie sie auf dem Wasser dabin laufen, fliegen sie nuch wieder von dort fort; Anpassungen an das Leben an diesem Aufenthaltsort wie bei Taumelkäfern und Wasserlänfern sind mir nicht bekannt. - An vierter Stelle kïnnte man hier vielleicht noch die winzigen Springschwäinze (Poduren) nennen, die sich bisweilen in der Nähe des Ufers in grossen Scharen ansammeln und dann einer Masse Schiesspulver gleichen, dessen Kürner auf rütselhafte Weise in hüpfende Bewegung versetzt sind. 
Oberfliche schwimmt, scheint or gleichzcitig dic Lmgebung über wie unter Wasser zu mustern; wenigstens weist darauf eine seltsame Einrichtung seiner. Augen hin. Jedes derselben ist nämlich durch eine breite Chitinleiste in einen nach oben und einen nach unten gewendeten Teil geschieden, so dass man bei unseren Tieren von vier Netzaugen sprechen kann.

Die Ausgestaltung ihrer Beine zum Schwimmen ist vollkommener als bei irgend einem anderen Käfer und zwar gilt das in annähernd gleichem Grade für Mittel- wie Hinterbeine, während die Vorderbeine, welche nur zum Greifen und Festhalten benutzt werden, armartig verlängert sind. An den Mittel- und Hinterbeinen sind besonders die Schienen und vier ersten Fussglieder flossenartig verbreitert und dabei etwas schaufelartig ausgehöhlt; der Aussenrand ist überdies mit Schwimmborsten besetzt. Schwimmen, besonders schnelles Schwimmen mit den Gliedmassen, ist eine ansehnliche Arbeitsleistung und stellt daher an die Festigkeit des Körperbaues, vornehmlich hinsichtlich der Anfügung der Gliedmassen, hohe Anforderungen. Wer den Bau unseres Käfers auf diesen Gesichtspunkt hin untersuchen will, wird ihn in Einklang mit jenen Forderungen finden. Besonders die Hinterhüften sind auffallend gross und fest mit dem Brustskelett verwachsen; an der Mittelbrust, von deren Hüftteilen annähernd Gleiches gilt wie ron den Hinterhüften, fillt besonders der grosse Mittelteil (Mesosternum) auf, dessen Ausdehnung einen Schluss erlaubt auf die auch in diesem Brustring entwickelten Muskelmassen.

Die Anpassung der Beine an das Schwimmen ist eine so ausgeprägte, dass die Käfer auf dem Lande ebenso unbeholfen sind wie manche Vertreter der im Wasser lebenden Säugetiere. Wollen sie jedoch von einem Gewässer zum anderen wandern, so stehen ihnen wie allen Wasserkäfern dazu die Flügel zu Gebote.

Sind die Gyriniden hinsichtlich ihrer Bewegung ausgesprochene Wassertiere, so bieten sie dagegen rücksichtlich der Atmung nichts Besonderes dar. Befinden sie sich an der Oberfläche, also mit der Rückseite ganz an der Luft, so atmen 'sie wie gewöhnliche Landkäfer; tauchen sie unter, so sieht man am Hinterencle stets 
ein kleines Luftbläschen glïnzen. Ganz anders verhalten sich in diesem Punkte die Larven der Taumelkäfer. Diese besitzen (Fig. 5, I Larve ron Gyrints strintus) jeme cigenartigen Atmungurgane. welche

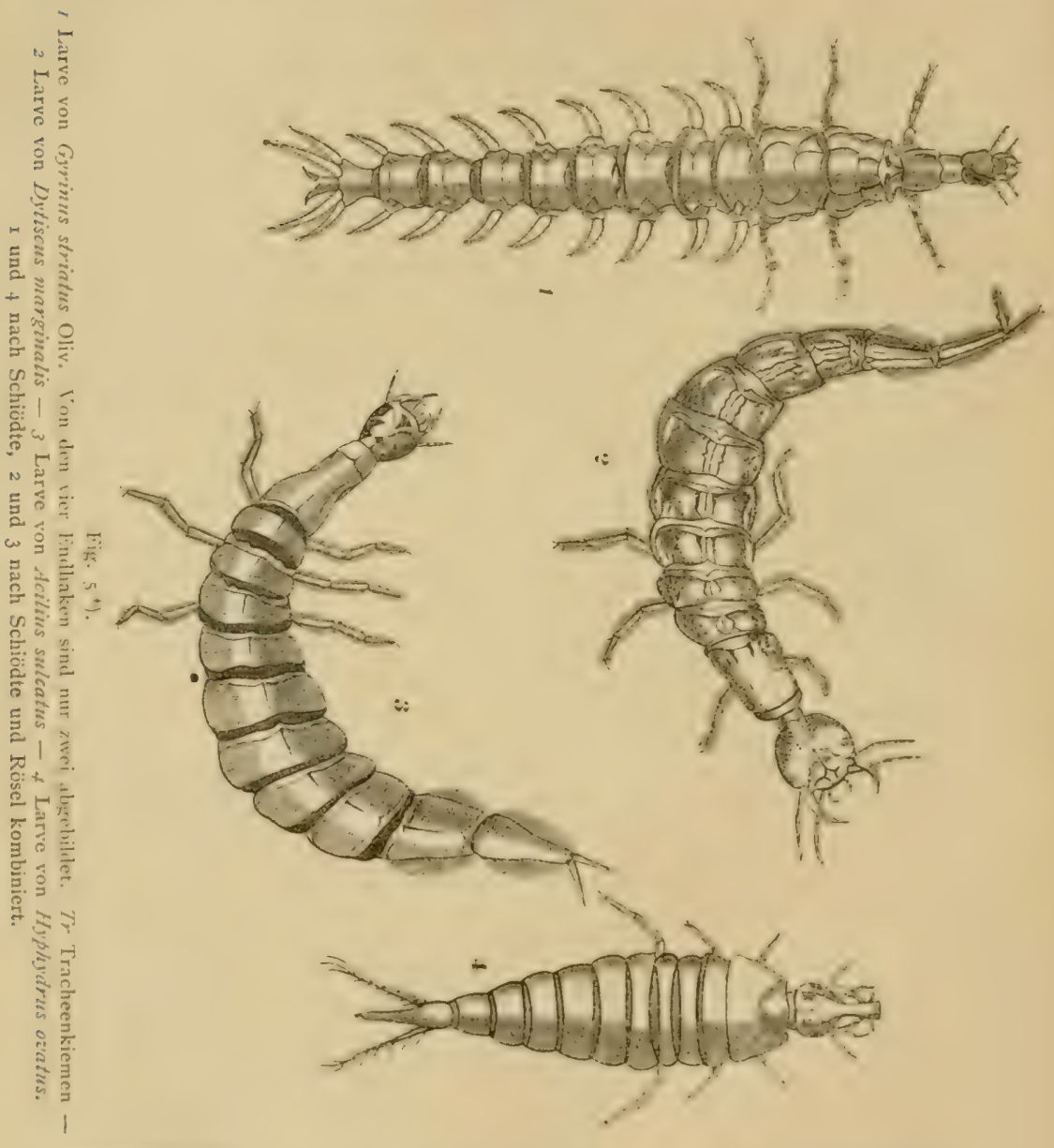

*) Die vergrüsserten lïguren für die Zinkographie sind von IIerrn Kupferstecher Ette1, Berlin, dem ich dafür zu Dank verbunden bin, teils nach vorhandenen Abbildungen, teils nach meinen Handzeichnungen, teils nach der Natur gezcichnet worden; im letzteren Falle ist stets Zeichnung und Objekt von mir verglichen worden. Im ersten Falle ist stets der Schriftsteller genannt worden, dem die Figur entlehnt wurde, in den beiden letzten ist angegeben worden: nach der Natur. 
einem Teil der Insektenlarven des Wassers zukommen und mit dem Namen Tracheenkiemen belegt worden sind. Wie die gewöhnlichen Kiemen vermögen diese Organe dem Wasser den absorbierten Sauerstoff zu entnehmen, enthalten jedoch nicht einen lebhaften Blutstrom, sondern verzweigte Luftröhren (Tracheen), welche von zartem Protoplasma umgeben sind. Bei den Gyrinidenlarven sind diese Organe seitlich bewimpcrt (s. Fig. 5, I); jeder Hinterleibsring trägt an der Seite je ein Paar dieser Kiemenfidden, der letzte aber vier derselben, die nach hinten gerichtet sind. In schlechtem, d. h. sauerstoffarmem Wasser habe ich unsere Larve mehrfach den Hinterleib auf- und niederschwingen sehen, während sie sich mit den Beinen festhielt. Offenbar dienten diese Bewegungen zur schnelleren Erneuerung des für die Atmung nötigen Wassers. Durch gleichartige Bewegungen des Körpers, also ebenso wie die Egel unserer Gewässer, vermag auch die Larve ziemlich schnell durch das Wasser zu schwimmen; dabei gewinnen auch wohl die Wimpern der Tracheenkiemen ihre Bedeutung. An der Gestalt und Verteilung dieser Organe, an den sechs Brustfüssen und an den vier gekrümmten Chitinhaken am Hinterleibsende (in unserer Figur sind nur zwei davon sichtbar) sind unsere Larven leicht kenntlich.

So häufig übrigens die Taumelkäfer sind, so selten habe ich - und wie es scheint auch Andere - die Larven angetroffen. Vermutlich halten sich dieselben in Schlupfwinkeln, etwa unter Steincn am Boden der Gewässer, auf; dafür sprechen ihre Atmungsorgane, die sie davon befreien, wie andere Wasserkäferlarven zur Atmung an die Oberfläche kommen zu müssen, die zarte Beschaffenheit des Hinterleibes und der Besitz der gekrümmten Haken am Körperende, die anscheinend zum Festhalten in Güngen oder an Gegenständen dienen. Die Larven leben übrigens wie die Küfer vom Raube. Zur Verpuppung verlassen sie, wie das fast für alle Käferlarven des Wassers gilt, dieses Element und gehen an das Land.

\section{Schwimmkäfer (Dytisciden).}

Ungleich reicher an Arten als die nur in zwei Gattungen mit. zwölf Arten vertretenen Taumelkäfer ist die Schar der eigentlichen 


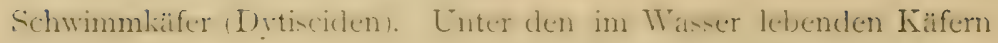
sind sie schon durch die fadenförmigen, auch im Wasser stets frei getragenen Fühler gekennzeichnet. Nahezu I50 deutsche Arten werden unterschieden, für die zwölf Gattungen aufgestellt worden sind. Die ansehnlichsten Vertreter unserer Familie sind die Arten der Gattung Dytiscus und Cybister (über $21 / 2$ cm gross); unter ihmen wierler ist wohl der Gelbrand, Dytiscus marginalis, diejenige Art, welcher man am häufigsten begegnet*).

Der Gelbrand hält sich wie alle seine Familiengenossen, sofern er nicht fliegend das bisher bewohnte Gewässer mit einem anderen vertauscht, nur in, nie auf dem Wasser auf, dort seinem räuberischen Treiben nachgehend. In nicht zu langen Zwischenräumen muss er jedoch, um zu atmen, an die Oberfläche kommen. Die Hauptmenge der Atemöffnungen liegt aber an der Rückseite des Hinterleibes unter den Flügeln und daher steckt der Käfer, das Kopfende schräg nach unten haltend, nur das Ende des Hinterleibes heraus und lüftet dabei ein wenig die Flügeldecken. Bei der geringsten Beunruhigung fährt er sofort in die Tiefe. Eine schnelle Erledigung des in dieser Lage offenbar geführlichen Atemgeschäftes wird nun ermöglicht durch ungewöhnlich grosse, mit wilkwmmenen Schutzorrichtungen gegen Staub versehene Luftlöcher; besonders die dem Körperende näheren sind im Gegensatz zu dem bei Landkäfern üblichen Verhalten durch Grösse ausgezeichnet. Sind sie es doch auch, welche hier zunächst in Anspruch genommen werden. Durch die Luft, welche sich in den Tracheen und unter den Flügetn lefindet, wird äbrigens der Kö̈per im Verhältnis zu seinem Rauminhalt so leicht, dass der Käfer infolgederen in Watser emporsteigt und also sich anstrengen muss, nicht wenn er zur Oberfläche will, sondern umgekehrt, wenn er zur Tiefe hinab will. Den Weg dahin nimmt er meist nicht in einfach senkrechter Richtung, sondern fast immer etwas schraig; er benutzt so den Widerstand, welchen seine breite Gestalt der Wirkung

*) Im Lictz gebärdet er sich gewühnlich sehr unruhg; fasst man ihn, so sucht er sich durch Entlecrung seines Unrats und ciner milchigen Flüssigkeit, die dem Vorderbrustring entyuillt, zu befreien. 
des Auftriebes entgegenstellt, wie der Arbeiter, welcher das Fass nicht einfach hebt, sondern auf der Schrotleiter emporrollt.

Einer bemerkenswerten, auf die Atmung bezüglichen Benbachtung sei hier noch gedacht, die ich zuerst bei Cybister Roesclii machte: die Haut der Bauchseite dieses Käfers ist so durchsichtig, dass an dem auf den Rücken gelegten Tier die Luftröhren, besonders die stärkeren, querverlaufenden Stämme unter den Ringen des Hinterleibes und eine grosse Tracheenblase der Brust deutlich zu erkennen sind. An ihnen kann man nun ohne Schwierigkeit wahrnehmen, wie zum Auspressen und Wiedereinsaugen der Luft ihre Wandungen abwechselnd zusammen und wieder aus einander gehen. Das erstere geschieht infolge besonderen MIuskeldruckes, das Öfnen dagegen infolge der Spannkraft der Luftröhrenwände.

Zum Schwimmen benutzt der Gelbrand fast nur die Hinterbeine, deren Schienen und Fussglieder mit Schwimmharen versehen sind, und zwar beim Männchen mit zwei Reihen, beim Weibchen mit einer. Wie ein geschulter Schwimmer bewegt der Käfer die in ihren Fussgliedern nach oben gekrümmten Beine dieses Paares stets gleichzeitig. Von auffälliger Grösse sind wiederum die fest mit dem Körper verwachsenen Hüften, die bei der ersten Betrachtung ein Teil der Brust zu sein scheinen; eigenartig ist die Befestigung der übrigen Beinteile daran, nämlich derart, dass den Schenkeln und Schienen nur die Bewegung von vorn nach hinten möglich ist. Die Mittelbeine sind zwar auch mit einigen Schwimmborsten versehen, ihre Bedeutung beim Schwimmen besteht aber nur darin, dass sie mithelfen, wenn nötig, die Richtung des Körpers zu ändern. Ihre Hüften sind klein, kugelig, die ganze Mittelbrust ist an der Unterseite von der Hinterbrust fast verdrängt, so dass dadurch die Unterseite des Käfers ein charakteristisches Gepräge erhält. Dass die geringe Ausbildung der Mittelbrust in Beziehung stcht zu ihrer geringen MIuskelmasse und diese wieder zu der geringen Inanspruchnahme der Mittelbeine, braucht hier wohl nur angedeutet zu werden. Die Vorderbeine sind fast ganz in den Dienst des Mundes getreten; sie halten die Beute und führen sie dem Munde zu. In sprechender Weise kommt die Arbeitsteilung unter den 
Beinen zum Ausdruck, wenn man dem Tier etwa einen Regenwurm bietet. Mit den Vorderbeinen ihn haltend, schwimmt der Käfer mit den Ilinterbeinen einem Ruhepunkte zu, wobei die Mittelleine die oben angegebene Nebenrolle spielen; angelangt, hält er sich mit den Mittelbeinen fest, während die Hinterbeine in einer eigentümlich fediummen I Ialtung stehen und die Vorderbeine den Munclteilen Handlangerdienste leisten. Der Unterschied in der Thätigkeit der drei Beinpaare prägt sich auch in der Krallenbildung aus; nur an den IInterbeinen sind die Krallen in ziemlichem Grade verkümmert.

In Beziehung zum Schwimmen steht ferner offenbar die feste Ineinanderfügung von Kopf, Brustschild (Halsschild) und den übrigen Körperteilen, wobei besonders auch der Dorn an der Unterseite der Vorderbrust, der sich in eine Rinne der Mittelbrust legt, zu beachten ist, und ebenso die Verwachsung der ersten Bauchringe: Durch alle diese Punkte wird erreicht, dass beim Schwimmen die Teile sich nicht hin und her bewegen und dass keine unnötigen vorspringenden Teile dic Reibung erhöhen. Zum Durchschneiden des Wassers ist so der flache Körper trefflich eingerichtet. Als Besunderheit bleibt endlich zu erwähnen, dass beim Männchen die drei ersten Fussglieder der Aittel- und Vorderbeine in ausgeprägter Weise zu Hafturganen ungebildet sind; die der Vorderbeine bilden eine rundliche Scheibe, von deren mit Saugnäpfchen versehenen Haaren sich besonders zwei durch Grösse auszeichnen. Dass infulge der Elastizität der Wandung die einmal angedrücliten Teile eben nach dem Prinzip) von Saugnaipfen ohne weiteres Zuthun des Käfers haften, lehrt ein Versuch mit den toten Tieren. Drückt man die feuchte Haftscheibe etwa an eine Glasplatte, so bleibt nicht nur beim Aufheben dieser Platte der Käfer daran hängen, sondern man kann auch noch einen zweiten und dritten an den ersten anhängen.

Die Weibchen anderseits zeigen einen eigentümlichen Dimorphismus, insufern nümlich, als die eine Reihe derselben mit gefurchten, die andere mit glatten Flügeldecken versehen ist.

Die Larven der Gattung Dytiscus (Fig. 5, 2) sind im Frühjahr in unseren stelenden Gewiissem eine recht häufige Erscheinung 
Abgesehen von den Larven der Libellen, die wegen der bald entwickelten Flügelansätze nicht mit Käferlarven verwechselt werden können, sind sie wohl mit denen von Cybister die grössten Insektenlarven des süssen Wassers; erwachsen messen sie etwas über $5 \mathrm{~cm}$. Als Schwimmkäferlarve ist sie kenntlich durch die grossen sichelförmigen, auf der Innenseite nicht gezähnten Oberkiefer, durch den Mangel einer eigentlichen Mundöfnung, durch den platten Kopf, ferner durch die Zweizahl der Krallen an den drei Brustfüssen und endlich durch die stärkere Chitinisierung der Rückenseite - nur der letzte Hinterleibsring ist ringsum stärker chitinisiert*). Als unterscheidend für die Larven unserer Gattung wäre neben der Grösse hervorzuheben, dass zwischen den vier längeren Fühlergliedern anscheinend je ein kürzeres eingeschaltet ist, dass die beiden letzten Leibesringe seitlich mit stärkeren Schwimmhaaren versehen sind und dass die beiden am Körperende befindlichen Anhänge gross und stark befiedert sind.

Wie der Käfer muss die Larve zum Atmen an die Oberfläche kommen; die beiden einzigen thätigen Luftlöcher**) liegen am Ende des letzten Ringes. Die beiden Körperanhänge flach auf dem Wasser ausbreitend, hängt die Larve beim Atmen in S-fürmiger Krümmung an der Oberfläche.

Wird sie beunruhigt, so schnellt sie sich durch einen kräftigen Schlag des Hinterleibes ein gut Stück in die Tiefe. Diese Zuhilfenahme des Abdomens bei der Bewegung ist übrigens ein charakteristischer $\mathrm{Zug}$ vieler Insektenlarven gegenüber dem entwickelten Tier. Schwimmt die Larve ruhiger im Wasser umher, so benutzt sie dazu in gleichmässiger Weise die drei mit Schwimmhaaren versehenen Beinpaare, die Beine desselben Paares aber meist nicht wie der Käfer gleichzeitig bewegend.

Die Larve führt ein ausgesprochen räuberisches Leben, dabei frisst sie ihre Beute nicht, sondern saugt derselben die Säfte aus;

*) Vgl. dazu den Versuch einer Tabelle ïber die Kerflarven am Ende dieses $\Lambda$ ufsatzes.

**) Die sieben anderen Stigmenpaare des Hinterleibes und die beiden Paare der Brust sind geschlossen und besonders an jüngeren Tieren schwer wahrzunehmen; eine Bedeutung haben sie nur noch bei den Häutungen der Larve, indem sie dann als Anheftepunkte der alten. Tracheen dienen, die aus den neugebildeten herausgezogen werden müssen. 
besmders oft habe ich sie so Kaulyuapten aussaugend bechachtet. Wie schin ahen crwaihnt, fehlt eine eigentliche Mrundïfnung: alser die Oberkiefer haben auf der Innenseite eine durch Ineinandergreifen der Ränder geschlossene Rinne, welche nach der Spitze zu oflen ist und nach dem Grunde $z u$ in den Verdaunngskanal muindet. Will man die Larven zur Verpuppung bringen, so darf man es nicht an Nahrung und einer Gelegenheit, an das Land zu kommen, fehlen lassen.

Ist hier auch nicht der Ort, auf die Besonderheiten der anderen Gattungen allgemeiner einzugehen, so möchte ich mir doch nicht versagen, auf den einzigen, nicht eben häufigen Käfer unserer Familie hinzuweisen, der bei Berührung Töne von sich giebt er benutzt dazu die Flügeldecken. und letzten Hinterleibsringe und der auch sonst eine eigenartige Stellung in der Familie einnimmt: Pelobius Hermami, und ferner auf die beiden Gattungen Haliplus und Cnemidotus, deren kleine Arten bei abweichender Ilüftenbildung der I interbeine nicht regelrecht schwimmen, sondern pudeln.

Zur Bestimmung der Käfer stehen zahlreiche Bücher zur Verfügung; die Bestimmung der Larren bietet dageren grosse Schwierigkeiten $\left.{ }^{*}\right)$; ja viele von ihnen sind erst durch die hervorragenden Arbeiten Schiödtes bekannt geworden. Ich versuche hier noch einige der häufigeren, wenigstens der um Berlin häufigeren Larven kenntlich zu machen.

Leicht zu kennzeichnen ist die nicht seltene Larve von Acilius sulcatus (Fig. 5, 3), die erwachsen etwa $3 \mathrm{~cm}$ misst. Der erste Brustring ist etwa dreimal so lang als in der Mitte breit; die mittleren Hinterleibsringe sind stark verbreitert, die beiden letzten Ringe seitlich mit Schwimmhaaren versehen, die beiden Anhảnge dagegen unbewimpert. Der Kopf ist durch schwarze Flecke in der Nitte und an den Seiten ausgezeichnet; die Fühler haben auch hier abwechselnd längere und kürzere Glieder. Die ersten Jugendstadien der Larve sind übrigens fast ganz schwarz.

\footnotetext{
*) Die Nummern verweisen auf die Litteratur am Schluss des Aufsatzes.
} 
Gewissermassen ein Gegenstück zu der Larve von Acilits bildet die bis $2.2 \mathrm{~cm}$ lange Larve von Colymbetes fuscus. Der erste Brustring derselben ist nämlich I $1 / 2 \mathrm{mal}$ so breit als lang und breiter als die Mitte des sich nach hinten verjüngenden Abdomen. Nur der letzte Ring trägt einen seitlichen Haarbesatz, dagegen sind die beiden Schwanzanhainge gleichmässig und beiderseitig bewimpert. Die Fühler sind einfach viergliedrig. Sehr nahe schliessen sich hieran die Larven von Agabus und Ilybius. Larven dieser Gruppe habe ich vielfach in einzelnen Exemplaren auch überwinternd angetroffen.

Unter den kleineren, $d . h$. bis I $c m$ grossen Larven ist die von Hyphldrus oututus (Fig. 5, 4) durch die lange, schmale, schnabelartige Verlängerung des Kopfes nach vorn auffällig. Das Körperende läuft in drei Anhänge bez. Fortsätze aus, von denen der mittlere haarlos ist.

Einen ähnlichen, aber weit kürzeren und breiteren Stirnfortsatz besitzen die noch kleineren Larven von Hydroporus parallelogrammus.

Endlich erwähne ich wegen ihrer Eigenart die kleinen Larven von Cnemidotus, die an Brust und Hinterleib mit fadenförmigen, gegliederten Tracheenkiemen versehen sind und wie die von Haliplus nur je eine Kralle an den Beinen besitzen, und die nach Schiödte mit wahren, d. h. bluterfültten Kiemen ausgestatteten Larven von Pelobius.

\section{Kolbenwasserkäfer (Hydrophiliden).}

Ein bemerkenswertes Gegenstück zu den Schwimmkäfern bilden in fast allen Punkten die Arten der dritten dem Wasser angehörigen Familie, der Kolbenwàsserkäfer oder Hydrophiliden. Als Vertreter wollen wir auch wegen seiner Grösse $(3.5$ bis $4.5 \mathrm{~cm})$ den pechschwarzen Wasserkäfer (Fig. 6, 5 S. 66) wählen, der treffend hie und da beim Volke Wasserkuh heisst.

Kolbenwasserkäfer werden unsere Käafer wegen der Gestalt ihrer Fühler genannt; wenn man freilich dieses unterscheidende 
Kennzeichen an unserem Vertreter oder an irgend einem seiner Verwandten, so lange er im Wasser ist, aufsuchen will, kann einem
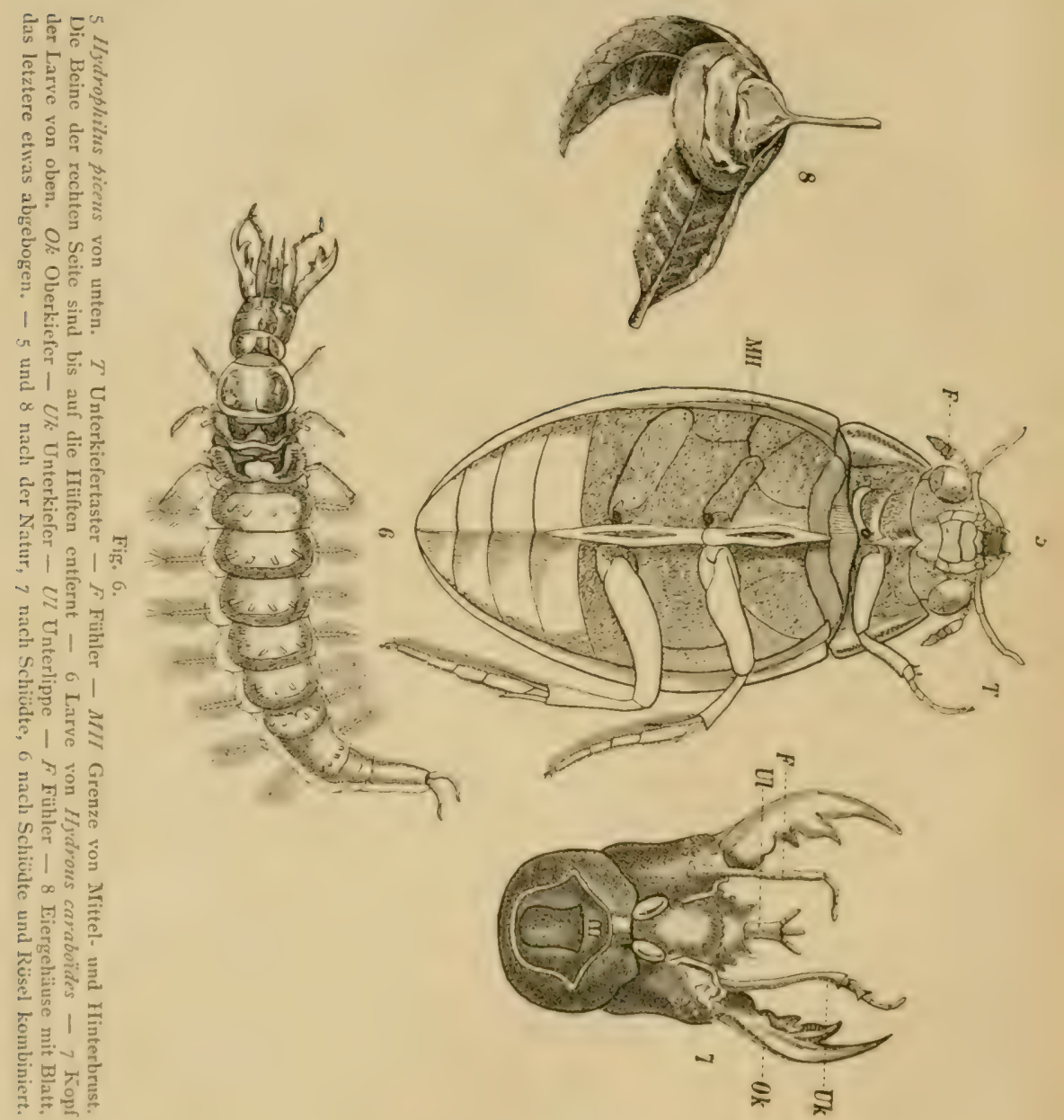

Seltsames begegnen: die Fühler scheinen doch fadenförmig, nicht kolbenfürmig zu sein. Die Lösung ist: der Küfer trilgt im Wasser nie wie die Dytisciden die Fühler vorgestreckt, sondern nach unten 
und hinten in die an der Unterseite haftende Luftmasse zurückgelegt; dafür aber sind die Kiefertaster so auffallend lang, dass sie leicht für Fühler gehalten werden können. Palpicornes wurden cleswegen auch die Käfer genannt. Sobald sie freilich aus dem Vasser genommen werden"), pflegen sie die Fühler aus dem Versteck hervorzustrecken. Es macht den Eindruck, als ob er wie alle seine Verwandten in Fühlern und Tastern für Luft und Wasser besondere Sinnesorgane hätte.

Atmung. Zur Atmung kommt der pechschwarze Wasserkäfer wie der Gelbrand zur Oberfläche, jedoch hierbei einen charakteristischen Unterschied gegen den letztern zeigenad. Nicht das Ende des Hinterleibes steckt er aus dem Wasser, sondern den Kopf bringt er an die Oberfläche, beugt ihn zur Seite, so dass die behaarte Stelle an der Hinterseite der Augenwülbung die Oberfläche berührt, und legt dann die konkave Seite der behaarten Glieder der Fühlerkeule, diese zwischen dem ersten und zweiten Gliede umbiegend, hier von aussen an, so dass ein röhrenförmiger Zugang für die Luft zu der behaarten und unbenetzten Unterseite gebildet wird. Durch die nun beginnenden Pumpbewegungen des Tieres wird der Körper im Wasser gehoben und gesenkt. In der seidenartigen Behaarung der Unterseite, die sich in der ganzen Breite bis zum ersten Hinterleibsringe einschliesslich und von da an den Seitenrändern erstreckt (Fig. 6, 5), wird die Luft zu den Stigmen des Hinterleibs fortgeleitet. Doch dürften die Luftlöcher in der Verbindungshaut zwischen Vorder- und Mittelbrust, welche der Zugangsstelle der Luft soviel nüher liegen, bei unserem Käfer clie wichtigere Rolle spielen. Darauf weist wenigstens der Umstand

*) Beim Gelbrand hatten wir bei dieser Gelegenheit seiner nicht eben sauberen Bemühungen zu gedenken sich $z u$ befreien. Hydrophilus scheint ausser den lebhaften Bewegungen der mit Dornen versehenen Beine, die zusammenwirken mit einem scharfen Stachel der Hinterbrust, noch ein besonderes Mittel zu gleichem Zweck anzuwenden. Ergriffen, etiva mit der Pincette an den Beinen, und zwar nur dann, lässt er einen knirschenden Ton hören. Fasst man den Käfer mit starker Pincette am Kiel der Mittelbrust, so sicht man, wie er bei der Erzeugung des Tones den Hinterleib zugleich in der Richtung von hinten nach vorn und von oben nach unten bewegt. Man kann bei toten wie lebenden Tieren einen gleichartigen Ton erzeugen, indem man entweder den Brustkiel niederdrückt oder mit der Pincette den Hintericib von hinten nach vorn und etwas nach dem Rücken zu bewegt. Über die Lage der tonerzeugenden Stellen vermag ich trotzdem keine sicheren Angaben zu machen. 
hin, dass sie, ganz abweichend von den Verhältnissen beim Gelbrand, die Hinterleibsstigmen an Grösse übertreffen. Für das Festhalten der Luft an der Unterseite - der Käfer trägt unter Wasser also einen den grössten Teil des Körpers einnehmenden "Silber"überzug - ist auch die Eigentümlichkeit von Bedeutung, dass die Flügeldecken über den Hinterleib nach unten vorragen.

Schwimmt der Gelbrand eigentlich nur mit den Hinterbeinen, so benutzt der Kolbenwasserkäfer dazu Mittel- und Hinterbeine. Die Beine desselben Paares bewegt er dabei abwechselnd (er pudelt), so dass der Körper beim Schwimmen hin und her "wackelt". Eine Hilfe, trotzdem die Richtung zu halten, gewährt wohl die dach- bez. kielförmige Gestaltung der Unterseite des Hinterleibes. Die ganze Bewegung ist ungleich schwächlicher als die des Gelbrandes. Dem entspricht auch die schmale Gestalt der Hinterhüften, dic ül)crdies nicht wie beim Gelbrand mit der Hinterbrust fest venwachsen, sondern ihr beweglich eingefügt sind. Die Beteiligung der Mittelbeine am Schwimmen zcigt sich nicht nur in ihrer Behaarung, sondern auch darin, dass die Mittelbrust nicht wie beim Gelbrand durch die Hinterbrust von der Unterseite verdrängt ist. Ähnlich wie der Hinterleib ist auch die Brustunterseite gekielt; der Kiel der Hinterbrust geht nach hinten in einen langen und scharfen Schutzdorn aus.

Übrigens sind auch bei unserem Küfer die Vorderbeine der Männchen ausgezeichnet: das letzte Tarsenglied ist beilförmig verbreitert. Anderseits findet sich bei einem Teil der Weibchen am vordern Teil des Seitenrandes der Flügeldecken ein leistenartiger Vorsprung.

Nahrung. Gewöhnlich werden die Hydrophiliden kurzweg als Pflanzenfresser bezeichnet und das würde den Gegensatz zu den fleischfressenden, räuberischen Dytisciden recht scharf machen. Doch ist jene Bezeichnung nicht olne Einschränkung zutreffend; oft habe ich Hydrophilus piceus und ebenso den nah verwandten mittelgrossen ( $\mathrm{I} .5$ bis $1.75 \mathrm{~cm}$ ) Hydrous carabö̈des tote oder auch nur matte. Wassertiere auffessen sehen. Anderseits ist schon auf

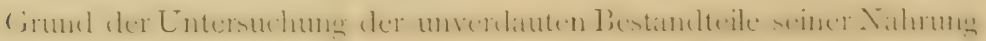


deren häufige Herkunft aus dem Pflanzenreiche nicht zu bezweifeln. Man bezeichnet ihn also wohl am besten als Allesfresser.

Alles, was wir bisher an dem Vertreter der Kolbenwasserkäfer kennen gelernt haben, weist darauf hin, dass irgend eine nähere verwandtschaftliche Bezichung der beiden Käferfamilien zu cinander nicht besteht, und jeder weitere Untersuchungspunkt bestätigt diese Auffassung. Können wir auch auf Einzelheiten hier nicht weiter eingehen, so sei doch wenigstens kurz erwähnt, dass neben den schon erwähnten Punkten (Bildung der Fühler, Brust, Beine etc.) besonders auch dic Bildung der MIundteile und die Flügeladerung für diese Auffassung spricht. In allen diesen Punkten stellen sich die Dytisciden, soweit nicht die Anpassung an das Leben im Wasser in Frage kommt, unmittelbar neben die ebenfalls räuberischen Laufkäfer des Landes und mit ihnen thun das, wenngleich nicht ebenso nahe, die Taumelkäfer; dagegen muss für die Hydrophiliden der Anschluss bei ganz anderen Familien der Landkäfer gesucht werden.

Entwickelung. In nachdrücklicher Weise wird diese Ansicht auch durch alles, was auf die Entwickelung Bezug hat, gestützt. Schun in der Eiablage thut sich ein Gegensatz zwischen Hydrophiliden und Dytisciden kund: während die Dytisciden lieine besondere Fürsorge irgend welcher Art für die Eier und die ausschlüpfenden Larven treffen, gilt das für die Hydrophiliden in auszeichnender Weise. Die Arten unserer Gattung und mehrerer anderer fertigen aus einer Masse, die in Fäden aus röhrenartigen Vorsprüngen des Hinterleibsendes tritt, ein weisses, rundliches, ansehnliches Gespinst (Fig. 6, 8), das an einer Seite in einen nach oben gerichteten schornsteinartigen Fortsatz ausläuft. Im Innern liegen die grossen lïnglichen Eier und bringen die ausgeschlüpften Larven geschützt die crste Zeit zu. Bei HY'drophilus ist das Gespinst der Lnterseite eines Blattes angeklebt, bei Hydrous ist das Blatt ringartig um das Gespinst befestigt. Wer diese Masse nicht schon von Ansehen kennt, wird leicht in die Versuchung kommen, vom Ufer aus sie für Papierstücke zu halten, die in das Wasser gefallen sind. 
Die anfangs bräunlichen, später schwärzlichen, zum grösseren Teile weichhäutigen Larven*) unterscheiden sich weitgehend von denen der Schwimmkäfer. Als systematisch wichtiges Kennzeichen ist $\mathrm{zu}$ betonen, dass die Beine nicht Fuss und Klaue gesondert haben und die Beine nicht wie fast immer bei den Schwimmkäiferlarven mit zwei Klauen, sondern nur mit einer solchen versehen sind. Stärker fällt in die Augen der Unterschied der IIundteile: die Unterlippe ist gross und vorstehend (bei den Schwimmkäfern bis auf die Taster sehr winzig), die Oberkiefer (Fig. 6, 7 ) nicht einfach sichelförmig, sondern auf der Innenseite mit Höckern (bei den Verwandten mit starken Zähnen) versehen. Die Nahrung besteht nämlich auch bei diesen Larven aus erbeuteten Wassertieren, z. B. Schnecken; dieselben werden aber nicht durch die Oberkiefer ausgesogen, sondern vor der MIundöffnung mit den Oberkiefern

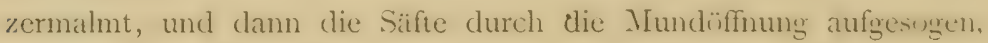
während die Chitinteile vor derselben liegen bleiben. Durch diese eigentümliche Art der Nahrungsaufnahme wird die Gewohnheit der meisten Hydrophiliden-Larven bedingt (für die von IIydrophilus selbst habe ich es noch nicht beobachtet), die Beute ausserhalb des Wassers zu tragen, den Kopf dann so zu heben, dass die Mundöffnung und die davorliegende Beute gerade nach oben gerichtet ist, und in dieser eigentümlichen Haltung die Beute zu verzehren. Die nicht benutzbaren Chitinteile werden zuletzt bei Seite geworfen. Im Wasser würde bei dieser Weise der Nahrungsaufnahme ein grosser Teil der Süfte der Beute verloren gehen und viel Wasser in den Verdauungskanal aufgenommen werden; in der Luft dagegen gelangen nur zum Schluss einige Luftblasen mit in den Verdauungskanal. Dieselben fallen bei mikroskopischer Betrachtung lifeinerer durchsichtiger Larren leicht auf: ihre Herkunft konnte ich mir lange nicht erklïren. Die Bewegung der Larven ausserhalb des Wassers erinnert übrigens durch das abwechselnde

*) Die Larven von IJydrophilus piceus habe ich in erwachsenem Zustande nicht zu häufig angetroften; ungleich häufiger die von dem schon erwähnten nahe verwandten Hydrons caraboïde's. Deswegen ist auch das Gespinst und die Larve dieses Küfers Fig. 6,6 und 7$)$ in die Abbildung aufgenommen worden. 
Strecken und Verkürzen der vordern und hintern Körperhälfte lebhaft an die Bewegungsirt vieler madenfïrmiger Zweiflüglerlarven. Mit dieser Bewegungsart hängt augenscheinlich auch die Weichhäutigkeit des Hinterleibes und der beiden letzten Brustringe bi. auf kleine Teile des Rückens sowie die in der Abbildung nicht wiedergegebene Faltenbildung des Hinterleibes zusammen.

Zur Atmung dienen der Larve wiederum nur zwei Stigmen an Ende des Hinterleibes; dieser Körperteil wird also auch hier an die Oberfläche gebracht. Zum Schwimmen dienen die oben und unten stark bewimperten Beine; die vier hinteren werden dabei anders als beim Käfer, nämlich gleichzeitig bewegt. Bei den Larven von Hydrous caraboïdes trägt der Hinterleib (Fig. 6, 7) an den Seiten grössere bewimperte Anhänge, die an die Tracheenkiemen der Gyrinus-Larve erinnern. Doch können die Anhånge hier nicht als Tracheenkiemen angesprochen werden, da ihnen ein reicher entwickeltes Luftröhrensystem fehlt. Auch vom Blutstrom werden sie, wenigstens bei älteren Larven, nicht durchzogen. Ihre Bedeutung liegt vielleicht in der Oberflächenvergrösserung für mediane Schwimmbewegungen des Hinterleibes. Für gewöhnlich sieht man freilich auch unsere Larve nur mit den Beinen schwimmen und zwar auffälligerweise mit allen gleichzeitig.

Zur Verpuppung gehen die Larven der Hydrophiliden ebenso wie die der Dytisciden ans Ufer, um dort eine geschützte Stelle über dem Wasser aufzusuchen.

\section{Die übrigen Hydrophiliden.}

Ziemlich zahlreich sind die Verwandten des pechbraunen Wasserkäfers, wenn auch nicht so zahlreich wie die des Gelbrandes; die Artenzahl der Hydrophiliden ist etwa halb so gross wie die der Dytisciden. An Grösse kommt unserem Käfer, von der zweiten Art seiner Gattung Hydrophilus aterrimus abgesehen, leine Art auch nur annähernd gleich; die nächst grösste, oben mehrfach genannte Art geht schon auf i $7 m m$ herab, die folgenden / IIrdrobiusArten) meist auf $7-8 \mathrm{~mm}$ und die meisten anderen erreichen nicht mehr 5 mmi Länge. Mit Ausnahme von Hýdrous caraboüdes, den 
Arten von Hy'drobius und Berosus besitzt keine Art mehr bewimperte Beine und die Fähigkeit zu schwimmen. Die Mehrzahl der Arten kriechen also nur an den Pflanzen unter Wasser umher; losgerissen treiben sie hilflos zur Oberfläche und suchen dann, den Bauch nach oben, mühsam wieder eine Pflanze oder das Ufer zu erreichen*). Auch die genannten Arten benutzen übrigens keineswegs immer ihre Schwimmfihigkeit, um von einer Stelle zur andern zu kommen, wie das für die Dytisciden gilt, sondern oft genug sieht man sie, besonders die Arten von Hydrobius, an Gegenständen im Wasser umherkriechen.

Die Fähigkeit, willkürlich Töne hervorzubringen, habe ich ausser bei Hydrophilus noch bei I/ydrous caraboüdes, Spercheus emarginatus, IIydrobius oblongus und Berosus luridus beobachtet**). Besonders die beiden letzten Arten knirschen bei Berührung bez. nach derselben sehr laut und regelmässig; bei Hydrous habe ich die Töne mehrfach abends gehört, als eine Schale mit mehreren Tieren dieser Art unmittelbar vor mir stand. Auf Berührung hat er dagegen nicht geantwortet.

Abgesehen von diesen beiden Punkten stimmen jedoch auch die übrigen im Wasser lebenden Verwandten mit unserem Vertreter in fast allen binlogischen P'unliten ebenfalls überein, so besonders in Fühler-, Kiefer-, Brustbildung. Sie zeigen auch z. B. unter Wasser stets nur die Taster, erst an der Luft die Fühler; so nehmen sie ferner stets auf der Unterseite die Atemluft mit in das Wasser und zwar ist bei allen ausser der Gattung Hydrophilus die ganze Unterseite mit Luft bedeckt. Auch sorgen alle in besonderer Weise für die ausschlüpfenden Larven, wenn auch nicht genau in der Weise wie Hy'drophilus. Für Hydrous wurde das Gespinst für die Eier schon erwähnt. Ähnliche mit hornartigem Ansatz versehene Gespinste in freilich viel kleinerem Massstabe werden von Ilelephorus gefertignt. Ein Weibchen de's Helephorus atpuaticus z. B.,

*) Einige Arten, welche der Familie zugerechnet werden, leben sogar bestïndig ausserhalb des Wassers.

**) Bei Sperchens wurde, wie ich beobachten konnte, bei der Erzeugung des Tones der Hinterleib nicht in der Mittellinie des Kïrpers, sondern seitlich bewegt. 
das ich für sich in einer kleinen Schale hielt, lieferte Ende Mai solche Gespinste an Kork angeklebt in Mehrzahl mit ungefähr je zehn Eiern. Hydrobius und Phillydrus kleben ihre weissen, pantoffelförmigen, „ungehörnten" Gespinste im ersten Frühjahr an den Blättern stehender Pflanzen fest; besonders oft habe ich sie in Mehrzahl an Grasblättern getroffen. Die Weibchen von Spercheus und Helochares tragen die verklebten Eierpakete unter dem Hinterleibe mit sich herum, sie mit den Hinterbeinen und den vorstehenden Rändern der Flügeldecken haltend. Beide sind im Nai um Berlin recht häufige Erscheinungen. Die Larven der Mehrzahl dieser Arten kann man, wie ich vielfach erprobt habe, aus den gekennzeichneten Gespinsten oder Paketen leicht erhalten. Deswegen glaube ich darauf verzichten zu sollen, noch die Unterschiede der Larven der einzelnen Arten anzugeben. Sie besitzen übrigens in den MIundteilen, der Beinbildung (Fussglied und Klaue nicht gesondert), Zahl der Fussklauen, Weichhïutigkeit des Hinterleibes alle die oben geschilderten Merkmale. Hervorgehoben sei nur, dass nach Schiödte die mir unbekannte Larve von Berosus spinosıs mit sieben Paar fädiger Tracheenkiemen und die von Philhydrits testaceus mit fünf Paar Afterbeinen ähnlich denen der Raupen, jedoch in anderer Verteilung, versehen ist.

\section{Käfer und Käferlarven anderer Familien.}

\section{a) Parnus.}

Mit den kleineren Hydrophiliden findet man oft an Wasserpflanzen einen 5 mm grossen Käfer bräunlicher Farbe, Parnus prolifericomis, der ebenso wenig zu schwimmen vermag wie diese Hydrophiliden, der ebenso wie jene die Luft zur Atmung an der Aussenseite des Körpers mit unter Wasser nimmt, aber nicht allein an der Unterseite, sondern wie die Wasserspinne an der ganzen Körperoberfläche. Als Mittel, diese Lufthülle zu halten, dient ihm wie der Spinne ein seidenartiger Haarüberzug des Körpers. Biologisch schliesst er sich ganz den kleineren Hydrophiliden an;. Fühlerbildung und andere morphologische Eigenschaften 
weisen ihm dagegen mit wenigen anderen Genossen, die teilweise ebenfalls das Wisser lieben, eine hesondere systematische Stellung an*).

\section{b) Cyphon-Larven.}

Recht hảufig trifft man schon zeitig im Frühjahr in Gräben mit verwesenden Blïttern in Gemeinschaft mit den Larven der Sterhmücle eine Käferlarve, die offenlsar keiner der oben genannten Familien angehört. Wie die Zucht des Tieres ergab, gehört sie zu einer Art der Gattung Cyphon; die Käfer selbst halten sich gern auf Blättern in der Nähe des Wassers auf. Die zarthäutige, dunkle Larve wird bis I $\mathrm{cm}$ lang und ist von oben nach unten stark zusammengedrückt; als gutes Kennzeichen dient die für Larven ganz ungewöhnliche Lünge der Fühler, welche bei sehr zahlreichen Glieden länger als die Iailfte des Kïrpers sind, und der Mangel an Hinterleibsanhängen irgend welcher Art. Zur Atmung kriecht dic Larve zur Oberfläche: die beiden thätigen Luftlücher liegen auch hien am Kïrperende. Die MLundteile lassen sie als I'lanzenfresser erkennen. Zur Verpuppung geht auch sie an das Ufer. Die Larve einer andern Art, die sich durch lichte Fürbung von der obigen unterscheidet, fand ich im Juni besonders an den Blättern des Froschbiss.

c) Donacia-Larven und - Puppen.

Zum Schluss sei endlich der ganz eigenartigen biologischen Verhailtnisse wegen der Latren und l'uppen der Schildkifer / Donacia und Hacmonia) gedacht. Die bleichen, bis $\mathrm{I}^{1 / 2} \mathrm{~cm}$ langen Larven leben im Schlamm an den Wurzeln verschiedener Wasserpflanzen, der Seerosen, Igelkolben, Schachtelhalme, so dass man ohne besonderes Suchen ihrer kaum gewahr wird. Da sie ohne Tracheenkiemen oder eigentliche Kiemen und von sehr träger Bewegung sind, da ferner ihre derbe Haut und Gestalt den Gedanken an Hautatmung ausschliesst, so sind sie dem Beobachter hinsichtlich

* Die Larve unserer Art ist meines Wissens noch nicht bekannt, die von Parnus auriculatus fand Hh. Th. Beling in feuchter Erde, S. Verh. d. Zool.-botan. Vereins in Wien $18 \times 2$. 
ihrer Atmung zunächst ein Rätsel. Die Lösung der Atemaufgabe ist bei ihnen so seltsam wie möglich: sie benutzen die Luft, welche in den stets reich entwickelten Luftgängen von Wasserwurzeln vorhanden ist. Ich habe mich bemüht*) den Nachweis dafür zu führen, dass die Larven dazu die beiden sichelförmigen braunen Anhänge am Ende des Hinterleibes benutzen, die nichts anderes seien als eigentümlich einseitig über die Kürperhaut verlängerte Stigmenränder. Diese Anhänge werden, wie unmittelbare Beobachtung und das Torhandensein der entsprechenden paarigen Narben an den Wurzeln ergab, in die Pflanze eingedrückt, durch den Druck des Pflanzengewebes werden zwei Längsspalten an der Rückseite der Anhänge geöffnet und nun die Luft eingesogen. Zur Ausatmung dürften die beiden kurzen Stigmenüfinungen an der Basis der Anhäinge dienen. Auch zur Nahrung dienen den Larven, wenigstens denen von D. crassipes, die Wurzeln. Zur Zeit, wenn die Verpuppung naht, fertigt die Larve ein elliptisches Gehäuse, das der Wurzel angeklebt ist, beisst hier ein Loch in die Wurzel, so dass die ausströmende Luft das Wasser aus dem Gehäuse verdrängt, und schliesst nun völlig das Gehäuse, um so von Luft umgeben der Umwandlung zur Puppe und zum Käfer entgegenzugehen. Diese Gehäuse trifft man an Wurzeln und Rhizomen ungleich häufiger als die Larven, welche leicht beim Herausziehen der Wurzel abgestreift werden. Im Gehäuse ist dann entweder noch die Larve, oder schon die Puppe, nicht selten auch der meist farbenprächtige Käfer vorhanden. Frisst sich endlich. der Käifer durch das Gehäuse durch, so steigt er infolge der Luftschicht, welche seiner kurzseidenhaarigen Unterseite anhaftet, an die Oberfläche. Man trifft ihn nicht selten beim Fischen zwischen den Blättern und Binsen der Oberfläche an. Die Eier werden an den Blättern bestimmter Pflanzenarten abgelegt. Donacia crassipes benutzt die Bliitter der Seerose und zwar werden die Blätter an einer Stelle durchbissen und die Eier in zwei Bogenreihen auf der Unterseite neben diesem Loch angeklebt. S. $299-308$.

*) S. Berliner entomologische Zeitschrift Bd. XXXI, S. 325-334, und Bd, XXXIII, 


\section{Die Zweiflügler.}

Durch die Zartheit und Ungeschütztheit der Flügel sind die Zweiflügler selbst, d. h. die Mücken und Fliegen, von dem Leben im Wasser*) so gut wie völlig ausgeschlossen; von den Larven und Puppen derselben aber lebt eine recht erkleckliche Anzahl im Wasser, und diese Zahl wächst besonders noch an, wenn dabei auch diejenigen Fliegenlarven mitgerechnet werden, welche sich in Lachen kleinsten Umfangs aufhalten und halb ein Wasser-, halb ein Luftleben führen. Von den letzteren soll im folgenden ganz abgesehen werden; auch dann werden wir noch gezwungen sein, uns auf die häufigeren und typischen Formen zu beschränken.

Vorweg sei der Merkmale gedacht, an denen wir Larven des Wassers als Dipteren-Larven zu erkennen vermögen.

Zunächst fehlen ihnen stets echte, d. h. gegliederte Beine, die sonst bei allen Insektenlarven des Wassers vorhanden sind. Bei einigen Gattungen der Mücken (z. B. (hironomus, Tanypus, Simulia) kommen zwar sogenannte falsche Beine vor, nämlich solche, die ungegliedert und mit einer Gruppe von Haken versehen sind, aber selust abgesehen von die'sem Unterschied der Bildung lässt schon die Stellung derselben, ein Paar am ersten Brustring und meist ein Paar am Hinterleibsende, eine Verwechselung dieser Larven mit denen anderer Ordnungen nicht zu. Da die Verwandlung der Zweiflügler wie die der Käfer eine vollkommene ist, also den Larven jede Spur von Flügelansätzen fehlt und auch oft der Kopf wenig deutlich ist, so haben manche von ihnen ein recht wurmähnliches Aussehen. Im Zweifelfalle wird stets der Besitz von Tracheen oder von einem chitinösen Kopfskelett mit Kiefern oder von einer Schlundkapsel mit. Chitinhaken die Dipteren-Larve kenntlich machen.

Unter den Dipteren-Larven des Wassers nimmt fraglos die Gruppe der „Eucephalen“ (Fig. 7, 9-I3), d. h. derjenigen, welche

*) Der Dipteren, welche a uf dem Wasser angetroffen werilen, wurde schon oben beim Taumelkäfer kurz geclacht. Eine winzige Mücke, Clunio adriaticus, lebt seltsamerweise nach v. Frauenfeld bei Triest unter dem Mecresspiegel an Miesmuscheln. 
einen deutlichen Kopf mit Fühlem, Jugen und ordentlichen Kiefern besitzen, und für welche die Larve der gemeinen Stechmücke ein

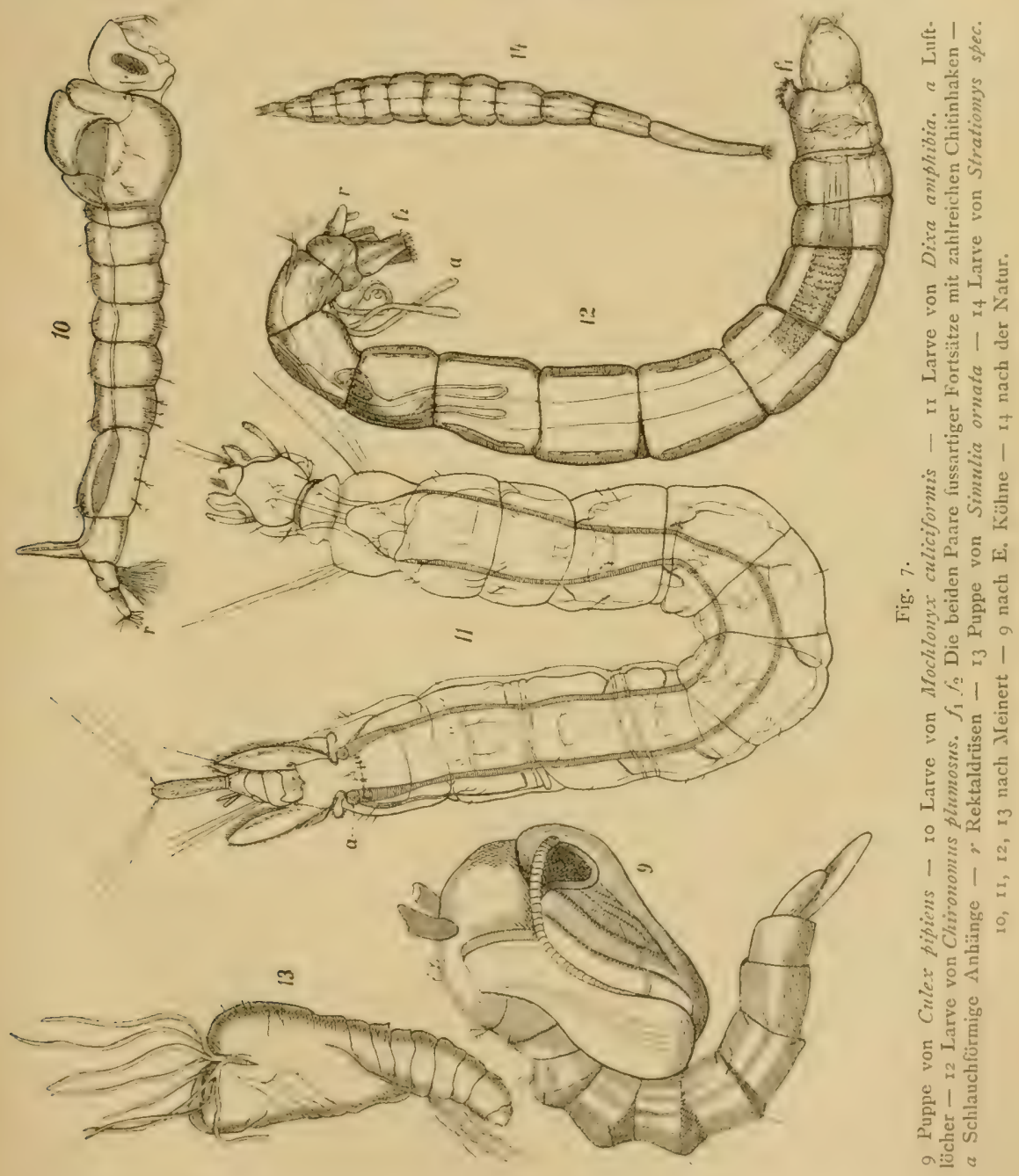

gutes Beispiel ist, den ersten Rang ein. Ihnen werde ich dic mit fadenförmigen Tracheenkiemen versehene Schnakenlarve (Pliala- 
(rocera replicata) anschliessen. Die nächst wichtige Gruppe bilden die Larven der Waffenfliegen (Fig. 7, I 4), gekennzeichnet durch den einziehbaren, unansehnlichen Kopfteil, durch die deutliche Gliederung des Kïnpers und den Kranz von Atemhaten am Ende des Hinterleibes. An letzter Stelle werde ich endlich die Larven der Schwelfliegengattung Firistulis anzuführen haben, denen ein Kopfulischnitt fehlt, deren Körpergliederung wenig deutlich ist und die mit einem fernrohrartig einzichbaren Atemanhang versehen sincl.

\section{Eucephale Zweiflüglerlarven (Mückenlarven).}

Unter allen unseren Insektenlarven giebt es vielleicht keine zweite, die so leicht zu haben, so leicht zu halten und in ihrer Entwickelung zu verfolgen ist, und deren Verwandlung dabei einen so überraschenden Eindruck macht, wie die unserer StechmückenArten*) (Culex). Im März, gleich nach dem Auftauen der Gewasser, bei mildem Wetter oft auch im Dezember und Januar, trifft man in Gräben mit stehendem Wasser, besonders wenn diesclben vermodernde Latubliatter enthalten, die Larven der Gattung Culex oft in ausserordentlicher Menge an. Sie sind um diese Zeit meist noch winzig, etwa $3-4 \mathrm{~mm}$ lang, wachsen aber schnell heran. Zur Aufzucht hat man nur nötig ein Glas oder eine Schale mit Wasser, zur Nahrung einige vermodernde, untersinlende Blitter. Die Bälge der Larven findet man nach den bald eintretenden Häutungen im Wasser schwimmen, den Kopf und Atemanhang derselben von schwärzlicher Farbe, die übrigen Teile recht durchsichtig. Ist dann nach einigen Wochen oder, wenn man später grössere Larven nahm, oft nach einigen Tagen, die Verpuppung eingetreten, so kann man nach einer Frist von neun bis zehn Tagen das Ausschlüpfen der Mücke erwarten.

$\mathrm{Zu}$ erkennen sind die Larven der Gattung Culex unter den anderen, mit deutlichem Kopf versehenen Zweiflüglerlarven unschwer 1) durch die Verwachsung der Brustringe, deren Zahl noch

*) Bis zu gewissem Grade teilen alle cucephalen Larven diese Eigenschaften mit den 
durch drei grössere Borstenbündel angedeutet ist, und 2) durch den langen, zur Atmung an der Oberfläche benutzten Fortsatz des achten Hinterleibsringes. Das Ende des Leibes geht also scheinbar zweiteilig aus; den einen Gabelast bildet der eben genannte, von den beiden Hauptluftröhrenstïmmen durchzogene Fortsatz, den andern das eigentliche Körperende mit dem After (vgl. Fig. 7, IO). An diesen stehen vier ausstreckbare, zarte Fortsïtze (Fig. 7, Ior), die sogenannten Rektaldrüsen; es stehen ferner am letzten Segment in der Mittelebene des Körpers nach unten gerichtet in deutlicher Reihe die wichtigsten Schwimmborsten.

Bewegung. Wie freilich die Bewegung zu stande kommt, lässt sich, wenn sie recht schnell ausgeführt wird, kaum erkennen; purzelnd schiesst dann das Tier bald dahin, bald dorthin vorwärts. Erst bei langsamerer Bewegung unterscheidet man das Wie derselben, so z. B., wenn das Tier zur Atmung zur Oberfläche kommt und fast dieselbe erreicht hat, dann zeigt sich, dass der Hinterkörper mit seiner in der Mittelebene des Körpers stehenden Borstenreihe rechts und links schlägt und so den Körper, das Afterende voran, vorwärts treibt. Dem entspricht nun, dass am Vorderteil die Borsten seitlich gerichtet sind. Eine eigenartige Fortbewegung kann man ausserdem oft wahrnehmen, wenn die Larven an den Wänden den Algenansatz benagen: durch die Bewegung der Mundteile selbst rücken sie dann ziemlich schnell an der Wand fort.

Atmung und Nahrung. Dass die Larven zum Atmen an die Oberfläche kommen und dass die vereinigten Atemöffnungen an dem Fortsatz des achten Segmentes liegen, ist schon oben angedeutet worden. Die Zeit, in welcher sich dieses Emporkommen wiederholt, ist ziemlich kurz. Die Tiere hängen dabei in etwas schräger Körperhaltung an der Oberfläche; bei richtiger Haltung des: Auges liann man die Einsenkung der Oberfliichenschicht an der betreffenden Stelle deutlich wahrnehmen. Schliessen sie die Atemöfnungen, so sinken sie langsam an den Boden. Dort beginnen sie wieder ihre Nahrung, besonders vermodernde Pflanzenstoffe, zu verarbeiten. Tritt übrigens irgend eine Beumruhigung bei der Atmung ein, so purzeln sie nach allen Richtungen fort. Bisweilen heben 
die Larven auch, wenn sie an der Oberfläche hängen, ihren Kopf bis zu derselben empor und drehen sich, indem sie lebhaft die Kiefer bewegen, nach dem Prinzip der Rückwirkung, kreisend um den Atemfortsatz.

Puppe (Fig. 7,9). Während bei den Käfern die Larven stets zur Verpuppung das Wasser verlassen, bleibt bei den Dipteren, deren Larven im Wasser leben, auch die Puppe im Wasser. Dadurch werden auch bei den Puppen eigenartige Verhältnisse hinsichtlich der Atmung und Bewegung bedingt. Die Puppen der "eucephalen" Larven werfen alle, wie das bei den Insekten ja die Regel ist, bei einem grossen Teil der Dipteren aber gerade nicht zutrifft, die letzte Larvenhaut völlig ab; es lassen also ihre Puppen (s. Fig. 7,9 u. 13) wie die Schmetterlingspuppen deutlich bereits Kopf mit Augen, Fühlern und Mundteilen, Brust mit Flügeln und Beinen und endlich den Hinterleib unterscheiden. Flügel, Beine und Fühler sind aber nicht wie bei den Schmetterlingspuppen mit dem übrigen Körper verklebt, sondern frei.

Die Puppen von Culex atmen wie die Larven die Luft direkt, müssen also entweder stets an der Oberfläche hängen oder die Fähigkeit haben, sich zu derselben zu bewegen. Das letztere ist der Fall und so besitzen sie eine für echte Inseltenpuppen ganz überraschende Bewreglichkeit. Dabei ist die Art der Bewegung plötzlich eine ganz andere als bei den Larven: zwar ist auch hier der Hinterleib der treibende Teil, wie ja auch bei anderen Puppen, z. B. Si:hmetterlingspuppen, derselbe durch Ineweglichkejt ausgezcichnet ist. derselbe schlight aber nicht seitlich, sondern in der Mittelebene, und ist im Zusammenhang damit am Ende mit zwei seitlich gestellten Platten versehen. Atemöfnungen sind zwei vorhanden, nicht aber am Hinterleib, sondern an der Rückseite der Brust, am Ende zweier leicht beweglicher, trichterförmiger Anhänge*).

*) Palmén behauptet in seiner wichtigen Arbeit über die Morphologie des Tracbeen. systems (Leipzig 1877) S. 64 auffallenderweise, dass diese $\Lambda$ nhänge keine Öftnungen haben. Ich fand keine Schwierigkeit, mich an Längsschnitten der \} \backslash \text { nhänge vom Gegenteil zu über- } zeugen; als Luftsicb - die Staubteilchen dort beweisen es - dienen Haare, die in zierlicher Weise nach Art von Strebepfeilern emporragen, gruppenweise zusammenneigen und oben verwachsen sind. Leichter noch gewinnt man dic Uberzeugung von der Endïffnung dieser Anlänge, indem man cine Puppe auf ausgeschliftenem Objekttrïger unter Wasser bringt, 
Fragezeichen ähnlich hängen die Puppen zur Atmung an der Oberflaiche.

Es möge gleich hier vermerkt werden, dass bei allen Puppen dieser Gruppe sich gleiche oder homologe Anhünge an der Rückseite zwischen Vorder- und Mittelbrust befinden und dass im Zusammenhang damit die Bewegung der Puppe stets durch Schlagen des Hinterleibes in der Mittelebene erfolgt. Die: Erklïrung dafür dürfte in folgender Eigentümlichkeit der Entwickelung liegen: Will das Insekt der Puppenhaut entschlüpfen, so platzt in der ganzen Unterordnung, welcher unsere Tiere nach dem System von Brauer zugehören, die Puppenhaut in einem Tförmigen Spalt an der Rückseite der Brust. Diese muss sich daher bei unseren Puppen zu der Zeit an der Oberfläche des Wassers befinden, also muss der ganze Bau der Puppe und ihre immerhin beschränkte Bewegungsweise derart sein, dass die Rückseite der Brust an die Oberfläche gebracht wird. Die mit Luft erfüllten Atemtrichter halten dann zuletzt, auch ohne Bewegung des Hinterleibes, die Puppe in der rechten Stellung an der Oberfläche. - Das Ausschlüpfen der Mücke und die Erhärtung ihrer Teile erfolgt in recht kurzer Zeit, in einer bis zu einigen Minuten*). Dass der ganze Entwickelungsschritt schnell vollzogen wird, ist der gefahrvollen Lage wegen, in der sich das Tier währonddem befindet, von Wichtigkeit. Nicht nur die Feinde im Wasser und in der Luft bereiten ihm dann Gefahr, auch jeder Windstoss kann verderblich werden. Gern warten daher die Tiere die ruhige, feuchtwarme Luft nach einem Gewitterregen ab.

Der Laich bildet nach allgemeiner Angabe eine flache runde Scheibe, die in der Mitte etwas ausgehöhlt ist und deswegen auf dem Wasser schwimmt. Ich selbst habe das Ablegen der Eier und den Laich noch nicht beobachten -können; so oft ich Laich von der beschriebenen Form auffand, erwies er sich doch stets bei

und mit einem Deckglas bedeckt; bei leichtem Druck auf das letztere sieht man dann eine grosse Luftblase aus den Enden der Anhänge hervorquellen und, wenn man rechtzeitig wieder aufhört, beim Nachlassen des Druckes wieder in den Anhang zurücktreten.

*) Genauere Notizen habe ich von unserer Art dariber nicht zur Verfügung. Bei einer Puppe von Chironomus plumosus, aus der die Mücke, wïbrend ich dies niederschrieb, ausschlüpfte, dauerte der Akt vom ersten Platzen der Haut bis zum ersten Aufliegen der Mücke nicht ganz 20 Sekunden!

Tier- und Pflanzenwelt des Süsswassers. II. 
weiterer Entwickelung als der von Corethra plumicornis. Stechmücken, die im Aquarium in Menge ausgeschlüpft waren, haben niemals bei lïngerer Gefangenschaft, wie ich das bei anderen Gattungen beobachtet, den Laich abgelegt. Selbst als ich solche IIürken mit verdünntem I Ionig und Blut fütterte und wrochenlang unter einer Glasglocke bei Gegenwart einer kleinen Schale mit Wasser hielt, erhielt ich keinen Laich.

Anopheles sp. und Dixa (Fig. 7, I I). Biologisch schliessen sich an die Larven von Culex am nächsten die von Anopheles und Dixa an; beide atmen durch zwei Stigmen (Fig. 7, I I $a$ ) am achten Hinterleilssinger und beide sind Pflanzenfresser. Sehwimmen sie, so gesehieht dats greichfalls durch seitliches Sihlagen des Hinterleibes. Von Culex unterscheiden sie sich durch den Mangel eines Atemfortsatzes und biologisch dadurch, dass sie sich ganz vorwiegend an der Oberfläche aufhalten, meist auf dem Rande schwimmender Blätter oder Gegenstände ruhend. Die schwärzliche Larve von Dixa nimmt dabei stets die Gestalt eines lateinischen $\mathbf{U}$ an und schiebt sich in dieser Haltung ziemlich schnell durch abwechselnde Bewegung der beiden Schenkel des $\mathbf{U}$ fort, die entsprechend mit Borsten versehen sind. Weder Kopf noch Kürperende, sondern die Mitte des Tieres schreitet hier also voran: ein seltsamer Anblick. Den Kiopf nach oben und hinten zurückgeschlagen, wirbelt sich die Larve durch die Bewegung der Mundteile die Nahrung zu. Dem gegenüber ist die Larve von Anoplecles durch lichtere Färbung und cinfache geracte Kërperhaltung gekennzeichnet; ülurelies sind bei Anopheles die drei Brustringe wie bei Culex verwachsen, bei Dixa wenigstens der erste deutlich frei. Wie die Larve von Dixa wirbelt auch sie sich die Nahrung durch die Bewegung der Mundteile zu; auch sie hält dabei die Unterseite des Kopfes nach oben, erreicht dies aber durch eine Drehung des Kopfes von $180^{\circ}$ um die Längsachse. Die Puppen gleichen in ziemlichem Grade denen von Culcx:

Einen zweiten Typus der mit deutlichem Kopf versehenen Mückenlarven stellt die viel untersuchte Larve von Corethra plummcornis dar. Dieselbe liebt pflanzen- und deswegen tierreiche 
stehende Gewässer mit grösseren Stellen freien, klaren Wassers. Un Berlin ist sie eine recht häufige Erscheinung; sie scheint auch stets in grosser Zahl zu überwintern. Gekennzeichnet wird sie fast hinlänglich durch die Bemerkung, dass sie von glasartiger Durchsichtigkeit ist; nur die beiden Luftblasenpaare im vorderen und hinteren Teile des Körpers, sowie gewöhnlich der gelbliche bis schwach gelbrote Darm machen sie wahrnehmbar. Anfangs entgeht sie wohl Jedem oft genug, wenn sie ruhig im Netz liegt. Als weitere Kennzeichen seien hier noch folgende genannt: ein Atemfortsitz am achten Hinterleibsring ist nicht vorhanden, ebensu wenig Luftlücher, der Kopf ist schnabelfürmig verlängert, die MLundteile und selbst die Fühler sind zum Rauben eingerichtet.

Atmung und Bewegung. Da bei der Larve von Corethra vom Tracheensystem nur zwei paurige lufterfüllte Anschwellungen vorn und hinten entwickelt sind, thätige Luftlöcher und auch Kiemen völlig fehlen, so kann nur Hautatmung für dieselbe angenommen werden. Gestützt wird diese Annahme in hohem Masse durch die ausserordentlich zarte und durchsichtige Haut des Tieres, die sie zu einem so beliebten Objekt für mikroskopische Betrachtung macht. Die Larve kommt also auch nicht zur Oberfläche; in horizontaler Lage steht sie oft lange Zeit still im Wasser, um sich dann plötzlich durch einen seitlichen Schlag fortzuschleudern und zwar anscheinend in völlig regelloser Weise. Der wirksame Teil ist auch hier der hintere Körperabschnitt; der neunte Hinterleibsring trägt zalhlreiche, lange, in der Mittelebene stehende, fieclerfürmig bewimperte Schwimmhaare. Nährt sich die Larve von Culcx von Pflanzenstoffen, so ist die von Corethra durchaus räuberischer Natur; zartere Wassertiere, ja selbst kleinere Larven der eigenen Art bilden ihre Nahrung.

Puppe. Ungleich ähnlicher als die Larven sind die Puppen von Culcx und Corcthra. Auch die Corethra-Puppe beweent sich durch mediane Schliage des I Interleibes, der an Ende chenfalls besondere, seitlich gestellte Schwimmplatten trägt. Auch die Anhänge der Vorderbrust finden sich wieder, aber sie sind nicht wie bei der 
I'uppe von Culex trichterfürmig offen und dienen nicht der Atmung "\% Mehrfach habe ich 30-40 Puppen in einem höheren Becherglase vor mir stehen gehabt, ohne dass in Stunden auch nur eine an die Oberläiche zur Atmung gekommen wäre. MIehrere Centimeter tief unter der Oberflache schweben sie. Erst wenn sie dem Ausschlüpfen sich nähern, wenn zwischen Puppen- und Mückenhaut sich cine Luftshicht ansammelt, steigen sie infolge der Verringerung des spezifischen Gewichtes dauernd empor. Aber auch dann habe ich nie die Oberflächenschicht, des Wassers an der betreffenden Stelle unterbrochen gesehen, wie das sonst bei richtiger Stellung des Auges stets zu sehen ist, wenn Insekten oder Insektenlarven zur Atmung an die Oberfläche kommen. Die Bedeutung der luftcrfültten Anhänge am Rücken der Vorderbrust kann also bei Corethra nur darin liegen, dass sie der Puppe olnne weiteres besonders beim Ausschlüpfen die geeignete Körperstellung geben. Das Ausschlüpfen der Mücke vollzicht sich auch hier in recht kurzer Zeit.

Laich. Dass die abgelegten schwarzen Eier eine flache Scheibe bilden, erwähnte ich schon bei Culex. Nicht selten habe ich diesclben im Freien angetroffen und atuch von ausgeschlüpften Mücken erhalten, denen durch eine übergestülpte Glasglocke das Furtliegen verwehrt war. Die Larven schlüpfen, wenn man nur das Wasser der Schale durch untergetaucht lebende Pflanzen, z. B. Riccien, frisch erhält, bald aus der Laichmasse aus.

In merkwürdiger Weise vermittelt den Übergang von Culc.v zu Corethra die Larve von Mochlony'x culiciformis (Fig. 7 , I0). In Körpergestalt, in Durchsichtigkeit hält sie die Mitte zwischen jenen beiden Gattungen. Wie bei Corethra finden sich zwei Paar Luftrïhrenanschwellungen worn und hinten: aber es sind atuch noch die beiden freilich schwachen Längsstimme des Luftröhrensystems vorhanden und lufterfüllt, die wie bei Culcx in einen Anhang des achten Hinterleibsringes ausgehen. Und nun wird dieser „Atemfortsatz" doch wieder nicht wie bei Culcx zur Atmung benutzt; die Larven schweben ebenso wie die von Corethra in horizontaler

*) VEl. auch Palmín, "Morphologic des Tracheensystems". 
Lage im Wasser und niemals habe ich sie an die Oberfläche kommen sehen. Auch die MIundteile zeigen eine Bildung zwischen denen von Culex- und Corethra-Larven; freilich stehen sie denen der letzteren näher. In der räuberischen Lebensweise stimmen sie mit diesen völlig überein. Die Puppe schliesst sich der von Corethra nahe an. Die schon von De Geer beobachtete Larve scheint lange Zeit der Aufmerksamkeit entgangen zu sein. Ich habe sie um Berlin seit einer Reihe von Jahren vielfach gefunden und zwar stets mit Larven von Culex zusammen.

Chironomus und Tamypus. Einen dritten Typus stellen die Larven der Gattungen Chironomus und Tanypus dar, die nicht der Oberfläche oder den mittleren Schichten der Gewäisser, sondern hauptsäichlich dem Boden der Gewässer, und zwar sowohl fliessender wie stehender, angehören. In stehenden Gewässern sind wohl die blutroten Larven von Chironomus phmmosus (Fig. 7, 12) mit die häiufigsten und auffälligsten. Gekennzeichnet sind die Larven dieser beiden Gattungen durch den Besitz von winzigen Punktaugen und von je zwei sogenannten falschen Beinen am Vorderbrustring und am Kürperende (Fig. 7, I $\left.2 f_{1}, f_{2}\right)$ - die Beine sind ungegliedert und mit einer Gruppe von Chitinhaken versehen -, ferner durch das Fehlen der Atemüffnungen und eines ausgebildeten Luftrührensystems. Die Larven der beiden Gattungen unterscheiden sich unter einander vornehmlich dadurch, dass bei den Larven von Tamypus die drei Brustringe mehr oder minder zu einer Masse verwachsen, bei denen von Chiroviomus aber frei sind. Überdies besitzen manche Chironomus-Larven, z. B. die von Ch. plumosus, vier schlauchfürmige, zarte Auswüchse an der Bauchseite des achten Hinterleibsringes (Fig. 7, $12 a$ ).

Atmung. Die Larven von Chironomus leben, wie schon angegeben wurde, auf dem Boden, wo sie sich mit Hilfe einer Schleimmasse, die unterhalb der Mundöffnung austritt, aus den Schlamm- oder Sandteilchen Röhren zum Schutz und Aufenthalt bauen*). Thut man z. B. in eine Schale mit Larven von

*) $\mathrm{Ob}$ das auch für einzelne Arten von Tanypus gilt, muss ich dabingestellt sein lassen. 
Chironomus plumosus etwas Sand, so nimmt der Boden in kurzer Zeit ein Aussehen an, welches im Ḱleinen an das Bild einer Viese erinnert, an deren Oberfläche zahlreiche Maulwürfe ihre Gänge gezogen haben. Zur Wasseroberfläche kommen die Larven nicht; ihre Atmung ist wie die von Corethra Hautatmung. Die Auswüchse am achten Hinterleibsring der Larve von Ch. plumosus sowie die vier Drüsen um den After unterstützen wohl die Atmung, da sie von einem lebhaften Blutstrom, in dem eigenartige, fadenförmige Blutkörperchen treiben, durchzogen werden*).

Hält man Larven unserer Gattungen in sauerstoffarmem Wasser, so sieht man oft, wie sie sich mit den Haken der "falschen" Vorderfüsse an einigen Gespinstfidden, welche sie am Gefäss befestigt haben, festhalten und nun lebhaft in medianen, wellenförmigen Bewegungen das Wasser schlagen, offenbar, um sich bestaindig frischeres Atemwasser zuzuführen.

Bewegung und Nahrung. Am Boden bewegen sich die Larven von Chironomus mit Hilfe der vorderen und hinteren filschen Beine den Spammerraupen ähnlich fort; im Watsser schwimmen sie, wenn man es so nennen darf, recht ungeschickt olne feste Richtung durch Sförmige Krümmungen des Körpers**). Als Nahrung dienen ihnen die Schlammteile des Budens oder richtiger die darin enthaltenen organischen Bestandteile.

Puppe. Auch während und nach der Verpuppung bleiben die Tiere in den Schlammröhren; dabei ist die Larvenhaut oft noch nicht vollständig vom Hinterleibsende der Puppe abgestreift. Als gutes Kennzeichen der Puppen von Chironomus ist die eigenartige Ausbildung der Vorderbrustanhänge zu erwähnen; diese sind nicht einfach und trichter-oder keulenförmig wie bei den früheren Gattungen und bei Tanjpus, sondern bestehen aus einer grossen Menge zarter Fidden, die von feinen Tracheenröhren durchzogen

*) Dieser Blutstrom wird leicht bei ungünstiger Lage der Larve auf dem Objekttrïger unterbrochen und entgeht dann dem Beobachter. Auch mir war er fruher entgangen; erst jüngst, als ich durch eine Äusserung von Mrn. Weltner, der Larven von Chivonomus auf den Boden tiefer Seen gefunden hatte, zu erneuter Beobachtung veraulasst wurde, nahm ich denselben wahr.

**) Bei einer Tanypus-Larve, wohl T:monilis, beobachtete ich Schwimmen durch wellenförmige Bewegungen in der Mittelebene des Kürpers. 
sind und deswegen silberweiss erscheinen (vgl. Fig. 7, 13). Sie sind also nach ihrer Bildung als Tracheenkiemen anzusprechen. Die Puppe zeigt übrigens lebhafte Atembewegungen, und zwar ein Schwingen in der Mittelebene des Körpers. Zur Zeit, wenn das Ausschlüpfen naht, steigt sie an die Oberfläche, wobei die lufthaltigen Brustanhänge ihr den Weg zeigen.

Laich. Unter allen Mücken ist Chironomus diejenige, deren Laich ich am häufigsten angetroffen habe. Die länglichen, schwach bräunlichen Eier liegen in wurstförmiger, durchsichtiger Gallertmasse. Wenig auffällig, entgehen sie leicht der Wahrnehmung. Ihre Zugehörigkeit lässt sich leicht dadurch feststellen, dass man die Larven in besonderer Schale mit Wasserpflanzen ausschlüpfen lässt.

Simulia. Biologisch und auch wohl morphologisch schliessen sich an die Larven von Chironomus und Tanypus die der Simulia-Arten an. Dieselben leben ausnahmslos in fliessenden Gewässern. In der näheren Umgegend von Berlin kenne ich sie nur aus der Panke oberhalb Schönhausen und aus der Wuhle, die bei Köpenick in die Spree mündet. Sie sind leicht daran kenntlich, dass zwar ein vorderes, weit verwachsenes falsches Beinpaar wie bei Chironomus und Tanypus vorhanden ist, dagegen das hintere fehlt, und dafür ein Kranz von Haken am Ende des im hinteren Abschnitt verdickten Abdomens steht. Auch sie sind

- Hautatmer und kommen nie an die Oberfläche. Einen recht seltsamen Anblick gewährt ihre Bewegungsweise. Mit einer Gespinstmasse, welche ithnlich der der Raupen aus einem Vorspruny oberhalb der Unterlippe austritt, ziehen sie am Boden einige lurze Fäden, greifen in diese mit dem Hakenkranz der Vorderfüsse, krümmen den Körper zu einer Schleife, greifen nun mit dem hinteren Hakenkranz in diese Fäden, lassen dann vorn los, strecken sich, spinnen neue Füden u. s. w. So bewegt sich die Larve ausgesprochen spannermüssig. Hült man sie im tief ausgeschliffenen Objelittriger oder einer andern derantigen Vorrichtun:(angekitteter Glasring), so kann man das Ziehen der Fäden gut 
beobachten*). Durch dieses Mittel sind sie befähigt, sich im strïmenden Wasser an Wasserptlanzen und Steinen festzuhalten. Oft richten sie sich, mit dem hinteren Hakenkranz in die Spinnfïden greifend, senkrecht zur Oberfläche des Blattes und lassen dann ihren Strudelapparat am MIunde spietern, der ihnen mit dem entstehenden Wasserwirbel die winzigen Nahrungsbestanclteile zuführt.

Puppe. Die sehr gedrungene Puppe (Fig. 7, I3) lebt in einem tütenfürmigen Gehäuse, das seitlich an Wasseryflanzen mehr oḍer minder tief befestigt ist. Ihre Vorderbrustanhänge gleichen denen von Chironomus, doch sind die Fäden weit weniger zahlreich. Erst zum Ausschlüpfen steigt sie zur Oberfläche.

Rückblick. Alles in allem genommen, zeigen also die „eucephalen“ Mückenlarven der Gewïsser und deren Puppen eine urosse Mannigfaltigkeit der biologischen Verbailtnisse. Atmen die Larven von (ulex, Dixa und Anopheles Luft in gewöhnlicher Theise an der Oberfläche, so sind die von Mochlonyx, Corethra, Chironomus, Tanypus, Simulia Hautatmer; bei einzelnen Arten von Chironomus findet sich dem Anschein nach nebenbei Atmung durch echte schlauchförmige Kiemen**). Sind die Larven von (ulex, Inotheles, Mochlonix, Corethra auschliesslich oder fast ansschliesslich Schwimmer und zwar unter seitlicher Bewegung des Hinterleibes, so zeigt die von Dixa, die U-Larve, daneben eine seltsame, uben beschriebene Art des Furtschiebens, die ChironomusLarven ein unregelmässiges Schwimmen durch Sförnigre Krümmungren, die Tanypus-Larven ein Schwimmen durch mediane Bewegungen, beide Gattungen ausserdem und Simulia eine spannerartige $\mathrm{Be}$ weyung unter lenutzung von Hakenkriinzen am Vorker- und Ilinterende des Körpers und teilweise (Simulia, Tanypus) von Gespinstfaiden. Als Nahrung dienen den meisten Larven Pflanzenstoffe, Mochlony'x und Corethra aber sind ausgesprochene Raubtiere. Leben die Larven von Dixa und Anopheles fast ausschliesslich an der Oberflache, so die von Chironomus und Tanypus meist in

*) Auch bei Tanypus-Larven babe ich diese Bewegungsweise, wenn auch nicht so ausgeprïgt wie bei Simulia, beobachtet.

**) Auftäligerweise fehlt dic Atmung durcb Traicbenkiemen ganz. 
Schlammröhren am Boden, bisweilen in ansehnlicher Tiefe, die von Simulia an allen müglichen Gegenständen des Wassers: tummeln sich Culex-Larven durch alle Schichten hindurch, so bevorzugen die von Mochlonyx und Corethra die mittleren Wasserschichten. Dazu kommt dann noch das plötzliche Umspringen der Bewegungsarten - bei der Verpuppung der Mehrzahl der Larven und die Übereinstimmung aller Puppen in dem Besitz besonderer Anhänge am Rücken der Vorderbrust und in der Bewegungsart: zwei Punkte, die ich schon oben biologisch zu deuten suchte.

Es kann hiernach nicht überraschen, dass sich die Larven im Anschluss an diese Unterschiede oft scharf nach der Art der Gewässer in ihrem Vorkommen sondern. Während ich z. B. in der oberhalb Schönhausen stark fliessenden Panke nur Larven von Simulia, Chironomus und Tamypus fand, zeigte sich dicht daneben ein Wiesentümpel mit Laubblättern, aber ohne nennenswerten Pflanzenwuchs nur von zahlreichen Culex-Larven bevölkert, und ein naher Graben mit stehendem Wasser und dichtem Pflanzenwuchs die schwarzen Larven von Dixa und die helleren von Anopheles. Um Corethra zu beherbergen, schien er wegen des Mangels an grösseren pflanzenfreien Stellen nicht geeignet zu sein. Es haben, möchte man sagen, die verschiedenen biologischen Gruppen die Gewässer unter sich geteilt, oder richtiger ausgedrückt: es haben sich die Gattungen nach den verschiedenen Lebensbedingungen der Gewässer unter einander differenziert.

Phalacrocera replicata. Den eucephalen Mückenlarven schliesse. ich am besten die Larve einer Schnake, Phalacrocera replicata, an, die schon De Geer bekannt war. Sie scheint seitdem wenig aufrefunden zu sein, wahrscheinlich jedoch nicht wegen ihrer seltenheit, sondern weil sie den Blicken so leicht entgeht. Ich habe sie um Berlin fast überall gefunden, sobald der Pfuhl oder Teich am Grunde reichlich mit Wassermoosen bedeckt war. An solchen lebt und frisst sie; den älteren blattlosen Stengeln sieht sie recht ähnlich und wegen der Trälgheit ihrer Bewegungen übersieht man sie doppelt leicht. Sie ergänzt in merkwürdiger Weise in einer Hinsicht die Mückenlarven; keine derselben hat Tracheenkiemen, 
unsere Schnakenlarve ist auf der Rückseite mit ziemlich starren, gegabelten, fadenfimigen Tracheenliemen rersehen. Der mangelhat

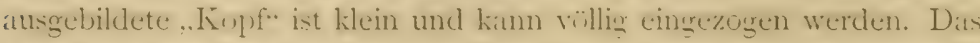
Hinterende des kïrpers trägt zwei grusse, gekrümmte Chitinhalien.

Die Puppe besitzt wie die der eigentlichen Mücken zwei Vorderbrustanhänge und lässt Kopf, Flügel, Beine u. s. w. deutlich erkennen. Mit zwei Paaren von Fortsätzen an den hinteren Körperringen - ausserdem stehen noch zwei andere Paare dort hält sie sich an Pflanzen fest und streckt die Anhänge zur Atmung heraus. Von der Verpuppung bis zum Ausschlüpfen der ansehnlichen Schnake verfliessen nur wenige Tage.

Larven der Waffenfliegen. Von anderen Zweiflüglerlarven sind mir als einigermassen häufig und auffallig*) nur noch die unter einander recht ähnlichen Larven der Waffenfliegen (Stratiomyden) (Fig. 7, 14) entgegengetreten. Sie sind deutlich gegliedert und mit undeutlichem, einziehbarem Kopfteil versehen, aus dem zwei seitliche "Fressspitzen" hervortreten. Am Ende des Kïrpers steht ein zierlicher Kranz von Haaren, den die Larven auszubreiten und zusammenzulegen vermügen. Inmitten dieses Kranzes liegt nümlich der Eingang $\mathrm{zu}$ einer Art Vorhof der Luftlöcher der Larve; wollen die Tiere atmen, so strecken sie das Körperende an die Oberfläche und breiten den Haarkianz aus. Ihre Beweang ist recht unbeholfen; (lurch lebhaftere Krümmungen liommen sie langsam in ziemlich regelloser Weise vorwärts. In Übereinstimmung mit ihrer Atmungsweise und mit ihrer schwachen Bewegungsfahigkeit, leben sie nur an der Oberfläche stehender pflanzenreicher Gewässer. Trift man übrigens etwa im Mai, Juni Larven an der Oberflïche, die andauernd bewegungslos bleiben, so - hat man es ziemlich sicher mit einer Puppe zu thun. Sicherheit kann-man über diesen Punkt leicht

*) Bisweilen habe ich auch in Griben mit vielem NIgenschleim und wenig sauberem Wasser die bekannten Rattenschwanzlarven der Schlammtliege angetroften. Kienntlich sind die zarthïutigen Larven an dem Mangel eines hopies und an dem fernrohrartig ausstreckbaren Atemrohr am linde des Kürpers. Ziemlich ähnlich sehen ihnen wegen eines gleichen Atemanhangs die Larven von Ptychoptera (Schnake); doch ist der liopf deutlich, wenn auch einzichbar, und die I'uppe eine echte Schnakenpuppe (Mumienpuppe) mit einem sehr verlïngerten Vorderbrustanhang. - Wegen mehrerer Musciden-Larven und -I’uppen des Wassers sei hier nur auf G. Gerke, "Verh. des Vereins tür naturw. Unterhaltung zu Hamburg", 1876 ff., verwiesen. 
gewinnen dadurch, dass man die "Larve" am Ende öffnet; im zutreffenden Falle ist nämlich die Haut an den Enden hohl und mehr in der Mitte liegt die zarte, ziemlich fliegenähnliche Puple. Ei wird also bei der Verpuppung die letzte Larvenhaut nicht abgestreift, sondern das Tier hat sich innerhalb derselben zur Puppe umgebildet. Erst beim Ausschlüpfen der Fliege wird auch diese Larvenhaut gesprengt und zwar in einem Tförmigen Spalt. Von den echten sogenannten Tonnenpuppen der grossen Menge der Fliegen unterscheiden sich übrigens diese Puppen wesentlich dalurch, dass erstens die Larvenhaut bei der Verpuppung weiter keine Veränderung der Form erführt und dass das Aufspringen nicht in einem Ringe, sondern in einem Tförmigen Spalt erfolgt.

\section{Schmetterlinge ${ }^{3}$ ).}

Die Schmetterlinge selbst sind ebenso und aus gleichem Grunde von dem Leben im IVasser ausgeschlossen*), wie die Fliegen; von den Larven und Puppen dagegen leben einige auch aus dieser Insektengruppe im Wasser.

Die interessanteste und nach meinen Beobachtungen häufigste dieser Wasserraupen ist die von Parapony'x stratiotata; ich habe dieselbe um Berlin fast nirgends vermisst, wo ihre Haupt-Nährpflanze, die stachlige Wrasseraloü (Stratiotes aliö̈des), wäichst. Ihren Raupencharaliter bekundet die bis atuf Kopf und ersten Brustring zarthïutige Larve durch den Besitz von Afterbeinen mit Hakenkränzen am dritten bis sechsten und letzten Hinterleibsringe neben den sechs gegliederten Brustbeinen sowie durch die Bildung der Mundteile. Dass sie aber ein wohlangepasstes Wassertier ist, zeigt das Fehlen von offenen Atemlüchern und die Ausbildung von fadenfürmigen Trachecenliemen, welche die Seiten und den Rücken vom zweiten Brustring an einnehmen**). Oft findet man die Raupe zwischen zwei Blïtterm der Wasseraloë, die lose durch Fäden zusammengeheftet sind;

*) Dabei muss freilich von den flügellosen Weibchen des Acentropus niverus abgesehen werden, welches nach Litteraturangaben mit dem Rücken nach unten auf der Wasserobertlïche umherschwimmt.

**) Auch dic Wasserraupen von Acentropus nizeus sind nach den Angaben in der Litteratur mit Tracheenkiemen versehen. Aus eigener Beobachtung kenne ich dieselben nicht. 
anscheinend dient sulthe Stelle dann als Zufluchtsort. In rollkommnerer Weise spinnt sich die Raupe zur Zeit der Verpuppung ein geschlossenes, dichtes Gehäuse, das den Blittem fest angeliel,t ist. Schneidet man ein solches Gehäuse auf, so findet man die Puppe nicht in Wasser, sondern in $\mathrm{Luft}$ liegend. Sie hat auch nicht mehr Tracheenkiemen, sondem Luftlëcher, an denen nur auffallig ist, dass die vorderen auf einer Erhöhung liegen. Woher stammt nun die Luft im Puppengehïuse, das doch unter Wasser hergestellt ist? Ich habe an andrer Stelle*/ wahrscheinlich zu machen gesucht, dass die Luft ähnlich wie bei den Puppengehäusen von Donacia aus der Pflanze stammt und dass diese unter Druck aus dem Innern der Pflanze hervortretende Luft das Wasser aus dem noch nicht vällig geschlossenen Gehäuse verdrängt. Man findet nümlich einerseits die Blätter dort, wo ein Puppengehäuse angeklebt ist, bis zu ihren grossen Luftgingen angefressen und anderscits ist eine andere Weise als die angedeutete, das Gehäuse mit Luft zu füllen, unter (len gregebenen Verhältnissen kaum vorstellhar *). Ist das Gehäuse vüllig fertig, so sind übrigens die Frasslöcher zu den Luftg̈̈ngen zugesponnen.

Eine zweite Gruppe von ziemlich häufigen Wasserraupen gehört den Gattungen Hydrocampa und C'atacly'sta an. Äusserlich sind diese Zünsler-Larven den weiter unten zu behandelnden Phryganiden-Larven recht ähnlich, da sie sich aus zwei zurechtgebissenen Blattstücken, die von $H$. nymphacata z. B. aus den Blättern der Seerose oder des Laichkrautes oder (Cataclysta) aus zahlreichen verklebten IV abserlinsen ein Schutzgehäuse herstellen und damit in Wasser herumkriechen. Sobald man freilich die Larve aus diesem Versteck herauskriechen sicht, zeigt sich auch atgesehen von den Hinterleibsbeinen ein wichtiger Unterschied geegen die Phryganiden-Larven: die Raupen besitzen keine Tracheenkiemen, sie sind vielmehr bis auf den Kiop und ersten Brustring mit einer im Wasser silherglänzenden Luftschicht umgeben und ebenso ist auch das Gehiuse mit Luft

*) Siche oben die Angabe bei Donacia.

**) Für die ebenfalls kiementragende Wasseraupe ciner brasilianischen Cataclysta-Art hat freilich WV. M üllor cine andere Weise, das Puppengebïuse mit Luft zu füllen, beschrieben. 
erfült. Sie sind also einfache Luftatmer und auf die Oberfläche des Wassers angewiesen. Die Puppe liegt gleichfalls in diesem Lufthett.

Andere Arten von Wasserraupen, deren Gattungszugehörigkeit mir unsicher geblieben ist (vielleicht Scirpophaga?), habe ich mehrfach in ausgefressenen Binsen- oder Schachtelhalmstücken getroflen; das Verfahren zur Herstellung des Schutzgehäuses war also ein recht einfaches. Zur Verpuppung fand ich solche Gehäuse an den Stengeln von Wasserpflanzen in senkrechter Stellung angekleht und die abstehende Öffnung verschlossen, ähnlich dem, was man bei den Gehäusen der Phryganiden beobachtet.

\section{Netzflügler ${ }^{4}$.}

Während in den drei obigen Ordnungen diejenigen Kerfe, die entweder im entwickelten Zustande oder als Larve im Wasser leben, einen kleinen oder selbst verschwindenden Teil ihrer Gruppengenossen ausmachen, ändert sich das plötzlich bei den Netzfüglern in auffälliger Weise. Die entwickelten Tiere meiden zwar wie die Fliegen und Schmetterlinge das Wasser, aber unter den Larven lebt die Mehrzahl der freilich nicht artenreichen Ordnung im Wasser, und zwar stellt die Gruppe der Köcherfliegen (Phryganiden) die Hauptmasse derselben. . Welcher Art ein Gewässer auch immer sein mag, ob stark fliessend oder stehend, ob pflanzenreich oder pflanzenarm, ob mit Sand- oder Schlammboden: fast immer wird man Larven dieser Gruppe darin finden und oft in sehr auffälliger Menge. Durch einen eigentümlichen Zug in ihrer Lebensweise machen sie sich auch dem Laien auffällig. Die meisten von ihnen kitten sich nämlich aus diesem oder jenem Stoff ein köcher- oder röhrenförmiges Schutzgehäuse, welches sie mit sich herumschleppen und in das sie sich bei Beunruhigung sogleich zurückzichen. Sie nehmen dazu feinern Sand, gröbere Kieskörner, Schneckenhäuser mit oder ohne Bewohner, Gras und breitere Pflanzenblïtter, abgebissene Stücke von Pflanzenstengeln, oder alte Holzstïcke etc., und legen diese Teile der Länge nach oder der Quere nach (Fig. 8, I6 u. I 7) oder in spiraliger Anordnung an einander. Wegen ilırer Auffalligkeit 
haben sie auch vom Tollic besondere Namen erhalten: Sprottwürmer oder Sprocken heissen sie z. B. in einzelnen Teilen der Mark.
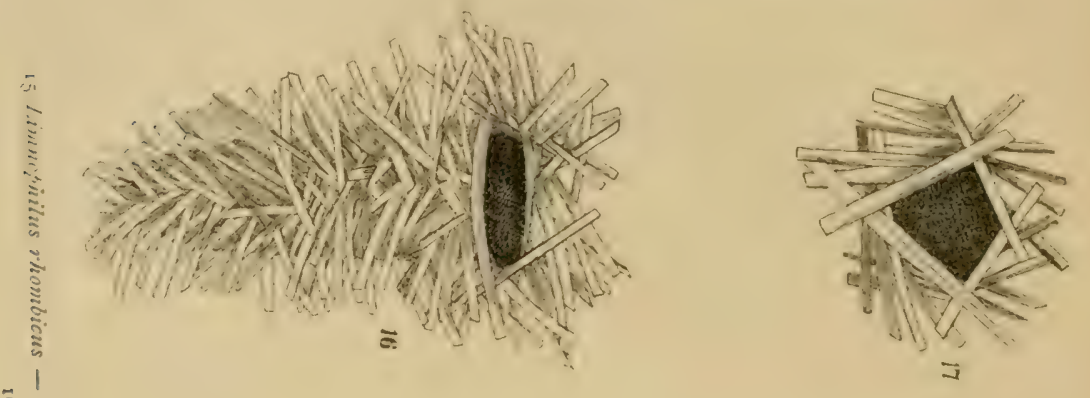

ב

5

$\stackrel{4}{y}$

$\stackrel{2}{2}$

䓀

के

$M=\frac{1}{32}$

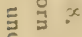

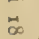

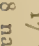

है

ริ둥

고

$\stackrel{2}{\rightleftarrows}$

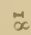

牙
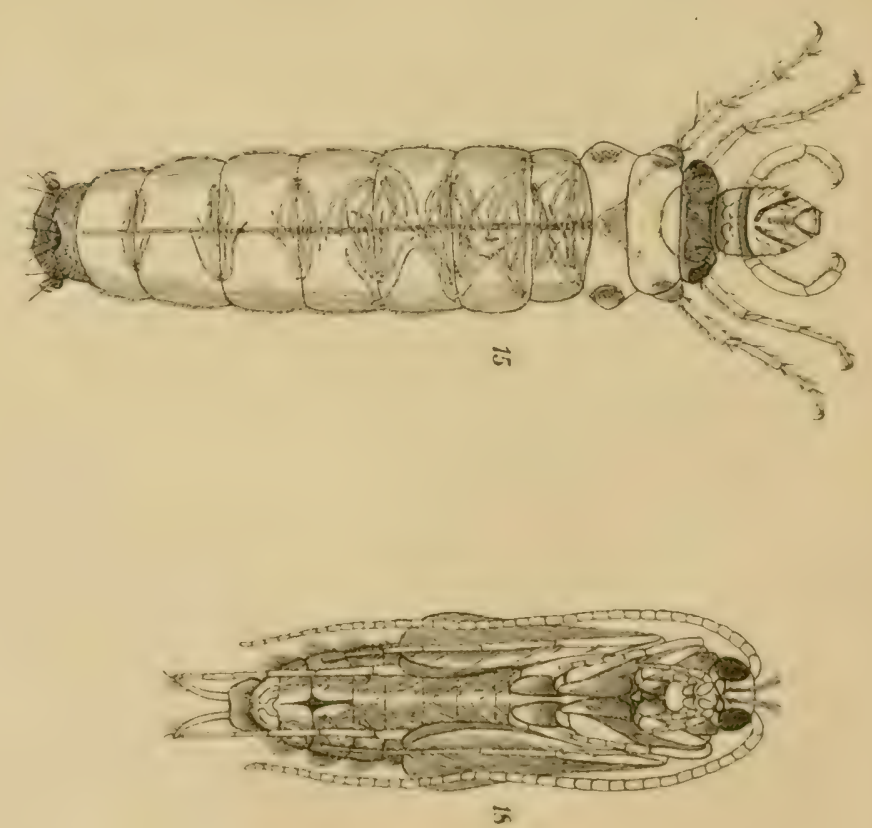

Ob ein aufgefundenes Tier zu den Phryganiden-Larven gehört oder nicht, darüber wird auch beim Anfinger selten ein Zweifel sein. In den bei weitem meisten Fällen wird man die gewöhnliche 
Larvenform (Fig. 8, I 5) vor sich haben, die durch den Besitz des Gehäuses und von drei Brustbeinpaaren, durch die stärkere Chitinisierung des ganzen Kojfes und mehr oder minder ausgedehnter Teile der Brust, sowie endlich durch die fadenfürmigen Tracheenkiemen und die beiden Endhaken des zarten Hinterleibes gekennzeichnet ist*). So leicht nun die Zugehörigkeit einer Larve zu unserer Gruppe festzustellen ist, so schwierig und umständlich ist anderseits die Unterscheidung der zahlreichen Gattungen, von den Arten ganz zu schweigen. Ich werde also im folgenden ganz davon Abstand nehmen und nur an einem Vertreter der Gruppe - es möge die Larve von Limnophilus rhombicus ${ }^{* *}$ ) dazu dienen - die biologischen Verhältnisse und die damit in Beziehung stehenden morphologischen Eigenschaften zu schildern versuchen.

Unsere Larve lebt besonders in Pfühlen und Gräben mit stehendem Wasser. Das Gehäuse (Fig. 8, I6 u. I7) besteht in der Regel aus dünnen Stengelstücken, die quer zur Lüngsachse verklebt sind, und zwar schliessen je vier bis fünf einmal den Umfang; im Querschnitt ist also die Aussenseite des Futterals vierbis fünfeckig, wobei die Seiten noch über die Ecken verlängert sind. Nicht selten benutzt die Larve daneben auch Moosstücke oder Früchte oder Steinchen und Schneckenhäuser, die Queranordnung jedoch, soweit möglich, beibehaltend.

Der Kopf und die beiden ersten Brustringe oben sind ebenso wie die Beine, von denen das erste Paar besonders kräftig, wenn auch kurz ist, stark hornig; diese Teile sind nämlich beim Fressen und Umherkriechen mehr oder minder ausserhalb des Futterals, dürfen also nicht zart sein. Über die helleren und dunkleren Flecke dieser Teile verweise ich auf die Abbildung (Fig. 8, I5). Der dritte Brustring hat auf der Oberseite sechs dunkle, mit Haaren besetzte Hornflecke und ebenso ist die Haut oberhalb der Hüften stärker chitinisiert. Die Mundteile, besonders auch die mit der

*) Über die in Gehäusen lebenden Wasserraupen, d. h. Larven von Schmetterlingen, vergleiche man oben den dritten Abschnitt, über Phryganiden-Larven ohne Gehäuse weiter unten. **) Dass die betreffende Larve zu Limuophilus rhombicus gehört, habe ich freilich nicht durch Zucht festgestellt, sondern ich schliesse es nur aus dem Vergleich mit den Zeichnungen und Angaben bei Pictet (Fig. 8, 16, 17). 
Unterlippe verwachsenen Unterkiefer ähneln denen der echten Raupen; auf die besondere Gestalt dieser Teile bei unserer Art ohne Abbildung näher einzugehen - für die Unterscheidung der Gattungen ist das wichtig - erscheint zwecklos. Wie bei den Raupen liegt übrigens der Ausgang der Spinndrüse in der Mitte der Lnterlippe. Fühler fehlen wie bei fast allen Phryganidenlarven vollständig und die Augen sind nur winzige Punktaugen.

An dem zarten, gelbweissen Hinterleib hebt. sich in der Mitte als dunklerer Streifen das Rückengefüss ab, dessen won hinten nach rom fortschreitende Kuntraktionen schon mit unbewaffnetem Auge zu verfolgen sind. An den Seiten zieht sich je eine dichte Reihe dunkler Hatare hin, die sogenannte Seitenlinie. Teils unmittelbar über und unter derselben, teils etwas weiter nach oben und unten stehen rom zweiten Hinterleibsinge an und zwar nahe dem vordern und hintern Rande die haarförmigen, weissglänzenden Tracheenkiemen (s. Fig. 8, I5). Um die Zahl und Verteilung derselben kurz darzustellen, hat sich meines Wissens Klapalek zuerst besonderer Schemata bedient; ich gebe hier ein nach seiner Weise gebildetes Schema für unsere Larve.

\begin{tabular}{|c|c|c|c|c|}
\hline Oben. & \multicolumn{2}{|c|}{ Sl. } & \multicolumn{2}{|c|}{ Unten. } \\
\hline 3 & $3 !$ & & 3 & \\
\hline 3 & & 3 & 3 & II \\
\hline 3 & 3 & & & \\
\hline 3 & & 3 & 3 & III \\
\hline 3 & 2 & & 3 & \\
\hline 3 & & 2 & 3 & IV \\
\hline 3 & 2 & & 3 & \\
\hline 2 & & I & 3 & V \\
\hline 2 & & & 3 & \\
\hline 2 & & & 2 & VI \\
\hline 2 & & & 2 & \\
\hline 2 & & & I & VII \\
\hline 2 & & & I & VIUI \\
\hline
\end{tabular}

\%um Verstindnis dessellsen braucht wohl nur bemerkt zu werden, dass Sl. die Seitenlinie, die römischen Ziffern die Hinterleibsringe und 
die arabischen Ziffern die Anzahl der Kiemenfüden bedeuten, welche teils nahe dem Vorder-, teils nahe dem Hinterrande, und zwar nahe der Seitenlinie oder weiter nach oben oder unten stehen. Am ersten Hinterleibsringe stehen keine Tracheenkiemen, dagegen in der Mitte oben und an jeder Seite je ein vorstülpbarer Fleischzapfen; am letzten Hinterleibsring befinden sich seitlich zwei kurze derbe Chitinhaken und in der Mitte in einem länglichen Spalt der After. Mit den Chitinhaken des Hinterleibsendes halten sich die Tiere recht erfolgreich im Gehüuse fest. Erwachsen kriechen die Larven langsam im Wasser umher; jugendliche Phryganiden-Larven habe ich fast immer - ob freilich solche, unserer Art dabei waren, ist ungewiss - daneben lebhaft mit Hilfe der langen, stark bewimperten Hinterbeine umherschwimmen sehen. Solche jugendliche, wohl ebèn dem Ei entschlüpfte Larven sind übrigens von den älteren noch durch den Mangel an Tracheenkiemen unterschieden, so dass sie ganz auf Hautatmung angewiesen sind.

Dass die Atmung bei den älteren Larven durch Tracheenkiemen und daneben wohl durch die zarte Hinterleibshaut geschicht, ist oben schon angedeutet worden. In Beziehung zur Atmung dürfte auch die sogenannte Seitenlinie, d. h. der beiderseitige Wimpersaum des Hinterleibes stehen, wenigstens wenn sie stärker entwickelt ist. Bei durchsichtigen Phrrganiden-Gehäusen sieht man nämlich oft, besonders wenn das Wasser sauerstoffarm ist, die Larve den Hinterleib in der Mittelebene schwingen, höchst wahrscheinlich, um das den.Körper umspülende Wasser schneller zu emeuern. Die Seitenlinie macht nun, indem sie den Hinterleib verbreitert, dieses Verfahren sicher wirksamer. Auch die Fleischzapfen des ersten Hinterleibsringes finden dabei ihre Verwendung; der Körper wird durch sie mehr in der Mitte des Gehäuses gehalten, ein allseitig den Kürper umspülender Wasserstrom alsu wohl dadurch erleichtert. Wenn übrigens das Wasser recht schlecht zur Atmung wird, so sieht man die Larven vorn weit aus dem Gehäuse kommen und nun lebhaft in gleicher Richtung wie im Gehäuse das Wasser schlagen.

Tier- und Pflanzenwelt des Süsswassers. II. 
Dass die Phryganiden-Larven wie die Raupen vorherrschend Pflanzenfresser sind, kann man leicht beobachten; doch lësst sich ath unschwer fentitellen, class sie lieineswegs Fleischliost, lebende und tote Tiere, deren sie habhaft werden können, verschmähen. Hat man einer Larve das Gehäuse genommen, so ist man nicht sicher, ob dieselbe nicht in kurzer Zeit von ihres Gleichen angefressen wird.

Zur Verpuppung spinnt unsere Larve wie die meisten anderen Ihryganiden-Larven das Gehäuse an IV asserpllanzen oder Steinen ete. fest, schliesst die Öffnungen durch ein Gitterwerk von Füden, denen noch Stengelstückchen angeklebt sind, so dass einerseits Feinde dadurch abgehalten werden und anderseits das Atemwasser hindurchspülen kann.

Die Puppe (Fig. 8, I8) bietet mit ihren frei abstehenden Fühlern, Beinen und Flügeln, mit den stark auffalligen Augen und gekreuzten, hakenfürmigen Oberkiefern, mit den weissen, fädigen Tracheenkiemen und der schwarzen, michtig entwickelten Seitenlinie am Hinterleib einen seltsamen Anblick dar. Die nach dem Geschlecht verschiedene Gestaltung der Hinterleibsanhänge und die Zahl und Verteilung der Dorne an den Beinen geben zusammen mit dem Kiemenschema wichtige Inhaltepunkte zur Unterscheidung der Gattungen und Arten. Dass auch hier die Seitenlinie gleiche Iecleutung für die Atmung hat wie die oben beschriebene, scheint mir zweifellos. Die Atmungsbewegungen der Puppen hann man unschwer beobachten.

Hailt man die Puppen im Zimmer, so steht Einem unmittelbar vor dem Ausschlüpfen der Köcherfliege noch eine seltsame Beobachtung bevor. Die Puppen kommen eines Tages aus dem Gehïuse, indem sie die Oberkiefer zum Öffnen benutzen, und schwimmen mit dem bewimperten zweiten Beinpaar oder kriechen mit Hilfe der beiden vorderen Beinpaare lebhaft umher, bis sie eine gecignete Stelle an der Oberfläche für das Ausschlüpfen gefunden haben. Die ausgeschlüpften Insekten, denen die (Herkiefer der Puppen fehlen, sehen so schmetterlingsartig und im besondern mottenartig aus, dass sie von Laien wohl stets für 
Motten gehalten werden. Das Fehlen des Saugrüssels, die Aderung der Flügel und die Faltung der Hinterflügel können zur Unterscheidung von den Schmetterlingen dienen.

Der Laich der Phryganiden - den unserer Art im besondern kenne ich nicht - bildet meist eine grosse, oft ringfürmige Schleimmasse, in der die Eier eingebettet liegen; leicht kann derselbe mit Schneckenlaich verwechselt werden.

Ist diese Larvenform der Köcherfliegen auch die unbedingt vorherrschende im Tieflande, so möchte ich doch nicht ganz den Vertreter des zweiten unter den Phryganiden-Larven vorhandenen Typus übergehen, welchen ich um Berlin mehrfach, besonders auch an Stratiotes, angetroffen habe. Nach Vergleich mit den Abbildungen und Angaben von Klapalek gehört diese Larve zur Gattung Polycentropus (Unterfamilie Rhyacophilidac). Der auffälligste Unterschied der ziemlich durchsichtigen, etwas grünlich und rötlich gefärbten Larve gegen die des ersten Typus bildet das Fehlen eines Gehäuses und der Tracheenkiemen. Die Larve ist ein Hautatmer*).

Es fehlen auch die Seitenlinie und die Fleischzapfen des ersten Hinterleibsringes, was nach unserer obigen Deutung beim Fehlen des Gehäuses ohne weiteres verständlich ist. Die Chitinhaken am Unterleibsende stehen dagegen auf langen, zweigliedrigen „Nachschiebern"; die Larven gebrauchen dieselben besonders, wenn sie beunruhigt werden und sich dann unter medianen Schwingungen des Hinterleibes rückwärts in Sicherheit zu bringen suchen**).

Mangelt den Larven auch das Gehäuse, so heften sie doch mit Hilfe der Spinnmasse an Blättern einzelne Gegenstände derart fest, dass ein gedeckter Gang entsteht, der ihnen als Zufluchtsort dient. Zur Zeit der Verpuppung wird dann eine festere Schutzhülle hergestellt. Die Puppe ist mit Tracheenkiemen und Seitenlinie versehen.

*) Es ist bemerkenswert, dass keine Neuropteren-Larve des Wassers durch Luftlücher atmet, während das in allen früheren Ordnungen ein recht häufiger Fall war.

**) Eine derartige Rückwärtsbewegung der Larven, sobald sie beunruhigt werden, scheint im ganzen Gebiet der Netzflügler, glerchgültig ob die Larven im WVasser leben oder nicht, die allgemeine Regel zu sein. 
Eine Mittelstellung zwischen den beiden obigen Typen nehmen die Larven der Gattung Hydropsyche ein, die in stïrker fliessenden Gewässem, z. B. hier in der Panke, an und unter den Steinen des Bodens leben. Sie haben ebenfalls kein Gehäuse, welches sie mit sich herumtragen, sondern fertigen sich aus grüsseren und kleineren Sandlï̈nern Gänge an den Steinen, dagegen besitzen sie büschelförmige Tracheenkiemen. Abweichend ron der oben beschriebenen Verteilung der Kiemen bei Limmophilus, stehen dieselben hier nur auf der Unterseite von Brust und Hinterleib. Die Nachschieber sind von ähnlicher Lünge wie bei Poly'centropus und durch ein starkes, auffilliges Borstenbüschel an der Ansatzstelle der Krallen ausgezeichnet.

Zur Verpuppung wird auch von diesen Larven ein besonderes Schutzgehäuse hergestellt.

\section{Die übrigen Neuropteren.}

In den übrigen Familien der Netzflügler giebt es nur noch vereinzelte Gattungen, deren Larven im Wasser leben, nämlich die Gattungen Sialis, Sisyra und Osmylus. Häufiger habe ich daron nur dic Sialis-Larven angetroffen und zwar stets am Boden stehender, mit Schlammgrund versehener Gewïsser. ITan muss schon mit dem Netz etwas Schlamm mitfassen, wenn man die Larven fangen will. Die Ähnlichlicit mit den Phryganiden-Iarven ist nicht zu verkennen. Nur der Kopf, die Beine und die Brustringe sind stärker chitinisiert, der Hinterleib ist zarthäutig und an den sieben ersten Ringen mit je einem Par verhältnismässig starker, gefiederter und gegliederter Tracheenkiemenfäden versehen. Das Ende des Ilinterleibes läuft in eine einzelne kraftige, gefiederte Endborste aus.

Ausser der abweichenden Bildung der Tracheenkiemen und des IInterleilssendes kann zur Unterstheidung won den Phry granden-Larven auch der Umstand dienem, dass der Kopf deutliche, mehroliedrige Fühler trägt. Die Mundteile, besonders die Oberkiefer, sind zum Raube eingerichtet. Als Kiemenatmer brauchen die Larven nicht an die Oberfläche zu kommen; auf dem Schlammboden kriechen sie nach Beuto umher. Beunruhigt schwimmen sie ganz nach Art 
der Phryganiden-Larven, die ihres Gehäuses beraubt wurden, durch mediane Schwingungen des Körpers rückwärts.

Zur Verpuppung gehen die Larven wie die Käferlarven an (las Ufer: die Puppe ruht dann dort im Moose. Das ausgeschlü1fte Insekt, die "Schlammfliege", findet man im Mai und Juni in der Nähe von Gewässern an Pflanzen träge ruhend, leicht kenntlich an den auch mit zahlreichen Queradern verschenen, eigentümlich grauen Flïgeln. Die schwärzlichen Eier werden in regelmässigen dichten Reihen an Pflanzen oberhalb des Wassers abgelegt. -

Die kleinen, etwa $4 \mathrm{~mm}$ langen Larven von Sisyra leben in Süsswasserschwämmen. Ausgezeichnet sind dieselben durch vielgliedrige Fühler und sehr lange, gebogene, aus Ober- und Unterkiefer zusammengesetzte Saugzangen. Fühler wie Saugzangen übertreffen den Kopf um das Mehrfache an Länge. Die Hinterleibsringe tragen auf der Unterseite je ein Paar gegliederter Tracheenkiemen und auf der Rückseite je vier mit Borsten versehene Auswüchse.

Die Larven des Bachameisenlöwen (Osmylus) lieben stark strömendes Wasser; in Gebirgsbächen unter Steinen ist nach den Litteraturangaben ihr Aufenthalt. Ich habe sie noch nicht angetrofien.

\section{Geradflügler 4, 5).}

Wie bei den Netzflüglern fast die ganze Familie der Köcherfliegen*) in ihren Larven dem Wasser angehört, so unter den Geradflüglem die drei Familien der Wasserjungfern (Odonaten oder Libelluliden), der Eintagsfliegen (Ephemeriden) und Afterfrühlingsfliegen (Perliclen). Mit einigen anderen Geradflüglern wurden sie früher ihrer Flügelbildung wegen der vorigen Ordnung zugezählt und werden bisweilen heute noch Pseudoncuroptera genannt. Im Larvenheer der Gewässer nehmen ihre Larven einen hervorragenden Platz ein.

Die Zugehörigkeit einer Wasserlarve zu einer dieser drei Familien ist sichergestellt, wenn sie neben beissenden Mundteilen und drei l'aar grosser, meist kräftiger Brustbeine an Mittel- und Hinterbrust

*) Nur die Larven der Gattung Enoicyla sind davon ausgenommen. Dieselben leben zwischen Moos. 
meist recht deutliche Flügelansätze (Fig. 9, I9-23, Fig. IO, 24) hesitzt \%). Unsere Tiere machen nämlich licin Puppenstadium durch, d. h. ein Ruhestadium, in dem weder Nahrung aufgenommen wird

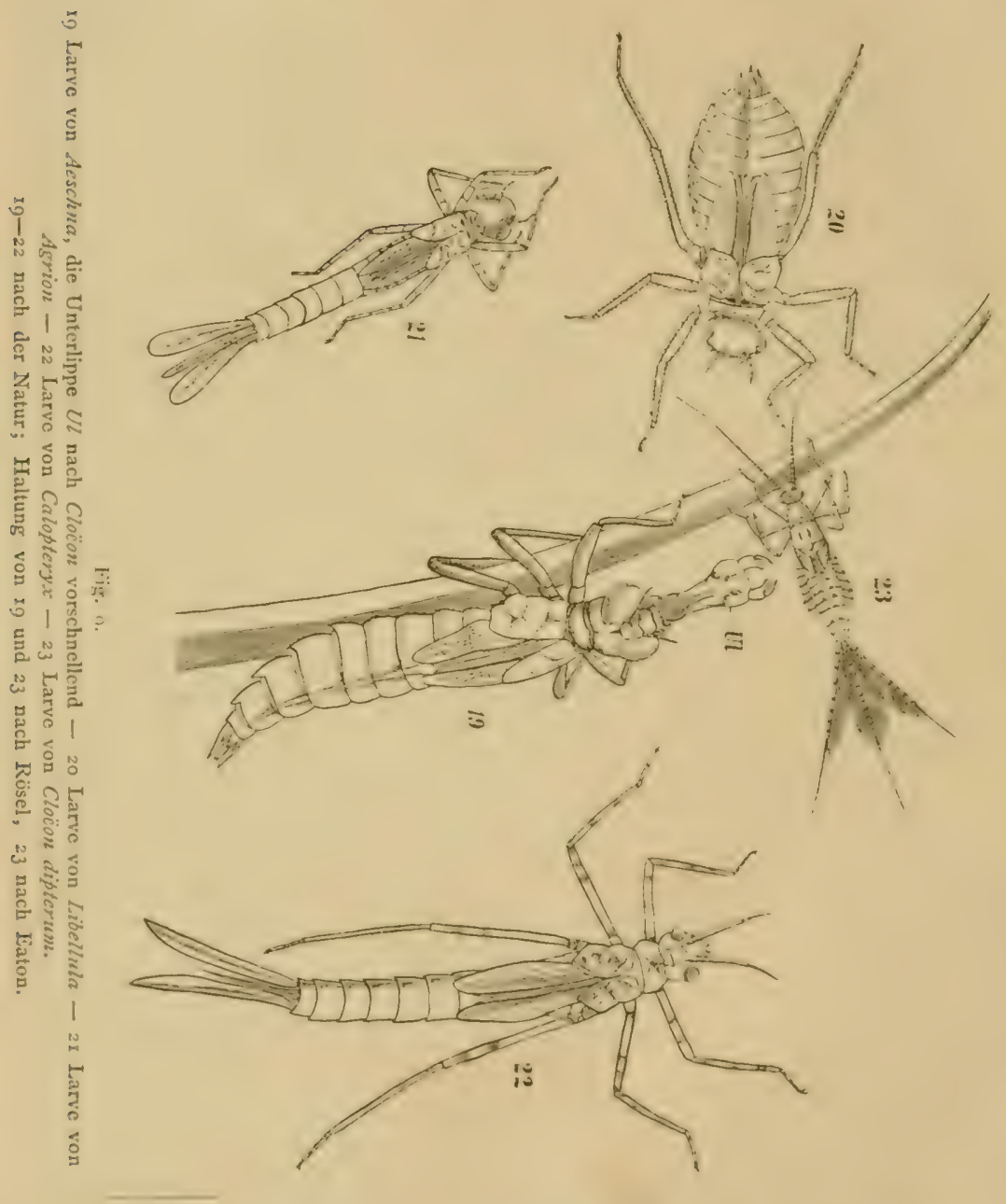

*) Nur den jüngsten Larven fehlen diese Flügelansitze. Dic Übereinstimmung in den anderen Punkten mit den ungleich hïufigeren :̈̈lteren Stadien lïst sic trotzdem unschwer erkennen. 
noch lebhaftere Ortsbewegung stattfindet und in dem der grosse Entwickelungsschritt von der Larve zum vollkommenen Insekt geschieht; solche Larven erhalten die Flügel schrittweise mit den verschiedenen Häutungen.

Die Larven der Libelluliden und Ephemeriden finden sich sowohl in stehendem wie fliessendem Wasser, die der Perliden habe ich nur in fliessendem Wasser angetroffen. Die Larven der Libellen sind unter den, anderen Larven der Ordnung leicht kenntlich an der armartig vorstreckbaren Unterlippe (Fig. 9, I9), die der Ephemeriden an den blatt- und fadenförmigen Tracheenkiemen, die nur an den Seiten des Hinterleibes stehen, und an den drei Afterborsten (Fig. 9, 23). Die Larven der Perliden (Fig. IO, 24) besitzen keines dieser besonderen Kennzeichen; besitzen sie Tracheenkiemen, so stehen sie meist auf der Unterseite der Brustringe.

\section{Die Larven der Libelluliden oder Odonaten.}

Unter den Libellenlarven der stehenden Gewässer treten dem Beobachter ohne weiteres drei Typen entgegen, die der Agrion-, Libellula- und Aeschna-Gruppe. Die ersteren (Fig. 9, 2I) sind langgestreckt und schwächlich; am Ende des Hinterleibes mit drei ziemlich langen blattartigen Tracheenkiemen versehen. Die hierher gehörigen Agrion- und Lestes-Larven unterscheiden sich dadurch, dass der Mittelteil der Unterlippe bei Lestes fast stielrund, dagegen bei Agrion fast ebenso breit wie der Endabschnitt ist. Die Larven der Libellula-Gruppe (Fig. 9, 20) sind ohne solche äussere Tracheenkiemen, dafür besitzen sie aber eigenartige innere Tracheenkiemen, nämlich an den Wandungen des Enddarmes. Die Hinterbeine sind länger als der gedrungene Hinterleib und der Vorderabschnitt der Unterlippe ist so ausgehöhlt, dass er in der Ruhelage die Mundteile von vorn wie eine hohle Hand bedeckt. Dieser Gruppe gehören auch die Larven der Gattungen Cordulia und Epitheca an. Die Larven endlich der Aeschna-Gruppe (Fig. 9, I9) stimmen in den Atemorganen mit denen von Libellula überein, dagegen ist hier die Unterlippe im Vorderabschnitt einfach flach und der schlanke Hinterleib ist langer als die Hinterbeine. 
Alle unsere Larven sind also Tracheenkiemen-Atmer, aber in verschiedener Weise. Die Larven der beiden letzten Typen ziehen willkürlich das Atemwasser durch den mit Schutzwehren versehenen After ein und stossen es wieder aus. Diese Atembewegungen werden kriiftig, aber unregelmässig ausgeführt; oft sieht man minutenlang umsonst nach dem ein- und austretenden Wasserstrum. Agrionund Lestes-Larven besitzen natürlich derartige Atemberegungen nicht, dagegen sieht man nicht selten, dass sie, mit den Beinen sich festhaltend, durch seitliches Schlagen des Hinterleibes das Atemwasser erneuern. Eine recht eigentümliche Thatsache bei allen diesen Larven ist nun, dass an der brust Luftü̈her vorhanden sind, deren Ränder für gewühnlich dicht aneinander liegen, die aber geöffnet werden können. Beweis dafür ist die Erscheinung, dass aus diesen Stigmen, wenn man die Larven *) in Allohol oder heisses Wasser wirft, eine Reihe von Luftblasen aufsteigen.

Welche Bedeutung können nur diese Luftlöcher haben? Ich vermühte nur ungeprüfte Vermutungen als Antwort auf diese Frage zu geben.

Bewegung. Bei allen unseren Larven dienen die Atembewegungen zugleich zum Schwimmen. Lange Zeit freilich liriechen oft die Larven am Boden oder an Wasserpflanzen umher. Wollen Agrioniden-Larven schwimmen, so treiben sie sich durch seitliches Schlagen des Hinterleibes mit seinen Kiemenblïttern vurwärts. Seltsamer aber nimmt sich das Schwimmen der anderen Larven aus: mit angelegten Beinen sieht man sie plötzlich durch das Wasser schiessen, ohne dass man zunächst zu erkennen vermag, wie das bewirkt wird. Genauere Beobachtung zeigt - ein sandiger Grund leistet dabei gute Dienste -, dass die Larven mit grosser Kraft das. Wasser aus dem After ausstossen und dadurch nach dem Prinzip des Rückstosses vorwärts schiessen. Hebt man die Larve im rechten Augenblick ausser Wasser, so kann man das ausgestossene Wasser oft drei bis vier Spannen weit fliegen sehen.

*) Nur bei den jüngsten Larven tritt das nicht cin. - Dass die Stigmen nicht verwachsene Räinder haben, stelite ich auch an Querschnitten derselben fest. 
Der Ernährung nach sind alle diese Larven Raubtiere und zwar erbeuten sie die Tiere durch plötzliches Vorstrecken der Unterlippe. Bietet man einer Aeschna-Larve z. B. Ephemeridenund Mückenlarven, so zeigt sich zugleich-dabei, dass die Beute erst wahrgenommen wird, wenn sie sich zu bewegen beginnt: eine Bemerkung, die für fast alle Räuber unter den Wasserinsekten und Wasserlarven zu geltén scheint.

Andere Libelluliden-Larven. Von anderen LibellulidenLarven, die ich nur in fliessenden Gewässem, nicht wie die obigen in beiderlei Gewässern, angetroffen habe, nenne ich noch zur Ergänzung die von Calopteryx (Fig. 9, 22), der prachtvoll dunkelblauen oder grünen Libelle der Ufer, und von Gompluıs. Die ersteren bilden einen eigenartigen Typus dadurch, dass sie sowohl Schwanzkiemen wie innere Kiemen haben. Kenntlich sind sie vor allem dadurch, dass sie bei ähnlicher Gestalt wie die AgrionidenLarven Fühler besitzen, die weit länger als der Kopf sind und deren Grundglied mehrfach länger und stärker als die übrigen Glieder zusammengenommen ist. - Die Larven von Gomphus schliessen sich am nächsten denen von Acschna an; die Unterlippe ist vorn ebenfalls flach, der Darm mit Kiemen versehen; das unterscheidende Merkmal liegt vornehmlich in dem auffallend breiten und grossen Endglied der Fühler.

\section{Ephemeriden-Larven.}

Die Larven der Eintagsfliegen (Fig. 9, 23) sind in stehenden wie fliessenden Gewässern eine recht häufige Erscheinung; aber fast immer gehörten die Tiere, welche ich um Berlin in stehenden Gewässern fing, einer Art an: Cloëon dipterum. Erwachsen sind dieselben, die drei langen, befiederten Schwanzanhänge nicht mitgerechnet, etwa I cm lang. Die drei letzten Hinterleibsringe sind ohne Kiemenblättchen, das viertletzte hat ein einfäches rundliches Blättchen, die sechs vorhergehenden Ringe aber je zwei solcher Kiemenblätter. Unschwer erhält man das Insekt selbst, welches nach der Zweizahl der Flügel und nach den Schwanzborsten leicht zu- bestimmen ist. Die den Ephemeriden einzig zukommende 
Eigentümlichkeit, dass dás der Larvenhaut entschlüpfte, mit beweglichen Flügch versehene Insekt (Subimago genannt) sich noch einmal häutet, beobachtete ich nicht immer, anscheinend fehlte den Tieren dazu häufig die Kraft; sie starben vorher ab.

Durch den Besitz der blattartigen Tracheenkiemen ist die Atemart unserer Laren himeichend bezcichnet: zu erwähnen bleil, nur, dass dieselben zur Erneuerung des Wassers oft schnell hintereinander auf- und niederbewegt werden, ohne dass sich etwa das Tier vom Platze bewegt. Für gewöhnlich gehen die Larven mit den gut entwickelten Beinen am Boden einher; bei der geringsten Beunruhigung jedoch fahren sie jäh durch das Wasser dahin. Durch kräftige mediane Bewegungen des Hinterleibes mit seinen beficderten Inhängen schnellen sie sich fort. Ihre Nahrung besteht aus Pflanzenkust: wie erfolgreich sie clieselbe verarbeiten, zeigt sich z. B. darin, dass eine Schale mit Cloëon-Larven und Pflanzen sich am Boden bald mit den Resten guter, gesegneter Verdauung füllt.

Ausser den Cloëon-Larven habe ich in kleineren stehenden Gewässern nur noch hie und da die von Caenis luctuosa angetroffen. Dieselben sind leicht daran zu erkennen, dass das erste Paar Kiemenblättchen zu Schutzdecken für die folgenden umgewandelt ist und dass die letzteren blattartig, aber am Rande mit zarten Fortsätzen versehen sind. Die vier letzten Hinterleibsringe sind von jenen Schutzplatten nicht bedeckt.

Ungleich reicher als in stehenden Gewissern sind die Ephemeriden-Larven in thiesienden entwickelt; reicher und manniwfaltiger gestalten sich dert auch die Lebenshedingungen derselben. Manche von ihnen (z. B. Ephemera und Palingenia) graben sich mit den kräftigen Vorderbeinen Gänge in das Ufer; andere wieder, wie die der alten. Gattung Bä̈tis, drücken sich bei eigenartig platter Gestalt dicht den Steinen an und vermögen sich so im Strome zu halten; noch andere kriechen, wohl an ruhigeren Stellen, auf alles Andere Verzicht leistend, im Schlamme umher*). Recht mannigfach undert dabei auch die Gestalt der Tracheenkiemen ab. bereichnet.

*) Dic Clö̈on-Larven würden zu denen gehüren, welche I'ictet als Schwimmer 
Niher hierauf einzugehen, muss ich mir schon aus iusseren Gründen versagen 5).

\section{Larven der Perliden oder Afterfrühlingsfliegen.}

Die Larven der Perliden scheinen stehende Gewässer ganz zu meiden; auch schwächer fliessende sind arm an ihnen, wogegen reissende Gebirgsbäche ihre rechte Heimat sind.

Die einzige Larve, welche ich in schwach fliessenden Gräben um Berlin angetroffen habe, ist die ron Nemura arirgata (Fig. 10. 24 S. IOo)). Als Orthopteren-Larve ist sie, wenigstens in den älteren Stadien, an den Flügelansätzen des zweiten und dritten Brustringes kenntlich; von den Ephemeriden-Larven, mit denen sie noch am ersten verwechselt werden könnte, unterscheidet sie sich erstens durch den Nangel an Tracheenkiemen und zweitens dadurch, dass sie nicht drei, sondern nur zwei lange Anhänge am Hinterleibsende hat. Innerhalb der Familie gehört die Larve zu denen, bei welchen das zweite Glied des dreigliedrigen Fusses kleiner ist als das erste.

Die Larve besitzt keine Tracheenkiemen; wie atmet sie denn? Ich habe sie weder jemals zur Atmung an die Oberfläche kommen sehen, noch spricht die Derbheit ihrer Haut und ihre Grösse für Hautatmung, so dass mir die Atemverhältnisse der Larve rätselhaft sind.

Eigenartig nimmt sich die Bewegung der Larve aus. Bei keiner bisher genannten Larve sind die Beine so kräftig und lang zugleich, wird der Hinterleib so wenig auf dem Boden nachgeschleppt, ist die Bewegung ein so flinkes Gehen wie bei dieser Larve. Thre Lebensweise ist eine räuberische.

Die Ähnlichkeit zwischen der älteren Larve und dem entwickelten Insekt ist recht auffallend; der Schritt von dem einen zum andern Zustand scheint deswegen auch recht leicht und schnell zu geschehen. Brachte ich Larven in feuchter Schachtel mit Moos zusammen heim, so fand ich am nüchsten Tage meist mehrere davon schon ausgeschlüpft.

Von den übrigen Larven der Familie, die sich alle einander recht ähnlich sehen, möchte ich nur noch die grösseren Perla- 
Larven erwähnen, dic durch Tracheenkiemen an der Unterseite der Brust ausgezeichnet sind*).

Schlussbemerkung. Sowohl am Anfang dieser wie der vorigen Ordnung hob ich hervor, dass die Anzahl der Wasserlarven innerhalb der Ordnung ungleich grösser als bei den früheren ist. Dazu kommt nun noch ein Arideres. Bei den Larven der Kafer, Zweiflügler und Schmetterlinge war die Anpassung an das Wasserleben, besonders hinsichtlich der Atmung, eine recht verschiedene; eine Reihe von Arten atmete noch durch Luftlöcher, daneben fand sich mehr oder minder ausgedehnt Atmung durch die Haut, echte Fiemen oder Tracheenkiemen. Ungleich einheitlicher, geschlossener erscheinen darin die Larven der Neuropteren und amphibischen Orthopteren: fast alle sind sie Tracheenkiemenatmer, selten finden sich daneben Hautatmer und nie einfache Luftatmer. Ferner sind sie einerseits alle nach ihrer Organisation ausgesprochene Wassertiere, und anderseits werden die einzelnen Gruppen den verschiedenartigen Bedingungen des Wasserlebens in oft recht eigenartiger Weise gerecht. Das Alles legt die Frage nahe: Ist das Verhältnis dieser Larven zum Wasserleben nicht ein ganz anderes als dás der Käfer-, Zweillügler-, Schmetterlings- und - wie wir gleich hinzufügen wollen - Wanzen-Larven? Diese verglichen wir den Seehunden und Walen, d. h. wir hielten für recht wahrscheinlich, dass sie von Vorfahren abstammen, die samt ihren Larven in der Luft lebten; sind jene Larven dagegen nicht vielleicht echte, ursprüngliche Wasserticre. Besonders für dic Elhemeriden ist wegen der unvollkommenen Verwandlung, wegen der einfachen Bildung der Mundteile und weil sich die Bildung der Flügel bei ihrem ersten Auftreten mit der der Tracheenkiemen vergleichen lässt, schon öfters ausgesprochen worden, dass sie dem Urtypus der Insekten ziemlich nahe stehen dürften; leiten sie sich vielleicht unmittelbar von einer im Wasser lebenden Stammform $a b$ ? Sind sie also den Amphibien im Kreise der Wirbeltiere zu

*) Zuerst bei Tieren dieser Familie wurde die überraschende Thatsache festgestellt, dass auch entwickelte herfe noch Tracheenkiemen besitzen. I'almén hat dann diese Erscheinung als allgemeiner verbreitet nachgewiesen. 
vergleichen? Diese Frage näher zu erwägen*), ist hier nicht der Ort, doch möchte ich hier kurz auf den einen Punkt hinweisen,

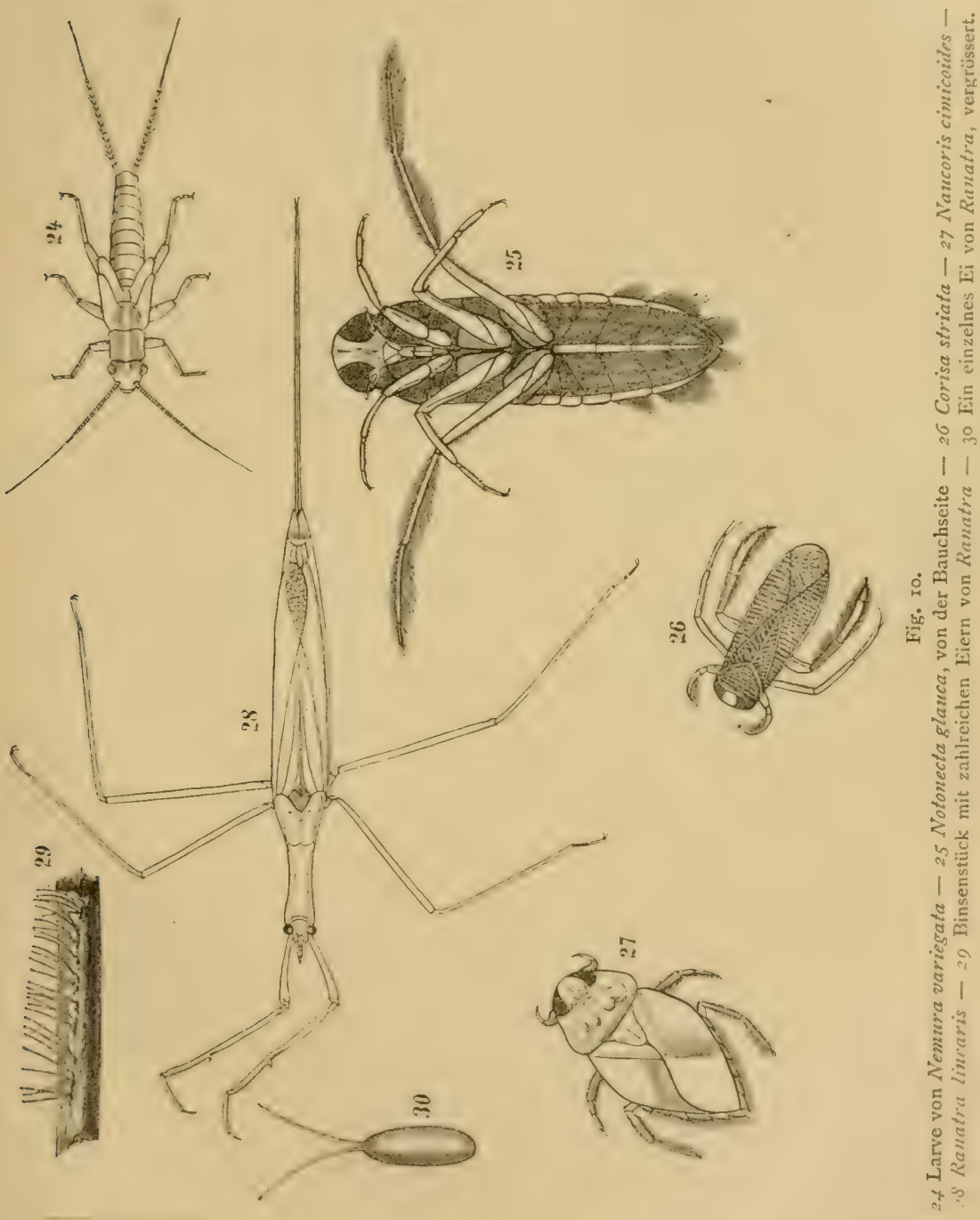

*) Verwiesen sei hier besonders auf die für die Frage wichtigen Untersuchungen und Erörterungen von Palmén (,Mforphologie des Tracheensystems"). 
dass man im Falle der Bejahung annehmen müsste, die Bildung eines Tracheensystems und zwar eines geschlossenen, das für die Bewegung der Luft im Körper so ungünstige Bedingungen bietet, sei bei Tieren, die unter Wasser leben, an Stelle der Kiemen entstanden!

\section{Schnabelkerfe ${ }^{6}$.}

Die Schnabelkerfe oder Rhynchoten lassen sich hinsichtlich ihres Verhaltens zum Wasser recht wohl mit den Käfen vergleichen; wie bei diesen leben unter den Schnabelkerfen nicht nur eine Reihe von Larven im Wasser, sondern auch entwickelte Kerfe, die in beiden ()rdnungen freilich nicht vïllig an diesen Aufenthalt gedsunnt sind. Ferner gilt auch in dieser Ordnung wie in jener*) der Satz, dass, wenn das entwickelte Tier diesem Element angehört, auch die Larve im Wasser lebt. Endlich stellen sich, wie schon bei den Käfern erwilhnt wurde, beide Ordnungen auch darin neben einander, dass einige ihrer Arten auf der Wasseroberfläche leben:' neben den sich auf der (Herfliche herumtummelnden Grriniden finden sich die nicht minder auffälligen Wasserläufer, welche innerhalb der Ordnung eine besondere kleine Familie bilden.

Am häufigsten trifft man auf stehenden Gewässern die Arten der Gattung Hydrometra an. Der Körper ist ebenso wie die beiden hinteren Beinpaare auffallend lang und dünn, die Vorderbeine, zwischen denen der zlemlich lange, mit Stechborsten versehene Rüssel liegt, ungleich kürzer. Eigenartig ist der Eindruck, den ihr Stehen und ihre Bewegung auf dem Wasser macht. Mit den wagerecht gestreckten Fussgliedern der Mittelbeine und zeitweise der Vorderbeine, sowie den Schienen und Fusseliedern der Ilinterbeine ruhen sie auf der Wasseroberflache, die an der betreffenden Stelle eingedrückt erscheint, wie bei einer auf der Oberfläche shwimmenden Nähnadel. Durch ein feines, lufthaltiges Inaurleicl der Beine ist die Gefahr des Einsinkens gemindert. Bei der

*) Vergl. jedoch die Ausnahme von Parnus. 
Bewegung gebrauchen die Tiere vornehmlich die Mittelbeine, dieselben gleichzeitig bewegend; stossweise gleiten sie auf der Oberfläche ziemlich schnell dahin*).

Die Nahrung der Hydrometriden besteht aus schwächeren Insekten, besonders wohl auch aus eben ausgeschlüpften Mücken, die sie mit ihrem Stech- und Saugrüssel aussaugen. An den Larven fält besonders die ganz ausserordentliche Verkürzung des Hinterleibes**) auf; hiervon und von dem Mangel ausgebildeter Flügel abgesehen, gleichen sie, besonders auch in der Lebensweise, sehr den entwickelten Kerfen.

Die ïbrigen Schnabelkerfe nun, welche dem Wasser angehören, führen ein Leben ähnlich dem der Dytisciden und Hydrophiliden; einige von ihnen, nämlich die Gattungen Notonecta (Fig. IO, 25), Plea, Corisa (Fig. 10, 26), Naucoris (Fig. 10, 27), sind lebhafte Schwimmer, andere dagegen, Nepa und Ranatra (Fig. IO, 28), kriechen mehr den Hydrophiliden ähnlich an den Wasserpflanzen umher. Alle aber kommen, den Käfern gleich, zum Atmen an die Oberfläche, im einzelnen dabei freilich verschiedene Einrichtungen und Weisen zeigend. Systematisch sind sie übrigens auch dadurch zusammengehalten, dass sic neben dem gegliederten Saugrüssel und den beiden ungleichartig ausgebildeten Flügelpaaren ausserordentlich kurze Fühler besitzen, die sie verborgen am Unterkopf tragen.

1. Notonecta glauca (Fig. 10, 25).

Unter den Schwimmern ist der ansehnlichste und mit auch der hüufigste Notonecta glauca, in kennzeichnender Weise Rüclienschwimmer genannt. Fassen wir ihn, wenn er aus dem Netz genommen werden soll, nicht vorsichtig, so lernen wir wahrscheinlich auch durch seinen empfindlichen Stich verstehen, weshalb er hie und da Wasserbiene heisst.

*) Die Gattung Velia, welche schattige, fliessende Gewässer liebt, schreitet oder lïuft dagegen auf dem Wasser.

**) Sonst ist bei Insektenlarven der Hinterleib der am kräftigsten entwickelte Körperteil. Das ist nach der Lebensaufgabe des Larvenstadiums ohne Weiteres verständlich. Hier wird die Abweichung von der Regel durch die Bewegungsweise auf der Obertlïche und die damit verbundenen $A$ forderungen bedingt. 
Die Eigentümlichkeit, mit dem Bauch nach oben zu schwimmen*), kennzeichnet unser Insekt hinreichend. In Beziehung zu dieser Schwimmart steht auch die Fürbung des Tieres: nicht der Rücken ist, wie das bei den meisten Wasserinsekten die Regel, dunkel grefürbt, sondern der Bauch, während unter Wasser die Rückseite durch anhaftende Luft lebhaft weiss erscheint. Nachdrücklich wird hierdurch in ähnlicher Weise wie durch die Färbung der Flundern die Auffassung gestützt, dass die dunklere, dem Boden ähnliche Färbung der Rückseite und die lichtere der Bauchseite so vieler Wassertiere, z. B. so vieler Fische, eine Schutzfärbung ist.

Als Ruder sind nur die stark verlängerten kräftigen Hinterbeine thätig, die an Schienen und Fussgliedern mit zwei Reihen Schwimmhaaren versehen sind: ihre Endkrallen sind verkïmmert. Als ordentlicher Schwimmer gebraucht das Tier die Ruder gleichzeitig. IVie es Vorder- und Mittelbeine verwendet, sieht man leicht, wenn man auf die Oberfläche etwa eine Fliege wirft. Nieist nimmt der vornehmlich nach oben schauende Rückenschwimmer die Beute schnell wahr, schiesst jahlings darauf los und packt sic mit armartig geliümmuten Vorder- und Mittelbeinen, um schwebend sie auszusaugen.

Zur Atmung streckt er, den Schwimmkäfern ähnlich, das Hinterleibsende aus dem Wasser; man möchte also hier auch grosse und ansehnliche Luftlöcher vermuten. Die Luftlöcher des Hinterleibes jedoch sind auffallend klein; grosse, mit zarten Schutzhaaren versehene Luftlücher, welche fraglos für die Atmung in erster Linie in Betracht kommen, liegen dagegen ziemlich verborgen seitlich an der Brust, etwas nach hinten und bauchwärts von der Ansatzstelle der Hinterflügel, ferner in der Verbindungshaut der Vorder- und Mittellorust, sowie zwischen . .Iittel und Iinterhrust und zwar am Rande. der Unterseite. Die Luft aber wird von dem Hinterleibsende nach diesen Stigmen in eigentümlicher Weise geleitet. Es ist ntimlich der Bauch in der Mitte gekielt (Fig. I0, 25) und wiederum an den Rändern erhaben, sodass zwei seitliche, freilich flache Rinnen entstehen. Über diesen Rinnen stehen je zwei Haarreihen, eine

*) Nur bei der kleinen, $2 m m$ grossen Verwandten, Plen minutissima, finclet sich die gleiche Schwimmart. 
vom Aussenrande und eine von der Mitte her und unter solchem Haardach wird die Luft in den beiden Rinnen von hinten her zur Brust und zwischen Haaren derselben weiter zu den Stigmen fortgeleitet. Nicht selten sieht man die Hinterheine, Geigenbogen vergleichbar, über den Hinterleib hinfahren, um die Luft in der einen oder anderen Richtung fortzuschieben. Hin und wider klappen auch an der Oberfläche die Haarreihen aus einander. Die Aussenränder der drei letzten Ringe sind übrigens noch mit nach aussen gerichteten Haarreihen versehen und diese ruhen beim Atmen aut der Oberfläche: auch die Bürste zur Reinigung der Schwimmhaare befindet sich anscheinend hier.

Laich und Larven. Im Zimmeraquarium habe ich die Eier des Rückenschwimmers mehrfach schon im Mürz erhalten; sie waren einzeln an lebenskräftigen, grünen Blättern abgelegt. Die ausschlüpfenden Larven lassen die Zugehürigkeit zu dem entwickelten Insekt in allen Punkten bis auf die weissliche Fürbung und den Mangel der Flügel erkennen. In Menge trifft man die Larven während der Sommermonate in den Gewässern an, dem Raube obliegend wie die entwickelten Kerfe. Ende Juni thun die ersten den letzten Schritt in der Entwickelung, der bei den Schnabelkerfen im Vergleich z. B. zu den Käfern recht klein ist. Dass hier kein Ruhe- d. h. Puppenstadium nötig ist, um die letzte Häutung vorzubereiten, ist ohne Weiteres verständlich.

2. Corisa (Fig. 10, 26).

Mit Notonecta und Plea werden bisweilen die zahlreichen und teilweise recht häufigen Arten der Gattung Corisa zu einer Familie vereinigt. Ist auch eine gewisse oberfächliche Ähnlichkeit vorhanden, so erweist sich doch Corisa bei eingehenderer Betrachtung so verschieden von den beiden anderen, dass eine derartige Vereinigung recht gewaltsam erscheint. Ich beschränke mich hier darauf, hervorzuhehen, dass die Corisa-Arten, unter denen C. Geoffroy (fast I,5 cm messend) die grösste, aber nicht häufigste ist, nicht mit dem Bauch, sondern mit dem Rücken nach oben schwimmen, dass sie ferner nicht das Hinterleibsende zur Atmung an die

Tier- und Pfanzenwelt des Süsswassers. II. 
Oberfläche bringen, sondern den Vorklerkïrper, und zwischen Kopf und Vorderbrust oder Vorder- und Mittelbrust, die dabei von einander gebogen werden, die Luft einsaugen. Besonders grosse Luftlücher liegen in der Gelenkinaut der Vorder- und Mittelurust, an den Seiten der Mittelbrust und scheinbar an denen der Hinterbrust. Im Wasser erscheint die ganze Unterseite mit einer silberglanzenden Luftschicht bedeckt. Natürlich fehlen nun auch die cigentümlichen Luftrinnen an der Bauchseite des Hinterleibes.

Von den Beinen ist wiederum das letzte Paar zu Schwimmbeinen umgestaltet. Das Schwimmen erfolgt regelrecht unter gleichzeitiger Bewegung beider Beine. Eine eigenartige, schaufelfurmige Ausbildung zeigt das Torderbeinpaar. Es dient mit dem Schnabel zusammen bei einzelnen Arten (uder bei allen?) als Musikinstrument. Die ziemlich laute und anhaltende "Nusik" habe ich übrigens bei den Tieren, welche ich hielt, stets erst am Abend gehört. Die Tiere hielten sich unter Wasser mit den Mittelbeinen fest und geigten mit den Vorderbeinen über den Schnabel. Deutlich liess sich die Gleichzeitigkeit des Tones mit der Bewegung der Vorderbeine beobachten.

Wie alle Schnabelkerfe des Wassers leben auch die CorisaArten vom Raube; aber sie dürften bei der Eigenart ihrer MIundteile nicht nur zu saugen, sondern auch kleinere, festere Sachen zu zerkleinern vermögen*). Hüufig habe ich sie an winzigen Mückenlarven gesehen. Der Schnabel weicht wesentlich von dem des Rückenschwimmers schon durch die auffallende Kürze und Breite ab. Die Hauptmasse desselben wird freilich, wie ich im Gegensatz zu den meisten mir bekiunten Angaben, welche gleichmaissige beteiligung der Ober- und Lnterlippe an der Schnabelbildung behaupten, fand, hier wie bei den anderen Rhynchoten von der nach oben zusammengelegten und gegliederten Unterlippe gebildet, in der die kurze Oberlippe und die vier Stechbersten liegen $* *)$.

*) Vergl. hierzu dic Angaben von Geise, "Dic Mfundteile der Rhynchoten" im Archiv für Naturgeschichte 1886.

*) Sielso auch Geisc a. a. O. 
An der Bildung der Mundteile sind auch die im Mai ausnehmend häufigen Larven als Corisa-Larven leicht zu erkennen. Dieselben bieten vor der ersten Häutung in ihrer Atmung eine Abweichung sowohl von den Notonecta-Larven als auch von den eigenen entwickelten Zuständen. Sie kommen nämlich nicht dazu an die Oberfläche, sondern atmen durch die zarte Hautoberfläche. Das Tracheensystem ist zu dieser Zeit an manchen Teilen der Haut sehr fein und reich verzweigt, aber es besitzt, wie bei dem durchsichtigen Kö̈per mit Hilfe des Miliruskin)s leicht festzustellen ist, keine thätigen Luftlöcher. Oft sah ich solche Larven sich mit den Hinterbeinen frisches Wasser zufichehn, während sie sich mit den Mittelbeinen festhielten. Larven mit Flügelansïtzen zeigen freilich schon die. Atmungsweise der entwickelten Tiere*).

\section{Nepa, Ranatra, Naucoris.}

Den dritten Typus der im Wasser lebenden Schnabelkerfe bilden die beiden, je nur eine Art umfassenden Gattungen Nepa und Ranatra (Fig. I0, 28). Beide sind kenntlich an den langen, aus zwei seitlichen Halbrinnen bestehenden Atemröhren am Kürperende und an den ausgeprägten, nach vorn gerichteten Raubbeinen des ersten Brustringes. Die Schiene derselben kann gegen den Schenkel wie die Schneide eines Taschenmessers gegen den Griff umgeschlagen werden; die Krallen am Ende fehlen, der eingliedrige Fuss selbst sieht dagegen krallenartig aus. Hinsichtlich der Beinbildung bildet die Gattung Naucoris (Fig. IO, 27) den Übergang zu Nepa; sonst freilich weist sie nicht viel Übereinstimmung mit derselben auf.

Nepa cinerea, der Wasserskorpion, und Ranatra linearis unterscheiden sich von einander leicht durch die Gestalt; der erstere ist breit, verhältnismässig kurz und von oben nach unten platt gredrückt, während Ranatra am besten gekennzeichnet wird durch den Namen, welchen ihr jüngst einer meiner Schüler gab: Strohhalmwanze. Wer sie nicht kennt, dürfte sie in der That oft

*) Die sehr äbnliche Gattung Sigara, besonders durch die Zahl der Fühlerglieder unterschieden, babe ich bisher nur in grüsseren Gewässern, nicht in Gräben und Teichen gefunden. 
genug jener Ähnlichlecit wegen, da sie äberdies meist bewegungshs mit abgestreckten Beinen im Netz liegt, übersehen.

Mit der sihwimmbefahigung und Schwimmneigung beider int es nicht sonderlich bestellt; die Mittel- und Hinterbeine, welche dabei gebraucht werden, sind nur schwach bewimpert. Sie bewegen jeduch die Beine desselben Paares gleichzeitig und Ranatra, des-en Beine ausserordentlich lang sind, kommt schwimmend ziemlich schnell fort. Die Lieblingsstellung beider Tiere ist übrigens, sich schräg abwärts gerichtet an einer Wasserpflanze mit den beiden letzten Beinpaaren zu halten, so dass die Atemröhre eben zur Oberfläche emporragt, und so bewegungslos auf Raub zu lauern. Blitzs hnell erfassen sie mit ihren Vorderbeinen vorbeischwimmende Tiere, auch winziger Grösse, z. B. Daphnien. Einmal gefasst, entwindet sich keine Beute so leicht diesen Zangen. Bisweilen sah ich Ranatra eine Daphnia aussaugen und gleichzeitig mit jedem Vorderbeine eine neue Beute halten*).

Die Eier legen beide Wanzen im Mai an abgestorbenen schwimmenden Binsen u. dergl. ab und zwar so, dass das eigentliche $\mathrm{Ei}$ in die Pflanze eingesenkt ist und nur die eigenartigen, fadenfürmigen Anluängsel der Eier (bei Ranatra zwei, bei Nipa mehrere) hervorragen (Fig. IO, 29 u. 30). Von Ranatra habe ich mehrfach die Eier im Mai zu vielen Hunderten angetroffen. Die jungen Larven schlüpfen nach kurzer Zeit aus; die Zugehöriglecit zum entwickelten Tier ist bei ihnen wie bei Nepa ohne Weiteres zu erkennen. Es fehlen ihnen zunächst nur die Flügelansätze und die Atmungsweise ist eine etwas andere. Bei den entwickelten

*) Die Mundteile der Nepiden bieten übrigens eme morphologische Besonderheit dar; die Unterlippe derselben besitzt am vorletzten Schnabelgliede eingliedrige Taster im Gegensatz zu der allgemeinen Angabe, dass den Rhynchoten eigentliche Lippentaster fehlen. Das hatte bereits Savigny erkannt und abgebildet. Seine Abbildung ist in Lehrbüchern immer wieder kopiert worden, aber anscheinend ohne Verständnis und Nachuntersuchung, denn die Taster sind in den Abbildungen recht undeutlich geworden und in den Eirklïrungen und Texten völlig verschwunden. Burmeister, der auch dic Abbildung von Savigny bringt, hat sogar auf das Fehlen der Unterlippentaster hin eine besondere Deutung der Gliederung des Rüssels aufgestellt, dic oft wiederholt wurde, und $\mathrm{Huxlcy}($, Wirbellose Tiere" $)$ zieht mit deswegen in lirage, ob die Mundteile der Rhynchoten mit denen der anderen Insekten homologisiert werden künnen. Auffallenderweise giebt auch Geıse, der die Mundteile der Schnabelkerfe so genau untersucht hat, an, dass bei Nepa und Ranatra die Lippentaster fehlen. Vgl. meine Mitteilungen über Mundteile der Rhynchoten und die Stigmen derselben in d. Sitzungsber. der Gesellschait naturforschender Freunde zu Berlin, I8gx. 
Kerfen liegen die einzig offenen Stigmen am Ende des Hinterleibes, am Grunde der Atemröhre; die übrigen Stigmen desselben sind auf der Bauchseite zwar vorhanden, aber geschlossen und nicht in Thätigkeit; bei den Larven sind dagegen an der Bauchseite zwei gleichartige Haarrinnen vorhanden wie bei Notonecta, und unschwer erkennt man 'auch, dass von der kurzen Atemrinne aus - eine zweiteilige Atemröhre ist noch nicht ausgebildet - die Luft in diesen seitlichen Gängen zu den dort liegenden Luftlüchern fortgeleitet wird. In allen anderen Punkten aber, in der Bildung der Mundteile, im Schwimmen, in der gewöhnlichen Körperhaltung, sind die jungen Tiere ein getreues Abbild der alten.

\section{Schlussbemerkungen.}

Reich und mannigfaltig ist also, wie wir sehen, das Kerf- und besonders Kerflarvenleben der süssen Gewässer entwickelt. Naturgemäss drängt sich da zum Schluss die Frage auf: Wie verhält sich dazu die Kerfwelt des Meeres? Ist dort ein ähnlicher Reichtum an Formen vorhanden; sind es verwandte und gleiche Formen wie die des süssen Wassers? Die Auskunft auf solche Fragen muss für Jeden zunächst überraschend sein: Von Kerfen und besonders Kerflarven des Meeres ist so gut wie garnicht die Rede: Ausser einer Gattung der Wasserläufer (Halobates, Meerwanze) giebt es nur ganz vereinzelte Meerestiere unter den Kerfen und Kerflarven. Dass der Salzgehalt des Meenwassers die Ursache dieser auffallenden Erscheinung sein sollte, ist, auch schon wegen der Fauna der salzigen Gewässer des Binnenlandes, nicht wohl anzunehmen. Vielleicht ist dieselbe im folgenden zu suchen. Die fast nie ruhende Bewegung der Meeresoberflïche, besonders auch näher der Küste, macht zunächst allen Kerfen und Larven, die zur Atmung an die Oberfläche kommen, oft auf lange Zeit das Atmen und also das Leben im Meere unmöglich; aber auch für diejenigen Larven, bez. Puppen, welche durch Kiemen oder Tratheenliemen atmen und die also zunächst in der schützenden Tiefe verbleiben können, kommt früher oder später der Zeitpunkt, wo 
sie zur Verpuppung oder zum Ausschlüpfenlassen des Insektes das Wasser verlassen müssen, und welehe schwierigkeit bietet sich dann für die schwachen Lebewesen durch die Brandung das Ufer und und weiter eine Stelle $z u$ erreichen, an der sie nicht eine spätere Welle oder die steigende Flut erreiche. Wie dem nun auch sein möge, jedenfalls bilden die Kerfe hierin einen bemerkenswerten Gegensatz zu der verwandten Klasse der Kruster, den echten Wassertieren, welche im MIeere so ungleich reicher als im süssen Wasser entwickelt sind.

\section{An hang.}

\section{Tialielle \\ zurr annïhlernden Bestimmung der im Wisser lebenden Kerllarren \%.}

I. (8) Mit Flügelansïitzen ${ }^{3 *}$ )

2. (3) Mit gegliedertem Rüssel

Schnabelkerfe $\dagger$ ) oder Rlymuchoten (Fig. 10, 25-28).

3. (2) Mit beissenden Mundteilen (Orthoptera amphibiotica) . +

4. (5) Unterlippe zum Fangorgan ausgebildet, weit vorstreckbar

(Fig. 9, r9). Nit drei blattförmigen Kiemen ††) am

Ende oder mit Darmkiemen Odonaten (Fig. 9, 19-22).

*) Die weitere Unterscheidung der unten folgenden Gruppen siehe teilweise im Text.

**) Die eingeklammerten Zahlen weisen auf den Gegensatz hin.

***) Die jüngsten Larven sind zwar ohne Fliggelansätze, aber durch ihre sonstigc Äbnlichkeit mit den ungleich häufigeren älteren Larven, die solche Ansätze haben, leicht kenntlich. Ubrigens lassen sich die Larven der vier ersten Gruppen auch abgesehen von den Flügelansätzen durch die oben gekennzeichneten Merkmale der Mundbildung, der Kiemen und Endanhänge von den folgenden Larvengruppen unschwer unterscheiden. Zu Hilfo kann man noch nehmen, dass die Larven dieser vier Gruppen alle Netzaugen und grosse, wohl entwickelte Beine mit fast immer (oder immer?) teilweise gegliederten Tarsen haben und dass Brust- und Hinterleibsringe meist deutlich in ihrer Bildung von einander unterschieden sind. zu bestimmen.

†) Die Gattungen sind unschwer durch die Öhnlichkeit mit den erwachsenen Tieren

11) Kiemen steht in der Tabelle der Kürze wegen statt Traclieenkienten. 
5. (4) Unterlippe gewöhnlich, tief geteilt .

6. (7) Mit Kiemen nur an den Seiten des Hinterleibes. Meist drei lange Endanhänge. Ephemeriden (Fig. 9, 23).

7. (6) Ohne Kiemen an den Seiten des Hinterleibes, oft mit solchen an der Brust. Meist zwei Endanhånge.

Perliden (Fig. 10, 24).

S. ( I) Ohne Flügelansätze. Larven, deren Brust- und Hinterleibsringe meist recht gleichartig und deren Tarsen nie gegliedert sind . . . . . . . . . . . 9 .

9. (I0) Ohne gegliederte Beine an den drei Brustringen, bisweilen mit fussartigen, ungegliederten Fortsätzen, die zahlreiche Chitinhaken tragen

Dipteren (Fig. 7, 9-I4).

Iо. (9) Mit gegliederten Beinen an den drei Brustringen. . I I.

I I. (I 2) Mit je einem kräftigen Chitinhaken an zwei kürzeren oder längeren Afterbeinen am Hinterleibsende. Fühler meist fehlend, selten vorhanden und dann zweigliedrig, winzig. Mit oder ohne fadenförmige mehrreihige Kiemen. Mit oder ohne Gehäuse

Phryganiden (Fig. 8, I5).

I2. (i I) Ohne derartige Chitinhaken an besonderen Afterbeinen; mit Fühlern . . . . . . . . . I3.

I3. (14) Raupen; mit fünf Paar Afterbeinen am dritten bis sechsten und letzten Hinterleibsringe. Afterbeine mit Hakenkränzen

Wasserzünsler. (Paraponyx, Hydrocampa, Catacly'sta, Acentropus).

14. (I3) Fast immer ohne Afterbeine*), oder doch nie mit Afterbeinen in obiger Anordnung . . . . . I5. I5. (I S) Mit fadenfürmigen Kiemen, olıne thätige Luftlïcher ${ }^{* 4}$ ) I ().

*) Meines Wissens kommen nur bei Philliydrus testacens Afterbeine vor und zwar stehen sie am dritten bis siebenten Hinterleibsring.

**) Hierher gehören eigentlich auch wegen ihrer Kiemen Berosus (Hydrophilide), Cnemidotus und Pelobius (Dytisciden). Von den Gyriniden, Sialis und Sisyra unterscheidet sich Cnemidotus dadurch, dass auch an den Brustringen Kiemen stehen, Pelobius durch bluterfülite echte Kiemen an der Unterseite der Brust und Berosus durch die besondere Oberkiefer- und Beinbildung (S. 24) der Hydrophiliden. 
120 Kerfe und Kerflarven des süssen Wassers: Anhang.

10. (I ) Chne Chitinlıalien am Kürperende; Kiemen grenliedert, am Hinterleib.

Sialis, Sisyra.

1\%. (I (1) Mit vier Chitinhaken am Kürperende; Kiemen ungegliedert, am Hinterleib . . Gyriniden (Fig. 5, I).

I8. (I 5) Ohne fadenförmige Kiemen; mit zwei thätigen Luftlöchern am Körperende . . . . . . . . . I9.

I9. (20) Fühler länger als der halbe Körper; Körper platt

Cyphon.

20. (I9) Fühler kürzer als der halbe Körper; Körper mehr oder minder walzenförmig . . . . . . . . $2 \mathrm{I}$.

21. (22) Vorletzter (eigentlich drittletzter) Hinterleibsring mit zwei langen sichelförmigen Chitinhaken. Körper weichhäutig, bleich . . . . . . . Donaciden.

22. (2 I) Ohne solche Chitinhaken; Kürper nicht bleich. . 23.

23. (24) Oberkiefer sichelförmig, ohne Zähne auf der Innenseite; Beine mit gesonderter Kralle, also sechsteilig. Fast immer zwei Krallen

Dytisciden (Fig. 5, 2-4).

24. (23) Oberkiefer mit deutlichen Zähnen oder doch Höckern auf der Innenseite. Tarsus und Kralle nicht gesondert, Beine also fünfgliedrig. Nie zwei Krallen Hydrophiliden (Fig. 6, 6 und 7). 


\section{Litteratur.}

I) Zum Bestimmen der im Wasser lebenden Käfer wie der Käfer überhaupt ist zu empfehlen der betreffende Band der „Fauna austriaca“, nämlich Redtenbacher: „Die Käfer". Wien I858. Die Litteratur über die Käferlarven und Käferpuppen ist übersichtlich zusammengestellt in M. Rupertsberger, „Biologie der Käfer Europas“. Linz I880. Für unsern Zweck sind fraglos am wichtigsten die Arbeiten Schiödtes, welche in der Naturhistorik Tidsskrift von Kröyer, Kopenhagen, erschienen sind und zwar in den Jahrg. I 802, I 864, I 867 , I 872 . Der Text ist teilweise dänisch, teilweise lateinisch; die wichtigste Auskunft geben übrigens schon die vorzüglichen Abbildungen. Nicht unterlassen möchte ich, gleich hier auf die unser ganzes Gebiet behandelnden älteren Werke von Rösel v. Rosenhof, Réaumur und De Geer hinzuweisen.

Rösel, ,.MIonatlich herausgegebene Insektenbelustigungen “. $\left.I 7 f^{(}\right)$ bis $176 \mathrm{r}$.

de Réaumur, Mémoires pour servir à l'histoire des Insectes. Paris $1734-42$.

de Geer, Mémoires pour servir à l'histoire des Insectes. Stockholm I752-78. (Deutsch von Götze. Nürnberg I 778-83.)

2) Eine umfassende Zusammenstellung der Litteratur über die Metamorphose der Dipteren giet, Fr. Brauer, „Die Zweiflügler des kaiserlichen Museums zu Wien"6 (Denkschr. d. k. k. Akad. d. Wiss. Bd. 47. Wien I883). Dort sind auch die Larven systematisch gruppiert und kurz geschildert. Für die eucephalen Larven ist wegen seiner vortrefflichen Abjildungen besunders zu empfehlen: 
Fr. Meinert, ,Eucephale Mrgecliner" (Tidensk. Selsk. 1) Raikki naturvidensk. og math. Ath. III 3). Kopenhagen I 886.

3) Abbildungen der Wasserraupen finden sich in v. Praun, „Abbild. u. Beschreib, europäischer Schmetterlingsaupen”. Herausgereben von E. Hoffmann, is it. Tergl. auch Sorhagen, ..Kleinschmetterlinge der Mark"“.

4) Für Phryganiden, Ephemeriden und Perliden sind mit Vorteil zu benutzen die Werke von F. J. Pictet, I) Recherches pour servir à l'histoire et à l'anatomie des Phryganides. Genf-Paris I 834. 2) Histoire naturelle des insectes neuroptères. Genf-Paris I 84 I - I 843 .

Ferner ist für beide Ordnungen zu empfehlen: Fr. Brauer, Neuroptera austriaca. Wien 1857. Eine Anzahl Beschreibungen und Muster für genaue Beschreibung der Larven und Puppen der Phryganiden findet man in: Klapalek, „Metamorphose der Trichopteren". Prag I 888.

Für die Bestimmung der entwickelten Inselten ist besonders zu nennen: Mc. Lachlan, A monograph revision and synopsis of the Trichoptera of the European Fauna. London I874-80.

5) Die Ephemeriden nebst ihren Larven sind sehr eingehend behandelt in: Eaton, A revisional monograph of recent Ephemeridae. (Transact. of the Linnean Society.) London. Zoology. N. S. 3. I888. Das Werk enthält zahlreiche Tafeln über die Larven.

6) Zur Bestimmung der Gattungen der Wasserwanzen dürften die allgemeinen systematischen Handbücher ausreichen, z. B. das ron Ludwig-Lounis. Zur Lnterscheidung der Arten sind die Arleiten von Fieber, besunders .Hemiptera europaca”, zu empfehlen. 


\section{Die Mollusken des Süsswassers.}

Von S. Clessin in Ochsenfurt. 

Unsere Gewässer, von der kleinsten Pfütze bis zu den grössten Seen und von der spärlichsten Quelle bis zu den wasserreichsten Flüssen, werden won Mollusken verschiedener Gattungen bewohnt. Aber obwohl die in den Gewässern vorkommenden Arten meist in reicher Individuenzahl auftreten, fallen sie dennoch dem nicht geübten Beobachter nicht so leicht ins Auge und es bedarf selbst der gewandte Sammler in der Regel besonderer Instrumente, um lebende MIollusken in grösserer Anzahl zu fangen. Leere Gehäuse werden dagegen oft in reicher Menge an gewissen Lokalitäten angeschwemmt gefunden.

Die Mollusken spielen im Haushalte der Natur eine wichtige Rolle, indem sie faulende Pflanzenstoffe, welche in den Gewässern sich ansammeln, verzehren und dadurch die Wasser rein erhalten. Die Mehrzahl der Arten werden ihrer geringen Grösse und verborgenen Lebensweise wegen leicht übersehen, doch beherbergen unsere Gewässer auch grosse, recht ansehnliche Arten, namentlich aus der Ǩlasse der Muscheltiere, die hezüglich ihrer Entwickelungsgeschichte noch besonderes Interesse bieten.

\section{Einteilung der Mollusken.}

Die im Wasser lebenden Conchylien gehören zwei sehr verschiedenen Klassen an. Die eine besteht aus Tieren, welche einen Kopf mit Fühlern und Augen haben, die gewöhnlich an der Basis der Fühler sitzen, im übrigen aber jenen der Landschnecken, der 
Klasse der Gasteropuden oder Batuchfuister ahnlich sind. Sie haben mit wenigr Aunnahmen (Genus Ancylus Geoff, und Volletia Gray**) eine gewundene Schale, und ist das Gehäuse zuweilen mit einem Deckel verschlossen. Die zweite Klatse die Muscheltiere, Bivalven oder Zweischaler, haben keinen Kopf und keine Augen; das Tier besteht nur aus einem sackartigen Kürper, dessen unterer, ausdehnbarer Teil als „Fuss“ die Bewegung vermittelt. Den Körper umhüllen auf jeder Seite zwei buchblattartig am Rücken angeheftete Fiemen und wird das ganze Tier von einem Mantel umschlossen, dessen Ründer entweder ganz frei bleiben, oder teilweise zusammengewachsen sind; im letztern Falle hat der Mantel einen Schlitz am Vorderteile des Tieres zum Durchgange des Fusses und eine Öffnung für die Anal- und Atemröhre. Die Schalen der Bivalven sind nicht gewunden, sondern bestehen aus zwei gleichgrossen Klappen, die durch ein elastisches Band, das Ligament, verbunden sind und sich nur wenig öffnen können. Das Tier ist an den gegenüberstehenden Enden durch zwei sehr starke Muskeln (die Schliessmuskeln), welche zugleich das (Iffnen der Schalen regeln, und durch einen kleinen Wirbelhaftmuskel an die Schale angeheftet sind.

Die meisten Süsswassermuscheln
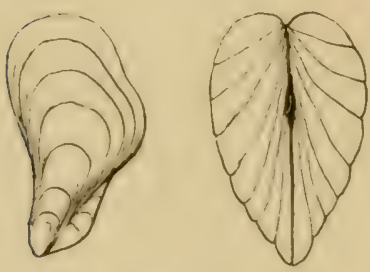

Fig. II.

Dreissena polymorpha. sind freibeweglich; nur eine Art unserer heimischen Arten heftet sich durch einen Byssus (einen Büschel spröder Haare) an anderen Gegenständen an (Dreissena polymorpha Pallas Fig. I I ).

Die Genera der nicht gedeckelten Süsswasserschnecken sind durchweg Lungenatmer. Sie haben sehr verschiedene Formen, indem der Modus des Aufwindens der Umgänge sehr mannigfaltig ist. Die meisten Arten haben eine rechtsgrewundene Schale, nur die Genera Amplipiplea, Plyse und Aplexa

*) Bezüglich der Arten und Genera verweise ich auf meine Werke: „Deutsche Excursions-Mollusken-Fauna". 2. Aufl. Nürnberg 1884 , Bauer \& Raspe, und ,Molluskenfauna von Ústerreich-Ungarn und der Schweiz". Nürnberg 1890 , Bauer \& Raspe. 
winden ihre Umgänge nach links. Ferner besitzen die Genera Limnaca, Ply'sa, -1 plexa, I Implupeplea ein mehroder weniger erhïhtes Gewinde, nur Genus Planorbis rollt scine Umginge in platter Form auf, für welche der Name "Tellerschnecke" sehr bezeichnend ist. Die Genera Ancvlıs (Fig. I 2) und I clletia haben eine napffürmige Schale, von denen diejenige des ersteren Genus einer Jakobinermütze sehr ähnlich ist; bei beiden beschränkt sich die Windung des Gehäuses auf eine geringe Neigung des Wirbels nach rechts oder links. Die meisten Arten haben eine rauhe Schale, an welcher die Zuwachsstreifen deutlich erkennbar sind. Nur Genus Physa und Aplexic haben glatte, glänzende Gehäuse.

Die Deckelschnecken, mit Ausnahme des Gen. Vivipara, bestehen aus kleinen Arten. Alle sind mit Kiemen zur Wasseratmung ausgerüstet. Gewöhnlich bleiben die Kiemen in der Kiemenhöhle ver-

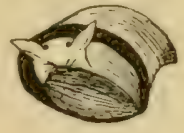

Fig. I2. Ancylus fluviatilis mit Tier. borgen, nur GenusValvata (Fig. I3) besitzt die Fähigkeit, die federförmige Kieme auszustülpen und frei hervortreten zu lassen.

Das Gewinde ist bei diesen Schnecken ein kreiselförmiges (Gen. Vivipara und Valvata) oder ein mehr oder weniger getürmtes, nur Gen. Neritina und Lithoglyphus haben ein kurzes, wenig hervortretendes Gewinde und eine starke Schale und weite Mündung; die Oberfläche der Arten des Gen. Neritina ist mit hübschen netzartigen Zeichnungen bedeckt.

Die frei beweglichen Muscheln gehören zwei

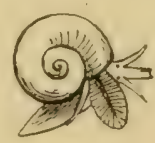

Fig. I 3 . Valvata piscinalis mit Tier. Familien an. Die grossen Arten gehören in die Familie der Najaden. Diese haben offenen Mantel, zwei gleichgrosse Kiemen und an der Mundöfnung jederseits zwei MIundlappen: der Mantel ist an seinem Rande am Hinterteile mit einem Kranze dunkelgefärbter Papillen besctzt. Die Kiemen dienen zugleich als Erutbehailter, haben gitterfürmige Abteilungen, dic, wenn Brut vorhanden, mit einer ungeheuren Anzahl von Embryonen besetzt sind.

Die kleineren Zweischaler der Familie Cy'cladidae haben geschlossenen Mantel, und je eine Anal- und Atemröhre, welche mehr oder weniger über den Mantelrand hervortritt. 


\section{Wohnorte und Gewohnheiten.}

Die ungedeckelten Wasserschnecken der Familie der Limnaeiden halten sich den grössten Teil des Tages auf dem Grunde' der Gewäser im Schlamme auf, und ziehen die meisten Arten stehende Gewässer vor; nur wenige Spezies finden sich in fliessenden Wassern, für welche sie wegen ihrer dümnen, zerbrechlichen Sihale wenig geeignet sind. In fliessenden Wassern kommt in der Regel nur Limmaea peregra vor. - Die übrigen Limnaea-Arten, die Spezies der Gen. Physa, Aflexa, Amplipeflea und Planorbis bewohnen nur stehende Gewässer.

Die Limnacen (Limnaca stagnalis, auricularia, vïata, palustris) steigen bei heiterem, warmem Wetter an Wasserpflanzen an die Oberfläche des Wassers und kriechen, die Fusssohle nach oben gerichtet, das Gehäuse untergetaucht, ebenso sicher dahin, als wenn sie an einem festen Gegenstande kröchen. Wahrscheinlich saugt sich die Sohle an der auf dem Wasser aufstehenden Luftsäule an, da die Tiere sich jederzeit plötzlich zu Boden fallen lassen können. - Das Aufsteigen der Limnaeen an die Oberfliche wird mit dem Bedürnnisse der Tiere, Luft zu atmen, in Verbindung gebracht, dat die Limnaeiden mit Lungen ausgerüstet sind, wahrend die mit Kiemen versehenen Deckelschnecken nie an die Oberfläche

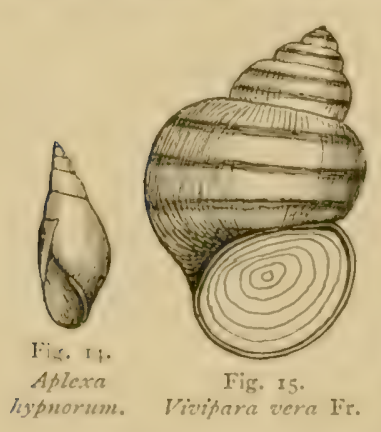

kommen. Die Limnaeen haben jedoch dieses Bedürfnis nur bei heiterem Wetter und bei erhöhter Temperatur des Wassers ihrer Wohnorte.

Eine Aplexa-Art (Apl.hy'pnorum Fig. I 4 ) besitzt sogar die Fähigkeit, plötzlich vom Grunde des Wassers an die Oberflache aufzutauchen, von wo sie sich nach einigen Sekunden ebenso schnell wieder zu Boden fallen lassen kann.

Die gedeckelten Wasserschnecken der Genera Vivipara(Fig. I 5), Bythinia und Valvata leben im Schlamme der Gewässer, und zwar meist in stehenden, hüchstens in sehr langsam fliessenden Wassern. - 
Die Arten der Genera Neritina und jene der Familie der IIclaniiden leben nur in bewegtem Wasser, in welchem sie sogar stark flutende Stellen bevorzugen, für welche die Jeritinen durch ihr kaum herwortretendes Gewinde und ihre weite IIundüfnung rorzugsweise geeignet erscheinen, weil sie den Fluten wenig Fläche darbieten. - Die Bythinellen (Fig. I6) finden sich nur in Quellen an Steinen sitzend; die Vitrella-Arten kommen ausschliesslich in Höhlengewässern vor. - Velletia lacustris lebt in stehendem, Ancylus flutiatilis und verwandte Arten nur in fliessendem Wasser. Doch findet sich erstere zuweilen auch in Bächen, während Ancylus-Arten aach in Seen vorkommen.

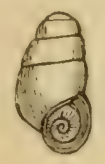

Fig. I6. Bythinella austriaca Frf.

Die Muscheln stecken am Grunde der Geiwässer im Schlamme, in dem sie fast völlig eingebettet sind, so dass nur das hintere Ende frei ins Wasser hervorragt. Sie saugen das Wasser durch die Mundöffnung am vordern Ende der Muschel ein, lassen das-

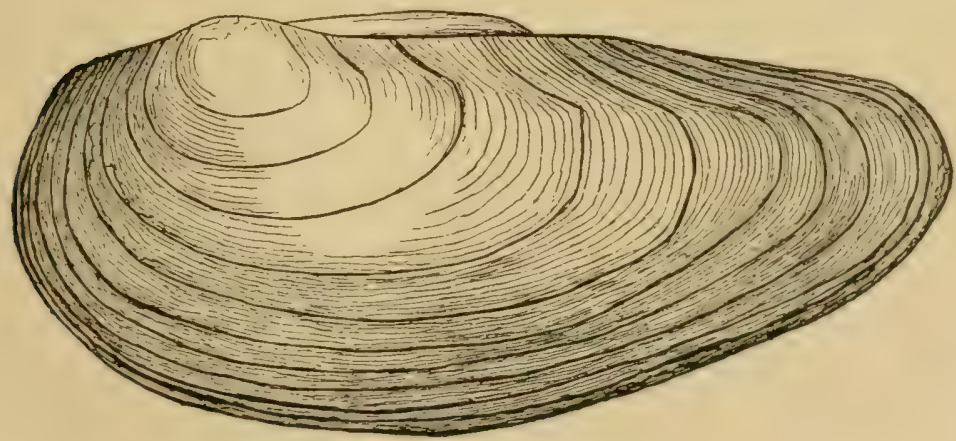

Fig. I7.

Anodonta nutabilis $v$. cellensis Chem.

sclbe durch den Körper zirkulieren und stossen es durch die Atemöffnung am hintern Ende wieder aus. Wenn man eine Muschel rasch aus dem Wasser nimmt, schliesst sie ihre Schalen und das Wasser spritzt dann, oft in ziemlich lebhafter Weise, durch dic Atemöffnung aus. Beim Einblick in helles nicht tiefes Wasser kann man die im Schlamme steckenden Muscheltiere leicht bemerken. Man gewahrt jedoch nur die mit Cirren am hintern Mantelrande 
besetzte Atem- und Analöffnung. Schiebt man vorsichtig ein Rütchen in diese Öfnung, so schliesst das Tier die Schalen, und die Splitze des Rütchens wird mit eingelilemmt. MIit dem Rütchen lässt sich dann die MIuschel aus dem Schlamme ziehen, wenn man dieselbe fangen will. "

Die Muscheln (s. Fig. I 7) heften sich in fliessendem Wasser mit dem ausgestreckten Fusse in den unter der Schlammschicht befindlichen festen Boden. Ihre Bewegungsfähigkeit ist eine sehr geringe, und ihr ruckweise erfolgender Marsch erstreckt sich nur auf I $-2 m$ Länge. Derselbe wird durch Ausstrecken und Einziehen des Fusses bewerkstelligt: bei letzterer Operation wird die Mruschel nachgeschleift, wobei sie in Schlamme eine Furche zurücliässt, an welcher man die Länge und Richtung des Marsches erkennen kann. Die kleineren Muscheln der Familie der Cycladen leben ebenfalls frei beweglich im Schlamme. Nur eine Art unserer Süsswassermuscheln, Drcissena polymorpha, heftet sich durch einen Byssus an andere im Wasser liegende feste Gegenstände an, und wechselt dann ihren Standort nicht mehr bis zu ihrem Tode. Die Muschehn sitzen oft in ganzen Klumpen zusammen und verstupfen beispielsweise leicht Wasserleitungsröhren, wenn sie in selbe gelangen. - Das Festsitzen dieser durch ihre dreieckige Form auffallenden MIuschel ist die Veranlassung zur Verschleppung in die nord- und westeuropäischen Gewässer geworden: Ursprünglich in den Flüssen heimisch, welche ins Schwarze Meer münden, wurde sie durch Schiffe, an deren Planken sie sich angehängt hatte, an die Küsten der Ost- und Nordsee, sowie des Atlantischen NIeeres verschleppt, und gelangte von hier wieder durch Flussschiffe in alle grösseren ins Meer mündenden Flüsse, von welchen sie in deren Nebenflüsse vordrang. Durch den Donau-Main-Kanal war es ihr sogar möglich, die Wasserscheide zwischen Rhein und Donau zu überschreiten und in die obere Donau zu gelangen, wo ich im Jahre 1868 das erste Exemplar fand. Einige Jahre spatter wurde sie bei Deggendorf beobachtet und so wird sie nun sicher die Donau abwärts wandern, bis sie wieder das Schwarze Meer, ihren Ausgangspunkt, erreicht hat. 


\section{Entwickelung und Alter der Mollusken.}

Die meisten Wasserschnecken sind Zwitter; wenigstens die nicht gredeclielten Arten, also insbesondere die Limnaea- (Fig. I S), Planorbis-, Physa-, Ancylus-, Velletia- und Amphipeplea-Arten. Bei Limmaca peregra habe ich mehrfach beobachtet, dass ganze Ketten, 6-8 Individuen, bei der Begattung zusammenhingen. - Bei den Deckelschnecken, wenigstens bei Vivipara, lassen sich männliche und weibliche Formen unterscheiden, ebenso nach Hazay*) bei den Muscheln der Familie der Najaden. Ich halte dies jedoch noch immer für sehr zweifelhaft, bis weitere verlässliche Beobachter und Anatomen dieses Verhältnis bestätigt haben.

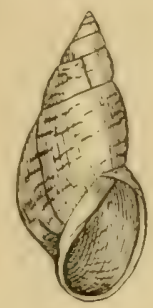

Fig. I8. Lim. palustris v. corvus.

Die Wasserschnecken legen Eier; nur bei den Vivipara-Arten entwickeln sich die jungen Individuen schon im Muttertiere, so dass sie bereits mit einem etwa aus zwei Umgängen bestehenden Gehäuse ausgestossen werden. Auch die Arten der Familie Cycladidea stossen ihre Jungen schon als fertige Muscheln aus.

Die Schnecken und Muscheln sind schon fortpflanzungsfähig lange bevor sie ausgewachsen sind. Die im Mai ausgekrochenen Jungen der Limnaea- und Planorbis-Arten begatten sich noch im selben Herbste, obwohl sie ein Alter von 3-4 Jahren erreichen.

Die Eier werden in Schnüren oder in Paketen an Steinen, WVasserpflanzen oder häufig sogar auf die Gehäuse anderer Individuen derselben Art abgesetzt, so z. B. bei Limmaea ampla. Hazay hat auf den Gehäusen dieser Art 8-I2 Eierschnüre gefunden, so dass das Tier nur mühsam sich fortbewegen konnte. - Liminaea auricularia setzt $20-25 m m$ lange, $7-8 m m$ breite raupenförmige Eierschnüre ab, welche 80 - I 50 Eier enthalten, die kugelrund sind und I $m m$ im Durchmesser haben. Der Eidotter ist weisslichgelb und wird während der Furchung hellweiss. - Limnaea stagnalisvariegata Hazay setzt eine Eierschnur von 45-55 mm Länge

*) ,Mollusken-Fauna von Budapest". Kassel $\mathrm{x} 88 \mathrm{I}$, Theodor Fischer. 
ab, die I IO- I80 Eier enthält; die Eierchen sind länglich-oval und $\mathrm{I}^{1 / 2}-2 m m$ gross. Der Dotter ist strohgelb, das Eiweiss wasserhell; Aplexa hypnorum legt den Laich in ganz flachen rundlichen Scheiben von 4-7 mm Durchmesser und $2 / 3 m m$ Dicke, mit den Enden gegeneinandergeheftet, ab. Die Zahl der Eier wechselt zwischen 20-50. - Planorbis corneus legt ebenfalls eine 25 bis $30 \mathrm{~mm}$ lange, $5 \mathrm{~mm}$ breite, glatte, an den Enden zusammengeheftete Eierschnur ab. Zahl der Eier 45-70.

Die Entwickelung des Embryo beansprucht bei Gen. Limnaea gewöhnlich 20, bei Planorbis und Plyysa nur I5, bei Bythinia 25 Tage. Je nach der Temperatur des Wassers wird der Entwickelungsprozess beschleunigt und verzögert. Hazay hat beobachtet, dass bei Laich der Limnaea palustris var. Clessiniana die Embryonen sich schon in 12 Tagen entwickelten.

Die jungen Tiere wachsen ziemlich rasch und erlangen vier bis sieben Umgänge schon im ersten Jahre, jenachdem sie mehr oder weniger frühzeitig im Iahre als Laich abgesetzt wurden. Das grüsste Wachstum entfallt auf das erste und zweite Jahr und nimmt dasselbe dann von Jahr zu Jahr ab. Im Herbst und Winter erfolgt nicht das geringste Wachstum. Wïhrend der letzten Wachstumsmonate wird der letzte frische Anbau des Gehäuses verdickt und die Mündung verstärlkt.

Die Lebensdauer der Limnäen erstreckt sich im höchsten Falle auf 4-5 Jahre; nur wenige erreichen jedoch dieses Alter. Die Jahre, welche die Mollusken zum Ausbau ihres Gehäuses brauchen, lassen sich an den Jahresabsätzen deutlich erkennen, da diese Tiere gleich den Insekten, Lurchen etc. einen Winterschlaf halten. Schon im Hochsommer wächst das Gehäuse, dessen Weiterhau im Frühjahr sofort nach dem Erwachen aus dem Winterschlafe, meist im Monat April, beginnt, nicht mehr weiter; die Zeit bis zum Eintritt der Winterruhe wird dazu benutzt, die Mündung des Gehäuses durch Allige einer Schmelzsthicht zu verstirlien, dimit dieselbe beim Einbohren in den Schlamm nicht beschidigt wird. Die Jahresabsätze sind daher an den Geháusen, durch die meist nach aussen durchscheinenden Verstärkungsschichten, leicht zu 
erkennen, und lassen sich aus der Zahl dieser Absätze die Jahre, die das Tier bis zur Vollendung des Gehäuses braucht, ablesen. Die Limnäen weisen zwei bis drei solcher Absätze, unter Umständen sogar deren vier, auf. Limnaea peregra hat in der Regel nur drei; ich habe jedoch auch aus höheren Lagen im Gebirge. stammende Gehäuse dieser Art mit vier Jahresabsätzen gefunden, so dass anzunehmen wire, dass die kürzere Sommerperiode hïher gelegener Lokalitäten die Lebensdauer verlängert. - Limnaea auricularia und oi'ata sterben meistens schon im zweiten Jahre ab, Linnaca palustris (Fig. I 8) gewöhnlich im dritten. Planorbis corneus, marginatus und carinatus vollenden ihre Gehäuse im dritten und leben selten länger als $3-3^{1 / 2}$ Jahre; Planorbıs albus, spirorbis und alle kleineren Arten dieses Genus sterben in der Regel schon im zweiten Jahre. Amplippelea glutinosa lebt nur ein Jahr.

Unter allen Wasserschnecken werden die Limnäen am meisten von Schmarotzertieren gequält, so dass die allermeisten derselben meist schon, bevor die Schale ausgewachsen ist, zu Grunde gehen. Hazay sagt hierüber folgendes: Keine einzige der Limnäen, welche das dritte und vierte Lebensjahr erreicht hat, bleibt von denselben verschont; in diesem Alter fallen alle denselben, wie einer allgemein herrschenden Alterskrankheit, zum Opfer. Im zweiten Lebensjahre bereits finden sich einzelne Sporocisten an dem Darm und der Leber als längliche gelbe Schläuche vor, im dritten Lebensjahre sind dies schon massenhafte Schlauchbündel, welche alle inneren Organe bedecken, die ganze Leber erfüllen, langsam Herz und Lungenwand durchsetzen, so dass endlich das Tier absterben muss. Dieser Zustand der Tiere macht sich durch auffallende Trägheit und durch eine starke gelbe Fürbung bemerkbar. Zieht man solche Tiere aus dem Gehäuse, so erscheint unter cler Haut das ganze Innere des Kürpers als grelbe Masse, alle ()rgane sind vin spurucistenbündeln belegt und von der Leber ist keine Spur mehr vorhanden.

Die Vivipara-Arten setzen keinen Laich $\mathrm{ab}$; die Eier entwickeln sich im Muttertiere bis zu Gehäusen von I I mm Lünge und $7 \mathrm{~mm}$ Breite, welche etwa $3^{1 / 2}$ Umgänge zählen (Vivipara lumgarica Hazay, I. c. p. 9I). Die Schalen solch junger Tiere 
haben eine dichte Spiralstreifung und sind die Streifen mit an einander gercihten rundlichen Wärzchen besetzt, ron denen manche kurze Borsten tragen. Hazay fand im Uterus des Weibchens der genannten Art sechsundvierzig schon mit Schale und Binde versehene junge Tierchen und sehr viele Eier in allen Stadien der Entwickelung. - Nach demselben Autor sind die Tiere getrennten Geschlechtes und lassen sich die Geschlechter an der Form der Schale gut unterscheiden. - Die Schalen ausgewachsener Tiere erreichen sieben Umgänge und erlangen dieselben ein Alter von 8-io Jahren.

Die Arten der Familien Valvatidae und Hydrobiidae setzen Laich ab. - Sie erreichen ein Alter von 2-3 Jahren. Neritinaund Lithoglyphus-Arten können nach Hazay ein Alter von 5 Jahren erreichen.

Die Muscheln der Familie der Najaden sind wahrscheinlich Zwitter, obwohl mehrere Autoren männliche und weibliche Formen an den Muscheln (vorzugsweise an der mehr aufgeblasenen Form der Schalen) unterscheiden wollen. $\mathrm{Da}$ nümlich die Kiemen als Brutbehälter für die Eier dienen und strotzend mit denselben gefüllt werden, wird die Muschel schr aufgetrieben, während jene Muscheln, die keine Eier in die Kiemen bringen und aus irgend welchem Grunde vielleicht nicht fortpflanzungsfihig sind, wenig aufgeblasene Schalen behalten. - Die Anodonta- und Unio-Arten produzieren ganz enorme Massen von Eiern, die aus den Ovarien in die Kiemen gelangen und hier die ersten Stadien ihrer Entwickelung durchmachen. Bei Anodonta anatina wurden I20000, bei An. cygnea sogar 400000 Eier gezühlt. Die Einlagerung solch grosser Massen von Eiern kann nicht auf einmal erfolgen. I)ieselben werden allniillich, je nach ihrer Entwickelung, eingeführt und zwar füllen sich die mittleren Fücher der Kiemen zuerst, denen dann die gegen die Enden der Muschel zu gelegenen folgen. In den Kiemen entwickeln sich die Eier zu Larven, wozu sie nach Hazay je nach den Temperaturverhältnissen 2-3 Monate brauchen. - Die Eihülle wird erst gesprengt, wenn sich die eigentumlich erestaltete Laurenschale willwmmen atugehildet hat. Dieselbe 
ist ron dreieckiger Form und besitzt in der Mitte der Bauchseite einen kleinen Hücker (Fig. I9). Ist die Eihülle entfernt, so bilden sich an den Larven Byssusfiden, mit denen sich die in cinem Kiemenfache befindlichen Individuen derart verwickeln, dass sie wie aneinandergeheftet erscheinen. Die zusammenhängenden Larvenklumpen werden vom Muttertiere ausgestossen, und fallen in den Gewässern zu Boden, wo die Byssusfäden der Larven im Wasser flottieren. Die Byssusfäden verfangen sich an langsam über dem Schlamme schwimmenden Fischen, hängen sich an dieselben an, bilden an den Fischen kleine Cysten, in welchen

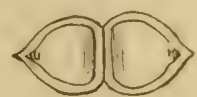

Fig. 19. Junge Muschel von Anodonta zur Zeit, wenn dieselbe aus den Kiemen ausge stossen wird. (Vergrüssert.) sie sich so lange aufhalten, bis die junge Muschel soweit ausgereift ist, dass sie nun ohne Schutz, allein ihre weitere Entwickelung finden kann. Hazay hat an folgenden Fischarten die Cysten von Najaden gefunden: Perca fluviatilis L., Acerina cermua L., Acerina Schractzer L., Cottus gobio L., Squalius cephalus L., Leuciscus virgo Heck., Rhodeus amarus Blain., Tinca vulgaris Cuv., Carassius vulgaris Nils, und Cyprinus carpio L. Die Zeit, während welcher sie als Schmarotzer an Fischen leben, beträgt nach Braun $70-73$ Tage.

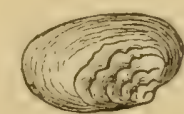

Fig. 20.

Junge Muschel von Unio batavus im ersten Lebensjahre.

Es ist sehr wahrscheinlich, dass die Existenz der Muscheln durch das Vorhandensein von Fischen bedingt ist, da sich in stehenden Wassern, welche keine Fische beherbergen, sich auch keine Najaden finden. - Bei diesem Verhältnisse der beiden so verschiedenen Tierklassen ist es gewiss gerechtfertigt, dass auch die grossen Muscheln den Fischen einen Gegendienst erweisen. ES finden sich nämlich in denselben in der innern Kieme Fischembryonen vor, die hier ihre Entwickelung erfahren. Hazay fand Mitte April bei kiementrächtigen Anodonten (bei fast jedem zweiten der untersuchten Tiere) in den inneren Kiemen 4-8, ebenso bei Unio pictorum 5-I6 Fischembryonen, die möglicherweise von den Muschellarven sich genährt haben. Bei der grossen Anzahl der Eier, welche die Fische absetzen, ist es wahrscheinlich, 
dass diese Fischembryonen nur durch einen glücklichen Zufall zwischen die Kiemen der Muscheln geraten. Es ist leider noch nicht festgestellt, ob gewisse Fischarten nur auf diesem Wege ihre Embryonen-Stadien durchzumachen haben. Hazay hat ferner beobachtet, dass die Fische sich in den Muscheln bis zu voller Ausbildung aufhalten, und dass die jungen Fischehen auserhall) der IIurchel sich ganz nahe der Atemüffnungr der IIuschel halten und durch dieselbe in die Muschel hineinschlüpften.

Die Fortpflanzungsfähigkeit tritt bei Genus Unio im dritten, bei Genus Anodonta im dritten oder vierten Lebensjahre ein.

Die Muscheln erreichen ein verhältnismässig hohes Alter, welches sich auf zehn bis zwölf Jahre erstrecken kann, was sich aus der Zahl der Jahresabsätze leicht erkennen lässt. Die ersten Jahresabsitze sind durch breite Zwischenräume getrennt, die mit fortschreitendem Alter inmer schmiler werden, und ist hei Aluscheln hüheren Alters der Rand der Schalen ein häutiger, während jüngere Muscheln (Fig. 20) scharfe Ränder haben. Häufig verändern dieselben mit zunehmendem Alter ihre Formen derart, dass sie mit der jugendlichen Gestalt nur noch wenig Ähnlichkeit haben.

Die Muscheln, insbesondere die Arten des Genus Anodonta, werden häufig von einer Milbenart geplagt, die auf den Mantelhäuten des Tieres lebt und sich vom Blute der Muschel nährt. Diese Milbe, Limnocharis Anodontae Pfr., kriecht, sich langsam fortschleppend, auf den schlüpfrigen Hiuten des Muscheltieres herum, an welchen sie sich mittels der Krallen an den Füssen und den Spitzen der Palpen festhält. Die Eier befestigt sie an der Mantelhatut und zwar gewönlich dem Hinterteil nüher. C'. I'feiffer fand in einer Muschel 30-50 solcher Tiere. Das Muscheltier wird mager, unfruchtbar und seine Kiemenblätter sind schlaff und befinden sich in einem der Verwesung ahnlichen Zustande.

Die Arten der Cycladeen (Gen. Sphacrium, Calyculina und Pisidium) sind Zwitter und gebüren lebendige Junge, die beim Abstoss aus dem Muttertiere schon eine verhältnismässig betrichtliche Grösse erreicht haben. Die Zahl der Jungen eines Tieres ist deshalb auch eine geringe und wird selten 20 übersteigen. Die 
Calyculinen sind einjährige Tiere, die nur überwintern, wenn sie im Spätsommer ausgestossen werden. Die Sphaerien und Pisidien haben eine Lebensdauer von zwei bis vier Jahren.

\section{Anpassungsfähigkeit der Mollusken.}

Es giebt wohl keine Tierklasse, welche sich mehr an die Beschaffenheit ihrer Wohnorte anzupassen im stande ist, als jene der Mollusken. Die Ursache dieser Erscheinung liegt in der eigenartigen Bildung des Gehäuses, an welches das Tier bei den Schnecken nur durch den Spindelmuskel, bei den Bivalven durch die zwei Schliess- und den Wirbelhaftmuskel gebunden ist. Die älteren Umgänge der ersteren oder die älteren Schichten der letzteren fallen deshalb alsbald den zersetzenden Einflüssen der Umgebung zum Opfer und können nicht mehr nachgebildet werden; dennoch ist die Schale ein unentbehrlicher Teil des Tieres, welcher den weichen Körper desselben gegen die schädigenden Einflüsse der Umgebung schützen muss, und dessen Zertrümmerung den Tod des Tieres zur Folge hat.

Das Gehäuse verändert sich nach den eigenartigen Verhältnissen des Wohnortes bezüglich der Fürbung, Dickschaligkeit, ja sogar bezüglich der Form, und der Kenner wird an den Merkmalen (ler Schalen mit Sicherheit auf die Beschaffenheit der unmittellaren Umgebung schliessen können. Die Schalen werden durch die Ausscheidungen des Mantels gebildet, und zwar wird die Oberhaut nur vom Saume desselben, die Kalk- und Perlmutterschichten aber, welche dieselben widerstandsfähig machen, von den übrigen Teilen desselben ausgeschieden werden. Die Thätigkeit des Mlantels, beziehungsweise die Fühigkeit Kalkteile auszuscheiden, erlischt erst mit dem Tode des Tieres. Die Dickschaligkeit der Gelüuse ist deshalb als Merkmal des Alters zu betrachten. Besonders ist die Schale der Wassermollusken Veränderungen ausgesetzt, und zwar weit mehr als jene der Landmollusken, welche Thatsache ihren Grund in den Eigentümlichkeiten des Mediums, in dem sie leben, nämlich des Wassers, findet. Die chemische Zusammensetzung des 
Wassers gestattet weit grössere Verschiedenheiten, als jene der Luft, und elenso ist die Zusammensetzung des Schlimmes, die Bewathsung der Gewässer u. s. w. weit veränderlicher und steht zu den Wassermollusken in engerem Verhältnis, als die Bodenhesthaffenheit und der Pflanzenwuchs zu den Landconchylien. Es muss deshalb den Wassermollusken ein viel grösserer Spielraum der Variation eingeräumt werden, als den. Landschnecken. Die Schaffung einer Menge neuer Arten von Wasserschnecken und Muscheln, wie sie zurzeit, vorzugsweise von französischen Autoren, beliebt wird, ist deshalb unbedingt zu verwerfen. Wer die Wassermollusken langere Zeit im Freien beobachtet, wird sehr bald zur Überzeugung kommen, dass fast jeder einzelne Fundort derselben eigenartige, mehr oder weniger ausgeprägte Abweichungen vom Typus der bezüglichen Art erzeugt, und dass es geradezu zu den allergrüssten Seltenheiten gehoürt, zwei ziemlich übereinstimmende Formen von verschiedenen Fundorten zu konstatieren. Ja, sogar derselbe Fundort erzeugt bei geänderten Verhältnissen andere Varietäten, und oft genug finden sich verschiedene Formen ein und derselben Art an sich perührenden Stellen desselben Gewàssers, wenn die Beschaffenheit des Grundes, die Strömung des Wassers, die Bewachsung u. s. w. sich ändert. So kommen in den grossen Seen der Voralpen Schnecken und Muscheln mit ausgeprägtem Seecharakter und solche, welche nicht oder kaum von jenen $\mathrm{zu}$ unterscheiden sind, die in Sümpfen leben, neben einander vor, und zwar jenachdem die bezüglichen Wohnplaitze bei seichtem Wasser und mangelnder Bewachsung der vollen Wirling des Wedlenschliges ausgesetzt sind, oder die Ufer in sumpfige Stellen übergehen.

Manche Arten ziehen fliessendes, andere stehendes Wasser vor; nur wenige Spezies jedoch bewohnen ausschliesslich das eine oder das andere, obwohl hie und da auch einmal eine Art sich an ihr nicht zusagenden Stellen halten kann. Velletia lacustris ist eine nur in stehenden, sumpfigen Gew'issern sich aufhaltende Spezies; dennoch habe ich sie in einem kleinen Bächlein bei Jettingen im Mindelthal (Bayem) mit. Incylus fluitulitis zusammen an Steinen sitzend gefunden. Allerdings war dieses Büchlein aus 
kleinen sumprigen Pfützen, welche durch kurze Strecken raschtliesind1den Wassers mit steinigen Grunde verbunden war, zusammengecetzt.

Die Veründerlichkeit der Schalen ist bei den Wassermollusken eine sehr beträchtliche. Als Beispiel für dieselbe möge Limnaea stagnalis (Fig. 2 $\mathrm{x}$ ) herausgegriffen werden. Diese Art findet sich als i'ar. subulata West. in sehr schlanker Form, mit langem, spitzem Gewinde und wenig erweitertem letzten Umgange; als var.producta Colb. (Fig. 22) mit ähnlichem Gewinde, aber sehr aufgeblasener letzter Mündung. Beide Varietäten finden sich in wenig mit Wasserpflanzen durchwachsenen Altwassern oder Weihern mit nicht sumpfigem Boden. In stark mit Wasserpflanzen besetzten stehenden Wassern, welche mehr mit

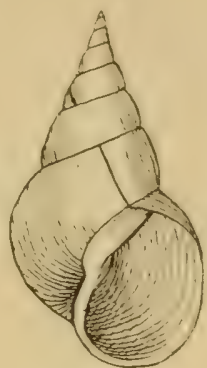

Fig. 2I.

Limmaea stagnalis Typ.

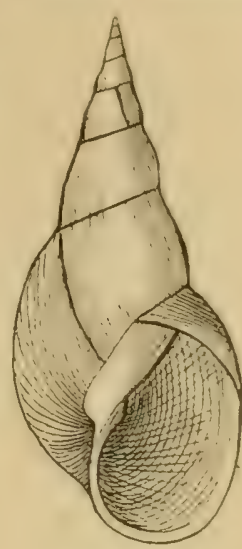

Fig. 22 ,

Limmaea stagnalïs $v$. producta Colb.

taulenden Pflanzenstoffen gemischten Schlamm am Grunde haben, bilden sich Formen mit kürzerem Gewinde und aufgeblasenem letzten Umgange: var. tur gida Mke. (Fig. 24), roseolabiata Wolf, und ist bei dieser Varietät die Spindel meist rosenrot gefärbt. Ähnlich gestaltet ist var. borealis Brgt. (Fig. 23), nur nehmen die Umgänge rascher an Breite $\mathrm{zu}$ und ist deshalb das Gewinde weniger spitz ausgezogen. Gehäuse mit sehr verkürztem Gewinde und starker Schale (var. lacustris, Fig. 26

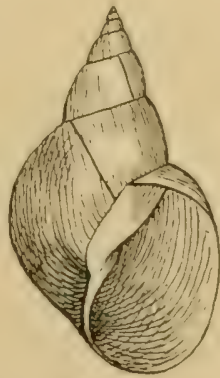

Fig. 23. Limnaer stagnalis v. borealis Brgt.

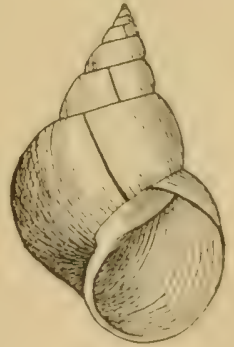

Fig. 24 . Limraea stagnalis v. tursita Mke.

S. I40) finden sich an den Ufern der grossen Seen, wo die Tiere, dem Wrellenschlarge ausgesetzt, sich an den Steinen oder im Benlen 
festllammern müssen, und wo ihnen in der Nahrung sehr viel Kalk geboten wird. Zwischen diesen Varietäten finden sich Zwischenformen aller Art, so dass sich fast eine fortlaufende Reihe allmählicher Ulergainge zwishen den extremsten Fomen herstellen lisist. Gerät L. stagnalis bei Hochwasser. in des Pflanzenwuchses ent-

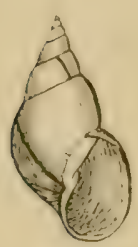

Fig. 25.

Limn. stagnalis \%, arenaria Colb.

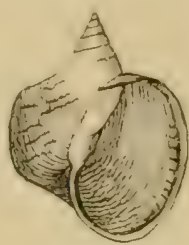

Fig. 26. Limn. stagnalis V. Lacustris Stud. behrende Lachen am Ufer grosser Flüsse, so bilden sich sogenannte "Hungerformen"; die Tiere verkümmern, wachsen langsam und nehmen deshalb die Umgänge gleichförmiger zu; als solche Hungerformen mögen var. arenaria Colb. (Fig. 25) und var. aquarii Colb. gelten.

Ähnlich wie $L$. stagnalis verhalten sich die übrigen Arten des Genus; ja es haben sich aus Limnaca atricularia $\mathrm{G}$. im Laufe der Jahre in den Seen sogar eigenartige festschalige Arten (Limm. tumida Held [Fig. 27] und Limn. rosea Gall.) ausgebildet,

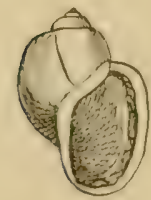
welche für ihre Wohnorte charakteristisch geworden sind, und welche durch die Unregelmässigkeit ihrer Formen sozusagen die Eigentümlichkeiten ihrer Wohnorte dokumentieren. Limnaca peregra, welche sich auch in fliessenden Wassern findet, ist die formenreichste aller Arten ihres Genus, weil sie cben in beiden Gattungen unserer Gewësser rorkommt.

Die Planorbis-Arten mit ihrer flachen, tellerförmigen Schale, die sehr leicht Verwerfungen der Windungsebene ausgesetzt sind, finden sich nahezu ausschliesslich in mit Wasserpflanzen durchwachsenen stehenden Wassern, wo sic an den Stengeln und Blättern der Pflanzen herumkriechen. Die ver-

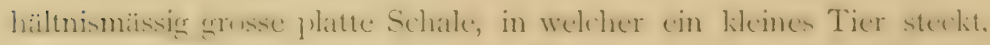
bietet den Fluten eine zu grosse Flïche dar, die denselben zu leicht zum Opfer fallen und an Orte transportiert werden würde, wo sie nicht die ihrer Organisation entsprechenden Verhailtnisse 
findet. Deshalb fehlen in den grossen Alpenseen alle Arten mit Ausnahme von Plan. albıs, welche nur vier, höchstens fünf Umgänge erreicht. Wie hart übrigens der Kampf ums Dasein sich für diese Art gestaltet, beweist die Verwerfung der Umgänge, welche bei ihr in den Seen zur Regel wird (Plan. deformis Hartm.).

Aber auch an anderen Arten des Genus finden sich zuweilen Verwerfungen der Schalenfläche in grosser Zahl. Ich habe einmal Plan. contortus L. in einer ausgetrockneten Pfütze fast durchaus mit verkrüppelter Schale gesammelt. Die Tiere hatten sich beim Verschwinden des Wassers in den Boden eingewühlt und sich hier so lange lebend erhalten, bis sich die Pfütze wieder mit Wasser füllte, und die Tiere wieder aus ihren Schlupfwinkeln hervorkriechen konnten. Beim Verkriechen in den Schlamm wurden die noch weichen, in der Bildung begriffenen Ansätze der Umgänge beschädigt und aus ihrer normalen Lage gedrängt und dadurch wurde die Fläche des Gehz̈uses uneben und die Gewinde verschoben sich.

Der interessanteste Fall von massenhaften Gehäuseverkrüppelungen der sonderbarsten Art wurde von Prof. Piré in Magné (Belgien) beobachtet. Hier fand sich in einem kleinen Teiche massenhaft Plan. marginatus Drap. (Fig. 28) vor. Die ganze Oberfläche des Teiches war aber mit Wasserlinsen, bedeckt, die einen dichten Filz bildeten. Die Tiere mussten sich durch denselben durchwinden, um an die Oberfläche zu kommen und um dort Luft zu atmen. Beim

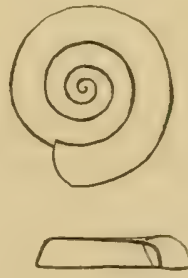

Fig. 28 Planorbismarginatus Drap.

Durchwinden durch den Linsenfilz wurden aber die weichen, neugebildeten Umgänge abgestreift und aus der normalen Windungsebene gedrängt, und es bildeten sich nicht nur kegelförmige Gehäuse, sondern auch solche, bei

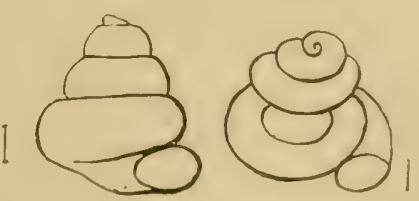

Fig. 29.

Planorbis marginatus (abnorme Gehäuse). welchen die Umgänge nach ganz verschiedenen Richtungen gedrängt wurden, und welche die sonderbarsten unregelmässigsten Formen 
annahmen (Fig. 29). In Linsenfilzen, welche in einem Kübel mitgenommen wurden, fanden sich am anderen Niorgen alle normal gewumlenen Exemplare tot am Boden kes Fülels liegend. wähend die skalariden und abnorm gestalteten munter an der Oberfläche des Wassers herumkrochen.

Da die Arten des Genus Planorbis bezüglich ihrer Wohnorte auf einen engeren Kreis beschränkt sind, ist die Formveranderlichkeit der einzelnen Arten auch bei weitem keine so grosse, als bei den Limnaea-Arten, nur Plan. corneıs macht in dieser Beziehung eine Ausnahme.

Ganz besonders für flutendes Wasser gebaut sind: Die AncylusArten, die durch den breiten Fuss, mit dem sie sich an Steine u. s. w. anklammern kïnnen, und die mützenfömige schate den Willen am leichtesten Widerstand leisten können; ferner die Neritina-Spezies, die mit weiter Mündung und dem wenig hervortretenden Gewinde von cler Natur zum Aufenthalt im flutenden Wasser besonclers ausgestattet wurden. - Die Fürbung und Zeichnung der Oberfläche der Neritina-Arten wechselt sehr mannigfaltig nach der Beschaffenheit des Wassers; doch liegen nuch keine genatueren beobachtungen in dieser Richtung vor.

Die grösste Anpassungsfahigkeit besitzen die Muscheln der Familie der Najaden. Jeder Fundort derselben hat bezüglich der chemischen Zusammensetzung des Wassers, des Schlammes und des Bodens, in dem die Muscheln stecken, der physikalischen Verhältnisse des Wassers u. s. w. eine unbeschränkte Zahl von Eigentümlichlieiten, welche die Schalenhildung lecinflussen und an derselben ihren Ausdruck finden. Selbst an cinander stossende Fundorte erzeugen ganz verschiedene Formen, jenachdem der Ioden steinig oder schlammig, jenathdem der schlamm ein erdiger uder humusreicher ist. Werden, wie es in grïsseren Flüssen häufig worlommt, durch Hochfluten IIuscheln aus Altwassern oder Abschnitten mit stehendem Wasser in das Flussbett versetzt, so entstehen notwendigerweise Mischformen. Leider werden diese Verhältnisse viel zu wenig beachtet; gewühnlich werden nur neue Varietåten beschrieben, ohne dass man den Umstanden nachforscht, welche 
dieselben veranlasst haben. In den Beiträgen zur MIolluskenfauna der bayrischen Seen (Corresp)-Blatt zoolog.-mineral. T'er. Regensburg I 873-75) habe ich den Versuch gemacht, die eigenartigen Formen der Seemuschehn aus der Eeschaffenheit ihrer Wohnorte zu erkiären, aber ich habe bisher wenig Nachfolger gefunden.

Im allgemeinen ziehen die Anodonta-Arten stehende Gewässer vor. Nur in diesen finden sie ihre volle Entwickelung (als var. cygnea L.). - In fliessenden Wassern findet sich meist nur die kleine, gewissermassen verkümmerte Varietät var. anatina L., welche durch schmale Jahresansätze, dunkle Färbung der Oberhaut u. s. w. charakterisiert ist. Die grösste Form, var. cygnea L., findet sich in Weihem mit erdig-schlammigem Boden. Diese Varietät zeichnet sich durch rundlich-eiförmige Gestalt, durch die feste Schale, die lebhaft gefürbte Epidermis und reines glänzendes Perlmutter aus; sie erreicht bis I $90 \mathrm{~mm}$ Länge. Anodonta rostrata Kok. ist die Varietät, welche sich in Altwassern mit tiefem Humusschlamm am Grunde bildet. Die Muscheln haben eine verlängerte Gestalt mit breitem abgestutzten Hinterteile, eine meist dunkle Färbung der Epidermis und mehr oder weniger fettfleckiges Perlmutter. Bei zunehmender Versumpfung der Altwasser werden die Muscheln dünnschaliger, die Wirbel werden kariös, von Insekten angebohrt, das Perlmutter wird noch schmutziger, die Tiere verlieren die Fähigkeit sich fortzupflanzen, und sterben deshalb bald an dem betreffenden 'Wohnorte völlig aus. Ich suche "den Grund dieser Erscheinung in der Überhandnahme der Humussäure im Bodenschlamm. Auch mit zunehmendem Alter verändern die Anodonten ihre Umrissform. Die jungren MIuscheln haben in der Regel mehr eine rundliche Gestalt und scharf hervortretendes Schild und Schildchen. Später wird dieselbe lïnglicher, die vortretenden Ecken verschwinden und es bilden sich die Varietäten: cellensis, rostrata, ponderosa und anatina. Nur in Flüssen erhält sich zuweilen die rundlicheiförmige Gestalt var. piscinalis Nils. länger, wenn auch hier die Ecken des Schildes und Schildchens mehr zurücktreten.

Die bisher aufgeführten Varietäten haben eine sehr ausgedehnte Verbreitung, so dass man sie fast mehr als Standorts-Formen, denn 
als Varietäten betrachten könnte, da sie sich in mehr oder weniger übereinstimmender Weise überall entwickeln, wo sie die ihre Form bedingenden Verhailtnisse finden. Die grussen Alpen- und Vuralpenseen der bayrischen Hochebene und der Schweiz erzeugen dagegen, ihren eigentümlichen physikalischen Verhältnissen u. s. w. entsprechend, eigenartige Formen, von denen sogar fast jeder See eine oder mehrere ihm eigentümliche Varietïten enthält. Die Seevarietäten erreichen meist nur eine geringe Grösse, haben hellgefirlute Epidermis, starle Schale, reines Perlmutter und ist meistens das Vorderteil durch dicke Ablagerungen der Perlmutterschicht ausgezeichnet. Dieselben bilden sich aber gewöhnlich nur an solchen Stellen der Ufer, die bei seichtem Wasser und mangelnder Bewachsung der wollen Wirkung des Wigenschlages ausgesetzt sind. Hier kann sich leine tiefere Schlammschicht, die den Muscheln Schut\% gewihrt, anhäufen und werden deshalb dieselben oft genug von den Wellen mit lebendem Tiere aufs Trockene geworfen, wo sie verschmachten und Vögeln zur Beute fallen. Ich möchte als Beispiel einer solchen Seemuschel hier nur An. callosa aus dem Chiemsee erwähnen, da die Aufzủhlung aller mir aus den verschiedenen Seen bekannt gewordenen zu weit führen würde.

Auch die Arten des Genus Unio nehmen in den Seen besondere Formen an. Ich habe beobachtet, dass die Muscheln von Unio

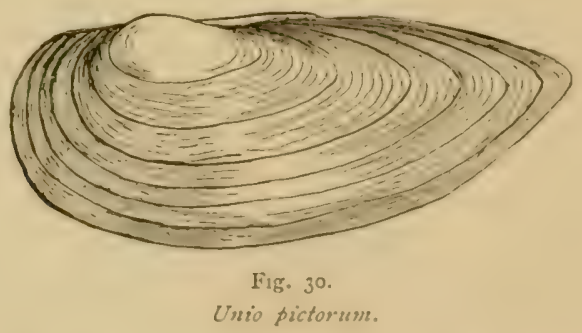

pictorum (Fig. 30) und batavus, wenn sie im tieferen Wasser in einer hohen Schlammschicht sich aufhalten, ein sehr verlängertes I Iinterteil erhalten, weil sich dieschlen im festen Boden festlikmmern, dabei aber mit dem Hinterteile aus dem Schlamme hervorzuragen 
suchen, um die Atemröhre freizuhalten. Das Hinterteil wird dadurch bei fortwährendem Strecken des Tieres verlängert, und krümmt sich dabei oft mehr oder weniger nach abwärts, so dass die Muschel eine etwas hakenförmige Gestalt annimmt, wie es bei Unio arca Held aus dem Chiemsee und Unio platyrhynchus Rossm. (Fig. 3I) aus dem Wörthsee der Fall ist. Merkwürdigerweise kommt in den bayrischen, Schweizer und wahrscheinlich auch in den oberösterreichischen Seen nur L'nio pictornun vor, während Unio bataüus

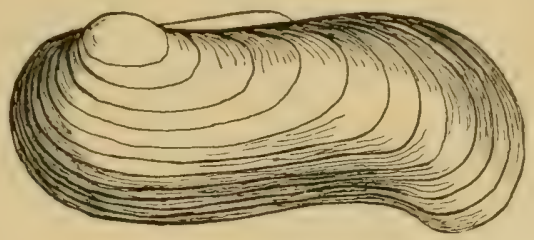

Fig. 3x.

Unio platyrhynchus Rossm.

in denselben fehlt, obwohl diese letztere Art in den zufliessenden Bächen reichlich vorhanden ist. In den Schweizer Juraseen findet sich Uno tumidus, die in allen im Alpengebiete liegenden grossen Wasserbecken nicht vorkommt. Unio batavus dagegen ist auf die Kärntner- und Juraseen beschränkt.

\section{Die Mollusken der Tiefenfauna.}

Den Untersuchungen Dr. Forels*), welcher die Tiefenfauna der grossen Schweizer Seen untersucht hat, verdanken wir die Kenntnis, dass auch die Klasse der Mollusken zu derselben ihr Kontingent stellt, und dass sich auch in den grössten Tiefen derselben noch einzelne Arten von Schnecken und Muscheln aufhalten. Unter den ersteren sind sogar Lungenatmer des Genus Limnaea, welche im seichten Wasser bei heiterem, warmem

*) Matériaux pour servir à l'étude de la Faune profonde du lac Léman. Lausanne I874.

Tier- und Pflanzenwelt des Süsswassers. II. 
Wetter die Gewohnheit haben, an die Oberfliche des Wassers aufzusteigen, was aus einer Tiefe von $2-300 m$ zur Unmöglichkeit wird.

Dr. Forel teilt die Fauna der Seen in drei Abteilungen:

I. Die Uferfauna; sie umfasst die Tiere, welche sich an der Oberflache des Wassers und in einer Tiefe bis zu $5 \mathrm{~m}$ aufhalten.

2. Die pelagische Fauna, welche jene Tiere umfasst, die entfernt von den Ufern oder untergetaucht im Wasser leben.

3. Die Tiefenfauna, welche den Seeboden von $25-30 \mathrm{~m}$ an abwärts bewohnt.

Die Uferfauna enthält Arten aller Genera unserer heimischen Süsswasserconchylien, welche unter Cmstünden eigenartige Varictïten bilden, die wir in vorhergehenden Abschnitten schon erwähnt haben. Die pelagische Fauna entbehrt der MIollusken. Die Tiefenfauna dagegen besitzt noch einige Arten der Genera Limnaca, Tripara, Valvata und Pisidium, die ich sümtlich, soweit sie mir bis jetzt bekamnt wurden, in meiner ,..MIolluskenfauna von Österreich-Lngarn und der Schweiz" S. 768-79I beschrieben habe.

Die eigentümlichen Verhältnisse am Seeboden, geringe Temperatur des Wassers (wenig um $4^{\circ}$ C. schwankend), der grosse Druck der Wassersitule, die sehr spärliche Nahrung, welche ihnen der Schlamm des Seebodens bietet, geten die Veranlassung, dass die in so grossen Tiefen lebenden Conchylien nur kleine, verkümmerte, unscheinbare Arten sind, die sich naturgemäss ron den Arten der Uferfauna abgezweigt haben müssen. Diese Tiefseemollusken führen ein kümmerliches Dasein. Da die Temperatur des Wassers das ganze Jahr über eine sehr gleichförmige ist und der Wechsel der Jahreszeiten das geringe Wachstum der Schalen nicht unterbricht, fehlen die Marken der Jahresabsitze; die Epidermis ist sehr dünn und stösst sich, trotz der fast völligen Ruhe des Wassers, leicht ab; die Muscheln bleiben dünnschalig und leichtzerbrerhlich. Eine Art I'isidium fragillinum Cless. aus dem Sillaiplaner See besitzt eine so dünne Schale, dass jede Berührung an 
derselben einen Eindruck zurückliisst. Jeder der bisher untersuchten Seen beherbergt wenigstens eine eigentümliche Art des Genus Pisidiun. Limnäen wurden nur im Genfersee beobachtet; Vivifara (eine Art) findet sich im Gardasee; Valvata-Arten (drei) gehören nur der Tiefseefauna des Genfer- und des Gardasees an.

\section{Höhlen-Mollusken.}

In den Kalkgebirgen, vorzugstweise in den Juraformationen, finden sich ausgedehnte Höhlen, in denen Bäche und im Karstgebiete sogar Flüsschen auf weite Strecken unterirdisch dahinfliessen. Es ist selbstverständlich sehr schwierig, diese unterirdischen Wasserläufe auf ihre Fauna zu untersuchen; gewöhnlich sind die in denselben lebenden Mollusken nur in leeren Gehäusen im Geniste oberirdischer Bäche und Flüsse zu bekommen. Nur in seltenen Fällen ist es geglückt, lebende Tiere zu erbeuten, welche sämtlich einem für die Höhlenfauna eigentümlichen Genus Vitrella Cless. (Fig. 32), Bythiospeum Brgt., angehören. Die Untersuchungen derselben durch Wiedersheim*) und Rougemont**) haben ergeben, dass diese Höhlen-Mollusken blind sind, ebenso wie die Tiere anderer Tierklassen, welche die gleichen Aufenthaltsorte bewohnen. Die Tiere, welche seit vielen Generationen nur im Dunkeln leben, haben die Augen

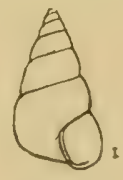

Fig. 32. Vitrella pellucida. nicht mehr nötig. Rougemont hat lebende Tiere der Vitrella (Rougemonti Cless.) aus dem Brunnen des Anatomiegebäudes in München heraufgepumpt, welche gleichfalls augenlos waren.

Die unterirdischen Wasserläufe werden fast ausschliesslich von Vitrella-Arten bewohnt, von denen jeder derselben eine ihm eigentümliche Art zu besitzen scheint. Ausser diesen kleinen, zierlichen, am meisten an das Genus Hy'drobia crinnernden Deckelschnecken fand sich in der Uracher Höhle (schwibische Alp in Württemberg)

*) Beiträge zur Kenntnis der württ. Hühlenfauna.

**) Etudes des faunes des eaux privées de lumičre. 
eine Ancylus-Art, Ancylus fluitatilis, und in Krainer Höhlen einige Valvata-Spezies. Diese Arten sind lileine, verkümmerte Formen mit dünner, farbloser Schale und geben dieselben somit wieder ein merkwürdiges Beispiel von der Anpassungsfihigkeit der Mollusken.

\section{Die Perlenmuschel.}

Die kalkarmen Bäche unserer Urgebirgsformationen beherbergen eine grosse und sehr diclischalige. Iuschel, Margaritana margaritifere (Fig. 33), welche einen sehr wertrollen Schmuck, nämlich die Perlen,

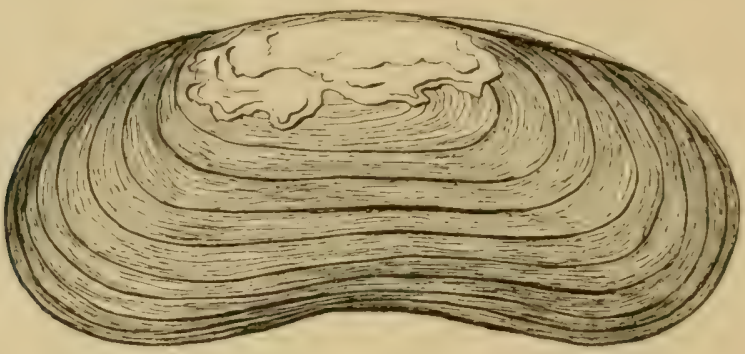

Fig. 33 .

Margaritana margaritifera.

liefert. Die Muscheln stecken oft in sehr grosser Anzahl in sandigen Stellen so völlig im Sande eingesenkt, dass nur an den flottierenden Cirren der Atemöffnung sich das Vorhandensein der MIuscheln erkennen lässt.

Die Perlenmuscheln haben in ausgewachsenem Zustande eine nierenförmige Gestalt und erreichen eine Lünge von $120 \mathrm{~mm}$. Sie haben eine dunkle, fast schwarze Oberhaut, sind in der Regel um die Wirbel stark zerfressen und ihr Perlmutter ist gewönnlich durch schmutzig-gelbe Fettflecken verunziert.

Die Erzeugung von Perlen vollzieht sich in dem Raume zwischen Mantel und Schale und muss die Perle hier frei beweglich bleiben, so dass sie ständig in rollender Bewegung erhalten wird. Eine Perle bildet sich nur dann, wenn ein kleiner fremder 
Körper, ein Sandkörnchen, ein Stückchen eines abgestorbenen Schmarotzertieres u. s. w. an die enwähnte Stelle gerät. Der Druck, welchen dieser fremde Körper auf die äussere Mantelfäche ausübt, veranlasst eine stürkere Ausscheidung des Perlmutterstoffes, welcher sich in Schichten um denselben legt und allmählich den fremden Körper umhüllt. Die Entstehung der Perlen ist also gewissermassen eine zufällige, und deshalb liommt nach Beobachtungen aus den bayrischen Perlenbächen auf etwa 95-100 Muscheln nur eine Perle. Aber nicht einmal alle Perlen sind brauchbar und wertvoll, sondern nur jene, welche weisse Farbe und schönen Glanz haben. Man unterscheidet drei Klassen brauchbarer Perlen und zwar I. Klasse: ganz helle, weisse Perlen von schönstem Glanze; 2. Klasse: weisse Perlen von minder vollkommenem Glanze; 3. Klasse: sogenannte Sandperlen, welche noch so viel Glanz und weisse Farbe besitzen, um verwertet werden zu können. Eine gute Perle ersten Ranges kommt nach v. Hessling*) auf 270r, eine Perle mittlerer Qualität auf 22I5 und eine schlechter Qualität auf IO3 Muscheln. Ausser diesen weissen Perlen finden sich aber auch, und in grösserer Häufigkeit als diese, solche von brauner und von schwarzer Farbe. Zusammengesetzte Perlen von Stübchenform sind sogar häufig zur Hälfte braun, zur anderen Hälfte schwarz gefürbt. Die dunklen Perlen werden als "unreif" bezeichnet, obwohl diese Benennung durchaus nicht zutreffend ist, weil auch grosse Perlen die dunkle Farbe behalten. Die Ursache dieser Erscheinung ist jedenfalls in der Nahrung der Tiere zu suchen, welche ja auch das fettfleckige, unreine Perlmutter der Schalen erzeugt. Die aus der Urgebirgsformation kommenden Gewässer haben in der Regel eine dunkle Färbung, welche durch eine starke Beimischung von Humussäure erzeugt wird, und dieses die Bildung wertvoller Perlen sehr beeinträchtigende Verhältnis wird sich wohl nicht beseitigen lassen.

Versuche, um auf künstlichem Wege Perlen zu erzeugen, beziehungsweise durch Einschieben kleiner Kügelchen u. s. w.

*) Theod. จ. Hessling: „Die Perlmuscheln und ibre Perlen". Leipzig I859. Ich bin im ganzen den Ausfübrungen dieses $\Lambda$ utors gefolgt. 
zwischen Mantel und Schale das Tier zur Perlenbildung zu veranlassen, haben keine günstigen Resultate ergeben.

Die Ernte der Perlenbäche gilt in Deutschland durchaus als Staats-Regal; sie wird aber gewöhnlich an Private verpachtet, welche das Fischen und die Behandlung der Muscheln ohne jede Kenntnis der Eigentümlichkeiten derselben betreiben und dadurch den Bestand an Perltieren arg schädigen. 


\section{Die deutschen Süsswasserfische}

\section{und ihre Lebensverhältnisse.}

Von Dr. A. Seligo in Heiligenbrunn bei Danzig. 

Herrscher im Wasser ist der Fisch. Es giebt kaum irgend einen Wasserorganismus, der ihm nicht direkt oder indirekt Nutzen bieten muss. Das Wasser ist auch ausschliesslich das Element, in welchem die Fische dauernd zu leben vermögen. Zwar können nicht wenige Fische ausserhalb des Wassers eine mehr oder minder kurze Zeit am Leben bleiben, - es giebt, besonders in den Tropen, sogar Fischarten, welche freiwillig an das Land gehen*), - aber auch in diesen Fällen kann das Luftmeer nur vorübergehend mit dem Wasser vertauscht werden, und die Fische müssten zu Grunde gehen, wenn man ihnen die zeitweilige Rückkehr in das Wasser verwehrte.

Ist das Vorhandensein des Wassers die erste Lebensbedingung des Fisches, so ist in zweiter Linie die Beschaffenheit des Wassers in Betracht zu ziehen. In dieser Beziehung sind namentlich die mittlere Wärme des Wassers, sein Luftgehalt und sein Gehalt an anderen gelösten Stoffen für die Arten der Fische als Lebensbedingungen massgebend.

Das natürliche Wasser kommt auf der Erdoberfläche nirgends in chemischer Reinheit vor. Der grösste Teil des irdischen Wassers, das Meerwasser, enthält bekanntlich etwa $3.5 \%$ an Kochsalz und zahlreichen anderen Salzen in Lösung. Da die meisten Fischarten des .Ieeres im süssen Wasser bald sterben, anderscits die Sürswatsser-

*) 2. B. dic Labyrinthfische und Salarias scandens Ehrenberg. 
151 Die deutschen Süsswasserfische und ihre Lebensverhältnisse.

fische im Meerwasser meist nicht lange aushalten, so scheidet die Stiirlie des Salzgehaltes im Wasser, dessen die Fischarten bedürfen, diese in Süsswasserfische und Meerfische.

Eine Anzahl von Fischarten ist allerdings im stande, von Zeit zu Zeit den Aufenthalt in der einen Wasserart mit dem in der andern zu vertauschen. Diese als Wanderfische bezeichneten Arten folgen bei dem Wechsel ihres Lebenselementes dem maichtigen Fortpflanzungstriebe.

Das süsse Wasser enthält in der Regel noch 0.004 bis $0.02 \%$ Salze, meist Kalksalze, in Lïsung. Bringt man die Fische in ganz salzfreies destilliertes (wenn auch lufthaltiges) Wasser, so tritt der Toul in wenigen Stunden ein, indem die Gewebe der vom Wasser direkt bespülten Organe, namentlich der Kiemen, quellen und funktionsunfähig werden 1). Eine geringe Nenge im Wasser gelüster Salze ist also für das Leben auch der Süsswasserfische nötig, welche den ausschliesslichen Gegenstand dieser Schilderung bilden werden.

Der unbeschränkten Ausbreitung der Süsswasserfische stehen im allgemeinen die Grenzen der von ihnen bewohnten Gewässer, nämlich das feste Land und das Meer, entgegen. Das letztere wird nicht nur von den eigentlichen Wanderfischen, sondern auch von einigen anderen Arten, welche gegen den Salzgehalt minder empfindlich sind, gelegentlich passiert ") und dient daher ausuahmsweise zur Verbreitung solcher Arten 2). Auch das Land, welches die Flusssysteme trennt, ist keine absulute Schranke für die Fische. Die Ubertragung der Fischeier durch Wrasservïgel und Landtiere, Überschwemmungen niedriger Teile der Wasserscheiden, unter Umstiunden auch dauemde geologische Veränderungen der letzteren crmöglichen die Verbreitung der Fischarten aus einem Flusssystem in ein benachbartes. Hierzu kommen die allmihlichen Veränderungen, welchen die Konturen des Festlandes im Laufe der geologischen Perinden unterworfen sind und welche die weitliufige Trennung von

*) Es kommt auch vor, dass cinzelne Seefische, welche den Aufenthalt im Süsswasser vertragen, sich gelegentlich in die Ströme verirren und in diesen weit aufwärts schwimmen, z. B. die Flunder, die Lamprete. Indessen sind diese Fische nicht zur Süsswasserfauna zu rechnen, vielmehr als Meerfische zu betrachten. 
ursprünglich eng verbundenen Landmassen bewirken, während sie anderseits Lünder, die von einander entfernt gelegen haben, durch Landbrücken mit einander verbinden können. Dies sind die Umstände, welche die Verbreitung der Fischarten des süssen Wassers herbeizuführen pflegen.

Das Gebiet, mit dessen Süsswasserfischen wir uns hier zu beschäftigen haben ${ }^{3}$ ), möge so begrenzt sein, dass es die Flusssysteme, welche vom Rhein bis zur Memel an den Südküsten der Nord- und Ostsee münden, sowie das Donaugebiet4) umfasst. Ausserhalb des so umschriebenen Gebietes liegt von deutschen Ländern nur der zum Etschgebiet gehörige Teil von Tirol 5). Das so umgrenzte deutsche Fischgebiet gehört bezüglich seiner Fischarten dem europäisch-nordasiatischen Gebiete an, liegt also nach Sclaters ${ }^{6}$ ) zoogeographischer Einteilung in der paläarktischen Region. Unter den Fischarten des Gebietes sind daher am stärksten vertreten die Familien der in dieser Region so verbreiteten Cypriniden und Salmoniden.

Der Ursprung dieser Familien ist ein fast entgegengesetzter zu nennen. Die Cypriniden bilden etwa ein Dritteil aller bekannten Süsswasserfische der Gegenwart. Günther 7) nimmt an, dass sie ihren Ursprung in der Alpenregion genommen haben, welche die gemässigten und tropischen Teile Asiens scheidet. Von hier breiteten sie sich nach Norden und Süden, nach Osten und Westen aus. Australien nebst Celebes und die übrigen ozeanischen Inseln, sowie Südamerika wurden von ihnen nicht erreicht. In der Gegend unseres Gebietes fanden sie sich schon in der Tertiärzeit vor. Die Salmoniden dagegen scheinen ihren Ursprung im kalten Norden genommen und während der Eiszeit sich in einzelnen Vertretern weit nach Süden verbreitet $z u$ haben. Die meisten Arten finden sich auch jetzt in den nördlichen Teilen unserer Hemisphäre und auch die Arten unseres Gebietes beschränken sich fast durchgehends auf kühle Gegenden der Gewïsser.

Nicht gering an Zahl sind in unserem Gebiet auch die Vertreter der Familie der Perciden. Diese Familie ist weit verbreitet im Süsswasser und in den Meerküstengegenden aller 
Regionen. Ihre Reste findet man in den Ablagerungen seit der Terticirzeit.

Die Zahl der im Gebiet vertretenen Familien der Fische beträgt vierzehn, aus ihnen gehören hierher vierzig Gattungen mit siebzig bis achtzig Arten. Die übenwiegende Zahl gehört, wie überall im Süsswasser, zu den Knochenfischen.

Aus der Familie der Perciden kommen vor die Gattungen der Barsche, Zander, Streber und Kaulbarsche. Der Flussbarsch (Perca fluviatilis L.)*) ist nicht nur durch das ganze Gebiet verbreitet, sondern findet sich durch ganz Europa, Nordasien und Nordamerika. Er ist bei uns einer der gemeinsten Fische, und fehlt kaum in irgend einem Tümpel. Der Zander oder Schill (Lucioperca sandra C.) ist ein östlicher Fisch, welcher sich von Osteuropa aus nach Westen verbreitet zu haben scheint. Er findet sich ursprünglich nicht im Rheingebiet und im Gebiet der Weser. Obwohl er in den Seen, in denen er vorkommt, vortrefflich wächst und daher durchaus nicht als ausschliesslicher Flussfisch bezeichnet werden kann, so findet man ihn doch in zahlreichen von den von ihm bewohnten Hauptströmen weit abgelegenen Seen desselben Flussgebietes nicht, was darauf schliessen lïsst, dass seine Ausbreitung spat nach dem Ende der Eiszeit, wenn auch während des Bestehens der Verbindung zwischen Elbe, Oder und Weichsel erfolgt ist. Eine nahe verwandte Art ist L. volgensis Pall., die sich in der Donau und ihren grossen ungarischen Nebenflüssen, suwie in den ülrigen Flüssen des pontischkaspischen Gebietes findet. Ganz auf die Donau, bezw. auf das pontische Gebiet beschränken sich die Arten der Streber (Aspro singel C. und A. streber Syb.), welche gelegentlich auch in den Zuflüssen der obern Donau gefunden werden. Von den Kaul-

*) Da für die vorliegende Abhandlung nur ein im Verhältnis zu dem weiten Umfange des Themas geringer Raum zur Verfügung gestellt werden konnte, so musste aú die Beschreibung der einzelnen Fischarten sowie auf $\mathrm{Abbildungen} \mathrm{verzichtet} \mathrm{werden.} \mathrm{Man} \mathrm{findet}$ mehr oder weniger ausfübrliche Beschreibungen in den im Litteraturverzeichnis angefuhrten Werken von IIeckel und Kner, von Siebold, Benecke u. a.; neuerdings sind mehrere Werke ${ }^{8}$ ) erschienen, welche eine zum Bestimmen der Fischarten bequeme Ubersicht der Ilauptmerkmale bieten, sowie Auszüge aus dem Beneckeschen (Werke ${ }^{9}$ ), welche die meisten deutsclien Fische in guten $A$ bbildungen geben. 
barschen ist der gemeine Kaulbarsch (Acerina cermua L.) durch das Gebiet, durch ganz Mitteleuropa und Sibirien verbreitet. Auch er fehlt bei uns kaum in irgend einem. Gewässer. Der ihm verwandte Schrätzer (Acerina schrätzer Lo) dagegen findet sich ausschliesslich in den Zuflüssen des Schwarzen Meeres, also auch im Donaugebiet.

Vährend die Perciden ziemlich gleichmässig im ${ }^{-}$Salzwasser und in den süssen Gewässern verbreitet sind, gehört die Familic der Cottiden fast ausschliesslich dem Meere an. Ein Vertreter dieser Familie, der Kaulkopf (Cottus gobio L.), lebt auch in den süssen Gewïssem der palïarktischen Region, wïhrend er im MIeere nur in der salzarmen Ostsee östlich von Gotland vorkommt. Wenig verschieden von ihm ist der $C$. poccilopus Heck. ${ }^{10}$ ), welcher sich in den. Gewässern der Karpathen aufhält, sonst nur noch aus den Pyrenäen bekannt ist. Gleichfalls aus den Küstengegenden des Meeres stammt die Familie der Stichlinge (Gasterosteiden), welche meist Bewohner des Seewassers wie des Süsswassers sind. Wir haben in unseren süssen Gewässern zwei Stichlingsarten, von denen die kleinere (Gasterosteus pungitius) rornehmlich in den süssen Gewässern der Küstengegenden vorkommt, die grössere (G. aculcatus) auch die mehr im Binnenlande belegenen Gewaisserteile bewolnt, ohne dass beide Arten indessen sich ausschliessen. Man unterscheidet bei beiden Arten je zwei Varietäten, von denen die eine (trachurus) an den Seiten des Schwanzes ebenso wie an den Ǩ̈̈rperseiten Knochenplatten trägt und lüngere Stachehn besitzt, während die zweite (lenurus) kleinere Stacheln und einen unbewehrten Schwanz hat. Beide Stichlingsarten sind durch das ganze Gebiet mit Ausnahme der Donau und ihrer Zuflüsse verbreitet. Über unser Gebiet hinaus findet sich der kleine Stichling an allen Küsten der Nordmeere, der grosse Stichling durch ganz Europa mit Ausnahme des pontischen Gebietes, sowie in Algier und in Nordamerika 11 ).

$\mathrm{Zu}$ einer echten Seefischfamilie, den Dorschen (Gadoiden), gehört ferner ein anderer unserer verbreitetsten Fische, die Aalquappe oder Rutte (Lota vulgaris C.), welche sowohl in Flüssen 
und Bächen, als auch in tieferen Seen der paläarktischen Region sich überall verbreitet findet. Als einzigen Vertreter einer überaus zahlreichen Familie des Süsswassers, der Siluriden, besitzen wir den WVels oder Schaiden (Siluris glanis L.), der durch Osteuropa bis zum Rhein und in Nordasien verbreitet ist. Die Siluriden bilden nach Günther ein Vierteil aller bekannten Süsswasserfische. Ihre Heimat ist anscheinend in Ostindien zu suchen; von dort haben sie sich durch die süssen Gewässer fast aller Gegenden, besonders aber in den Tropen, verbreitet.

Von Cypriniden 12) besitzt unsere Fauna, abgesehen von lokalen Varietäten und Bastardformen, etwa dreissig Arten. Man hat die zahlreichen Arten der Cypriniden zu Gruppen zusammengestellt. Zu der Gruppe der Cypriniden gehören der Karpfen, die Karausche, die Barben und die Gründlinge.

Der Karpfen (Cyprinus carpio L.) stammt anscheinend aus Südosteuropa, wo er im Gebiete des Pontus und des Caspisees bis weit nach Mittelasien hinein wild lebt. In Europa, neuerdings auch in Nordamerika ist er durch die Fischzucht jetzt weit verbreitet. Die Teichwirtschaft, welche in Bühmen sich besonders stark entwickelt hat, hat mehrere Varietaten erzeugt. $\mathrm{Zu}$ diesen gehört der Lederkarpfen, welcher keine Schuppen trägt, der Spiegelkarpfen (C. rex cyfrinorum), welcher an jeder Körperseite nur eine Reihe sehr grosser Schuppen trägt, der blaue Karpfen, der Goldkarpfen (Carpe d'or), dessen rötlicher Schimmer nach Carbonnier ron der Lachsfarbe seines Fleisches herrührt, der galizische Karpfen u. a. Die Karausche (Curassüs änlgaris Nils.) ist üher das ganze Gebiet wie überhaupt in der palianktischen Region verbreitet. Sie bewohnt stehende und langsam fliessende (iewässer mit weichem Gruncle. Als Giebel bezeichnet man im Gegensatz zu der hochrükigen sug. Seekarausche die schlankeren Furmen, welche sich in Heinen Gewässern entwickeln. Eine nahe verwandte Kitrauschenart, vielleicht nur eine Abart unserer gewöhnlichen Karausche, ist der aus Jatran und China stammende Guldfisch (Carassius auratus), der in zahlreichen Varietiten (Telesknffich, Schleierfisch) jetzt auch in Europa gezogen wird ${ }^{13}$ ). 
$\mathrm{Zu}$ den artenreichsten Gattungen der Süsswasserfische gehören die Barben, von denen man etwa 200 meist tropische Arten kennt. In unserem Gebiet ist allverbreitet nur die auf Mitteleuropa beschränkte Flussbarbe (Burbus fluariatilis . $\mathrm{g}$.), die Seen und Flüsse bewohnt. Eine andere Art (Barbus Petenyi Heck.) ist in den Karpathenflüssen, auch in der Weichsel gefunden worden. Neuerdings glaubt man sie auch in der Lohe, einem Oderzufluss, aufgefunden zu haben 14). Der Gründling (Gobio fluviatilis C.) ist über ganz Europa verbreitet, wo er in fliessenden und stehenden Gewässern vorkommt. Eine verwandte Art, Gobio uranoscopus Ag., bewohnt die Nebenflüsse der Donau, sowie einzelne Gewässer der obern Weichsel.

Aus der Gruppe der Rhodein kommt bei uns ein typischer Vertreter, der Bitterling (Rhodeus amarus Bl.), vor, der über ganz Europa verbreitet ist.

In reicherer Zahl finden sich in Deutschland die Abramidina, zu denen die Bressenarten, der Blei, Rapen, Uklei, die Ziege und das Moderlieschen gehören. Der Bressen oder Brachsen (Abramis brama L.) findet sich in ganz Mitteleuropa, mit Ausnahme der Alpen. Ebenso verbreitet ist die Zärthe ( $A$. vimba L.), doch scheint sie vom Rheingebiet ausgeschlossen zu sein. Einen viel engeren Verbreitungsbezirk haben der Seerüssling ( $A$. melanops H.) und der Pleinzen (A. sapa), welche auf das pontische Gebiet beschränkt sind. Die Zope (A. ballerns) findet sich in den Unterläufen der Ströme und in den grossen Seen im Gebiet allenthalben. Sehr gemein in Seen und Flüssen ist der Blei oder Güster (Blicca Björkna L.), der in Mittel- und Nordeuropa vorkommt. Seltener, aber in den grösseren Gewässern des Ostens ebenfalls überall verbreitet, ist die Ziege oder der Sichling (Pelecus cultratus L.); westlich von der Oder scheint dieser Fisch zu fehlen. Dagegen ist der Uklei oder die Laube (Alburmus lucidus Heck.) über ganz Mittèleuropa bis nach Frankreich verbreitet. Nicht weniger verbreitet, aber selten und vielfach übersehen ist der Schneider (A. bipunctatus $\mathrm{Bl}$.). Dagegen ist die nahe verwandte Mairenke ( $A$. mento Ag.) auf das pontische 
Gebiet beschränlit. Der Rapen oder Schied (atspins rapax Ag.) und das Moderlieschen, Mutterlosken oder Motken (Leucaspius delincatus Sieb.) sind dagegen im Gebiete überall zu finden.

Die grosse Gruppe der Leuciscina enthält ebenfalls mehrere Arten des Gelietes, die Plützen, Rutaugen, Dübehn, Orfen, Schleien, Nasen, Elritzen und Strömer. Die Plötze (Leuciscus rutilıs L.) ist in ganzen Geljet wie in ganz. Mittel- und Xordeuropa verbreitet und einer der gemeinsten Fische. Dagegen ist der Frauennerfling (L. virgo Heck.) auf die Donau beschränkt, während der Frauenfisch (L. Meidingeri Heck.) zu jenen Bewohnern der tiefen Alpenseen gehört, welche nur zur Zeit der Laichablage gefangen werden können, sonst aber ihr Leben in unzugänglichen Tiefen verbringen. Eine ähnliche Verbreitung wie die Plötze hat das mit ihr oft verwechselte Rotauge oder 'die Rotfeder (Scardinizis erythrophthalmus L.). Auch die Orfe (Idus melenotus IIeck.) ist über das ganze Gebiet verbreitet. Eine schöne Varietät derselben ist die Goldorfe (var. miniatus). Der Döbel oder Aitel (Squalius cephahus L.) und der Häsling oder Hasel (S. lcuciscus L.), sowie die Elritze oder Pfrille (Phoxinus laevis Ag.) sind ebenfalls im Gebiete, namentlich in fliessenden Gewässern, überall $\mathrm{zu}$ finden.

Sehr sporadisch trifft man dagegen den Strömer (Tclestes Agassizii Val.) an, der ausser im Rhein und in den Zuflüssen der Donau neuerdings auch in einem kleinen Oderzufluss am Zobten aufgefunden ist 15). Die Nase (Chondrostoma naszus L.) ist ein osteuropäischer Fisch, welcher in den Flussgebieten der Nordsee mit Ausnahme der Elbe (wie der Zander) fehlt. Eine andere Nasenart, C. Genei Bon., welche im allgemeinen auf Südeuropa beschränkt ist, wird von Siebold auf Grund eines gelegentlichen Vorkommens zur Fauna des Rheins gerechnet.

Die Schleie (Tinca vulgaris C.) ist ein in ganz Europa verbreiteter Fisch weichgründiger Gewåsser.

Zweifelhaft ist es, ob man zu den Cypriniden auch die kleine Gruppe der Acanthopsiden oder Schmerlen zu rechnen 
hat, die sich namentlich durch ihre knöcherne Schwimmblasenhülle und durch den Bau ihrer Unterschlundlinochen von den ihnen sonst nahestehenden Cypriniden unterscheiden. Aus unserer Fauna gehören hierher die Steinbeisser, Schlammpeitzker und Schmerlen. Der Steinbeisser (Cobitis tacnia L.) findet sich durch ganz Europa, die Schmerle (C. barbatula L.) auch in Asien, der Schlammpeitzker (C. fossilis L.) endlich in Asien und dem östlichen Europa mit Einschluss unseres Gebietes.

Eine ganz isolierte Stellung nimmt die kleine Familie der Umbriclen ein, welche nur aus zwei Süsswasserarten besteht, ron denen die eine im mittleren Nordamerika, die andere, der $\mathrm{H}$ unds fisch (Umbra Crameri Müll.), in einigen Nebengewässern der unteren Donau (Neusiedler See, Plattensee u. a.) und anscheinend auch in anderen Teilen des Pontischen Gebietes sich vorfindet.

Die Familie der Salmoniden 16) ist bei uns durch fünf Gattungen vertreten, deren Arten grossenteils zur Varietätenbildung neigen, sodass eine Übereinstimmung unter den Fischliundigen über die Abgrenzung der Arten in mehreren Fällen noch nicht erzielt ist. Die meisten Arten sind als Sport- und Speisefische hochgeschätzt und werden als Edelfische bezeichnet. Die Gattungen, welche hierher gehören, sind: die Maränen oder Renken, die Aesche, der Stint, die Saiblinge und die Forellen und Lachse.

Es ist schan enwähnt, dass die Salmoniden sich anscheinend von Norden her verbreitet haben, dass sie noch jetzt im Norden die stärlsste Artentwickelung besitzen und in unserem Gebiet meist lühle Wohnplätze aufsuchen. Solche finden die Bewohner der Seen in den sehr tiefen Seen der Alpen und in einigen norddeutschen Seen, in Tiefen, in welchen beständig eine Temperatur von nur $2-6^{\circ} \mathrm{C}$. herrscht. Grösstenteils Bewohner solcher Seen sind die Maränen oder Coregonen. Nüsslin 18) hat die Arten derselben nach der Form der Schnauze und der Bezahnung der Kiemenbögen geschieden; nach diesem System hat man zu unterscheiden: den Nordseeschnepel (Coregomus oxyrhynchus L.), einen Wanderfisch, der die Nordsee bewohnt und ihre Ströme zur Laichzeit aufsucht, die kleine Maräne (C. albula L.), die in den 
tieferen Seen der baltischen Seenplatte won Ifultein bis nach Rusland hinein, sowie in den skandinavischen Seen lebt, den Kilch oder Kropffelchen ( $C$. hiemalis Jur.) aus der Tiefe des Bodensees und des Ammersees, den Ostseeschnepel (C. lavaretus L.), der die Ostsee bewohnt und in den Buchten und Haffen derselben laicht, die Madümaräne (C. maraena $\mathrm{Bl}$.) aus dem Madüsee in Pommern, die Bodenrenke (C. for $a$ Jur.) aus den tiefen schweizerischen, oberösterreichischen und bayrischen Seen, die Pulsseemaräne (C. generosus Peters) ${ }^{17}$ ) aus dem Pulssee in der brandenburgischen Neumark 1s) (Ostseeschnepel, IIadümaräne, Bodenrenke und Edelmaräne werden von Anderen für Varietäten einer Art gehalten) 19), ferner den Blaufelchen (C. Wartmanni Bl.) aus den tieferen nordalpinen Seen, die Traunseemaräne $(C$. Stcindachneri Nüisl.), Pfäffikoner Maräne (C. Sulseri Nüssl.) aus dem Traunsee bezw. Pfäffikoner See, und den Gangfisch (C. macrophtthalmus Nü.sl.) atus dem Bodensee (die drei letztgenamnten Arten werden von anderer Seite für Varietäten des Blaufelchen gehalten).

Die Aesche (Thymallus vulgaris Nils.) ist ein anderer Salmenicle, der kleine, raschflicssende Flüsse im ganzen Geliete bewhnt und über dasselbe hinaus durch Europa verbreitet ist; verwandte Formen finden sich in Nordasien und Nordamerika. Der Stint (Osmcrus cpcrlanıs L.) findet sich an den Küsten des nördlichen Teiles des Atlantischen Ozeans und in dessen Zuffüssen, in denen er laicht. Im Rhein ist er nicht beobachtet worden. In cinigen norddeutschen Seen kommt er ebenfalls vor, ohne zum MIeere zu wandern.

Die naheverwandten Gattungen der Saiblinge, Lachse und Forellen hat man nach Siebolds Vorgange nach der Bezahnung des in der Gaumendecke liegenden Pflugscharbeins unterschieden.

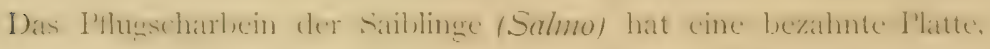
aber einen unbezahnten Stiel; das der Lachse (Trutta) hat cinen bezalınten Stiel bei unbezahnter Platte, während bei den Forellen (Trutta) sowohl Stiel wie Platte bezahnt sind. Der Saibling (Salmo salvclimus L.) bewohnt die tiefen Gebirgsseen Mittel- und Nordeuropas. Der ebenfalls zu den Saiblingen gerechnete Huchen 
(S. Iucho L.) kommt ausschliesslich im Donaugebiete vor. Der Lachs (Trutta salar Li) bewohnt den nordatlantischen Ozean, mit Ausschluss des Schwarzen Meeres und des Mittelmeeres, und steigt in die Flüsse, welche sich in die von ihm bewohnten Meere ergiessen, zum Laichen auf. Die Forellen unterscheidet man als Bachforelle (T. fario L.), Seeforelle (T. lacustris L.) und MIeerforelle ( $T$. truttc L.). Die beiden letzteren Arten sind ursprünglich wohl Abarten der Bachforelle 20), aber durch verschiedene Lebensweise und körperliche Abweichungen von ihr unterschieden. Während die Bachforelle in raschfiessenden Bächen im ganzen Gebiete lebt, bewohnt die Seeforelle die tiefen Gebirgsseen, die Meerforelle die Nord- und Ostsee; alle drei Arten laichen aber ausschliesslich in Bächen, in welche die See- und die Meerforelle zu diesem Zweck aufsteigen. Die Meerforelle hat also eine ähnliche Lebensweise wie der Lachs, mit dem sie deshalb oft verwechselt wird.

Die Familie der Hechte (Esociden) ist bei uns durch den allbekannten, in allen süssen Gewässern Europas, Nordasiens und Nordamerikas lebenden Esox lucius L. vertreten.

Aus der Familie der Heringe (Clupeiden) sind zwei Wanderfische zu unserer Fauna zu rechnen, der MIaifisch (Alosa vulgaris C.) und die Finte (Alosa finta C.). Ersterer bewohnt die Küstengegenden im nördlichen Atlantischen Ozean, die letztere verbreitet sich noch mehr südlich und östlich bis zum Nil. Beide besuchen zum Laichen die Süsswasserströme. Die Weichsel wird indessen nur von der Finte besucht. Zur Familie der MIuräniden gehört unser Aal (Anguilla vulgaris Flem.), der in allen Flüssen lebt, die in den Nordatlantischen Ozean gehen, mit Einschluss des Mittelmeergebietes, mit Ausschluss aber der Pontischen Flüsse.

Wenden wir uns nun von den Knochenfischen zu den Ganoiden, so finden wir die Familie und Gattung der Acipenserinen 21) in mehreren Arten vertreten. Der Stör (Acipenser sturio L.) ist ein Wanderfisch und bewohnt den Nordatlantischen Ozean mit Ausschluss des Mittelmeeres und seiner Nebenmeere, also auch des Schwarzen Mleeres. Das letztere wird dagegen von mehreren verwandten Arten bewohnt. Es sind dies der Glattdick 
(A. glaber Heck.), der Scherg (A. stcllatus Pall.), der Dick ( $A$. schypa Güldenst.), der Waxdick (A. Güldenstädlii Brandt) und der Hausen ( $A$. huso L.). Alle diese Stüre wandern zur Laichzeit in die Flüsse, die letztgenannten in dic Donau und dic anderen Ströme des Pontusgebietes, der Stör in die europäiischen und amerikanischen Flüsse seines Wohngebietes, um hier zu laichen. Mehr Standfisch ist der Sterlet (A. ruthenus L.), welcher die Pontischen Flüsse, ausserdem aber auch die in das Eismeer mündende Düna bewohnt und das Mieer in der Regel nicht aufsucht.

Aus der Ordnung der Cyclostomen endlich, deren von den übrigen Fischen völlig abweichender Bau Anlass gegeben hat, diese Tiere von der Klasse der Fische ganz auszuschliessen, gehören zu unseren Süsswasserfischen zwei Vertreter der Familie der Petromyzontiden, das Flussneunauge ( $P$. fluviatilis L.), ein Wanderfisch, der zum Zweck der Laichablage aus dem Mlecre in die Süsswasserströme wandert, wo seine Larve mehrere Jahre lang aufwïchst, und das Bachneunauge ( $P$. Planeri $\mathrm{Bl}$.), welches sein ganzes Leben in Bächen und kleinen Flüssen zubringt. Beide Arten sind durch die ganze arktische Region verbreitet.

Überblickt man die jetzige Ausbreitung unserer Fischarten, so lassen sich zwei Hauptrichtungen der Verbreitung erkennen, eine aus Nordwesten bezw. Nord und West kommende, und eine aus Süclost bezw. Süd und Ost kommende. Der ersteren ausschliesslich gehüren die Fische des nordatlantischen Küstengebietes an: die Stichlinge, Stint, Lachs, Nordseeschnepel, Miecrforelle, MLaifisch, Finte, Aal und Stör. Alle diese Fische sind von dem Gebiet des Schwarzen

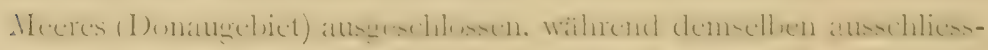
lich angehören: Wolgazander, die Streber, Schrätzer, Secrüssling, l'leinzen, Mairenke, Frauennerfling, Hundsfisch, Huchen, Glattdick, Dick, Scherg, Waxdick und Hausen. Eine kileine Reilie von anderen Fischen weist auf allmihliche Verbreitung von Ost nach West hin: der Wels, der seine Westgrenze im Rhein hat, die Ziirthe, die westlich der Weser sich nicht findet, der Zander und die Nase, deren Verbreitung nach Westen mit der Elbe abschliesst, endlich die Ziege, welche nicht über die Oder hinaus nach Westen geht. 
Noch andere Fische finden sich im Gebiet stellenweise, so aus dem Süden eingewandert der Barbus Pctenyi, der Gobius uranoscopus, der Strömer, das Chondrostona Genei, aus dem Osten der Sterlet, ferner an gewisse (Ortlichkeiten gebunden der kitrathische hiullionif, der Ostseeschnepel, endlich die auf die tiefen Seen beschränkten Arten: der Frauenfisch, die kleine Marüne, die übrigen Felchenund Renkenarten, der Seesaibling und die Seeforelle.

Die übrigen Fische sind dem ganzen Gebiete gemeinsam. Eine kleine Zahl von ihnen ist über die ganze arktische Region 1.Nordasien, Europa und Nordamerika) verbreitet: Barsch, Aalquappe, Hecht, Fluss- und Bachneunauge. Einige finden sich allgemein im Norden der alten Welt: Kaulbarsch, Kaulkopf, Karausche und Bachforelle. Die übrigen gehüren dem europäischen Gebiete nürdlich von den Alpen an und sind teilweise bis Asien hinein verbreitet, nämlich die meisten Cypriniden, die Acanthopsiclen sowie die Aeschre.

Haben wir uns in dem bisherigen über die in unserm Gebiet vorkommenden Arten und ihre Verbreitung orientiert, so wenden wir uns nun zur Betrachtung der Lebensverhältnisse derselben, welche wir am besten an der Hand ihres Körperbaues ${ }^{22}$ ) und ihrer Organe kennen lemen.

Die äussere Körperdecke, die Haut, ist wie bei den höheren Wirbeltieren eine doppelte, indem sie aus der Oberhaut oder Epidermis und der Lederhaut oder dem Corium zusammengesetzt ist. Die Oberhaut besteht aus einer mehrschichtigen Lage von Zellen, deren äusserste Schichten zerfallen und in Gemeinschaft mit dem Schleim einzelner grosser Drüsenzellen die Oberfläche der Haut schlüpfrig machen. Die unter der Oberhaut liegende Lederhaut besteht aus Bindegewebsfasern und ist meist sehr zähe (Aal). In taschenfürmigen Vertiefungen clieser Haut liegen die Schup pen n 2:1, Homplättchen, welche sich meist dachziegelartig decken und einen dichten Schutzpanzer bilden (Perciden, Cypriniden, Salmoniden, Clupeiden, Hecht). Bei dem Hundsfisch ist auch der Kopf mit Ausnahme der Schnauze mit Schuppen bedeckt, wihrend derselbe bei den übrigen Fischen frei von Schuppen ist. Bei manchen Fischen sind die Schuppen so fein und die Oberhaut so dick, dass 
die Schuppen nicht ohne Weiteres erkannt werden können (Aal, bei (lem sie in Zickzacklinien liegen, Aalquippe, Schleihe, Schmerlen). Die stirhlinge tragen an stelle der sihupen an den seiten shnate dünne Knochenschienen, welche zusammenhängende Seitenpanzer bilden. Der Kürper der Störe ist mit starken, mit scharfen Hückern versehenen Hautknochen als wirksamen Schutz besetzt. Ganz ohne Hautbewehrung sind von unseren Fischen die Kaulküpfe, der Wels und die Neunaugen.

Der Silberglanz, welchen die meisten Fische zeigen, wird dadurch hervorgerufen, dass die Oberfläche der Lederhaut (bezw. die Innenseite der Schuppen) mit einer Lage von milisoskopisch kleinen, krystallartig geformten Plittchen bedeckt ist, welche neben Kalk auch Guanin 24) enthalten*). Letzterer Stoff findet sich auch in der glanzlosen Haut der Neunaugen 25). Bei manchen Fischen bringen die Glanzlörperchen, namentlich zur Laichzeit, schöne Interferenzfarben hervor (Stichling, Bitterling u. a.). Sie werden in der Farbenwirkung unterstützt durch die Farbzellen (Chromatophoren)26), welche in der Lederhaut liegen. Die meisten Farbzellen sind mit schwarzem Farbstoff, viele auch mit rotem oder gelbem Farbstoff gefüllt. Die letzteren, Zooerythrin und Zoofulvin, kommen nach Krukenbergi ${ }^{27}$ ) auch bei den Vögeln vor, fehlen aber eigentümlicherweise ganz bei allen anderen Wirbeltierklassen. Die Farbzellen der Fischhaut haben in hohem Grade die Fúhigheit, sich bald fast punktfürmig zusammenzuzichen, wodurch sie fast unsichtbar werden, bald sich wieder zu sternförmigen, weit ausgebreiteten Kürpen auszudehnen und damit ihre Farbe zur Virkung zu bringen. Auf diese Weise kann die Farbe der Fische sich der ihrer Umgebung anpassen und dadurch den Fisch vor Verfolgern schützen oder die Wachsamkeit seiner Beute täuschen. Dieser Farbwechsel ist von der eigenen Lichtempfindung des Fisches abhingig; geblendete Fische zeigen nach Pouchet29) diese Farbanpassung nicht. Bei manchen Fischarten, namentlich Cypriniden (Karausche, Schleihe, Orfe, Barbe, Plötze), finden sich Varietäten,

*) Der Schuppenglanz mancher Cypriniden wird im grossen rein gewonnen zur Iferstellung der Farbe künstlicher Perlen. 
denen die schwarzen Farbzellen ganz oder stellenweise fehlen, wihrend die roten und gelben stark entwickelt sind. Diese Varietäten werden oft als Zierfische in Parliteichen gezogen. In seltenen Fällen sind auch die roten Farbstoffe nicht entwickelt (Albinismus), oder die Silberglanzkörperchen fehlen (Alampia). Normal fehlen die Glanzkörper beim Stint.

Seine Stütze erhält der Fischkörper durch die ihn der Lïnge nach durchziehende Wirbelsäule. Bei den Knochenfischen besteht dieselbe aus durchbohrten bikunkaven cylindrischen Knochenstücken, den Wirbeln, deren Innenräume durch die elastische Chorda ausgefüllt sind. Nach oben und unten setzen sich an jeden Wirbelkörper paarweise knöcherne Fortsätze an, die Rücken- und Bauchstrahlen. Die Rückenstrahlen jedes Wirbelkörpers bilden einen Kanal, indem sie an ihren oberen Enden mit einander verschmelzen. In dem so gebildeten Kanal an der Oberseite der Wirbelsäule liegt das Rückenmark. Die Bauchstrahlen verschmelzen nur im Schwanzteil des Fischkörpers mit einander zu einem Kanal, der die grossen Blutgefässe des Schwanzes*) aufnimmt. Im Vorderteil des Körpers bilden sie als Rippen die Stützen der Seitenwände der Leibeshöhle.

Die Körperform der Fische ist entweder eine seitlich mehr oder minder zusammengedrückte, oder mehr spindelförmig bis walzig. Erstere Form zeigen am stärksten ausgeprägt der Bressen und die Seekarausche, letztere der Aal und die Neunaugen, sowie die Aalquappe, der Schlammpeitzler, der IVels, der Kaulkopf, lauter Fische, die vorzugsweise am Grunde der Gewässer leben und sich gelegrentlich auf demselben schlïngehd bewegen. Dic hauptsichliche Bewegungsart unserer Fische ist aber das Schwimmen im freien Wasser, und hierzu ist der Fischkörper nicht nur selbst in geeigneter Weise geformt, sondern auch mit besonderen Anhängen versehen, den Flossen. Die Flossen sind gebildet durch Hüute, welche durch eingelagerte bewegliche linücherne Spangen ausgespannt werden können, etwa wie ein Schirm oder ein mit Zeug bezogener

*) Diese Blutgefüsse sticht man beim Schlachten grosser Fische an, die man durch Verblutung töten will. 
Fächer. Man unterscheidet paarige Flossen, welche an den Seiten des Kürpers stehen, und unpaare Flossen, welche in der Mittellinie des Rückens und des Schwanzes stehen.

Die paarigen Flossen sind meist zu zwei Paaren vorhanden, welche man nach ihrer gewölnnlichen Stellung als Brustflossen und Bauchflossen unterscheidet; sie entsprechen den Gliedmassen der höheren Wirbeltiere. Sie sind an Knochen befestigt, welche bei

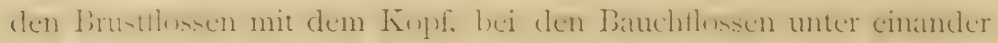
verbunden sind. Sie fehlen ganz den Neunaugen, wührend der Aal nur Brustilossen, keine Bauchflossen hat. Die unpaaren Flossen unterscheidet man je nach ihrer Lage als Rückenflossen, Schwanzflossen und Afterflossen. Rückenflosse und Afterflosse sind dadurch am Fischkörper befestigt, dass jeder Strahl der Flosse scharnierartig verbunden ist mit einer Knochenschiene von kreuzförmigem Querschnitt, welche im Körper des Fisches liegt und sich je an einen Rückenstrahl bezw. Bauchstrahl der Wirbelsitule anlehnt. Rückenflossen sind in Zweizahl vorhanden bei den Perciclen, Aalquappe, Kaulkopf und den Neunaugen. Bei den Stichlingen sind die ersten Strahlen, ebenso wie die Bauchflossen, zu einzeln stehenden, teilweise zackigen Stacheln umgewandelt, welche als Waffen dienen. Bei den Salmoniden findet sich hinter der Rückenflosse eine kleine sogenannte Fettflosse, welche diese Familie von allen anderen einheimischen Fischen leicht unterscheiden lisst. Diese Fettlosse wird als ein Überbleibsel aus dem Larvenstadium des Fisches betrachtet; sie hat keine festen knüchernen Strahlen, wie die übrigen Flossen, sonclern an deren Stelle nur weiche hornige Fiden, wie alle Flossen der Neunaugen, der Haic und Rexhen und der eben ausgeshlïgften Jungen der Knochenfische. Die Afterflosse fehlt nur den Neunaugen. Sie beginnt stets kurz hinter der Afteröfnung. Die Schwanzflosse liegt bei den meisten Fischen mit dem grüssten Teil unterhalb der Wirbelstiule. Die trotzdem vorhandene Symmetrie des Schwanzes wird dadurch ermüglicht, dass die letzten Wirbelkürper $\mathrm{zu}$ einem Stiel verschmolzen und so nach oben gebogen sind, dass die Unterseite der Wirbelsiule und die an sie sich ansetzenden Schwanzflossenstrahlen nach hinten gerichtet sind. 
Sehen wir uns nun nach den Muskeln um, welche die Bewegungen des Fisches bewirken, so finden wir zunächst zu beiden Seiten der Wirbelsëule starke Fleischmassen, welche leicht einen eigentümlichen Bau erkennen lassen. An jeden Wirbelkörper setzen sich beiderseits Muskelplatten an, welche hohlkegelförmig gewölbt sind, so dass ein Querschnitt durch den Fischkörper mehrere hinter einander liegende Muskelplatten ringförmig blosslegt. Die vier an einer Stelle der Wirbelsäule sich ansetzenden Muskelplatten bilden einen Muskelabschnitt (Mokamma). Dic Muskelalsschnitte sink unter sich durch dünne Bindegewebshäute (Ligamente) getrennt*), die einzelnen Muskelbündel liegen in den Muskelabschnitten in der Längsrichtung des Fisches, ihre Enden setzen sich daher nicht an Knochen, wie die meisten Muskeln der höheren Wirbeltiere, sondern an Ligamente an (interligamentale Muskulatur). Die Muskiclplatten bilden zusammen zwei grosse Seitenmuskeln, welche den grössten Teil des Fischkörpers einnchmen und dic Bewegungen des Schwanzes bewirken. Neben den Seitenmuskeln treten die Muskeln des später zu betrachtenden Kopfes und die der Flossen an Umfang sehr zurück. Die Muskulatur der unpaaren Flossen besteht aus zahlreichen kleinen MIuskelzügen, welche einerseits an die inneren Halteknochen der Flossen, anderseits an die Flossenstrahlen sich ansetzen (interosteale Muskulatur) und die letzteren aufrichten, niederziehen und seitwärtsbiegen können. Bei den paarigen Flossen wird die Ausbreitung und die fächelnde Bewegung, welche diescllx.n ausführen, durch stärkere Muskelbündel bewirkt, welche ebenfalls an den inneren Gerüstlknochen dieser Flossen befestigt sind. Wie kommt nun mittels der Flossen und ihrer Muskeln die Ortsbewegung zu stande29)? Die Flossen, die paarigen sowohl wie die unpaaren, sind für sich allein nicht im stande, den Fisch schwimmend zu erhalten, wie durch Versuche festgestellt ist. Die paarigen Flossen halten den Fisch, wenn er im freien IVasser

*) Beim Erwärmen des toten Fischkörpers lüsen sich diese Hảute unter Leimbildung auf, sodass die einzelnen IIuskelplatten sich von einander trennen und leicht schollenartig auseinanderfallen. In den Ligamenten liegen namentlich bei den Perciden und Cypriniden feine, spitze Stützknochen, Fleischgrïten, welche sich als Knochen beim Kochen nicht aufiösen. 
schwimmend steht, im Gleichgewicht, auch wirken sie mit bei Wendungen und bei der Rückwärtsbewegung sowic beim plützlichen Aufhalten. Die unpaaren Filossen künnen durch leichte wellenfürmige Bewegungen eine langsame Vorwärtsbewzgung des Fisches bewirken. Das rasche Schwimmen der Fische dagegen wird durch Ruderschläge des Hinterleibes bewirkt, dessen Fläche, um den Viderstand des leicht ausweichenden Wassers zu erhöhen, durch Aufrichten der unpaaren Flossen vergrössert werden kanm, wobei die Schwanzflosse hauptsächlich als Steuer dient. An diesen Bewegungen, welche durch abwechselnde Kontraktionen der beiden Seitenmuskeln vor sich gehen, nimmt der hintere Teil des Körpers teil, welcher durch eine durch die Vorderenden der Rückenflosse und der Afterflosse gelegte Ebene abgegrenzt wird. Der Ǩ̈̈rperteil vor dieser Ebene enthält die Leibeshöhle mit ihren Organen der Blutzirkulation, der Verdauung und der Fortpflanzung. Ein Zwerchfell trennt die kleine Brusthöhle, welche das Herz enthailt, von der geräumigen Bauchhöhle.

Das Herz ${ }^{30}$ ) liegt, vom Herzbeutel umschlossen, dicht hinter dem Kopfe. Es besteht aus der muskulösen Herzkammer und der cünnwandigen Vorkammer, die durch ein Klappenventil getrennt sind. Der Vorkammer schliesst sich der Simus venosus an, der das Venenblut aufnimmt und der Vorkammer zuführt. Aus der Herz-

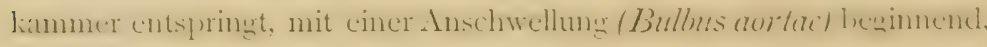
die Kiemenarterie, welche das venöse Blut aus dem Herzen in die Kiemen führt. Aus den KKiemen sauerstoffreich zurückikehrend sammelt sich das Blut in der grossen Kürperarteric (Aorta descendens), aus welcher es sich in die Organe des Kürpers verteilt. Das hier gebrauchte Blut wird zur Ausscheidung der nicht gasförmigen Stoffwechselprodukte durch die Leber und die Niere geführt. Das Produkt der Leber ${ }^{31}$ ), die Galle, sammelt sich in der Gallenblase und gelangt aus dieser in den Darm. Das Prodult der Nieren, der Harn, wird durch die Harnkanalchen in die beiden Harnleiter und sodann in der Regel zuniichst in eine Erweiterung des gemeinsamen Endteils derselben, die Harnblase, geführt, von wo er clurch einen Ausführungsgang hinter dem After nach aussen gelangt. 
Bei den Fischen liegen die Nieren an der Decke der Bauchhöhle als zwe dicht an der Wirbelsäule durch die ganze Länge der Bauchhühle sich erstreckende, grossenteils mit einanter rerschmolzene, dunkelrote, sehr weiche Organe. Sie dienen bei den Fischen nicht allein zur Harnabsonderung, sondern sie sind daneben, wie auch wahrscheinlich die zwischen den Eingeweiden liegende Milz32), die Vermehrungsstätten der roten Blutkörperchen 33).

Die Organe der Ernährung und ihre Hilfsorgane liegen teils in der MIundhöhle, teils in der Bauchhöhle. Die Mundhöhle nimmt den unteren Teil des Kopfes ein, während in dem oberen, in einer Kapsel aus Knorpel (Neunauge, Stör) oder Knochen (bei den meisten Knochenfischen), das Gehim eingebettet ist. Die Knochen, welche den vorderen Teil des Bodens des Hirnschädels bilden, sind das Dach der Mundhöhle, deren Seitenwände und Boden teils aus den Kiemenbögen und den ihnen homologen Knochenbögen, den Unterschlundknochen und dem Zungenbein, teils aus den Kieferknochen, und aus ihren häutigen und muskulösen Verbindungen bestehen. Die Öffnungen zwischen den Kiemenbögen führen in die Kiemenhöhlen, welche nach aussen durch die mehr oder minder beweglichen Kiemendeckel geschlossen sind.

Alle Knochen der Mundhöhle sind mit einander beweglich verbunden, sodass die Mundhöhle bedeutender Erweiterung fähig ist. Je nach der Nahrung des Fisches sind die Gestalt der Mundöffnung und die Bezahnung der Mundknochen verschieden. Die Perciden, Kaulköpfe, Aalquappe, Wels, auch manche Cypriniden, wie Rapen, Döbel, Orfe, ferner die Aesche, der Stint, die Salmound Trutta-Arten, Hecht und Aal haben ein breites, weit aufsperrbares Maul und, mit Ausnahme der Cypriniden, auf mehr oder minder zahlreichen Knochen desselben teils nur feine Zähnchen, die in grosser Zahl mehr oder minder dicht beisammen stehen (Sammet-, Bürsten-, Hechelzähne, z. B. beim Aal, Barsch, Wels), teils zwischen diesen noch grössere Fangzïhne (Zander, Hecht, Lachs, Forelle) ${ }^{34}$ ). Diese Fische sowie die Stichlinge nähren sich ausschliesslich, wie Lachs, Hecht, Wels und Zander, oder teilweise ron Fischen, welche sie, auch wenn sie über dic Mundhühle 
hinausragen, mittels der Zähne festhalten können. Die meisten Cypriniden, Maränen und Clupeiden haben dagegen eine kleine rundliche oder mehr hohe als breite MIundöffnung, welche am Ende ciner rüsselartig vorstreckbaren, häutigen Röhre liegt, die oben von den hallsingfümigen Zwischen- und oberkieferlinochen, unten won lem Lnterkiefer gestützt wird. Mittels dieses Saugrüssels schlürfen diese Fische ihre aus kleinen niederen Tieren bestehende Nahrung ein, nach welcher sie teils im freien Wasser, teils an den festen Gegenstïnden in demselben, den Pflanzen, Steinen, dem Holzwerk, oder auf dem Grunde suchen. Sie finden hier kleine Crustaceen aus den ()relnumgen der Cladoceren, der ( stracoden, der Copepoden, ferner die das Wasser bewohnenden Larven vieler Insekten, namentlich der Mücken und Eintagsfliegen, auch Würmer, Rädertiere, kleine Weichtiere, nehmen wohl auch die schleimigen Massen der Kieselalgen und den für sie allerdings unverdaulichen MIulm zerfallener Pflanzenteile, Sand und Schlamm ein, verschonen auch nicht, wie hier gleich erwähnt sein mag, Eier und Brut von Fischen, selbst nicht die eigene Nachkommenschaft. Man unterscheidet die letztgenannte Gruppe von Fischen als Kleintierfresser oder Friedfische von den ersterwähnten Raubfischen ${ }^{35}$ ).

Während die Kiemenspalten der breitmäuligen Fische ziemlich weit und nur mit weitläufig gestellten Zähnen versehen sind, sind die Kiemenspalten der engmäuligen Fische eng, meist kurz, die Kiemenbogen sind an der Innenseite mit je zwei Reihen dicht gestellter Stibchen besetzt, welche in einander greifend einen reusenartigen Verschluss bilden, durch den wohl das in die Mundhühle aufgenommene Wasser, nicht aber die feinliörnige Nahrung in die Kiemenhöhle entweichen kann. Am Gaumen vieler Cypriniden findet sich ein muskulöser Wulst, welcher Sinnesorgane (Schmeckbecherchen) enthält. Jede Berührung dieses Organs bringt eine Anschwellung der berührten Stelle hervor. Es scheint auch durch seine Kontraktionen beim Aufsaugen der Nahrung mitzuwirken.

Am hinteren Abschluss der Mundhöhle haben die Cypriniden, welche sonst ganz zahnlos sind, auf den Unterschlundknochen stumpfe aber starke Zähne, deren bei den einzelnen Arten 
verschiedene Form ein vorzügliches Mittel zur Abgrenzung und Erkennung der Arten ist. Diesen Zühnen gegenüber steht am Gaumen eine harte Knorpelplatte. Zwischen den Zühnen und der Gaumenplatte wird die Nahrung zerdrückt. Die Zähne werden bei den Cypriniden nach v. Siebold jährlich in der Laichzeit abgestossen und ernevert.

Abweichend von dem Maul der übrigen Fische ist das der Neunaugen gebaut. Es ist eine am vorderen Körperende gelegene Saugscheibe, welche mit mehreren zahntragenden Homplatten ausgestattet ist. Es dient dem Fisch vornehmlich dazu, sich an feste Gegenstände oder an seine Beute anzusaugen. Die letztere wird dann mittels der Zähne angebohrt und ausgesaugt.

Das durch die Kiemenspalten abfliessende Wasser gelangt in die Kiemenhöhlen, in welchen sich die Kiemenbögen befinden. Die Kiemenbögen bestehen aus gebogenen rinnenförmigen Knochenplatten mit nach unten gekehrten Rinnęn. In diesen Rinnen laufen die Blutgefässe, welche das Blut aus dem Herzen in die Kiemen leiten, und andere, die das Biut aus den Kiemen dem Körper zuführen. In den Kiemenblättchen, welche an jedem Bogen in zwei Reihen dicht gedrängt stehen, tritt das kohlensäurehaltige Blut mit dem sauerstoffhaltigen Wasser in Gasaustausch, das Blut tritt sauerstoffreich in den Körper zurück, während das verbrauchte Atemwasser unter dem Kiemendeckel durch die Kiemenöffnung abfliesst und durch neues aus der Mundhöhle ersetzt wird. In der Regel sind vier Paar Reihen von Kiemenblättchen auf jeder Seite des Kopfes vorhanden. An der Innenseite des Kiemendeckels sitzt häufig noch eine sogenannte Nebenkieme (z. B. beim Stör), welche aber funktionslos ist. Die Acanthopsiden (Schlammpeitzker, Steinbeisser und Schmerle) kïmmen im Notfalle auch durch den Darm die Atmung vollziehen, indem sie Luft einschnappen und durch den Darm treten lassen, wobei sie einen quietschenden Ton erzeugen. Die anderen Fische atmen dagegen hauptsächlich durch die Kiemen. Manche Fische, welche einen sehr fest schliessenden Kiemendeckel haben, wie der Aal und viele Cypriniden, künnen stundenlang, selbst tagelang ausserhalb des Vassers zubringen, ohne zu ersticken, indem die Wassermenge, 
171 Die deutschen Süsswasserfische und ihre Lèbensverhältnisse.

wellhe in den nath ausen fert geschlensenen Fiemenhählen zurükgehalten ist, genügt, um die Aufnalime der durch den Mund eingeschnappten Luft durch die Kiemen zu vermitteln. Andere Fische, namentlich die mit sehr weiten Kiemenspalten und kurzen Kiemendevlictn versetenen salmoniden, sterben aus dem Wasser genommen sehr bald ab. Bei den Neunaugen weichen auch die Kiemen von denen der anderen Fische ab. Sie sind nicht an Kiemenbögen befestigrt, sonckern bestehen jederseits in sieben sidkchen, wckhe durch ein festes Knorpelgerüst gestützt werden, und im Innern mit zahlreichen Kiemenfalten, welche die stelle der Fiemenblittchen vertreten, bekleidet sind. Das Atemwasser wird aus der Mundhöhle durch einen

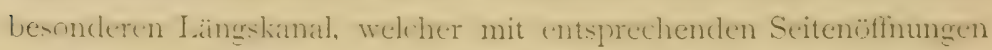
versehen ist, zugeführt, und fliesst aus judem Fiemensïkdhen durch eine besondere Öffnung nach aussen ab. Die sieben äusseren Kiemenöffnungen samt dem Auge und dem einfachen Nasenloch sollen dem Fisch seinen Namen „Neunauge“ gegeben haben.

Ausser den Kiemen atmen die Fische auch durch die Haut, wie A. von Humboldt und Provençal 36 ) durch Versuche nachwiesen. Kohlensäure wirkt nach diesen Forschern tödlich auf die Fische, während Stickstoff und Wasserstoff, wie bei den hüheren Wirbeltieren, indifferent sind. In luftlosem (ausgekochtem) Wasser starben die eingesetzten Fische nach $\mathrm{I}^{3} / 4$ bis 4 Stunden. Nach den genannten Untersuchungen berechnete Treviranus, dass die Schleihe, deren Sauerstoffbedürfnis für gering $z u$ halten ist, für je I 00 Gran Körpergewicht in 100 Ninuten 0.01 cbcm Kohlensüure erzeugt, während Süugetiere das fünfzigfache an Kohlensiuture produzieren.

Das verschiedene Sauerstoffbedürnis ist anscheinend, neben dem Wärmebedürfnis, eine der Hauptursachen der Verteilung der Fischarten auf die einzelnen Gegenden eines und desselben Flussgebietes. Der Sauerstoffgehalt einer Wassermenge ist teils von der Temperatur, teils von der Menge der Stoffe bezw. der Organismen abhängig, welche den Sauerstoff zu absorbieren vermügen.

Die Temperatur übt einen wesentlichen Einfluss auf die Fihigkeit des Wassers, Luft aufzunehmen, aus. Eine Wassermenge, welche bei $5^{\circ}$ C. Ioo Raumteile Sauerstoff aufnimmt, Jaun 
davon bei $20^{\circ}$ nur etwa 79.2 Teile in Lüsung halten. Man stelle sich vor, der Sauerstoffgehalt der von den Landtieren eingeatmeten Luft nehme an einer Örtlichkeit um etwa $1 / 5 a b$, und man wird es natürlich finden, dass die Lebewelt an dieser Örtlichkeit eine abweichende ist.

Viel bedeutender noch kann die Verminderung des Sauerstoffs durch die Einwirkung oxydierbarer Substanzen werden. Untersuchungen des Themsewassers in der. Umgegend von London haben ergeben, dass das Wasser dieses Flusses, welches etwa 5 Meilen oberhalb London bei Kingston $7.4 \mathrm{cbcm}$ Sauerstoff im Liter enthảlt, dicht bei London davon nur I.5 $\mathrm{cbcm}$, nach dem Durchgange durch die Riesenstadt, bei Woolwich, sogar nur $0.25 \mathrm{cbcm}$, also nur eine Spur Sauerstoff, den 30. Teil von seinem Gehalte in der minder verunreinigten Flussgegend, enthält 37 ).

Bei so enormer Verminderung des Gehaltes an Atemluft kann es nicht in Verwunderung setzen, wenn die mit leicht oxydierbaren organischen Substanzen gefüllten Abwässer grosser Städte und industriereicher Gegenden den Bestrebungen zur Vermehrung und Veredelung des Fischbestandes ein kaum zu überwindendes Hindernis entgegensetzen ${ }^{38}$ ).

Nicht so jäh und verderblich, wie die Abfuhrstoffe der Städte und Fabriken, aber sicher auch von erheblicher Wirkung auf den Sauerstoffgrehalt des WTassers sind die Reste abgestorbener Lebewesen, der organische Mulm, welcher durch die Regen- und Schneewåsser aus dem Niederschlagsgubiet de. Flussisystems clem Wasser clesselben auf seinem Laufe zum Meer in immer steigender Menge zugeführt wird. Auch das Gefälle und die Bodenbeschaffenheit des Flussbettes sind von Einfluss: Ein über Kiesbïnle und Steine rauschender Bach bictet scinem Waaser meln Gelegenheit zur Sauerstoffaufnahme, als ein träges, tiefes Gewässer, in dem noch dazu der hineingeschwemmte Mulm sich ablagert. Die Wirkung des Sauerstoffmangels im Wasser ist für die Fische eine doppelte: Nicht nur mangelt dèn Organismen, Tieren wie Pflanzen, die notwendige Lebensluft, sondern es nimmt auch die Bildung schadlicher Stoffe, besonders des betiiubenden Sumpfgases, zu. 
Unter diesen Verhältnissen ist es verständlich, dass sauerstoffbedürftige Fische sauerstoffarme Gewässer vermeiden. Anderseits bedürfen manche Fische einer gewissen Wärme des Wassers (z. B. der Karpfen), damit ihre Lebensfunktionen, Ernährung und Fortpflanzung, zur Thätigkeit angeregt werden. Solche Fische sind von dauernd kühlen Gewässern ausgeschlossen.

Man hat gefunden, dass viele Arten der Fische gemcinsame Lebensbedürfnisse haben, so dass sie in Flussstrecken, welche eine gewisse Beschaffenheit haben, leben können. A. Fritsch 39) hat zuerst die Flussregionen Bühmens, welche charalkteristische Fisch-

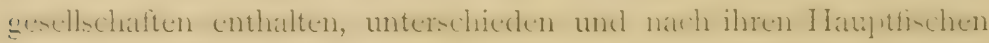
benannt. M. von dem Borne ${ }^{3}$ ) hat diese Methode für die deutschen Gewäisser durchgeführt, und sie ist jetzt allgemein angenommen. MIan unterscheidet:

I. die Forellenregion, mit Bachforelle, Elritze, den Kaulliöpfen, Schmerle, Dübel,

2. die Aeschenregion, mit Aesche, Barbus Petenyi, Gründling, Bachneunauge (im obern Teile dieser Region liegen dic Laichstellen der Lachse),

. . die Barbenregion, mit Barbe, Huchen, Nase, Rapen, Zürthe, Schneider, Häsling, Karpfen, Quappe, Bitterling, Mairenke, Streber, Strömer, MIotken,

4. die Bressenregion (Bleiregion), mit Bressen, Blei, Wels, Orfe, Rotauge, Schleihe, Karausche, Aal.

Nanche Fische finden sich in allen Regionen, wie Hecht, Barsch, Plötze, Stichling. Auf cine einzige der angeführten Regionen beschränkt ist kein Fisch, vielmehr werden die benachbarten Regionen auch häufig aufgesucht.

Etwas abweichend von den fliessenden Gewaissern verhalten sich die Scen, deren Lebensverhältnisse wesentlich ron ihrer Tiefe abhängen. Man unterscheidet hier flache Bressenseen, Seen ron mehr als $20 \mathrm{~m}$ 'Tiefe, in welchen sich die kleine norddeutsche Marine aufhilt, und Seen von über $50 \mathrm{~m}$ Tiefe, in welchen, je mach ihrer 'Tiefe, rerschieclene Martinenarten, der Seesaibling und die Seeforelle leben. 
Bei der Wichtigkeit des Atmungsprozesses spielt die Funktionsfahigkeit der Kiemen eine grosse Rolle. Sobald ihre Oberfläche durch Trockenheit abstirbt oder sobald sie sich mit einem dichten Belag von Fremdkörpern bedeckt, sind die Fische einem raschen Erstickungstode ausgesetzt: die Ursache, weshalb Trübungen des Wassers von den Fischen gemieden werden und ihnen, wenn sie dauernd, z. B. durch Fabrikwässer, verursacht werden, den Tod bringen können.

Während das in die Nundhöhle aufgenommene Wasser durch dic Kiemenspalten abfliesst, gelangt dic Nahrung clurch den trichterförmigen Schlund in den eigentlichen Darmtractus 11 ). Der Darm der Fische ist mehr oder minder gewunden und bei den Cypriniden ein Schlauch von fast überall gleicher Weite. Bei den übrigen Fischen ist eine mehr oder minder ausgeprägte magenartige Erweiterung vorhanden. Immer ist der Magendarm durch eine ringfürmige Einschnürung, die Pfürtnerklappe, rom Mitteldarm getrennt. Die mit einem Magen versehenen Fische, mit Ausnahme des Welses, des Hechtes und des Hundsfisches, haben auf der Grenze zwischen Magen und Mitteldarm Blindschläuche, wenige bei den Perciden, den Kaulköpfen und Stichlingen, viele bei den Salmoniden und der Aalquappe. Der Enddarm ist im Vergleich mit dem Nitteldarm weit. Der Darm der Neunaugen ist gerade und ohne Anhänge, der des Störs trägt an der Innenwand eine spiralig verlaufende Hautleiste (Spiralklappe). Ton den dem Darm anhüngenden Drüsen ist die Leber schon erwähnt. Die zweite bei den Wirbeltieren sonst vorkommende Verdauungsdrüse, das Pankreas, fehlt den meisten unserer Fische; es ist bis jetzt nur nachgewiesen bei Schmerle, Stichling, Hecht, Barsch, Aal und Forelle, meist stark zerstreut zwischen den Eingeweiden ${ }^{42}$ ).

Die verdauende Flüssigkeit der Fische wird daher, da auch Speicheldrüsen fehlen und die Galle nur bei der Aufnahme der Fette durch den Körper mitwirkt, meist ausschliesslich vom Darm geliefert. Dafür vermag aber auch nicht nur der Magendarm, wie bei den höheren Wirbeltięren, sondern jeder Abschnitt, selbst die 
kurze Speiseröhre der mit Magen versehenen Fische, Pepsin abzusondern, den Stoff, welcher in Verbindung mit der bei den Fischen reichlich vorhándenen Säure die Eiweissstoffe für die Aufnahme in den Körper geeignet macht (peptonisiert 43)). Von dem Pepsin der höheren Wirbeltiere unterscheidet sich das Pepsin wenigstens der Forelle und des Hechtes dadurch, dass es selbst bei $0^{\circ}$ noch verdauend wirkt 4t). Die Auflösung der Nahrung beginnt schon in der Speiseröhre und braucht erst im Enddarm mit dem Auswerfen der unverdauten Nahrungsteile aufzuhören. Am kräftigsten ist die Verdaum bei den Fischfressem, minder intensiv bei den Kleinticrfressern. Die Absonderung der Nahrungsflüssigkeit erfolgt wahrscheinlich von allen Zellen der Darmschleimhaut, die je nach ihrem Reifestadium ein verschiedenes Aussehen haben können 45).

Von grosser Wichtigkeit, namentlich für die Fütterung der Teichfische, ist, dass die Fische rohe Stärke, das Hauptprodukt der meisten Pflanzen, fast gar nicht zu verdauen vermögen, während gequollene (gekochte) Stärke verclaut wird 46 ). Diese Thatsache bietet die Erklärung zu der erst neuerdings gehörig gewürdigten Erscheinung, dass die Fische sich fast gar nicht von Pflanzenstoffen, sondern meist von Tieren nühren, so dass in der Regel die von den Pflanzen erzeugte Nahrung erst in den Körper eines niedern Tieres aufgenommen sein muss, bevor sie zur Ernährung der Fische dienen kann. Eine nur scheinbare Ausnahme hiervon bilden die Kieselalgen (Diatomeen), welche man oft in Menge in dem Fischdarm findet. Diẹse in grosser Menge im Wasser auftretenden mikroskopischen Pflänzchen, welche eine Hauptnahrung vieler niederer Wassertiere bilden, erzeugen nicht, wie die meisten anderen Pflanzen, Stärke, sondern an deren Stelle Öl, das als Fett den. Verdauungssäften der Fische zugänglich ist. Ähnlich verhält sich die Algengattung Vaucheria, die also den Fischen ebenfalls direkt Nahrung liefern könnte.

Als Grund für das Fehlen der stärkeartigen Stoffe in der Fischnahrung hat man angeführt, dass die Fische ebenso wie die Amphibien es nicht nütig haben, ihren Kürper mit diesen wärmeerzeugenden Kohlehydraten gewissermassen zu heizen, da ihr Ǩ̈̈rper 
seine Wärme von dem ihn umgebenden Wasser erhält. Immerhin bewirkt auch bei den Fischen die Respiration eine Erwärmung des Körpers über die Temperatur des Wassers. Dieselbe beträgt nach Broussonet bei kleinen Fischen $1 / 2$ bis $2 / 3^{\circ}$, beim Aal $3 / 4^{\circ}$, beim Karpfen $I^{\circ}$. Despretz fand bei $10.53^{\circ} C$ Wassertemperatur die Körperwärme von zwei Karpfen zu. I I.69 ${ }^{\circ}$, von zwei Schleihen zu II.5 ${ }^{\circ} \mathrm{C}$.

Änderungen in der Wasserwärme haben auch den grössten Einfluss auf die Lebensfunktionen der Fische, namentlich auf die Ernälhrung und Fortpflanzung. Wïhrend die meisten unserer Fische bei steigender Wärme laichen (Sommerlaicher: die Perciden, Kaulkïpfe, Stichlinge, Wels, Cypriniden, Acanthopsiden, Hecht, Clupeiden, Stïre und Neunaugen), legen andere ihre Eier bei sinkender Wärme ab I Tinterlaicher: Aalquappe und die Salmoniden ausser Stint, Huchen und Aesche). Manche Arten bedürfen einer bestimmten Mindestwärme, um laichreif zu werden, namentlich die Karpfen, welche nicht in Wasser unter $19^{\circ} \mathrm{C}$. laichen. Auch das Nahrungsbedürfnis ist abhängig von der Wasserwärme. In kaltem Wasser künnen die Fische wochenlang, ja manche Arten monatelang ohne Nahrung bestehen. Viele Cypriniden nehmen im Vinter auch im Freien keine Nahrung zu sich; der Karpfen z. B. frisst nur, wenn das Wasser minclestens $9^{\circ} \mathrm{C}$. Wärme hat, dabei verliert er während der Zeit, in welcher er nicht frisst, nur etwa $3-5 \%$ seines Köppergewichtes. Bei der Bachforelle und anderen Raubfischen nimmt zwar die Fresslust im Winter ab, hört aber nicht völlig auf. Die Forelle lässt auch im Sommer in der Ernährung nach, wenn die Wassertemperatur über $25^{\circ} \mathrm{C}$. steigt.

Bei höher steigender Wärme sterben die Fische. Der Karpfen verträgt eine Höchsttemperatur von $32-35^{\circ} \mathrm{C}$., der Barsch eine Temperatur von $28^{\circ} \cdot \mathrm{C} .87$ ). Rasche Ablühlung vertragen viele Fische ebenfalls nicht, allmailhliches Sinken der Temperatur diagegen hat keinen schädlichen Einfluss auf unsere Fische, welche in eiskaltem Wasser lebend bleiben, ja, soweit sie geringe Ansprüche an Luftersergung machen (Schleihe, Karausche), auch cinfrieren kïmnen, wenn nur die Eislälte nicht über die Eigenwürme des Fïsches siegt 
und wenn durch die letztere eine Wasserschicht um den Fisch flüssig erhalten bleibt (Johannes Müller).

Bei direkter Einwirkung des Frostes auf den Fischkörper erstarren die Fische zunächst, lönnen aber, wenn die Frostwirkung nicht stundenlang dauert, zuweilen wieder belebt werden. Beim Durchfrieren des Fischkörpers sterben die Fische dagegen natürlich $a b$ ss).

Die Menge der von den Fischen aufzunehmenden Nahrung richtet sich wahrend der Hauptfresszeit in erster Linie nach der Menge der vorhandenen geeigneten Nahrungsmittel.

Die Fische können mit geringen Mengen von Nahrung erhalten werden, haben dann aber ein entsprechend geringes Wachstum und zeigen oft auch in ihrer Körperform Abweichungen von dem normalen Aussehen ihrer Art (so ist die als Giebel bekannte Abart der Karausche eine Hungerform, - den Fischzüchtern ist es lïngst bekannt, dass Fische mit kurzem IFopf rascher gewachsen und deshalb geeigneter "zur Zucht sind, als Fische mit gestrecktem Kopf). Anderseits künnen sie sehr grosse Mengen von Nahrung aufnehmen und dementsprechend wachsen. Man weiss aus guten Beobachtungen, dass ein Karpfen am Ende des ersten Jahres bei ungünstiger Nahrung nur wenige (iramm. lee günstiger Xihrung genen I Kilo wiegen kann, und dass das Gewicht der Hechte im ersten Herbst ihres Lebens zwischen 100 Gramm und mehreren Pfund schwanken kann.

Bei der Fütterung verbraucht die Forelle zur Zunahme um einen Gewvichtsteil fünf bis acht Gewichtsteile Futterfleisch, während der Karpfen schon aus drei bis vier Gewichtsteilen in gleichem Masse eiweisshaltigen Futters einen Gewichtsteil Körperzunahme gewinnt. Man benützt bei der Fütterung der Fische hauptsïchlich

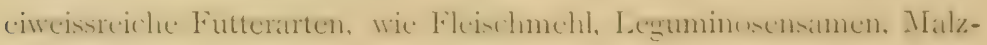
treber u. a.

Eine Anzahl von Fischarten erreicht in der Regel nur eine bestimmte geringe Grösse; man liann diese Fische als Zwergfische

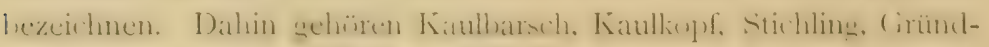
ling, Bitterling, Uklei, MIoderlieschen, Elritze, kleine Marïne, Stint, 
die Neunaugen. Die meisten anderen Fische wachsen entsprechend ihrer Ernährung sehr ungleichmässig. So erreicht die Bachforelle in den nahrungsarmen Gebirgsbiichen selten ein Gewicht von einem Pfund, während sie in Teichen, Flüssen und Seen (z. B. im IVeitsee bei Berent in Westpreussen) es zu einem Gewicht von I 2 Kilo bringen kann. Karpfen und Hechte hat man bis 25 Kilo schwer, Welse noch bedeutend grösser gefangen. In engen Gefüssen bleibt das Wachstum der Fische beschränkt, wie die konstante Grösse der in engen Gläsern gehaltenen Goldfische zeigt.

Über dem Darm und seinen Anhängen und Drüsen liegt die Schwimmblase, ursprünglich eine Ausstülpung des Darmes, bald mit dem Anfangsteil desselben durch einen im Alter oft geschlossenen Kanal verbunden (Plyysostomi: Siluriden, Cypriniden, Salmoniden, Hecht, Hundsfisch, Clupeiden, Aal, Stör), bald ohne Ausführungsgang (Perciden, Stichlinge, Aalquappe). Die Schwimmblase fehlt dem Kaulkopf und den Neunaugen. Sie ist ein häutiger Sack, prall gefüllt mit einer Gasmischung aus Stickstoff und Sauerstoff in wechselnden Mengen und etwas Kohlensäure. Diese Gase gelangen nicht etwa durch den zuweilen vorhandenen Ausführungsgang in die Schwimmblase, sondern sie werden von der Innenfläche derselben, wo sich oft Anhäufungen feiner Adern, sogenannte Vundernetze, finden, ausgeschieden. Man hält die Schwimmblase deshalb für ein Homologon der Lunge der höheren Wirbeltiere; dem ist jedoch widersprochen worden, weil sie oberhalb, nicht unterhalb des Darmkanals wie die Lunge, liegt 47). Auch die Funktion der Schwimmblase wird verschieden gedeutet. Vielfach hält man sie für einen hydrostatischen Apparat, der den Kë̈rper im Gleichgewicht erhält und zugleich geeignet ist, durch Kontralitionen das Steigen und Sinken des Fisches zu regeln. Indessen glaubt CharbonnelSalle nachgewiesen zu haben, dass die Druckschwankungen der Schwimmblase keinen Einfluss auf das spezifische Gewicht des Fisches und auf scin Auf-und Niedertauchen austiben'). Lrsprünglich

*) Platzt cinem Fisch die Schwimmblase und verbreitet sich die nicht mehr unter Druck stehende Luft derselben in der Leibeshöhle, so kann der aufgebliihte Fisch nicht mehr die Oberfläche verlassen und schwimmt auf dem Rücken. Diese Erfalrung spricht gegen.Charbonnel-Salles Ansicht. 
war sie vielleicht ein Sauerstoffreservoir (nach Biot\$5) hat man bei Tiefenfischen bis $87 \%$ Sauerstoff in der Schwimmblasenluft gefunden). Sie steht mit dem Hörorgan in Verbindung und wird wohl auch andere Druckwirkungen als die Schallwellen zur Empfindung bringen helfen.

Neben den Organen des Darmtractus liegen in der Bauchhöhle die Fortpflanzungsorgane der Fische, deren Produlte bei den männlichen Fischen als Milch, bei den weiblichen als Rogen bezeichnet werden. Danach heissen die Männchen auch Nilchner, die Weibchen Rogner. Unsere Fische sind sümtlich getrennten Geschlechtes; nur bei einzelnen Individuen ist, wie in allen Tierklassen, gelegentlich Hermaphroditismus nachgewiesen.

Die Männchen sind bei den Fischen oft kleiner ${ }^{49}$ ) und häufig seltener als die Weibchen. Unter den Steinbeissern hat man sogar nur ro $\%$ Männchen gefunden 50 ).

Das Geschlecht ist bei manchen Fischen, besonders zur Laichzeit, auch äusserlich durch die Beschaffenheit der Geschlechtsteile oder durch sekundüre Geschlechtsmerkmale erkennbar. Die weiblichen Fische zeigen in der Laichzeit einen durch die reifen Eier gewölbten Bauch, während die Männchen schlank bleiben. Die Geschlechtsöffnung, welche hinter dem After liegt, befindet sich beim Weibchen oft an der Spitze einer kegelförmigen Erhöhung, die in der Laichzeit gerötet ist und beim Bitterling zu einer $3-4 \mathrm{~cm}$ latugen Legeröhre auswïchst. Ensere einheimischen süsswalsserfische sind sämtich uvipar, d. h. die Weilxhen legen Eier ab; die Rier werden erst nach dem Austreten befruchtet. Da eine innere Befruchtung der Eier anscheinend nie erfolgt, su fehlen den Mïnnehen besundere Organc für die innere Begattung, ihre Geschlechtsïflinung liegt meist in der Tiefe einer flachen Rinne. Selindäre Geschlechtscharaktere finden sich namentlich als lebhafte Fürbung bei den Mámnchen vieler Fischarten, meist nur in der Brunstzeit. So glanzen namentlich die Männchen der Stichlinge und der Bitterlinge während der Laichzeit in bunten Farben. Bei anderen Fischen werden die immer vorhandenen Farben des Kürpers und der Flossen lebhafter. Bei den meisten Cypriniden tritt an den Minnchen in der Laichzeit 
an den Seiten und teilweise auch am Kopfe auf jeder Schuppe ein weisses hartes Höckerchen auf, das aus Oberhautzellen besteht und nach der Laichzeit wieder verschwindet. Bei den Coregonen finden sich ähnliche Hautwarzen zur Laichzeit bei beiden Geschlechtern als Brunstmerkmale. Beim männlichen Schleih ist der zweite Strahl der Bauchflossen stark verbreitert, verdickt und gelirümmt, gleichzeitig ist das Stützskelett dieser Flossen etwas verstärkt. Eine ähnliche Abweichung findet sich- bei den männlichen Steinbeissern am zweiten Strahl der Brustflossen.

Die Geschlechtsreife der weiblichen Fische tritt in der Regel im dritten Jahre ein, seltener später oder schon im zweiten Jahre. Die Männchen werden oft schon im zweiten Jahre laichreif. Manche Individuen (bei den Cypriniden, Lachsen, Forellen, Stören, Aalen) bleiben ganz unfruchtbar. Da diese Exemplare besonders fett und wohlschmeckend sind, so hat man die Fische auch, und zwar mit dem gewünschten Zuchterfolge, kastriert.

Die Neunaugen machen nach ihrem Ausschlüpfen aus dem Ei noch eine lange dauernde Metamorphose durch 40). Die Larven, Querder (früher für eine besondere Art, Ammocoetes branchialis, gehalten) sind blind und leben im Grunde der Bäche. Gegeri den Herbst des vierten oder fünften Jahres beginnt die Verwandlung in die Form der erwachsenen Neunaugen, nach deren Ausbildung die Flussneunaugen, etwa $20 \mathrm{~cm}$ lang, in die See hinabwandern, von wo sie nach mehreren Jahren laichreif zurückkehren, während die Bachneunaugen ihre Laichreife in ihren Heimatsbächen erreichen können. Die Neunaugen laichen nur einmal in ihrem Leben, nach dem Laichen sterben sie ab.

Bei den Stören und den meisten Knochenfischen sind die Eierstöcke und Hoden ${ }^{40}$ ) paarig vorhanden, bei den Perciden und Acanthopsiden einfach. Die Hoden besitzen besondere Ausführungsgainge, welche sich rereinigen und gemeinsam mit den Harnleitern hinter dem After münden. Auch die Eierstöcke besitzen meist Ausführungsginge, welche nach ihrer Vereinigung zwischen dem After und der dahinter liegenden Harnöffnung nach aussen münden. Diese mit Ausführungsgängen versehenen Eicrstöclie sind im übrigen 
geschlossene Säicke, in deren Falten die Eier sich entwickeln. Die Salmoniden, Acanthopsiden und der Aal haben dagegen Eierstöcke, welche nur gefaltete Platten darstellen, aus denen die Eier nach ihrer Reife in die Bauchhöhle fallen. Aus dieser treten sie durch eine besondere Öffnung, welche die gewöhnliche Lage hat, ins Freie. Bei den Salmoniden finden sich beiderseits vom After offene oder nur durch Rudimente angedeutete sogenannte Abdominalporen, durch welche die Bauchhöhle nach aussen mündet. Huxley ${ }^{51}$ ) hält diese Poren, ebenso wie ähnlich gelegene Spalten in der Leibeswand beim Stör, für rudimentäre Eileiter, während W Weber ${ }^{52}$ ) sie für rudimentäre Segmentalgänge erklärt (also den Mündungen der Segmentalorgane der Anneliden entsprechend). Anderer Art als

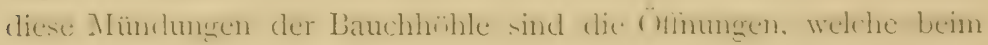
Wels hinter den Brustflossen sich finden und nicht in die Bauchhühle, sondern in Taschen, die in der Haut liegen, münden. Auch über die Bedleutung dieser Öfrnungen weiss man nichts Gewisses.

Die Samenfäden der Fische bestehen aus einem meist rundlichen Köpfchen, welches den Kern enthült, und einer fädlichen Geissel von etwa $0.05 m m$ Länge. Die Eier der einheimischen Fische sind fast kugelig und mit mehreren Hautschichten umschlossen, welche von zahlreichen Poren clurchsetzt sind. An einer Stelle finclet sich eine etwas vertieft gelegene Verdünnung der Eihäute, die Mikropyle, clurch welche in der Regel der Samenfaclen in clas Ei tritt. Die Eier der Salmoniden-Arten sind verháltnismïssig gross, das Lachsei hat $5-7 m m$ Durchmesser. Die übrigen Fischeier haben nur $1-3$ mm Durchmesser.

Dic Ablage und Befruchtung der Eier findet an dem Orte statt, wo die Eier die ihmen zusagenden Entwickelungsbedingungen finden. Die meisten Eier werden kJebend, sobald sie in das Wasser kommen, indem die ausserste Schicht der ïusseren Eihaut, der Zona radiata, entweder gleichmäsig aufquillt oder beim Quellen in Zotten oder Futden zerreisst53). Auf diese Weise kleben die Eier an den Gegenstäinden fest, auf die sie fallen, namentlich Pflanzen, Steine, Baumwurzeln, Kies, je nach der Örtlichkeit, die die Fische 
zum Laichen aufsuchen. Die Hechte, die am frühsten im Jahr laichen, legen ihren Laich auf dem Grase überschwemmter Wiesen $\mathrm{ab}$, die Cypriniden, die sich auf den Laichplätzen in Scharen zusammenfinden, meist auf Wasserpflanzen, andere auf Kiesbänken im strömenden Wasser oder am Abhang des Ufergrundes der Seen. Die Coregonen lassen ihre Eier entweder in die Wassertiefe sinken oder sie streuen sie an die auf Mergelboden wachsenden Armleuchtergewïchse, auf Ceratophyllum oder ähnliche starre Wasserpflanzen. Häufig tritt bei manchen Arten nach dem Laichen eine- starke Sterblichkeit ein, z. B. bei den Maifischen.

Besonclere Eigentümlichkeiten in ihren Laichverhältnissen zeigen einige Fischarten, welche teils im Meer, teils im Süsswasser leben. Dahin gehört namentlich der Aal.54). Die Eierstöcke dieses Fisches wurden zuerst von Mondini55) entdeckt, später von Rathke+1) von Neuem aufgefunden. Es sind zwei weisse, gekräuselte Bänder, die sogenannten Manchettenorgane, welche zu beiden Seiten der Schwimmblase von vorn bis hinten sich erstrecken. Betrachtet man ein Stückchen dieser Bänder unter dem Mikroskop (bei 50-IOOfacher Vergrösserung), so sieht man ausser vielen ungleich grossen Fettzellen die durchsichtigen runden Eier, jedes mit einem „Keimbläschen" (dem Kern) im Innern. Diese Eier sind zu mehreren Millionen in einem weiblichen Aal enthalten, werden aber im Süsswasser nicht grösser als etwa $1 / 4-1 / 3 m m$ im Durchmesser. Da man männliche Individuen unter den Aalen lange Zeit nicht fand, so hielt man die Aale für Zwitter. Man glaubte auch die Hoden in Fettwulsten neben dem Ovar gefunden zu haben. Erst Syrski56) fand I 874, dass beim Aal die Geschlechter getrennt sind, indem er in den männlichen Aalen die Hoden (Lappenorgane) nachwies. Man weiss nun, dass die Aale in den süssen Gewässern meist Veibchen sind, dass dieselben im fünften oder sechsten Lebensjahre in die See wandern, dass sie im Brackwasser die Männchen finden und dass die ausgewachsenen Individuen beider Geschlechter sodann in der Tiefe des Meeres verschwinden, ohne wiederzukehren. Darüber hinaus ist unsere Kenntnis von der Fortpflanzung der Aale noch nicht gekommen. Ein Versuch, erwachsene Aale in grossen 
Fischkästen in der Ostsee laichreif werden zu lassen, führte auch zu keinem Resultat $\left.{ }^{5} \bar{i}\right)$. Man nimmt daher an, dass die Aale in der Tiefe des Meeres*) (die der Ostsee in der Nordsee) ähnlich den übrigen Fischen den Laich ablegen und befruchten, und zwar im Winter, und dass sie dann absterben. Im Frühjahr kommen im März oder April die jungen Aale in ungeheuren Massen als fingerlange, schlanke, durchsichtige Tierchen an die Küsten, und ziehen an diesen entlang in die Ströme und bis in deren kleinste Nebenwässer. Sie wandern immer gegen die Strömung und nur nachts, besonders bei warmem Wetter; am Tage halten sie sich an ruhigen Stellen, zwischen Kies, unter Steinen, im Kraut auf. Sie wachsen während ihrer Wanderung. Kommen sie an Mühlenwehre oder andere Stauwerke, so suchen sie an schadhaften Stellen, an denen ein wenig Wasser herabrieselt, aufzusteigen. Ihre klebrige Oberhaut und ihr gelenkiger, dünner Körper begünstigt diese Kletterversuche, so dass ein Teil von ihnen in der Regel die nicht zu hohen und nicht ganz festgeschlossenen Stauwerke zu überwinden vermag. Erst die kalte Jahreszeit scheint ihren Wanderungen ein Ziel zu setzen, doch hat man noch bei ein- und zweijährigen Aalen Wanderungen gegen das strömende Wasser beobachtet.

Ein anderer interessanter Wanderfisch ist der Lachs. Im allgemeinen bewohnt er das. Meer und steigt aus diesem in das Süsswasser auf, um hier laichreif zu werden. Ausnahmsweise hat man gefunden, dass Lachse auch im Nieere laichreif geworden sind 59). Anderseits haben Fritsch (0) und Metzger61) beobachtet, dass Lachsmilchner, ohne das Süsswasser verlassen zu haben, schon im zweiten Herbst ihres Lebens laichreif geworden sind und die Eier der in ihre Wohnbäche aufgestiegenen Lachsrogner befruchtet haben. Doch sind beide Fülle vermutlich nur Ausnahmen. Die Zeit des Eintritts in die Stromsysteme ist sehr verschieden. In das kurische Haff (Memel) geht der Lachs im Mai, in die in der Nahe der Weichsel in die Danziger Bucht mündende Rheda steigt or am stärksten im Juli auf, während er in die Weichsel

*) Fritsch nimmt an, dass die Laichstellen in der Gegend von Süsswasseriquellen liegen, aus welchem Grunde, ist leider nicht gesagt iy). 
selbst fast ausschliesslich im Herbst eintritt. In der untern Oder findet sich der Lachs im August und September. Im Rhein 62) unterscheidet man nach der Zeit ihres Auftretens und nach ihrem Körperzustande den St. Jakobsalm, der in Holland um Jakobi (25. Juli) in den Rhein tritt und etwa $\mathrm{I}^{1 / 2} k$ schwer und $40-50 \mathrm{~cm}$ lang ist, und den Wintersalm, der viel grösser und schwerer ist und um Mitte September in Holland erscheint.

Die Geschlechtsorgane sind beim Eintritt in das Süsswasser noch wenig entwickelt, der Eidurchmesser etwa $0.5 \mathrm{~mm}$ gross, das Gewicht der Geschlechtsorgane beträgt kaum $0.5 \%$ des Körpergewichts, während dieselben im reifen Zustande fast ein Viertel des Körpergewichtes ausmachen. Im Süsswasser entwickeln sie sich allmälhlich und zwar ausschliesslich auf Kosten der Rumpfmuskulatur. welche nicht nur verhältnismässig ärmer an Fett und Eiweissstoffen wird, sondern auch an absolutem Gewicht stark abnimmt, weil der Lachs im Süsswasser keine Nahrung aufnimmt 63), sondern ganz auf Kosten seiner im Meere gut genährten Organe sein Leben fristet. Das Fleisch der im Süsswasser sich so entwickelnden Fische wird daher immer schlechter und verliert seine rote Farbe. Gleichzeitig treten sekundäre Geschlechtscharaktere auf. Die Haut verdickt sich namentlich am Kopfe und Rücken schwartenartig und wird dunkler, die Männchen bekommen rote Flecken an den Seiten, namentlich auf den Kiemendeckeln, an der Spitze ihres Unterkiefers entwickelt sich ein knorpeliger Haken, der bei grösseren Tieren so stark wird, dass er das Schliessen des Maules hindert. Endlich, bei den im Herbst ins Süsswasser gelangten Fischen, meist erst im Herbst des folgenden Jahres, tritt die völlige Laichreife ein. Die Fische suchen nun, wie Fritsch 64 ) schildert, die seichten Stellen der Båche auf, am liebsten oberhalb stärkerer Strömungen, dort wo das Wasser sich $\mathrm{zu}$ brechen anfängt. Hier wirft das Weibchen durch Schwanzbewegungen die Kiesel des Bachgrundes zur Seite und stellt dadurch eine seichte Grube her, die Laichgrube. Nach einiger Zeit stellen sich bei der Laichgrube täglich morgens und abends das Weibchen und ein oder mehrere Nǐnnchen ein. Sie liegen oft still in den Laichgruben, so dicht neben einander, dass 


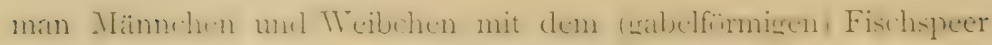
zugleich spiessen kann. Beim Laichgeschäft streicht das Weibchen, indem es den Bauch auf dem Grunde der Grube reibt, die Eier $\mathrm{ab}$; das Männchen steht etwa I $m$ stromaufwärts und lässt die Milch in das Wasser, die Milch strömt zu den Eiem und bewirkt die Befruchtung. So setzen sie es mehrere Wochen lang fort, wenn sie nicht gestört werden.

Nach dem Laichen, in Bühmen beim Fallen des ersten Schnees, verschwindet der Laichlachs. Er ist dann ganz abgemagert, mit schlaffem Körper, und völlig kraftlos und wird, wenn er nicht abstirbt, von der Strömung abwärts zum Meere. getragen. Nach Miescher kommt der männliche Lachs in der Regel zwei- bis dreimal in mehrjährigen Zwischenräumen, der weibliche ein- bis zweimal zur Laiche in den Rhein. Unter den kleinen Jakobsalmen sind wenige Weibchen zu finden; man schliesst daraus, dass die Weibchen oft erst später reif werden, als die München.

Die aus den Eiern schlüpfenden Lachse werden als Salmlinge bezeichnet. Sie halten sich in der Regel nur bis zum näichsten Hochwasser in dem Bach, in dem sie geboren sind, auf, und gehen mit dem Hochwasser als etwa handlange Fische in das Neer hinab. So lange sie in den Bäichen bleiben, leben sie hier ähnlich wie die verwandten Salmoarten, sind aber nicht so lichtscheu, wie die Forellen, sondern stehen gern im fliessenden Wasser gegen die Strömung gerichtet.

Die Forellen haben :hnliche Laichverhältnisse wic die Lachse. Die Necrforellen und Seeforellen wandern zur Laichzeit stromaufwirts, letztere gegebenen Falles auch stromabwirts, um in geeigneten Bächen auf Kies- oder Sandgrund zu laichen.

Alle einheimischen Salmoniden mit Ausnahme des Stint, des Huchen und der Aesche, laichen im Herbst oder Winter, und die Jungen schlüpfen erst im Beginn des Frühjahres aus den Eiern. Diese bleiben also monatelang unausgebrütet, ohne jeden Schutz, der Vernichtung durch zahlreiche tierische Feinde, durch Wasserschimmel, durch die Abwässer der Fabriken ausgesetzt. 
Um diese als Delikatesse gesuchten Edelfische nun vor der Ausrottung zu bewahren, hat man sich in grossem Nasstabe und mit viel Erfulg eines I Iilfsmittels bedient, welches ihnen den Kimnp ums Dasein mit den übrigen Wassertieren erheblich erleichtert, der sogenannten künstlichen Fischzucht ${ }^{65}$ ), durch welche nicht nur die Vermehrung der Salmoniden in den deutschen Seen, Flüssen und Meeren, sondern auch die vieler anderer Fische in stehenden und fliessenden Gewässern, sowie die Übertragung von Fischarten in neue, von ihnen nicht bewohnte Gewässer in zahlreichen Fällen erzielt ist.

Unter ,künstlicher Fischzucht" versteht man zunächst die Befruchtung und Erbrütung von Fischeiern unter Zuthun des Menschen. Ein Detmolder Landwirt, Jakobi, erfand diese Methode in der Mitte des vorigen Jahrhunderts, doch wurde sie wegen der mühsamen Bedienung des im Bache stehenden Brutkastens selten angewendet. In Norwegen, Russland, namentlich aber in Frankreich wurden später ähnliche Verfahren entdeckt. Professor Coste in Paris interessierte sich dafür, und auf seine Veranlassung wurde I 852 von der französischen Regierung die Brutanstalt in Hüningen bei St. Ludwig im Elsass gegründet, welche I87 I vom Deutschen Reiche übernommen wurde. Von Deutschen ist zuerst in München ein Bruthaus für künstliche Fischerbrütung angelegt. Inzwischen ist die Methode besonders in Amerika, in neuerer Zeit auch in Deutschland weitergebildet und sehr vervollkommnet worden 66 ), und jetzt zählen die Anstalten für künstliche Fischzucht in Deutschland nach hunderten.

Zur künstlichen Befruchtung werden die Eier des reifen Weibchens, welche lose im Ovar, bezw. in der Bauchhöhle liegen, durch gelindes Streichen herausgedrückt und in einer Schale aufgefangen, eine kleine Menge Samen, welcher in gleicher Weise aus . den Hoden eines Männchens herausgestrichen ist, wird auf die Eier gebracht und durch vorsichtiges Umrühren zwischen die Eier verteilt, Wasser hinzugegossen und dann die Schale mit ihrem Inhalt für kurze \%cit sich selbst überlassen. Die simenfiiclen fangen ihre Schwärm- und Bohrbewegungen an, sobald sie mit dem Wasser 
in Berührung kommen. Die Eier vieler Fische schwellen durch Wasseraufnahme auf und saugen dabei gewissermassen die Samenfaden in sich ein. Auf diese Weise werden alle reifen Eier, die sich in der Schale befinden, befruchtet (während bei der Laichablage in der freien Natur eine grosse Menge der abgesetzten Eier unbefruchtet bleibt) und sind dann entwicklungsfähig. Sie können jetzt sofort in die freien Gewisser gebracht und dort an geeigneten Stellen, d. h. an solchen, an welchen die Fische ihrer Art laichen würden, ausgesetzt werden. Allein der Fischlaich ist im Freien unzähligen Gefahren ausgesetzt. Fast alle Wassertiere, welche ihn bewalltigen können, stellen ihm nach, ungünstige Witterung tötet ihn, Wellenschlag wirft ihn auf das Land. Deshalb ist es besser, ihn so lange als möglich unter Obhut $\mathrm{zu}$ behalten, ihn künstlich $\mathrm{zu}$ erbrüten. Man bringt ihn in Brutapparate. Die Brutapparate sind fast durchgehends so eingerichtet, dass in ihnen die Eier von fliessendem, klarem, reinem, aber sauerstoffreichem und gleichmässig kühlem Wasser bespült werden. In Jakobis Brutkiste lagen sie auf Kies, die Kiste hatte auf den Sclimalseiten Gitter und war so in einen Bach gestellt, dass das Wasser durch die Gitter über die Eier floss. Coste legte die Eier auf einen Glasrost, der in einem Gefiss stand. Solche Gefüsse stellte er staffelfürmig über einander, so dass das Wasser, das in das höchststehende geleitet war, aus diesem in das nächst tiefere floss etc. Später wandte man Sicbe aus Metall oder Thon an. Die Amerikaner scheinen zuerst Drahtgeflechte zur Aufnahme der Eier angewandt zu haben. Dies ist jetzt die übliche Unterlage. Man lässt das Wasser entweder seitlich an den Eiern vorbeifliessen, oder man richtet die Apparate so ein, dass das Wasser von unten her durch die Unterlage und dann durch die Eierschichten strümt, wodurch das Wasser am besten ausgenutzt wird. In anderen Apparaten werden die Eier nicht ruhend, sondern schwebend ausgebrütet, indem in das kelchförmige oder cylinderförmige Brutgefïss ein krïftiger Wasserstrahl von unten her eingeleitet wird, welcher die Eier in die Höhe trägt; nach oben hin verteilt sich der Wasserstrom und verliert an Kraft, die Eier geraten in das ruhigere Wasser an den Gefusswänden, sinken hier 
durch ihre Eigenschwere hinab und werden ron dem Wasserstrom unten sofort in erneutem Spiel in die Höhe getrieben ${ }^{6}$ ). Diese Apparate sind besonders für kleinere Eier, wie die der Hechte und Coregonen, geeignet. Sie haben unter anderem den besondern Vorteil, dass die abgestorbenen Eier, welche etwas leichter werden als die lebenden, sich von den letzteren absondern und bei etwas verstärktem Strome von selbst mit dem durchgeleiteten Wasser abschwimmen können. Man nennt sie deshalb Selbstausleser.

Eine dritte Methode ist die Erbrütung in Eisschränken, in welchen die Eier nur von dem tropfenweise herabrinnenden Schmelzwasser des über ihnen angebrachten Eises feucht und kühl gehalten werden. Diese Eisbrutschränke dienen auch zum Transport von Eiern, welche wochenlang unterwegs sein müssen. MIan hat in ihnen die Eier fremder Fischarten über die Ozeane in neue Gebiete, selbst über den Äquator hinaus, eingeführt, z. B. den Lachs der nördlichen Hemisphäre in australische Gewässer.

Leider ist die Nethode der künstlichen Befruchtung und Erbrütung nur bei einer beschränkten Zahl von Fischarten pralitisch anwendbar. Der erste Mangel, den diese Methode hat, liegt in der Notwendigkeit, dass die Laichfische in dem gerade zur Befruchtung geeigneten Laichreifestadium zur Hand sein müssen. Einige Fische kïnnen dieses Stadium in der Gefangenschaft enreichen. Viele andere aber werden, auch kurz vor der Laichreife eingefangen, in engen Behältern nicht laichreif. Bei anderen Fischarten (Karpfen, Bressen, Stör und den meisten anderen Sommerlaichern) quillt, wie oben erwähnt, die Eihaut bei der Berührung mit Wasser zu einer klebrigen Substanz auf; diese Eier ballen sich zu zähen Klumpen zusammen, wenn sie abgestrichen sind, so dass die Zuführung von Wasser und Sauerstoff zu den im Innern des Klumpens gelegenen Eiern und dadurch ihre Erbrütung unmöglich gemacht wird. NIan kann diese Eier indessen unmittelbar nach der Befruchtung auf Wacholder, MLos oder Wasserkräuter vorsichtig in dünner Schicht verteilen und sie in flachen Kürben in stillem, warmem Wasser ausbrüten lassen; die Jungen schlüpfen dann nach einigen Tagen aus und gelangen durch die Korböffnungen in das Gewässer, in 
dem der Korb steht, worin sie, wenn das Gewässer fischleer ist, so lange aufwachsen, als sie Nahrung finden.

Die Eier der meisten Salmoniden sind sehr geeignet zur kïnstlichen Erbrütung. Forellen und Lachse werden in Behailtern reif, und ihre Eier sowie die der Coregonen und Aeschen kileben nur wenig. Gerade diese Salmoniden bedürfen aber auch des besondern Schutzes in hohem Masse. Ihre Laichzeit fallt, bis auf die der Aesche, in den Herbst und den Winter, die Entwickelungsdauer der Eier ist cine sehr lange, und die Eier sind gross und oft lebhaft gefärbt. Dabei ist die Zahl der Eier, welche die Salmoniden produzieren, nicht so bedeutend, wie die vieler im Sommer laichender Fische. Deshalb ist es nötig, den Laich dieser Edelfische so gut als möglich zu schützen und ihn künstlich befruchtet in Bruthäusern ausschlüpfen zu lassen.

Wie auf die meisten anderen Lebensverhältnisse der Fische, so ist auch auf die Länge der Entwickelungszeit der Eier die Wasserwärme von grösstem Einfluss. Je kälter das erbrütende Wasser ist, um so längere Zeit muss es auf die Eier einwirken, bevor dieselben ausschlüpfen*). Die Eier vieler Sommerlaicher vertragen dabei nur schlecht die Kühle und sterben im Freien oft ab, wenn das Wasser auf die Dauer kalt bleibt. Die Eier der

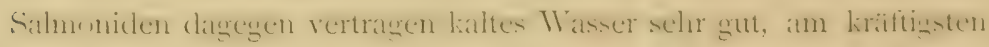
entwickeln sich die Fische aus Eiern, die in eiskalten Wasser gebrütet sind. Man unterscheidet während der Brütung der Salmoniden-Eier zwei Hauptperioden. Die erste reicht von der Befruchtung bis zum Sichtbarwerden der schwarzen Augenpupillen des Embryo, und dauert für Lachse und Forellen bei einer Durchschnittstemperatur des Wassers von $5^{\circ}$ C. etwa $3^{1 / 2}$ Monate; die zweite umfasst die Zeit bis zum Ausschlüpfen, sie dauert bei Lachs und Forelle etwa 2 Monate bei der angeführten Wassertemperatur 68). Die Eier der Coregonen haben eine kürzere Ent-

7) Man muss aus den Resultaten der Untersucbungen von Barfurth (Jahresbericht des Rheinischen lïschereivereins 1888) allerdings schliessen, dass die L̈ntwickelungsuauer der Salmoniden nicht genau in dem Verhältnis verkïrzt wird, in welchem man die Wassertemperatur erhüht, dass vielmehr die Eier in wïrmerem Wasser mehr Wïrme verbrauchen als in kilterem Wasser. 
wickelungsdauer. In der zweiten Entwickelungsperiode sind alle. Salmoniden-Eier ziemlich widerstandsfiihig; sic lïmnen dann, kïhlgehalten, auf weiche Unterlage gebettet und mit dieser fest verpackt, weithin versandt werden und wochenlange, im Eisschranke sogar monatelange Reisen überdauern. Nach dem Ausschlüpfen schwärmen die jungen Coregonen wie die Brut der meisten anderen Fische sogleich frei umher, obwohl die Brustflossen noch gar nicht und die Bauchflossen erst als Stummel entwickelt sind. Die Brut der Forellen und Lachse dagegen ist mit einem grossen Dottersäckchen beschwert, das ihr am Bauche hängt und bei den Schwimmbewegungen anfangs hinderlich ist, weshalb diese Tierchen in den ersten Wochen, ohne sich viel zu bewegen, am Boden der Brutgefässe liegen. Erst wenn der Dottervorrat eingesogen ist, haben auch sie freie Beweglichkeit erlangt. Dann ist es Zeit, sie in die freien Gewàsser zu bringen.

Die Erfolge, welche bis jetzt durch die künstliche Fischzucht erzielt sind, sind recht erhebliche. Zunächst ist mit ihrer Hilfe der Bestand an Lachsen nachweisbar vermehrt worden. Der Lachs hat seines hohen Preises wegen und weil er verhältnismässig sicher zu fangen ist, grosse Bedeutung für die Fischerei, und zwar sowohl für die Binnenfischerei als auch für die Meeresfischerei (wenigstens in der Ostsee). Seit 1879 hat sich nach der holländischen Verkaufsstatistik ${ }^{69}$ ) der Ertrag des Lachsfanges in den Rheinmündungen etwa verdoppelt, und diese günstige Änderung wird mit Recht auf die Aussetzung zahlreicher Brutmengen in die Nebenbäche des Rheins zurücligeführt. Ebenso ist der Lachsbestand in der Ems und der WVeser, in denen er sehr zurückgegangen war, allem Anschein nach wieder durch Bruteinsetzungen gehoben worden. In der Elbe ist der Lachsbestand besonders durch künstliche Lachszucht in Böhmen vermehrt worden. Im Odergebiet liegen die Laichpläze der Lachse in einigen Nebenflüsschen der Netze, der Drage und der Küddow, wahrscheinlich, weil den Lachsen der Zutritt zu den. Quellgebieten der Oder in Schlesien durch die grossen Wehre bei Breslau seit langen Zeiten 


\section{Die deutschen Süsswasserfische und ihre Lebensverlä̈lnisse.}

alugeschnitten ist, und an diesen Wehren leider noch keine Fischwege angebracht sind. In der Weichselmündung hat sich der Lachsfang infolge der Brutaussetzung in Galizien und Westpreussen ebenfalls deutlich vermehrt.

Ein dem Lachs nach Körperform, Grösse und Lebensweise sehr ähnlicher Fisch ist die Meerforelle. Auch mit ihr sind durch kïnstliche Fischzucht, namentlich in den hulsteinischen Auen, vorzügliche Resultate erzielt worden.

Die stärkste Vermehrung durch künstliche Fischzucht dürfte der Bachforelle zu teil werden, von der alljährlich mehrere Millionen künstlich erbrüteter Jungfische zur Pesctzung von Zuchtbächen und Teichen benutzt werden, um als $2-3$ jährige Fische zum Verbrauch ausgefischt zu werden.

Wie oben auseinandergesetzt ist, gelingt es nicht bei allen Fischen, den Laich zur künstlichen Erbrütung zu verwenden. Wo dies unbequem oder unmöglich ist, ist man für die geschützte Vermehrung der Fische darauf angewiesen, die Fische das Laichgeschäft auf natüliche Weise in ablassbaren Bassins, Teichen uder ahnlichen Behältern, deren Inhalt man in sciner Gewalt hat, vollziehen zu lassen und die gewonnene Fischbrut in geeignetem Alter wie die durch künstliche Erbrütung gewonnene zu verwenden. Die Teichzucht gehört deshalb auch zur künstlichen Fischzucht, und um so mehr, als die künstlich erbrüteten Fische zweckmässigerweise zuerst einen Sommer über in einem Teich oder einem ablassbaren Graben gezogen und erst, wenn sie hier zu kräftigen Fischehen heranewathsen sind, in die freien Gewässer ähertragen werden.

Besonders häufig wird der Karpfen in Teichen gezogen ${ }^{70}$ ). Am geeignetsten für die Karpfenzucht sind flache Teiche. Da aber die Karpfen in diesen in Winter unter dem Eise leicht ersticken, so nimmt man sic im Herbst aus solchen Teichen in der Regel heraus und bringt sie in kleine, tiefe, durchströmte Teiche (Winterheller). Da eine gleiche Zahl Karpfen je nach ihrem Alter und ihrer Grüsse mehr oder mincler grosse Teichliaichen 
beansprucht, so setzt man die einzelnen Jahrgänge in besondere Teiche zusammen, deren Grüsse ihrem Nahrungsbedürfnis entspricht. Die für das Ablaichen und die erste Entwickelung der Brut bestimmten Teiche heissen Streichteiche. Aus ihnen überträgt man die Jungen in die sogenannten Streckteiche, wo sie I-2 Jahre aufwachsen, bis sie zur Erreichung der Grösse, in der sie verkauft werden (meist I-I $1 / 4$ Kilo schwer), in die sogenannten Abwachsteiche kommen, in denen man ihnen meist kleine Raubfische (Hechte, Zander, Furellen) beigiebt, damit die etwa ron frühreifen Karpfen erzeugte Brut sogleich beseitigt wird und nicht den zum Auswachsen bestimmten Karpfen das Futter schmälert. AIan nimmt an, dass die Fische um so wohlschmeckender sind, je rascher sie gewachsen sind. Aus diesem Grunde und weil ein rasches Wachstum, ein müglichst gründliches Ausnützen des vorhandenen Futters für den Züchter offenbar von Vorteil ist, bemüht man sich, möglichst schnellwüchsige Karpfen zur Zucht zu nehmen. Man erreicht dies einerseits dadurch, dass man nur die am besten gewachsenen unter den zur Laichreife gelangten Karpfen in die Streichteiche nimmt, anderseits, indem man die Karpfenbrut schon im ersten Sommer ihres Lebens durch reichliche Nahrung und Schutz vor Feinḍen zu kräftigen Tieren erzieht. Ein Verfahren, um dies zu erreichen, ist von dem schlesischen Fischzüchter Dubisch erfunden. Man nimmt danach die Karpfenbrut schon acht Tage nach ihrem Ausschlüpfen mit Gazenetzen aus dem Teich und bringt sie in andere Teiche, so dass etwa 25000 auf den Heltar Teichfläche kommen. Schon nach vier Wochen fängt man sie abermals heraus und überträgt sie in andere Teiche, so dass nur 1000 Stück im Heltar enthalten sind. Im zweiten Frühjahr bringt man sie in eine dritte Klasse von Streckteichen, in welchen nur 500 im Hektar sich befinden. Endlich im dritten Frühjahr bringt man sie in Abwachsteiche und setzt in diesen auf den Hektar 200 Karpfen. Man erzielt auf diese Weise pro Hektar Teichfläche etwa I20 Karpfen von etwas über I Kilo Schwere, was einem jährlichen Ertrag von etwa I62 Mark aus jedem Helitar entspricht. 
Mit Hilfe der künstlichen Erbrütung von Eiern und der durch das Dubisch-Verfahren vervollkommneten Teichwirtschaft hat man auch eine Anzahl ausländischer Fischarten in Deutschland eingeführt, die man zwar noch nicht gut als der deutschen Fauna angehörig betrachten kann, die aber teilweise doch einmal eine Rolle in unserer Tierwelt werden spielen können.

Man sollte bezüglich der Einführung neuer Fischarten sein Augenmerk zunächst auf die Gegend wenden, von wo die meisten unserer einheimischen Fischarten herstammen, nach Gsteurnpa und Nordasien, da die Fische dieser Gegenden sich ohne Zweifel in ähnlichen Lebenswerhältnissen befinden, wie unsere einheimischen. Nan hat aus dieser Gegend den Sterlett in die norddeutschen Ströme einzuführen versucht; leider sind die Fische bezw. Eier auf dem Transport meist zu Grunde gegangen, wahrscheinlich nur infolge von Zufälligkeiten.

Am leichtesten gelingt der Transport der sich langsam entwickelnden Eier der Salmoniden. Man hat in dieser Form nicht nur europäische Lachse und Forellen nach Tasmanien und Neuseckind i1), Furellen und Marainen i2) nach Amerika gebracht, sondern auch eine ganze Anzahl von Salmoniden Amerikas in Deutschland eingeführt 73 ). Ton diesen sind der Iachsaibling f.Salmo fontinalis Gemminger) aus den Baichen Nordamerikas und die Regenlugenforelle (Salno irideus, Livingston Stone) aus dem Höhenlande Kaliforniens weit verbreitet und, der erstere in rasch fliessenden Büchen, die selbst der Forelle zu reissend sind, die letztere auch in Teichen, vortrefflich gediehen. Auch einige amerikanische Sommerlaicher sind durch die Bemühungen des Fischzüchters M. von dem Borne in Deutschland verbreitet. Es sind dies der Schwarzbarsch (Grystes nigricans Günther) und der Forellenbarsch (Grystes salmoides Gü.), zwei Fische der Barben- und Bleiregion, denen ein vorzüglich feines Fleisch zugeschrieben wird und die bezüglich ihrer Lebensbedingungen, wenigstens was die Reinheit des Wassers betrift, anspruchsloser als die feineren einheimischen Tafelfische sind 74 ), - ferner, erst neuerdings eingeführt, der Steinbarsch, Centrarchus acneus C., aus dem 
Nississippi 75), und der Zwergwels, Amiurus catus Jord. u. Gilb., aus den flacheren Gewässern dieses Gebietes 76$)$.

Auch innerhalb unseres Gebietes haben mehrere Fischarten mit Hilfe der Fischzucht oder der aus derselben gezogenen Erfahrungen eine weitere Verbreitung erhalten, als ihnen von Natur zukommt. Dahin gehört der Karpfen, der seit alter Zeit in ganz Deutschland gezüchtet wird, und der Zander, welcher in die Gebiete des Rheins, der Ems und der Weser, sowie in zahlreiche norddeutsche Seen, in denen er bisher fehlte, künstlich eingeführt ist.

Vorzügliche Resultate sind mit der Verbreitung der Aalbrut erreicht worden, die in den Mündungen des Po und der Flüsse der französischen Ozeanküste in Menge gefangen wird. Direktor Haack bringt jährlich grosse Massen davon nach Hüningen, von wo die jungen Tiere in feuchtes Kraut verpackt bequem mit der Post versendet werden. Zahlreiche Gewässer, welche die Aalbrut auf ihrer Wanderung nicht aufsuchen kann, sind auf diese Weise mit Aalen bevölkert worden. Auch ist ein gross angelegter Versuch gemacht worden, das Donaugebiet, das wie alle Flussgebiete des Schwarzen Meeres den Aal bisher nicht besass, mit diesem Fisch zu besetzen. Zahlreiche junge Aale sind in dem oberen Donaugebiet ausgesetzt worden und die Tiere wuchsen dort gut auf. Der grösste Teil der eingesetzten Brut bestand indessen aus Weibchen. Um die Fortpflanzung zu sichern, wurde daher eine grosse Zahl erwachsener Aalmännchen aus der Nordsee in das Schwarze Meer gebracht. Man hofft dadurch den Fortbestand der Aale im Gebiete des Schwarzen Meeres gesichert zu haben.

Auf die Entwickelung der Fische im Ei kann hier des Raummangels wegen nicht eingegangen werden 77).

Einige Fische behüten ihre Eier und Jungen eifrig vor den Nachstellungen der Feinde, so der Zander, der Schwarzbarsch, der Stichling, der die Eier in ein Nest aus Pflanzen legt, das mit aus den Harnkanälen stammenden Schleimfïden ${ }^{78}$ ) befestigt ist, der Kaulkopf, der ebenfalls ein Nest im Bachgrunde bereitet, und zwar 
sind es meist die Münnchen, welche Wache halten und selbst die Weibchen den abgelegten Eiern nicht nahekommen lassen. Der weibliche Bitterling legt seine Eier mit Hilfe seiner langen Legeröhre in die Kiemenräume der Teichmuscheln (Unioniden), wo sie bis zum Ausschlïpfen geschützt bleiben (während anderseits die Teichmuscheln bekanntlich ihre Larvenzeit als Hautparasiten der Fische und anderer Wasserwirbeltiere zubringen).

Werden die Fische an der Laichablage verhindert, so werden die Geschlechtsprodulte resorbiert, oft unter Krankheitserscheinungen 79 ).

Wenige Worte seien noch dem Nervensystem und den Sinnesorganen der Fische gewidmet.

Das Gehirn ${ }^{80}$ ) liegt in der Schädelkapsel unter einer dicken Fetthülle, es ist im Verhältnis zur Körpermasse und zu den übrigen Teilen des Nervensystems klein. Auffallend ist, dass für das Grosshirn, an welches bei den höheren Wirbeltieren Bewusstsein und Wille gebunden erscheinen, bei dem Fisch noch gar keine bestimmte Funktion "hat nachgewiesen werden kömnen ${ }^{81}$ ). Döbeln, deren Grosshirn herausgenommen war, zeigten in keiner Weise eine $\mathrm{Ab}$ weichung ihrer Lebensthätigkeiten.

Das Auge ${ }^{52}$ ) wird von der Körperhaut überzogen, welche an dieser Stelle völlig durchsichtig ist. Die darunter liegende Hornhaut (Comea) ist sehr flach, die Linse dagegen fast kugelrund. Die Fische gelten deshalb für kurzsichtig; für den Hecht ist eine Sehweite von etwa $65 \mathrm{~cm}$ nachgewiesen worden $\mathrm{s} 3$ ). Die Regenbogenhaut (Iris) ist motallylinzend infulee der Finlagerung wn Glanzlintperchen, wie sie auch sonst den Glanz der Fische verursachen. Übrigens ist die Regenbogenhaut nicht kimtralktil, wie bei den höheren Wirbel-

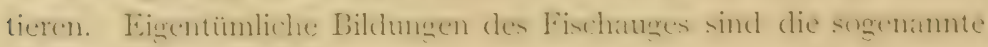
Glandula chorioudea, ein in der Nähe des Eintritts des Sehnervs liegender, an Blutgefüsscapillaren reicher K̈̈̈rper, und eine zweite Falte der Gefüsshaut (Chorioidea) des Auges, welche die Nervenhaut (Retina) des Auges durchsetzt und an der Linse mit einer Verdickung, der Campanula Halleri, endet. 
Das Hörorgan der Fische ${ }^{5 t}$ ) liegt seitlich vom Gehirn im Grunde des Schädels in der Nähe des Hinterendes desselben, oft in einer besonderen Ausbuchtung des Schädels. Ein äusseres Olır kommt bei den Fischen nicht vor. Das Hörorgan besteht aus mehreren häutigen Teilen, nümlich dem Säckchen (Sacculus), das eine Ausstülpung zeigt, die der Schnecke der höheren Wirbeltiere entspricht und einen oder mehrere Gehörsteine (Otolithen) von zahnschmelzartiger Substanz enthïlt, und dem Liriculus uler Aliens communis, an welchem sich bei den Neunaugen zwei, bei den übrigen Fischen drei „halbzirkelförmige Kanäle" befinden, die zuweilen in Erweiterungen ebenfalls Otolithen enthalten. Im Sercculus endigen die Nervenfasern des Hörnervs in Sinneszellen, welche am ätusseren Ende je eine kleine starre Borste tragen. Ähnliche in Haare ausgehende Sinneszellen finden sich auch in den sogenannten Seitenorganen. An den Seiten der Fische, mit Ausnahme der Neunaugen, findet sich nämlich eine Reihe von Poren, welche die Schuppen durchsetzen und die "Seitenlinie“ bilden. Sie führen in Kanäle, welche unter der Haut liegen. In diesen Kanälen ${ }^{85}$ ) liegen im Grunde von Vertiefungen kleine Erhebungen, welche aus ebensolchen Sinneszellen bestehen, wie sie sich in dem Cortischen Organ des Hörapparates finden. Man nimmt daher an, dass diese Organe, welche keinem der Sinne der höheren Wirbeltiere entsprechen, eine ühnliche Funktion haben wie das Hörorgan, indem die Seitenorgane zwar nicht die kurzen, rasch verlaufenden Schallwellen, aber andere Druckwirkungen, wie die Bewegungen anderer Körper im Wasser, empfinden sollen.

Schon bei Erwähnung der Schwimmblase ist hervorgehoben. worden, dass diese mit Luft prall gefüllte Blase bei den meisten unserer Fische mit dem Gehörorgan in Verbindung steht. Diese Verbindung wird bei den Perciden und Clupeiden dadurch hergestellt, dass Verlängerungen der Schwimmblase dicht an den Utriculus herantreten, bei den Cypriniden und dem Wels durch eine Reihe von kleinen Knochen, deren Reihe einerseits die Schwimmblase, anderseits einen Verbindungskanal der Vestibula beider. Seiten berührt. Auf diese Weise dient gewissermassen der 
ganze Mittelkörper, soweit in ihm die Schwimmblase liegt, als eine Art äusseren Ohrs. Die Prallheit und Elastizität, welche die schwimmllase dem Fischkörper gicht, mag auch zur Folge haben, dass die Druckwahrnehmungen der Seitenorgane deutlicher empunden werden.

Die einander verwandten Empfindungen des Geschmacks und des Geruches werden bei den meisten Fischen anscheinend nur durch ein Sinnesorgan, das der Nase der höheren Wirbeltiere entspricht, wahrgenommen. Indessen kann man, wie J. MI üller hervorgehoben hat, deshalb den Geruch der Fische mit dem Geschmack derselben nicht identifizieren, wiewohl die Geruchsstoffe im Wassen gelöst sind, denn auch bei den Luftwirbeltieren muss sich der Geruchsstoff erst im Wasser der Nasenschleimhaut lösen, um empfunden zu werden. Besondere Geschmacksorgane hat F. E. Schulze in der MIundhöhle einiger Cypriniden entdeckt, wie schon bei der Beschreibung dieses Körperteils erwähnt ist. Das Geruchsorgan 84) kommt allen Fischen zu, es ist bei den Neunaugen einfach, bei den anderen Fischen doppelt vorhanden. Es liegt jederseits zwischen den Augen und dem Mund in einem längeren oder kürzeren Hautkanal, welcher am Vorderende oft in eine häutige Röhre verlängert ist, die geschlessen und gerifhet werken kamn, sudass es im Belicben des Fisches liegt, während des Schwimmens einen Wasserstrom durch das Organ gehen zu lassen und mittels desselben zu prüfen, oder dasselbe ruhen zu lassen. Das Geruchsorgan selbst ist eine regelmässig gefaltete Schleimhaut, in welcher die Sinneszellen liegen 86$)$.

Das Tastgefühl scheint mehr oder minder um den Mund konzentricrt zu sein, wo sich bei vielen Fischen lüngere oder kürzere „Barteln“, Tastfäden, befinden, wie bei Aalquappe, Wels, Karpfen, Barbe, Gründling, Schleihe, den Acanthopsiden und Stüren.

Die Sinnesorgane, die in vielen Punkten von denen der Landwirbeltiere verschieden sind und in ihrer Funlitionsweise dem Wasserleben entsprechen, leiten den Fisch zu den Stitten im Wasser, deren er jeweilen bedarf. In der Hauptnahrzeit, im Sommer, ver- 
teilen sich die Süsswasserfische fast stets weit in den Gewässern, jeden zugänglichen Winkel nach der ihnen geeigneten Nahnung durchsuchend. In zwei Zeitperioden sind die Fische dagegen wählerisch in ihrem Aufenthalt: zur Laichzeit und zur Zeit des herabgeminderten Nahrungstriebes, im Winter. Zur Laichzeit suchen sie die für die Entwickelung der Eier und der ausgeschlüpften jungen Brut geeignetsten Wassergegenden auf, Kiesberge, I'flanzenrasen, Röhricht, schwimmendes Pflanzengewirr, überströmte Kiesbänke u. s. w. Im Winter ziehen sie sich an geschützte Stellen, meist in die Tiefe des Wassers, zurück. Einige Arten scheinen sich in den weichen Grund einzuwühlen, besonders in flacheren Gewåssern, welche bis in die Nåhe des Grundes gefrieren. Andere Arten suchen reinen, schlammfreien Grund, Sandfiichen, auf (Bressen, Karpfen), oder sie halten sich an der Oberfläche des offenen Wassurs und stehen auch unter dem Eise hoch über dem Grunde (Uklei). Nicht nur die Friedfische, auch die Raubfische, namentlich die jüngeren Generationen, suchen geeignete Stellen zur Überwinterung auf (Barsch, Wels). Da nun die besonderen Bedürfnisse der Art in weiten Wasserstrecken oft nur an wenigen Stellen erfüllt sind, so sammeln sich an diesen Stellen die Fische einer Art in grossen Scharen. Die Laichzeit und die Zeit der Winterruhe sind daher für die praktische Fischerei von Bedeutung, da man die Fische dann verhältnismässig leicht in Menge mit Netzen umstellen und fangen kann. Die Erhaltung der Fischart erfordert es allerdings, dass die laichenden Fische weder gefangen, noch auch nur gestört werden, und dass man den Massenfang auf den Winter beschränlit, eine Forderung, welcher der Fischer, im Gegensatze zum Fischzüchter, nicht immer gern nachkommt.

Ohne Zweifel ist es der wissenschaftlichen Fischkunde vorbehalten, unterstützt von einer gründlichen Kenntnis der Natur der Gewässer und aller ihrer Bewohner, die nur scheinbar entgegengesetzten Bestrebungen der Fischzüchter und der Fischfänger zu vereinigen und unter Förderung rationeller Fangmethoden sowohl wie der Fischzucht die Grundsäitze einerseits einer zweclimässigen Fischereigesetzgelung, anclerseits der praktischen Verwertung der 
202 Die deutschen Süsswasserfische und ihre Lebensverhältnisse.

Gewässer durch Fischzucht völlig sicher und unangreifbar zu ermitteln. Bis jetzt liegen Theorie und Praxis der Fischerei noch

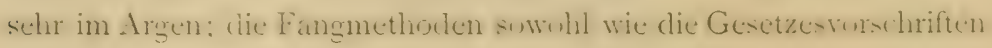
„schleppen von Geschlecht sich zu Geschlechte", während andere Zweige der Wasserverwertung, namentlich die der Landwirtschaft und der Industrie, mächtig vorwärtsgeschritten sind und der Fischerei liaum das Dasein gönnen. 


\section{Litteratur.}

I) Ringer in: Journ. of Physiologie Bd. 5 S. 98.

2) K. Moebius und F. Heincke, Die Fische der Ostsce. I $88_{3}$.

3) E. Th. E. von Siebold, Die Süsswasserfische von Mitteleuropa. I 863 .

Marcus Eliezer Bloch, Oelonomische Naturgeschichte der Fische Deutschlands. I $782-84$.

Berthold Benecke, Fische, Fischerei und Fischzucht in den Provinzen Ost- und Westpreussens. I880.

Cuvier et Valenciennes, Histoire naturelle des poissons. 22 Bde. I 828 - I 848 .

A. Günther, Catalogue of fishes of the British MIuscum. S Bde. I 859 - I 870.

Agassiz, Histoire naturelle des poissons d'eau douce de l'Europe' centrale. I 842 .

Wittmack, Beiträge zur Fischereistatistik des Deutschen Reiches u. s. w. 1875 .

Max von dem Borne, Die Fischereiverhältnisse des Deutschen Reiches u. S. w. I 882 .

4) Heckel und Kner, Die Süsswasserfische der Oesterreichischen Monarchie. 1858 .

5) C. Heller, Die Fische Tirols und Vorarlbergs. I $8^{\circ}$ I.

6) Sclater, Über den gegenwärtigen Stand unserer Kenntnis der geographischen Zoologie. I 857 . 
204 Die deutschen Süsswasserfische und ihre Lebensverhältnisse.

7) A. Gïnther, Handbuch der Ichthyologie, übersetzt von G. v. Hayeli. I 886 .

8) G. Henschel, Praktische Anleitung zur liestimmung unserer Süsswasserfische. I 890 .

E. Schulze, Fauna piscium Germaniae. I 890 .

9) Benecke, Die westpreussischen Fische. 5 Tafeln. I 887.

Gemeinfassliche Belehrung über die Süsswasserfische des Elbgebietes. Schriften des Sächsischen Fischereivereins Nr. I. 1884.

IO) Nowicki, Fauna und Verbreitung der Fische in den Gewissem Galiziens. Mitteilungen des Usterreichischen Fischereivereins, 2. Jahrg., S. I 49.

I I) F. Heincke, Untersuchungen über tichlinge. Ofversigt af K. V. Akad. Förhandling. Jahrg. 46, Nr. 6. I889. S. 399.

I2) Heckel, Abbildungen und Beschreibungen der Fische Syriens nebst einer neuen Klassifikation und Charakteristik sämtlicher Gattungen der Cyprinen. Stuttgart I $4+3$.

I3) Dürigen, Fremdländische Zierfische. I 886.

I. ) Knauthe, Üher Barbus Petenyi Heck. in Schlesien. Zoolog. Anz. I $890, \mathrm{Nr} .352$.

I 5$)$ Knauthe, Der Strömer am Zobten. Allgemeine Fischereiztg. I 888 , S. I 53.

I6) F. A. Schmitt, Iiritisches V'erzeichnis der im (Schwedischen) Reichsmuseum befindlichen Salmoniden. K. Svensk, vetensk. akad. Handlingar Bd. $2 \mathrm{r}$.

I7) $\boldsymbol{W}$. Peters, Über eine neue Art von Maranen, Coregonus generosus, aus der Mark Brandenburg. Monatsberichte der ligl. Akademic d. IV, zu Berlin. I874.

I8) Nüsslin, Beiträge zur Kenntnis der Coregonus-Arten des Bodensees und einiger anderer nahegelegener nordalpiner Seen. Zool. Anzeiger I 882.

19) Klunzinger, im Amtl. Bericht der 56. Versammlung Deutscher Naturforscher und Ärzte zu Freiburg I883, S. I I3.

Fatio in: Archive d. sc. physic. et nat. Genève t. 12, p. 433.

20) Day, The fishes of Gr. Britain. I $880-84$.

21) Fitzinger und Heckel, Mromegraphlic der Gattung Lipenser. $\quad{ }^{8} 8_{3} 0$.

22) Stannius, Zootomie der Fische. I 854.

23) Salbey, Über die Struktur und das Wachstum der Fischschuppen. Berlin 1868. 
24) C. v. Voit in: Zeitschr. f. wiss. Zoologie, Bd. I5, S. 515.

25) Ewald und Krukenberg, Unters. d. physiol. Instituts zu Heidelberg, Bd. 4, S. 253.

26) Heincke, Bemerkungen über den Farbwechsel einiger Fische. Schr. d. naturw. Vereins f. Schleswig-Holstein 1875.

27) Krukenberg, Vergl.-physiolog. Studien, 2. Reihe II. Abt. S. 55, III. Abt. S. I.38.

28) Zitiert von Weiss, Bayer. Fischereiztg. I 883 , S. I73.

29) H. Strasser, Zur Lehre von der Ortsberwegung der Fische. I 882.

30) Kasem-Beg und Dogiel, Zeitschr. f. wiss. Zoologie, Bd. 36. Archiv, Bd. 2.

3I) E. H. Weber, Die Leber von Cyprinus carpio. Meckels

32) Phisalix in Comptes rend., Acad. d. sc. Paris, t. 97, S. I 90. Archive d. zoologie expérim. (2) t. 3, S. 369.

33) F. M. Balfour, Quart. Joyrn. of microsc. science, Bd. 20.

Bizzozero et Torre, De l'origine des corpuscules sanguins rouges dans les différentes classes des vertébrés. Arch. ital. d. biologie, t. I4.

34) Owen, Odontographie I 840.

35) Šusta, Die Emährung des Karpfen und seiner Teichgenossen. I 888 .

30) Provençal et Humboldt in Schweiggers Joumal für Chemie and Physik, Bd. I, S. 84.

37) Miller, mitgeteilt in Roscoe-Schorlemmer, Ausführl. Lehrbuch der Chemie, Bd. I, S. 205.

38) C. Weigelt, Schädigung der Fischerei durch Abwässer der Fabriken. Archiv für Hygiene, Bd. 3, I 885 .

König, Die Verunreinigung der Gewässer. I887.

39) Fritsch, Arbeiten der zool. Sektion der Landesdurchforschung von Böhmen. Prag I 872 (Arch. d. naturw. Landesdurchforschung von B., 2. Bd., 4. Abt., S. II 2 u. f.).

40) August Müller, Über die Entwickelung (ler Nemangen. Joh. Müllers Archiv I 856 , S. 334.

4 I) H. Rathke, Üher den Darmkanal und die Zeugungsingane der Fische. Neueste Schr. d. Naturforschenden Ges. in Danzig, I. Bd., 3. Heft, I 824 .

42) Cajetan, Beitrag zur Lehre von der Anatomie und Physiulogie des Tractus intestinalis der Fische. I883. 
$43)$ Decker, Zur Physiologic des Fischelarms (in: Festschrift für Kölliker). I 887 .

44) A. Fick, Über d. NIagenferment kaltblütiger Tiere. Verhandl. d. physikal.-medic. Ges, zu Würzburg. N. F. 2. Bd.

+.5) Edinger, Zur Kemntnis der Drüsenzellen d. Magens: Arch. f. mikrosk. Anatomie, Bd. I7.

Trinkler, Bau der Magenschleimhaut. Arch. f. mikrosk. Anatomie, Bd. 24.

f(1) Richet et Morrut, De quelques faits relatifs ì la cligestion gastrique des poissons. Comptes rend. $\mathrm{Bd} .90$.

47) Albrecht in: Nature, Bd. 3 I, S. 380.

48) Gilberts Annalen d. Physik, Bd. 26.

49) Ch. Darwin, Abstammung des Menschen (Carus). I 87 I. Bd. 2, S. 5 .

.50) Canestrini, C̈luer das Männchen von Cubitis taenia L., 1 \$ 1 .

51) Huxley, Contribution to morpholugy. I hathyopsidae, Iid. I, I 883 , S. I32.

52) M. Weber, Miorphol. Jahrb., Bd. I2, S. 366.

$5.3)$ C. K. Hoffmann, Ontogenie der Knochenfische. Verhandll. d. k. Acad. van Wetenschapen i. Amsterdam, Bd. 2 I.

54) Jakoby, Der Fischfang in der Lagune von Comacchio nebst einer Darstellung der Aalfrage. I 880.

55) Carlo Mondini, De anguillae ovariis. De Bononiensi scientiarum et artium instituto atque academia commentarii. T. 6. Bon. I 783 .

56) Syrski in: Abhandl. d. Kaiserl. Akademie d! Wissensch. in Wien. I874.

5) Moebius, Ier. üler Untersuchungen des Zustandes der Geschlechtselrüsen weil, licher und männlicher Aake. 5. liericht d. Kemm. zur wissensch. Untersuchung der deutschen Meere, I887, S. I27.

58) Fritsch, Erwägungen über die Aussetzung von Lachsen und Aalen in das Donaugebiet. Mitth. d. Österreich. Fischereivereins 1884 .

59) Day in: Proceed. zool. Societ. London 1884, Bd. I, S. 17.

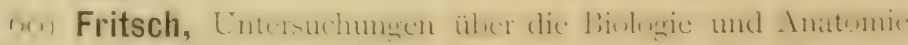
des Elblachses.. Mitteil. d. Österr. Fischereivereins I 885, S. 99.

6I) Metzger, Beitraige zur Statistik und Kiunde der Binnenfischerei d. Irenssischen Staates. Is80. 
(1) Miescher und Glaser, Statistische und biologische Deitritge zur Renntnis des Rheinlachse's im Rhein. In: Ichthyolog. Mittheilungen aus der Schweiz. 1880.

03) Barfurth, Nahrung und Lebensweise der Salme, Forellen und Maifische. Archiv f. Naturgeschichte I875.

64) Fritsch in: Circ. d. Deutschen Fischereivereins, I882, S. 46.

(15) M. von dem Borne, Benecke und Dallmer, Handbuch der Fischzucht und Fischerei. I 886.

66) Zenk, Über Brutapparate für Salmoniden. Bayerische Fischereizeitung I $88 \mathrm{I}-\mathrm{I} 88_{3}$.

(1;) Weiss, Anleitung zur Handhalsung des Brutapparats u. s.w. Allgem. Fischereiztg. I 889, S. I 4 I.

os) Metzger, Fischerei und Fischzucht in den Binnengewässem. In: Loreys Hdb. der Forstwissenschaft, Bd. I, I887.

ug) ten Houten und de Raadt, Zufuhr ron Lachsen am Kralingsche Veer. Deutsche Fischereiztg. 1888, S. 23.

7o) Horak, Die Teichwirthschaft mit besonderer Rüclisicht auf das südliche Böhmen. I 869 .

Niklas, Lehrbuch der Teichwirthschaft. I880.

7 I) A. Nicols, The acclimatisation of the Salmonidae at the Antipodes. I 882.

72) Smiley in: Bull. Unit. Stat. Fisherie Commission, Bd. 5, S. 468 .

73) von Behr, Fünf amerikanische Salmoniclen in Deutschland. Circ. d. Deutschen Fischereivereins. I882.

von dem Borne, Sechs amerikanische Salmoniden in Europa. Neudamm i 890 .

74) von dem Borne, Der Schwarzbarsch und der Forellenbarsch in Deutschland. I 888 .

75) von dem Borne, Der amerikanische Steinbarsch in Deutschland. I 890 .

(i) von dem Borne, Der amerikanische Zwergwels in Deutschland. I 890 .

77) Kupffer, Die Befruchtung des Forelleneies. Allg. Fischereizeitung, I 886, S. 2.

K. E. von Baer, Über die Entwickelungsegeschichte der Fische. 183.5.

His, Untersuchungen über das Ei und die Eientwickelung bei Knochenfischen. I873.

Michal Girdwoyn, I'athelegre des poissons. Tratiti des maladies. des monstrosités et des anomalies des oeufs et des embryons. Paris 
208 Die deutschen Süsswasserfische und ilıre Lebensverhälnisse.

1880. Text und einige Figuren auch in der Deutschen Fischereizeitung, I 88 I, S. 4 I 3 u. f., I 882, S. 2 u. f.

S. auch Nr. 53 .

78) Moebius in: Arch. f. mikroskop. Anat., Bd. 25, S. 554.

7) Barfurth, Biologische Lintersur hungen über die İuflurelle. Arch. f. mikroskop. Anatomie, Bd. 27.

So) Rabl-Rückhard, Das Gehirn der Knothenfische und seine Anhangsgebilde. Arch. f. Anat. und Physiol., Anatom. Abt. I883.

L. Stieda, Über die Deutung der einzelnen Teile des Fischgehirns. Zeitschr. f. wissensch. Zoologie, Bd. 23.

8I) Steiner, Die Funktionen des Zentralnervensystems und ihre Phylogenese. 2. Abt.: Die Fische. I 888.

\$2) Berger, Beitrige zur Inatmie des cithrgans der Kumchenfische. Morphol. Jahrb., Jahrg. 8, Bd. I.

$83)$ Hirschberg i. Arch. f. Anatomic und I'hysingeie. I'lysiol. Abt., I 882, S. 493.

84) G. Retzius, Das Gehörorgan der Wirbeltiere.

$8,5)$ Leydig, Über die ichlemkanäle der Knothenfische. Müllers Arch. für Anatomic und Physiologie, I800.

Leydig, Über das Organ eines sechsten Sinnes. IS68.

F. E. Schulze, C̈ber die sinnesnrgane der seitenlinic bei den Fischen und Amphiloien. In : Arch. f. milirusliop. Anatomie, Bd.6, I $8-0)$.

86) Dogiel, Bau des Geruchsorgans bei Fischen und Amphibien. I 886 .

87) Bulletin of Unit. Stat. Fisherie Commission, Bd. 5, S. I 42.

Sis) Knauthe, Erfahrungen äler dats Verhalten von Amplabion und Fischen gegenüber Kälte. Zool. Anzeiger, ISg I, S. I u. f. 


\section{Die \\ Parasiten unserer Süsswasserfische.}

Von Prof. Dr. Fr. Zschokke in Basel. 
$E_{S}$ ist eine gewöhnlich kaum beachtete Thatsache, dass der Kü̈per des Fisches den Angriffen verschiedenartigster Schmarotzer ausgesetzt ist. Eine stattliche Zahl von durch Bau und Gestalt weit von einander abweichenden Parasiten sucht und findet am und im Fisch bleibende oder vorübergehende Wohnung und Nahrung. Es sind Geschöpfe, die den verschiedensten Stämmen des Tierreichs angehören, Protozoen, Mollusken, Krebse, Plattwürmer, Rundwürmer, Blutegel. Nur ein gemeinschaftliches Band verbindet sie, ein biologisches, dieselbe Lebensweise, das Schmarotzertum; nach Abstammung, Struktur, Entwickelungsgeschichte gehen sic weit aus einander. Allerdings hat die Angewöhnung an dieselbe Lebensweise, an den Parasitismus, die ihm unterworfenen Geschöpfe in derselben Richtung modifiziert, und so zwischen ursprünglich einander fernstehenden Tieren Ähnlichkeiten im Bau und im Lebensgang in sekundärer Weise geschaffen.

Die den Fisch heimsuchenden Schmarotzer sind übrigens recht unscheinbare Wesen. $\mathrm{Zu}$ ihrer niedrigen Lebensweise passt es ja am besten, wenn sie weder durch besondere Grösse, noch Form und Farbe die Aufmerksamkeit auf sich ziehen. Der Laie macht wohl gelegentlich die Beobachtung, dass ein Lachs mit gierigen Blutegeln überdeckt ist, oder sieht, wie sich der Leibeshöhle eines frisch geöfneten Karpfens ein breiter, hïsslicher Riemenwurm entwindet; der eine oder andere Fisch wird wohl auch mit Recht oder Unrecht beschuldigt, dem Menschen gegenüber die Rolle eines 
Zwischenträgers schmarotzender Würmer zu spielen. Weiter geht die Kenntnis der Fischparasiten kaum. Das mit dem verächtlichen Namen Schmarotzer belegte Geschöpf fesselt nicht durch sein Äusseres und stösst geradezu ab durch seine Lebensweise.

Und doch wäre der Fischparasit eingehenden Studiums so sehr würdig. Schon vom rein praktischen, medizinischen Standpunkt aus verdienen die ungebetenen Gäste der Fische unsere volle Aufmerksamkeit. Hat uns doch die neuere Forschung gelehrt, dass eince der verbreitetsten Bandwürmer, der durchaus nicht unledenkliche Bothriocchlaalus lutus, grerade durch die gesuchtesten Tafelfische des süssen Wassers auf den Menschen übertragen wird. Für andere Wümer liegt die Vermutung nahe, dass sie auf ahnlichem Wege, eingekapselt in Zwischenwirte aus der Klasse der Fische, in unsen Kürper eingeschmuggelt werden. DiesNotwendigkeit unsere Feinde zu kennen, um uns ihrer entledigen, sie von uns fernhalten zu können, weist uns also schon gebieterisch darauf hin, Bau und Eigenschaften der Fischparasiten $z u$ ergründen und ihrem oft so verwickelten Lebensgang $\mathrm{zu}$ folgen. Ausgerüstet mit den nötigen Kenntnissen dürfte es uns wohl auch gelingen, Fischepidemien parasitärer Herkunft einzudämmen, die unter den Bewohnern unserer Gewåsser, jenem nicht gering anzuschlagenden Teil des nationalen Gutes, zahlreiche Opfer furdern. Ausser rein praktischen Erwätgungen medizinischer und nationalïkonomischer Art müissen uns aber auch wissenschaftliche Gesichtspunkte und Ziele beim Studium der Fischparasiten leiten. Die Frage, welchen Einfluss übt die parasitische Lebensweise auf ursprünglich freilebende Geschöpfe aus, wie werden im Laufe ungezählter parasitischer Generationen Bau und individuelle Geschichte des früher nicht schmarotzenden Tieres verändert, tritt uns vor allen anderen schwerwiegend entegegen. 1)er l'arasitismus führt ja zu ciner vollkommenen Ungentaltung und Neuschëpfung in Anatomic und Entwickelungsgeschichte. Und um diese Neuschöpfung ihrer Entstehung nach würdigen zu künnen, bietet uns gerade die Parasitenfauna der Fische Gelegenheit und Material. Manche Schmarotzer beziehen den Fisch nur temporär, um Nahrung aufzunchmen, sonst führen 
sie eine freie Lebensweise. Andere bewohnen ihn wohl stationär, begnügen sich aber damit, als Elktoparasiten die Oberfläche des Wirtes zu bewohnen und dort ihren Unterhalt zu suchen, ohne jemals innere Organe zu besetzen. Wieder andere werden Entoparasiten, siedeln sich aber in offenen mehr oder weniger leicht zugänglichen Teilen, den Kiemen, dem Darmkanal, an. Zahlreiche endlich liegen eingekapselt iri allseitig geschlıssenen Organen, den MIuskeln, den Augen, der Schwimmblase.

Grad und Dauer des Schmarotzertums sind bei den Fischparasiten höchst verschieden. Manche schmarotzen während des ganzen Lebens, bei anderen sind freie Stadien in mehr oder weniger reichem Masse in die Lebensgeschichte eingestreut. Vom nur gelegentlich parasitierenden Blutegel, von der jungen Muschel, die sich nur kurze Zeit vom Fisch herumtragen lässt, bis zum Bandwurm im Darmkanal des Hechtes oder des Lachses und dem Spulwurm aus dem Barsch, typischen, entoparasitischen Gestalten, stossen wir auf mancherlei Zwischenstufen. Und gerade in diesen verschiedenen Stadien, mit ihrem durch den Parasitismus mehr oder weniger veränderten Bau und der ebenfalls verschieden stark beeinflussten Lebensgeschichte, sehen wir noch Punkte, Stationen, die von der Natur auf dem Wege berührt worden sind, als sie aus dem ursprünglich freien Geschüpf den Parasiten schuf. Wir kümnen den Weg verfolgen, der vom freien Vorfahr zum parasitierenden Enkel führt. So kann es uns klar werden, welch tiefen Einfluss die Angewöhnung an eine so spezielle und niedrige Lebensweise, wie sie der Parasitismus nun einmal ist, auf tierische Organisation und ticrisches Leben ausübt. Nit dem zunehmenden Schmarutzertum treten anatomische Vereinfachungen und Umbildungen allmïhlich ein; Organsysteme werden rudimentär und verschwinden zuletzt. Die Entwickelungsgeschichte weist oft Komplikationen auf und schlägt Lmwege ein, die ihre Erliärung cinzig in der Angewïhnung an die neue Lebensweise und in der Erfüllung der von dieser gestellten Bedingrungen finden. Das Studium der Parasiten führt so den Forscher ein in die interessantesten und weitgehendsten Fragen der Piologic. Die Fischschmarotzer aler, in ihrer bunten Formenfülle 
und mit ihrer mannigfaltigen Lebens- und Entwicleclungsgeschichte bieten zur Behandlung dieser Probleme ein reiches Material.

Noch manche andere Frage wird sich auf diesem Gebiete stellen und teilweise wenigstens beantworten lassen. Wie becindunsen sich gegenseitig Wirt und Gast? Wie passt sich der Parasit den ihm vom Träger gebotenen Bedingungen an und welche Eigenschaften werden infolge dieser Anpassung erworben? Wie findet sich auf der andern Seite der Fisch mit den ihn bewohnenden Würmern $\mathrm{ab}$; erwirbt nicht auch er gewisse Eigenschaften, um die Eindringlinge abzuhalten, oder die einmal Eingedrungenen bis zu einem gewissen Grad unschädlich zu machen? Welche Veränderungen erleidet der Fischkörper unter dem Drucke der Parasiteninvasion?

Interessant wird es auch sein, die bis jetzt liaum berührte Frage in Fluss zu bringen. welchen Einfluss die Le(t)ensweise. speziell die Ernährungsweise des Fisches auf die Zusammensetzung der ihn bewohnenden Parasitenfauna ausübt. Pflanzenfresser werden andere Formen von Schmarotzern beherbergen als Fleischfresser, Schlammbewohner andere als frei pelagisch schwimmende Geschöpfe. Der Fisch des schnellfliessenden Stroms, des Sees, des Teiches wird von einander verschiedene Elemente in seiner Parasitenfauna aufweisen. Desonders eigentünlich werden sich diese Verhältnise gestalten bei den Wanderfischen, die bald das süsse Wasser, bald die salzige See aufsuchen und in beiden Medien eine oft recht verschiedene Lebensweise befolgen.

Eine mehr oder minder starke Vermischung von Meer- oder Süsswasserparasiten wird sich in diesem Falle wohl nachweisen lassen. Reine Meerformen werden weit hinauf in die Flüsse getragen, Süsswassershmamitzer dagegen dem Mecr zugeführt. Wieder wird uns die verschiedene Mischung der beiden Parasitenelemente im Wanderfisch, das Überwiegen des einen oder anderen, Rückschlüsse auf die Lebensweise des Wirtes gestatten. Die Parasitenfauna wird so bis zu einem gewissen Grade zum Spiegelbild der Gewohnheiten ihres 'Triigers. 
Von diesen Erwägungen geleitet ist eine erste kleine Arbeit über die Parasitenfauna des Rheinlachses erschienen, deren Resultate geeignet sind, die rorangehenden theoretischen Betrachtungen zu stützen. Sie mögen deshalb hier in kurzen Zügen skizziert werden.

Der Rheinsalm, so bewiesen es His und Miescher, und so wussten es auch schon längst die Lachsfischer, nimmt vom Aufsteigen aus dem MIeer bis er verlaicht hat, niemals Nahrung zu sich. Als Folge dieses Fastens im Süsswasser durfte wohl erwartet werden, dass die Parasitenfauna von Trutta salar typisch marinen Anstrich zeige. Mit dem Ausschluss der Nahrungsaufnahme ist für jedes Geschöpf ja gleichzeitig die Hauptinfektionsuuelle mit parasitischen Würmern verstopft.

Von 45 untersuchten Lachsen aus dem Rhein waren 42 mit Würmern besetzt, nur drei erwiesen sich als vollkommen parasitenfrei. Elf Arten Schmarotzer konnten bestimmt werden; mehrere fanden sich nur in einem der geprüften Fische, andere öfters, der Spulwurm Agamonema capsularia Dies. sogar in 35 Wirten. Parasitenarm waren in den 45 Lachsen die offenen Organe. Im Darmkanal fand sich kein einziger Schmarotzer unterhalb der Appendices pyloricae. Die meisten Parasiten waren in verschiedenen Organen eingekapselt, seltener lagen sie wohl geborgen in den Falten des Schlundes und in den Pylor-Anhängen. Es erinnert dies an das Verhalten gefangener Meerfische, die im Aquarium verhältnismässig rasch ihre Darmschmarotzer verlieren. Man hat ja auch geradezu behauptet, viele Wanderfische ziehen ins Süsswasser, um sich ihrer Parasiten zu entledigen. Die Schmarotzerfauna der 45 Rheinlachse hatte einen fast reinen marinen Charaliter. Die Hauptmasse der gefundenen Würmer gehörte nach Arten und Individuen äusserst typischen Meerformen an. Auch die von mir noch nicht nachgewiesenen Lachsparasiten sind wesentlich Güste von Meerfischen. Ein einziger der gefundenen Schmarotzer gehört neben den Wanderfischen ausschliesslich dem süssen Wasser an. So spiegelt die Zusammensetzung der Parasitenfauna die eigentümliche Gewohnheit des Rheinlachses wider, im Süsswasser lieine Nahrung aufzunehmen. Sie unterscheidet sich scharf von der 
Schmarotzerwelt anderer Wanderfische, deren Nahrungbedürfnis im Fluss nicht aufhört.

Über diese Verhältnisse mag die folgende Zusammenstellung näheren Aufschluss geben.

\section{Perbreitung der parasitisclien Iïrmer der Wanderlische :}

\begin{tabular}{|c|c|c|c|c|c|c|}
\hline \multirow[b]{2}{*}{ Name des Fisches: } & \multirow{2}{*}{\multicolumn{2}{|c|}{ 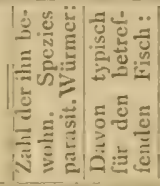 }} & \multirow{2}{*}{ 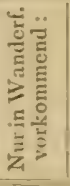 } & \multicolumn{3}{|c|}{$\begin{array}{c}\text { Ausser in } \\
\text { Wanderfischen: }\end{array}$} \\
\hline & & & & 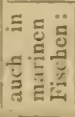 & 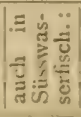 & 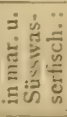 \\
\hline I. Trutta salar, Lachs . . & 20 & 7 & 7 & 7 & I & 5 \\
\hline 2. Trutta trutta, Lachsforelle & I 5 & I & I & I & 8 & 5 \\
\hline 3. Osmerus cperlamus, Stint . . & I 7 & IO & I I & I & 4 & I \\
\hline 4. Coregonus oxyr/zyncluns, Schnäpel & 6 & 0 & I & 0 & 4 & I \\
\hline 5. Alausa vulgaris, Maifisch . . & 7 & 3 & 4 & I & o & 2 \\
\hline 6. Alausa funta, Finte . . & 4 & I & 2 & o & 0 & 2 \\
\hline 7. Anguilla vulgarts, Aal . . . & 25 & IO & 10 & 5 & 5 & 5 \\
\hline 8. Petromyzon fluviatilis, Neunauge & 4 & 2 & 2 & o & I & I \\
\hline
\end{tabular}

Besonders typisch für die Würmerwelt des Rheinlachses ist das Auftreten der sogenamnten Tetrarhynchen, eigentümlicher, mit vier starken, hakentragenden Rüsseln bewchrter Bandwurmarven, die sich häufigr in den verschiedensten Knochenfischen des Meeres einnisten, um mit ihnen in den Verdauungstractus der Haifische zu gelangen und dort $\mathrm{zu}$ enwachsenen Bandwürmern, Rhynchobothrien, auszuwachsen.

Eine in weit vorgeschrittener Vorbereitung sich befindende zweite Arbeit über die Lachsparasiten, der hier nicht vorgegriflen werden kann, wird, auf reiches MIaterial gestützt, den marinen Charakter der den grossen Wanderfisch bewohnenden Würmer noch viel greller hervortreten lassen. Sie wird auch Ermittelungen über mordische und schottische Lachse enthalten, die im Süsswanser dem Fasten nicht so strenge zu huldigen scheinen wie ihr Vetter vom Rhein und bei denen infolgedessen die parasitologischen Verhältnisse sich wesentlich anders gestalten. 
Den relativ grossen Parasitenreichtum verdanken die Fische verschiedenen Lmständen: zunächst wohl ihrer Eigenschaft als Wasscrbewohner. Neben zahlreichen entoparasitisch die inneren Organe aufsuchenden Schmarotzern kann auch mancher Elitoparasit an ler Aussenfläche des Wassertiers sich ansiedeln, der nur im feuchten Element sein Leben zu fristen vermag. So wird denn die Obernliche des Fisches, die Haut, sowie die verhältnismäissig freiliegenden, von einem fortwährenden Wasserstrom bespülten Kiemen von manchem Wurm als geeigneter Standort gewïht.

Auch die so mannigfache Ernährungsweise wird den Fischen manchen Schmarotzer verschaffen. Nit der Nahrung dringt ja der grosse Haufe ungebetener Gäste in den tierischen Körper ein. Die Parasitenfauna einer Tiergruppe, die Pflanzen- und Fleischfresser umschliesst, wird den verschiedenen Nahrungsstoffen gemiiss ebenfalls mannigfaltig ausfallen.

Mit dem Atmungswasser können ferner Jugendstadien von Schmarotzern in das Innere des Fisches gelangen. Der Invasion ist somit eine neue, bei anderen Geschöpfen geschlossene Pforte geöffnet. Manche Parasiten werden auch aktiv eindringen, an wenig geschützten Kürperstellen mittels spezieller Apparate sich einbohren.

Die äusseren Lebensbedingungen, unter denen der Fisch steht, seine Beziehungen zu anderen Lebewesen sind endlich sehr mannigfaltiger Natur. Mit der grüsseren Vielseitigkeit dieser Beziehungen steigert sich im allgemeinen auch die Mï̈glichkeit und Gelegenheit - einer Infektion. Von zahlreichen anderen Tieren verfolgt und verzehrt wird sich der Fisch als Zwischenträger von Parasiten wohl eignen. In ihm stellen sich zahlreiche Jugendstadien von parasitierenden Würmern ein, die mit dem Fisch sicher in den Darmkanal eines weitern Wirtes übertragen werden sollen, um dort zum weschlechtsreifen Tier heranzuwachsen. So gelangen die Larren des treiten Bandwurms mit dem Fleisch ron Fischen in den Verdaumestractus des Menschen. Aber auch als Hauptwirt von Parasiten ist der Fisch berufen eine grosse Rolle zu spielen; mit den zahllosen lileinen Geschüpfen, die ihm zur Nahrung dienen, kïmnen auf leichte Weise eingekapselte Larven in ihn eingeschmuggelt werden. Die 
Fische erscheinen durch ihre Beziehungen zu anderen $\mathrm{Ge}$ schöpfen besonders geeignet, bald als Zwischenträger von jungen Würmern, bald als definitive Wirte der geschlechtsreifen Form zu figurieren.

So vereinigen sich manche Umstände, um den Fischkörper zu einer richtigen Parasitenherberge zu machen. Einer Invasion ist Thür und Thor geöffnet. Die Oberflüche des Wirtes und die nach aussen offenen Organe werden vorzugsweise von geschlechtsreifen Schmarutwern, egeschlussene Fürperteile von jungen Stadien bewohnt. Kein Organ bleibt aber gelegentlich verschont. Zwölf Fischarten des Genfersees beherbergten 37 verschiedene Parasiten, die sich folgendermassen im Körper einquartiert hatten:

Bewohntes Organ: Zahl der Arten :

Ösophag und Magen . . . . . 2

Darm . . . . . . . . . I5

Rectum . . . . . . . . 2

Pylor-Anhänge . . . . . . 2

Leber . . . . . . . . . 0

Milz . . . . . . . . . . . I

Schwimmblase . . . . . . . . I

Harnblase . . . . . . . . . I

Auge . . . . . I

Muskulatur . . . . . . . . $\quad 2$

Kiemen . . . . . . . . . 2

Leibeshöhle . . . . . . . . . I

Peritonäum und Darmwand . . S.

Die Zahl der bis jetzt bekannten Parasiten der Süsswasserfische aus dem Kreise der Würmer ist schon eine sehr beträchtliche, sie dürfte laum unter 250 zurückbleiben; sie steigt jährlich an und nichts lisst voraussetzen, dass die diesbezüglichen Listen so bald als vollständig geschlossen betrachtet werden künnen. Dem momentanen Stand unserer Kenntnisse über die Vertretung von schmarotzenden Würmern im Kürper der verbreitetsten Fische des süssen Wassers dürfte etwa folgende Tabelle entsprechen: 


\begin{tabular}{|c|c|c|c|c|c|c|c|c|c|}
\hline \multirow{2}{*}{\multicolumn{5}{|c|}{ Name der Fische: }} & \multicolumn{5}{|c|}{ Zahl der bei ihm vorkommenden Parasitenarten } \\
\hline & & & & & \multirow{2}{*}{ 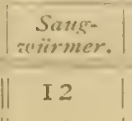 } & \multirow{2}{*}{$\frac{\left|\begin{array}{c}\text { Band. } \\
\text { antïmer. }\end{array}\right|}{\mid 8}$} & \multirow{2}{*}{$\begin{array}{l}\text { Faden- } \\
\text { wiirmer. } \\
\frac{3}{3}\end{array}$} & \multirow{2}{*}{$\frac{\text { Kratser. }}{4}$} & \multirow{2}{*}{$\frac{\text { Total. }}{27}$} \\
\hline Barsch . & . & . & . & . & & & & & \\
\hline Kaulbarscl & & . & - & . & 8 & 2 & 5 & 3 & I 8 \\
\hline Zander. & . & . & . & . & 7 & I & 2 & 3 & I 3 \\
\hline Groppe & . & . & - & - & 3 & 2 & o & 2 & $T$ \\
\hline Stichling & . & .. & . . & - & 4 & 4 & 6 & 3 & I 7 \\
\hline Aalraupe ( & Qua & tappe & e) & . & 6 & 9 & 6 & 4 & 25 \\
\hline TVels . & . . & .. & . . & . & 2 & 2 & 6 & 3 & I 3 \\
\hline Karpfen & . & . & - & . & 8 & I & 2 & 4 & I 5 \\
\hline Gründling & . & . & - & . & 3 & 2 & 3 & 5 & IO \\
\hline Barbe . & . & . & . & . & 7 & 3 & I & 5 & I6 \\
\hline Aitel . & . & . & . & . & 7 & 2 & 4 & 2 & $I_{5}$ \\
\hline Rotauge & . & . & . & . & 8 & 3. & 5 & 3 & I9 \\
\hline Hasel . & . & . & . & . & 7 & 2 & 3 & 4 & I 6 \\
\hline Elritze & . & . & . & . & 5 & I & 4 & 3 & 13 \\
\hline Schleihe - & . & . & . & . & 2 & 5 & 3 & 4 & I 4 \\
\hline Laube . & . & . & . & . & 3 & 4 & 3 & 3 & I 3 \\
\hline Schmerle & . & . . & . & . & 3 & 2 & 6 & 2 & I3 \\
\hline Schlammp & eitzg & ger . & . & . & 3 & 0 & 3 & 0 & 6 \\
\hline Saibling & . & . . & . & . & 4 & 9 & I & I & I 5 \\
\hline Lachs . & . & . & . & . & 6 & I 5 & 7 & 2 & 30 \\
\hline Forelle. & . & . & . & . & 4 & 2 & 4 & 7 & $I_{T}$ \\
\hline Stint . & . & . & . & . & 6 & 4 & 9 & 2 & 21 \\
\hline Schnäpel & . & . & . & • & 4 & 2 & 3 & I & IO \\
\hline Felchen & . & - & . & • & 4 & 7 & I & I & I 3 \\
\hline Aesche & . & . & . & . & 7 & 2 & 5 & 2 & I 6 \\
\hline Hecht. & . & . & . & . & 10 & 6 & 7 & 3 & 26 \\
\hline Maifisch & . & . & . & • & 4 & I & 4 & 3 & I 2 \\
\hline Aal . & . & . & . & . & I 4 & 3 & I 2 & 8 & 37 \\
\hline Neunauge & & . . & . & . . & 5 & I & 3 & o & 9 \\
\hline
\end{tabular}

Die vorangehenden Zahlen bedürfen kaum eines weiteren Kommentars. Sie sind wiederum geeignet, die Abhängigkeit der Parașitenfauna von der Lebensweise des Wirtes mit Beispielen zu 
belegen. Am reichsten an Schmarotzern sind die grossen Rüuber und die omnivoren Fische, denen sich jeden Augenblick eine Infektionsgelegenheit bietet. In ihrem Darm wohnt eine reiche Fauna von geschlechtsreifen Band- und Saugwürmern, die in die Nahnung eingchipleselt leicht in den detinitiven Wirt getangt sind.

Bei den Karpfen, die mehr an pflanzliche Kost gewöhnt sind oder höchstens kleine Tiere verzehren, sinkt die Zahl der Parasiten bedeutend. Die Band- und Saugwürmer spielen hier eine untergreordnete Rolle, während die Kratzer, deren Jugendstadium in likinen Krustacen eingeschlossen liegt, mehr in den Vordergrund treten. Am reichsten und buntesten gestaltet sich die Parasitenfauna des Aals, dessen mannigfaltige Letrens- und Emährungsweise ihn auch vielfacher Infektionsgefahr aussetzen wird. Fleisch- und Pflanzenfresser unter den Fischen beherbergen eine ziemlich verschiedene Schmarotzerwelt; die letzteren dienen oft als Zwischenwirte für die Parasiten der ersteren. In Fischen mit gemischter Ernährungsweise mengen sich auch die Bestandteile der beiden Faunen. Wahrscheinlich wird in ein und derselben Fischart in den verschiedenen Monaten des Jahres eine Veränderung der Parasitenwelt nach Auswahl der sie bildenden Arten und nach Zahl der Individuen sich nachweisen lassen. Die Beobachtungen üher diese Schwankungen sind noch äusserst lürkenhaft und litsisen uns nicht einmal vorlậufige Schlüsse ziehen. Immerhin glaubte ich im Reichtum der Schmarotzerfauna der grossen Rüuber, Hecht, Ouaple, Fonelle, Saitlinge, während dor ganzen fahres keine wesentliche Veränderung zu bemerken. In den Karpfen dagegen vermehren sich die Parasiten nach Arten und Individuen im ersten Frühjahr, nachdem der Fisch seine Winterruhe mit einem aktiven Leben vertauscht hat. Der Barsch ist besonders im Mrarz bis Mai reichlich infiziert. Weitere Studien über die Saisonverteilung der parasitierenden Würmer wären sehr erwünscht, auf ein reiches und sorgfültig beobachtetes Naterial sich stützend würden sie sicher zu interessanten biologisch-faunistischen Resultaten führen.

Dass ein Fisch Parasitenträiger ist, scheint fast als der normale Zustand zu betrachten zu sein. Von 382 nach dieser Richtung 
geprüften Bewohnern des Genfersees war kaum ein Drittel prartsitenfrei. Lönnberg öfnete in Schweden 870 Fische des süssen und salzigen Wassers; 564 trugen Parasiten, 306 waren nicht infiziert. Cestoden beherbergten I 28 Individuen, Trematoden go, Fratzer 204, Nematoden 205. Oftmals bewohnen die Schmarotzer ihren Wirt in gewaltiger Individuenfülle. Ihre Gegenwart kann so für das infizierte Tier kaum gleichgültig sein, schon aus dem naheliegenden Grunde nicht, weil die Parasiten eine Menge Nahrungsstoffe verzehren, die in den fischlichen Organismus hätten aufgenommen werden sollen. Die Pylor-Anhänge von Forelle, Saibling, Hecht, Aesche sind meist vollgepfropft von unzühlbaren Exemplaren eines Bandwurms (Bothrioceplualus infundibuliformis Rud.). In einem Hecht von fünf bis sechs Kilo fand ich mehr als dreihundert Exemplare dieses Schmarotzers, von 28 bis $35 \mathrm{~cm}$ Länge; ungezählte hunderte von jungen Würmern waren über die Schleimhaut des ganzen Darmes zerstreut. Grosse Massen desselben Cestoden bevölkern in der Regel auch den pylorischen Darmteil des Lachses, wie ja die Pylor-Anhänge überhaupt der Lieblingsstandort vieler Fischparasiten sind. Die Würmer finden dort neben sehr reichlicher Nahrung sichere Wohnung. Auch ein anderer grosser Bandwurm (bis $50 \mathrm{~cm}$ lang), der Triaenophorus nodulosus Rud., stellt sich oft in 80 bis Ioo Exemplaren im Hecht ein. Ein Saugwurm, Distoma nodulosum Zeder, bewohnt in grösster Menge den Darm des Barsches; ein anderes Distoma, D. folium Olfers, füllt oft buchstäblich die ganze Harnblase der Groppe an, so dass dieses Organ prall aufgetrieben erscheint; die Kapsehn eines larvïren Saugwurms, des Tetracotyle Percac, durchsetzen fast regelmitssig in grösster Menge die Wandungen der Schwimmblase der Barsche. Die beiden Kratzer Echinorhynchus proteus Westrumb. und E. angustatus Rud. bewohnen das Eingeweide ihrer zahlreichen Wirte oft in hunderten von Individuen. Von den Spulwürmern tritt in bedeutender Zahl auf der Kappenwurm, Cucullanus elegans Zeder, ein für den Barsch üusserst charakteristischer Parasit; im Hecht findet sich oft zahlreich die Ascaris acus Bloch, in der Leibeshöhle der verschiedensten Fische spiralig 
cingrerollt, und allen Organen angreheftet, dic noch geschlechtshise Aganonema capsularia Dies.

Diese wenigen Beispiele mögen das massenhafte Auftreten einer Parasitenspezies im Fischkörper illustrieren. Es sei nur noch darauf hingewiesen, dass auch die Larve des breiten Bandwurms des Menschen in ein und demselben Wirt sich massenhaft einstellt. So schälte ich aus Leber, Milz, Nieren, Wandungen des Darmkanals ciner seeforelle über 200 Finnen des Bothriocephalus latus. Es erklïrt sich dadurch leicht die gelegentliche Masseninfelition des Menschen mit dem breiten Bandwurm. Roux trieb einer einzigen Person über 90 Exemplare gleichzeitig ab.

Die verschiedensten Arten parasitischer Würmer können übrigens nebeneinander in ein und demselben Wirt leben. Dass ein Fisch gleichzeitig fünf bis acht Schmarotzerformen beherbergt ist keine Seltenheit. Im Lachs ist oft der pylorische Darmabschnitt mit Bandwürmorn angefültt, wiilhrend zahlreirhe Individuen des für diescn Fisch typischen Distoma áaricum im schlund neben verschiedenen Spulwünnern leben und die Darmwandungen reichlich gespickt sind mit Larven von Tetrarhynchen, Bothriocephalen und aufgerollten Agamonemen. Barsch, Hecht, Aalraupe, Saibling geben oft wahre Parasitenherbergen $\mathrm{ab}$, in denen gleichzeitig acht bis zehn Arten Schmarotzer, meist in grosser Individuenzahl, als ungern gesehene Gäste die verschiedensten Organe bewohnen. Die zahlreichen Parasiten dürften das Leben des Fisches in seiner kühlen Wasserheimat kaum so angenehm und wohlig gestalten, wie man es sich etwa vorstellt.

Ist schon der Süsswasserfisch von sehr zahlreichen Würmern heimgesucht, so trifft das noch in bedeutend höherem MIasse für seine marinen Verwandten zu, die in weit grösseren Verhältnissen

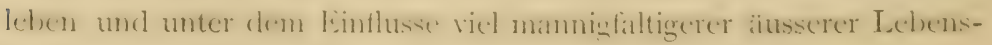
bedingungen stehen. Die Parasitenfauna der Meerfische ist mindestens ebenso reich an Individuen und sehr viel mannigfaltiger an äusserst verschiedenartigen Formen, als die der Süsswasserbewohner. Wenige Angaben mögen wenigstens einen kurzen Vergleich der 
bezüglichen Verhältnisse gestatten. Lönnberg suchte Parasiten in 342 Meerfischen; $24 \mathrm{I}$ davon waren infiziert, IOI parasitenfrei. 78 trugen Bandwürmer, 39 Saugwürmer, 28 Kratzer, I I4 Spulwürmer. In Neapel waren von 257 Fischen nur 74 parasitenlos. Von 72 Arten erwiesen sich 53 als infiziert, bei 34 waren sämtliche untersuchte Exemplare mit Würmern besetzt. Es wurden in den 257 Fischen 77 Parasitenarten - 38 Bandwürmer, I6 Saugwürmer, 3 Kratzer und 20 Spulwürmer - gefunden, während 382 Fische des Genfersees nur 35 Schmarotzer aus dem Kreise der Würmer (I I Bandwürmer, II Saugwürmer, 3 Kratzer, Io Spulwürmer) beherbergten. Auch im Meere ist die Parasitenfauna der grossen Räuber, Haie und Rochen, viel reicher und aus anderen Elementen zusammengesetzt, als die der kleineren Knochenfische. Nur sechs Parasitenarten waren Selachiern und Teleosteern gemeinsam, erstere waren ausserdem von 34 , letztere von 36 Schmarotzern heimgesucht.

Es wurden auf ihre Parasiten geprüft:

Zahl der Arten: Zabl der Individuen: Zahl der Parasitenarten:

$\begin{array}{lrrr}\text { Selachier: } & 20 & 96 & 40 \\ \text { Teleosteer: } & 34 & \text { I } 60 & 42 \\ \text { Ganoiden: } & \text { I } & \text { I } & \text { I }\end{array}$

Die Hauptmasse der Parasiten von Rochen und Haien setzt sich aus geschlechtsreifen Bandwürmern und teilweise aus Saugwürmern zusammen, während die Teleosteer vorzüglich Spulwürmer, Kratzer, Saugwürmer und larväre Bandwürmer beherbergen.

Nach diesen allgemeinen und einleitenden Auseinandersetzungen sollen eine Anzahl der hüufigsten und praktisch wie wissenschaftich wichtigsten Schmarotzer unserer Süsswasserfische spezieller lesprochen werden. Bau und besonders Entwickelungsgeschichte vieler, ja der meisten Formen ist uns noch unbekannt. Doch werden wir in dem, was durch die Arbeit der Forscher durchsichtig und zugünglich gemacht worden ist, manche spezielle Illustration $\mathrm{zu}$ den vorangehenden allgemeinen Betrachtungen über die I'arakiten der Fische des Süsswassers finden. 
Die an und in unseren Süsswasserfischen schmarotzenden Frustaceen und die Muschellarven (Glochidien), welche die Oberfliche der Fische während einer gewissen \%eit parasitieh bewhlnen, haben an anderer Stelle dieses Werkes bereits Berücksichtigung gefunden. Hier wäre es somit nur die Aufgabe, der Fischgäste aus dem Kreise der Würmer zu gedenken. Sie rekrutieren sich aus sehr verschiedenen Abteilungen des Wurmreiches. Vertreten sind unter diesen Schmarotzen die Blutegel (Hinudinei), dic Spulwürmer (Nematodes), die Kratzer (Acanthocephali) und zwei Gruppen der Plattwürmer, die Saugwürmer (Trematodes) und die Bandwürmer (Cestodes).

Kleine Blutegel schmarotzen häufig und oft in ziemlich bedeutender Zihl auf der ()berfliche karpfenartiger Fische. Karpfent Schleihen, Barben; sie sind aber atuch im schlunde der I fechte und atn der Kürperbedeckung des Rheinlachses angetroffen wurden. Bei letzterem Wirt scheinen sie Exemplare zu bevorzugen, die infolge langer Wranderschaft wundgeriebene Stellen an Bauch und Flankien aufweisen. Die Würmer gehören zur Gattung Piscicola, aus der Gruppe der Rüsselegel. Ausser einer vorderen, kleineren und hinteren, doppelt so grussen Haftscheibe hesitzen sie in der. MIundhöhle einen kräftigen, vorstreckbaren Rüssel. Acht Augen sind paarweise auf dem vorderen Saugnapfe verteilt. Der gestreckte, cylindrische Körper verschmälert sich nach vorn nur schwach. Die Farbe ist gelblich oder aschgrau mit feinen braunen Punkten, und einzelnen Reihen hellerer elliptischer Flecke. Nach anatomischen Unterschieden des Magendamins und der Geschlechtsurgane wurden zwei Arten, Piscicola geometra L., und P. respirans Troschel, unterschieden. Der Parasitismus der Fischenel darf nur als ein temporïrer bezeichnet werden. Es werden die Würmer nach Leydig häufig frei schwimmend, oder zu mehreren an der Unterfläche der Steine dicht zușammensitzend ingetreffen. Ist dem Nahrungsbedürfnis. durch Aufnahme von Fischblut für einmal wieder Genüge gethan, so verlässt die Fiscicola den Wirt, sich so in der Lebensweise scharf won dem Kredsegel (branchobdellal unterscheidend, der sein ganzes Leben auf dem Flusslirebs schmarotzend zubringt. Die 
kleinen, gelbroten, längsgestreiften Eier der Piscicolen sollen auf der Aussenfläiche der Fische befestigt werden.

Die weite Gruppe der Nematoden oder Fadenwürmer, zum grüssten Teil aus Parasiten verschiedensten Grades zusammengesetzt, liefert auch für die Süsswasserfische ein stattliches Kontingent von Schmarotzern. Es sind alles cylindrische, gestreclite, von einer derben Cuticula umhüllte Würmer, mit endständigem Mund und etwas vor dem Hinterende liegendem After. Der meist wohl entwickelte Darmkanal zerfällt in der Regel in drei bis vier mehr oder weniger differente Abschnitte; die Geschlechter sind beinahe immer getrennt.

Es ist fast unmöglich, den Darmkanal eines Flussbarsches zu öffnen, ohne in den Pylor-Anhängen in oft sehr beträchtlicher Zahl kleine Rundwürmer (요 I $2-18 \mathrm{~mm}$ lang, $65-8 \mathrm{~mm}$ ) anzutreffen, die durch ihre gelbe oder selbst grell rote Farbe sich von den sonst farblosen Parasiten auffallend unterscheiden. Die lebhaft beweglichen Tiere sind auch in anderen. Fischen Hecht, Forelle, Quappe, Felchen, Zander, Kaulbarsch — zu Hause. Was sie ganz besonders auszeichnet, ist die starke, kappenförmige, hornige Mundkapsel, der sie auch ihren Namen, Kappenwürmer (Cucullanus elegans Zed.) (Fig. 34) verdanken. Der merkwürdige, eine weite Mundhöhle umschliessende Apparat besteht im wesentlichen aus einer längsgestreiften Kapsel. Sie steht jederșeits in Beziehung mit zwei kleineren, nach hinten gerichteten Hornstäben. Am Vorderrand ist die Kapsel durch vier dreieckige

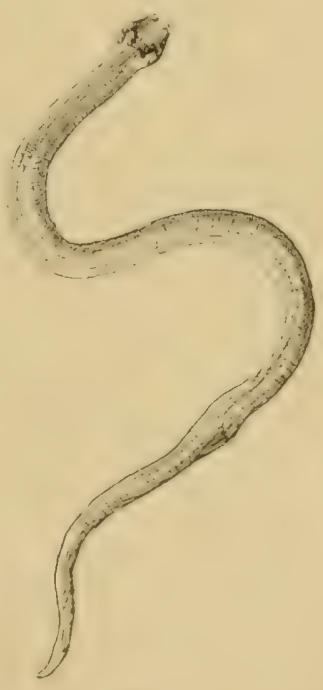

Fig. 34.

Cucrullanus elegrus aus dem Barsch.

Ansatzstücke verstärkt. Nach hinten wird der ganze Apparat durch einen Chitinring abgeschlossen. Männchen und Weibchen weichen in äusserer Erscheinung und innerem Bau nicht 
unketrächtich von einander ab, eine bei Xematsden sewöhnliche Erscheinung.

Die Entwickelungsvorgänge im befruchteten Ei der Kappenwürmer sind von Bütschli zum Gegenstand einer Untersuchung gemacht worden. Leuckart verfolgte das weitere Schicksal der Embryonen, die schon im Muttertier die zarten Eihüllen verlassen und oft zu tausenden die Geschlechtswege anfüllen. Trächtige Weibchen fand ich während des ganzen Jahres. Die Jungen sind etwa $0.4 \mathrm{~mm}$ lang, äusserst beweglich; ihr Darm ist noch einfach,

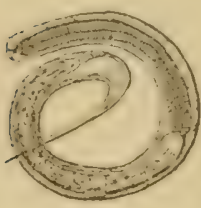

Fig. 35. Larve von Cucullanus elegans aus Cyclops. ohne weitere Einteilung, der komplizierte Mundbecher fehit oder ist nur durch einen Chitinzahn vertreten; das Hinterende läuft in einen langen, spitzen, lebhaft schlagenden Schwanz aus (Fig. 35). In diesem Zustande durch eine starke Cuticula genügend geschützt, leben die Tierchen während Wochen im Wasser. Früher oder später wird ein Zwischenwirt bezogen, in der Regel ein kleiner Krebs, ans der Gruppe der Cyclupiden, seltener Insektenlarren. Die jungen Parasiten werden durch die Mundïffinung aufgenommentn, wh in grosser Zahl. Leuckart zählte in einem Cyclops nicht weniger als 34 Eindringlinge. Im Zwischenwirt durchbrechen sie mit ihrem Bohrzahn die Darmwand und gelangen so in die Leibeshöhle, wo sie nach wenigen Tagen eine Häutung eingehen, die ihren Bau wesentlich verändert. Der Bohrzahn, der ja seinen Zweck erfüllt hat, ist verschwunden, der Schwanz ist kürzer

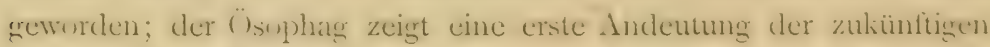
Gliederung in NIuskel- und in Drüsenmagen. In der Folge entwickelt sich allmählich der chitinüse MIundiecher zu seiner typischen Gestalt. Eine neue Hautung tritt ein; das Nervensystem und der Hautmuskelschlauch erscheinen in der definitiven Form, während die. Geschlechtsorgane noch wenig entwickelt sind und das Hinterleibsende dem des erwachsenen Tieres noch unihnlich aussieht. Auch Grösse und Skulptur des Mundbechers weichen noch von den bezüglichen Verhältnissen beim erwachsenen Tier ab. Im Sommer

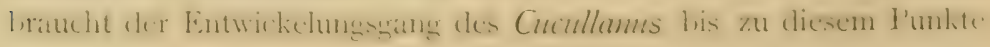


nur wenige Tage, im Winter dagegen mehrere Wochen. Damit ist aber auch die Grenze der im Zwischenwirt müglichen Ausbildung erreicht. Jetzt müssen die Kappenwürmer eingeschlossen in die Cyclopiden auf den definitiven IVirt, den Barsch, übertragen werden. Mit der Nahrung nimmt der Fisch gleichzeitig die jungen Schmarotzer auf. Im Magen des Hauptwirtes freigeworden; beziehen die Kappenwürmer die Pylor-Anhänge, wachsen dort rasch heran, um nach einer weiteren Häutung bald die Geschlechtsreife zu erreichen. Schon zehn bis vierzehn Tage nach der Infektion findet im Darm des Barsches die Begattung der Würmer statt.

Einen ähnlichen den Stempel des Parasitismus tragenden Entwickelungsgang mit C̈bertragung des jungen Schmarotzers auf einen Zwischenwirt, in dem lïngere Zeit ein latentes Leben geführt werden kann, bis wiederum mit der Nahrung der Parasit in den definitiven Wirt eingeschmuggelt wird, durchläuft ein bekannter Fadenwurm des Hechts, die Ascaris acus Bloch.

Schon seit längerer Zeit sind aus vielen karpfenähnlichen Fischen kileine Nematoden bekannt, die wenig umfangreiche (bis I $m m$ lange) Kapseln der Miesenterien und des Lebergewebes bewohnen. Im Genfersee sind die betreffenden, höchstens 2. $m m$ langen TUürmer speziell in der Laube (Alburmus lucidus) häufig. Verwandte Arten sind von v. Linstow in der Quappe und Aesche eingekapselt gefunden worden. Die schlanken Tierchen zeichnen sich durch einen weiten Mund mit kräftigem Bohrzahn und einen drüsigen, vom Pharynx sich abzweigenden Blindsack aus. Sie sind geschlechtslos. Diesing legt ihnen in seinem Hauptwerk ,Systema Helminthum" fälschlich den Namen Trichina cyprinorım bei (Fig. 36). Offenbar sind sie vom Darm

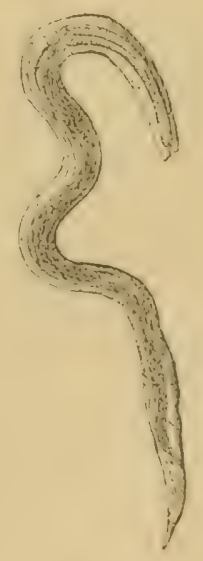

Fig. $3^{6 .}$

Larve von siscaris acus (Trichina cyprinorum) aus den Weissfischen. her in Leber und Mesenterien der Weissfische eingewandert. Im Zwischenwirt können sie wohl längere Zeit ein latentes Leben führen, eine für die Erhaltung der parasitischen 
Spezies wichtige Eigenschaft. Die Dauer der Möglichkeit einer erfolgreichen Übertragung auf den Hauptwirt wird so verlängert und der Verbreitume des Sehmarotzers diclunch kräftiger Virshul, geleistet. Während seines Aufenthalts im Zwischenträger gehen mit dem jungen Wurm keine weiteren Veränderungen vor sich; er wächst bis zu einem gewissen Grade, ohne eine Metamorphose durchzumachen, ein Verhalten, das von dem des Cucullanus bedeutend abweicht. Mit den IVeisslischen, der Lieblingsnahrungy des Hechtes, gelangen die Nematoden in den Magen dieses grossen Räubers des Süsswassers. Leuckart fand sie dort wieder eingekapselt in den Wandungen des Verdauungstractus, dann aber auch frei in den verschiedensten Grössen und Entwickelungsstadien Magen und Darm des Wirtes bevölkernd. Von der Trichina cyprinorum bis zur ausgewachsenen, geschlewhtseifen Ascaris acus liessen sich alle wünschbaren Übergangsformen nachweisen. Der Bohrzahn geht verloren; die drei für Ascaris charakteristischen Lippen crscheinen am Lnfange der Mundiffinung; die Geschlechtsorgane wachsen schlauchförmig aus. Dagegen bleibt im erwachsenen Tier jener eigentümliche Blindsack des Ösophagus bestehen, der schon die junge Larve in den Weissfischen auszeichnet und so junge und alte Form leicht auf einander zurückführen lässt.

Ascaris acus Bloch ist kein seltener Gast im Darm und auch in der Leibeshöhle von Hecht, Quappe und Forelle. In jüngeren Stadien, frisch aus den Weissfischen stammend, lebt sie zundichst cingekapselt in den Wandungen des Verdaumgstractus ihrer Wirte, wie dies Leuckart beobachtete. Nachdem sie eine bestimmte Grösse erreicht hat, bricht sie nach dem Darm oder der Leibeshöhle durch. Lünge des $q$ bis $40 \mathrm{~mm}$, des $\hat{b}$ bis $30 \mathrm{~mm}$. Die Muncllippen sind stark entwickelt, Cutieula deutlich quer gestreift. Wie bei fast allen Parasiten werden Eier in grösster Mienge gebildet. An diesen Ascariden des Hechts hat Bunge durch eine Reihe interessanter Experimente nachzuweisen verstanden, dass sie

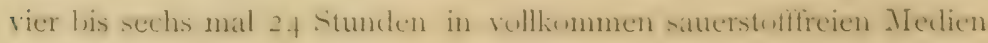
leben können. 
Eingekapselte, geschlechtslose Nematoden sind in den verschiedensten Organen von Fischen des süssen und salzigen Wassers eine ganz gewöhnliche Erscheinung. Über ihre Zugehörigkeit zu erwachsenen Formen aber sind wir bis jetzt in den wenigsten Fälen genügend aufgeklärt. Äusserst verbreitet und oft in ungeheuerer Zahl auftretend ist in sehr vielen Fischarten die Agamonema capsularia Dies., die wahrscheinlich mit der unter ähnlichen Umständen vorkommenden Ascaris capsularia Rud. und der Filaria piscium Rud. zusammenfallen dürfte. Es liegen die Würmer spiralig aufgerollt und von einer leichten Kapsel umschlossen an und in den verschiedensten Organen: Leber, Nieren, Milz, Geschlechtsorganen, im Peritonäum, auf der Aussenfläche des gesamten Verdauungstractus, besonders zwischen den Appendices pyloricae. Aus ihrer Kapsel befreit, schwimmen die glänzenden, äusserst beweglichen, schlanken Würmer sehr lebhaft im Wasser. Es gelang mir in zahlreichen Versuchen Exemplare aus dem Lachs Monate lang in kleinen Wassermengen am Leben zu erhalten, nie aber nach vollkommener Austrocknung dieselben durch Anfeuchtung wieder zu beleben. Länge bis $20 \mathrm{~mm}$, Tegument glatt, keine Seitenmembranen, Vorderende etwas verschmälert, drei kleine rudimentäre Lippen. Der Ösophag trägt auch hier wieder ein kleines seitliches Caecum. Keine Geschlechtsorgane. Früher wurden diese „Filarien" fälschlich zum Entwickelungscyklus gewisser die marinen Fische bewohnender Cestoden (Tetrarhynchen) gezogen! Wahrscheinlich erreicht Aganonoma capsularia die Geschlechtsreife in grossen Raubfischen. Wenigstens fand ich im Magen eines Haifisches freie Agamonemen neben halbverdauten Resten eines Meeraals, ein Fisch, der mit larvären Würmern oft besetzt ist. Neben den Cysten der Agamonemen liegen in manchen Organen vieler Süsswasserfische noch Kapseln anderer Nematoden. Kapsel und Insasse aber unterscheiden sich durch Lage, Form, Bau leicht von den soeben beschriebenen Bildungen. Sie gehören wohl verschiedenen geschlechtsreifen Arten von Fadenwürmern an, doch ist ihr Zusammenhang mit erwachsenen Formen nur sehr wenig klargestellt. 
An die Klasse der Nematoden schliesst man gewöhnlich die Gruppe der Iŕratzer, Acanthocephalen oder, wie sie nach ihrer einzigen Gattung genannt wird, der Echinorhynchen an. Es sind dies ohne Ausnahme typische Darmschmarotzer. Ihr Bau verrit sofort den l'arasitismus durch den mit kriftigen Haken bewadincten, in eine Scheile zurückziehbaren Rüssel, der als starlier Haftaplarat dient, und durch die völlige Abwesenheit des Verdauungssystems. Die Nahrungssäfte werden aus dem Wirt osmotisch clurch die gatnae Förperoberfläiche aufgenommen. Im gestreckten, oder eifürmigen Körper liegen, von einem aus Quer- und Längsfasern zusammengesetzten Muskelschlauch umschlussen. hauptsiichlich dic lomplizient gebauten Geschlechtsorgane. Die Geschlechter sind getrennt, die Fruchtbarkeit erfährt auch hier eine für den Parasiten so wünschenswerte starke Steigerung. Im Grunde der Rüsselscheide entwickelt sich das Nervensystem in Gestalt eines Ganglions mit davon ausstrahlenden Nerven; in die Leibeshöhle ragen noch zwei eigentümliche, schlauchartige Bildungen, die Lemnisken, denen man die Funktion ron Exkretionsorganen zuschreibt. Dic Lebensegeshichte der Echinorhynchen ist durch das Schmarutzertum stark leeinflusst.

Kratzer im Darme von Süsswasserfischen sind eine recht häufige Erscheinung. Besonders verbreitet in allen Fischen aus der Familie der Karpfen, aber auch in Barsch, Quappe, Hecht, Aal, Stür, Forclle, Acsche; Grople, Sailling, Kaullarsch finclet sich der Echinorhynchus proteus Westrumb. Oft ist der Enddarm des Wirtes von den rötlichen oder gelblichen Schmarotzern prall angefültt. Die Länge der Tiere betrågt bis $30 \mathrm{~mm}$; vom Januar bis Juni nahm sic bei den Exemplaren aus dem Genfersee stetig zu. Äusserlich zeichnet sich die Art durch einen langen, schmalen, unbewehrten Hals aus, der an der Übergangsstelle zum Rüssel eine durchaus charakteristische, kugelige, als Bulla bezeichnete Bildung trijgt. Der Rüssel selbst ist nach Hamanns neuester, schöner Arbeit mit 23 bis 25 Querreihen von Haken bewaffnet, die drei verschiedenen Formen angehüren. Eine verwandte, von Hamann zuerst genau festgestellte Art, der E. Linstowi, besitzt nur zehn Hakenreihen mit zweierlei Formen der Haftgebilde. 
Gesamtzahl der Haken für $E$. protens 230-250, für $E$. Linstowi 60. Die Grösse der Exemplare von E. proteus richtet sich nach der Grösse des bewohnten Fisches, ein Verhältnis, das für Wirt und Gast bei parasitischen Geschöpfen überhaupt oft gültig ist. In der Jugend sind die Echinorhynchen noch liaum angeheftet; ältere Individuen versenken Rüssel und Hals tief in die Schleimhaut des Fisches.

Die reifen, bereits embryonenhaltigen Eier fallen, nachdem das Ovarium geplatzt ist, in die Leibeshöhle; sie werden von einem eirentümlichen, sich fortwïhrend öfhenden und schliessenden Teil des Geschlechtsapparats, der Uterusglocke, aufgeschluckt und von da durch die Leitungsapparate an die Aussenwelt abgegeben. Von einzelnen Kratzern werden so Millionen sehr kleiner Eier in der freien Natur zerstreut. . Ihre Entwickelungsfähigkeit bleibt lange Zeit eine ungestörte. Die Embryonen sind in drei starke Hüllen von verschiedener Natur eingeschlossen. Ihre Gestalt ist die eines schlanken Kegels mit abgerundeten Enden; das breitere, ventral scheibenartig abgeflachte Vorderende trägt einen aus zehn bis zwölf stilettfirmigen Borsten zusammengesetzten Stachelapparat, der durch eine spezielle Muskulatur bewegt werden kann. Leuckart hat schon vor längerer Zeit nachgewiesen, dass die Eier unseres $E$. proteus in den Darm des weit verbreiteten, gewöhnlichen Flohkrebses (Gammarus pulex) gelangen müssen. Die Eihülle und endlich auch die Darmwand des Zwischenwirtes wird von den Embryonen mit Hilfe ihres Stachelapparates durchbrochen; in der Leibeshöhle des Krebses läuft die weitere Entwickelung ab. Noch drei Wochen bleiben die Bewegungen im Zwischenwirt recht lebhafte; nach und nach werden sie langsamer, um endlich ganz aufzuhören. Der embryonale Hakenkranz ist inzwischen verloren gegangen; die Tiere liegen wie Puppen von Insekten, von ihrer äusseren, derben Haut wie von einer Kapsel umgeben und mit eingezogenem Rüssel in der Leibeshöhle des Gammanus. Die weitere Entwickelung des scheinbar ruhenden Körpers ist eine höchst komplizierte. Aus einer zentralen Körnermasse der Larve, dem sogenamnten Embryonalliem, geht die Iatuptmanse der Organe, 


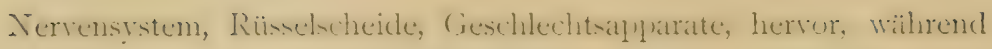
die Körperwandung mit den Lemnisken, dem eigentümlichen, sie durchziehenden Lakmensistem und dem .Iuskelschlanch den peripherischen Teilen des Embryos den Ursprung verdankt.

Eingeschlossen in den Zwischenwirt müssen die jungen Echinorhynchen in den Verdauungstractus der ihnen als Hauptwirte zusagenden Fische gelangen. Dort werden sic frei, fixieren sich, ihre volle Grösse wird erreicht und nach definitiver Ausbildung der Geschlechtsorgane wird die Begattung vollzogen.

Hamann hat indessen die Beobachtung gemacht, dass die Lebensgeschichte noch kompliziertere Bahnen einschlagen kann. In manchen Fischen, Stichling, Birte; (iroppe, Gründling, besunders massenhaft aber in der Elritze (Phoximus laevis) fand der Göttinger Zoologe der Oberfäiche der Leber angeheftet regelmässig kugelige bis eiförmige Gebilde von etwa 2 mm Durchmesser. Sie bestehen aus einer von der Leber aus gebildeten Kapsel, die die orangefarbene Larve einer Echinorhynchus-Art umschliesst. Diese jungen Tiere aus der Leibeshöhle der kleinen Fischarten entsprechen in jeder Beziehung den Jugendstadien von Echinorhynchus protcus aus dem Flohkrebs. Sie müssen unbedingt als zum Entwickelungsgang des besprochenen Kratzers gehörend betrachtet werden. Es gelang Hamann sogar, aus den in Fischen gefundenen Larven in der Forelle den typischen Echinorlyynchus proteus gross zu ziehen. Also kann ein Fisch, z. B. die Elritze, so gut wie der Flohlirebs zum Zwischenwirt eines Kratzers werden, der selbst wieder Raubfische bewohnt. Die genannten kleinen Fische künnen übrigens

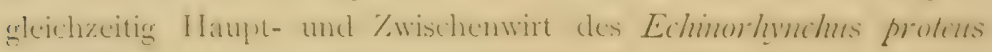
sein. Sie beherbergen ihn als geschlechtsreifen Wurm massenhaft im Darmkanal, gleichzeitig findet er sich ganz konstant, oft in der Zahl von zwanzig Exemplaren, als geschlechtslose Larve der Leber und den MIesenterien angeheftet. So sucht ja auch die Trichine den Menschen in zwei verschiedenen Entwickelungsstadien heim, als geschlechtsreifer Darmbewohner und als in clen Aruskeln ruhende, unreife Larve. Hamann nimmt an, dass die Elritzen u. s. w. gelegentlich Flohkrebse verschlucken, in deren Darm frisch aufgenommene, noch 
nicht geöffnete Eier von $E$. protcus liegen. Die Embryonen gelangen nun im Fischdarm zum Ausschlüpfen, sie durchbohren die Wandungen des Verdaungstractus und benützen den Fisch an Stelle des von ihm verschlungenen Krebses als Zwischenwirt. Ein Raubfisch wie die Forelle ist also einer doppelten Infektionsgefahr ausgesetzt, sie kann den Echinorhynchus vom Fisch oder vom Krebs beziehen. Für die Verbreitung des Parasiten aber wird die geschilderte Vermehrung der Zahl von Zwischenwirten von Bedeutung und Vorteil sein.

Kaum weniger verbreitet als der Echinorhynchus protcus ist ein anderer Kratzer zahlreicher Süsswasserfische, der $E$. angustatus Rud. Als seine gewöhnlichsten Wirte dürfen wohl Barsch, Hecht, Quappe, Karpfen und Forelle bezeichnet werden. In gewissen Bächen, die den Zwischenwirt des IVurmes, die Wasserassel (Asellus aquaticus), häufig beherbergen, ist auch der Darm der Forellen regelmässig mit hunderten der Schmarotzer angefüllt. Der gestreckte, spindelförmige oder cylindrische Körper besitzt nur einen kurzen Hals. Der walzenförmige Rüssel trägt $8-20$ Hakenreihen, deren Elemente von zweierlei verschiedener Form sind. Bei mittelgrossen Tieren mit I5 Reihen beträgt die Hakenzahl I 20 (Fig. 37).

Es kamen mir keine Exemplare von E. ang $\ell^{-}$ statıs aus Süsswasserfischen zu Gesicht, deren Gesamtlänge $25 \mathrm{~mm}$ überstieg. Die Lebensgeschichte dieses Kratzers kopiert die für $E$. proteus näher geschilderten Vorgänge. Wie dort bedàrf die Larve bis zu ihrer vollständigen Ausbildung acht bis zehn Wochen Zeit. Die Eier des Parasiten werden von der Wasserassel in grosser Menge aufgenommen. Im Gegensatz aber zu den bereits geschilderten

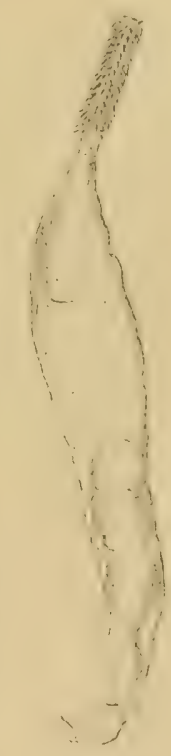

Fig. 37 . Echinor-hynchus angustatus.

Verhältnissen gelangen die ausschlüpfenden Embryonen von $E$. angustatus schon in der Drüsenschicht des Darmes ihres Zwischenträgers, die sich in beträchtlicher Dicke zwischen Chitinwand und 
Muskelhaut legt, zur Ruhe. Hier liegen sie in grosser Zahl be-

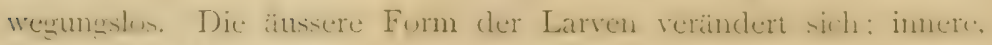
komplizicte Umbildungen finclen statt: die Körpergrïsse nimmt zu. Endlich fallen die jungen Schmarotzer infolge von in der Wandung des Darmes eintretenden Veränderungen passiv in die Leibeshöhle des Zwischenwirtes. Von der Bluttlüssigkeit des Krebses umspült, und so reichlich ernährt, wächst der Schmarotzer verhältnismässig rasch unter allmählicher Gestaltveränderung. Es entsteht auf verwickeltem WVege der junge Echinorhynchus, der mit der Assel auf den Hauptwirt (Fische) übertragen werden muss, um dort seine Geschlechtsreife zu erlangen.

Für einen andern Kratzer, den E. clavaeceps Zed., hat Villot den Zwischenwirt in der wasserbewohnenden Larve eines weit verbreiteten und massenhaft auftretenden Netzfüglers, der Sialis lutaria L., entdeckt. Der junge Wurm liegt eingekapselt im Fettkörper des Insekts; er sieht in Form und Bau dem erwachsenen

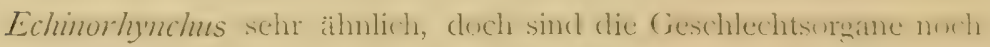
unentwickelt. Zufälig finden sich die Larven des E. clavacceps auch in einem Blutegel (Nephelis octoculata) und in Wasserpulmonaten (Limnaeen); doch scheint die Sialis-Larve der richtige Zwischenträger zu sein. Ihr wird vom Hauptwirt des betreffenden Kratzers, der Schmerle (Cobitis barbatula), eifrig nachgestellt. E. clavaeceps ist übrigens auch kein seltener Gast zahlreicher Karpfenarten.

Dịe formenreiche Gruppe der Trematoden oder Saugwürmer umschliesst ausschliesslich parasitierende Wesen. Doch leben sie bald als Entoparasiten in den inneren Organen ihres Wirtes, bald heften sie sich ektoparasitisch auf seiner Oberfliche an. Es sind meist flache, blattfürmige, ungegliederte Würmer, die als Haftapparate Saugnäpfe und oft daneben noch Hakengebilde besitzen.

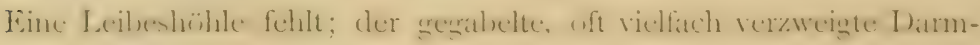
kanal endigt immer blind. Über dem Schlunde liegt ein Doppelganglion, das mehrere Nervenstämme, speziell zwei nach hinten ventral verlaufende, abgiebt. Rühriges, meist durch einen unparigen hinteren Porus ausmündendes Exkretionssystem, das mit zahlreichen 
Wimpertrichtern im Parenchym beginnt. Die Trematoden sind fast ausschliesslich Zwitter mit sehr komplizierten Geschlechtsapparaten. Ihre Lebensgeschichte ist oft äusserst verwickelt. Sie setzt sich besonders bei den entoparasitischen Formen für ein und dieselbe Art aus mehreren, auf verschiedene Weise aus einander herworgehenden Generationen zusammen (Gencrationswechsel). Freite Stadien wechseln mit parasitischen; oft werden mehrere Wirte durchlaufen.

Von den entoparasitischen Formen, die mit höchstens zwei Sauggruben, nie mit Haken bewehrt sind, stellt besonders die artenreiche Gattung Distonna zahlreiche Schmarotzer für die Süsswasserfische. Stossich kennt I jo Distomeen aus etwa zweihundert Fischarten; davon parasitieren etwa vierzig Arten in. Süsswasserund Wanderfischen. Sie bewohnen oft in sehr grosser Individuenzahl hauptsächlich die verschiedenen Abschnitte des Verdauungstractus, vom Schlund bis zum Enddarm. Doch fehlen sie auch nicht in anderen, nach aussen offenstehenden Organen, wie z. B. in der Harnblase (Distoma folium Olfers bei Groppe, Hecht, Forelle, Aesche, Saibling). In Körpergestalt, Grösse und Bau weisen die Distomeen der Süsswasserfische gar mancherlei Verschiedenheiten auf. Als Extreme seien erwähnt das D.tereticolle Rud. aus dem Schlund von Hecht, Aalraupe, Forelle, Saibling etc. mit gestrecktem bis $50 \mathrm{~mm}$ langem, halbcylindrischem Körper, und das schon angeführte $D$. folium aus der Harnblase mancher Fische, dessen Leib eine flache Scheibe von kaum 2 mm Durchmesser bildet, von der ein Halsteil sich scharf abhebt. In zahlreichen Fischen lebt das D. appendiculatum Rucl., ausgezeichnet durch einen in den Körper rückziehbaren Schwanzteil; im Schlunde des Lachses stösst man oft auf das auch sonst verbreitete $D$. varicum Zeder mit drehrundem, geknicktem Körper, konkaver Rücken- und konvexer Bauchfläche. In den Karpfen lebt das durch seinen kugeligen Bauchsaugnapf ausgezeichnete D. globiporum Rud.

Über die Lebensgeschichte der die Süsswasserfische bewohnenden Distomeen ist uns fast nichts bekannt. Sie wird wohl wie diejenige verwandter Formen durch mehrere provisorische Wirte 
führen und für ein und dieselbe Art aus verschiedenen Generationen zusammengesetzt sein. Parasitische und freie Zustände werden mit einander wechseln, bis sich.endlich ein junges geschlechtsloses Distoma entwickelt hat, das eingeschlossen in einen letzten Zwischenwirt, wie beim Leberegel unserer Rinder und Schafe, in den Darm des Hauptwirtes grelangt. Die Fruchtbarlecit der in Frage stehenden Saugwürmer ist eine gewaltige. Bei dem abscheulichen Ausireutumgerstem, das den l'araitismus nun einmal charaliterisiert, können Stoffe zur Ausarbeitung der Eier in Hülle und Fülle aufgenommen werden. So wird der weitern Verbreitung der schmarotzenden Spezies starker Vorschub geleistet. Die mit einem kleinen Schalendeckel versehenen Eier werden mit dem Kot des Wirtes an die Aussenwelt abgegeben. Vom Distoma laureatum Zed. der Salmoniden berichtet uns v. Willemoes-Suhm, dass den ins Wasser gelegten Eiern nach Verlauf von 34 Tagen ein grosser, bewimperter Embryo mit schwarzem Augenfleck entschlüpfte (Fig. 38). Bei Distoma globiportm ist nach demselben Gewährsmann der lünglichrunde Embryo ebenfalls stark bewimpert. Er besitzt

Fig. $3^{8 .}$

Flimmerembryo von Distoma inureatums. Seitengefässe und trägt an einem Ende ein saugnapfartiges Gebilde, aus dessen Mitte sich ein konischer Zapfen erhebt. Der Embryo von $D$. folitum ist

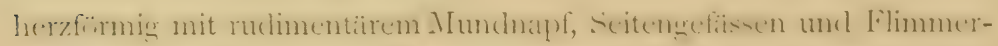
überzug. Auch die erste Jugendform von $D$. nodulosum aus dem Magen von Hecht, Zander, Barsch etc. zeigt ähnlichen Bau. In seinem schwarzen Pigmentfleck ist deutlich eine rundliche Linse erkennbar. Der Embryo von D. tereticolle besitzt im Exkretionsapparat deutliche Flimmerläppchen. Über die weiteren Schiclisale all dieser bewimperten, freischwimmenden Jugendstadien der Süsswasserdistomeen wissen wir leider fast gar nichts. Speziell ist es uns selır oft unbekannt, in welchen Zwischenwirt eingeschlossen sie endlich in den Darmkanal des definitiven Wirtes übertragen werden. In manchen Fillen mag der letzte Zwischenwirt dem Kreis der Mollusken angehüren. So lebt die noch geschlechtslose Larve ron 
D. globiponum Rud. in dünnwandigen Cy'sten weitverbreiteter Wasserschneclien (Limnaca stagnalis, Planorbis marginatus, Succinea putris, etc.). Es können übrigens auch die Süsswasserfische die Rolle von $Z$ wischenträgern von Trematoden gegenüber anderen Geschöpfen — Raubfischen, Wasservögeln — spielen.

In der grossen Mehrzahl der Individuen des Flussbarsches ist die Wandung der Schwimmblase durchsäet mit kleinen, kugeligen, starkwandigen, opalescierenden Cysten. Sie umschliessen larväre Trematoden mit gut entwickeltem Mrundnapf, an dessen Seite zwei bohnenfürmige Organe - Drüscnausmündungsstellen - liegen. Auch ein hinterer Bauchnapf lässt sich nachweisen. Der Leib ist reichlich mit Kalkkörperchen durchsetzt; er umschliesst einen kurzen gegabelten Darm. Es sind diese Larven mit dem Namen Tetracotyle belegt worden. Ähnliche junge Saugwürmer siedeln sich nicht selten im Auge verschiedener Fische, Barsch, Quappe, Zander, Karpfen, an, wo sie als Diplostomum beschrieben worden sind. Eine Kapsel fehlt ihnen. v. Nordmann fand in der Linse einer Quappe 290 solcher Würmer, im Glaskörper 15\%.

- Es ist in hohem Grade wahrscheinlich gemacht worden siehe ausser Leuckart die Arbeit von Brandes -, dass diese Tetracotylen und Diplostomen, die ausser Fischen auch Mollusken, Amphibien, Reptilien, Vögel und Säugetiere infizieren, im Darme des Hauptwirtes - Reptilien, Säugetiere und besonders Vögel sich zu geschlechtsreifen Vertretern der Familie der Holostomiden entwickeln. Der bewimperte Embryo dieser Trematoden sucht einen passenden Zwischenwirt auf und reift in ihm zur völlig ausgebildeten Holostomiden-Larve heran, die, mit dem Zwischentrigger in den Darm des definitiven Wirtes übergeführt, dort zum geschlechtlichen Tier auswäichst. Ein Generationswechsel wäre in dieser Lcbensgeschichte ausgeschlossen, dagegen wird immer ein Zwischenwirt aufgesucht. Der Zwischenträger fällt nun bei den sofort zu besprechenden ektoparasitischen Saugwürmern ebenfalls fort.

Die an der Aussenfläche von Wassertieren, speziell Fischen, lebenden Polystomeen bechüfen zu ihrer Festsetzung weit krifftigerer Haftorgane als die entoparasitischen Distomeen. Ist doch fur sie 
die Gefahr, vom Wirte abgestreift zu werden, eine immer drohende. So wird denn bei ihnen nicht nur die Zahl der Saugnäpfe bedeutend vermehrt, sondern es werden dieselben in ihrer Funktion oft nowh durch mannigfaltige Chitinhalien und Dorsten unterstiitzt. Bei diesen mit der freien Aussenwelt während des ganzen Lebens in Bezichung stehenden Schmarotzern sind auh Sinnesorgane, besonders Augen, lieine soltenheit, Bihlungen, die bei den Entoparasiten unter den Trematoden höchstens während der frei schwärmenden Jugendzeit auftreten. Die Polystomeen bilden meistens nur wenige, aber grosse und oft mit verschiedenen Anhängen versehene Eier aus. Die denselben entstammenden Embryonen entwickeln sich am häufigsten ohne Generationswechsel und Wanderungen zum definitiven Geschlechtstier. Die Eier werden oft mit ihren Fortsätzen am Wirt befestigt, aus ihnen entspringt ein üusserlich und innerlich schon hoch differenzierter Embryo. Das für ihn unnütige Wimperkleid ist schwach, oder gar nicht entwickelt; dagegen lesitzt er schon einfache Haftorgane, die sich meistens später komplizieren. Die Distomeen liefern ungemein zahlreiche, einfache Embryonen, von denen wenigstens einige alle mannigfaltigen Wendungen des Geschicks des entnparasitischen Entwickelungsganges glücklich überstehen werden; die Polystomeen entlassen aus wenigen, aber dotterreichen Eiern einige Junge, die im ganzen schon den Eltern ähnlich sincl. Zuweilen werden inclessen auch weitergehende Metamorphosen durchlaufen.

In manchen Fällen bietet der Lebensgang der ektoparasitischen Saugwürmer trotz der direkten Entwickelung Verhältnisse, die zum cirentümlichsten gchüren, was uns tierische Gerchichte lehrt. spezicll unter den Parasiten der Süsswasserfische stossen wir in dieser Bezichung auf höchst seltsame Vorgünge.

Zeller hat uns in seinen schönen Arbeiten sowohl mit Bau, als mit Lediengesechichte des Diflosoon paradoxum Nordm., des fremdartigen Doppeltieres, beliannt gemacht. Es ist ein Trematode, der hiufig an den Kiemen zahlreicher Süsswasserfische - Elritze, Quappe, Groppe etc. - schmarotzt. Im ausgewachsenen, geschlechtsreifen Zustand erscheint der Kürper des Diplosoon als ein 
x- oder kreuzförmiges Gebilde, das, wie wir sehen werden, durch die dauernde und enge Verwachsung von zwei ursprünglich getrennten Wurmleibern entstanden ist. Die Hinterenden besitzen zwei grosse, in vier Gruben geteilte Haftscheiben, zu denen sich noch vier starke Klammerpaare gesellen (Fig. 39).

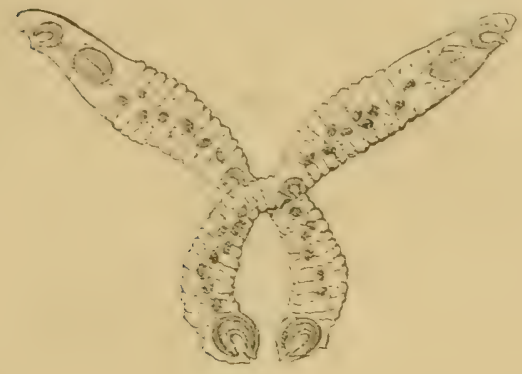

Fig. 39.

Diplosoon paradoxum von den Kiemen der Elritze.

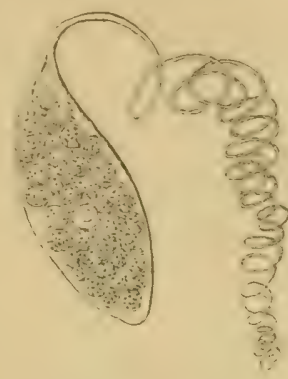

Fig. 40 .

Beide das Diplozoon zusammensetzenden Tiere sind gleich, hermaphrodit, bringen Eier hervor und befruchten sich gegenseitig. Mit dem Eintritt der kälteren Jahreszeit hört die Eierbildung auf, die weiblichen Organe existieren dann nur andeutungsweise. Bei steigender Temperatur (künstlich orler natürlich) beginnt die Ausarbeitung der Eier sofort wieder, die Geschlechtsorgane entwickeln sich und treten in Thätigkeit. Die Eibildung und Befruchtung kann nun in allen Einzelheiten verfolgt werden. Das reife, hochgelb gefärbte, gedeckelte $\mathrm{Ei}$ ist 0.28 bis $0.30 \mathrm{~mm}$-lang; seine Schale besitzt zunïchst an einem Pol einen kurzen, schnabelartigen Fortsatz, der allmählich $\mathrm{zu}$ einem langen, sich aufrollenden und erstarrenden Faden auswächst (Fig. 40). Am siebenten bis achten Tag werden die Eier aus dem erweiterten Ende des Ovidukts ausgestossen. In reinem Wasser läuft die weitere Entwickelung rasch ab. Nach acht Tagen umschliesst die Eischale einen deutlichen Embryonalkörper, der sich zuerst schwach, dann immer krïftiger bewegt. Am fünfzehnten Tag etwa wird der Deckel des Eies abgeworfen, der Embryo schwimmt leicht im Wasser. In diesem Zustand ist das 
junge Tier, was sich schon durch die Eischale erkennen liess, mit zwei dorsal liegenden Augen und einem Wimperbesatz ausgestattet. Die Augen sind Schälchen eines bräunlichen Pigments, die ein helles, kugeliges, linsenartiges fö̈rperchen umseldiensen. Das ganze

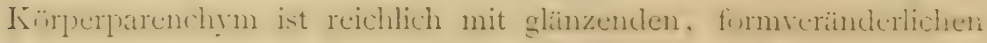
Kügelchen durchsetzt. Am Vorderende liegt der MIund mit zwei eigentümlichen seitlichen Saugnäpfen, das Hinterende trägt zwei Klammern und zwei kleine Angeln. Im Innern des Körpers erscheint der stark muskulöse, in einen einfachen Darm fülırende Schlundkopf (Fig. 4I). Die Bewegungen dieser jungen

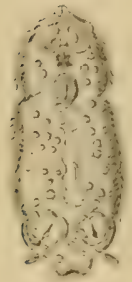

Fig. 4r.

Flimmerembryo vin lliple:and fotret $x$ mm Tierchen sind äusserst mannigfaltig und ausgiebig. Bietet sich indessen im Verlauf von sechs Stunden keine Gelegenheit zur Fixierung auf den Kiemen eines Fisches, so gehen die Diplozoon-Embryonen zu Grunde. Hat die Festsetzung aber stattgefunden, so verwandelt sich der Embryo zu einem Geschöpf, das als kiemenbewohnender Parasit schon von Dujardin unter dem Namen Diporpa beschrieben worden ist. Der unnötig gewordene Schwimmaplatat, der Wimperhesatz, geht verloren; die Augen, die gleichfalls keinen Dienst mehr zu leisten haben, zerfallen, der Darm füllt sich mit dem Wirt entzogenen Stoffen. Im Juli und August findet man die Kiemen der Elritzen oft mit hunderten von Diporpen besetzt. Es sind diese Wesen von lanzettförmiger, abgeplatteter Körpergestalt; ihre Bauchfläche trägt etwas unterhalb der Mitte einen kleinen Saugnapf, am Rücken liegt, noch etwas kleiner als der Bauchnapf,

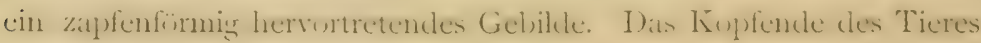
verlängert sich rüsselartig, an ihm liegt zentral ein quergestellter MIund; seitlich öfnen sich zwei Saugnäpfe in die Mundhöhle. Der Darm beginnt seitliche Ausstülpungen zu treiben. In jeder Körperlaalfte liegt ein Hauptstamm des Exkretionssystems. Am Hinterende ist schon das erste Haken- und Klammerpaar befestigt. In diesem /ustand auf den Kiemen schmarotzend und allmählich an Grüsse zunehmend, künnen die Diporpen Wochen und Monate lang leben. Nie aber wird das isolierte Einzeltier geschlechtsreif, 
es muss der Geschlechtsreife die enge, definitive Verwachsung zweier Diporpen zum Diplozoon vorausgehen, wie dies schon v. Siebold richtig erkannte. Die Vereinigung findet immer so statt, dass jedes der beiden sich konjugierenden Individuen mit seinem Bauchnapf den Rückenzapfen des Geführten umfasst. Die notwendige Folge dieser Verbindungsweise wird eine Kreuzung der beiden Exemplare und so die Annahme der typischen Diplozoongestalt sein. Eine Trennung findet nicht mehr statt, die Tierkörper verwachsen an den Berührungsstellen innig; aus zwei ursprünglich getrennten Individuen, hervorgegangen aus zwei verschiedenen Eiern, ist ein Geschlechtstier entstanden. Das Diplozoon wächst nun noch weiter; die vorderen Saugnäpfe gehen verloren, am Hinterende legen sich ein zweites, drittes und viertes Klammerpaar und entsprechende Sauggruben an, die übrigens oft schon in älteren Diporpen teilweise vorgebildet sind. Endlich erscheinen in beiden ursprünglichen Tieren die Geschlechtsorgane.

Eine ziemlich umfangreiche Gruppe von Kiemenparasiten der Fische sind die Gyrodactyliden, charakterisiert durch ihre grosse terminale Schwanzscheibe und den lirüftigen Hakenapparat. Im süssen Wasser sind diese sehr kleinen Schmarotzer in vielen Arten hauptsächlich auf verschiedenen Cypriniden, sowie Barsch, Kaulbarsch, Zander zu Hause. Die Gattung Grrodacty'lus besitzt zwei Kopflappen, acht bewegliche Pharynxstacheln, zwei starke Haken inmitten der Schwanzscheibe und zahlreiche kleine Häkchen am Umfange derselben.

Kaum minder gut mit Haftapparaten ausgestattet ist die verwandte Form Dactylogyrus. Sie trägt vier Kopflappen, zahlreiche kleine Randhaken, neben zwei grösseren Klammem auf der Scheibe. Oft stellt sich noch eine zweite, zentrale Haftplatte ein.

Die merkwürdige Geschichte von Gyrodactylus elegans Nordm. hat uns G. Wagener geschildert. Das junge Tier macht im Innern der Mutter seine vollständige Metamorphose durch und wird lebend, nach Gestalt und Bau dem Muttertier durchaus ahnlich geboren, während z. B. die verwandte Gattung Dactylogy'rus Eicr zur Welt bringt: Bevor aber der junge Gyrodactylus frei wird, umschliesst

Tier- und Pflanzenwelt des Süsswassers. II. 
er selbst bereits wieder einen Sprüssling, so dass drei Generationen in einander eingeschachtelt liegen. Das Muttertier umfasst die auf geschlechtlichem Wege erzeugte, aber noch nicht geschlechtsreife Tochter; diese birgt einen Keimling, der wie angenommen wird einer übrig gebliebenen Furchungskugel cles Eies, aus dem das Tochtertier hervorging, seinen Ursprung verdankt. Tochter- und Enkelindividuum wảren somit gleichzeitig aus der Masse gleichgentalteter und gleichaltriger Embrymalzdlen des ursprünglichen Fir: hervogegangen.

Unter dem Namen Sphy'ranura Osleri haben Ramsay Wright und Macallum jüngst einen interessanten ektoparasitischen Trematoden von der Haut des grossen Salamanders Necturus lateralis Raf. aus den Seen Nordamerikas beschrieben. Die fragliche Form schiebt sich anatomisch und embryologisch zwischen Polystomum und G'rodacty'lus ein. Ein weiterer Kiemenbewohner der Süsswasserfische ist die Gattung Tetraonchus.

Wie die Saugwürmer gehören auch die Bandwürmer (Cestoden) der grossen Abteilung der Plattwürmer an. Es fehlt sogar nicht an Formen, die morphologisch und embryologisch als Übergangsstufen sich zwischen die beiden parasitierenden Gruppen der Plathelminthen einschieben und es so unmüglich machen, Trematoden und Cestoden durch eine scharfe Grenzlinic zu scheiden. Letztere haben sich offenbar aus ersteren herausentwickelt, sind aus ihnen durch Anpassung an immer schärfer ausgeprägtes Schmarotzertum entstanden. Von Ektoparasitismus ist hier keine Rede mehr. Alle Bandwürmer bewohnen die inneren Organe ihrer Wirte. Unter dem Drucke des intensiver werdenden Schmarotzertums sind manche bei den Trematoden noch melır oder weniger entwickelte Organe und Organsysteme als unnütig vollkommen zurückgebildet worden. Sinnesorgane und Verdauungssystem sind spurlos verschwunden. Das schwach entwickelte Nervensystem besteht in der Regel aus zwei seitlichen Lüngsstammen, die im vorderen Körperende, dem sogenannten Kopf, durch einfache oder mehrfache Kommissuren verbunden sind. Gut ausgebildet ist das zweiseitig angelegte, rölrig gebaute Exliretionssystem, dessen feinste 
Verzweigungen im Körperparenchym mit zahlreichen FlimmerJäppchen endigen. In der Regel ist der Bandwurmkörper mehr oder weniger deutlich segmentiert, gegliedert. Sein vorderster, dic IIaft, rgane in (icstalt mamnigfaltiger Haken und saugniejpe tragender Teil wird als Kopf oder Scolex bezeichnet; auf ihn folgen nach hinten in in weiten Grenzen schwankender Zahl die Glieder, Ringe oder Proglottiden. Jede Proglottis umschliesst männliche und weibliche Geschlechtsorgane. Oft sind die Proglottiden, nachdem sie eine gewisse Entwickelung durchgemacht haben, nur noch lose mit einander verbunden; sie lösen sich sogar von der allgemeinen Kette ab, um selbständig als Einzelindividuen weiter zu leben. Das hat - zur Auffassung des Bandwurmkörpers als einer aus einem Hafttier (Scolex) und zahlreichen Geschlechtstieren (Proglottiden) zusammengesetzten Kolonie geführt. Doch giebt es auch Bandwürmer ohne jeden kolonialen Charakter. Die Glieder sind fest und dauernd verbunden, die äussere Segmentierung verwischt; die beiden Geschlechtsapparate kommen in gewissen Füllen im Körper überhaupt nur in der Einzahl vor. Zwischen Einzelindividualitït und Stocknatur des Cestodenleibs lässt sich keine Grenze ziehen. Die den Trematoden am nüchsten stehenden Formen zeigen von Segmentierung noch keine Spur; die Gliederung tritt zuerst schüchtern, dann immer deutlicher hervor und führt zuletzt sogar zur Selbständigkeit der einzelnen Segmente. Für alle verschiedenen Stufen liefern gerade die bei den Fischen schmarotzenden Formen treffliche Beispiele. Auch in der vielfach verschlungenen Lebensgeschichte der Cestoden spiegelt sich ihr parasitärer Charalter wieder. Wanderungen und Wirtswechsel sind allgemein verbreitet; freie Lebensstadien spielen eine viel geringere Rolle als bei den Trematoden. Sie sind in den Entwickelungsgang der verschiedenen Bandwürmer in verschieden reichem Masse eingestreut.

Der Körper der Süsswasserfische bietet relativ zahlreichen und mannigfaltigen Cestoden Herberge, sei es als Zwischenwirt, sei es als Trüger der definitiven Geschlechtsform. Die eigentlichen Taenien, Cestoden, die für die höheren Wirbeltiere und speziell auch den Menschen eine ganze Anzahl von Arten stellen, sind im 
Süsswasserfisch nicht gerade häufig. Barsch, Kaulbarsch, im Genfersee auch Quappe, Felchen, Hecht, Forelle, Saibling beherbergen in ihrem Darm oft in grosser Zahl die Tacnia ocellata Rud., mit vier seitlich und einem endständig am Scolex liegenden Saugnäpfen. T. longicollis Rud. ist für die Salmoniden charaliteristisch. In den Pylor-Anhïngen und dem Dünndarm der befallenen Fische leben oft hunderte dieses Schmarotzers. Lünge bis $25 \mathrm{~cm}$, fünf Saugnäpfe. In Stichling und Barsch ist die mit vier kleinen, aber starken Saugnäpfen bewehrte $T$. filicollis Rud. nicht selten, während die Cypriniden sowie Felchen und Quappe nicht allzu häufig durch die T. torulosa Batsch infiziert werden. Bau und Entwickelung all dieser Fischtaenien sind uns fast vüllig unbekannt *).

Durch sein massenhaftes Auftreten in allen Salmoniden fallt der Bothriocephalus infundibuliformis Rud. auf. Ër fehlt auch nicht in Barsch und Hecht. Sein Scolex trägt - wie dies für die Gattung Bothriocephalus charakteristisch ist - zwei nur mässig starke Sauggruben. Hunderte ron Exemplaren des bis $40 \mathrm{~cm}$ langen Wurmes sind kräftig in den Pylor-Anhängen des Wirtes befestigt. Salm, Saibling und Forelle scheinen am meisten unter der Überzahl der Schmarotzer leiden zu müssen. In manchen Meerfischen und in der Quappe wird der $B$. infundibuliformis ersetzt durch die verwandte Form B. mgosus Rud. Seine Lünge geht bis $38 \mathrm{~cm}$; er ist ausgezeichnet durch randständige Geschlechtsüffnungen, während dieselben sonst bei den meisten Bothriocephaliden auf der Fläche der Glieder liegen.

An die Saugwürmer schliesst sich morphologisch und anatomisch eng ein nicht seltener Darmschmarotzer der verschiedenen Kiarpfenarten, der Nelkenwurm (Caryoplyyllaens mutabilis Rud.) an. Der Wurmkörper ist vollkommen ungegliedert, sein oft wie eine Nelkenblüte gefalteter, hakenloser Vorderrand dient als einziges Fixationswerkzeug. Männlicher und weiblicher Apparat, jüngst von Sain tRemy genauer beschrieben, sehen denen der Trematoden ïhnlich

*) O. v. Linstow hat uns jüngst iiber den Bau derselben einiges mitgeteilt; eine weitere Arbeit ïber Cestoden der Siisswasserfische wirl ron einem meiner Schüler vorlereitet. 
und bleiben wie dort in der Einzahl. Kompliziert ist das Fxkretionssystem mit seinen zahlreichen geschlängelten I.ingskanälen und wohl ausgebildeten Wimpertrichtern. Im Gegensatz zu den meisten Cestoden scheint die Entwickelung des Nelkenwurms relativ einfach zu sein. Eine Metamorphose ersetzt den Generationswechsel; dagegen ist die Wanderung durch den Zwischenwirt beibehalten. Wahrscheinlich lebt der junge.Caryopluyllacus in dem unter dem Namen Tubifex rivulorum belsannt gewordenen Ringelwurm und wird mit ihm in den Darm der Cypriniden übertragen, wo er die Geschlechtsreife erreicht.

Schon etwas mehr dem Typus der Cestoden nähert sich der ".Becherkopf" (Cyathocephalus truncatus Pallas), der sich mit scinem eigentümlichen, becher- oder trichterförmigen Scolex sehr fest in den Pylor-Anhängen von Hecht, Barsch, Felchen, Forelle, Quappe, Saibling ansaugt. Der bis gegen $40 \mathrm{~mm}$ lange Leib besteht aus wenigen, fest verbundenen und undeutlich gegeneinander abgesetzten Proglottiden, die flächenständigr männlichen und weiblichen Porus, suwie die Uterusöffnung tragen. Durch den Bau der Geschlechtsorgane scheint sich der Cyathocephalus der Gruppe der Bothriocephaliden anzuschliessen. Leider ist seine Anatomie erst unvollkommen, seine Lebensgeschichte gar nicht bekannt.

Traten uns in den bis jetzt geschilderten Fällen die Fische ausschliesslich als Wirte des ausgewachsenen, geschlechtwreifun Bandwurms entgegen, so sind doch auch genügend Beispiele bekannt, wo der Fisch die Rolle des Zwischenträgers spielt und in seinen Organen die Larven des Cestoden birgt. In einem gut beschriebenen Entwickelungsgang wird Haupt- und Zwischenwirt der Gruppe der Süsswasserfische entnommen. Es betrifft dies den Triacnophom nodulosus Rud., der als Bandwurm von bedeutender Länge (bis $1 / 2$ m) den Darm des Hechtes oft in recht beträchtlicher Zahl bewohnt. Seltener bezieht er im geschlechtsreifen Zustand Aesche, Forelle und Barsch. In den Fischen des Genfersees gehört der Triaenophorıs zu den gewöhnlichsten Erscheinungen. Sein undeutlich abgesetzter Kopf trägt neben zwei schwachen Sauggruben zwei Paar. starker Chitinhaken, die durch ihre dreizackige Gestalt an 
die starke Bewaffnung mancher Schmarotzer der Meerfische (Calliobothrien) erinnern. Äusserlich ist der Bandwurmkörper trematoden-

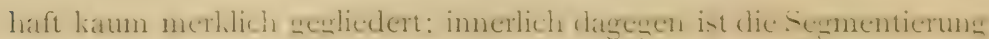
scharf ausgedrückt durch die sich regelmässig in grosser Zahl folgenden, nach dem Typus der Bothriocephalen gebauten Geschlechtsorgane. Im Jugendzustand soll der Triaenophorus eingeliapselt in der Leber der Beutefische des Hechtes, hauptsiichlich der Cypriniden, liegen. Doch fand ich ihn wenigstens für den Genfersee am häufigsten im Barsch, seltener im Hecht, am seltensten und nur in schwachen, kleinen Exemplaren in Forelle und Aesche. Bemerkenswert bleibt immerhin die Thatsache, dass auch hier wieder alle angeführten Fischarten Haupt- und Zwischenträger der nämlichen schmarotzenden Spezies werden künnen. Einmal traf ich den jungen Parasiten auch im Lachs. Die TriaenophorusLarven liegen meistens eingebettet in erbsengrosse dickwandige Bindegewebecysten der Leber ihres Wirtes. Seltener bewohnen sie Milz, Peritonäum und Muskeln. In der Leber ist die Larvenzahl oft sehr bedeutend - nach eigener Eirfahrung bis 36 -, so dass sich die Gegenwart von hunderten von ausgewachsenen Würmern im Hechtdarm wohl erklärt. Haken und Sauggruben sind im Jugendzustand schon wohl ausgebildet, zudem folgt auf den Kopf cin sehr langer (bis $25 \mathrm{~cm}$ ) Wurmkörper, der reich an Lallikörperchen ist und sich in der engen Cyste in den mannigfaltigsten Kniueln und Windungen aufwickelt. Der bandförmige Anhang ist übrigens bestimmt, nach der Übertragung auf den definitiven Wirt zum guten Teil verloren zu gehen. Auf den Hauptträger übergeführt werden die 'Triaenophorus-Larven wohl sehr bald geschlechtsreif. Ihre reifen Eier gelangen in ungezählten Mengen mit dem Kot des Fisches ins Wasser. Ihnen entschlüpfen schon nach sechs bis acht Tagen bewimperte, mit sechs provisorischen Haken bewehrte Embryonen, die auf der Suche nach einem Zwischenwirt munter umherschwimmen. $\mathrm{Ob}$ aber die oben aufgeziihlten Fische schon vom Embryo bezogen werden, oder ob ihnen der Parasit in vorgerückterer Entwickelung durch einen ersten, wirbellosen Zwischenwirt übertragen wird, ist noch fraglich. 
Die Leibeshöhle der karpfenartigen Fische beherbergt oft langgestreckte, bandförmige, schwach segmentierte Schmarotzer, ohne deutliche Haftapparate. Ihre Zahl in einem Wirt ist oft ziemlich beträichtlich; ihre Länge kann sehr bedeutend werden - kenne ich doch aus einem Rötel ein Exemplar von $83 \mathrm{~cm}$ Länge und $2 \mathrm{~cm}$ Breite. Kein Wunder, dass unter dem Drucke des wachsenden Wurmes die von ihm mannigfaltig umschlungenen Organe des Fisches verkümmern. Meist tritt tödliche Peritonitis ein. Schwere Fischepidemien, die viele Karpfenteiche entrölkerten, sind einzig auf die Gegenwart dieser Riemenwürmer oder Liguliden zurückzuführen. Es ist also schon praktisches Interesse, wenn wir die Lebensgeschichte der Ligula simplicissima Rud., die uns im ganzen und grossen von Donnadieu geschildert worden ist, verfolgen. Wir wissen nun, dass die Schmarotzer aus der Leibeshöhle der Karpfen nichts anderes sind denn aussergewöhnlich grosse Larven von Bandwürmern. Sie wachsen schon im Zwischenwirt, eben den Fischen, zu ungewöhnlicher Lünge aus und bilden auch schon die Geschlechtsorgane vor. Doch treten diese erst in Funktion, wenn der kaltblütige Zwischenträger mit einem warmblütigen Hauptwirt vertauscht wird. Dazu bietet sich am besten Gelegenheit, nachdem die Ligula, durch die unter dem Drucke immer dünner werdenden Bauchdecken des Fisches hindurchbrechend, ins Wasser gelangt, in dem sie längere Zeit frei leben kann, ein für einen Parasiten nicht gewöhnliches Verhältnis. Forel hat freie Exemplare von Ligula in den grossen Tiefen des Genfersees gefischt. Jetzt muss der noch nicht geschlechtsreife Wurm von einer Ente oder einem anderen Wisservogel aufgenummen werden. Liguliden von mindestenn IO cm Länge, ja sogar Bruchstücke grösserer Exemplare werden im Entendarm schon nach Verlauf von 24 Stunden vollkommen reif; kleinere Tiere werden ausgeworfen. Die beiden Sauggruben treten deutlicher hervor; die Segmentierung des Körpers prägt sich etwas schürfer aus; der Leib streckt sich; in den in grosser Zahl sich regelmässig folgenden Geschlechtsapparaten beginnt die Eibildung und Befruchtung. Durch spezielle in jeder Proglottis sich wiederholende Uterusöffnungen werden die ron einer harten, 
gedeckelten Schale umschlossenen Eier in den Darm des Wirtes und von dort, gemäss der echt parasitischen Fruchtbarkeit der Ligula, in ungeheueren Mengen an die Aussenwelt abgegeben. Geschlechtsreife Liguliden verweilen übrigens nur kurze Zeit im Darme ihres Trägers, schon nach zwei bis drei Tagen sollen sie nach Donnadieu ausgestossen oder verdaut werden. Im Wasser dagegen künnen die ausgestossenen Würmer bis zelın Tage lang weiterleben.

Die Eier in Wasser gebracht entlassen nach acht bis vierzehn Tagen einen flimmernden, sechshakigen, lebhaft schwärmenden Embryo .-- eine Jugendform, die ja überhaupt bei Plattwürmern verbreitet ist, welche wasserbewohnende Zwischenwirte aufzusuchen haben. Nach Donnadieus Erfalırungen muss der Embryo von den Karpfen in den Darmkanal aufgenommen werden. Er wird die Wandungen des Verdauungstractus durchbrechen und, vielleicht nach vorübergehender Einkapselung in der Leber, die Leibeshöhle des Fisches beziehen. Wenige Wochen nach der Infelition mit flimmernden Embryonen beherbergt der Körperraum der Karpfen schon typisch ausgebildete Liguliden, von 6-I 2 mm Länge.' Die Entwickelungsgeschichte der Riemenwürmer ist ausgezeichnet durch zahlreich eingestreute freie Stadien und die weitgehende Differenzierung der Larve schon im Zwischenwirt. Es bedarf das junge Tier nur noch eines kurzen Aufenthaltes im warmen Darm des Hauptwirtes, um reife Eier zu liefern. Eine Infeltion der Karpfen wird natürlich am besten durch Ausschluss der Hauptwirte - der Wasservögel - von den Teichen verhindert.

In Bai und Lebensgeschichte schliesst an dic Ligula unmittelbar der Schistocephalus dimorphus Crepl. an. Lir lebt als bandförmige, bereits gegliederte Larve in der Leibeshühle des Stichlings, als reifer Bandwurm im Darm der Wasservögel. Es sei endlich noch erwähnt, dass in der Gallenblase und zwischen den Darmzotten der Schleihen zwei verschiedene Larven von Bandwürmern aufgefunden worden sind, die sich durch manche Eigentümlichkeiten auszeichnenden Gyporhynchen. Nach ihrem Übertritt in den Darm der Reiher entwickeln sie sich zur Tacnia macropeos Wedl und T. milatcralis Rud. 
Aus den Süsswasserfischen bezicht endlich auch der Mensch cinen häufigen Bewohner seines Darmkanals, den Grubenkopf (Bothrioccphalus latus Brems.). Dieser laingste aller in unserem Körper vorkommenden Bandwürmer - kann er doch bis Io $m$ erreichen - kommt besonders in weiter Verbreitung in Länderstrichen vor, die reich an Süsswasserseen sind. Es lässt sich das nach der Natur seiner Zwischenwirte ja zum voraus erwarten. So treffen wir ihn häufig in der Westschweiz, im Seengebiet Oberitaliens, in den weiten an das baltische Neer grenzenden, zu Deutschland und Russland gehörenden Seebezirken, in Polen, in gewissen Teilen Russlands, in Schweden, in Japan. Auch am Ufer des Stambergersees hat sich ein Infektionsherd gebildet. Bis vor wenigen Jahren war die Herkunft des so häufigen und nicht unbedenlilichen Schmarotzers unbekannt; das Verdienst, den Schleier über diesem Dunkel gelüftet zu haben, gehört in erster Linie Prof. MI. Braun. Doch bleiben auch heute noch weite Lücken in cler Kenntnis der Lebensgeschichte des Bothrioceplaalıs auszufüllen. Aus der Uterusöffnung der einzelnen Bothriocephalenglieder treten die gedeckelten, ovalen Eier, die auch bei diesem Wurm, dank der parasitischen Lebensweise, und zu Gunsten der Verbreitung der schmarotzenden Spezies, in Übermenge gebildet werden (Fig. 42). Im Wasser zerstreut entwickelt sich in ihnen ein Embryo nach Vorgängen, die jüngst ron Schauinsland verfolgt worden sind. Er verlässt die Eischale je nach den üusseren Temperaturbedingungen und der Masse des das Ei bespülenden Wassers früher oder später. Im Sommer findet das Ausschlüpfen schon zwei bis vier Wochen nach der Eiablage statt; unter ungünstigen Umständen (im Winter) können aber acht und mehr Monate vergehen, bis der junge Embryo frei wird. Er ist thnlich wie das erste Jugendstadium von Ligula und Triacnophorus, Würmer, die übrigens auch im anatomischen Bau des erwachsenen Tieres dem Bothriocephalus nahekommen, mit sechs Haken bewaffnet und schwimmt im Wasser mit Hilfe eines langen Wimperpelzes (Fig. 43 S. 250). Das freie 
Leben der Embryonen kann bis eine Woche dauern, dann sinken die Tierchen zu Boden und streifen gewöhnlich die Flimmerbekleidung ab, um sich noch eine Zeit lang kriechend zu bewegen. Was nun mit den jungen Bothriocephalen geschieht, ist uns völlig unbekannt. Hier öfnet sich eine weite Lücke in unserem Wissen. Es hat in keiner Weise gelingen wollen, die sechshakigen Embryonen direkt auf Fische zu übertragen; ebensowenig ist es geglückt, niedere wirbellose Wasserbewohner mit den Flimmerembryonen zu infizieren. So steht die Frage noch rollkommen offen, ob die Süsswasserfische den ersten und einzigen Zwischenwirt für den Grubenkopf abgeben, oder ob die Embryonen, etwa wie die ihnen nach Bau und Lebensweise so ähnlichen frühesten freien Jugendstadien der Trematoden, zunüchst in einen wirbellosen Zwischenwirt eindringen müssen, um dort weitere Veränderungen durchzumachen.

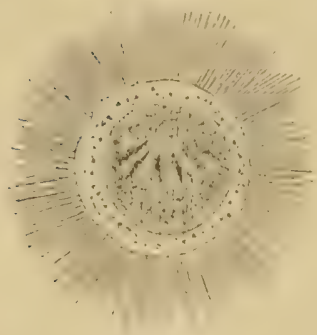

Fig. 43 .

Flimmerembryo von Bothrioceplialus latus.

Wie dem auch sei, wir finden die jungen Bothriocephalen erst wieder unter ganz veränderter Gestalt im Leibe mancher Süsswasserfische. Von Braun ist $\mathrm{r}_{8} 8_{3}$ zunächst der Hecht als Zwischenträger des Grubenkopfes erkannt worden, seitdem haben Parona und Grassi in Italien, Ijima in Japan, ich in Genf und Basel die Bothriocephalus-Finnen in einer ganzen Reihe von Fischen der Süsswasserseen entdeckt und meist mit gutem Infektionserfolg auf den Menschen übertragen. Die Zwischenwirte des breiten Bandwurms sind fast ausschliesslich Rutuber, cine Thatsache, die vielleicht darauf hindeutet, dass ihnen der junge Wurm bereits in einen ersten Träger eingeschlossen übermittelt wird. Als Wirte der Finnen von $B$. latus kennen wir heute den Hecht, die Quappe, den Barsch, die Forelle, die Aesche, den Saibling, die Seeforelle, sowie die beiden japanischen Lachsarten Onchorhynchus Huberi und O. Perryi, cine Liste, die sich mit der Zeit noch bedeutend vergrössern dürfte. Im Lachs sind Finnen von $B$. latus, entgegen der 
Annahme ron Küchenmeister, nicht gefunden worden. Auch die Flusstische sind häufig mit dem Jugendstidlium unseres Schmarntzers besetzt; wenigstens fand ich die Finnen in Forellen und Hechten aus dem schnellfiessenden Rhein und der reissenden Aare.

Die Finnen sind gestreckt 8 bis $25 \mathrm{~mm}$ lang, I bis $3 \mathrm{~mm}$ breit, von schwach abgeflachtem Körper. Vorn trägt das Tier einen konischen Kopfaufsatz, der in zwei seichten Sauggruben schon die liünftigen Haftapparate des erwachsenen Bothrioccphalus aufweist. Oft ist übrigens das Vorderende in den Körper eingestülpt. Der Leib ist solid, ungegliedert, höchstens die Kutikula zeigt eine starke Querrunzelung. Gegen hinten wird der Leib in völlig gestrecktem Zustand etwas schmäler. Auffallend ist der grosse Reichtum von im Körper zerstreuten Kalkkügelchen (Fig. 44). Die Finnen liegen, von dünnwandigen Kapseln umschlossen, oft in bedeutender Zahl in den verschiedensten Organen des Fisches. Speziell hëufig treten sie auf in den Wandungen des Schlundes, in der Leber, in Milz, Nieren, Geschlechtsorganen und endlich, für die Übertragung wohl am wichtigsten, in der Rückenmuskulatur. Oft trifft man sie auch frei wandernd in der Leibeshöhle. Die Zahl der Finnen in einem Fisch kann recht bedeutend werden (50-roo); auf das massenhafte Vorkommen derselben in einer Seeforelle ist schon hingewiesen worden. Im Wasser leben die Würmchen längere Zeit weiter. Solche Jugendstadien in den menschlichen Verdauungstractus gebracht entwickeln sich zum typischen breiten Bandwurm, zum Bothriocephalus latus. Es ist dies besonders durch Experimente an Dorpater und

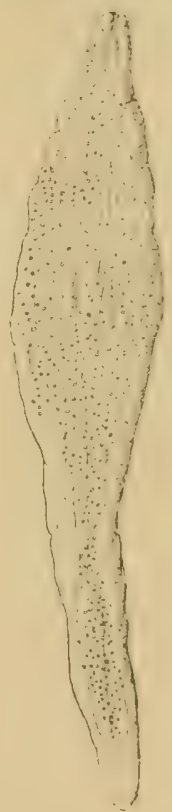

Fig. 44.

Larve von Bothriocephalus lutus atis verse hierlenen Si, ... wasserfischen. Genfer Studenten bewiesen worden. Das Wachstum des Kettenwurms im menschlichen Darm ist ein ungemein rasches; es betrïgt unter günstigen Umständen 6 bis $8 \mathrm{~cm}$ im Tag, so dass der Schmarotzer bald, nach Metern gemessen und seine eng verbundenen Proglottiden 


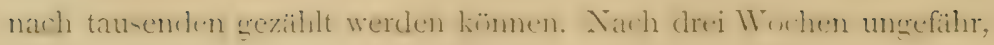
von der Infektion an gerechnet, werden wieder reife Eier abgegeben.

Wir erwerben den breiten Bandwurm durch den Genuss ungenügend zubereiteter Fische.' In den Ostseeprovinzen spielt der Hecht vorzüglich die traurige Rolle des Zwischenträgers; in Genf ist der Hauptsünder die Quappe. Sie gelangt massenhaft auf den Markt, ihre Leber wird ganz leicht gebacken als Leckerbissen verzehrt, gerade dieses Organ aber beherbergt fast regelmässig Bothriocephalus-Finnen. Auch der Barsch muss in dieser Hinsicht stark angeschuldigt werden.

Ausser den Larven von B. latus wohnen in vielen Süsswasserfischen noch die Finnen anderer Grubenkopfarten. Im Lachs speziell fand ich gelegentlich fünf verschiedene Formen solcher jugendlicher Würmer, die wohl mehreren Arten angehörten, von denen aber weder morphologisch noch experimentell eine auf den breiten Bandwurm des Menschen bezogen werden konnte. Die Art und Weise ihres. Vorkommens im Fisch war analog den für die Jugendstadien von $B$. latus beschriebenen Verhäiltnissen. Die Bothriocephaliden scheinen vorzugsweise Fische als Zwischenträger zu benutzen.

So gewinnt die Annahme Leuckarts, dass ein anderer Grubenkopf, der Bothriocephalıs cordatus Lt., der in Grönland häufig den Darm von Hund, Seehund, Walross, zufallig den des Menschen bewohnt, durch Fische in seine Wirte eingeschmuggelt werde, sehr an Gewicht. 


\section{Litteratur.}

I) G. Brandes, Die Familie der Holostomiden. Zoolog. Jahrbücher. Abt. f. Systematik, Geographie u. Biologie der Tiere. Bd. 5.

2) M. Braun, Zur Entwickelungsgeschichte des breiten Bandwurmes. Würzburg I883.

3) 0. Bütschli, Zur Entwickelungsgeschichte des Cucullanus elegans. Zeitschr. f. wiss. Zoologie. Bd. 26. 1876.

4) G. Bunge, Weitere Untersuchungen über die Atmung der Würmer. Zeitschr. f. physiol. Chemie. Bd. I 4. I 889.

5) C. M. Diesing, Systema Helminthum.

o) Donnadieu, Contributions it lhistuire de la Ligule. Journal de l'anatomie et de la physiologie. I87\%.

7) F. Dujardin, Histoire naturelle des Helminthes.

8) 0. Hamann, Die Nemathelminthen. Erstes Heft: Dic Acanthocephalen. I89 I.

(1) F. Küchenmeister, Dic Finne des lintluriocuphalus latus und ihre Übertragung auf den MIenschen.

Io) R. Leuckart, Die Parasiten des Mensehen und die von ihnen herrührenden Krankheiten. I. und 2. Auflage. nover 1878 .

I I) 0. v. Linstow, Compendium der Ifeminthologie. Ilan-

I2) 0. v. Linstow, Nachtrag dazu. Die Litteratur der Jahre I 878 - I 889 .

1.3) E. Lönuberg, If(minthologische Bubachtungen von der Westküste Norwegens. Erster Teil: Cestoden. Svenska Vet. Akad. Handlingar. Bd. I6. Afd IV. 
I4) E. Lönnberg, Bidrag till Kännedomen on i Sverige förekommande cestoder. Ibid. Bd. It, IV.

I, F. Miescher-Rüsch, Statistische und bindugiche Iscitrige zur Kenntnis rom Leben des Rheinlachses im Süsswasser. Ichthyologische Mitteilungen aus der Schweiz zur internationalen Fischereiausstellung zu Berlin is8o.

I6) A. Moquin-Tandon, Monographie de la famille des Hirudinées avec atlas. Paris 1846.

I7) E. Parona, Intorno la genesi del Bothriocephalus latus (Brems.) e la sua frequenza in Lombardia. Torino $188 \%$

I8) M. Stossich, I Distomi dei pesci marini e d'acqua dolce. Trieste 1886.

I9) M. Stossich, Appendice al mio lavoro i Distomi dei pesci marini e d'acqua dolce. Trieste I888.

20) G. Saint-Remy, Recherches sur la structure des organes génitaux du Caryophyllaeus mutabilis. Revue biologique du Nord de la France. T. 2. I889-90.

2I) A. Villot, Echinorhynchus clavaeceps. Note sur son organisation et son développement. Bulletin de la société des sciences naturelles du Sud-Est.

22) R. v. Willemoes-Suhm, Iremintholugische Nutizen. II. Zeitschr. f. wiss. Zool. Bd. 20, I870.

23) E. Zeller, Untersuchungen über die Entwickelung des Diplozoon paradoxum. Ibid. Bd. 22. I872.

24) E. Zeller, Über den Geschlechtsapparat des Diplozoon paradoxum. Ibid. Bd. 46. I888.

25) F. Zschokke, Recherches sur l'organisation et la distribution zoologique des vers parasites des poissons d'eau douce. Archives de Biologie. I884.

26) F. Zschokke, Helminthologische Bemerkungen. Mitteilungen a. d. zool. Station zu Neapel. Bd. VII.

27) F. Zschokke, Der Bothriocephalus latus in Genf. Centralblatt f. Bakteriol. u. Parasitkunde. Bd. I. 1887.

28) F. Zschokke, Ein weiterer Zwischenwirt des Bothriocephalus latus. Ibid. Bd. 4. 1888 .

zo) F. Zschokke, Uther Inthrincephalentarven in Trutta salar. Ibid. Bd. $\%$ I 890 . 


\section{Über \\ die quantitative Bestimmung des Plankton im Süsswasser.}

Von Dr. C. Apstein in Kiel, Zoolog. Institut. 

In seinem Werke $\left.{ }^{*}\right)$ „Über die Bestimmung des Planktons oder des im Meere treibenden Materials an Pflanzen und Tieren" bezeichnet Hensen mit Plankton "Alles, was im Wasser treibt". Es sind also darunter alle Organismen, sowohl Pflanzen wie Tiere, zu verstehen, die willenlos der Wellenbewegung und den Strümungen folgen. Der Begriff ist enger gefasst als „Auftrieb oder pelagische Organismen", denn zu letzteren gehüren beispielsweise die freischwimmenden Fische, die aber nicht zum Plankton zu zählen sind, da sie vermöge ihrer Grösse und Stärke nicht machtlos im Wasser treiben, dagegen bilden die schwimmenden Fischeier und junge Fische einen Teil des Plankton. Ebenso könnte es scheinen, als ob die Copepoden ausscheiden müssten, die bekanntlich einer ziemlich energischen Bewegung fähig sind; doch ist. dieselbe zu wenig ausgiebig, um den bewegenden Agentien irgend einen nennenswerten Widerstand entgegensetzen zu können.

Schon im Jahre 1884 hat Hensen in seiner Arbeits): „Über das Vorkommen und die Menge. der. Eier einiger Ostseefische, insbesondere der Scholle, des Flunder und des Dorsch" ein Problem in Angriff genommen, an dessen Lösung niemand vor ihm gedacht hatte, nämlich die quantitative Bestimmung der im Meere treibenden Organismen.

*) Die Zahlen verweisen auf das Littcraturverzeichnis.

Tier- und Pflanzenwelt des Süsswassers. II, 
Nur einmal ist, unabhängig von Hensen*), jedoch nach diesem, dieselbe Art der Forschung versucht worden von Asper und Henscher1) I886, welche die Organismen aus einer bekannten Wassermenge sammelten und dann die Zahl der Individuen bestimmten, die sich in einem Tropfen Flüssigkeit, von denen fünfzehn auf I ccm gingen, befanden. Dadurch erhielten sie einen ungefähren Überblick über die Menge der pelagischen Tiere in dem untersuchten Süsswasserbecken. Doch ist dieser Versuch nicht in eine Reihe zu stellen mit den sorgfältigen Methoden der Hensenschen Forschungen. Hensen blieb nicht bei den einfachen quantitativen Bestimmungen stehen, sondern zeigte auch, warum diese von so hoher Wichtigkeit sind. In letzter Linie kam es ihm darauf an, den Stoffwechsel des Mieeres näher kennen zu lernen. Bekanntlich vermögen nur die chlorophyllführenden Wesen, also Pflanzen und Peridineen, von denen letztere noch von manchen zu den Flagellaten gerechnet werden, aus anorganischen Stoffen organische Verbindungen herzustellen; die Kraft, durch die diese Umbildung geschieht, liefert das Sonnenlicht. Dieses dringt bis höchstens $400 \mathrm{~m}$ in das Wasser ein und soweit finden wir auch nur dhlorphyllhaltige Organismen. Dieser Fähigkeit wegen kïnnen wir auch die pflanzlichen Wesen mit Einschluss der Peridineen Nahrungsproduzenten $\left.{ }^{2}\right)$ nennen. Ihnen stehen die Nahrungskonsumenten gegenüber, welche die oben erwähnte Fähigkeit nicht besitzen, also ganz von den Pflanzen ablüngig sind; es sind, um es kurz zu sagen, die Tiere. Wo keine Pflanzen sind, können also auch keine Tiere sein! Da, wie oben erwähnt, die Sonne die Kraft den Pllanzen giebt, organische Verbindungen zu bereiten, so hätten wir ein Mass für die Produltion des Wassers an belebter Substanz, wenn wir alle unter einer bekannten Oberlläche - als Einheit I $q m$ - vorhandenen Pflanzen bestimmen

*) Hensen hat schon im Jahre 1885 mehrere Mitteilungen über sein Verfahren verüfentlicht, so in den Sitzungsberichten des physiologischen Vereins in Kiel, in den Jitteilungen des Vereins schleswig-holsteinischer Arzte, im 8. Jahresbericht des Central. fischereivereins für Schleswig- Holstein, dann 1886 im Tagesberichte der NaturforscherVersammlung in Berlin. 
könnten. In clieser Richtung hat Hensen zur ersten ()rientierung(ine Anzahl analytischer Gewichtsbestimungen gemacht, denen wir folgende Daten entnehmen.

Ein ganzer Fang (aus der Ostsee) vom Februar I885, der reich an einer Diatomeenart (R/hi=osolenia) war, enthiclt unter I $7 \mathrm{~m}$ Oberfläche I608.3 ccm Plankton. Davon wurden $70 \mathrm{~cm}$ weiter verarbeitet. Diese enthielten $0.18 \mathrm{gr}$ organische Substanz $=42.1 \%$ und $0.2575 \mathrm{gr}=57.9 \%$ Asche. Der ganze Fang würde also $4.296 \mathrm{gr}$ organische Substanz geliefert haben. Dies ist sehr wenig, aber da die Diatomeen so zahlreich waren, so ist der beträchtliche Aschenanteil durch die Kieselsäureskelette verständlich.

$\mathrm{Zu}$ ferneren Analysen wurden einzelne Bestandteile des Plankton verwendet, so die Ceratien und Copepoden. Von ersteren fanden sich in $7.25 \mathrm{ccm}$ Fang 12.45 Millionen. Diese enthielten $0.389 \mathrm{gr}$ organische Substanz $=96.05 \%$ und nur $0.010 \mathrm{gr}$ Asche $=3.94 \%$.

Auf I Million Ceratien käme also 0.031245 organische Substanz.

Von Copepoden wurde einmal Rhinocalanus gigas zur Bestimmung benutzt. $4 \mathrm{ccm}$ davon $=32 \mathrm{I}$ Stück ergaben $0.0527 \mathrm{gr}$ $=99.4 \%$ organische Substanz und nur $0.0003 \mathrm{gr}=0.6 \%$ Asche.

Diese Zahlen benutzt Hensen weiter, wobei hervorzuheben ist, dass alle Angaben nur Minimalzahlen sind. Hensen hat nun nach Versuchen ${ }^{* *}$ ) - denen er selbst nur einen vorläufigen Wert beimisst - berechnet, dass ein Copepod zu seiner Emährung täglich I 2 Ceratien, das ist pro Jahr 4370 Ceratien becłarf. Da nun auf I qm Oberfläche (also einer Wassersäule, die I qm zur Grundfäche und die Tiefe des Wassers***) zur Höhe hat) ungefähr I Million Copepoden lebt, so bedürfen diese zur Nahrung 4370 Millionen Ceratien, welche $4370 \times 0.031245=133.35 \mathrm{gr}$ organische Substanz liefern.

Die Jahresproduktion an Diatomeen $\dagger$ ) berechnet Hensen auf $6570 \mathrm{ccm}$ pro Quadratmeter Oberfläche, diese enthalten I 4.5 bis $17.7 g r^{\circ}$ organische Substanz. Es würden also in Summa

*) Planktonwerk S. 34. (Siche Litteraturverzeichnis 9.)

**) ibid. S. 95. ***) Hier in der Ostsee etwa $20 \mathrm{~m}$. †) jbid. S. 96. 
pro Jahr von Diatomeen und Ceratien $133+\mathrm{I} 7 \mathrm{gr}=\mathrm{I} 50 \mathrm{gr}$ organische Sulstanz pro Quadratneter Oberfläche erzeugt werden.

Nach Berechnungen von Rodewald erzeugt I $q m$ bebauten Landes (in Form von $\mathrm{Heu}$ ) $179 \mathrm{gr}$ organische Substanz. Es ist also die Produktion des Plankton nur um 20\% geringer als die der gleichen Fläche Ackerlandes"). Da jedoch für die Berechnungen des Wassers nur Minimalzahlen gennmmen sind, so wäre es müglich, dass in der That die Produktion des Wassers gleich ist der des Landes. Hiermit ist also ein Mass für die Ertragsfăhigkeit des Wassers gewonnen und zugleich ein Ausdruck für die belebende Wirkung des Sonnenlichtes.

Die oben gewonnenen Zahlen lassen sich jedoch noch weiterhin benutzen, z. B. für pralitische Zwecke (ler Fischerei, wie Heincke i) dargethan hat. Jedoch würde es uns zu weit führen, auf alle diese interessanten Berechnungen weiter einzugehen, wir müssen auf die Originalwerke verweisen.

Ein Punkt ist jedoch noch von Wichtigkeit, der es klarlegen sroll. dass die Planktonmethode zu den vorhin dargelegten Schlüssen berechtigt. Haben wir ein Recht, von der Beobachtung, die wir aus einem kleinen Wasserquantum gewonnen haben, auf die Zusammensetzung des Plankton eines ganzen Wasserbeckens zu schliessen? Da hat sich nun gezeigt bei Untersuchungen in der Ostsee, dass die Verteilung des Plankton eine ziemlich**) gleichmässige ist. Diese gleichmässige Verteilung ist von Hensen in seiner Arbeit $\left.{ }^{8}\right)$ : „Über das Vorkommen und die Menge der Eier einiger Ostseefische, insljesondere der Scholle, des Flunder und des

*) Dasselbe erwähnt Seligo ${ }^{23}$ ) in seinen „Hydrobiologischen Untersuchungen". Er sagt: ,Wie cine Wiese ist die Wasserflïche gleichmässig bewachsen. Allerdings liegen die Pflänzchen normal nicht dicht an einander, aber dafür beschränkt sich ilure Anwesenheit und ihr Gedeihen nicht auf die Wasseroberflïche, sondern die oberen Wasserschichten bis zu mehreren Metern Tiefe sind davon durchsetzt, sodass die Gesamtmenge der unter einem bestimmten Teil der Oberfläche wachsenden Pflinzchen ungefähr so viel Pflanzenmenge sein dürfte, wie auf einer gleichgrossen Fläche einer dünn bewachsenen Wiese sich findet".

**) In ciner neuen Arbeit IIensens ${ }^{10}$ ): ,Einige Èrgebnisse der Plankton-Expedition der Humboldt-Stiftung" heisst es: „... Die Expedition ging von der rein theoretischen Ansicht aus, dass in dem Ozean das Plankton gleichmissig genug verteilt sein müssc, un aus wenigen längen über das Verhalten sehr grosser Meeresstrecken sicher unterrichtet zu werden, und diese Voraussetzung hat sich weit vollstïndiger bewahrheitet, als gebofit werden konnte". 
Dorsch" so erklärt. Trifft ein Stoss, z. B. eine Welle, ein schwimmendes Ei, so können zwei Fälle in Betracht kommen: erstens, ist der Stoss senkrecht, so wird das Ei in der Richtung des Stosses fortbewegt; zweitens, ist der Stoss unter einem Winkel auf das Ei gelangt, so schiebt eine Komponente des Stosses das Ei weiter, während die andere es dreht. So werden die Eier nach und nach auseinandergetrieben, wenn sie auch an einer Stelle der Oberfliche sich befanden, da ein Stoss nicht alle Eier in derselben Richtung trifft. WVas für die Eier gilt, ist auch für die anderen Organismen des Plankton anzuwenden. So wird durch die Wellen, welche wie eine Schűttelbewegung wirken, die Zerstreuung besorgt. Diese Thatsachen hat Hensen auch noch direkt durch Experimente (siehe die gleiche Arbeit) erhärtet, indem er mehrere versilberte Glaskugeh, die so beschwert waren, dass sie gerade noch schwammen, in das Wasser versenkte und nach einiger Zeit wahrnahm, dass sie weit auseinandergetrieben waren.

Nachdem wir gesehen haben, was für weitgehende Schlüsse Hensen mit Hilfe seiner Planktonmethode, d. h. der Art und Weise der Gewinnung und Verarbeitung eines Planktonfanges, zu ziehen imstande war, wollen wir diese Methode*) näher ins Auge fassen.

Ich möchte daher den Leser bitten, mich auf einer Exkursion zu begleiten und nachher den Arbeiten am Lande beizuwohnen. Wir besteigen einen Dampfer und haben Zeit, ehe wir an Ort und Stelle anlangen, die Ausrüstung zu der "Planktonfahrt" in Augenschein zu nehmen.

Vor allem fällt uns das grosse Vertikalnetz ${ }^{* *}$ ) auf (Fig. 45 S. 262): An ihm können wir drei Teile unterscheiden, erstens das eigentliche konische Netz (A), dann den ebenfalls konischen Aufsatz $(B)$ und drittens den Blecheimer (Fig. 48 S. 265).

*) Diese Methode hat in neuester Zeit von E. Häckel eize sehr absprechende Beurteilung erfahren; da jedoch schon von anderer Seite die Missverstïndnisse und Entstellungen der Häckelschen Schrift riclitiggestellt sind, so gebe ich nicht weiter auf dieselbe ein, sondern verweise auf die Arbeiten Brandts ${ }^{3}$ ) und Hensens.

**) Ich habe in folgendem die Masse des Netzes nach denen von der PlanktonExpedition auf dem $A$ tlantischen Ozean verwendeten Apparaten wiedergegeben. Da, wo auf Süsswasserseen kein Dampfer zur Verfügung stebt, müssten die Netze verkleinert werden, denn vom Boote aus ist es unmöglich, mit den fast $2 m$ hohen Netzen zu fischen. 
262 Über die quantitative Bestimmung des Plankton im Süsswasser.

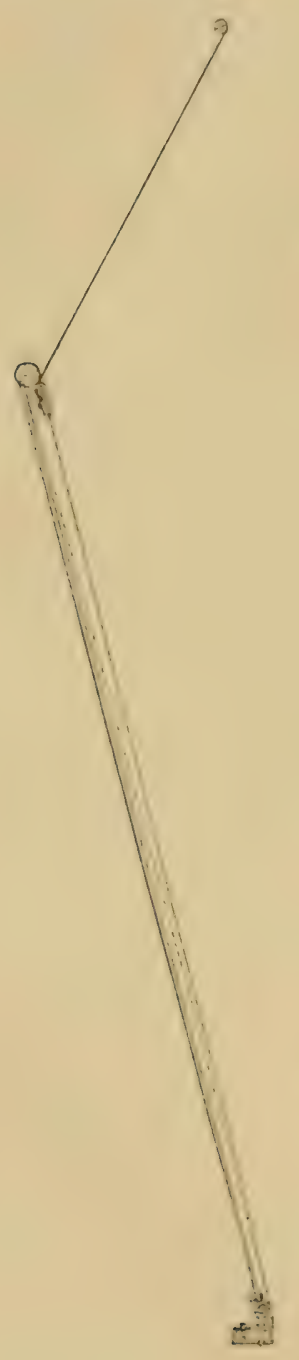

$B$

$A$

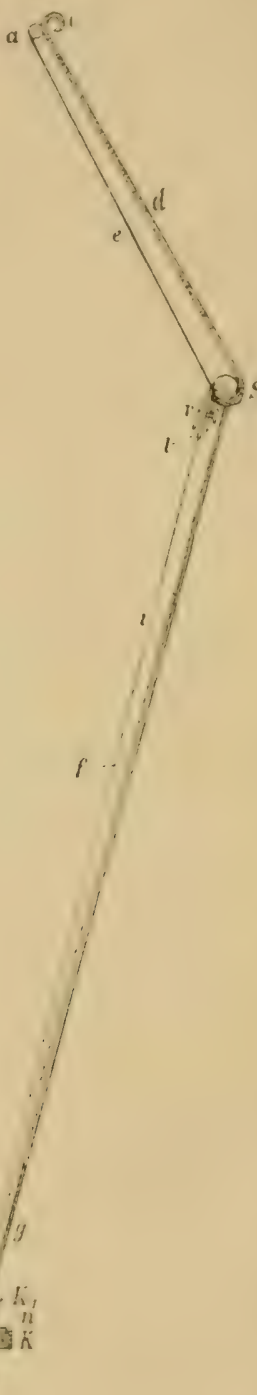

Das eigentliche Netz ist folgendermassen gebaut:

An einem starken Eisenringe (S), der $90 \mathrm{~cm}$ Durchmesser hat, ist innen eine $5 \mathrm{~cm}$ grosse Falte von Barchent befestigt $\left(v^{\circ}\right)$, deren “usserer Teil eine grössere Anzahl Knopflöcher trägt. Von hier soll nach dem untern Ringe $(K)$ das weiterhin $\mathrm{zu}$ beschreibende Netzzeug ausgespanntwerden. Dieser untere Ring (K) trägt drei gabelartige Vorsprünge, an welchen durch Überfallschrauben der Blecheimer befestigt werden liann. Auf diesem Ringe ist ein zweiter Ring $\left(K_{1}\right)$ durch mehrere mit Ösen versehene Schrauben (m) befestigt.

Das Gazenetz (i)

Fig. 45.

trïgt an seinem obern Rande einen Leinwandstreifen (l), welcher mit Knüpfen versehen ist, die in die oben erwahnten Knopflücher 
der Barchentfalte hineinpassen*), unten ist das Netz an einen Barchentring angenitht, welcher an dem Messingringe (K) durch mehrere Schrauben (n) befestigt werden kann. Damit das feine Gazenetz nicht allein den Druck der filtrierenden Wassermasse auszuhalten hat, ist an seiner Aussenseite ein einfaches Fischernetz $(f)$ ausgespannt, das oben an dem Ringe $S$ mit Bindfaden angebunden ist und unten zwischen die beiden Ringe $K$ und $K_{1}$ geklemmt wird. Die beiden erwähnten Netze sind aber zu schwach, den an den Ringen $K$ und $K_{1}$ hängenden Eimer zu tragen, es sind daher zwischen $S$ und den Schraubenösen (m) einige starke Schnüre (g) ausgespannt.

Bei der Wahl des Netzzeuges handelt es sich einerseits darum, dass die Lücher müglichst fein und gleichmässig sind, damit auch die kleineren Organismen nicht hindurchgehen künnen, anderseits auch darum, dass die Fäden des Gewebes nicht quellen und sich nicht verschieben können. Diese Bedingungen werden allein durch die Müllergaze erfüllt, die in mehreren Sorten in den Handel kommt, und sich durch die Grösse der Löcher unterscheidet. Diese Gaze ist aus Seidenfäden verfertigt und wird in Mühlen zur Trennung des Miehles nach der Korngrösse benutzt. Dieses Gewebe (Müllergaze Nr.20) ist von solcher Feinheit, dass auf einen Quadratcentimeter Fläche 5926 Löcher kommen**), von denen jedes eine Seitenlänge von 0.053 mm hat. Mit diesem Netzzeug werden fast alle Organismen gefangen, nur wenige Diatomeen, die mit ihrer Längsachse auf ein Loch treffen, werden hindurchschlüpfen. Einen grossen Vorzug besitzt dieses Gewebe noch durch seine grosse Glätte, es bleiben einmal wenig Organismen daran hängen, dann auch fasert es nicht aus, so dass der Fang nicht durch Fäden verunreinigt wird.

Ein aus diesem Seidengewebe gefertigtes Netz soll nun zwischen den beiden Ringen so ausgespannt werden, dass es lieine Falten schlägt. Es ist dazu nötig, ein Muster zu entwerfen ${ }^{* * *}$ ), nach dem

*) Es ist daher jederzeit möglich, das Netz herabzunchmen und auszuwaschen.

**) Planktonwerk S. \$.

***) Dic Bercchnung weicht von der von Hensen im Planktoawerk S. 6 angeführten $a b$, da statt der Sehnen der Winkel an der Spitze benutzt ist. 


\section{4 Über die quantitative Bestimmung des Plankton im Süsswasser.}

das Netzzeug zugeschnitten wird. Eei dem vorliegenden Netze beträgt der Radius des obern Ringes $R=45 \mathrm{~cm}$, der des untern $r=10 \mathrm{~cm}$, die Mantelhühe des abgestumpften Kegels $i=150 \mathrm{~cm}$.

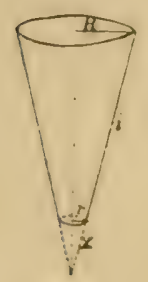

Fig. 46 .

Vervollständige ich den abgestumpften Kegel (Fig. 46), so kann ich mit Hilfe der Mantelhöhe des abgeschnittenen Stückes ( $x$ ) den Winkel an der Spitze (a) (Fig. 47) berechnen.

$$
\text { Es ist } \begin{aligned}
x: x+i & =r: R . \quad \text { Daraus folgt } \\
x & =\frac{r i}{R-r} .
\end{aligned}
$$

Nach unserem Beispiel erhalten wir für $x=42.9 \mathrm{~cm}$.

Denken wir uns jetzt den Kegelmantel aufgerollt (Fig. 47), so ist

$$
A B=U=2 R \pi
$$

und

$$
C D=u=2 r \pi \text {. }
$$

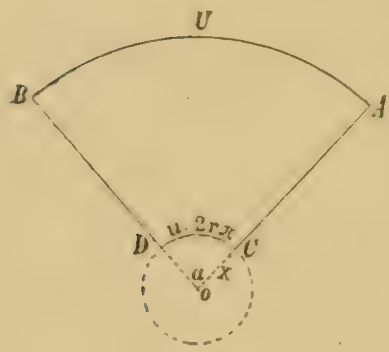

Fig. 47.

Es muss' sich verhalten der Umfang des Kreises, den ich mit dem Radius $x$ $(=2 x \pi$ ) schlagen kann, zu $u$, wie $360^{\circ}: \alpha$.

Also

$$
\frac{2 x \pi}{2 r \pi}=\frac{360}{\alpha} .
$$

Daraus folgt

$$
\frac{x}{r}=\frac{360}{u} \text {. }
$$

In unserem Beispiel erhalten wir für $\alpha=83.9^{\circ}$.

Ebenso wäre die Rechnung, wenn wir für $u$ : $U$ genommen hätten, dann häitten wir statt $x$ aber $x+i$ setzen müssen. Um nun nach vorstehenden Zahlen ein Nuster zu zeichnen, verfahren wir so, dass wir uns den Winkel $a=83.9^{\circ}$ konstruieren und von dem Scheitelpunkte desselben mit den Radien $x=42.9 \mathrm{~cm}$ und $(x+i)=192.9$ cm Kreisbogen schlagen, dann geben die Strecken dieser Bogen zwischen den Schenkeln des Winkels den obern und untern Umfang des Netzzeuges an. Nach diesem

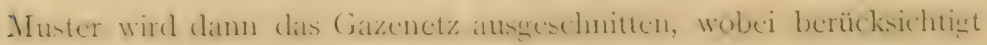
werden muss, dass bei $A C$ und $B D$ das Netz aneinandergenźtht wird, zu welchem Zweck eine Einschlagskante bleiben muss. Die 
Nähte müssen natürlich nach aussen kommen und ausserdem darf nur eine ganz feine Nadel verwendet werden, da jeder Nadelstich dem feinen Netzzeug gegenüber ein grosses Loch darstellt.

Der Aufsatz des Netzes besteht aus einem I $\mathrm{cm}$ dicken Eisenringe (a) von $36 \mathrm{~cm}$ Durchmesser, der mit dem obern Netzringe $(S)$ durch drei starke $60 \mathrm{~cm}$ lange Eisenstangen (d) verbunden ist, die oben in Haken (c) zur Befestigung des Taues auslaufen. Zwischen den beiden Ringen, jedoch unter den verbindenden Eisenstangen, ist ein Barchentmantel *) ausgespannt. Dieser Aufsatz ist von grosser Wichtigkeit für die Brauchbarkeit des Netzes. Wird das Netz auf den Grund des Wasserbeckens hinabgelassen, so würden, wenn dieser Netzteil fehlen sollte, Schlamm und Organismen von dem Boden in das Netz geraten können. Bei dieser Einrichtung jedoch stösst höchstens der Eisenring (S) auf den Schlamm auf, und dieser wird, wenn auch etwas aufgewirbelt, doch nicht die obere Netzöffnung erreichen und den Fang verunreinigen können. Ferner dient dieser Aufsatz auch als Reservoir, wenn bei stürmischem Wetter der Fang aus dem Netz hinaufgespült wird. Dann auch wird durch die Öfnung des Aufsatzes (= I000 qcm) ein nur geringer Wasserstrom in das Netz hineingelangen und durch die gegen $26 \mathrm{mal}$ so grosse Netzwand fast vollständig filtriert werden können.

Der Eimer (Fig. 48) ist ein cylindrisches Blechgefüss (Eisenblech), dessen Boden nach der Mitte zu abfatlt und hier eine durch eine Schraube verschliessbare Öffnung (u)

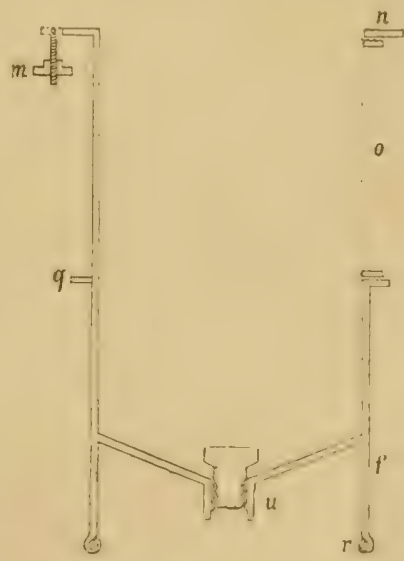

Fig. 48. trägt. Der obere Rand des Gefässes ist erhaben (n) und trägt drei Überfallschrauben ( $m$ ), die in die oben erwähnten drei gabelartigen

*) Derselbe wird ebenfalls nach den obigen Formeln konstruiert. 
266 Über die quantitative Bestimmung des Plankton im Süsswasser.

Fortsütze des untern Netzringes (Fig. $45 \mathrm{k}$ ) hineinpassen. In der Mitte ist der Blechcylinder noch von einem Reif (q) umgeben. Zwischen diesen beiden Reifen ( $q$ und $n$ ) ist die eine Seite der Eimerwand herausenommen und durch Müllergaze (o) verschlussem. Der ganze Eimer steht auf sechs Füssen $(f)$, die durch einen Ring (v) verbunden sind.

Neben dem Vertikalnetz kommt hauptsächlich der Filtrator (Fig. 49) in Betracht. Dieser stellt einen Metallcylinder dar, dessen

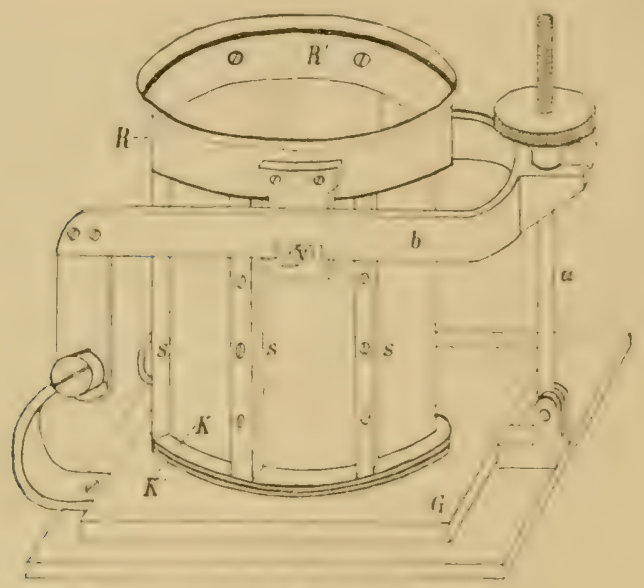

Fis. fN.

Wände durch Müllergaze ersetzt sind mit Ausnahme von einigen Stützen (s), die unten durch einen sehr flachen Reif $(K)$ verbunden sind. Die Müllergaze wird zwischen dem obern und untern Ringe ( $R$ und $K$ ) und den Stützen (s) folgendermassen ausgespannt. In dem obern Ringe $(R)$ befindet sich ein zweiter Ring $\left(R^{\prime}\right)$, der an den erstern angeschraubt werden kann; zwischen beide wird die Gaze eingelilemmt, ebenso geschieht dies bei dem untern Ringe ( $K)$, auf den ein zweiter Ring $\left(K^{\prime}\right)$ passt, und schliesslich auch bei den Stützen (s), an welche von innen die Gaze durch Metallplatten angedrückt wird. Indem man den obern und untern Rand der 
Gaze zwischen den beiden Ringen einspannt, die seitlichen Räncler aber zwischen einer Stütze und ihrer innern Platte, hat man den Vorteil, dass an dem Netzzeuge des Filtrators kein Nadelstich nötig ist.

Der Filtrator trägt an jeder Seite einen dreikantigen Vorsprung (v), der dazu dient, den oben beschriebenen Apparat mit Hilfe eines Bügels (b) und einer Uberfallschraube (a) auf eine Glasplatte $(G)$ fest anzudrücken, so dass unter dem Ringe $\left(K^{\prime}\right)$ liein Wasser entweichen kann, sondern dasselbe alles durch das Netzzeug filtrieren muss. Da die beiden unteren Ringe ( $K$ und $K^{\prime}$ ) sehr flach sind, so wird nur sehr wenig Wasser im Apparat zurückbleiben, welches man auch durch vorsichtiges Neigen des Filtrators nach einer Seite zum Ablaufen bringen kann.

Ferner sind wir mit einigen weithalsigen Stöpselgläsern versehen, die mit Konservierungsflüssigkeit gefüllt sind, und von denen jedes zur Aufnahme eines Fanges bestimmt ist. Am bequemsten ist die Anwendung der Pikrinschwefelsäure, die folgende Zusammensetzung hat:

300 Raumteile Wasser,

I OO " einer konzentrierten wässerigen Lösung von Pikrinsäure, 2 " von konzentrierter Schwefelsëure.

Der Fang kommt, wie weiter unten gezeigt werden soll, in diese Mischung und kann in derselben bleiben, wenn die Bearbeitung sogleich vor sich gehen soll. Muss der Fang jedoch einige Zeit stehen, so empfiehlt es sich, nachdem die Organismen zu Boden gesunken sind, die überschüssige Säure abzugiessen und durch Alkohol von $600 \% \mathrm{zu}$ ersetzen, der mehrmals gewechselt werden sollte. Jedoch muss das mit der grüssten Vorsicht geschehen, da noch zahlreiche Diatomeen in der Flüssigkeit suspendiert sind und sich sehr langsam absetzen. Bleiben die Organismen zu lange in der Säure, so werden die Kalksalze aus einigen ausgezogen und noch anderweitige Veränderungen bewirlit, die Tiere werden schliess-lich ganz weich und sind für nachfolgende Bearbeitung wenig geeignet. 
268 Über die quantitative Bestimmung des Plankton im Süsswasser.

Ebenso wirksam ist eine konzentrierte Lösung von Sublimat; bei dieser tritt nur der Übelstand ein, dass man sehr lange mit Wasser*) auswaschen muss, um eine nachfolgende Ausscheidung nadelfömigcr sublimatlirystalle zu verhindern; natürlich muss das Wasser spïter durch Alkohol ersetzt werden.

Wie andere Fixierungsmittel sich bewähren, kann ich nicht angeben, glaube aber, dass Osmiumsäure (event. Chromosmiumessigsiuure) sehr gut anwendbar ist. Der Fang wird in ein Glas, in dem etwas Wasser sich befindet, gebracht und darauf einige Tropfen Osmiumsïure zugesetzt. Nach einigen Minuten oder sobald alle Organismen getötet sind, wird das Glas mit Wasser gefüllt, dann lässt man die Organismen sich absetzen, decantiert und setzt schliesslich Alkohol zu.

Von kleineren Apparaten sind noch vorhanden ein Spatel, eine Spritzflasche, eine Giesskanne und einige Papierzettelchen, die mit Bemerkungen versehen und in die Fanggläser gelegt werden können.

Unterdessen sind wir an dem Punlite angelangt, an dem wir die Untersuchung auszuführen gedenken. Das Schiff hält still und das Fischen kann beginnen. Das Tau, an dem das Vertikalnetz befestigt ist, wird über eine Rolle, die an einem galgenartigen, eisernen Gestelle angebracht ist, gelegt. Der freie Schenkel dieses sogenannten "David" ragt über die Schiffswand hinaus und erleichtert, da die ganze Vorrichtung um ihre Achse drehbar ist, das Einholen des Netzes. Das Netz, an dem der Eimer angeschroben ist, wird in das Wasser hinabgelassen, zuerst langsam, damit das Netzzeug angefeuchtet wird, dann etwas schneller. Die Hand, diè das Tau leitet, kann leicht den Zug des sinkenden Netzes spüren und daher auch den Moment wahrnehmen, in welchem der Netzring auf dem Boden aufstösst. Um letzteres jedoch zu verhindern, ist es ratsam, vorher zu loten, dann kennt man die Wasserticfe und auch dic Bodenbeschaffenheit, da sich

4) Statt dessen kann man Jodalkohol benutzen, den man so lange wechseln muss, bis dic Firbung des Jods nicht mehr verloren geht. 
Grundproben an dem unten mit Talg versehenen Lote eindrücken. Das Tau des Vertikalnetzes trägt in Entfernungen von je I $m$ bunte Läppchen und alle ro $m$ anders gefärbte. Man kann also das Tau langsam ablaufen lassen, da man die gelotete Tiefe ablesen kann und kein Aufstossen zu befürchten braucht. Sobald das Netz in der Tiefe angelangt ist, wird es mit mittlerer Geschwindigkeit von $1 / 2-3 / 4 m$ pro Sekunde senkrecht aufgezogen. Die Geschwindigkeit hängt von der Filtrationsgrösse*) des Netzzeuges ab. War z. B. das Netz $20 \mathrm{~m}$ hinabgelassen, so können wir, da die Netzöffnung 0.1 q $m$ beträgt, die Wassermenge, die durch das Netz gegangen sein sollte, berechnen, sie ist $20 \times 0.1 q m=2 \mathrm{cbm}$ gross. In Wahrheit ist jedoch etwas weniger Wasser filtriert worden, nämlich nur I.s cbm, wie Versuche von Hensen ergeben haben. 2 cbm würden durch den Netzring gehen, wenn kein Netz daran hinge, so wird aber durch den Widerstand des Netzzeuges jener Bruchteil (10\%) über den Netzring abfliessen. Sobald das Netz über dem Wasserspiegel angelangt ist, wird dasselbe von aussen mit Wasser beworfen. Dadurch wird das dem Netze anhaftende Material in den Eimer hinabgespült, durch dessen filtrierende Fläche das übcrschüssige Wasser abläuft. Nun befinden sich alle Organismen -im Eimer und zwar in einer verhältnismässig kleinen Wassermenge, die nun weiter zur Verarbeitung kommt.

Der Eimer wird vom Netze gelöst, die Schraube, die sich in der Röhre am Boden des Eimers befindet, herausgedreht, so dass der Inhalt in eine darunter gestellte Flasche gelangt. Aus der Flasche kann man dann nach und nach die Masse in den Filtrator giessen. Diese Methode ist sicherer, als wenn man den Fang direkt aus dem Eimer in den Filtrator bringt, da bei schwankendem Schiffe leicht etwas vorbeilaufen kann.

Das Wasser sickert nun allmählich durch die Gazewände des Filtrators durch, und zwar verschieden schnell, je nach der Beschaffenheit des Fanges. Sind viel Diatrmeen oder Nostocaceen (Limnochlide) 
vorhanden, so hat der Fang ein schleimiges Aussehen und filtriert sehr langsam. Sind dagegen Copepoden oder Peridineen am zahlreichsten, so läuft das Wasser sehr schnell $\mathrm{ab}$, da sich die Poren des Netzzeuges nicht verstopfen. Nachdem auf diese Weise die (1) Geanismen ziemlich vollständig vom Wasser befreit sinel, wird die Glasplatte, denn auf dieser hat sich jetzt der Fang niedergesetzt, unter dem Filtrator hervorgenommen und mit Spatel und Spritzflasche werden die Tiere und Algen in die Konservierungsflüssigkeit gebracht, in der sie bis zur Verarbeitung bleiben oder, wie oben auseinandergesetzt ist, in Alkohol übertragen werden. In jedes Glas wird ein Zettelchen gelegt, auf dem der Fundort, das Datum, die Tiefe des Planktonzuges, die Konservierung, die Temperatur des Wassers und allenfalls noch die Windrichtung angegeben sind.

Die nun folgenden Arbeiten, die die quantitative Bestimmung des Fanges bezwecken, werden ausgeführt, nachdem wir zu Hause angelangt sind. Zuerst wird das Volumen des Fanges festgestelit. $\mathrm{Zu}$ dem $\mathrm{Zwecke}$ wird der Inhalt eines einen Fang enthaltenden Glases in einen Messcylinder entleert. Nach und nach sinken die Organismen zu Boden, die grösseren schneller, die kleinen langsamer. Unter letzteren sind namentlich die Diatomeen zu erwähnen, diese setzen sich, wenn sie in grösseren Mengen vorkommen, so langsam ab, dass nach tagelangem Stehen noch immer eine Volumenverringerung zu beobachten ist. Befinden sich grosse Tiere im Fange, so muss bei diesen das Volumen besonders bestimmt werden und dieses geschieht am besten und grenauesten durch "Verdrängung", d. h. das Tier wird in einen Messcylinder hineingebracht, in dem sich eine bckannte Menge Flüssigkeit (Wasser — oder Alkohol, wenn der Fang in Alkohol war -) befindet, dann kann man durch das Steigen der Wasseroberfliiche das Volumen des Kö̈rpers bestimmen. Meist hat sich die Masse in 24 Stunden so weit abgesetzt, dass das Volumen derselben abgelesen werden kann. Da die Volumenbestimmung zum Vergleiche der einzelnen Fünge unter sich dienen soll, so ist es zweckmässig, allen Fängen die gleiche Zeit zum Absetzen zu lassen und zwar genügen dazu 2+t Stunden. 
Nachdem so das Volumen des Fanges festgestellt ist, wird zur Zählung der Organismen geschritten. Es ist selbstverständlich, dass nicht alle Individuen des Fanges gezählt werden kömnen, das beweisen schon folgende Zahlen, die ich Zühlungen Hensens*) entnehme: Hensen fand im Oktober I884 in I cbm Ostseewasser (Kieler Bucht) I 3 Millionen Ceratium tripos, und im März I 885 ebenda IO2 Millionen Rhizosolemia semispina, und wenn wir gar lesen, dass im September sich im Stettiner Haff in 1/2 cbm Wasser 9983 Mill. Fäden von Limnochlide**) fanden, dann ist es klar, dass diese Zahlen auf anderem Wege gewonnen sind, als durch Zählung jedes einzelnen Individuums. Die sinnreich von $\mathrm{Hensen}$ erdachte und angewendete Methode ist folgende:

Von dem Fange wird die überschüssige Pikrinschwefelsäure abgegossen und dann Wasser so viel zugesetzt, bis sich die Masse gut durcheinanderschütteln lïsst. Befindet sich der Fang in Alkohol, so muss der Alkohol durch Wasser erst ausgewaschen werden, was mehrere Tage in Anspruch nimmt. Nehmen wir an, dass nach der Verdünnung das Volumen $500 \mathrm{~cm}$ betrage, so ist es klar, dass sich in I $c c m$ die verschiedenen. Organismen nicht in der gleichen Zahl finden. Während wir vielleicht eine Leplodora finden, befinden sich in demselben Volumen gegen 20 Millionen Limnochlide. Um letztere zählen zu können nehmen wir von dieser ersten Verdünnung I $\mathrm{ccm}$ ab und verdünnen ihn auf I000 $\mathrm{ccm}$, dann haben wir in dieser zweiten Verdünnung in jedem Kubikcentimeter nur $\frac{20000000}{1000}=20000$ Fäden der Alge. Von dieser Verdünnung können wir $1 / 10 \mathrm{ccm}$, der 2000 Fäden enthalten würde, bequem zählen. In dieser Wassermasse würden wir aber keinen einzigen der selteneren Organismen finden, daher dürfen wir, wenn wir diese zählen wollen, die Verdünnung nicht so weit treiben, sondern vielleicht I ccm der ersten Verdünnung nur auf Ioo oder Io $\mathrm{cm}$ verdünnen, für

*) Hensen, Planktonwerk.

**) Die letzte Zahl entnehme ich einem Zählungsprotokolle von Herrn Geheimrat Hensen, das er mir freundilich für diese Arbeit überliess und das am Ende des Kapitels sich abgedruckt findet. Die folgenden Zahlen sowie Betrachtungen beziehen sich auf dieses Protokoll. Siehe auch Hensen II). 
die ganz seltenen werden wir aber die erste Verdünnung selbst zur Zählung benutzen.

$\mathrm{Da}$, wie wir gesehen haben, sich in I ccm Flüssigkeit noch Millionen von Organismen vorfinden können, so muss das Entnehmen einer bestimmten Menge von Flüssigkeit durch ganz besondere Vurkehrungen geschehen: denn das Abmessen in einem Messcylinder kann für diesen Zweck nur ganz rohe Werte geben. Es sind (laher von Hensen besondere stempelpipetten?) (Fig. 50) lonstruiert worden, die ganz Vorzügliches leisten. Solch cin Instrument besteht aus einem kräftigen Glasrohr $(B)$, das unten ganz eben abgeschliffen ist. In diesem Rohr bewegt sich ein Stempel, der abwechselnd aus Forli- ( $h$ ) und Metallplatten (i) zusimmengesetzt ist, die durch zwei Schrauben fest an einander gedrückt werden. An diesen Stempel ist ein massiver Aletalleylinder (m) angerchraubt. der genau in die Glasröhre hineinpasst. Von diesem Cylinder wird num so viel Metall ausgeschliffen, dass zwischen ihm und dem Glasrohr ( $B$ ) genau ein bestimmtes Volumen bleibt, z. B. I ccm. Dies wird so bewerkstelligt, dass zuerst ein Teil aus dem NIetallcylinder herausgenommen wird. Dann wird die Pipette gewogen; hierauf wird die Höhlung mit (Juceksilher gefüllt und wieder gewogen. Da man nun das Gewicht eines Kubikcentimeters Quecksilber kennt, so kann man genau den Punkt treffen, wo die Höhlung im Stempel I $\mathrm{ccm}$ fasst. Es sind ron diesen Stempelpipetten sechs verschiedene Grüssen zum Gebrauche nötig, nämlich zu 0.1; 0.2 ; $0.5 ; 1 ; 2.5 ; 5 \mathrm{ccm}$. Diese Pipetten werden so angewendet, dass sie mit vorgestossenem Stempel in ein durch einen durchbohrten Kork verschlossenes Glas mit starken Wandungen (A), in dem die Flüssigkeit sich befindet, von der ein Teil entnommen werden soll, hineingestellt werden (siehe Fig. 50). Die Masse wird durch kraftiges Schütteln aufgerührt, und sobald sich die Organismen

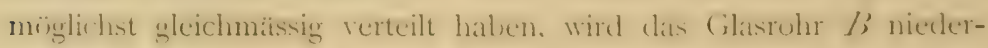
gestossen; dann ist zwischen dem Glasrohr und dem Stempel $m$

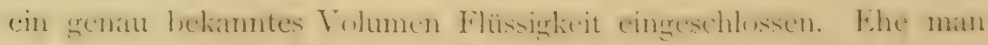

*) Hensen, Planktonwerk S. 16 . 
jedoch diese Flüssigkeitsmenge entleert, ist es nötig, den unteren Rand des Glasrohres mit Fett zu bestreichen, da sonst leicht ein Tropfen daran hängen bleiben kann. Nach Entleerung des Volumens wird dann noch mit einigen Tropfen Wasser nachgespült, so dass man sicher sein kann, dass keine Organismen zurückgeblieben sind. Dieses abgemessene Volumen wird dann zur Verdünnung benutzt resp. gezählt.

Haben wir uns eine genügende Verdünnung hergestellt, dann kann die Zählung beginnen. Hierzu wird das $Z a ̈ h l-$ mikroskop*) benutzt. Dieses Mikroskop zeichnet sich durch seinen Objekttisch aus. Dieser ist so gross, dass er Glasplatten von I I $1 / 2>$ Io $c m$ fassen kann, und was die Hauptsache ist, er ist durch zwei Schrauben sowohl von vorn nach hinten, als seitwärts verschiebbar. Auf den rahmenförmigen Objektttisch werden Glasplatten aufgelegt, die fein mit dem Diamanten liniiert sind und zwar hat jede Platte ein bestimmtes Liniensystem. Wühlt man die passende Vergrösserung, so kann man im

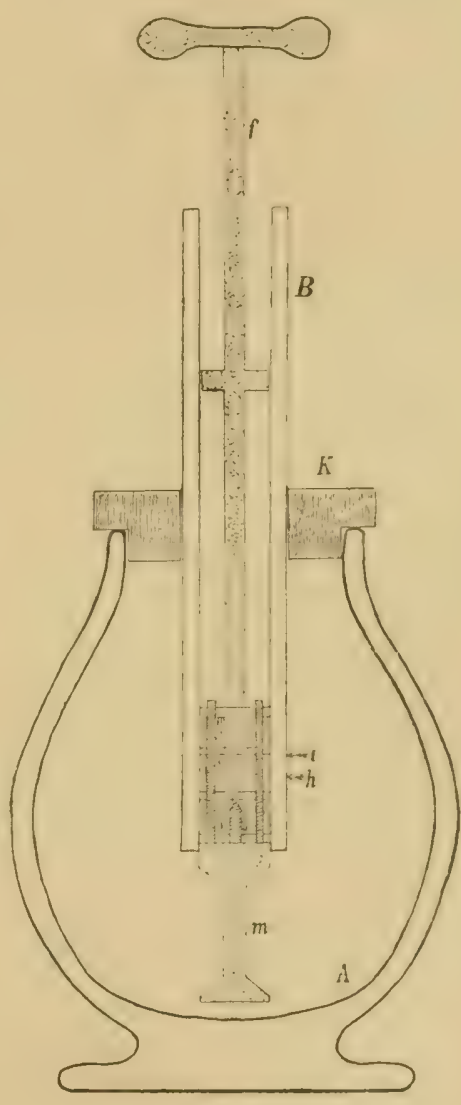

Fig. 50.

(Nat. Grüsse für $1 / 2 \mathrm{~cm}$.)

Gesichtsfelde zwei parallele Linien laufen sehen, und wenn man an einer seitlichen Schraube dreht, so bewegt sich die Glasplatte

*) Hensen, Planktonwerk S. 17 und Taf. I Fig. 2.

Tier- und Pflanzenwelt des Süsswassers. II. 
274 Über die quantitative Bestimmung des Plankton im Süsswasser.

langsam weiter, wobei man immer den Raum zwischen denselben Linien im Auge behalten kann. Ist man am Ende eines Zwischenrame's angelangt, so wird mit Hilfe der anderen Geluraube der Objekttisch senkrecht zu der vorherigen Richtung um einen Zwischenram weiter gedroht und damn in dienem die Beobachtung weiter fortgesetzt. So kann man allmählich die ganze Platte mit dem Mikroskop untersuchen und ist sicher, dass kein Punkt übersehen ist.

Bringen wir nun auf eine liniierte Glasplatte ein bestimmtes Mass einer Verdünnung, so können wir die Zahl der einzelnen Organismen, die sich in diesem Volumen befinden, bestimmen. Die Verdünnung wählt man am besten so, dass man von der häufigsten Spezies nie mehr als 3000 und nie weniger als 1000 auf der Platte hat. Würde es sich nur um eine Spezies handeln, so wåre die Zảhlung leicht auszuführen. Man brauchte nur die Platte allmählich zu durchsuchen und jecles Individum, das in das Gesichtsfeld kommt, zu zählen, dann wüsste man, wie viel Grunismen auf der Platte sind und könnte, da man die Verdünnung kennt, die Summe der Organismen im ganzen Fange berechnen. Hätten wir z. B. eine Verdünnung von I : IO angewendet und i ccm Verdünnung durchgezïhlt und fünden If') Ciscinodiscen, damm wären im ganzen Fange (von $500 \mathrm{ccm}$ ) $146 \times 10 \times 500=730000$ Coscinodiscen vorhanden.

Handelt es sich jedoch um mehrere Spezies, so kann man diese nicht im Kopfe getrennt zählen. Doch auch hier hat Hensen Rat geschafft. Da in einem Fange $30-50$ verschiedene Spezies von Tieren und Pflanzen vorhanden sind, so werden an einem Setzerkasten, fer ebenso vicl Fächer enthält, die Namen der vorhandenen Organismen angehracht, für jecle spezies cin Fach. Tontersucht man jetzt eine Platte, so werden die mannigfaltigen (Yrganismen nicht mehr gezahhlt, sondern sobald irgend einer in Gesichtsfelde sich blicken lässt, wird für ihn ein Pfennig (Spielmarke etc) in sein betreffendes Fach gelegt. So kann man leicht eine Platte, auf der sich 50 vershodedene Arten durchcinandergemengt befinden, zaihlen. 
Auf den ersten Platten werden die Diatomeen, die meist am zahlreichsten in einem Fange vorhanden sind, gezählt, andere Organismen natürlich auch berücksichtigt. Zuerst wird ein stark verdünnter Teil des Fanges genommen, da trotzdem genug Individuen auf die Platte kommen. Die Vergrösserung muss anfangs sehr stark sein, etwa 200, zum Zählen der Diatomeen und anderer Algen. Auf die Platte kommt nur $0.1 \mathrm{ccm}$ Flüssigkeit, die mit der betreffenden Stempelpipette abgemessen wird. Für die starke Vergrösserung bildet diese geringe Wasserschicht aber immerhin noch ein Hindernis alle Organismen zu sehen; hat man das Mikroskop auf die Oberfläche der Platte eingestellt, so entgehen einem die Organismen, die an der Oberflüche der Flüssigkeit sich befinden. Daher ist es vorteilhaft, die Diatomeen trocken zu zählen. Es wird zu diesem Zwecke ein bestimmtes Volumen Flüssigkeit auf eine Platte gebracht und diese dann der Wärme eines heizbaren Objekttisches oder eines Ofens ausgesetzt, damit die Flüssigkeit verdunstet; dann sind die Diatomeen auf der Platte in einer Ebene ausgebreitet und können nicht so leicht übersehen werden. Da die Mischungen und Verdünnungen nie ganz genau sein können, so wird natürlich die Zühlung jeder neuen Platte etwas abweichende Resultate ergeben, es fragt sich daher, wie lange eine Spezies gezählt werden muss; wann solch ein Grad von Genauigkeit erreicht ist, um von den wenigen Zählungen auf die quantitative Zusammensetzung des ganzen Fanges schliessen zu können. Im allgemeinen lässt sich sagen, dass es bei den häufigsten Formen genügt, wenn man einen Bruchteil (z. B. 1/10) der Quadratwurzel sämtlicher Individuen zähltt. Haben wir (siehe Protokoll) auf der ersten Platte für Mclosira 27 Fäden gefunden und wissen wir, dass die durchzählte Wassermasse der 5000000 . Teil von dem ganzen Fange ist, so würden wir nach dieser ersten Zühlung schliessen, dass I 35000000 Mielosir $a$ im Fange sein werden, daraus nehmen wir 1/10 der Quadratwurzel = II62. Haben wir also mindestens II62 Mcloswa gezähit, so künnen wir cliese aus den Zïhlungen ausscheiden, d. h. wir brauchen sie nicht mehr mitzuzählen. 
Um die Genauigkeit zu finden, bis zu welcher die Zühlung erfolgen muss, führt Hensen*) noch folgende Erwägung an. Nachdem einige Zählungen gemacht sind, zieht man aus diesen das Mittel. Denken wir nun, dass noch eine Zählung hinzugekommen wäre und diese mit der am meisten abweichenden übereinstimmen würde, und nähmen wir dann aus diesen das Mittel, so genügen die Zühlungen, wenn das Resultat sich nicht mehr als um $5 \%$ ändert. Im Protokoll finden wir für Melosira die Zahlen 382, 396, 396, Summe II 74, Mittel daraus 391. Käme noch cine Zählung hinzu und zwar 382 , so wäre die Summe 1556 , Nittel daraus 389 .

Es verhält sich $391: 100=389: x$,

$$
x=99.4 \text {. }
$$

Das Resultat weicht also nur um $0.6 \%$ ab, die Zählung ist genau genug, kann also unterbrochen werden; jedoch ist es stets besser, mehr Platten zu zählen, als zu wenig.

Haben wir eine genügende Genauigkeit erreicht, so können wir die Diatomeen beim Zühlen überspringen und schwächere Verdünnung und schwächere Vergrösserung zur Zählung benutzen. Für seltenere fornen wird selliesslich die erste Verdümung benutzt und von dieser I $\mathrm{ccm}$, zuletzt 2.5 durchzählt, was meist sehr schnell geht, da man nur mit sehr schwachen Vergrösserungen zu arbeiten braucht und nur wenige Tiere zu zahlen hat.

Die einzelnen Zühlungen werden notiert und zwar in Form eines Protokolles. Ein solches Protokoll ist im Anhange beigegeben und aus diesem die Einrichtung zu ersehen. Folgendes möge noch zur Erläuterung desselben erwähnt sein. In der linken obern Ecke findet sich Datum und Ort des Fanges, hier also: I3. September 1887 , Stettiner Haff. Über sämtliche Fange wird ein Journal geführt, es bedeutet J. No. I $=$ Journal No. I. Daselbst finden sich die näheren Daten, die bei Erlangung des Fanges als wichtig notiert wurden, wie die Tiefe des Fanges (hier $5 \mathrm{~m}$ ), die Temperatur des Wassers und der Luft, Windrichtung,

*) Planktonwerk S. 2 I. 
Beschaffenheit des Fanges, ob locker, flockig, schnell absetzend; letztere Aufzeichnungen sind wichtig, da sie, wie wir oben gesehen haben, schon einen Einblick in die Zusammensetzung des Fanges erlauben.

In dem Protoliolle sehen wir einige Vertikalreihen, darauf Horizontalreihen. Betrachten wir zuerst die Vertikalreihen. In der ersten Kolumne mit der Überschrift "Art der Untersuchung" steht überall feucht, d. h. alle Platten, die durchzählt worden sind, enthielten die Organismen in Wasser suspendiert. Den Gegensatz bilden die trockenen Platten, die, wie oben erwähnt wurde, meist zum Zählen der Diatomeen verwendet werden. In unserem Fange waren Diatomeen in verhältnismässig geringer Anzahl vorhanden, Melosira, Coscinodiscus und Bacillaria zusammen etwa Ioo Millionen, diesen standen von anderen Algen allein Limnochlide mit 9653 Millionen gegenüber. Letztere würden beim Trocknen bis zur Unkenntlichkeit geschrumpft sein und daher die Zühlung vereitelt haben, während die kieselschaligen Diatomeen nicht nur ihre Form behalten, sondern auch leichter in trockenem Zustande zu bestimmen sind.

In der zweiten Vertikalreihe sind die Vergrösserungen angegeben, bei denen die einzelnen Platten gezählt worden sind. Das stärkste der angewendeten Objektive (Vergrösserung 200) hatte einen solchen geringen Abstand von der Glasplatte oder von der Flüssigkeitsmenge $(0.1 \mathrm{ccm})$, die sich auf der Platte befand, dass es nur der gleichmässigen und leichten Verschiebung des Objekttisches zuzuschreiben ist, dass das Objektiv nicht in das Wasser eintauchte. Dadurch ist einerseits einer weiteren Erhöhung der Vergrösserung ein Ziel gesetzt, anderseits würde die Zählung einer Platte mit noch stärkeren Objektiven viel längere Zeit in Anspruch nehmen und die Augen übermässig anstrengen. Beiläufig will ich noch erwähnen, dass die Zählung solch einer Platte etwa drei stunclen dauert*). Nach und nach nahm die Vergrösserung, bei der gezählt wurde, ab bis auf 22 ; mit letzterer wurden nur noch Leptodora,

*) Die genaue und bis in dic Einzelheiten gehende Züblung eines Fanges nimmt ctwa vierzehn Tage in Anspruch bei vierstündiger Arbeitszeit. 
278 Über die quantitative Bestimmung des Plankton in Süsswasser.

Milben und ein nicht bestimmtes Rädertier gezählt. Die anderen Organismen waren entweder schon zu zahlreich auf der Platte und lagen infolgedessen zu dicht an einander, oder es war schon die genügende Zahl gezählt, oder endlich reichte die Vergrösserung nicht mehr aus, die lileineren Organismen genau und schnell zu erkennen. Aus letzterem geht hervor, dass man nie ein schwächeres Linsensystem anwenden darf, ehe nicht alle Organismen genügend gezählt sind, die mit diesem System nicht mehr genau erkannt werden können.

In der dritten Reihe ist die Grösse der Verdünnung angegeben. Aus dem oben Gesagten erklären sich die Angaben leicht. I : I000 heisst also, dass I $\mathrm{ccm}$ der ersten Verdünnung mit $999 \mathrm{ccm}$ Wasser verdünnt wurde, so dass das Gesamtrolumen IOOO $\mathrm{ccm}$ = I Liter war. Man richtet sich am besten solche MIessflaschen ein, die $1000,500,200,100,80 \mathrm{ccm}$ halten, und benutzt dazu

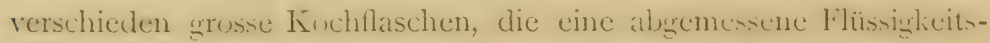
menge so aufnehmen können, dass diese gerade noch in den Hals der Flasche hineinragt, dort bringt man mit dem I) iamant cine Martie an. Dann hat man für jede Verdünnung sogleich eine Flasche bereit. $\mathrm{Zu}$ den letzten Zählungen ist die erste Verdünnung genommen worden, es wurden aber auch nur die grössten Tiere gezählt, so auf einer Platte, die $2.5 \mathrm{ccm}$ Flüssigkeit enthielt, nur

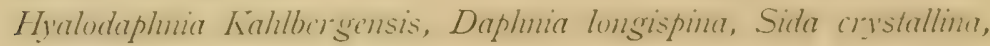
Leptodora hyalina, Milben und das oben erwailnnte Rüdertier. Es waren im ganzen (in No. 27) 94 Individuen, so dass, trotz der grossen Flüssigkeitsmenge, die Zählung nur ungefähr eine halbe Stunde in Anspruch nahm.

Die nảichste Spalte enthält die "Nummern" der gezảhlten Platten. Meist genügen 22-24 Platten; in unserem Fange waren aber die grossen Formen selten, so dass, um einen einigermassen sicheren Einblick in die Massenhaftigkeit ihres Vorkommens zu erhalten, mehrere Platten allein für sic verarbeitet werden mussten (Platte 26-31). Die fortlaufenden Nummern der Platten sehen wir wieder als Kopfzahlen bei den Horizontalreihen, zu denen wir weiter unten übergehen werden. 
Wir überspringen einige Spalten und sehen uns die letzte mit der Überschrift "Gebrauchtes MIass" an. Die Zahlen dieser Rubrik besagen, eine wie grosse Wassermenge jedesmal zur Untersuchung benutzt worden ist. Aus der ersten Zeile ersehen wir, dass $0.1 \mathrm{ccm}$ gezïhlt wurde und zwar - wie aus den daneben stehenden Reihen hervorgeht - von der Verdünnung I : IOOO bei einer Vergrösserung von 200 auf feuchter Platte. Die Flüssigkeitsmengen werden mit den oben beschriebenen Stempelpipetten abgemessen und auf die Platte übertragen. Es sind, wie das Protokoll ausweist, alle dort erwähnten Grössen in Anwendung gekommen, mit Ausnahme von $5 \mathrm{ccm}$, die nur zum Abmessen der Volumina zwecks der Verdünnung gedient hat (siehe Platte $2 \mathrm{I}-25$, auch IO-20).

Kehren wir nun zuz der alten Reihenfolge zurück, so treffen wir die Spalte, die die Wahren Masse enthält. Diese unterscheiden sich insofern von dem "Gebrauchten Mass", als sie nicht angeben, wie viel Flüssigkeit auf jeder einzelnen Platte durchzählt wurde, sondern der wievielste Teil diese Flüssigkeitsmenge von der ganzen betreffenden Verdünnung ist. Wie wir diese Zahlen erhalten, ergiebt sich am leichtesten an der Hand unseres Protokolls: Bei Platte I haben wir I $\mathrm{ccm}$ der ersten Verdünnung auf $\mathrm{I} 000 \mathrm{ccm}$ (zweite Verdünnung) gebracht; würde ich hiervon I $\mathrm{ccm}$ abnehmen, so wäre dieser der 0.001 . Teil der ganzen zweiten Verdünnung oder des einen Kubikcentimeter der ersten Verdünnung, den ich für die zweite benutzt habe. Zur Zählung ist aber nur $0.1 \mathrm{ccm}$ verwendet, dieser ist dann nur der 0.0001 . Teil der ganzen zweiten Verdünnung, enthält also auch nur den 0.000 . Teil der Organismen der ganzen zweiten Verdünnung resp. des I ccm der ersten Verdünnung, von dem die zweite Verdünnung hergestellt ist.

Bei Platte ro haben wir die Verdünnung Io: 100, also 0.1; davon $0.2 \mathrm{ccm}$ genommen, erhalten wir 0.02 als wahres Mass.

Bei No. 2 I haben wir $30: 100$, also 0.3 , ein Kubikcentimeter davon also 0.3 wahres Mass.

Dieses wahre Nass ist nun wichtig für die Berechnung des Koeffizienten. In der Rubrik "Berechnung" ist dieselbe aus- 
geführt. Bei der Besprechung des wahren Masses sahen wir, wie wir z. B. bei Platte I fanden, dass die gezühlten Organismen auf dieser Platte den 0.0001 . Teil der in I $c c m$ enthaltenen Wesen bilderr. Eezichen wir aber die grezahlte \%ahl auf das ganze Flüssigkeitsvolumen von $500 \mathrm{ccm}$ (erste Verdünnung), so haben wir nur $\frac{500}{0.0001}$ gezuihlt, das ist der $\frac{5000000}{I}=5000000$. Teil. Finden wir also auf der ersten Platte in $0.1 \mathrm{ccm}$ der Verdünnung I : 1000 2024 Limnochlide-Füden, so wissen wir, dass wir in dem ganzen Fange $2024 \times 5000000$ Limnochlide ungefähr werden finden müssen, was IO I 20 Millionen ergeben, eine Zahl, deren Fehler durch weitere Zählungen eingeschränkt wird.

Haben wir eine Spezies während mehrerer Platten gezählt und sehen wir, dass wir aburechen lïnnen ${ }^{*}$ ), (limn handelt es sich darum, den Koeffizienten für die Summe der gezühlten Individuen zu finden. $\mathrm{Zu}$ dem $\mathrm{Zwecke}$ addieren wir die wahren Mlasse aller der Platten, auf denen diese Spezies beobachtet wurde, und verfahren wie oben für eine Platte angegeben ist. Wir haben z. B. für Limnochlide fünf Platten gezählt $(I-5)$ und finden die Zahlen 2024, I835, 2048, 1954, I792, Summe 9653. Die Summe der wahren Masse für diese fünf Platten ist $5 \times 0.0001=0.0005$, dann (rhalten wir $\frac{500}{(0.0005}-$ I 000000 als Koeffizienten der Summe. I)ie gezählten Individuen 9653 bilden also den I 000 ooosten Teil aller im Fang vorhandenen Limnochlide, das ergiebt 9653000000 Limnochlide. Habe ich Spirogyra erst von der zwölften Platte bis zur zwanzigsten gezählt, so summieren für diese Alge nur die wahren Masse dieser Nummern, also Summe $12-20=0.51$, und wir erhalten den Koeffizienten 980.

Durch die letzteren Betrachtungen sind wir nun schon bei den Horizontalreihen angelangt.

In einer Spalte derselben stehen die Namen der Organismen, die sich in dem gezthlten Fange befanden. Rechts davon sind 
damn die Ergebnisse der Zaihlung jecler cinzelnen Platte angeweben und zwar in der Rubrik, deren Kopfzahl der betreffenden Platte entspricht. Hört man auf, einen Organismus mitzuzählen, so steht in der Rubrik der betreffenden Platte ein Fragezeichen. Wird auf einer Platte von einer Spezies kein Individuum gefunden, so steht natürlich eine Null. Ist dagegen eine Spezies beobachtet, aber auf einigen Platten nicht mitgezählt, wie z. B. bei Spirogyra I-I I, so wird auch hier ein Fragezeichen gesetzt.

In den beiden letzten Spalten sind zuerst die Summen der gezählten Individuen jeder Spezies angegeben, dann die Platten, auf denen diese Organismen gezahlt wurden.

Um nun die Gesamtsumme der in dem Fang vorhandenen Tier- und Pflanzenindividuen zu finden, brauchen wir nur die Summe der gezählten Organismen mit dem Koeffizienten, welcher der angewendeten Plattenzahl entspricht, zu multiplizieren. So haben wir bei Limnochlide 9653 Fäden gezählt, und zwar auf Platte I-5, der Koeffizient der Platten I-5 ist I 000000 , also sind im ganzen Fange 9653000000 Limnochlide-Füden vorhanden.

Diese Gesamtsumme "Gezählte Masse" steht in einer Rubrik vor den Namen, damit man mit diesen das Endresultat sogleich übersieht.

Vor der letzteren Rubrik finden wir eine solche mit der Überschrift "Ganze Masse". Wie wir oben gesehen haben, wird nicht die ganze Wassersäule filtriert, die dem Querschnitte des Netzes und der Tiefe des Wassers, bis zu der das Netz herabgelassen wurde, entspricht, sondern ein kleiner Teil fliesst über den Netzrand $a b$. Hensen hat deshalb für jedes Netz den Filtrationskoeffizienten*) berechnet, der besagt, mit welcher Zahl man Volumen oder Anzahl der Organismen eines Fanges multiplizieren muss, um die wirklichen Werte zu finden, wenn die ganze Flüssigkeitssïule filtriert worden wäre. In unserem Falle war der Koeffizient I.034. Von Leptodora waren z. B. 37 I Individuen im Fange. In der Wassersäule von $0.1 q m$ Querschnitt und $5 m$ Höhe waren aber

*) Planktonwerk S. ro-13. 
282 Über die quantitative Bestimmung des Plankton in Süsswasser.

37 I $>$ I.034 $=384$ Individuen vorhanden. In Folgendem habe ich aber die Zahlen der gezählten Masse benutzt.

Nachdem wir in Vorhergehendem die Hensensche Methode der quantitativen Untersuchung des Plankton kennen gelernt haben, erübrigt es noch, auf die qualitative Zusammensetzung des Süsswasserplanliton*) einzugehen. Jedoch muss ich noch ein par Worte vorausschicken. Die Planktonmethode ist bis jetzt fast nur auf das Meer angewendet worden, nur einmal ist bei einer Fahrt in der östlichen Ostsee von Hensen auch ein Fang im Stettiner Haff 11), also im Süsswasser, gemacht worden. Die Fänge wurden, wic wir oben gesehen haben, sofort konserviert, daher kommt es, dasis manche (granismen bei nathfolgenter \%ahhlung gan\% unlituntlich sind, da sie sich beim Töten zusammengezogen haben; dieses

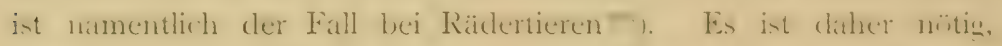
dass an Ort und Stelle auch lebendes Naterial untersucht wird, denn, wenn dieses bestimmt ist, sind die Organismen leicht in konserviertem Zustande wiederzuerkennen. Dieses ist nun bei einer grösseren Fahrt sehr schwer ausführbar, da sich auf dem Schiff; namentlich bei bewegter See, schwer oder gar nicht mikroskopieren lïsst. Anders verhailt sich die silehe, wenn das Institut, in dem die Arbeiten ausgeführt werden sollen, direkt am Wasser liegt, da

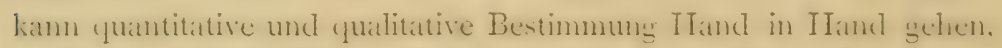
so ist dats hier in fiel, und atuch in der muanest von \%achariats

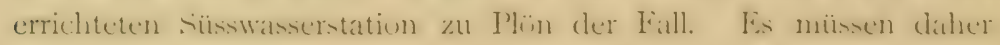
in den Protoliollen vorläufige Namen fir die unbestimmten****) Organismen gesetzt werden und späterer Zeit überlassen bleiben, das Versiiumte bei Gelegenheit an Ort und Stelle nachzuholen. Folgendes ist ferner auch noch von Bedeutung. Es genügt nicht, einen Fang zu beliebiger Zeit zu machen, sondern es müssen die Planktonfahrten in bestimmten Zeitabschnitten (alle zwei oder vier

\footnotetext{
") Von II äckel6) S. 2x Limnoplankton genannt.

*) Ausgenommen von diesen sind nur die gepanzerten (Loricata), dic srotzdem leicht 2 erkennen sinil.

***) Leider war der Fang aus dem Stettiner IJaff, da er als ausgebraucht betrachtes wurle, weggeschïttet, so dass auch nachträglich keine nähere Untersuchung vorgenommen werden kunnte. Lis empfiehlt sich daher, das Material stets aufzubewalren.
} 
Wochen)*) unternommen werden, dann erhält man erst einen Einblick in die wahre Zusammensetzung des Plankton, das in fortwährendem Werden und Vergehen begriffen ist. Dieses wäre eine sehr dankbare Arbeit für eine Süsswasserstation.

Nach dem Gesagten ist es kilar, dass die folgenden Darlegungen wenig positives bringen können, es kann nur gezeigt werden, in welcher Art ein Fang oder eine fortlaufende. Reihe solcher verwertet werden können. Ich beabsichtige also nur ein Beispiel zu der oben erläuterten Methodik zu geben.

Beginnen wir mit den Algen, der Urnahrung, so fallen uns die Vertreter zweier Ordnungen durch ihr massenhaftes Auftreten auf, es sind die Diatomeen und Schizophyceen. Weniger zahlreich sind Protococcoideen, von denen Pediastram, Gleocystis und Scenedesmus quadricaudatus gefunden wurden, und Konjugaten, die durch Spirogyrafäden vertreten sind.

Was die Diatomeen anbelangt, so müsste man glauben, dass sie wegen ihrer grossen Zahl, trotz des geringen Anteils an organischer Substanz, eine wichtige Nahrung für die pelagischen Tiere bilden. Jedoch werden sie, wie Hensen**) beobachtet hat, von allen Tieren verschmäht. Dagegen erwähnt Seligo ${ }^{13}$ ) in seinen Hydrobiologischen Untersuchungen, dass die Diatomeen die Hauptnahrung mehrerer Tierarten***) bilden. Leider sagt er nicht, für welche. Ihre Bedeutung ist also in anderer Richtung zu suchen. Alle Diatomeen haben eine Vegetationsperiode, d. h. sie vermehren sich zu einer bestimmten Zeit ganz enorm, um dann wieder allmählich oder fast plötzlich zu verschwinden. Letzterer Umstand ist durch das Bilden von Dauersporen, die bei vielen Meeresdiatomeen beobachtet sind, leicht erklärlich, da die Spore alsbald zu Boden sinkt. Ob bei Süsswasserdiatomeen die gleichen Verhältnisse vorkommen, kann ich nicht angeben. Die Sporen enthalten eine sehr

*) So werden die Untersuchungen in der Kicler Bucht von l'rol. Brandts) scit September 1888 ausgeführt und noch fortgesetzt.

**) Planktonwerk S. 99 .

***) Bei meinen Untersuchungen hiesiger Süsswasserseen habe ich den Darm von Hyalodaphnien und Bosminen dicht mit Melosirazellen angefült gefunden ( $189 \mathrm{r}$ ). 
284. Über die quantitative Bestimmung des Plankton im Süsswasser.

kinzentrierte oreanische Nahruner die den Tieren der Tiefenregion wohl zu gute kommt.

Da jede Diatomee aus zwei Schalen besteht, so muss man jede vollständige Diatomee als 2 zählen, jede allein liegende Schale als 1 , und dann die erhaltene Summe durch 2 dividieren, dann erhält man die Zahl der Zellen. Bei Mclosira würde dieses Verfahren zu viel Zeit in Anspruch nehmen, man zählt daher nur die Fiiden und stellt bei einer Zahl von Fiden die Zellenzahl fest. In unserem Fange fanden sich pro I $q m *$ ) $98+6$ I 4400 Fäden, von denen $20=2+6$ Zellen enthielten, es wären also im ganzen I 2 I IO 757 I 20 Zellen vorhanden gewesen. Ohne Berechnung der Zellen kann man Mclosira nicht mit anderen Diatomeen vergleichen. Von Melosira kamen zwei Arten vor, nämlich $M$. granulata und eine andere, nicht näher bestimmte. An 226 Fäden war erstere mit 208, letztere mit I 8 beteiligt. Coscinodiscus fand sich in 6440890 und Bacillaria paradoxa in 7388640 Individuen. Letztere Diatomee zeigt bei ihrer Zählung ziemlich abweichende Resultate, da mehrere Zellen an einander liegen und so Platten bilden, andere sind auseinandergefallen, so dass, wo einmal eine Bacillaria gefunden wird, ein ander Mlal eine Platte, die aus mehreren Individuen besteht, sich vorfindet. In geringerer Anzahl war eine Surirella-Art vorhanden, nämlich 477570 pro I $211 \%$. Gegen Mclosira tritt aber die Summe aller übrigen Diatomeen weit zurüick.

Die zweite Hauptgruppe der Algen bildeten die Schizophyceen. Einzelne von diesen verursachen zu Zeiten die sogen. "Wasserblüte". Sie sollen den Fischen verderblich werden, jedoch ist die Ursache davon noch unbekannt.

Vor allen trat Limmochlide flosaquae $\mathrm{K} t z$. hervor, es wurden von ihr unter I qu Oberfläche 96530000000 Fuden gefunden, von denen $20=29+$ Zellen enthielten, so dass wir fast $I \mathbf{1} / \mathbf{2}$ Billion Zellen erhalten. Die filtrierte Wassermenge betrug fast $0.5 \mathrm{cbm}$

-) Wenn die Zahlen in folgendem auf I qm Oberfliche bereclanet sind, so bedeuret dies stets eine Wassersilule vom Querschnitt I qm und ciner Tiefe von $5 \mathrm{~m}$. 
= 500 Millionen Kubikmillimeter, es fanden sich also in I cmm Wasser $28_{3} 8$ Zellen $=I_{42}$ Fïden. Ihre Bedeutung für den Stoffwechsel ist mir nicht klar, es wäre aber möglich, dass die Sporen dieser Alge ebenfalls (siehe Diatomeen) den Tieren der Tiefenregion zur Nahrung dienen könnten.

Neben Limnochlide kamen noch mehrere Arten von Chroococcaceen vor. Sie sind im Protokoll einfach mit Coccus bezeichnet und mit einem Beinamen versehen, der auf die Form der Kolonie oder der einzelnen Individuen Bezug hat. Sie gehörten meist der Gattung Polycistis an, der sogenannte feinkörnige Coccus war $P$. ichthyoblabe. Dagegen ähnelte Coccus I (viereckig) mehr einer Merismopedia.

Die in Pikrinsäure konservierten Algen lassen aber nicht ihre natürliche Färbung erkennen und sind dann nicht mehr bestimmbar. Zusammen fanden sich Io9 824400 Kolonien, die einzelnen Individuen sind nicht zu zählen.

Zur Unnahrung müssen wir ferner, wie in der Einleitung erwähnt ist, die Peridineen rechnen. Es waren im Fange drei Arten vorhanden, Ceratium tripos, C. fusus und Peridinium divergens. Diese drei Peridineen sind echte Meeresbewohner und es muss daher ihr Vorkommen im Süsswasser*) sehr auffallen. Ich vermutete daher zuerst, dass sie von früheren Füngen aus der westlichen Ostsee am Netze hängen geblieben waren, dieses war aber nicht der Fall, da, wie ich nachher erfuhr, ein ganz neues Netz zum Fischen verwendet war. Es müssen also sich die Peridineen dem Leben im Süsswasser angepasst haben. Der Salzgehalt im Stettiner Haff war so gering, dass er mit den Instrumenten nicht mehr gemessen werden konnte. Von den Peridineen, die bisher im Süsswasser gefunden wurden, sind keine beobachtet.

Von den Protozoen finden wir im Plankton die Tintinnen. Dieses sind die niedrigststehenden Tiere, die durch einen Mund geformte Nahrung aufnehmen. Worin diese Nahrung besteht, ist

*) Hensen ${ }^{21}$ ) führt auch an, dass Ceratintm tripos von Pringsheim nahe bei Berlin gefunden ist, also im Süsswasser (S. 74). 
286 Über die quantitative Bestimmung des Plankton in Süsswasser.

nicht bekannt, Hensen*) vermutet darunter der geringen Grösse ler Tintinnen wegen noch kleinere Wesen, als bis jetzt nacherewiesen

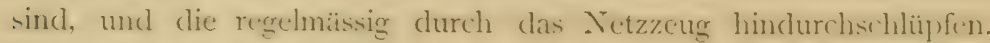
Tintinnen sind in zwei Arten im Fange vorhanden gewesen. Tintimus ventricosus, der auch im Meere zahlreich vorkommt, war sehr häufig, auf I qm Oberfäche I 586040 Tiere, noch mehr war $T$. borealis Hensen**) zu finden, eine neue Art, die eine Lïnge von nur $0.018 m m$ hat, und an Chactoceros und anderen Organismen festsass. Von ihm waren 288I 960 Individuen unter I qu Oberfläche.

Von Rädertieren wurden sechs Arten gefischt. Drei davon gehörten zu der Gattung Amuraca, die anderen drei konnten nicht bestimmt werden, da sie zu sehr kontrahiert waren, es befand sich darunter eine sehr grosse durchsichtige Art $\left.{ }^{* * *}\right)$, von der nur 3 I 80 unter I qu Oberfläche lebten.

Die beiden anderen unbestimmten Rotatorien waren sehr zahlreich zu finden, das eine in der Zahl von 776240 , das andere von 3203200 unter derselben Oberfläche. Von Amuraea fanden sich A. aculeata Ehbg. mit 203840 , quadridcntata mit 722 I 80 und foliacea Ehbg. mit 58240 Individuen. Ausserdem 2567380 Rådertiereier.

Von Daphniden wurden sechs Arten gefunden. Drei von diescn sind allgemein als pelagisch heliannt, nïmlich Leptodora

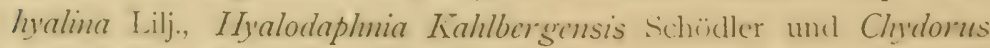
splıaericus O. Fr. MI., während die drei übrigen bei den bisherigen Untersuchungen wn Sïsswasserbecken meist als littorale Furmen nacherewiesen wurden. Daphnia longrispina Leyd. ist jedech auth von Zacharias ${ }^{15}$ ) in den $6-8 m$ tiefen Mansfelder Seen pelagisch gefunden, ebenso Sida crystallina von Forel5) in Schweizer Seen. Da die Daphniden vielen Süsswasserfischen zur Nahrung dienen, so ist ihre Bestimmung von hohem praktischen Interesse, namentlich da sie sich in Bezug auf ihren Gehalt an organischer Substanz

*) II asen, Ilanktonwerk S. $7 x$.

"*) If ensen ${ }^{11}$ ) hier auch Beschreibung und Figur.

on) Syrnchacta? 
ähnlich wie die Copepoden verhalten dürften, für die wir oben $99.4 \%$ gefunden haben. Wenn wir in unserem Fange unter einem Quadratmeter Oberfläche I 826 Ioo Daphniden finden, so können wir uns leicht ein Bild von ihrer Bedeutung für die Fischzucht machen. Mit Hilfe der Planktonmethode würde sich ein sehr klares Bild über den Entwickelungsgang dieser Tiere finden lassen. Bei fortgesetzten Untersuchungen könnte man das Auftreten der Daphniden im Frühjahr feststellen, sowic dessen Abhïngiglicit von der Wassertemperatur, ferner würde sich die rapide Zunahme gegen den Sommer hin zeigen; wobei es von Wichtigkeit wäre, die Zahl der Eier und Embryonen im Brutraume zu berücksichtigen, so dass sich für jede Art eine Durchschnittszahl ergeben würde. Zugleich liesse sich das Erscheinen der verschiedenen Arten in den einzelnen Monaten finden. Im Spätsommer würden dann die Männchen hinzukommen und schliesslich würde man die Cladoceren verschwinden sehen, nachdem man die Bildung der Dauereier beobachtet hätte.

Es würden sich alle diese Verhältnisse zahlenmässig klarlegen lassen und einen präzisen Ausdruck liefern für die bisherigen Ausdrücke, wie „im Frühjahr nach Schmelzen des Schnees massenhaft auftretend".

Die Copepoden, deren Bedeutung wir schon oben gesehen haben, bilden einen anderen Hauptbestandteil des Plankton. Sie waren unter I qm Oberfläche mit 697480 vertreten. Dazu kommen noch die Larvenformen mit 786520 .

In dem Protokoll sind die einzelnen Arten nicht getrennt aufgeführt worden. Es schien anfangs nicht möglich, während des Zïhlens die verschiedenen Spezies auseinanderzuhalten, und mit Hilfe der bisherigen Diagnosen ist dieses auch nicht auszuführen. Nachdem es sich aber herausgestellt hat, dass in einem Fange selten mehr als sechs Arten (bei Zählungen der Copepoden des Plankton im Kieler Hafen) vorhanden sind, ist die getrennte Zảhlung versucht worden und hat sich auch durchführen lassen, da jede Spezies irgend ein bestimmtes Merkmal besitzt, an dem sie sofort erkannt werden kann. Man kann schliesslich noch weiter 
gehen und auch die Geschlechter getrennt zählen. Neben den ansgewathsenen Coppepden werden dann die Larren berücksichtigt. Diese nach der Spezies zu zählen wird wohl fürs erste kaum geschehen können, da die Entwickelungsreihen vom Ei bis zum erwachsenen Tier nur erst für sehr wenig Formen festgestellt sind, bei genauem Studium und einiger Ausdauer liesse sich dieses vielleicht auch ausführen. Ebenso müssten die Eiersäckchen mit der durchschnittlichen Zahl der Eier berücksichtigt werden.

Nach den erwähnten Untersuchungen von Hensen nähren sich die Meerescopepoden von Peridineen. Die des Süsswassers müssen aber andere Nahrung zu sich nehmen, denn nach unserem Fange standen 697480 Copepoden, ohne Larven, nur 122090 J'eridineen zur Terfügung, die nach den IIensenschen Pierechnungen nur Io ooo Copepoden genügen würden. Nach Claus4) leben sie von pflanzlichem und tierischem Detritus, Vosseler ${ }^{14}$ ) hat dasselbe beobachtet, meint jedoch, dass noch Infusorien sich beigesellen. Ob dieses aber auch die Nahrung der pelagischen Copepoden ist, wäre noch experimentell festzustellen.

Von Hydrachniden wurde Nesaea clliptica Kram. in erwachsenen und jugendlichen Formen gefunden. Ihre immerhin betrichtliche Zahl von 2400 pro I $q m$ ist bemerkenswert. Ob sic in dem Haushalt der Natur irgend eine Rolle spielen, vermag ich nicht anzugeben. Eigentümlich ist das pelagische Vorkommen, obgleich Zacharias 16) in norddeutschen Seen die Milben nur littoral gefunden hat. Dagegen erwähnt auch Nordquist 12) in seinem Aufsatz über die pelagische und Tiefseefauna finnischer Seen pelagische Hydrachniden.

Von Mollusken wurden nur Muschellarven zahlreich gefangen, Schneckenlarven fehlten. Es fanden sich 40770 auf den Quadratmeter Oberfliche. Nimmt man für eine Muschel I qcm Bodenfliche an, so würden das auf I qm immer nur 10000 ausmachen, der Raum ist aber viel zu gering bemessen. Von den Larven kann also im günstigsten Falle nur $1 / 4$ am Leben bleiben und diese müssten den Boden dann dicht überziehen. Das ist aber nicht wahrscheinlich. Ob die Larven zu einer Spezies gehören, ist bei 
Über die quantitative Bestimmung des Plankton im Süsswasser. 289

der Zählung nicht berücksichtigt worden, die Art selbst zu bestimmen ist bis jetzt auch nicht möglich, würde sich aber bei speziellen Studien gewiss ausführen lassen. Es würde das ein Licht auf die Zeit und die Dauer des Schwärmens der Larven werfen.

Es konnte in Vorhergehendem nur meine Aufgabe sein, dem Leser die Methodik zur quantitativen Bestimmung des Plankton im Süsswasser zu erklärer; etwas Näheres über die Organismen des Plankton zu sagen, war nach dem einen Süsswasserfange noch nicht möglich. Es wäre zu wünschen, dass die Hensensche Methode auch in einem grösseren Landsee angewendet würde, interessante und wichtige Ergebnisse würde sie liefern, wie das schon der Fall bei ihrer Anwendung im Meere gewesen ist. Endlich möchte ich nochmals auf die epochemachende Arbeit Hensens hinweisen, die so viel des interessanten bietet, worauf ich nur hinweisen konnte, oder das ich wegen Raummangel ganz übergehen musste. 


\begin{tabular}{|c|c|c|c|c|c|c|c|c|c|c|c|c|c|c|}
\hline 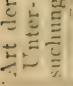 & 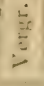 & 5 & No. & $=$ & $\stackrel{\Xi}{\Xi}$ & 党 & $\begin{array}{l}\text { Kueffi- } \\
\text { zient }\end{array}$ & $\frac{5}{3}=$ & $\begin{array}{l}\text { Ganze } \\
\text { Masse }\end{array}$ & $\begin{array}{l}\text { Gezullilte } \\
\text { Maisse }\end{array}$ & Same & 1 & 2 & 3 \\
\hline \multirow{2}{*}{ feucht } & \multirow{2}{*}{200} & \multirow{2}{*}{$1: 10010$} & \multirow{2}{*}{1} & \multirow{2}{*}{$0 . \ldots 1$} & & $5(1+1)$ & \multirow{2}{*}{ 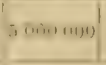 } & \multirow{2}{*}{ 0.1 } & 9983100000 & $|9653000000|$ & Limnochlide & $2+24$ & 1535 & $201+1$ \\
\hline & & & & & & $\sqrt{11 \ldots+18}$ & & & 1018288110 & 98461440 & Melosira & 27 & 24 & 22 \\
\hline \multirow[b]{2}{*}{.. } & \multirow[b]{2}{*}{, } & \multirow[b]{2}{*}{$\cdot}$. & \multirow{2}{*}{$\stackrel{2}{2}$} & \multirow[b]{2}{*}{$19 \cdots+1$} & & & & \multirow{2}{*}{ G.1 } & 438031 & 421656 & Pediastrum & 1 & 111 & 11 \\
\hline & & & & & & & & & $5 . j 060$ & $\mathrm{~S} 08496$ & Coccus 1 (vierechig) & 1 & 11 & 11 \\
\hline \multirow[b]{2}{*}{. } & \multirow[b]{2}{*}{$\ddot{-}$} & \multirow[b]{2}{*}{.. } & \multirow[b]{2}{*}{3} & & & & & & 7642950 & 7390200 &,$\quad 2$ trund. & 11 & $1 " 1$ & 1 \\
\hline & & & & $10.5 \times 1$ & & & & 0.1 & 820060 & 793022 & ., 3 grerundet & 11 & 11 & (1) \\
\hline & & & 4 & & & & & & 2059020 & 1990728 & .. 4 (feinkörnig) & $?$ & $1 ?$ & $?$ \\
\hline$"$ & $"$ & $"$ & 21 & 0.0001 & & & & $0 \cdot 1$ & 666047 & $644089^{\circ}$ & Coscinodiscus & 1) & 11 & (1) \\
\hline , & " & , & 5 & 0.0001 & $1-5$ & 500 & 1000000 & 0.1 & 764054 & 738864 & Bacillaria & 0 & 111 & 6 \\
\hline , & , & 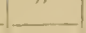 & & orous & $0.000 \mathrm{i}$ & 0.0005 & & 0.1 & 49356 & 47757 & Surirella & 11 & 10 & 0 \\
\hline , & 88 & $1: 100$ & 6 & 0.002 & & & & 0.2 & 5294 & 5242 & Spiral. Oscillarie & 1) & 0 & in \\
\hline$"$ & & & & & & & & & 298011 & 288196 & Tintinnus borealis & 0 & . 11 & II \\
\hline , & , & , & 7 & 0.000 & & & & & 164012 & 158604 & -.. ventricosus & "1) & i 11 & 0 \\
\hline$"$ & $"$ & $"$ & 1 & 0.002 & & & & 0.2 & 85135 & 82354 & Spiroggra & $\because$ & $1 !$ & $\because$ \\
\hline " & ", & ", & 8 & 0.002 & $1-8$ & 500 & 76923 & 0 & 71732 & 67649 & Coccus 5 (Gleocystis) & $\because$ & ? & $?$ \\
\hline$n$ & & 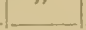 & & & 0.0065 & 0.0005 & & & 14001 & 13539 & Scenodesmirs & 0 & 10 & 61 \\
\hline$\because$ & 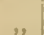 & $\mu$ & 9 & 0.00 & $1-9$ & 500 & 58824 & 0.0 & 6000 & 5803 & Goniaulax & $u$ & 111 & 0 \\
\hline$"$ & 3 & $n$ & & & ก., $x$ is: & $\overline{0 . \ldots i}$ & & & 6019 & 5824 & Ceratium tripos & 0 & 10 & $y$ \\
\hline$\because$ &, & $|10: 100|$ & 10 & 0.02 & & & & $0 .$. & 602 & 582 & _, fusus & 6 & 1) & 11 \\
\hline$" n$ & $n$ & & 10 & 0.02 & & & & 0.2 & 21048 & 21) 384 & Anuraea aculeata & 4 & a. & (1) \\
\hline. &., & , & 111 & 10.02 & & & & $0 . n$ & 74626 & 72218 & _. quadiritientata & u & 0 & ${ }^{11}$ \\
\hline 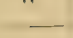 & , & $"$ & & & & & & & 6019 & 5824 & "foliacea & 11 & 11 & 11 \\
\hline ", & ", & ," & 12 & 0.02 & & & & $0 . .$. & 81257 & 77624 & Rädertier 1 & u & 는 & is \\
\hline$n$ & 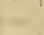 & & & & & & & & 331895 & 320320 & , 2 & 0 & $\bar{u}$ & 0 \\
\hline , &., & ,. & 13 & 0.02 & $1-13 \mid$ & inis & 5650 & 0.0 & 329 & 318 & 1, 3 (durchsicht.) & 0 & II & 1) \\
\hline & & & & & $0 ., \ldots=$ & $n_{-a n s}$ & & 3 & 281403 & 256738 & .. $\mathrm{Li}_{\mathrm{i}}$ & $?$ & $\because$ & $?$ \\
\hline . & .. & ., & 11 & v..... & $6-14$ & $3+11$ & 4029 & $0 \ldots$ & $7 t 94$ & 71.35 & Sida cryst. & 0 & u & 11 \\
\hline & & . & & & $0.1 \mathrm{~m}$ & $0.10 \mathrm{~s}$ & & & $3 \times 94$ & 20993 & Daphnia longisp. & 0 & 11 & 11 \\
\hline ., & ,. & , & 15 & 0. & & & & 19. $=$ & $111 \pm 39$ & 89403 & Hyalod. Kahlb. & 0 & 11 & 0 \\
\hline 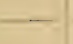 & 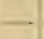 & 等 & - & & & & & & 41117 & 39767 & Bosmina rot. & 0 & 11 & a \\
\hline , & ", & ,", & 1i) & 0. .5 & & & & 11.5 & 127165 & 122148 & Chydorus sphaer. & 0 & 11 & (3) \\
\hline & & & & & & itut & & - & 384 & 371 & Leptodora & $\underline{-1}$ & "1 & $u$ \\
\hline ., & , & , & 17 & 0.05 & 1.18 & stili & 1931. & $10 . ;$ & 72133 & 69748 & Copepoden & 0 & 11. & 0 \\
\hline & - & & & & & $11 \cdot \ldots 2=5$ & & & 81382 & 78652 & -Larven & 0 & 11 & 3 \\
\hline , & ic & , & is & v.1 & & & & 1 & 245 & 240 & Milben & 0 & 11 & 11 \\
\hline ,. & & & & & & & & & 4213 & $40: 7$ & Muschellarwen & 0 & 0 & 11 \\
\hline & $\cdots$ & .. & Li & 0.1 & & & & 1 & & & & & & \\
\hline , & " & ", & 20 & 0.1 & $\begin{array}{l}1-2.11 \\
11 . \cdots .\end{array}$ & $\frac{5+14}{0 . \cdots-5}$ & $49 \div \ldots$ & 1 & & & & & & \\
\hline .. & . & 3t): $110 \mathrm{n}$ & 21 & 10. & $\begin{array}{l}1-21 \\
11 . . .6\end{array}$ & $\frac{x+1}{11 . \ldots .}$ & $\therefore 23.1$ & 1 & & & & & & \\
\hline .. & 44 & , & $\therefore 2$ & $11 .: 2$ & $\begin{array}{l}1 \ldots 21 \\
1 . \ldots\end{array}$ & $\frac{\therefore e n}{1.6 .0}$ & $311 \ldots$ & $2 \cdot 5$ & & & & & & \\
\hline ." & , & ," & $2: 3$ & 1). & \begin{tabular}{|}
$1-2.3$ \\
$2-25$
\end{tabular} & $\frac{\therefore i n}{3 \cdot \sin s}$ & 212 & $2 \cdot 5$ & & & & & & \\
\hline .. & .. & .. & $\therefore$ & 11.78 & & & & $\therefore$. & & & & & & \\
\hline .. & .. & .. & $\therefore i$ & $\because \%$ & $\begin{array}{l}1-2.5 \\
3 .-5\end{array}$ & $\frac{B+m}{\therefore \cdot a n s}$ & 126.6 & $\therefore$ & & & & & & \\
\hline.$\cdot$ &. & $\begin{array}{l}\text { unses: } \\
\text { Alitun: }\end{array}$ & $\therefore$ & $\because \cdot$ & & & & 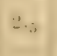 & & & & & & \\
\hline .. & .. & ,. & $\because$ & 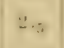 & & & & 2. & & & & & & \\
\hline ." & " & . & $\therefore$ & $\therefore$ & $\begin{array}{l}1-2 . \\
11 .\end{array}$ & $\begin{array}{l}\text { Sin日 } \\
11 .\end{array}$ & $41 .+1$ & 2.5 & & & & & & \\
\hline.$\cdot$ & $\because$ &.$\cdot$ & $\therefore$ & $\therefore$ & & & & $\therefore$ & & & & & & \\
\hline ". & " & ". & ." & $\therefore 3$ & & & & 2. & & & & & & \\
\hline ." & . & ". & : : & $\therefore$ & $\begin{array}{l}\mid 1-31 \\
1+.\end{array}$ & $\begin{array}{c}500 \\
1=.\end{array}$ & 26.4 & $\therefore$ & & & & & & \\
\hline
\end{tabular}




\section{Litteratur.}

1) Asper und Heuscher, Neue Zusammensetzung der pelagischen Organismen in: Zool. Anzeiger x 886, Bd. 9, S. 448.

2) Brandt, Über die biologischen Untersuchungen der PlankitonExpedition in: Verhandl. der Gesellschaft für Erclkunde zu Berlin I 889 , Heft Io.

3) Brandt, Häckels Ansichten über die I'lankton-Expedition in: Schriften des Naturwissenschaftl. Vereins f. Schleswig-Holstein, Bd. VIII, Heft 2. Kommissionsverlag von Homann in Kiel.

4) Claus, Anatomie und Entwickelung der Copepoden in: Arch. f. Naturgeschichte I 858 , Bd. I.

5) Forel, Faunistische Studien in den Süsswasserseen der schweiz. Zeitschrift für wissenschaftliche Zoologie $1875, \mathrm{Bd} .30$ Suppl.

(1) Häckel, l'lanktum-Studien. Vergleichende Untersuchungen über die Bedeutung und Zusammensctzung der pelagischen Fauna und Flora. Jena I 890. 
7) Heincke, Die Untersuchungen von Hensen über die Produktion des Meeres an belebter Substanz in: Mitteilungen der Sektion für Küsten- und Hochseefischerei, No. 3-5, März bis Nai 1889 .

8) Hensen, Über das Vorkommen und die Menge der Eier einiger Ostseefische, insbesondere der Scholle, des Flunder und des Dorsch in: 4. Bericht der Kommission zur wissenschaftlichen Untersuchung der deutschen Meere zu Kiel für 1877-8I. Berlin I 884.

9) Hensen, Über die Bestimmung des Planktons oder des im Meere treibenden Materials an Pflanzen und Tieren in: 5. Bericht der Kommission zur wissenschaftlichen Untersuchung der deutschen Meere zu Kiel I887, S. I-Io6.

(Oben kurz als „Planktonwerk" zitiert.)

Io) Hensen, Einige Ergebnisse der Plankton-Expedition der Humboldt-Stiftung in: Sitzungsberichte der Küniglich Preussischen Akademie der Wissenschaften zu Berlin.

Sitzung d. physikal.-mathemat. Klasse vom I3. MIärz I89o.

I I) Hensen, Das Plankton der östlichen Ostsee und des Stettiner Haffs in: 6. Bericht der Kommission zur wissenschaftlichen Untersuchung der deutschen Meere in Kiel I890.

I ra) Hensen, Die Plankton-Expedition und Häckels Darwinismus. Kiel, Lipsius und Tischer I89I.

I 2) Nordquist, Über die pelagische und Tiefsee-Fauna finnischer Seen in: Zoolog. Anzeiger I887, Bd. ro, S. 339 und 358 .

I3) Seligo, Hydrobiologische Untersuchungen in: Schriften der Naturforschenden Gesellschaft zu Danzig, N. F., Bd. VII, Heft 3. I 890. 
294 Uber die quantitative Bestimmung des Plankton im Süsswasser.

I4) Vosseler, Die freilebenden Copepoden Württembergs. Stuttgart I 886 .

I5) Zacharias, Fauna des süssen und salzigen Sees bei Halle a. d. S. in: Zeitschrift für wissenschaftliche Zoologie I 888 , Bd. 46.

11) Zacharias, Zur Kenntnis der pelagischen und litturalen Fauna norddeutscher Seen in: Zeitschrift für wissenschaftliche Zoologie I 887 , Bd. 45, S. 255. 


\section{Die Fauna des Süsswassers \\ in ihren Beziehungen zu der des Meeres.}

Von Dr. Otto Zacharias in Plön (Holstein). 

Unter den vielen bemerkenswerten Thatsachen, welche die in neuerer Zeit mit so grossem Eifer betriebene Erforschung der Binnenseen zu Tage gefördert hat, ist das unzweifelhafte Vorkommen mariner Tiere in süssen Wasser eine der interessantesten. Besonders waren es italienische Seen, in denen man zuerst jene überraschende Entdeckung machte. So beherbergt z. B. der weitab vom Meere gelegene Gardasee drei Fischspezies, welche marinen Gattungen angehören: I) einen heringsartigen Fisch (Alosa finta), zu dessen nächsten Verwandten die sog. "Maifische" zählen; 2) eine Meergrundel (Gobius) und 3) einen Schlcimfisch (IBlcunius anlgaris). Ausserdem kommt in demselben Wasserbecken ein Krebs (Palacmonetes) vor, von dem der bekannte Berliner Zoologe E. v. Martens sagt: „Er steht unserer Ostseegarneele (Palacmon squilla) nahe, unterscheidet sich aber von ihr durch geringere Grösse und durch die Gestalt des Schnabels". Auch in den Kraterseen von Albano und Nemi kommt dieser kleine Krebs zugleich mit der schon erwähnten Blcminis-Art vor.

Unter den schweizerischen Seen ist es der von Genf (Lac Léman), welcher in den Muschellirebschen Acanthopus resistans ( (1theridea lacustris Sars) und Acanthopus clongatus) Limnicythere relicta Lillj.) zwei Tierformen enthält, die der marinen Gruppe der Cytheriden sehr nahe verwandt sind und deren Anwesenheit im Süsswasser uns daher überrascht. 
298 Dic Fauna des Süsswassers in ihren Beziehungen zu der des Mecres.

Die skandinavisch-finnischen Seebecken besitzen ebenfalls in ihrer Fauna eine Anzahl von Krustern (Mysis relicta, Pontoporeia affinis, Idotea entomon u. s. w.), welche Vertreter von im Neere lebenden Gattungen sind.

Ganz ähnliche Thatsachen liegen für die grossen kanadischen Seen in Nordamerika vor. Wir begegnen dort den nämlichen Krebsen wie in Skandinavien und ausserdem noch zwei Fischen (Triglops-Arten), welche weit mehr die Charaktere von Meeresals diejenigen von Süsswasserfischen besitzen.

Diese Befunde, welche sich aus anderen Seengebieten leicht vermehren liessen, haben in der Folge dazu geführt, die Theorie der sogenannten "Reliktenseen" aufzustellen. Darunter versteht man solche Seen, welche für die Reste einer ehemaligen Meeresbedeckung angesprochen werden. Man fühlte sich befugt, diesen Ursprung hauptsäichlich denjenigen Wasserbecken beizumessen, in denen man die oben angeführten Krustaceen und Fische (bezw. andere zu marinen Gattungen gehörige Tiere) vorgefunden hatte. Ausser Stande oder nicht daran gewöhnt, das Vorhandensein solcher Fremdlinge auf eine andere Weise zu erklïren, als dadurch, dass dieselben Überbleilsel (Relikte) ciner vormaligen, an (Ort und Stclle heimisch gewesenen Meeresfauna seien, zog man hieraus den weiteren Schluss, dass in einer nicht sehr weit zurückliegenden Periode der Erdgeschichte eine mehrmalige Andersverteilung von Land und Vasser stattgefunden haben müsse, wobei Einsenkungen der Festländer mit Meerwasser angefüllt oder Fjorde direkt vom Meere abgesperrt worden wären, so class in den so entstandenen Seebecken gewisse marine Spezies zurückblieben, und dem durch Regengüsse sich immer mehr aussüssenden Wasser allmählich angepasst wurden.

Diese Ansicht war sehr lange Zeit in Geltung, und zum Teil ist sie es auch noch heute. Aber bei näherer Prüfung dieses "faunistischen Arguments" für den marinen Ursprung einer Anzahl von Binnenseen zeigt eg sich, dass dasselbe weder vor der geologischen noch vor der zoologischen Kritik Stand hält. 
In letzterer Hinsicht hat es sich nämlich herausgestellt, dass es eine grosse Anzahl von Tieren giebt, welche ebenso gut im süssen wie im Brack- oder Salzwasser leben können. Zunäichst ist hierbei an die allbekannten Wanderfische (Lachs, Aal, Scholle u. s. w.) zu erinnern, die sich gleich gut im Meere wie in den Flussläufen aufzuhalten vermögen. Dann bieten aber auch die Mollusken bemerkenswerte Beispiele dafür dar, dass manche Arten einen recht erheblichen Wechsel des Salzgehalts im Wasser vertragen kïmnen. So lebt eine kleine Meerschnecke (Hydrobia uliac) in dem beinahe ganz süssen Wasser der inneren Ostsee; sie ist aber ebenso zahlreich in der Nordsee zu finden. Neritina fluviatilis, eine Bewohnerin grosser Flüsse und Binnenseen, wurde 1887 von Prof. M. Braun auch in der Wismarer Bucht angetroffen. Noch anpassungsfïhiger ist aber die weitverbreitete Wandermuschel (Dreysscna polymorpha). Ursprünglich nur in Südosteuropa, namentlich im kaspischen Meere vorkommend, ist sie durch den Verkehr in den Schiffahrtskanảlen seit $\mathrm{I} 825$ von einem Flusssystem zum anderen (über (Istpreussen) nach Norddeutschland eingewandert, und hat sich von da flussaufwärts verbreitet, so dass sie nunmehr in der Saale bei Halle, im Neckar bei Heilbronn und im Rhein bei Basel angetroffen wird. Diese Verschleppung geschieht sehr leicht, weil sich die Muschel mittels ihrer Byssusfäden (vergl. diesen Band S. I26 u. I30) an Flosse und Lastkähne anheftet und auf solche Art als blinder Passagier weite und bequeme Reisen machen kann. Sie vermag im Brackwasser ebenso gut auszudauern wie in rein süssen Gewässern.

Was die Krebstiere anlangt, so sind dieselben der Mehrzahl nach allerdings streng in Süss- und Salzwasserbewohner geschieden, aber es giebt unter letzteren auch Formen, wie z. B. Mysis vulgaris, die in fast vollkommen süssem Wasser zu existieren vermögen. Auf der Westerplatte bei Danzig fand ich diese eigentlich dem Meere angehörige Art in einem nur Spuren von Salz enthaltenden Tümpel.

Parasitische Kruster, welche auf Aalen, Lachsen und Stören schmarotzen, sind gegen den Wechsel von Meer- und Flusswasser 
ganz unempfindlich. Fon den spaltfüssigen Krebsen wergl. Band I clieses Werkes $\therefore$. 34,1) soll Diaplomus castor, der in kleinen Lachen und Teichen des Binnenlandes lebt, auch an der Ostseeküste vorkommen.

Von den Hohltieren (Cölenteraten) vermag der See-Keulentrïger (Cordylophora lacustris) ebenso gut im Brackwasser wie im gewöhnlichen Flusswasser sein Leben zu fristen. Unser kleiner Süsswasserpoly]) (Hydra) stirbt dagegen sehr bald, auch wenn (r nur in ganz schwaches Salzwasser gebracht wird.

Medusen als Süsswasserbewohner waren bis in die neueste Zeit herein gänzlich unbekannt. Da entdeckte Dr. J. Kennel in vollkommen ausgesüssten Strandscen auf der Insel Trinidad (I 882) eine winzige Spezies dieser echten Meerestiere. Mit Recht hebt anlässlich dieses wichtigen Fundes der genannte Forscher hervor, dass dem Vorkommen einer (Qualle im Süsswasser gregenül)er nicht einzusehen sei, weshalb irgend einem anderen Meeresbewohner die Möglichkeit eines Wechsels seines Lebenselements, bezw. der Übergang aus dem Salzwasser in das Süsswasser verschlossen sein sollte.

Die plötzliche Versetzung von Meerestieren in gewöhnliches Brunnen- oder Flusswasser erweist sich nach den bisherigen Èfahrungen für die meisten als todbringend. Nicht so aber - wie die Experimente des Franzosen Beudant zeigen - eine allmählich vorgenommene Verdünumg des. Meerwassers mit gewöhnlichem Wasser. Auf die letztere Weise gelang es, zahlreiche Arten von marinen Weichtieren an fast vollständig ausgesüsstes Seewasser zu gewöhnen. Allerdings wird die Beweisliraft dieser Versuche daturh

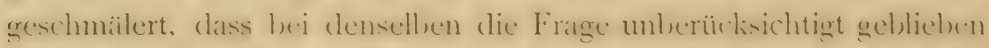
ist, ob die betreffenden MLollusken, welche für sich selbst den Aussüssungsprozess gut überstanden, nun auch fühig gewesen wären, sich in dem neuen Medium fortzuptlanzen. Von der Auster wissen wir z. B., dass dieselbe in erwachsenen Individuen, ohne Schaden zu erleiden, einen Aufenthalt in süssen Wasser vertright. Aber trotzdem wollen keine Austembainke in der salzarmen Ostsee fortliommen, woraus zu schliessen sein dürfte, dass es die junge Brut 
ist, die einen stärkeren Salzgehalt zu ihrem Gedeihen nötig hat, als er in jenem grossen Binnenmeere zu finden ist.

Dem gegenüber kann nun freilich der Umstand angeführt werden, dass wir auf Grund genlogischer Erwägungen die heutigen Süsswassermollusken von marinen Voreltern herleiten müssen, welche nach dem Auftauchen der Kontinente aus dem Urmeere in die Flusslïufe einwanderten und hier sich veränderten Lebensbedingungen anbequemten. Eine andere Entstehungsweise für die gegenwärtigen Bewohner unserer süssen Gewässer vermögen wir überhaupt nicht anzunehmen, und eben darum müssen auch die Mollusken unserer binnenländischen Wasserwelt als die Nachkommen von Schnecken und Muscheln des Meeres betrachtet werden.

Ein Beispiel dafür, wie dies einstmals vor sich gegangen sein mag, haben wir an den Verhältnissen, welche der Ortoire-Fluss im Süden der Insel Trinidad noch heute darbietet. Hier wird, nach Kennels Beobachtungen 1), die Einwanderung von Meerestieren durch die Thatsache begünstigt, dass die schwache Strümung täglich zwei Mal durch die Flutwelle zum Stehen gebracht wird, und dass dann der Übergang aus dem Meerwasser in das brackische und süsse ein ausserordentlich allmählicher ist. In bedeutender Hühe des Flusslaufes ( 12 engl, MIeilen von dessen Mündung entfernt) und weit oberhalb der Grenze des Brackwassers fand Kennel förmliche Anhäufungen von Tieren, denen man sonst nur im Meere begegnet; so namentlich mächtige Bänke von einer Mriesmuschelart, frei schwimmende marine Borstenwürmer, und einige Spezies von Seekrebsen - also eine unleugbare Meeresfauna im süssen Wasser. Es besteht natürlich nicht der Schatten eines Ziveifels darüber, dass alle jene Tiere zuerst mit der Flut in den Ortoire-Fluss hineingeraten sind, und sich hier — weil sie den allmählichen Wechsel im Salzgehalt auszuhalten vermochten - dauernd angesiedelt haben. In ganz analoger Weise haben wir uns auch die erstmalige Einwanderung von Meeresbewohnern in das süsse Wasser der Flüsse und der damit in Verbindung stehenden Seen geschẹen zu denken. 
Prof. Milnes MIarshall hat unlängst*) geltend gemacht, dass viele das Meer bewohnende wirbellose Tiere schon deshalb unfahig wären in das Süsswasser einzuwandern, weil sie das Ei als sehr kleine, bewimperte Larven verlassen, welche ganz ausser Stande seien, gegen irgend welche Strömung anzukämpfen. Es könnten daher - nach seiner Ansicht - nur solche Formen, welche sich von dem freischwimmenden Larvenzustand emanzipiert haben und welche das $\mathrm{Ei}$ in ansehnlicher Grösse und Stärke verlassen, dem Leben im Süsswasser angepasst werden. Diese Erklärung mag im allgemeinen wohl das Richtige treffen; indessen zeigt uns die neuerdings von E. Korschelt 10) zum Gegenstande einer speziellen Untersuchung gemarhte Entwickelung von Drelssena polimorpha, dass diese ursprünglich marine Muschel das freischwimmende Larvenstadium (Trochophora) beibehalten hat. Dieser Nachweis ist von hohem Interesse. Die Larven sind sehr klein und sic machen beim ersten Anblick den Eindruck von Infusorien. Wenn sich das Mundsegel ( $/$ chtm $)$ in stark wimpernder Bewegung befindet, könnte man sie auch für kleine Rïdertiere halten. Die Schwärmzeit dieser winzigen Wesen beläuft sich auf etwa acht Tage. Korschelt konstatierte, dass sie im Tegeler See bei Berlin ungefähr Ende Juni erscheinen und die oberen Wasserschichten in Nenge bevölkern. Im Grossen Plöner See waren sie nach meiner eigenen Wahrnehmung in diesem Sommer (189I) während der Zeit vom 5. bis Io. Juli ebenfalls massenhaft vorhanden, und zwar durchweg im freien Wasser des ganzen, mächtigen Sees bis zu $2 m$ Tiefe. Prof. F. Blochmann hat auch im Warnowflusse (bei Rostock) Dreyssena-Larven angetroffen, und hiermit wird eine Erklïrung für die schnelle Verbreitung dieser Muschel gegeben. Denn uflenbar kïnnen jene winzigen Wimperlanen innerhall, der achttigigen Schwärmzeit ausserordentlich weit von der Strömung fortgetragen werden. Das erstaunlich üppige Gedeihen der Drel'ssena in manchen Gewässem zeigt übrigens, dass sich die zarten Larven derselben in unseren Flüssen und Binnenseen sehr wohl befinden müssen.

*) „Uber Rekapitulation in der Embryologie." Recle zur Erüffnung der biologischen Sektion in der British Association (Jahresversammlung) zu" Lecds, 1890. 
Handelt es sich um die Erklürung des Vorhandenseins von Tieren marinen Charakters in solchen Seebecken, die heutzutage nicht mehr mit einem Flusssystem zusammenhängen, sondern eine völlig isolierte Lage haben (wie z. B. zahlreiche schwedische und finnische Seen), so hat man sich vor Augen zu halten, dass die hydrographischen Verhälnisse Nord- und Mitteleuropas am Schlusse der Eiszeit ganz andere waren, als sie jetzt sind.

Die Flussläufe weiter Länderstrecken sind gegenwärtig nur schwïchliche Abbilder früher ungleich wasserreicherer und breiterer Stromrinnen. Hindernisse, welche sich heute in Gestalt von Wasserfällen und Stromschnellen der Tiereinwanderung entgegenstellen, waren ehedem überhaupt nicht oder doch nur in geringerem Massstabe vorhanden. Zwischen jetzt getrennten Flusssystemen bestanden Verbindungskanäle; seeartige Erweiterungen der Flüsse existierten in weit grösserer Anzahl als unter den heutigen erdgeschichtlichen Verhältnissen und bildeten Etappen für die Wanderung der im Süsswasser sich ansiedelnden Meeresfauna. In den breit ausgewaschenen Thälem des baltischen Landrückens erkennen wir noch deutlich die alten Verbindungen der jetzt getrennten, ehemals aber $z u$ einem gewaltigen Urstromsystem vereinigten ostdeutschen Flüsse, durch welche die Gewässer der Weichsel, der Oder und der Elbe vereinigt zur Nordsee abflossen.

Es ist ein Verdienst des Greifswalder Professors der Erdkunde Rud. Credner, diese Momente zuerst nachdrücklich betont und zum Gegenstande einer umfangreichen Monographie gemacht zu haben 2), aus welcher der Zoolog die Mahnung schöpfen kann, dass er auf blosse Tierfunde hin nicht berechtigt ist, irgend einen See für den Rest einer vorzeitlichen Meeresbedeckung anzusehen. Nur wenn aus den geologischen Verhältnissen zugleich mit hervorgeht, dass wir es wirklich mit einem abgesperrten Fjord oder einer einstmaligen Meeresbucht zu thun haben, liegt Sicherheit dafür vor, dass wir in der anwesenden marinen Fauna keine späteren Einwanderer, sondern wirklich von der Mecresflut selbst hierher getragene und nach dem Rückzuge des Wassers in loco verbliebene Lebewesen vor uns haben. Ein See, der die vollgültige 
geologische Legitimation für seinen marinen Ursprung aufzuweisen vermag, ist damn ein echter Reliktensee im Gegensatz zu den viclen anderen ebenso bezeichneten Wasseransammlungen, die zu einer marinen Tierwelt nur dadurch gekommen sind, dass an das salzfreie Element bereits gewöhnte Meerbewhner alitiv oder passiv in sie einwanderten.

Mit dem Ausdruck „passive Wanderung“ benennt man die verschiedenen Arten von Verschleppung kleinerer Tiere, welche durch grössere Organismen, die dabei als Transporteure thitig sind, bewirkt wird. So wird z. B. ein asselartiges Krebstier (Idotea cntomon), welches als ein Hauptreprëisentant der Reliktenfauna zahlreicher skandinavischer Seen aufgeführt wird, durch Störe, an die es sich anheftet, in den Flüssen Sibiriens weite Strecken stromaufwärts gebracht. In ähnlicher Weise sind auch Sturmwinde und wandernde Sumpfvögel wirksam, insofern sie kleinere Tiere des Neeres oder deren Eier und Jugendformen (mittels Transports durch die Luft) dem Süsswasser oder zunächst salzärmeren und der Aussüssung unterworfenen Gewässern zuführen.

Ich war in hohem Grade verwundert, als ich bei einer im Sommer $188+$ vorgenommenen Durchfurschung der bekannten Ifochseen des Riesengebirges in jeclem dieser beiden isoliert grelegenen Wasserbecken eine Monotus-Art antraf. Hierunter sind Strudelwürmer zu verstehen, die einer im Neere lebenden Gattung angehüren. Überraschender Weise ist dieser Riesengebirgs-Monotus nahe verwandt mit einer im Sunde zahlreich vorkömmlichen Spezies, welche in der Litteratur unter dem Namen Monocelis spinosa Jensen aufgeführt wird. Spảiter entdeckte man die nämliche Spezies, für die ich die Pezeichnung Monotus lacustris in Vorschlag grebracht hatre, auch im Peipus (Russland) und in mehreren schweizerischen Seen ${ }^{4}$ ). Charakteristisch für die Biologie dieses Tierchens ist der Umstand, dass sein Vorkommen auf grosse und kühltemperierte Wasserbecken beschrinkt erscheint. In kleineren Teichen oder Tümpeln, die sich leicht erwärmen, ist es bis jetzt nicht aufgefunden worden. 
Diese Vorliebe des Süsswasser-Monotıs für kalte Seen, und die bereits hervorgehobene Eigentümlichkeit, dass dersclbe mit ciner marinen Spezies des Nordens in nëchster Verwandtschaftsbeychung steht, lassen die Hypothese nicht ungerechtfertigt erscheinen, dass wir es in dem eigentümlichen, kälteliebenden Tiere mit einem überlebenden Bewohner jener zahlreichen Schmelzwasserseen zu thun haben, die sich am Ausgange der Eiszeit bildeten, und die sowohl unter sich als auch mit dem nördlichen Meere durch natürliche Zwischenkanäle in Verbindung standen. In ein derartig zusammenhängendes System von grösseren und kleineren Wasseransammlungen komnte eine anpassungsfahige Turbellarienform des Meeres leicht einwandern und eine'grosse Verbreitung erlangen. Sie vermochte aber andernteils, wenn die einzelnen Seen aus Mangel an Wasserzufuhr verdunsteten, nur an solchen Örtlichkeiten auszudauern, welche annähernd die nämlichen Lebensbedingungen darboten, wie die von den Schmelzwässern der nordischen Eisströme gebildeten Gletscherseen. Auf solche Art erklärt sich auch die merkwürdige sporadische Verbreitung des Monotus lacustris am ungezwungensten, und es ist damit gleichzeitig motiviert, dass ich dieses Tier in einer früheren Publikation als eine fremdartige Erscheinung in unserer Süsswasserfauna bezeichnet habe. Natürlich halte ich diese Erklärung zunächst für hypothetisch, aber sie ist, im Anschluss an die oben mitgeteilten anclerweitigen Thatsachen, für den Augenblick entschieden annehmbar ${ }^{4}$ ).

Ein namhafter italienischer Naturforscher, Prof. Pietro Pavesi in Pavia, tritt mit grossem Eifer auch für den marinen Ursprung der sogenannten "pelagischen" Fauna unserer Landseen ein, insofern er die beiden Hauptvertreter dieser vorwiegend aus kleinen Krebsen bestehenden Tierschwärme (Leptodora und /yytholrephes) für Meene'sformen erklürt, welche die Gewohnheit, im Süsswasser zu leben, angenommen haben. Da sich für Bythotrcphes (Fig. 76 des ersten Bandes) in einem kleinen ozeanischen Krebse (Podon) ein in morphohgischer Bezichung verwandtes Geschüpf nachweisen lisst, und da Leptodora (Fig. 75 in Band I) ihrer Organisation nach völlig. isoliert unter den Süsswasserkrustern dasteht, so mag Pavesis 
306 Die Fauna des Süsswassers in ihren Beziehungen zu der des Meeres.

Ansicht für diese beiden pelagischen Spezies zu Recht bestehen. Weshalb aber die anderen Bewohner des freien Wassers unserer Binnenseen, deren nahe Verwandtschaft mit den Uferspezies sofort in die Augen fällt, gleichfalls mariner Herkunft sein sollen, dies ist schwer ersichtlich. Noch unbegreiflicher aber ist Pavesis Schlussfolgerung, dass diejenigen Seen, in denen sich eine pelagische Fauna lionstatieren lïsst, immer wirkliche Reliktenseen, d. h. Überbleibsel einer vormaligen Meeresbedeckung, sein sollen. Wäre diese Schlussweise zuliissigr, so müsste auch der Bremer Stadtgraben (in welchem Is38 die vielberufene Leptodora lyalina von Dr. Focke entdeckt wurcle) mit zu den echten Reliktenseen gezühlt werden, was wohl Niemand im Emste verlangen wird. Und ebenso hätte man das Recht, manche mit Wasser angefüllte Ziegelei-Ausschachtungen, weil in denselben einige pelagische Rädertierspezies vorkommen, für abgesperte Fjorcle eines vurzeitlichen Oreans \%u halten. Dies wäre aber einfach absurd. Prof. Pavesi lässt aus Liebe zu seiner Theorie der „Fauna relegata“ ganz ausser Acht, dass die kleinen Süsswassertiere (oder deren Eier) durch wandernde Sumpfvögrel leicht von See zu See verschleppt werden, sodass sie, wie durch Imhof erwiesen ist, selbst bis in die hochgelegensten Alpenseen hinauf verbreitet sind. Auf dem Wege solcher passiven Wanderungen - wie man es nennt - werden jene Organismen auch in die zahllosen binnenlïndischen Tümpel und Seen übergeführt, ohne dass letztere zu irgend einer Zeit mit dem Meere in direkter Verbindung gestanden haben.

Positive Beweise dafür, dass Schwimmvögel zur Verbreitung von kleinen Wasserorganismen beitratgen kïmnen, liegen mehrfuh vor. F. A. Forel wurde 1876 durch eine Beobachtung von Alo is II umbert in Genf zu der Überzengung gebracht, dass mindestens die kleinen Kruster auf solche $W$ eise gelegentlich verpflanzt werden. II umbert hatte nimlich Wintereier von Cladoceren (Wasserfö̈hen) dem Gefieder von wilden Enten und Tauchern anhängend gefunden. Diese einzige Wahmehmung warf mit einem Male Licht auf clas smst ratselhafte Vorhandensein von zahlreichen Spezies niederer ()rganismen in vïllig isolierten Wasseransammlungen. In welcher 
Menge solche Wintereier am Schlusse des Sommers vorkümmlich zu sein pflegen, darauf wirft eine Schilderung Licht, die ron Prof. G. Asper und J. Heuscher seinerzeit gegeben worden ist 5 ). „Als wir" - so heisst es in derselben - „am 27. Juli I 886 am oberen Ende des Fählensees (Schweiz) Steine umwenden wollten, um die darunter sich aufhaltenden Tiere zu sammeln, trafen wir den ganzen Ufersium etwa einen halben Meter breit mit einer dunklen Schicht bedeckt. Die ins Wasser eingetauchte Hand wurde beim Herausziehen schwarz durch eine Unzahl kleiner Körperchen, die hartnäckig anhafteten. Es waren die Ephippien (Eiersättel) einer Daphnie, sehr wahrscheinlich solche von D. longispina. Sie waren im Trockenen kaum von der Haut wegzubringen, lösten sich dagegen sehr leicht $\mathrm{ab}$, wenn man die Hand wieder ins Wasser tauchte. Die Kürperchen zeigten keine Adhäsion fürs Wasser, sie blieben trocken wie die. Federn der Schwimmvögel und flottierten an der Oberfläche. Der scharf über den See streichende Wind hatte wohl einen bedeutenden Teil der zerstreuten Eier an das obere Ufer getrieben. Die ungemein weite Verbreitung der genannten Spezies kann uns hiernach nicht in Erstaunen setzen. Denn wie viele Tausende von Eiern bleiben an den Füssen der Rinder hängen, die hier und dann anderwärts zur Tränke gehen; wie leicht kleben sie an der Brust jedes Vogels fest, der ins Wasser geht, oder auch an der Gemse, die hier ihren Durst stillt."

Was die Cyclops - oder Diaptomus-Arten betrifft (vergl. das IX. Kapitel des ersten Bandes), die fast niemals in einer grösseren Wasserlache fehlen, so scheint es, dass dieselben eine nahezu vollständige Austrocknung vertragen künnen. J. Vusseler bemerkt darüber in einer älteren Publikation ${ }^{6}$ ) folgendes: „Mehrere Male waren einige meiner Fundurte trocken gelegt und bis zu einer Tiefe von $I-I^{1 / 2}$ Fuss kein feuchtes Erdreich mehr zu finden. Kaum stand jedoch über dem trockenen Schlamm etwas Wasser, so war dies alsbald wieder von Cyclopiden belebt". Tiere von solcher Lebenszathigkeit werden also sicherlich auch, wenn sie auf das Gefieder eines Vngels geraten, einen weiten Transport durch die Luft auszuhalten vermögen. Übrigens würden die den weiblichen 
Spaltfusskrebsen anhängenden Eier auch dann entwickclungsfihig bleiben, wenn das Muttertier unterwegs zu Grunde gehen sollte.

Neben den Vügeln spielen aber, wie Dr. W. Migula gezeigt hat, auch die Wasserkiifer eine bedeutsame Rolle bei der Verbreitung der kleinen und zum Teil mikroskopischen Süsswasserorganismen. Der Genannte fand nïmlich, dass Eudorina elegans, Pandorina mornm, Scenedesmus obtusus und sonstige Algen durch derartige Käfer verschlept und in andere Wasserbecken verpflanzt werden. Migula fasst das Ergebnis seiner Untersuchungen in follgendem Passus zusammen 7 ): „Da die Wasserkïfer (besonders des Nachts) ihren Aufenthalt häufig wechseln und nachweisbar oft weit entfernte Gewässer aufsuchen, so vermitteln sie gewiss in allen jenen Fällen die Verbreitung der Algen, wo es sich um kleine Lachen und Tümpel handelt, die wohl für Wasserkäfer, aber nicht für Wasservögel von Interesse sind. Das konstante Vorkommen von Algen an den Körperteilen von Wasserkäfern lässt sogar darauf schliessen, dass diesen bei dem Transport von Mitgliedern der niederen Flora eine grössere Rolle zukommt, als den Wasservïgehn oder der strömenden Luft. In Wirklichkeit verhält es sich wahrscheinlich so, dass die Luft kleinste und der Austrocknung widerstehende Fomen verbreitet, Wasservïgel den Transport nach weit entfernten Gegenden vermitteln und Wasserkiffer in ausgedehnter Weise für die Ausbreitung einer Spezies imerhalb enger rïumlicher Grenzen thätig sind“. Dass mit den Algen zugleich auch eingekapselte Protozoen, Eier von kleinen Würmern u. S. w. transporticrt werden kinnen, wird Niemand als etwas Unwahrsheinlides betrachten.

Auf die ebenfalls weit verbreiteten Wassermilben (Hydrachniden) scheint der Modus einer Überführung derselben von einem (iewässer \%um anden überhaupt nicht anwendbar zu sein, weil diese Tiere für das Trockenwerden schr empfindlich sind und alusserhall, des Wassers schnell zu Grunde gehen. Um so dringlicher erhebt sich hicmach die Frage, auf wekhe Weise diese spinnenartigen Wesen in die grossen und kleinen Seebecken hineingelangen, wo wir sie vorfinden. Über diesen Punlt hat uns unlingst der französische 
Naturforscher Th. Barroiss) aufgeklärt. Derselbe entdeckte nämlich, dass es nicht die erwachsenen Individuen, sondern die durch einen dicken Chitinpanzer geschützten Puppen der Wassermilben seien, welche der passiven Wanderung unterworfen werden, insofern sich dieselben an den Leibern verschiedener Wasserwanzen ( $N c p a$, Notonccla) festheften und so von diesen fliegenden Insckten auf weite Entfernungen hin transportiert werden. Barrois zeigte durch das Experiment, dass Wasserwanzen viele Stunden auf dem Trockenen ausdauern künnen, ohne dass die Entwickelungsfähigkeit jener Puppen darunter leidet. Letztere werden also auch dann ungeführdet bleiben, wenn die Wasserwanzen, ihrer Gewohnheit folgend, während der Nacht von einem Teiche zum anderen fliegen. Auf solche Art gelangen nun zahlreiche zum Ausschlüpfen reife Larven von Hydrachniden an weit entfernte Wohnplatze und verbleiben dort für immer, nachdem sie die Puppenhülle gesprengt und verlassen haben. Ihr weiteres Wachstum vollzieht sich in dem einen Gewässer so gut wie in dem anderen, und daher kommt es, dass wir selten in einem Graben oder Tümpel vergeblich nach Hydrachniden suchen.

Andere überall vorkommende Tiere, wie z. B. die kleinen Süsswasser-Oligochäten (Nais, Chactogasler etc.), sind mit zahlreichen Büscheln von Hakenborsten ausgerüstet, und dies führt auf den Gedanken, dass sie durch diese Borsten in der Vornahme passiver Wanderungen stark begünstigt werden. Manche Turbellarien besitzen, wie wir früher sahen, sogenannte „Klebzellen" in der Nähe des hinteren Körperendes, und höchst wahrscheinlich dienen dieselben gelegentlich ebenfalls dazu, ihren Besitzern eine Luftreise zu ermöglichen. Jene Zellen sind einer so energischen Thätigkeit fähig, dass man die betreffenden Strudelwürmer oft eher zerreissen, als von ihrer Befestigungsstelle loslösen kann.

Eine ganz vorzügliche Geeignetheit zur Ausführung passiver Wanderungen müssen wir übrigens auch bei vielen Spezies von Wasserschnecken und Muscheln voraussetzen, denn diese Mollusken sind selbst nuch in manchen Gebirgssecen anzutreffen. 
Fand doch A. Brandt selbst in dem $1904 m$ hohen Goktschai (Armenien) Limnäen, Planorbis carmatus und Pisidien vor. Das Tisudium fossarimum konstatierte A. Wierzejsky in 2 I Seen der Hohen Tatra, und einer Notiz Imhofs zufolge ist die nämliche Muschel sogar noch auf dem Splügen zu finden.

Nach einer wertvollen Beobachtung Darwins scheint hauptsächlich den ganz jungen Schnecken das Vermögen zu weiten Wanderungen beizuwohnen, wie sich aus folgender Stelle des Kiapitels über geographische Verbreitung in der „Entstehung der Arten“ ergiebt. Darwin sagt dort: „Wenn eine Ente sich plötzlich aus einem mit Wasserlinsen bedeckten Teiche erhebt, so bleiben uft einige dieser kleinen Pflanzen auf ihrem Rücken hängen, und es ist mir vorgekommen, dass, wenn ich einige Wasserlinsen aus einem Aquarium ins andere versetzte, ich ganz absichtslos das letztere mit Süsswassermollusken des ersteren berölkerte. Doch ist cin anderer Umstand vielleicht noch wirksamer. Ich hïngte einen Entenfuss in einem Aquarium auf, wo viele Eier von Wasserschnecken auszukriechen im Begriffe waren, und fand, dass bald eine grusse Menge der äusserst kleinen Schnecken an dem Fusse umherkrochen und sich so fest an demselben anklebten, dass sie kaum alogeschabt werden konnten, obwohl sie in einem etwats vorgerü̈liten Alter freiwillig daron abgefallen wären. Diese frisch ausgeschlüpten Mollusken lebten an dem Entenfusse in feuchter Luft 12-20 Stunden lang, und während dieser Zeit kann eine Ente oder ein Reiher mindestens $100-700$ englische Meilen weit fliegen, um sich dann in einem Sumpfe oder Bache niederzulassen".

Im Anschluss an diese Nitteilung berichtet Darwin noch über den mexkwürdigen Fall, wo ein Watsserkiffer (Dytiscus) mit einer ilm anhaftenden Najpschnecke (Ancylus) gefangen wurde. Über andere, nicht weniger interessante Vorkommnisse, welche spezicll die passiven Wanderungen von Muscheh betreffen, berichtet Charles Darwin in einem Aufsatze der "Nature" vom Jahre I882.

Die kosmopolitische Verbreitung vicler Protozoen, hatuptsüchlich diejenige der D)ifflugien und Arcellen (die fast nirgends fenlen, wo etwats Feuchtigkeit vorhanden ist), geschicht vorwiegend durch den 
Wind, wenn er über die Böden ausgetrockneter Tümpel hinfegt. Doch wird es auch vorkommen, dass manche Spezies mit den Schlammklümpchen, die an den Schwimmfüssen wilder Enten u. s. w. hängen bleiben, einen Ortswechsel erfahren. Besondere Anpassungen scheinen bei diesen niederen Organismen sehr selten nachweisbar zu sein.

Doch ist mir gelegentlich eine Difflugria im Riesengebirge zu Gesicht gekommen, welche im Umkreise der weiten Wölbung ihres Gehäuses acht stachelartige Fortsätze besitzt, von denen jeder noch eine gekrümmte Spitze trägt, die sich wie eine winzige Kralle ausnimmt. Jedes Exemplar der von mir in nassen Moospolstern (Sphagnum) gesammelten Difflugien (siehe Band I, Fig. 16) zeigt konstant die geschilderte Eigentümlichkeit, während sie im übrigen fast ganz mit der von Leidy ${ }^{9}$ ) beschriebenen Difflugia corona übereinstimmt. Ich erblicke in der Riesengebirgs-Difflugia cin interessantes Beispiel dafür, dass auch bei Protozoen gelegentlich spezialisierte Haftorgane zur Ausbildung gelangen, die offenbar dazu dienen können, passive Wanderungen zu erleichtern. -

Nach allen vorausgegangenen Ausführungen und Erörterungen bietet also das Auftreten von marinen Tierformen im Süsswasser gar keine Gewähr dafür, dass diese Wesen an Ort und Stelle selbst den Anpassungsprozess von dem einen Medium ans andere vollzogen haben. Vielmehr ist es, wie einige der mitgeteilten Thatsachen zeigen, in den weitaus meisten Fällen als das Wahrscheinlichere $\mathrm{zu}$ betrachten, dass jene Spezies von marinem Habitus durch aktive oder passive Einwanderung in die jetzt von ihnen bewohnten Binnenseen gelangt sind. Nur wenn in überzeugender Weise durch den geologischen Befund erhärtet werden kann, dass die bezüglichen Seen wirkliche (aber im Laufe der Zeit ausgesüsste) Meeresabschnitte sind, kann von der Existenz einer eigentlichen Reliktenfauna in ihnen die Rede sein. Von den mehr als hundert Seen, in denen Tiere von marinem Charakter gefunden worden sind, leisten nur sehr wenige der obigen Bedingung Genüge. Echte Reliktenseen aber sind z. B. zahlreiche Wasserbecken des mittlem und südlichen Schweden. 


\section{Litteratur.}

1) J. v. Kennel, IBolngische und faunistische Notizen aus Trinidar?. Arbeiten aus dem Zool-anatom. Institut in Würzburg, I883.

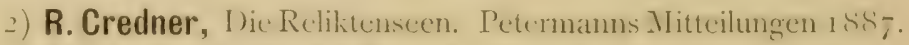

3) Yergl. G. Duplessis-Gouret, Issialy sur lat faune profonde des Lacs de la Suisse, I885.

4) Vergl. Fr. Zschokke, Die Tierwelt der IIochsecen. Verhandl. der Deutschen Zoolog. Gesellschaft auf der I. Jahresversammlung von 1891 .

5) G. Asper uncl J. Heuscher, Zur Naturgesehichte der Alpenseen. Jahresbericht der St. Gallisch. Naturw. Gesellschaft, I 885-86. 1886.

1) J. Vosseler, Thie freilebenden Copepuden W"ürttemberss etc.,

i) Verel. W. Migula, Die Verloreitungsweise der Algen. Biolug. Zentralblatt, 8. Bd., No. I7, I888.

8) Th. Barrois, Note sur la dispersion des Hydrachnides. Revue biologique du Nord de la France. T. I. I888-89.

9) Leidy, Freshwater Rhizopoda of North-America, 1879.

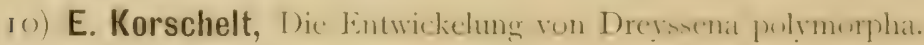
Sitzungsber. der Gesellsch, naturf. Freunde in Berlin, Jahrg. ISoI. 


\section{Über die wissenschaftlichen Aufgaben biologischer Süsswasser-Stationen.}

Von Dr. Otto Zacharias in Plön (Holstein). 



\begin{abstract}
A bekannt sein, dass ich vor einigen Jahren (I888) die Errichtung einer besonderen Anstalt zum Zwecke eingehender Untersuchungen über die Tier- und Pflanzenwelt des Süsswassers angeregt und in ihrer Notwendigkeit begründet habe. Es geschah dies durch einen Aufsatz in No. 269 des "Zoologischen Anzeigers". Seitdem sind drei Jahre verflossen und in der wissenschaftlichen sowohl wie in der Tagespresse ist der betreffende Vorschlag vielfach erörtert worden. Namhafte Zoologen und Botaniker zollten meinem Plane sogleich Beifall und bestärkten mich in meinem Vorhaben; andere, nicht minder ausgezeichnete Forscher nahmen aber das Projekt mit \%urückhaltung auf. Dies ist der gewöhnliche Gang der Dinge, sobald es sich um eine Neuerung handelt. Meistenteils werden in cinem solchen Falle auch noch absprechende Stimmen laut; diese Regel bestätigte sich jedoch meinen Bestrebungen gegenüber nicht. Im Gegenteil gesellte sich zu den beistimmenden Kundgebungen alsbald noch der weitere günstige Umstand, dass wohlhabende Fach- und Privatleute das Projelit in freigebigster Weise durch Geldspenden fürderten. Hierdurch und durch das wahrhaft liberale Entgegenkommen des Bürgermeisters *) und der Stadtgemeinde von Plön ist es mir schliesslich gelungen, meine Plüne zu verwirklichen, und gegenwärtig erhebt sich am Nurdufer des Grossen I'lüner Sees - in
\end{abstract}

*) Joh. kinder. 
316 Über die wissenschaftlichen Aufgaben biologischer Stisswasser-Stationen.

ummittellarster Wassernähe - ein stattliches, villenähnliches Gelüude, wekhes eine hinlängliche Anzahl von Räumlichkeiten umfasst, in denen wissenschaftiche Untersuchungen mit derselben Beyuemlichkeit vorgenummen werden künnen wie in den biolugischen Laboratorien kleinerer Universitaiten.

Von Seiten der Preussischen Staatsregierung wurde dem neubegründeten Institute in der Folge auch eine finanzielle Beihilfe (zuniichst auf fünf Jahre) zu teil, suclass ein recht glücklicher Anfang für das lediglich durch Privat-Initiative ins Werk gesetzte Unternehmen zu verzeichnen gewesen ist.

Der Studien-Aufenthalt in dieser ersten ,Biologischen SüsswasserStation" ist Jedem gestattet, der die zum selbständigen Arbeiten rrforderlichen Vurkenntnisse mitbringt. Insbesondere freilich sind die fünf vorhandenen Arbeitsplätze für Naturfurscher von Fach bestimmt, whlhe am Grossen Plüner See zoologische, pflanzenphysiologische oder auf das Fischereiwesen bezügliche Beobachtungen anstellen wollen. Für alle diese Zwecke sind in der Station die geeigneten Iilfsmittel (Fihrzeuge, Fanggerätschaften, Mikroskope, Reagentien und Aquarien) vorhanden.

Wer davon unterrichtet ist, mit welch interessanten Lebensformen uns die letytjahrigen Durchforschungen unserer heimatlichen Tümpel, Teiche und Seen bekannt gemacht haben, der wird die Nachricht von der Begründung einer Dauerstation zur näheren Intersuchung jener Organismen mit aufrichtiger Genugthuung begrüssen. Die Umgebung von Plön ist in vorzüglicher Weise für diesen \%weck geeignet, insofern das Thal des Schwentine-Flusses, in welehem das freundliche Städtchen gelegen ist, fast lediglich aus ciner Aneinanderreihung von Wasserbecken besteht, von denen die kleinsten so gross sind wie unsere ansehnlichsten mitteldeutschen Seen. Jlier int also ein weites Feld für faunistische und biolugische Forsthungen eröfnet, d. h. lür Studien, welche die Feststellung der verstherdene.n Tier- und P'lanzenorganismen des Süsswassers und dic: limittdung von deren Fixistenzbedingungen zum Ziel haben.

Im Hinblick auf den Reichtum an Lebewesen, welchen das Mecr in seinem Schosse birgt, waren Viele von der Ansicht 


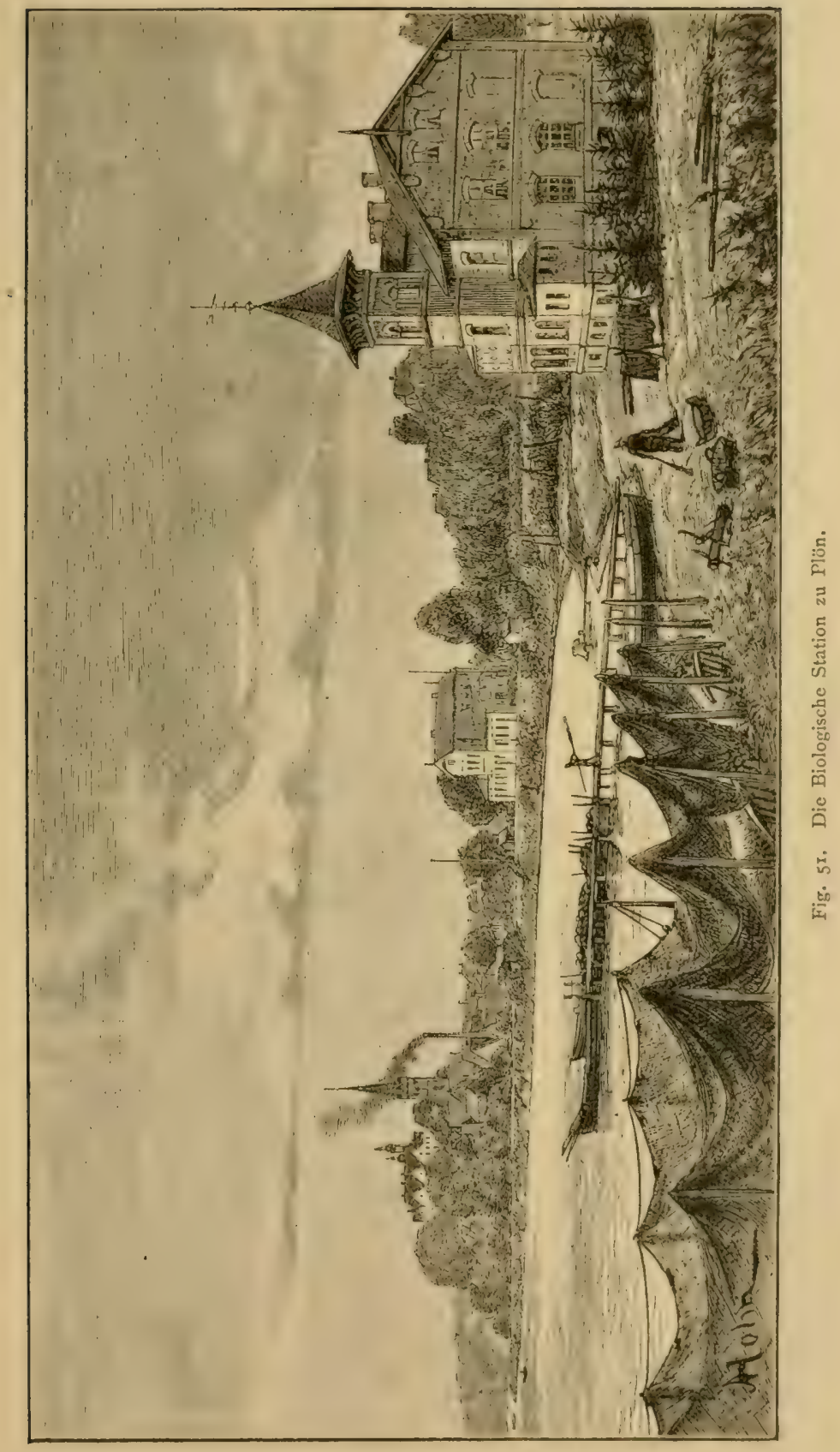


:18 Über die wissenschaftlichen Aufgaben biologischer Süsswasser-Stationen.

beherrscht, dass es sich wohl erst gar nicht verlohne, Zeit und Kraft an die Gewisser des Binnenlandes zu verschwenden. So wurde die Süsswassertierwelt allmählich zum Aschenbrïdel der wissenschaftlichen Zoologie degradiert, und wer sich wirklich noch damit abgab, lief Gefahr, von seinen für das Salzwasser schwärmenden Fachgenossen als ein nicht ganz ebenbürtiges Mitglied der Forschengilde betrachtet zu werden. Glücklicherweise giebt es aber zu jeder Zeit Leute, die den Mut haben, allgemeinen Vorurteilen zu trotzen, und so hat auch die Süsswasserfauna in den jüngstverfossenen zwei Jahrzehnten ihre Freunde und Bearbeiter gefunden. Mämer wie F. A. Forel, G. Asper und E. Imhof in der Schweiz, P. Pavesi in Italien, A. Fritsch, B. Hellich und W. Vavra in Österreich, O. Nordquist in Finnland, Jules Richard und Jules de Guerne in Frankreich (zahlreicher anderer nicht zu gedenken) haben mit bewundernswerter Unermüdlichkeit dem Studium der Wassertierwelt obgelegen und Erfolge erzielt, deren wissenschaftliche Bedeutung von Niemand mehr übersehen oder in Abrede gestelit werden kann. Ich selbst habe während des Zeitraumes von IS8 bis 1889 die Fauna der nord- und mitteldeutschen Seen, sowic diejenige der Eifelmaare durch eingehende Untersuchungen festgestellt. Durch eben diese Forschungen sind wir mit vielen neuen Arten von kleinen Krebstieren (Entomostraken) bekannt geworden, haben den Reichtum unserer Gewässer an schwimmenden und schlammbewohnenden Würmern, an Schnecken, Nuschehn, Moostieren und einzelligen Lebewesen (Protozoen und niederen Algen) kemnen gelent, sind in die bunte Gesellschaft der Wassermilben und IVasserkerbtiere eingedrungen, deren Gewimmel hauptsïchlich die seichtere Uferzone belebt - kurz, wir haben einen umfassenden Überblick über die mannigfaltige Bewohnerschaft unserer binnenlündischen Seebecken erlangt, die bisher nur Fïsche und „Gewürm“ (als deren Nahrung) zu enthalten schienen. Unsere vermehrte Kenntnis erstreckt sich aber nicht nur auf clie einzelnen Gattungen und Arten der äusserlich unscheinbaren Wasserfauna, sondern auch mit auf die Art und Weise, wie jede Spezies ihren besonderen Lebensverhailnissen angepasst ist, wie sie sich emahrt und ihren 
Platz im Kampfe ums Dasein behauptet, was für Nittel ihr zur ritumlichen Ausbreitung verliehen sind und welcher Zusammenhang zwischen der Bevölkerung des Seegrundes und derjenigen der oberflïchlichen Wasserschichten (bezw. der Uferzone) besteht. Aber mit Gewinnung dieser Einsicht sind wieder zahlreiche neue Probleme aufgetaucht, welche sich auf die Ursachen der Veränderlichkeit, die Wirkung der Isolierung, den mutmasslichen Einfluss des ,;iusseren Nediums" u. dergl. beziehen, sodass es niemals an Arbeit für zahlreiche Forscher auf diesem Gebiete fehlen kann.

Der Hauptvorteil eines dicht am Seeufer gelegenen und mit allen Einrichtungen der modernen Forschungstechnik versehenen Stationsgebäudes besteht augenscheinlich darin, dass man auf solche Weise in den Stand gesetzt wird, alle Chancen des Wetters und der Beleuchtungsverhältnisse beim Einsammeln der Untersuchungsobjekte wahrzunehmen, und dass sich einem in beständiger Wassernähe die MIöglichkeit zu zahlreichen Beobachtungen darbietet, welche auf nur gelegentlichen Ausfügen an dieses oder jenes Wasserbecken - aus Mangel an Zeit und Ruhe - überhaupt nicht gemacht werden können.

Ich denke da in erster Linie an die Erforschung der $\mathrm{Zu}$ sammensetzung der sogenannten pelagischen Süsswasserfauna (des Limnoplanktons) in (len verschiedenen Jahreszeiten, und an die sehr wünschenswerte Klarstellung der Beziehungen dieser merkwürdigen Tiergesellschaften zu den übrigen Bewohnern des betreffendes Sees, besonders auch ihr Verhältnis zu den Fischen, von denen einige, wie man glaubt, vorwiegend in ihrer Ernährung auf gewisse pelagisch lebende, $d$. h. beständig im freien Wasser sich aufhaltende Krebstiere angewiesen sind. Im Grossen Plüner See besteht jene Fauna pelagica nach meinen Ermittelungen ( $(*)$ i $\$ 80$ und I89I) aus folgenden Spezies:

\section{Crustacea:}

Leptodora hyalina Lilljeb.

Daphnella brachyura Liév.

Hyalodaphnia cucullata Sars., var. apicata Kurz.

Bosmina coregon Baird. 
Über dic wissenschaftliclien Aufgaben biologischer Süsswasser-Stationen.

Bosmina cormuta Jur.

Cyclops simplex Pogg.

Diaptomus gracilis Sars.

\section{Rotatoria:}

Asplanclina helvetica Imhof

Anuraea longispina Kellic.

Anuraea cochlearis Gosse

Polyarthra platyptera Ehrb.

Dazwischen kommt auch noch in grossen Mengen ein zur Flikgellaten-fialtung Dinobryon gedröriges Wesen (vergl. Fig. $3.5 \mathrm{im}$ ersten Bande dieses Werkes) und das ebenfalls zu den Geisselträgern gehörige Coratium hirundinclla vor. Ein feines Schwebnetz aus Müllergaze, mit dem wir vom Boote aus bloss zehn Minuten lang die oberflächlichen Wasserschichten der Seenmitte abfischen, enthält nach Ablauf dieser kurzen Zeit einen fürmlichen Brei auf seinem Grunde, weleher lediglide aus den soeben namhaft gemarhten Krebs-, Rädertier- und Flagellaten-Spezies besteht.

Die nähere Erforschung der Lebens- und Ernälhrungsweise dieser pelagischen Tiere, welche in staunenswert grosser Individuenzahl unsere Binnenseen bevölkern, wäre - wie schon betont -. eine sicher zu wichtigen Aufschlüssen führende Arbeit, welche von einer biologischen Süsswasserstation in Angriff genommen werden könnte. Frreilich würden zur Bewültigung einer solchen Aufgabe keineswegs nur Wochen und Monate, sondern zweifellos mehrere Jahre erforderlich sein. Was wir bis jetzt über die Biologie jener rastlos schwimmenden Wesen wissen, ist durch die verschiedensten Forscher bei Gelegenheit von Ferienreisen, in Sommerfrischen u.s. w.,

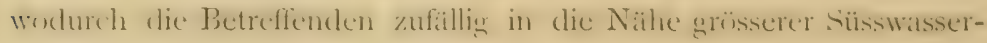
ansammlungen gelangten, festgestellt worden. Hin und wieder (ich erinnere nur an die ausgezeichneten Forschungen Prof. Aug. Weismanns über Daphniden) sind solchen Gelegenheitsstudien die schönsten und weittragendsten Resultate zu verdanken gewesen. Aber eben clarum, weil sich solche Untersuchungen schon öfters als im hohen Grade lohnend erwiesen haben, erscheint es geboten, 
Über die wissenschaftlichen Aufgaben biologischer Süsswasser-Stationen. 321

dieselben fortzusetzen und sie so zu organisieren, dass wertvolle Ergebnisse nicht bluss rum Zufall abhängen, sonclem vichnchr mit einiger Sicherheit erwartet werden können.

Eine andere Frage vom allgemeinsten wissenschaftlichen Interesse wäre die nach der IV interfauna unserer Landseen, d. h. eine Ermittelung derjenigen Tiere, welche während der Kältemonate unter der Eisdecke im Wasser ausdauern und weiter leben, wihrend andere beim Eintritt der niedrigen Temperatur hinsterben, nachdem sie den Fortbestand ihrer Art durch die Produktion und Ablage von Dauer-Eiern (vergl. Bd. I S. 367) gesichert haben. Diss verschiedene Infusoricnspezies, Spaltfusskrehohen und mancherlei Würmer in unseren Teichen während des Winters zu finden sind, weiss man schon seit längerer Zeit; aber auf diese wenigen Thatsachen beschränkt sich gegenwätig unsere Kenntnis, sudass es angezeigt wäre, sich einmal näher darüber zu unterrichten, welche Tiere (bezw: niedere Pflanzen) es clenn sind, deren Lebensfunktionen unter der Einwirkung von Kälte so gut wie gar keine Beeinträchtigung erfahren. Diese Aufgabe liönnte gleichfalls auf das Programm einer nahe am Seeufer befindlichen Station gesetzt werden, und sie wird wohl auch einer solchen reserviert bleiben, da es vollkommen unthunlich ist, derartige Untersuchungen ausserhalb des Bereichs einer den Forscher sowohl wie das von ihm aufgefischte Material vor Frost schützenden Unterkunft vorzunehmen.

Ein reiches und anziehendes Arbeitsgebiet für den in unmittelbarer Seenähe stationierten Zoologen würde selbstredend auch die Beobachtung der Wasserinsekten und der Larvenzustände von solchen Landkerbtieren sein, welche ihre Eier ins Wasser ablegen. Es ist nicht zu bezweifeln, dass Studien dieser Art, wenn sie auf eine grössere Anzahl verschiedener Objekte ausgedehnt werden, interessante Aufschlïsse in allgemein biologischer Hinsicht zu liefem im stande sind. Ich erinnere hier nur an die schöne Untersuchung, welche Dr. E. Schmidt-Schwedt unlängst (1887) über Atmung der Larven und Puppen cłes Schilfkäfers (Donacia crassipes) veröffentlicht hat 1), und an die auf den Gehïusebau der. Phryganiden-Larven (vergl. diesen Band S. 94 und ff.) 
\$2:2 C̈her die wissenschaftichen Aufrahen biologincher Süsswasser-Stationen.

bezüglichen Bewbachtungen der bekannten Naturforscherin Fräul. Marie v. Chauvin.

Ein nicht minder grosses Interesse würde die Erforschung jener eigentümlichen Fortpflanzungsterhïltnisse darbicten, welche bei cinigen unserer verbreitetsten Süsswasserturbellarien /Stenostoma leucops, Microstoma lineare) abwechselnd in der Form von geschlechtlicher und ungeschlechtlicher Vermehrung auftreten. Man weiss zwar, dass zu Beginn der kalten Jahreszeit die letztere an die Stelle der ersteren tritt, aber man ist noch sehr wenig darüber informiert, durch welche histologischen Vorgänge es zu einer IIervorbildung männlicher und woiblicher Zeugungsorgane in den bis dahin geschlechtslos gewesenen Würmern kommt, die sich nur auf dem Wege der Querteilung (vergl. Bd. I, S. 259) fortpflanzten. Dasselbe Problem liegt auch in betreff gewisser Anneliden, z. B. beim gemeinen Wasserschlängelchen (Nais) vor, und es wäre im hohen Grade wertvoll, äber den MIodus der geschlechtlichen Diflerenzierung in beiden Würmergruppen genauere Angaben zu erhalten. Dass wir solche noch vermissen, liegt an der Schwierigkeit der Materialbeschaffung. Befindet man sich nicht in näichster Nachbarschaft cines Sees oder grösseren Teiches, so ist es ganz unmöglich, den rechten Mfoment wahrzunehmen, um dic genannten Tiere in den geeigneten Stadien einzusammeln.

In solchen und ähnlichen Fallen hängt der Fortschritt unseres Wissens im wesentlichen nur von der rechtzeitigen und bequemen Erlangung der Beobachtungsobjekte ab. Und das ist der Hauptpunkt, welchen ich bei Motivierung der Notwendigkeit von permanenten statinen für die Frfurschung der Süsswasser-Lebewelt nicht oft genug betonen liann.

Faunistische Exkursionen in irgend einer Seengegend sind ganz gewiss für die Erweiterung unserer Kenntnis der Wasserfauna von Wert; aber wer eine derartige ambulante Forschungsthätigkeit längere Zeit hindurch betrieben hat, wird wissen, dass man dabei cigentlich niemals zur Ruhe kommt. Man schwelgt bei solchen Ausflügen hliufig in einer herzerquickenden Fülle von Material, hat aber unterwegs höchst selten so viel Zeit, um sich der Bearbeitung 
desselben mit der erforderlichen Musse zu widmen. Infolgedessen konserviert man möglichst zahlreiche Objekte und kehrt mit einer grossen MIenge von Glïschen nach Hause zurück. Hier findet nun erst die eingehende Besichtigung der verschieclenen Funde statt, wobei man aber in der Regel die wenig erfreuliche Wahnehmung macht, dass man von der einen Materialsorte viel zu viel, von der anderen aber leider lange nicht genug angesammelt hat. IVäre man an Ort und Stelle in der Lage gewesen, umfassendere Studien vorzunehmen, so würde bei demselben Zeit- und Kraftaufwande ein belangreicheres Resultat zu verzeichnen gewesen sein. Auch diese Erfahrung, mit der ich gewiss nicht ganz allein stehe, spricht klar für die Nützlichkeit von Dauerstationen, wenn es sich um das Studium unserer Süsswasserfauna handelt. Dasselbe gilt natürlich auch im Hinblick auf die lakustrische Pflanzenwelt.

Dass indessen auch faunistische Exkursionen, wenn sie mit Eifer und Gründlichkeit ausgeführt werden, nach verschiedenen Richtungen hin Neues zutagefördern können, dafür legt eine unlängst publizierte Arbeit von Prof. MI. Braun („Die Turbellarien Livlands", I885) beredtes Zeugnis ab. Ebenso liefert die bekannte Abhandlung Dr. K. Ecksteins über die Rädertiere der Ungebung ron Giessen eine schlagende Bestätigung für die beherzigenswerte Nahnung: "Sieh, das Gute liegt so nah'..." Auch durch meine cigenen Arbeiten über die niedere Fauna einheimischer Seebecken und Teiche hoffe ich den Beweis erbracht zu haben, dass in unseren süssen Gewässern noch mancherlei Neues zu entdecken ist. Ich brauche in diesem Bezug nur an die schon erwähnte Auffindung einer den Monotiden nahestehenden Turbellarie in den Hochseen des Riesengebirges zu erinnern, deren Anwesenheit später in verschiedenen schweizerischen Seen und neuerdings (1890) durch Prof. Fr. Zschokke auch im See von Partnun (auf der Rhätikonbergkette) nachgewiesen wurde. Von nicht geringerem Interesse war die Entdeckung mehrerer Vertreter der ausserordentlich merkwürdigen Turbellarien-Gattung Bothrioplana, welche sich ebenfalls als Folge der von mir unternommenen Ausflüge an die Riesengebirgsteiche ergab. Hierzu liommt noch die 
$32 \pm$ Üher die wissenschaftlichen $\Lambda$ ufgaben biologischer Süsswasser-Stationen.

Erbeutung mehrerer neuer Kruster- und Hydrachniden-Arten in den nord- und mitteldeutschen Wasserbecken bei Gelegenheit meiner Studienreisen in den Jahren I885 und r880. Besonders weise ich aber auch auf den von Dr. W. Weltner erst kürzlich konstatierten und bisher gar nicht vermuteten Reichtum der Spree an Spongillen (vergl. Bd. I, 6. Kapitel) hin und auf die umfassenden Ermittelungen W. Vavras über die Verbreitung der Ostracoden (Muschellirebse) in Böhmen 2).

Solche Exkursionen werden auch fernerhin nicht zu entbehren scin, namentlich wenn es sich um vergleichende Untersuchungen über die Fauna verschiedener Landseen handelt. Für Studien dieser Art kann dann eine permanente biologische Süsswasserstation, welche in einem seenreichen Gebiet gelegen ist, ein recht fruchtbarer Mittelpunkt werden. Man wird won einem solchen Zentrum aus vielleicht auch die Frage nach den äusseren physikalischen Ursachen der Veründerlichkeit mancher Organismengruppen in Angriff nehmen künnen, und möglicherweise mit der Zeit nachzuweisen im stande sein, warum der eine See in dieser, der andere in jener Weise auf die Gestalt der in ihm lebenden Wesen abandernd einwirkt. Augenblicklich wissen wir über die Falitoren, welche hier in Betracht kommen, so gut wie nichts. Und doch ist der Einfluss der jedesmaligen Lokalitiit auf manche Organismengruppen mit ausreichender Sicherheit erwiesen. Clessin hat diese Thatsache schon vor einem Jahrzehnt für die Mollusken festgestellt, und er nimmt zur Erkliarung derselben ,die Anpassung an gegebene Verhältnisse" in Anspruch. Es wird nicht überflüssig scin, in den Zusammenhang dieses Kapitels eine Stelle cinzuschalten, die der Leser bereits auf S. I 38 dieses Bandes vorgefunden hat. Sie ist aber besonders dazu geeignet, das, was wir hier besprochen, zu illustrieren. Clessin fasst das Resultat seiner reichen Erfahrung in folgenden Zeilen zusammen: "Wer die Wassermollusken längere Zeit im Freien beobachtet, wird sehr bald zu der Überzeugung L.mmen, dass fast jeder cinzelne Fundort eigenartige, mehr oder weniger ausgeprägte Abweichungen vom Typus der bezüglichen Art crzengt, und dass es geradezu zu den allergrüssten seltenheiten 
gehört, zwei ziemlich übereinstimmende Furmen an verschiedenen Fundorten zu konstatieren. Ja sogar der nämliche Fundort erzeugt bei geänderten Verhältnissen andere Varietïten, und oft genug finden sich verschiedene Formen einer und derselben Art an sich berührenden Stellen desselben Gewässers, wenn die Beschaffenheit des Grundes, die Strümung des Wassers, die Bewachsung u. s. w. sich ändert. So kommen in den grossen Seen der Voralpen Schnecken und Muscheln mit ausgeprägtem Seecharakter und solchc, welche nicht oder kaum von jenen $\mathrm{zu}$ unterscheiden sind, die in Sümpfen leben, neben einander vor, und zwar jenachdem die bezüglichen Wohnplätze bei seichtem Wasser und mangelnder Bewachsung der vollen Wirkung des Wellenschlags ausgesetzt sind, oder die Ufer in sumpfige Stellen übergehen".

J. Vosseler hat auf den gleichen Einfluss der chemischen und physikalischen Unterschiede unserer Gewässer auf den Habitus, die Färbung und Gliedmassengrösse bei spaltfüssigen Krebsen hingewiesen. So existiert z. B. in den Maaren der Eifel ein Copepode, der augenscheinlich dem Cyclops agilis Koch nahesteht, aber kürzere Antennen, schwächer entwickelte Mundteile, lïngere Schwimmbeine und eine sehr gestreckte Schwanzgabel besitzt. Vosseler hat diesen von mir aufgefundenen Krebs nüher untersucht und ihn seines beschränkten Vorkommens wegen Cyclops maarensis genannt. Höchstwahrscheinlich ist diese neue Spezies in den Maaren selbst entstanden und stellt eine interessante Lokalform dar, welche für ihre Bildung den Cyclops agilis als Ausgangsform gehabt hat.

Im Müskendorfer See bei Konitz in Westpreussen fand ich I 886 zahllose Exemplare einer merkwürdigen Varietät der Hyalodaplinia cucullata, deren Kopfteil sichelartig gelrümmt und ventralwärts stark herabgebogen ist. Diese Form (var. nov. procurva Poppe) kommt lediglich in dem genannten See vor ${ }^{3}$ ) und ist anderwirts bis jetzt nicht aufgefunden worden. Manche Abweichungen geringern Grades vom Typus der Art sind für gewisse Fundorte überhaupt charakteristisch. 
32 f; Üher die wiskenwhaftlichen Aufgahen hivlurischer Süsswas-er-Sitationen.

So variiert beispielsweise die bekannte Dinoflagellaten-Spezies Ceratium hirundinella O. Fr. M. von einem See zum andern hinsichtlich der Panzerbreite und der IÏ̈merlänge. Wahrnehmungen hierüber habe ich hauptsächlich bei meiner Durchforschung der westpreussischen Seen gemacht. Um dieselbe Zeit etwa konstatierte I'ruf. G. Asper ähnliche Gestaltungsolifferenzen zwischen den Ceratien des Thalalpsees und denen des Züricher Sees, wovon er in seiner Ahhandlung üluer die Naturgeschichte der Alpenseen berichtet ${ }^{1}$ ).

Das pelagische Rädertier Anuraea longispina, welches eine sehr weite Verbreitung besitzt, variiert nicht bloss hinsichtlich der Mrichtigkeit seiner langen (natlelfürmigen) Panzerfortsïtze, sondem auch in der Form des Körperquerschnittes, der gewöhnlich ein Kreissegment darstellt, häufig aber auch rollkommen dreieckig ist. In Westpreussen zeigten oft sugar benachbarte Seen langdornige Anuräen, die in der angegebenen Weise von einander verschieden waren. Nach Asper ist ein nicht minder verbreitetes Rotatorium, Anuraea aculeata, ebenfalls bedeutender Variation unterworfen, welche sich aber vorzugsweise nur auf die Felderung und Skulptur des Panzers erstreckt. Ähnliche Abweichungen hat Imhof bei Anuraca cochlearis Gosse angetroffen und die weitgehendsten davon mit besonderen Speziesnamen ( $A$. intermedia und $A$. tub $c$ rosa) bezeichnet.

Leptodora hyalina, der pelagische Krebs par excellence, zeigt an seinen verschiedenen Fundorten nicht bloss Verschiedenheiten der Körperlänge, sondern auch solche, welche die Grösse des Anges, die Entwickelung des ersten Paares der Schwimmfüsse und die Geräumigkeit des Brutraumes betreffen. Die gleichen Wahrnehmungen habe ich an Iolyplemus pediculus, eimem Kruster der Uferzone, gemacht, der in klaren und kühlen Bergseen grösser und farbenprächtiger zu werden scheint, als in den seichteren Gewilissern der Ebene.

Nach Anführung dieser Beispiele, welche noch durch Beobachtungen von A. Wierzejski über die Unbestindigkeit der Arteharaktere bei Spongilla lacustris vervollstindigt werden kïmnten i), wird es cinleuchten, dass auch die Süsswasserfauna Stoff zur 
Diskussion des Speziesproblems zu liefern im stande ist. Durch eine vergleichende Untersuchung hestimmter MIitglieder der Wassertierwelt aus verschiedenen Seen dürfte sich im Laufe der Zeit etwas Genaueres über die Richtung der Abweichungen und über deren Betrag bei einzelnen Arten ergeben.

Schliesslich möchte ich aber auch einen ganz praktischen Gesichtspunkt geltend machen, welcher die Errichtung ron ständigen Beobachtungsstationen in der Nähe von grösseren Süsswasserseen wünschenswert erscheinen lässt. Dies ist nämlich unsere noch sehr ungenügende Einsicht in die Ernährungs- und sonstigen Lebensbedingungen der Fische. Auf diesem Felde ist noch sehr viel zu thun, um für die Bewirtschaftung unserer Seen und Teiche rationelle Grundlagen zu schaffen. Ein guter Anfang dazu ist von dem üsterreichischen Fischzüchter Josef Susta in Wittingau gemacht worden durch dessen bekannte Untersuchungen über die Ernährung des Karpfens ${ }^{6}$ ). Aber nicht bloss die Umstände, welche das Gedeihen der Fische begünstigen, sondern auch deren natürliche Feinde und die Ursachen solcher Trrankheiten, welche gelegentlich eine Massensterblichkeit unter denselben hervorrufen - alles dies ist der näheren Erforschung wert und würdig. Aber die zahlreichen Fragen und Probleme, die wir im Vorstehenden als zum Programm der Thätigkeit einer Biologischen Süsswasserstation gehörig bezeichnet haben, sind unmöglich von einem einzigen Forscher zu bewältigen, sondern es müssen sich mehrere zu diesem Zwecke verbünden, und es bedarf hinsichtlich mancher Aufgaben lïngerer Zeiträume (oft vieler Jahre), um sie in befriedigender Weise zu lösen. Hierüber macht man sich in Laienkreisen häufig recht falsche Vorstellungen, und ich nehme deshalb in diesem Werke, welches seiner Tendenz nach für weitere Kreise bestimmt ist, Gelegenheit, allzu sanguinischen Ḣoffnungen vorzubeugen.

Das Plöner Stationsgebäude liegt, wie schon erwähnt, unmittelbar am Grossen Plöner See und die umgebende- Naturszenerie ist so beschaffen, dass ein \%eitungsberichterstatter") davon gesagt hat:

*) Berliner Tageblatt $589 x$ No. 154 . 
328 Über dic wissenschaftlichen Aufgaben biologischer Süsswasser-Stationen.

„Ein König könnte sich keinen herrlicheren Fleck der Ërde auswählen, wenn er, der Welthändel müde, glückliche Tage im Vollgenusse eines grandiosen Landschaftsbildes verleben wollte". Für die hier vorzunehmenden Forschungen ist die "herrliche" Lage selbstverstilndlich ganz gleichgültig, aber der See ist durch seine Grösse ( $50 \mathrm{qkm}=20000$ preussische Morgen) und durch seinen Organismenreichtum besonders dazu geeignet, ein Arbeitsfeld für zunlegische und phlanzenphysiolegische Untersuthungen zu bilden. Ditzu kommt nuch die Nachbarschaft anderer grosser Wasserbecken (Kleiner Plöner See, Trammersee, Behlersee, Dieksee, Kellersee, Grosser und Kleiner Eutiner See, Ukeleisee u. s. w.), sodass hierdurch zugleich die denkbar günstigste Gelegenheit zur Vornahme von faunistischen Ausflügen gegeben ist. Den Vẹrkehr auf den einzelnen Seen vermitteln grosse Segel- und Ruderboote. Der Biologischen Station steht ausserdem noch die Benutzung eines Petrolcum-Schraubenbrotes") zur Verfügung, welches eine ansehnliche Fahrgeschwindigkeit (IO-I $5 \mathrm{~km}$ pro Stunde) besitzt.

Das Stationshaus ist ein zweistöckiges Gebäude, welches ausser den erforderlichen Arbeitsrïumen (Laboratorium, Exyerimentierzimmer und Bibliothek) auch die Wohnung für den Direktor enthailt. Im Erdgeschoss sind die Aquarien untergebracht, welche durch cine Röhrenleitung mit fliessendem Wasser aus dem See gespeist werden können. Der Mikroskopiersaal hat dreiflügelige grosse Fenster und die Arbeitstische sind mit vorzüglichen Instrumenten aus der Optischen Werkstitte von C. Zeiss in Jena ausgerüstet. Bei aller Bescheidenheit ihrer Einrichtung besitzt die Plöner Station, wic man sieht, doch Alles, was zur Ausführung von mikreskepisch-anatemischen und entwickelungegeschichelichen Arbeiten erforderlich ist. Mehr ist nicht versprochen worden und zu einer luxuriösern Ausstattung wären auch die Mittel nicht vorhanden gewesen. Vom I. April I 892 ab werden die Arbeitsplätze in der Biologischen Station zu Plön für süsswasserfreundliche Zoologen und Botaniker ${ }^{7}$ ) benutzbar sein.

*) Daimlers l'atent (geliefert von der lïrma Meyer U. Renumers in Ilamburg). 
Mit Genugthuung übermittele ich am Schlusse dieses Kapitels dem Leserkreise unseres Buches die Nachricht, dass der beliamnte und verdienstvolle österreichische Zoolog, Prof. Anton Fritsch in Prag, neuerdings gleichfalls eine stabile Station für Erforschung der Süsswasserfauna ins Leben gerufen hat. Dieselbe hat ihren Stand am Unterpocernitzer Teiche bei Bechovic in Böhmen. Es ist ein festgebautes, hübsches Häuschen, welches ausser einem Arbeitszimmer von I2 $q m$ Fläche noch einen kleinen Wohnraum von $6 q m$ enthält. Dieses Forscherheim hat ein. Privatmann, Béla Freiherr v. Derschenyi, im Interesse der durch Fritsch so tüchtig geförderten Kenntnis der Wassertierwelt Böhmens auf eigene Kosten erbauen lassen. Überdies benutzt der Prager Forscher (schon seit Juni I888) zu seinen Studien noch eine ortswechselnde Station in Gestalt eines zusammenlegbaren hülzernen Häuschens, welches in $21 / 2$ Stunden aufgestellt und in $11 / 2$ Stunden wieder abgebrochen werden kann 8). Diese ,fliegende Station“ steht jetzt am Gatterschlager Teich bei Neuhaus, und hier ist besonders der Assistent des Prof. Fritsch, Herr W. Vavra, während des verflossenen Jahres thätig gewesen. Unter Anderem wurde in diesem Teiche unlängst ein neuer zu den Cytheriden gehöriger Muschelkrebs entdeckt, der vorläufig den Namen Limnicythere stationis erhalten hat. Es ist der kleinste bisher bekannte Vertreter seiner Gattung.

An die Errichtung solcher eigens dem Studium der Tier- und Pflanzenwelt des Süsswassers gewidmeter Forschungstationen ist merkwürdigerweise erst in allerneuester Zeit gedacht worden, obgleich dieselben Gründe, welche für die Anlage mariner Stationen zum Zwecke biologischer Studien sprechen, sich auch für lakustrische Observatorien ins Feld führen lassen. Das Weitere wird nun die Erfahrung und der Erfolg lehren. Da, wo etwas Neues ins Werk gesetzt wird, tauchen stets auch einige Pessimisten auf, welche Erwägungen darüber anstellen, ob es sich wohl auch verlohnen werde, die süssen Gewässer in der von Fritsch und mir inaugurierten Weise zu durchforschen. Besonders giebt es unter den Praktikern, d. h. unter den Fisschzüchten und Fischerei-Interessenten, 
330 Über die wissenschaftichen Aufgabon biolugischer Süsswasser-Stationen.

Leute, welche in erster Linie die Frage des "Verlohnens" auf der Zunge haben, ohne manchmal auch nur einen blassen Schimmer von den Aufgaben zu haben, welche durch die Thätigkeit einer Süsswasserstation in Angriff genommen werden sollen. Derartigen Leuten empfehle ich folgenden Ausspruch Prof. Anton Fritschs zur Beherzigung: „Eine genaue Kenntnis dessen, was der Teich in seinem Wasser beherbergt, ist die Grundbedingung für dessen rationelle Bewirtschaftung". Es ist zu hoffen, dass die Richtigkeit dieses Satzes in immer weiteren Kreisen zur Anerkennung gelange, und dass auch von massgebender site das Streben der Naturfurscher gebührende W"ürdigngrg und Unterstützung finde. 


\section{Litteratur.}

I) Berl. Entomolog. Zeitschrift, 3I. Bd., 1887, S. 325-334.

2) Vergl. Wenzel Vávra, Monographic der Ostracoden Bühmens. Archiv d. naturwiss. Landesdurchforschung von Böhmen, 8. Bd., No. 3 .

3) Eine Beschreibung der Müskendorfer Hyalodaphnia hat Poppe geliefert in: $\mathbf{0}$. Zacharias, Zur Kenntnis der pelagischen und littoralen Fauna norddeutscher Seen. Zeitschr. f. wiss. Zoologie, 45. Bd., 2, 1887 .

4) G. Asper und J. Heuscher, Zur Naturgeschichte etc. Jahresber. der St. Gallischen Gesellschaft, I 885-86.

5) A. Wierzejski, Beitrag zur Kenntnis der Süsswasserschwïmme. Verhandl. d. k. k. zool.-botan. Gesellsch. in Wien, 1888.

6) J. Susta, Die Ernährung des Karpfens und seiner Teichgenossen. Mit 2 Tafeln. I888.

7) Vergl. F. Ludwig, Die botanischen Aufgaben der von O. Zacharias geplanten lakustrischen Station. Biolog. Zentralbl., 9. Bd., No. г 3, r889.

8) Anton Fritsch, Die Stationen zur Durchforschung der Süsswasserfauna. Wiener Landwirtschaftl. Zeitung, x89 I. 



\section{Das Tierleben auf Flussinseln und am Ufer der Flüsse und Seen.}

Von Fr. Borcherding in Vegesack. 

$W_{\text {ie im }}$ Wasser selbst, so regt sich auch an den Ufern unserer Flüsse, Weiher und Seen ein mannigfaltiges Tierleben, auf welches am Schlusse dieses Werkes noch ein musternder Blick geworfen werden soll. Auf zahlreichen faunistischen Ausflügen hat der Verfasser dieses Kapitels Gelegenheit gehabt, die bunte Gesellschaft der in der Nähe des Wassers und in demselben sich aufhaltenden Säugetiere, Vöggel, Reptilien, Amphibien, Fische, Mollusken und Insekten zu beobachten und den eigentümlichen Reiz zu empfinden, den das Leben und Treiben dieser verschiedenartigen Wesen auf den Freund der Natur ausübt.

Wie schön und fast nur einer poetisch angehauchten Schilderung zugänglich ist das einsame, waldumgürtete oder von. Schilf umlränzte Ufer eines grossen, breit dahinfliessenden Stromes, oder der ebenso geschmückte Saum eines im Sonnenschein glitzernden Sees. Wie vielseitig, buntfarbig und anregend ist das Bild, welches sich hier an einem herrlichen Frühlingsmorgen oder an einem warmen Sommerabend unseren Augen darbietet. Überall regt sich vielgestaltiges Leben.

Schreiten wir bei einbrechender Dämmerung über eine Flussinsel oder fahren wir mit einem Boote geräuschlos am Ufer entlang, so können wir häufig mehrere Fledermaus-Arten beobachten, und zwar meistenteils die langohrige Fledermaus, Plecolus aurilus Geoffr., die frühflicgende Fledermalus, Vespertilio noctula K. u. Bl., und die Teichfledermaus, I'spertilio dasycneme Boie. 
Unermüdlich schwirren diese fluggewandten Tierchen unter dem Schutze der Dunkelheit durch die Luft, um ihren stets regen Appetit mit den erbeuteten Fliegen, Mücken, Käfen und Nachtfaltem zu befriedigen. Eine glcich erfolgreiche Inscktenvertilgung üben ausser den Fledermäusen wohl nur noch Maulwürfe, Talpa europaea L., und die Wasserspitzmäuse, Crossopus fodiens, aus.

Einzeln erscheint an den Seen und Flüssen auch der Fuchs, Canis vulpes L., um sich nach einem leckern Entenbraten umzuschen. Es ist hüchst anzichend, den Meister Reineke unbeobachtet auf seinen Jagdzügen belauschen zu können. Mlit eingezogenen Beinen, mehr über den Boden und durchs Rohr wegkriechend als gehend, die Rute romehm hinter sich herschleppend, diesclbe nur dann und wann bald etwas rechts, bald etwas links bewegend, schleicht er sich durchs Gras und Gebüsch unvermerkt der Stelle zu, von wo der Entenruf herübertönt, aber immer gegen den Wind, denn er weiss nur zu gut, wie unangenehm den Einten seine Witterung ist.

Das schädlichste Säugetier, welches die Ufer der Flüsse und Seen bewohnt, ist unstreitig der Fischotter, Lutra vulgaris Erxl. Trutz der vielen Nachstellungen von Seiten der Fïscher und Jïger hat dieser arge Räuber sich in den letzten Jahren in unserm Nordwesten ganz bedeutend vermehrt. Die grossen Rohr- und Weidendickichte an den Ufern der Flüsse und Seen und auf den wrösseren und kleineren filussinseln geben ihm soldh sichere Verstecke, dass er sehr leicht dem Jäger entgeht. Zudem ist der Tisch immer reichlich für ihn gedeckt; er braucht deshalb nicht, wie der Fuchs, die Nähe der menschlichen Wohnungen aufzusuchen. Welchen ungeheuren Schaden der Otter der Fischzucht zufügt, mag aus folgendem lieispiel erhellen. Ein ausgewachsener Otter gebraucht zu seiner täglichen Nahrung $2 \mathrm{~kg}$ Fische. Das macht für ein P'irchen olne Jungen in einem Jahre 2 mal 2 mal 365 , also $1460 \mathrm{~kg}$. Ist der Fischotter in sonst fischreichen Flussgebieten hảufig, so sieht man aus den angeführten Zahlen, wie stark damn der Fischbestand durch ihn dezimiert werden muss. 
Ein weiteres auch recht schädliches Mitglied der Familie der Mustelinae, Foctorius putorius K. u. Bl., verirrt sich. zum Glück nur einzeln an unsere Gewässer. Vor einigen Sommern erhielt Verfasser ein prïchtiges Mïnnchen vom Iltis, im Volksmunde „Ilk“", „Elk:" oder „Ülk" genannt, welches auf einer Weserhalbinsel erlegt worden war. Sodann mag noch ein für Deutschland sehr seltener Wasserbewohner enwähnt werden, der Nörz, Wasserwiesel oder auch wohl Sumpfotter genannt, Putorius lutreola K. u. Bl. Dieser wegen seines wertvollen Pelzes eifrig verfolgte Marder ist im üstlichen Europa ziemlich häufig, dagegen gehört er in Deutschland zu den grössten Seltenheiten. Der Nörz bewohnt mit Vorliebe die bewaldeten Ufer der Flüsse, ist aber vereinzelt auch in der Ebene angetroffen worden. $\dot{V}$ or einigen Jahren wurde im Blocklande an der Wumme (unweit Bremen) ein Exemplar erlegt.

Dass aus der Ordnung der Nager nur allzu häufig an den Gewässern die Wanderratte, Mus decumanus Pall., anzutreffen ist, mag ebenfalls nicht unerwaihnt bleiben. Auch die Wasserratte, Arvicola amplibius Lacep., findet sich an den Ufern der kleineren Gewässer nicht selten; in unserm Nordwesten recht häufig in schwarzer Fürbung. $\mathrm{Zu}$ einer wahren Landplage wird in manchen Jahren die gemeine Feldmaus, Arvicola arvalis Pall., welche in den Marschen und an den Deichen oft zu vielen Tausenden erscheint und dort grossen Schaden verursacht. Einige wenige Zahlen mögen ein Bild von ihrem massenhaften Auftreten geben. Im Amte Elsfleth an der Weser wurden im Jahre I880-I88I 34757 I Mäuse eingeliefert und 20284.80 Mark an Prämien dafür bezahlt; im Amte Brake nördlich vón Elsfleth, ebenfalls an der Weser gelegen, wurden I880 I58913 Mäuse eingeliefert und an Prämien I 2237.85 Mark bezahlt; I88 I wurden ebendaselbst 33878 I Mäuse eingeliefert und I9 I 27.3 I Mark an Prämien dafür bezahlt. 'Als Prämie wurde im. „Oldenburgischen Müuseverbandsbezirke" je nach der Häufigkeit der Mäuse 2, 5, Io oder 20 Pfennige für das Stück bezahlt. In diesem Sommer (I89I) war die Feldmaus nur vereinzelt anzutreffen; der lange und strenge Winter mit dem hohen Wasserstande hat stark unter ihnen aufgeräumt, stärker

Tier- und Pflanzenwelt des Süsswassers. II. 
als in den reichsten Jahren Mïusefïnger, Bussarde, Weihen, Raben und Füchse es vermögen.

Auf den Aussterbeetat ist wohl in unserm Vaterlande der Biber, Castor Fiber L., gesetzt. Nur wenig bekannte Kolonien finden sich in Deutschland, in denen er sich einstweilen, wenn auch nur in geringer Zahl, noch erhalten hat. Die bedeutendste ist zwischen Magdeburg und Wittenberg an der Elbe; auch an der Havel, Oder und Weichsel finden sich noch vereinzelte schwach bewohnte Kolonien. Leider wird diesem seltenen Nager seines kostbaren Pelzes wegen gar zu sehr nachgestellt und trotz des Regierungsschutzes, der ihm in letzter Zeit zu teil geworden ist, wird er in nicht zu ferner Zeit zu denjenigen Tieren Deutschlands gehören, die aufgehört haben zu leben, und einzelne Ortschaften, Gründe u. s. w. werden nur noch mit ihrem Namen an das frühere Vorkommen dieses stattlichen Nagers erinnern.

In die Flüsse, besonders die der Nordsee, steigt bei hohen Fluten mit starken Nordweststürmen vereinzelt auch der Seehund, Phoca vitulina $\mathrm{L}$., hinauf und kommt dann den Fischern zuweilen ins Garn. Häufiger findet sich in unseren Flüssen Phocacna commmnis Cuv., der Tümmler oder Braunfisch; denselben kann mạn bei Springfluten oft in der Nähe der Städte beobachten, wie er in kurzen Zwischenräumen sich an die Oberflïche des Wassers begiebt, um im naichsten Augenblicke wieder in die Tiefe zu verschwinden.

Versetzen wir uns in Gedanken um etwa 200 Jahre zurück, so finden wir sogar einen Walfisch im Weser- und Lesumflusse. lis war Hyperoodon rostratus Pontop., welcher damals in der

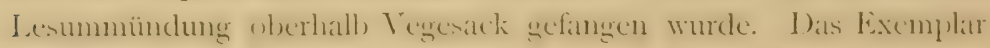
befindet sich im Bremer Museum.

Beendigen wir hiermit unseren Streifzug, auf welchem wir uns ausschliesslich nach den Sáugetieren, die an und in den Gewissern vorkommen, umgesehen haben, so gewahren wir, obwohl wir nicht jeclen Stunger, der sich uns auf unseren Exkursionen am Wasser zeigen künnte, angeführt haben, dass trotzdem die Zahıl der $\Lambda$ rten eine ziemlich geringe bleibt. Ganz anders gestaltet sich 
dagegen das Bild, wenn wir einen neuen Beobachtungsgang unternehmen und uns nun der Vogelfauna der süssen Gewässer zuwenden. Da hat fast jede Jahreszeit ihr eigenartiges Gepräge. Im Frühjahre finden wir ausser den ansïssigen und heimkehrenden Brutvögeln viele durchziehende Wanderer, die für kurze Zeit Rast an den Gewässern und auf den Inseln machen. Im Sommer und Herbste sehen wir ausser den alten Brutvögeln die junge Nachkommenschaft in den verschiedenartigsten Kleidern. Auf dem Herbstzuge kommen noch Hunderte von Gästen hinzu, welche der Vogelwelt (Ornis) eines bestimmten Gebietes oft ein ganz fremdartiges Aussehen verleihen.

Halten wir zunächst eine systematische Umschau unter denjenigen Vögeln, welche an den Ufern der Flüsse und Seen und auf den kleinen und grösseren Flussinseln ihre Wohnungen eingerichtet haben, und fassen wir dann die Gäste, welche sich zur Frühjahrsund Herbstzugszeit an unseren Gewässern bald längere, bald kürzere Zeit aufhalten, etwas näher ins Auge. Als Brutvögel treffen wir aus der Ordnung der Raubvögel zuerst zwei Weihenarten an, Circus aerugmosus Sav, die Rohr- oder Sumpfweihe, und Circus cincraceus Mont., die Wiesenweihe. Beide werden im Volksmunde gewöhnlich "Grashoafl" genannt. Wo dichtes Rohrund Weidengestrüpp auf wenig belebten Flussinseln und auf den einsamen Groden der Flüsse sich findet, da kann man mit ziemlicher Sicherheit den Horst der einen oder anderen Weihe erwarten. Derselbe befindet sich im dichtesten Gestrüpp am Boden und ist nur dann mit Sicherheit aufzufinden, wenn man die Alten, welche an ihrem schwebenden Fluge, den langen, spitzen Flïgeln und dem ziemlich langen Schwanze leicht von den Bussarden, Habichten und Milanen zu unterscheiden sind, beobachtet und sich genau die Stelle merkt, an welcher sie niedergehen. Dieses Ausspionieren muss jedoch mit der grössten Vorsicht geschehen; denn glaubt sich der Beobachter schlau, so ist der Beobachtete doch in vielen Fällen noch gewitzigter und hat ersteren oft viel eher bemerkt, als derselbe ihn. Viel leichter ist der Horst aufzufinden, wenn dic Weihen Junge haben; dann braucht man nur aus möglichster Ferne 
das Männchen, bei welchem man sehr leicht mit einem guten Glase die Beute in den Füngen erkennen kann, zu beobachten. Ist es in der Nühe des Horstes angelangt, so erscheint mit einem lauten, scharfen „kirrr" über der Rohrfliche das Weibchen, aber in bedeutend geringerer Flughühe als ersteres. Ist das Männchen über der Gattin angekommen, so wirft sich letztere geschickt auf den Rücken in dem Augenblicke, in welchem der Gatte die Beute fallen lisst. Mit grosser Sicherheit greift das Weibchen dieselbe auf und eilt raschen Fluges dem Horste zu. Das Männchen streicht sofort von dannen, um neue Beute heranzubringen. Das ist der günstigste Augenblick, um sicher den Nistplatz auszukundschaften, demn wir brauchen uns nur genau den Platz zu merken, an welchem das Weibchen sich niederliisst. Ist das Glück uns in dieser Weise günstig gewesen, so finden wir im hohen Grase oder Rohre auf dem Boden ein ziemlich grosses mit trockenem Grase und Rohr ausgepolstertes Nest, in welchem sich drei bis fünf hungrige, gelbgraue Junge befinden. In dem Horste der Wiesenweihe findet man Mitte Mai etwa vier bis fün weisse, etwas ins bläuliche übergehende Eier. Im Neste der Rohrweihe trifft man zur selben Zeit vier bis fünf grünlich weisse Eier. Befestigt man über dem Neste ein gutes Schlagnetz und entfernt sich dann müglichst weit, um im dichten Rohr eine gute Deckung zu suchen, so dauert es gewöhnlich nicht lange, bis das Weibchen zum Horste zurückkehrt, allerdings zuerst nur, um auszukunden, ob alles wieder in gewohnter Ordnung ist. Doch es lïsst sich noch nicht sogleich nieder, sondern in weitem Bogen umkreist es einige Mal die nähere und weitere Umgebung des Nistplatzes. Bald ist aber die fiurcht vor der Gefahr geschwunden, die Liebe zu den ängstlich kreischenden Jungen ist grösser, es streicht zum Horste, lïsst sich nieder und sitzt gefangen unter dem Schlagnetzc. Schwieriger ist es, des Münnchens habhaft zu werden, da letzteres selten das Füttern besorgt und noch seltener zum Horste geht. In den ersten Stunden nach dem Verlust der Gattin lisst es nur clie Beute aus der Luft ins Nest fallen und eilt wieder fort, um neue Nalırung zu beschaffen; doch endlich ist auch bei ihm die Liebe zu seinen Jungen, 
die ihn durch ihr Geschrei auf ihren Hunger und ihre Einsamkeit aufmerksitm machen, vollständig enwacht; es lässt sich nieder, um dits Ant der Gattin zu übernehmen. Aber dias Netz ist wieder aufgestellt worden, es schlïgt abermals zu und nun sitzt auch der Gatte gefangen bei seinen Jungen. Nicht immer glückt ein solcher Jagdzug, viel Geduld und Vorsicht gehört dazu. - Die Nahrung der Weihen besteht aus jungen Vögeln, welche aus den am Boden befindlichen Nestern geraubt werden, und aus Müusen. Der Nutzen, den sie durch Vertilgung der letzteren gewähren, wird wohl reichlich durch den Schaden, den sie durch Zerstören der jungen Vogelbrut verursachen, aufgehoben. Die Wiesenweihe erscheint im April, die Rohrweihe im März; beide verlassen uns im Oktober.

Von den Eulen treffen wir an unseren Gewässern als Brutvogel dann und wann Otus brachyotus Boie, die Sumpfohreule, im Volksmunde „Moorule" genannt. Häufiger ist sie nur in reichen Mäusejahren zu beobachten. Den Horst findet man, allerdings nicht leicht, auf den alten Weidenköpfen, die sich stellenweise an den Flussläufen finden. Einzeln entdeckt man ihn auch im langen Grase oder im Rohrdickichte. Im Neste finden sich Anfang Naai vier bis sechs fast runde weisse Eier. Die Nahrung dieses nächtlichen Räubers besteht fast ausschliesslich aus Mäusen, und muss die Sumpfohreule daher zu den nützlichen Vëgeln gerechnet werden.

Ein häufiger Bewohner unserer Inseln und Flussufer ist der Kuckuck, Cuculus canorus L. Nach der Meinung der Landleute ist derselbe im Sommer Kuckuck, im Winter "Stothoafl". Die Erklärung dieser irrigen Meinung ist sehr leicht. Im Frühjahre und Sommer findet sich der "Stothoafk", Astur nisis K. u. Bl., nicht in der Nähe der menschlichen Wohnungen, sondern in den dichten Waildern bei seinem Brutplatze. Der Kuckuck liisst dann aber überall seinen Ruf ertönen. Im Herbst, wenn der Kuckuck längst über alle Berge ist, erscheint aber der Sperber in der Nühe der menschlichen Wohnungen. Da etwas Ähnlichkeit im Gefieder der beiden besteht, findet obige Fabel leicht Glauben bei der Landbevölkerung. Als Pflegeeltern seiner Brut wïhlt der Kuckuck 
sich die Rohrsinger, die gelle Bathntelze, ja auch cinzeln dias Blankehlchen. Letztere besorgen die Pflege mit der grössten Gewissenhaftigkeit und oft sogar mit Aufopferung der eigenen Jungen, welke vor diesem gefrässigen Stiefbruder zurückstehen müssen. Verfasser dieses hatte Gelegenheit, in der Marsch cinen vollständig flüggen jungen Kuckuck zu beobachten, der sich durch sein klïgliches "zirrk, zirrk" bemerkbar machte, wie dieser grosse Bursche sich von seinen Pflegeeltern, Budytes flava Cuv., mit grosser Behaglichleit noch füttern liess. Der Kuckuck erscheint Ende April und verweilt bis Anfang September.

Dem hinsichtlich seines Gefieders schünsten und an die Ornis

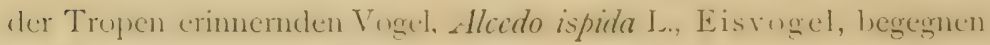
wir häufig an den Flüssen und auf den Inseln, welche steile, lehmige Ufer haben. Regungslos sitzt dieser prächtige Geselle auf einem über die Wasserfläche hinhängenden Zweige, seinen Blick unverwandt nach unten gerichtet; plötzlich stösst er ins Wasser, um im nächsten Augenblicke wieder auf der Oberfl̈̈che mit einem crbeuteten Fische im Schnabel zu erscheinen, welcher in wenigen Sekunden gierig verschlungen wird. Dieses interessante Schauspiel kann man oft in ganz kurzer Zeit mehrmals beobachten. Sein Nest, welches sich immer an den steil aufsteigenden Wänden der Flussufer befindet, ist am Ende einer etwa einen Meter langen Röhre angelegt, und dort findet man auf Fischgräten, wenigen Hülmchen u. dgl. Mitte April sechs bis sieben glänzend weisse Eier.

Einen ähnlichen Brutplatz, wie den des Eisvogels, wählt sich atuch aus der Familie der Schwalben die Uferschwalbe, Sand-, auch Bergschwalbe genannt, Cotyle riparia L. An den schroffen Stellen der Flussufer, an welchen die Geest unmittelbar an das Wasser tritt, kann man zur Frühjahrszeit Hunderte dieser geschickten Insektenjäger aus- und einfliegen sehen. Das Nest befindet sich am Encle einer oft zwei Meter langen, wagerechten Röhre, ist mit Federn weich ausgepolstert und enthält Ende Mai oder Anfang Juni fünf bis sechs schneeweisse Eier. Die Uferschwalbe erscheint Anfang Mai und verlísst uns Anfang oder Mitte September. 
An den Gewässern der gebirgigen Gegenden unseres Vaterlandes finden wir aus der Familie der Wasseramseln den Wasserstaar, auch Wasseramsel oder Wasserschmätzer genannt, Cinclus aquaticus Bechst. Ich hatte zu verschiedenen Malen Gelegenheit, diesen munteren halb Wasser- halb Singvogel in seinem Elemente zu beobachten, so unter anderen an den Berlebecker Quellen, an den Ilsefaillen u. a. m. Bald watet er bis an den Hals durchs Wasser, bald steht er regungslos auf einem erhöhten Steine, um im folgenden Augenblicke ins Wasser zu stürzen; bald läuft er am Boden des Gewässers hurtig dahin, bald fliegt er durch herabstürzende IVasserfälle, wobei ihm sein dichtes Gefieder von grossem Vorteil ist. Das einzige Nest, welches der Verfasser Gelegenheit hatte näher zu betrachten, befand sich hinter einem Wasserfalle in einer kleinen Felshöhle; obwohl auch seitlich dahin zu gelangen war, nahm das kecke Tierchen jedesmal seinen Weg durch die herabströmende Wassermenge. In dem Neste befinden sich im April vier bis fünf weisse Eier.

Der schönste Vogel, welcher unsere Flussufer und Inseln bewohnt, ist unstreitig das Blaukehlchen, Cyanecula suecica Brehm. Wo dichtes Weidengebüsch an unserm Weserufer oder auf den Platen*) vorhanden ist, da findet man auch dieses prächtige Tierchen, jedoch halten sie sich meistens sehr verborgen und laufen zwischen dem dichten Gestrüpp einher, aber ein klares, reines „fied, fied“ oder ein kurzes „täick, täck" verrät bald ihr Vorhandensein. Das Nest dieses schönen Sängers ist immer recht versteckt angelegt und es gehört zu den grössten Seltenheiten, ein solches aufzufinden, da es auf unseren Weserplaten immer im dichtesten Gestrüpp, oft hart am Ufer in Weidenstümpfen sich befindet. Selten fliegt der Vogel vom Neste, um dadurch seinen Brutplatz zu verraten, sondern gewöhnlich springt er unbemerkt auf den Boden und läuft, olme einen Laut von sich zu geben, im Gestrüpp davon. Es ist mir erst zweimal geglückt, ein solches Nest aufzufinden;

*) "Platen" heissen in Norddeutschland dic kleinen nit kohr und Weiden bewachsenen Filussinseln. 
disscllse ist ziemlich kunstroll gebaut und sitzt gewrihnlich in einer kleinen Vertiefung; es besteht aussen meist aus trockenen Grashalmen, innen dagegen vorwiegend aus der Wolle der Salix-Arten. In dem schön gerundeten tiefen Neste liegen gegen Ende April fünf schön grüngraue Eier, welche mit einzelnen zierlichen rothraunen Tüpfelchen und I'ünktehen bedeckt sincl. Dats Blaulichlehen crscheint schon Ende März mit dem IIausntschwänzchen zusammen und verliisst seinen Brutplatz Ende August, streicht aber dann noch bis Ende September umher. In den letzten Tagen des September oder Anfang Oktober verlässt es uns; einzelne Nachzügler dagegen verweilen oft bis Ende Oktober in unserm Gebiete.

Mit dem Blaukehlchen zusammen an fast denselben Lokalitïten treffen wir das Braunkehlchen, Pratincola muctra Koch, und einzeln auch die Braunelle, Accentor modularis Cuv., an. Beide haben mit ihm die versteckte Lebensweise sowie die Art des Nestbaues gemein; beide verlassen auch lauthes ihre Nester und eilen unter dem Gesträuch davon. Nur wenn die Vögel ihre Brut gefährdet sehen, lassen sie ihre Klagetöne hören und verraten allerdings dadurch dem aufmerksamen Beobachter, dass man sich unmittelbar beim Neste befindet, und trotzdem hält es manchmal recht schwer, dasselbe zu entdecken. Verfasser dieses Kapitels, welcher sich am 23. Mai I 89 I unmittelbar bei einem solchen Neste befand, gebrauchte über eine halbe Stunde, um dasselbe endlich in einem dichten Grasbüschel, kaum einen halben' Meter von ihm entfernt, zu gewahren. In dem sauber mit Ticrhaaren ausgepolsterten Neste befanden sich vier grünlich blaue, fein rot punktierte Eier. Das Nest der Braunelle aufzufinden ist mir, trotz eifrigen Suchens, bislang noch nicht gelungen. Das Braunkehlchen erscheint Mitte April und verlässt uns Ende September. Dic Braunelle dagegen kommt oft schon Mitte Mairz und verschwindet erst gegen Mitte Olitober.

Die "Kuckucksamme", Curruca cinerea Lath., ist ebenfalls nicht selten auf den Flussinseln anzutreffen. Die Dorngrasmücke führt den oben genannten Namen daher, weil der Kuckuck sehr gern sein Ei in ihr Nest legt und ihr auch dic Erzichung seines 
Sprösslings äberlitsst. Schon an frühen Morgen mit Simmentufgang lïsst die Dorngrasmücke ihr munteres Lied ertönen, und sic ist einer von denjenigen Vögeln, welche am längsten singen, ja oft vernimmt man noch Anfang August ihren fröhlichen Gesang. Mitte April trifft dieser Vogel bei uns ein und verlisst uns wieder Mitte September.

An den Flussufern und auf den Inseln beobachtet man ziemlich häufig clen Fitis-Laubrogel, Neidenzcisigr, Phyllopneuste trochilus Bp. Sehr bald verrät sich dieses zutrauliche Vögelchen durch sein angenehm klingendes „hüid, hüid, hoid, hoid“. Es lässt sich auch ganz in der Nähe beschauen, aber desto schwieriger ist es, sein Nest aufzufinden. Dasselbe befindet sich am Boden, meist im dichten Gestrüpp oder Gewirr; es ist vollständig überwölbt und man sieht nur ein kleines seitliches Loch. Anfang Mai findet man in demselben fünf bis sieben kleine, weisse, rötlich gefleckte Eier, an deren stumpfen Ende sich die Makeln und Pünktchen dichter als am spitzen Ende gruppieren. Dieser niedliche Sänger verweilt bei uns von Anfang April bis Ende September.

War das Vorkommen der bis jetzt angeführten Sänger an den Flussufern und auf den Inseln kein ausschliessliches - auch ausserhalb dieser Gebiete werden dieselben angetroffen _-, so wollen wir jetzt eine Gruppe kennen lernen, welche ausschliesslich ihre Heimat an den Ufern-der Flüsse, auf den Inseln und Groden haben. (Unter "Groden" versteht man die mit Weiden und anderm Gestrüpp bewachsenen Aussendeichsländereien, welche auch stellenweise Grasflächen haben.) Es ist dies die Gattung der Rohrsïnger. Schon ihr Name sagt uns deutlich genug, wo wir diese Bewohner aufzusuchen haben. Nicht weniger als sechs Arten dieser Gattung bewohnen das in Frage kommende Gebiet unseres Vaterlandes. Ausserdem giebt es davon noch eine Reihe Spezies, welche mehr dem südlichen Europa angehören. Für uns kommen in erster Linic unsere heimatlichen Sänger in Betracht. Es sind folgende: Der Schilfsänger, Calamoherpe phragmitis Bp.; der BinsenRohrsïnger, Calanoherpe aquatica Degland; der Sumpif-Rohr- 
sünger, Calamoherpe palustris Boie; der Heuschrecken-Rohrsïnger, Calamoherpe locustella Penn.; der Teich-Rohrsünger, Calamoherpe arundinacea Boie, und endlich der Drossel-Rohrsïnger, Calamolierpe turdoides Meyer. Erstere werden im Volksmunde gewöhnlich "Reitmeeschen", auch „Rohrsperlinge" genannt; der letztere heisst gewöhnlich die "Rohrdrossel“. Fast alle erscheinen bei uns Anfang Mai und bleiben bis Anfang September. Nicht alle sind gleich häufig anzutreffen; einzelne dagegen, wie die Rohrdrossel, der Schilfsänger, der Sumpf- und Teich-Rohrsänger, sind sogar ziemlich häufig. Sic entziehen sich aber durch ihre versteckte Lebensweise im Röhricht und durch die Lokalitäten, an denen sie leben, sehr oft dem Auge des Beobachters und daher ist manche Spezies vielleicht viel häufiger als an manchen Orten allgemein angenommen wird. Der Drossel-Rohrsänger ist sofort durch seinen weit vernehmbaren Gesang, der etwa: „düi, düi, düi, karre, karre, karre, kei, kei, kei, kerr, kerr, kerr, karra, karra, kied“ klingt, zu erkennen. Der Gesang von Calamoherpe palustris Boie ist dem

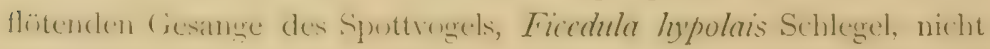
unähnlich und daher ein sicheres Erkennungszeichen des SumpfRohrsingers, da der Spottvogel in den Gebieten, wo die SumpfRohrsänger leben, nicht zu Hause ist. Beim Schilfsünger C. phragmitis Bp., besteht der Gesang fast ausschliesslich aus einem langen, wohllklingenden, flütenartigen Triller. Der Gesang beim T'eich-Rohrsänger, C. arundinacea Boie, gleicht mehr einem Geplapper der sehr rasch hinter einander ausgesprochenen Silben „terr, terr, terr, tri, tri, tri, zerrr, zerrr, zerrr, zä̀ck, zäck, zäck" u. a. m. Eine annühernde Ähnlichkeit hat der Gesang des Binsen-Rohrsäingers, C. aquatica Degland, mit dem des Schilfsüngers; doch kommen in dem melodischen Triller sehr häufig Töne wie ,jüpp, jüpp, jüpp, jüpp, tütt, tütt, tütt, tütt" vor. Den eigentümlichsten Gesang, wohl richtiger Geschwirre genannt, hat der Heuschreckensünger, C. locustella Penn. Mit aufgeblasener Kehle, am Boden zwischen den Rohr- und Weidenstengeln dahinlaufend, bringt er nur einen wie "sirmrrrrirr" klingenden lange anhaltenden Ton hervor. Für einen aufmerksamen Beobachter ist es nicht allzu 
schwer, das Vorkommen der einen oder andern Art nach dem Gesange festzustellen, und um so bequemer, als das Eindringen in die im und am Wasser belegenen Rohrfelder sowie auf die mit Schlick bedeckten Groden, in welchen sich die Rohrsänger ebenfalls gern aufhalten, mit grossen Schwierigkeiten und Anstrengungen verknüpft ist. Auch im Nestbau gleichen sich unsere Rohrsänger mehr oder weniger. Zwischen drei bis vier bei einander stehenden Rohrstengeln an oder über der Wasserfliche, zwischen Nesselpflinze'n oder zarten Weidenruten, zwischen starken Grashalmen oder anderen Pflanzenstengeln befestigen sie kunstvoll ihr Nest und zwar so, dass immer zwei oder drei Stengel durch die Seitenwandungen des Nestes hindurch gehen. Das schön gebaute Nest wächst mit den Pflanzen in die Höhe und ist so bei Hochwasser vor dem Überschwemmtwerden geschützt.

Aus der Familie der Motacillidae halten sich am Gewässer und in der Nähe desselben die drei bekannten Bachstelzenarten auf. Motacilla alba L., die weisse Bachstelze, auch Quäksteert oder Wippsteert genamnt; dic graue Bachstelze, Motacilla sulphurea Bechst., und die gelbe Bachstelze oder Kuhstelze "gäle Quälsteert", Motacilla flava Cuv. Obwohl man die erstere auch entfernt vom Wasser antrifft, so schligt sie doch mit Vorliebe ihre Wohnung unter Brücken, an Mühlen und auf den in der Nähe des Wassers stehenden Weidenstümpfen auf. Die im nördlichen Deutschland seltene graue Bachstelze hält sich fast ausschliesslich an Bächen, Quellen, überhaupt an fliessenden Gewässern auf und baut auch ihr Nest stets in die Nähe des Wassers, in Höhlen, unter Brücken, in Felslöchern u. dgl. m. Die gelbe Bachstelze dagegen bewohnt die freien, von menschlichen Wohnungen fern liegenden Weiden auf den Inseln und an den Flussufern; mit Vorliebe diejenigen Weiden, auf welchen Vieh weidet. Das Nest derselben findet man nicht selten in Carices-Büscheln. Die weisse Bachstelze erscheint in unserm Nordwesten oft schon im Februar - nach dem verflossenen harten Winter 9o/9 I wurden die ersten Bachstelzen erst am I6. März 9I beobachtet - und verlisst uns Olitober. Die weisse Bachstelze ist nach dem Staar unser erster Frühlingsbote. 
Die gelbe Bachstelze trift bei uns Anfang April ein und verweilt bis Mitte September.

In Gemeinschaft mit den gelben Bachstelzen trifft man ziemlich häufig den Wiesenpieper, Anthus pratensis L. Er wählt zu seinem Brutplatze dieselben Lokalitäten wie die Bachstelzen. Gewöhnlich erscheint er bei uns im März und bleibt oft bis November. Einzelne bleiben sogar in gelinden Wintern ganz bei uns. Charakteristisch und dabei ein sicheres Erkennungszeichen der Art ist ihr Verhalten beim Gesange, welcher etwa „witje, witje, witje, zick, zick, zick, jück, jück, jück, tirrrirrr" lautet. Plötzlich erhebt sich der Pieper singend einige Meter in die Höhe und fällt ebenso rasch wieder zur Errde, um auf einem Carex- oder ScirpusBüschel den Gesang fortzusetzen oder zu vollenden.

Von den Lerchen kommt für unser Gebiet nur die durch ihren jubilierenden herrlichen Gesang bekannte Feldlerche, Alauda arvcnsis L., insoweit in Betracht, als sie ziemlich häufig als Brutvogel auf den Flussinseln anzutreffen ist. Sie erscheint oft schon Mitte Februar und verkündet dann durch ihre schmetternden Lieder das Neuerwachen des Frühlings. Sie verlässt uns Ende Oktober oder zu Beginn des November.

Von den Ammern suchen auch einige zu ihrem Brutplatze die Nähe der Gewïsser auf. So findet sich auf den Weserinseln gar nicht selten die Grauammer, Emberiza miliaria Bp. Ihr Nest ist meist tief versteckt in den Grasbüscheln angelegt; auf dem Festlande dagegen withlt sie mit Vorliebe die Getreidefelder zu ihrem Nistplatze. Wenn man im Frühjahre die grösste unserer Ammern auf irgend einem Weidenstumpfe sitzen sieht und das ziemlich eintünige "zick, zick, zick, sirrrr" hürt, so kann.man sicher sein, dass in gar nicht zu grosser Entfernung sich das Nest befindet. Fast ausschliesslich an Gribenufern nistet die bekannte Goldammer, "Gälgüschen", Emberiza citrinella L. Der Gesang „si, si, si, si, siiiih" unterscheidet sie sofort, ohne dass man den Vogel zu schen braucht, von der Grauammer. Stets schliagt ihren Wohnsitz die Rohrammer, Rohrsperling oder Reithlüning, Embcrisa schoenichus L., in der Nähe der Gewässer auf. Das sehr verborgene 
Nest findet man in Carex-Büscheln. In demselben trift man Anfang Mai fünf bis sechs rütlich weisse Eier, deren ganze Schale mit braunroten Strichen und grösseren Flecken bedeckt ist. Wïhrend die beiden erstgenannten Ammern den Winter über bei uns bleiben und uns nur einzeln bei sehr strenger Kälte verlassen, whl auch nur etwas südlicher streichen, um bei der näichsten gelinden Witterung sich wieder bei uns einzustellen, verlässt uns die Rohrammer gewöhnlich schon Ende September, erscheint aber in März wieder auf der Bildfläche. In gelinden Wintern bleiben dann und wann auch wohl einzelne Pärchen hier.

Ganz einzeln trifft man auch den Hänfling, "Grauiserken", Fringilla camabina Bp., auf den Flussinseln an, welche viel hohes Gestrüpp haben. Auch der Feldsperling, Weidenspatz, Passer montamus Koch, ist als Brutvogel auf den Inseln zu finden, wo alte IVeidenstümpfe, die er zu seinem Nistplatze wählt, stehen. Der Hänfling ist den ganzen Winter hindurch auf den Inseln, Platen und an den Flüssen anzutreffen, wenn kein Schnee füllt; ein Teil derselben verlässt uns im September und kehrt im ersten Frühjahre, im März, zurück. Der Feldspatz ist im ganzen Gebiete Standvogel.

Selbst die Ordnung der Hühner ist auf den grösseren, mit langem Grase bewachsenen Platen durch das. Rebhuhn, Perdix cincrea Briss., vertreten. Wenn man am frühen Morgen oder gegen Abend in einem Boote an einer solchen.Insel entlang fathrt, so vernimmt man bald aus der nächsten Nähe, bald wieder aus weitcrer Ferme den wohlbekannten Ruf des Rebhahmes "girrrik" ". Noch häufiger hürt man des Abends von den Inseln und Groden das „rö̈irp, rüärp“, den gewöhnlichsten Ruf des Wachtellünigs, Crex pratensis Bechst., herübertönen. Obgleich dieser Vogel an den Flussufern und auf den Inseln ziemlich häufig ist - man kamn an warmen Abenden oft drei, vier und mehr zu gleicher Zeit rufen hören -, bekommt man denselben doch sehr selten zu Gesicht, da er gewöhnlich im Grase rasch fortläuft, ohne aufzulliegen. Selbst vor dem suchenden Hunde fliegt er nicht eher auf, bis er in die Enge, etwa an einen Graben, getrieben wird. Das Nest 
findet man sehr selten und schwer. Die prächtigsten Gelege zehn bis zwölf Eier von schöner graugelber Farbe mit vielen rötlich braunen Flecken -, die in meinen Besitz gekommen sind, verdanke ich ausschliesslich den Grasmähern. Der "Snarrentar", wie er im Volksmunde nach seinem Rufe genannt wird, erscheint bei uns gewöhnlich Anfang Mái und verschwindet Anfang September.

Von den Gallinulidae treffen wir weiter auf den Inseln und an den Flussufern als lirutrögel dass punlitierte Rohrhuhn, Rallus porzana L.; die Wasserralle, Rallus aquaticus L.; das grünfüssige Rohrhuhn, Gallinula chloropus Lath., und das schöne, grosse Blässhuhn, Fulica atra L., an. Diese echten Wasserbewohner sind in unserm ganzen Nordwesten an und auf den grossen Flussinseln, in den undurchdringlichen Rohr- und Schilffeldem der Groden an den grö̈seren und kileineren Seen fast überall anzutreffen, aber äusserst schwer zu beobachten, da sie dem Auge des Naturbeobachters durch geschicktes Tauchen oder durch Verschwinden zwischen dem dichten Schilf and Rohr auszuweichen wissen. Es ist interessant, diese gewandten Schwimmer und Taucher in ihrem nassen Elemente beobachten zu können. Hat man sich unbemerkit mit dem Boote in irgend eine gedeckte Bucht oder in ein Rohrfeld gelegt, so erscheint oft, wenn das Glück günstig ist, in unmittelbarer Nähe des Bootes einer dieser munteren Vügel, aber im nëchsten Augenblicke, kaum dass wir Zeit hatten, ihn auch nur halbwegs ins Auge zu fassen, verschwindet er in der kühlen Flut, schwimmt eine grosse Strecke unter der Wasserfliche

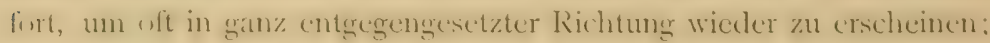
oft nimmt er sogar seinen Weg unter dem Boote durch, und im nächsten Augenblicke ist er auch schon wieder fort. Glaubt er sich erst in sicherer Entfernung, dann kann man ihn auch längere Zeit auf der Wasserfliche beobachten. Oft sieht man dann die ganze Familie, Alt und Jung, im bunten Durcheinander, bald ruhig dahinschwimmend, bald Tauchübungen anstellend, bald über die glatte Wasserfliche clahinlaufend; aber nie lassen sie dabei die nütige Vorsicht ausser Acht; bei dem geringsten verdächtigen Geritusch verschwinclet die ganze Gesellschaft im näichsten Rohrfelde 
und lïsst sich für lange Zeit nicht wieder blicken. Auch im Bau ihrer Nester, welche sehr versteckt und meist nach dem Wasser hin in den Rohr- und Binsenfeldern angebracht sind, gleichen sie sich. Auf niedergebogenem Rohr, oft auf halb schwimmendem Gestrüpp sind die ziemlich kunstlosen Nester angelegt. Die Zahl der Eier beträgt gewöhnlich acht bis zwölf. Die Gallinulidae erscheinen in unserm Gebiete Anfạng Mai und verlassen uns Mitte September.

Von den Charadriidae bewohnt die Flussinseln und Groden als Brutvogel der allen bekannte Kiebitz, Vanellus cristatus Meyer und Wolf, welcher leider von Jahr zu Jahr an Zahl bedenklich abnimmt. Die Ursache dieser von Jahr zu Jahr sich steigernden Abnahme dieses nützlichen Vogels liegt in dem leidigen, unvernünftigen Eiersammeln, welches einzig den Zweck hat, den Gaumen des Gourmands zu kitzeln. Allerdings tragen auch ein gut Teil Schuld die Entwässerungsanstalten, welche in jedem Frühjahre die nassen und sumpfigen Wiesen trocken pumpen und es dadurch den Eiersammlern ermöglichen, auf die Poller und höher gelegenen Stellen, die Brutplaitze des Kiebitzes, zu gelangen, um anch dort ihr Zerstörungswerk mit Erfolg zu betreiben. Der Kiebitz gehört zu unseren ersten Frühlingsboten; er erscheint gewöhnlich Mitte März und verlässt uns Ende September oder Anfang Oktober. In milden Jahren erscheint er oft schon im Februar und bleibt einzeln bis in den November. Nanchmal aber, wenn sie sich zu früh hergewagt haben und Kälte und Schnee zurückkehren, müssen sie wieder flüchten und auch dabei gehen viele żu Grunde. Am 23. Februar dieses Jahres beobachtete_Verfasser einen Trupp von etwa 50 Stück, welche sich trotz des vergangenen strengen Winters in unserm Nordwesten eingefunden hatten; als aber nach einigen Tagen von neuem Kälte eintrat und ziemlicher Schnee fiel, zogen sie auf einige Zeit wieder südlicher.

Mit dem Kiebitz erscheint und verschwindet fast zur selben Zeit der Flussregenpfeifer, Charadrus fluviatilis Bechst. Dieser hurtige, behende Geselle bewohnt mit Vorliebe die kahlen, kiesigen Ufer der Inseln und Flüsse und legt auch dort sein Nest an, welches 
sehr leicht übersehen werden kann. In einer kleinen Vertiefung fast olne alle Unterlage liegen auf kiesigen Grunde drei bis vier

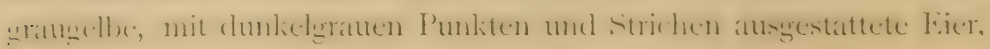
wclche in ihrer Färbung so sehr der Umgebung ähneln, dass man oft, wenn man das Nest gefunden, es auch schon wieder aus den Augen verloren hat und von neuem suchen muss. So ging es am I8. Mai dieses Jahres dem Verfasser, der, kaum zwei Fuss vom Neste entfernt, es erst nach längerem scharfen Umhersehen wieder entdeckte.

Der Rotschenkel, Totainus calidris Bechst., welcher sich in grosser Zahl als Brutvogel an unseren Nordseeküsten findet, wird auch einzein als solcher an den Ufern der Flüsse und auf den Flussinseln beobachtet. Er erscheint bei uns Mitte Mai und verlïsst uns Anfang September. Häufiger als den Rotschenkel kann man an den sandigen Ufern als Brutrogel den Flussuferläufer, Actitis hypoleucos Brehm beobachten, derselbe erscheint im März. und bleibt bis zum Oktober. Auf den feuchten, kurzgrasigen Wiesen unserer Flussniederungen stellt sich in ziemlich grosser Individuenzahl der durch seine possierlichen Kapriolen bekannte Kampfhahn, Machetes pugnax Cuv. ein. Stundenlang kann man, wenn ein Gestrüpp oder ein Grabenufer uns die nötige Deckung giebt, diesem tollen Treiben des Streithahns oder Streitvogels zusehen. Bei diesen sogenannten "Kümpfen", die besonders zur Paarungszeit häufig sind, nimmt er die wunderbarsten Stellungen ein, strüubt sein Gefieder bald so und im nächsten Augenblick wieder anders. Sie stürzen auf einander los, vorwärts, rückwärts, und scheinbar mit einer solchen Wut, dass der uneingeweihte Beobachter glauben muss, keiner verlasse lebend den Kampfplatz; indessen scheint es mehr eine Spiegelfechterci zu sein, denn sie lassen kaum Federn dabei und nach einiger Zeit, wenn sie des Kampfes müde sind, eilen sie vergnügt von dannen, um sich für ein späteres Turnier, deren man tïglich mehrere beobachten kann, wiecler zu stürken. Das Nest, welches im Bau sowohl wie im Aussehen dem des Kiebitzes :ahnlich ist, befindet sich in einer kleinen Vertiefung, einer Kuhspur oder dergleichen, und ist mit wenig Grashailmchen aus- 
gelegt. Nach beendigtem Paarungsgeschäfte verlassen uns schon meistens die MIännchen und ziehen an die Meeresküste, während die Weibchen und Jungen bis zum September an ihren Brutplätzen verweilen. Im MIärz treffen sie wieder zusammen an letzteren ein.

Auf den feuchten, mit kleinen Wasserlëufen durchzogenen Wiesen der Inseln der A.ussendeichsländereien und Groden, auf den Dobben und Platen treffen wir in ziemlicher Zahl als Brutvögel die einfache Bekassine, auch "Häwelamm" oder "Bäwerbuck" genannt, Scolopax gallinago L., und die Doppelbekassine, Scolopax major L., an. Unter Dobben versteht man beweglichen Moorboden, der oben durch eine Grasnarbe bedeckt und ziemlich fest, weiter nach unten aber noch weich ist. Beim Betreten solchen Bodens bewegt sich die ganze Fläche und der auf diesem Boden Unbekannte bricht sehr leicht ein; es bedarf einer besondern Geschicklichkeit, darüber hinwegzugehen. Pferde, welche ihn betreten wollen, bekommen Holzschuhe angeschnallt, und die Räder der Wagen werden, damit sie nicht einschneiden und dann versinken, mit dicken, gedrehten Strohseilen unwwickelt. An warmen Frühlingsabenden macht sich die cinfache Bekassine durch ihr eigentümliches Gemecker, dem einer Ziegè nicht unähnlich, daher „Häwelamm", "Himmelsziege" genannt, welches sie nur im Fluge vernehmen lässt, bemerkbar. An einzelnen MLorseen ist dieser, von Feinschmeckern sehr geschätzte Vogel oft zu hunderten anzutreffen, so am BalkSee, einem inmitten des unwirtlichen Moores bei Cadenberge unweit der niederelbischen Bahn gelegenen grossen Moorsees, dessen Ufer von grossen Dobbenfeldern gebildet werden. Auf solch sumpfigen Wiesen in der Mitte eines Carex-Busches findet sich das sehr schwer zu entdeckende. Nest. Die gemeine Bekassine erscheint bei uns oft schon im März und bleibt bis zum November. -Die Doppelbekassine kommt erst im April und geht schon im September.

Anfang Mai erscheint ebenfalls auf den feuchten Flussniederungen die Pfuhlschnepfe, Limosa melanma Leisler, um dort ihr Brutgeschäft zu verrichten; sie verlässt uns gewöhnlich 
354 Das Tierleben auf Flussinseln und am Ufer der Flüsse und Seen.

schon Anfang September. Auch die grosse Rohrdommel, Dotaurus stellaris Briss, "Iprump." nach ihrem unheimlich lilingenden Rufe „üi - prump" so genannt, ist als vereinzelter Brutvogel der Flussinseln aufzuzählen. Es hält schwer, dieses stattliche Tier zu Gesicht zu bekommen, da es durch eine eigentümliche List sich dem Auge des Beobachters zu entziehen weiss. Bemerkt die Rohrdommel einen Feind in ihrer Nahe, so richtet sie sich gerade auf, zieht den Hals cin, streckt Kopf und Schnabel senkrecht in die Hühe und bleibt in dieser Stellung unbeweglich stehen, bis die Gefahr vorüber ist. In dem Weidengebüsch, in welchem sie sich gern aufhält, gleicht sie in dieser Stellung, wobei ihr die Färbung ihres Gefieders, welche mit der Umgebung grosse Ähnlichkeit hat, sehr zu statten kommt, täuschend einem alten abgebrochenen Weidenstumpfe. Die Rohrdommel erscheint im April auf ihrem Brutplatze und zicht Ende September wieder von dannen.

Aus der Ordnung der Schwimmvögrel treffen wir zunächst an unseren süssen Gewässern einige Entenarten als Brüter an. Da mag zuerst die Löffelente, Rlyynchaspis clypeata L., erwähnt werden, welche im dichten Rohr, umgeben von Wasser, ihr verstecktes Nest anlegt; ferner die Knäickente, Anas querqucdula L., die Krickente, Anas crecca L., und die gemeine wilde Ente, auch Stockente genannt, Anas boschas L., gehören zu den

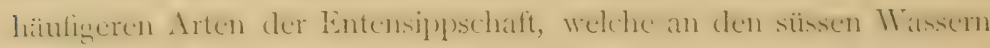
brïten. Die Enten erscheinen auf dem Frühjahrszuge meist im März und zichen Olitober wieder fort. Einzelne Exemplare von boschas und crecea trifft man fast den ganzen Winter an den Gewïssem an und diese verlassen uns nur dann, wenn auch die letzten offenen Stellen der Flüsse und Seen mit einer Eisdecke verschlossen sind.

An dem in Betracht kommenden Gebiete triff man von den Pelecanidae im Bimmenlande cinzeln die Kormoran-Scharbe, IIalicus Carbo Ill., als Brutrogel an. Im Nordwesten Deutschlands ist nur eine Kolonie dieses der Fischerei sehr schadichen Vogels bekannt und zwar im Lüneburgischen an der Elbe. Der Liormoran legt seinen Horst, entgegen der Gewohnheit der anderen Schwimm- 
vögel, auf Büumen an, benutzt aber gewöhnlich die Nester der Reiher und Raben für sich, wobei sich hüufig ein hartnäckiger Kampf zwischen diesen und jenen entspinnt. Trotz seiner grossen Schwimmfüsse bäumt der Kormoran sehr geschickt auf und weiss sich ganz sicher auf den Ästen zu benehmen.

Wenn der eigentliche Aufenthaltsort der Seeschwalben und Möven auch das salzige Meer, die Watten und die Inseln des Meeres sind, so giebt es doch eine Reihe Arten davon, welche vorziehen im Binnenlande an den süssen Gewässern sich aufzuhalten und dort ihr Heim einzurichten. Es sind dies die Küstenmeerschwalbe, Sterna macrura Naum.; die Flussmeerschwalbe, Sterna hirundo L.; die kleine Seeschwalbe, Stoma minuta L., und die schwarze Seeschwalbe, Sterna nigra Briss., und von den MIöven die Lachmöve, Larus ridibundus L. Ihre Nester, welche, fast ohne jegliche Unterlage, nur aus einer lileinen Verticfung bestehen, finden sich auf den kiesigen, sandigen Stellen an den Gewässern und sind sehr schwer von der Umgeburig zu unterscheiden, da die Plätze gewöhnlich alles Pflanzenwuchses entbehren. Im Winter bleiben immer einzelne dieser geschickten Segler bei uns, wenn auch als gewöhnlich anzunehmen ist, dass sie im März in grösseren Scharen erscheinen und uns im Oktober verlassen.

Endlich mögen noch zwei Brutvögel der Binnengewässer aufgezählt werden. Es sind dies der grosse Lappentaucher, auch Kronentaucher genannt, Podiceps cristatus L., und der kleine Lappentaucher, welcher im Volksmunde den etwas derben Namen "Pärküdel" führt, Podiccps minor L. Ersterer ist auf fast allen unseren Seen ein gemeiner Brutvogel. Schon von. ferne hören wir seinen lauten Ruf "koar, koar, koar" über die Wasserflïche zu uns herüberschallen, ehe man den geschickten Schwimmer und Titucher zu Gesicht bekommt. Er ist ein äusserst scheuer und schlauer Vogel, der seinen Beobachter immer in respektabler Entfernnng hält; kommt man ihm trotzdem unvermerkt zu nahe, so verschwindet er plötzlich unter der Wasserfläche und erscheint weit weg nur mit dem Kopfe über derselben, um schon im nïchsten Augenblicke von neuem zu verschwinden. Dieses Experiment 
wiederholt er so läufig, bis er sich wieder sicher fühlt. Einen Jäger lässt er daher sehr selten in Schussnähe kommen. Wird der Taucher angeschossen, und ist der Schuss nicht gleich tödlich, so taucht er fort und hält sich am Grunde des Gewässers am Rohr und Schilf fest, um nicht wieder an die Oberfläche zu kommen. Binsenschneider am Dümmersee brachten dem Verfasser, welcher sich zu der Zeit am See aufhielt, ein Exemplar des Kronentauchers, welcher am Vormittage von einem Herm angeschossen war, ohne dass er ihn bekommen hatte. Das Exemplar hatten dieselben beim Schneiden mit herauf gebracht. Es hatte noch die Binse, an welcher es sich festgehalten hatte, im Schnabel, und dieselbe auch im Todeskampfe nicht losgelassen. Der kleine Taucher ist ebenso geschickt im Schwimmen und Tauchen, wie sein grösserer Vetter. Das Nest der Taucher ist fast immer frei auf der Wasserlläche zwischen Rohr befindlich und an einzelnen Stengeln befestigt, damit es vom Winde nicht fortgetrieben wird. Die Nester sind äusserst schwer aufzuspüren, da man nur von der Wasserseite mit dem Boote an die Rohr- und Binsenfelder gelangen kann, in welchen sie angelegt sind.

Im vorhergehenden ist versucht worden, dem Naturbeobachter in liurzen Zügen ein Bild zu entwerfen von den Brutvögeln, welche derselbe auf Flussinseln, an den Ufern der Flüsse und Seen aufzufinden vermag. Es ist damit aber nicht beabsichtigt, ein genaues, vollständiges Verzeichnis aller an den in Frage kommenden Lokalitäten brütenden Vügel zu geben; im wesentlichen sind die häufigeren und ạm meisten ins Auge fallenden Arten berücksichtigt, welche den Nordwesten unseres Vaterlandes bewohnen. Im üstlichen und südlichen Deutschland finden sich noch einzelne Arten, welche nicht erwähnt worden sind. Auch im folgenden hat Verfasser vorwiegend die Bewohner der Gewilisser unseres Nordwestens im Auge gehabt. Wenn bei manchen Vügeln Angaben über Brutzeit, über Eintreffen und Verschwinden an ihren Nistplatzen gemacht worden sind, so beziehen sich dieselben ebenfalls auf Beobachtungen, welche im Nordwesten angestellt worden sind. 
Ist schon das Gesamtbild unserer befiederten Freunde zur Brutzeit ein buntes und mannigfaltiges, so gestaltet es sich noch viel reicher im Frühjahrs- und Herbstzuge, ja manchmal erhält das Bild ein ganz fremdartiges Aussehen; denn da erscheinen an unseren süssen Gewässern Gäste; die sonst nur im hohen Norden, am Meere oder anderen uns fern liegenden Orten anzutreffen sind. Es soll im folgenden versucht werden, dem Naturfreunde auch davon ein kleines, also nicht auf Vollständigkeit Anspruch machendes Bild zu entwerfen. Durchwandern wir im Geiste noch einmal die Vogelwelt und beginnen wir von neuem mit den Raubvögeln, so finden wir gar nicht selten zur Zugzeit auf den grossen Wasserflächen den Seeadler, Haliaëtos albicilla Leach, der besonders häufig erscheint, wenn viele wilde Gänse zur Herbstzeit in den Flussniederungen sich länger aufhalten. Im Volksmunde wird er deshalb gewöhnlich mit "Goosarnt"s bezeichnet. Der Fischadler, Pandion haliaëtos Less.; der Bussard, Buteo vulgaris Bechst.; die Gabelweihe, Milvus regalis Briss.; selbst der Wanderfalke, Falco peregrimes L.; der Baumfalke, Falco subbuteo L.; der Turmfalke, Falco timmuculus L.; selbst der Hühnerhabicht, Astur palumbarius Briss., und der Sperber, Astur misus K. und Bl., halten sich vorübergehend mit Vorliebe auf den Flussinseln und Flussniederungen auf, weil ihnen dort der Tisch reichlich und bequem gedeckt ist; ganz besonders finden sie zur Herbstzeit dort an Staaren und Feldmäusen reichliche Nahrung.

Der Mauersegler, Cypsehus apus L.; die Haus- und Rauchschwalbe, Hirme urbica L. und rustica L., halten sich, bevor sie fortziehen, eine Zeit lang an unseren Flüssen und in den Niederungen auf, um sich zu grossen Scharen dort zu versammeln. Ende September oder Anfang Oktober kann man Tausende dieser leicht beschwingten Flieger an den oben erwähnten Lokalitäten antreffen, bis sie auf einmal über Nacht fortgezogen sind.

Während des Herbstzuges sind auf den Platen die Blaumeise, Parus coeruleus L., der Krammetsvogel, Turdus pilaris L., und die Weindrossel, Turdus iliacus L., gar nicht selten anzutreffen. Selbst der grosse Würger, Lanius cxcubitor L., 
erscheint einzeln auf den alten Weidenstümpfen, um sich nach einem leckeren Mahle umzusehen. Der Volksmund hat ihn sehr treffend mit „Radäkster" bezcichnet. In seinem Äussern hat cr eine entfernte Älnbichkeit mit der Elster und er macht an freistehenden Zweigen oft radförmige Bewegungen. Dieser im Fliegen ziemlich ungeschickte Rauber sucht seine Beute zu überlisten. Eir sitzt bald

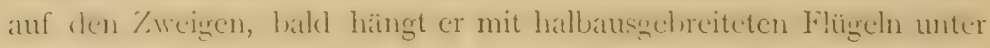
denselben, bald macht er radförmige Bewegungen um dieselben. Die kleinen arglosen Vögel werden durch dieses wunderliche (ieb)hren herangelockt, setzen sich auf die henarhbarten Sträucher, oft ganz in seine Nähe, um diesem tollen Treiben zuzusehen, und im unbemerkten Augenblicke werden sie von diesem arglistigen Rüuber gefangen. Seine erwischte Beute spiesst er oft auf Dornen, um sie dann stückweise und nach Bedarf zu verzehren.

Auch die Familie der Finken schickt ihre Vertreter an die Gewässer. Auf dem Frühjahrszuge bemerken wir den Flachsfinken, Acanthis linaria Bp.; zur Herbstzeit treffen wir den Berghänfling, Linota montium Bp.; ebenso den Stieglitz, den muntersten und schönsten seiner. Sippschaft. (irrduelis iliguns Steph.; den ungeschickten, im Baue etwas plumpen Grünling, Chlorospiza chloris Bp.; selbst "Jochen", der wohl mit Unrecht so sehr gescholtene Strauchdieb und Gassenbube, der Sperling, Passer domesticus Koch, dem sogar der Ausrottungskirieg angelündigt werden soll, mischt sich unter die Gäste auf den Inseln und Platen. Wenn man aber diesen, allerdings bei vielen gehassten munteren und kecken Burschen während der Brütezeit beobachtet, wie er von Zweig zu Zweig, von Blatt zu Blatt, von Blüte zu Blüte die Obstbäume absucht, um die heisshungrigen Jungen zu befriedigen, die or fast ausschliesslich mit Kerbtieren und deren Larven füttert, damn muss man ihm doch wohl etwas freundlicher gesinnt werden, denn der Nutzen, den er dadurch unseren Obstgürten zuwendet, ist jedenfalls ein recht bedeutender und hebt gewiss einen grossen Teil seines Schadens auf. Nehmen sie zu sehr überhand und fügen sic später den Komfeldern und Erbsenäckern zu grossen Schaden zu, so möge man sie im Herbste 
dezimieren, aber jedenfalls nicht zur Brutzeit, denn dann gerade stiften sie Nutzen. Ebenso thöricht ist es, die junge Brut zu zerstören, die gerade der Kerbtiere zu ihrer Nahrung bedarf.

$\mathrm{Zu}$ Tausenden und Abertausenden sind die Staare, Sturmus vulgarts L., im Spätsommer und zur Herbstzeit in den Flussniederungen, in den Rohrfeldern an Flüssen und Seen nach beendigtem Brutgeschäfte anzutreffen. Gegen Abend sieht man sie in dichten Wolken, bald nahe über dem Boden, bald hoch durch die Lüfte umherziehen, dann in die grossen Rohrfelder einfallen, um dort ihre Nachtruhe zu halten.

Ganz buntfarbig ist zur Herbstzugzeit das Bild der Sumpfund Schwimmvögel. Da treffen wir den nordischen Kiebitzregenpfeifer, Squatarola helvetica Cuv.; den Goldregenpfeifer, Charadrius pluvialis L.; den Halsbandregenpfeifer, Pluvialis hiaticula Briss.; den gravitätisch einherstolzierenden Austernfischer, Hacmutopus ostralegus L.; die rasch über die Sandfäichen dahintrippelnden Wasserläufer, Totonus glottis Bechst., Totomus fuscus Leisl., Totanus glareola Temm., Totanus ochropus Temm.; die zierlichen, blitzschnellen Strandläufer, Tringa subarquata Temm., Tringa alpina L., Tringa minuta Leisl. und Tringa Temminckii Leisl. Auch die stumme Bekassine, Telmatias gallimula Boie, gesellt sich hinzu.

Truppweise in Flügen $z u$ dreien und vieren besuchen im August und September auch die „Unwährsvögel", Numncnizis arquata Latham, ihr Flussrevier. Im Volksmunde führt dieser Vogel den Namen "Gütvoagel" nach seinem eintönigen Rufe, der etwa wie "tlaüd, tlaüd" klingt, oder „Unwährsvoagel"; denn meistens, wenn diese Vögel abends ziehen und ihren weitklingenden Ruf ertönen lassen, giebt es schlechtes Wetter, Unwetter. Ganz besonders zahlreich erscheinen zur Zugzeit die Günse; Anser cinercus W. u. M., die Graugans, und Anser segetum Bechst., die Saatgans - vereinzelt findet sich auch darunter die Blässgans, Anser albifrons Gm., und die Ringelgans, Bemicla brenta Pall. in den Flussniederungen und es wird in manchen Jahren eifrig 
Jagd auf die sehr scheuen Tiere gemacht. Doch selten wird in den Ebenen die Jagd mit Erfolg gekrönt, da die ausgestellten Posten den Jäger gewöhnlich viel zu früh wittern. Ehe derselbe zum Schuss kommen kann, geht die ganze Schar auf und davon. Günstiger ist der Erfolg, wenn mehrere Jäger sich verabreden und cine solche Fläche, auf welcher sich ein Gänseschwarm niedergelassen hat, unbemerkt umstellen können; dann treten plützlich an der einen Seite die Jäger vor, die Gänse streichen sofort nach der entgegengesetzten Richtung ab und kommen nun den dort versteckt stehenden andern in die Schusslinic.

Sehr zahlreich erscheinen auch im Herbst die Vertreter der Entenfamilien. Da können wir an unseren Gewässern beobachten die schöne Brand-, Fuchs- oder Höhlenente, Vulpansertadorna Pall.; die Schnatterente, Anas strepera L.; die Spiessente, Anas acuta L.; die Pfeifente, Anas Penclope L.; die Tafelente, Fuligula ferina L.; die Reiherente, Fuligula cristata Ray; die Bergente, Fuligula marila L.; die schöne Schellente, Glaucion clangula K. u. Bl.; die Eisente, Harelda glacialis Leach, und dic stattliche Trauerente, Oidemia migra Flemm. In manchen Flüssen und Insehn werden zur \%ugzeit in cigens diazu angelegten Eintenfingen oder in Entenhütten IIunderte dieser

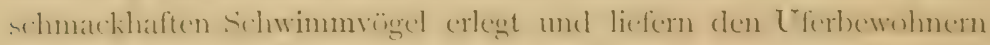
eine nahrhafte und billige Fleischspeise. Auch der kleine Säger, Mergus albellus L.; der grosse Säger, Mergus merganser L., und der mittlere Sïger, Morgus scrrator L., erscheinen zur Herbstzeit auf den Binnengewässern. Einzelne Möven, Rissa Iridactyla Leach, die dreizehige Nüve; Larus camıs L., die Sturmmöve; Larus argentatus Brünn., die Silbermöve letztere fast nur im Jugendkleide -; ganz vereinzelt die grosse, stattliche Mantelmöve, Larus marimus L., und die mittlere Raubmöve, Lestris pomarina Temm., halten sich vorübergehend an unseren Binnengewässern auf. Und endlich triflt man auch noch den rotkchligen Taucher, Eudites septcntrionalis Ill.; den Polartaucher, Eudites arclicus Ill,, sowie den gehörnten Lappentaucher oder arktischen Steissfuss, Colymbus cormutus L., 
zur Herbstzeit auf den grösseren, mit Rohr bewachsenen Binnengewässern und Flüssen an.

Nachdem wir so in der Ornis Umschau gehalten haben nach dem, was der Naturfreund an Flüssen und Seen, auf Inseln und Groden von der befiederten Welt antreffen. kann, wollen wir im Folgenden die Kaltblüter Revue passieren lassen. Die Klasse der Reptilien ist bald abgefertigt, denn hier kann es sich höchstens um ein Tier handeln, welches in dem oben bezeichneten Gebiete vorkommt. Es ist die europäische Sumpf-Schildkröte, Emys curopaca Gray, welche in den Seen und Flussgebieten des baltischen und karpatischen Höhenrückens in Sachsen, Schlesien, Mecklenburg, Brandenburg u. s. w. gelegentlich, aber nicht gerade sehr häufig, vorkommt. Ihre Verbreitung im nördlichen Deutschland mag eine grössere sein, als augenblicklich allgemein angenommen wird, da sie sich durch ihre versteckte Lebensweise - am Grunde der Gewässer - dem Beobachter entzieht. Meistens wird in den bekannten Gebieten ihr Vorkommen durch frei auf der Wasseroberfläche schwimmende Fischblasen verraten. Ihre Nahrung besteht vorwiegend aus Fischen und ist sie daher der Fischzucht sehr schädlich. Die Vermehrung geschieht durch Eier, welche das Weibchen ausserhalb des Wassers im Mai in selbstgegrabenen kleinen Gruben ablegt. Aus dem Ei entwickelt sich das vollkommene Reptil ohne Metamorphose.

Die Amphibien gehören sämtlich dem Süsswassergebiete an, wenigstens zur Paarungszeit und in ihrem Kaulquappenzustande. Von den fünf deutschen Froscharten, dem braunen Grasfrosch, Rana fusca Rösel; dem Mloorfrosche, Rana arvalis Nilsson; dem grünen Wasserfrosche, Rana esculenta L.; dem Seefrosche, Rana fortis Boulenger, und dem Springfrosche, Rana agilis Thomas, ist der letztere im nördlichen Deutschland noch nicht nachgewiesen worden. Ihren Laich legen sie klumpweise ab und sind auch nur dann, wảhrend der Begattungszeit, zahlreich bei einander und leicht zu fangen. Sie lassen sich bei der Begattung, ohne sich zu lösen, aus dem Wasser heben, ja zwei Pärchen von Rana arvalis, welche Verfasser in Spiritus abtötete, liessen auch 
im Tode nicht von einander und zieren jetzt in dieser Stellung die städtischen Sammlungen in Bremen.

Bedeutend schwieriger ist die Geburtshelferkröte, Alyles obstetricans Wagl., zu beobachten. Diese Art lebt das ganze Jahr hindurch in tiefen Erdlöchern, aus denen sie spät abends zum Vorschein kommt, und nur auf ganz kurze Zeit begiebt sich das Männchen ins Wasser, um die um die Hüften gewickelte Eierschnur, aus welcher dann sehr bald die jungen Larven ausschlüpfen, abzustreifen. Am leichtesten findet man ilure Verstecke, wenn man abends sich genau den Ort merkt, von welchem der helle, flötenartig klingende Ruf, der an den Ton, welcher durch Anschlagen an eine Glasglocke hervorgebracht wird, erinnert, herüberschallt, und nun am lolgenden Tage dic Erdhöhlen, sjablen, Steinhaufen u. s. w. in dem betreffenden Reviere untersucht.

Auch die Knoblauchkröte, Pelobates fuscus Wagl,, ist schwer zu beobachten, da sie den Tag über versteclit in der Ėrde lebt und nur zur Nachtzeit hervorkommt. Zur Paarungszeit im April geht sie ins Wasser und man trifft dann, wenn man einen solchen Laichplatz einmal ausgekundschaftet hat - sie wahlen alljührlich denselben Laichplatz wieder —, immer eine grössere Anzahl beisammen, aber fast immer am Boden der Gewaisser. Ihren Laich setzen sie schnurweise ab. Die Larven dieser Art sind von allen Anuren-Larven die grössten und erreichen etwa die Lïnge eines Decimeters. Schon an den Larven, die mit denen lieiner anderen Art rerwechselt werden kïnnen, litsst sich die Spezies identifizieren.

Die beiden Feuerkröten, Bombmator pachypus Bonap., mit gelbem Bauch und schwarzen Flecken, und Bombinator bombimes L., mit blauschwarzem Bauch und fast zinnoberroten Flecken, legen wic die Frösche ihren Laich klumpweise ab, sind auch fast ausschliesslich Wassertiere. Man findet sie mehr in gebirgigen Gegenden als in der Ebene, besonders in lehmhaltigen Tümpeln, welche sie, sobald sie sich beobachtet sehen, durch Aufwühlen des finklens trübe mathen und sich didurch dem Auge des licothathters entziehen. 
Die bekannten Vertreter aus der Familie der Bufoniden sind die gemeine Kröte, volkstümlich „Ütze", auch „Püidde" genannt, Bufo vulgarıs Laur.; die Kreuzkröte, Bufo calamita Laur., und die Wechselkröte, Bufo variabilis Pall. Nur zur Laichzeit trifft man sie zahlreich beisammen in stehenden Gewässern und vernimmt dann schon aus der Ferne ihren Unkengesang. Die Laichzeit beginnt oft schon im April und dauert gewöhnlich nur kurze Zeit; einzeln trifft man sie auch noch im Mai in der Begattung. Mit Vorliebe wählen sie mit Rohr bewachsene Tümpel und Gräben und man kann in denselben den Laich, welcher in Schnüren abgesetzt wird, um die Stengel geschlungen sehen. Bei Bufo vulgaris erreichen die Laichschnüre oft eine Länge von einigen Metern, die einzelnen Eier (oft mehrere Tausend) sind etwas schräg gestellt und dreireihig angeordnet. Beim Absetzen der Eier wird die Schnur bedeutend ausgedehnt und eršcheint sie dann oft zwei-, ja sogar nur einreihig. Die jungen Kaulquappen schlüpfen gewöhnlich nach vierzehn Tagen aus und man trifft sie dann zu Tausenden im Wasser umherschwimmend. Die Eier in der 3-4 $m$ langen Laichschnur von Bufo variabilis Pall. sind spiralig angeordnet und erscheinen daher bei einer oberflächlichen Betrachtung, als ob sie regelmässige Dreiecke bildeten. Bufo calamita Laur. setzt eine zweireihige dünne Laichschnur $a b$.

Aus der Abteilung der Discodactylia gehört schliesslich noch hierher der gemeine Laubfrosch, Hyla arborea L. Dieses muntere und zierliche Tier trifft man gewöhnlich nur einzeln auf den Blättern von Bäumen und Sträuchern an. Er weiss seine Farbe aber dem Blatte, auf welchem er sitzt, so anzupassen, dass er in den meisten Fällen von dem Beobachter übersehen wird. Anfang Mai jedoch, zur Paarungszeit, trifft man sie in grösserer Zahl bei einander und mit Vorliebe wählen sie alljührlich denselben Laichplatz wieder. Es sind gewöhnlich flache, etwas lehmige Tümpel, in denen sie ihren Laich, wie die echten Frösche, klumpweise absetzen, und auch nach beendeter Laichzeit trifft man sie dann noch einige Tage an den Ufern im Grase oder auf dem unmittelbar am Wasser stehenden Gesträuch. 
Lassen wir nun auch noch die Urodelen, welche ebenfalls zur Laichzeit unsere süssen Gewässer bewohnen, im Geiste an uns vorüberzichen. Wir bemerken da zuerst den stattlichsten aller Nolche, den Feuersalamander, Salanandra maculosa Laur. In den feuchten gethigigen Teilen unseres Vatertandes trift man diesen langsamen, plumpen Molch zur Abendzeit gar nicht selten an. Viel schwieriger ist er in unseren Ebenen, von wo auch cinzelne Aufenthaltsorte bekannt sind, aufzufinden. Bei uns treffen wir ihn nur in den allersumpfigsten dunkeln Wäldern und dort nur unter oder in alten halb vermoderten Baumstümpfen. Das Verbreitungsgebiet im Nordwesten ist ein eigentümliches. Bekannt ist er z. B. aus einzelnen feuchten Waldungen der Geest, welche auf der Wasserscheide zwischen Ems und Weser sich befinden. Aus dem Gebiete zwischen Weser und Elbe dagegen ist bislang kein Fundort bekannt. Es ist möglich, dass sein nächtliches und verstecktes Leben in den feuchten Wäldern, denn nur diese kommen für unsere Ebene in Betracht, ihn bislang noch vor dem weiteren Auffinden in unserm Nordwesten bewahrt hat. Aus den Eiern, welche in Waldtümpeln im Mai abgesetzt werden, schlüpfen die fast vüllig ausgebildeten Larven aus.

Eine ebenfalls eigentümliche Verbreitung haben die Tritonen speziell in unserm Nordwesten. Die vier bekannten deutschen Arten sind sämtlich hier vertreten. Es sind cler grosse Kammmolch, Triton cristatus Laur; der kleine Wassermolch, Triton tacniatus Schneider; der Alpenmolch, Triton alpestris Laur., und der Schweizermolch, Triton helvcticus Razoumowsky. Die beiden ersten finden sich zur Laichzeit im April fast in jedem lehmigen Graben und Tümpel. Triton alpestris Laur. dagegen ist nur ziemlich häufig an cinzelnen Orten der Oldenburger Geest; zwischen Weser und Elbe ist er nicht sicher nachgewiesen; aus dem Hamburger Gebiete dagegen ist er wieder bekannt. Noch eigentümlicher ist die Verbreitung unseres Triton helveticus Razoum. Von demselben hat Verfasser nur cinen Fundort, und zwar auf der rechtsseitigen Wesergeest, aufzufinden vermocht, obgleich zur Litichzeit seit fast zwei Dezennien viele Lokalitaten nach diesem 
seltenen Gaste durchsucht sind. Der fadenförmige Schwanzanhang, sowie die starken Schwimmhäute der Hinterfüsse des Männchens und die Mittelleiste des Rückens statt des Flossensaumes bei den anderen Arten sind so charakteristische Unterscheidungsmerkmale, dass er bei aufmerksamem Beobachten gar nicht mit den anderen verwechselt werden kann. Die Tritonen legen ihre Eier gewöhnlich im April, in milden Frühjahren oft schon im März, einzeln an Pflanzen, Laub, Stengeln u. dergl. im Wasser ab. Die Larven haben ihre volle Entwickelung gewöhnlich Ende des Sommers erreicht, alsdann verlieren sie auch die äusseren Kiemen, oft trifft man aber auch noch im Winter und im folgenden Frühjahre vollständig ausgebildete Tritonen mit den äusseren Kiemen. Verfasser traf in einem Tümpel fast alljührlich zur Laichzeit im April 6 bis Io $\mathrm{cm}$ lange Exemplare von Triton cristatus Laur. mit noch vollständig ausgebildeten äusseren Kiemen.

Den deutschen Süsswasserfischen und ihren Lebensverhältnissen ist in diesem Bande schon eine eingehende Abhandlung gewidmet. Wenn im folgenden auch noch wieder von den Fischen die Rede sein soll, so geschieht es nur zu dem Zwecke, dem Naturbeobachter auch hier ein Bild einer lokalen Fischfauna des süssen Wassers zu geben, um daran zu zeigen, welche Arten an bestimmten Lokalitüten zu finden sind. Zuerst möge das Bild einer Flussfischfauna, sodann das eines Geestsees und endlich das eines Moorsees folgen. Der Fischreichtum in unserer Weser - ich habe dabei das Gebiet etwa eine Meile unter- und oberhalb Vegesack im Auge - ist ein ziemlich bedeutender. Von den Barschen finden sich ziemlich häufig der Flussbarsch, Perca fluviatilis L., sowie der Kaulbarsch, Acerina cermua Cuv. In grossen Mengen ist im Frühjahre in allen Buchten der gemeine Stichling, Gasterostcus aculeatus $\mathrm{L}$., zu beobachten. Ebenso wird recht häufig die schmackhafte Quappe, Lota fluiatilis Bl., gefangen. Vim den Plimonictue ist Platessa flesus, der kleine Wasserbutt, fast nur im ersten Jugendstadium, etwa 2-4 cm gross, vorhanden. Einzeln kommen auch den Weserfischern der Karpfen, Cyprimus carpio L., die Karausche, Carassius inlgaris L., die Schleihe, Tinca vulgaris Cuv., und 
die Tarbe, Barbus flutintilis Cuv., ins Net\%. Letztere gehrirt allerdings mehr dem oberen Flussgebiete der Weser an. Zwischen den einzelnen Schlengen und in den flachen Ausbuchtungen ist sehr häufig der zierliche Gründling, Gobio fluviatilis Cuv., zu finden. Zu den gewöhnlichsten und an meisten vin den Fischern gefangenen Fischen gehören der Alander, Leuciscus Idus Selys-Long., der Rotflossen, Leuciscus erythrophthalmus Valenc., der Döbel, Leuciscus Dobula Valenc., das Rotauge, Lcuciscus rutilus Agassiz, der Bresen, Abranis Brama L., und der Schnaipel, Abramis vimba L. Auch wird einzeln der Lachs, Trutta salar L., und die Lachsforelle, Trutta trutta L., gefangen. In grossen Zügen erscheint im Januar, Februar und auch noch im März der Stint, Osmerus eperlanus Art. An Individuenzahl hat in den letzten Jahren der Tielemann, Corregonus oxyrrhynchus L., bedeutend abgenommen, ebenso der Naifisch, Alosa vulgaris Cuv. Letzterer wird jetzt viel weiter westribwäts gefangen. In̈ulige Bewohner der VIeser dagegen sind der Hecht, Esox lucius L., und der Aal, Anguilla anguilla L. Alljührlich wird in einzelnen, oft recht stattlichen Exemplaren auch der Stür, Acipenscr sturio L., gefangen. Von den Rundmäulern sind beide Neunaugen, die Lamprete, Petromyzon marimus L., und das Flussneunauge, Petronyzon fluviatilis L., zu den Weserbewohnem zu rechnen. Erstere ziemlich selten, letztere dagegen häufig. Gefangen werden die Neunaugen vom Dezember bis zum Februar.

Zum Vergleich möge nun eine Aufzählung der Fische folgen, welche im Zwischenahner MIcere, einem auf der Geest gelegenen grossen See, leben. Bekannt aus diesem „Meere" sind: Der Barsch, Perca fluviatilis L.; der Kaulbarsch, Accrina cernua Cuv.; der Stichling, Gasterostcus aculcatus L., und der kleine Stichling, Gastcrostcus pungiturs L.; dic Quappe, Lota fhuriatilis BI.; der Schlammpeitzger, Cobitis fossilis L.; der Karpfen, Cyprimus carpio L.; die Karausche, Carassizes vulgaris L.; die Schleihe, Iinca vulgaris Cuv.; der Gründing, Gobio fuviatilis Cuv.; der Alander, Lcuciscues Idus Selys-Long.; der Rotflossen, Leuciscus crythrophthalmus Valenc.; das Rotauge, Leuciscus mutilus Agass.; der Brassen, Abramis Brama L.; der Weissfisch, 
Abramis Blicca Agass.; der Lachs, Trutta salar L.; die Lachsforelle, Trutta trutta L.; der Stint, Osmerus eperlamis Art.; der Hecht, Esox lucins L., und der Aal, Anguilla anguilla L.

Und endlich ein Verzeichnis der Fische des Balk-Sees, eines mitten im Moore gelegenen 800 MIorgen grossen Wasserbeckens. Häufig werden dort der Sandard, Lucioperca sandra Cuv.; Perca fuviatilis L., der Barsch; Lota fhuriatilis Bl., die Quappe; Tinca vulgaris Cuv., die Schleihe; Abramis brama L., der Brassen; Esox lucius L., der Hecht; Anguilla anguilla L., der Aal, und vereinzelt auch Cyprinus carpio L., der Karpfen, gefangen.

Was die Mollusken anlangt, so ist denselben in diesem Bande schon ein längerer Aufsatz gewidmet. Im folgenden soll deshalb dem Naturbeobachter nur gezeigt werden, was er im und am Süsswasser von dieser Tierklasse auffinden kann. Von den Nacktschnecken findet man auf den Inseln der Flüsse, an den Ufern unter Genist und Steinen die schwarze Theerschnecke, Arion empiriconum Fér., Arion fuscus Müller, den gefrässigen Limax agrestis L. und den zierlichen braunen Limax brumneus Drap. Unter feuchten und faulenden Weidenblïttern lebt die glïnzende T/Yalima nitida Müller. An den Schlengen Helix hispida L.; Helix mibiginosa Zgl.; Helix liberta West. und besonders häufig da, wo Aster salicifolizus Scholler wächst, Helix arbustorum L. In Gesellschaft mit Hyalina trifft man Cionella lubrica Müll.; Cionella hubricella Zgl.; Cionella acioula Müll.; Pupa antivertigo Drap. und Carychizm minimuım Müll. An den Pflanzen am Wasser ist sehr häufig Succinea putris L. (die Bernsteinschnecke) mit ihren zahlreichen Varietäten, an Pflanzen im Wasser cbenso häufig Sucincer Pfeifferi Rossm. und am Berden sucrinct oblonga Drap. Von den eigentlichen Wasserschnecken findet der Naturfreund eine ganze Reihe: zunächst die zahlreichen Limnaeen, von der grossen Limnaea strignalis $\mathrm{L}$. bis zur kleinsten Limnaca truncatula Müll., dann die eigenartig gewundenen Tellerschnecken, Planorbis; die Napfschnecken, Ancylus; ferner eine Reihe von Paludinen, Bythinien, Bythinellen und Valvaten, darunter in der Weser und Elbe die seltene Valvata 
Auriatilis Colbeau, ferner Neritina furiatilis L. Von den Lamellibranchien gehören die simtlichen Unimen, Margaritana, Anodonten, Sphaerien und Pisidien hierher und endlich die seit I 828 in Deutschland bekannte, aus dem Osten eingewanderte Dreyssena polymorpha Pall. Es würde zu weit führen, die sämtlichen Süiswässersthecken und Inschehn hier cingehender zu behandeln und es möge genügen, im obigen auf die zahlreichen Vertreter dieser Gruppe hingewiesen zu haben. Eine besondere Aufmerksamkeit verdient die neuerdings aus dem Osten eingewanderte Süsswasserschnecke, Lithoglyphus naticoides Fér., welche vor einigen Jahren zuerst in der Weichsel aufgefunden wurde, dann etwas später auch in der Umgegend von Berlin und Küstrin entdeckt ist und schliesslich auch bei Rotterdam nachgewiesen ist. Bislang war sie nur bekannt aus dem südöstlichen Deutschland und aus den Flussgebieten des Schwarzen Meeres.

Werfen wir num noch einen flüchtigen Blick auf die Vertreter der niederen Tierklassen, so kann man sich nicht genug wundern über die Menge und Mannigfaltigkeit der niederen Geschöpfe. In einem kleinen Raume, den das Auge bequem mit einem Male überschen kann, welche Vielfachheit der Gestalten, welches Spiel der Farben, welche Emsigkeit in ihrem Leben und Weben, welch ein Huschen und Flattern, welch ein Springen und Hüpfen an Blüte und Strauch, auf Stein und Boden. In dem von der Flut elen zurürdigelassenen Geniste wimmelt es won verschiedenen Kifferarten. Hier sieht man die hurtigen Tachy's, dort huschen von dannen Nebrio- und Elaphrus-Arten; hier über Pflanzenstengel und Gestein, bald drüber, bald drunter weg, eilen Blithisa, Bembidium, Panagacus und manch andere Arten der kleinen und kleinsten Laufer. Dort erscheinen an der Oberflache des Wassers Dytisciden und Hydrophiliden. Hier tummeln sich im buntesten Durcheinander die lebendigen und nimmer rastenden Gyriniden. Auf den Blüten der Aster und am Weidengestrïuch schwirren die Cinthariden und an ebendenselben Pflanzen kriechen die bedichtigen Curculioniden. Auf den Blüten der Umbelliferen tummeln sidh die grazieisen Corambicilen. Hier wienen sich auf whwankendem 
Rohr die metallisch glänzenden Donacien und dort auf beweglichen Grashalmen schaukeln sich die oft in den herrlichsten Farben schillernden Chrysomeliden. Auf den Blüten von Cirsium oleraceum Scop. gaukeln bunte Falter. Raschen Fluges von Blüte zu Blüte, nirgends lange verweilend, eilen die Sesien dahin; dort sitzt bedüchtig an einer Weide, die Flügel übereinandergeschlagen und den Abend erwartend, der Weidenbohrer, Cossus ligniperda F., und neben ihm läuft hastig bald auf bald $a b$ am Stamme der Moschusbock, Aromia moschata L. Hier schwirren über die Wasserfläche die schlanken Agrion-Arten, dort sieht man bald am Rohr sitzend, bald raschen Fluges dahinschwirrend die stattlichen Aeschna- und Libellula-Arten. Über dem Wasser, besonders an warmen Sommerabenden, treiben Hunderte von Fliegen und Mücken ihr lustiges Spiel. Über die Wasserfläche eilen die flinken, langbeinigen Hydrometriden und unter Steinen treiben die lichtscheuen Myriapoden ihr Wesen, daneben hüpfen von Blatt zu Blatt, von Stein auf Stein die bunten Thysanuren. Überall regt sich Leben, am Rohr und im Gras, auf Blüte und Strauch, auf der Wasserfläche und am Grunde des nassen Elements, im Geniste und auf dem Sande des Ufers; ein Leben, welches den Naturfreund fortdauernd mit Wissbegier erfüllt und ihn anspornt, sich den noch unerforschten Problemen desselben mit Eifer zu widmen. 
Druck von J. J. Weber in Leipzig. 




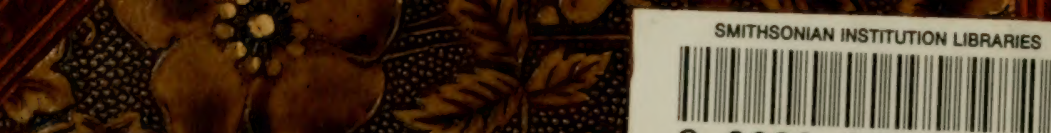

จำ

25

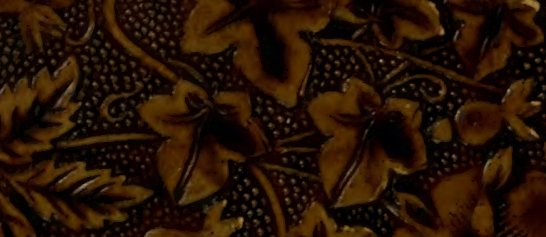

1)

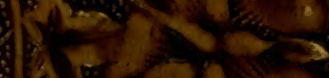

(2)

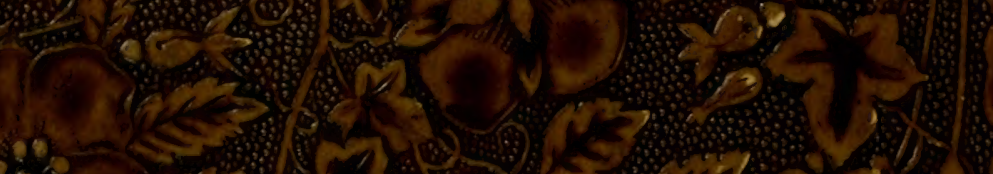

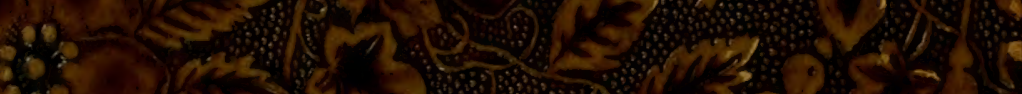
one

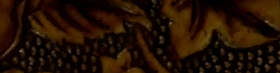

(a) 15

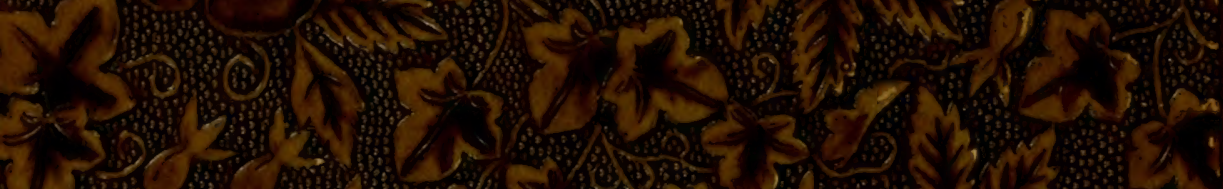
s.

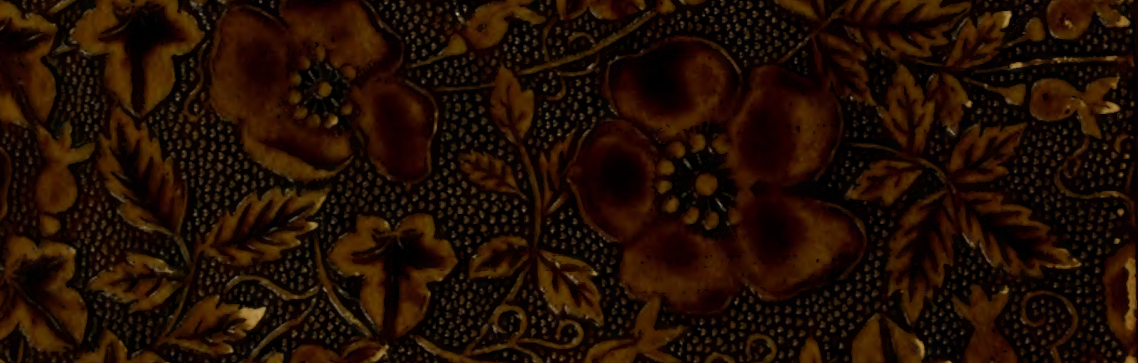

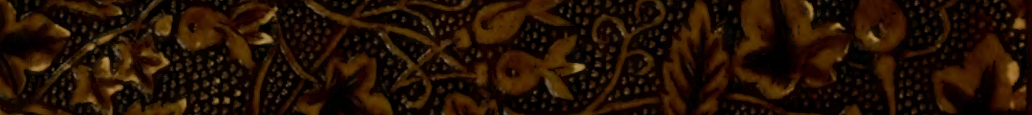

400 (3)

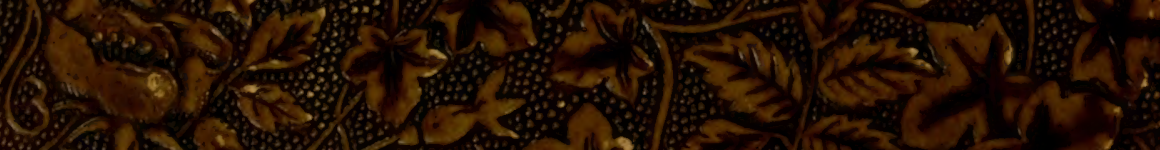
(1)

28

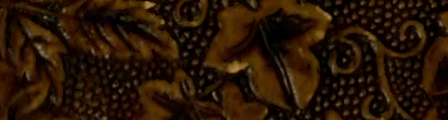

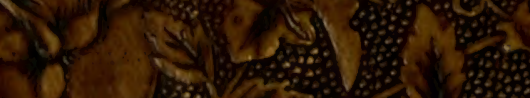

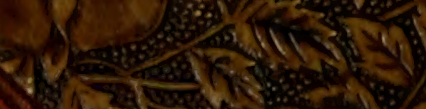

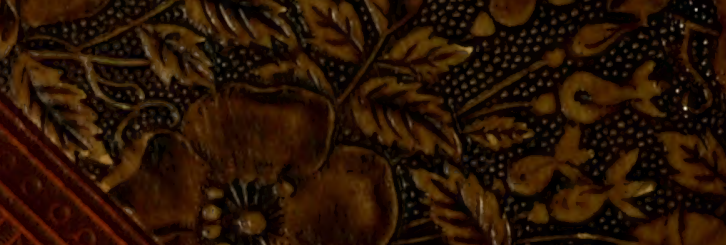

